\title{
Zigarettenalben im Kontext des Nationalsozialismus
}

Inauguraldissertation zur Erlangung des Grades eines Doktors der Philosophie im Fachbereich Philosophie- und Geschichtswissenschaften

der Johann Wolfgang Goethe-Universität

zu Frankfurt am Main

\author{
vorgelegt von \\ Mervin Damian Dominick \\ Gelsenkirchen \\ 2020 \\ 1. Prof. Dr. Andreas Fahrmeir \\ 2. Prof. Dr. Bernhard Jussen
}





\section{Inhaltsverzeichnis}

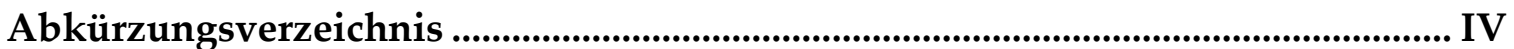

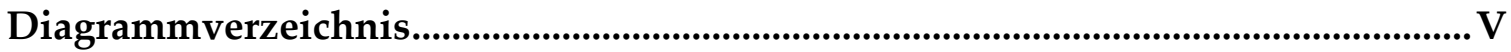

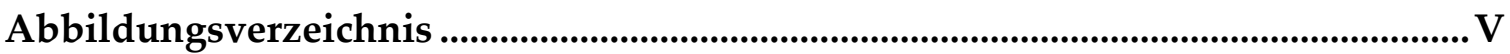

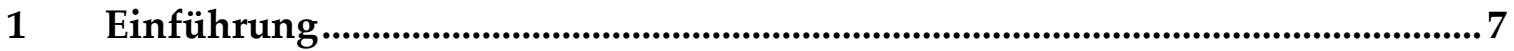

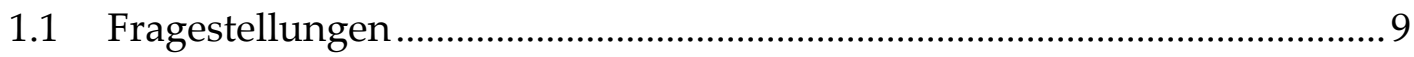

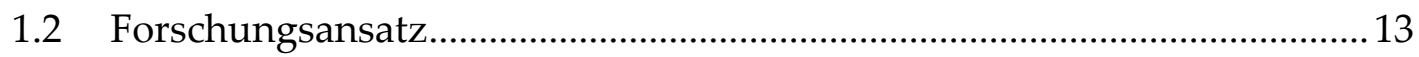

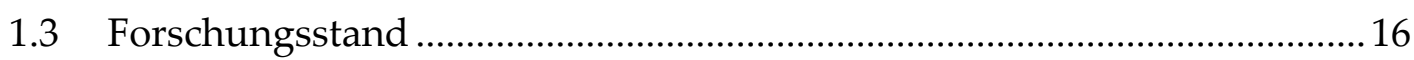

$2 \quad$ Sammelbilder im Kontext von Marketing und Propaganda................................ 18

2.1 Medium der Wissensvermittlung und des Marketings .............................. 18

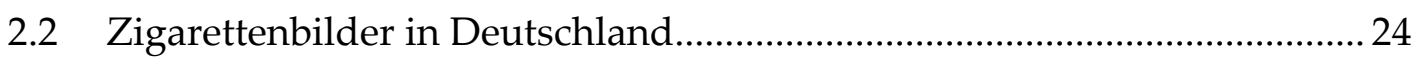

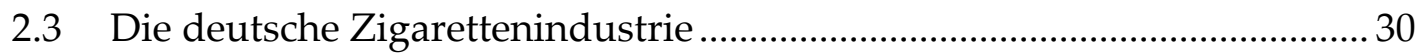

2.3.1 Arrangement mit dem NS-Regime ................................................. 31

2.3.2 Klein- und Mittelständische Zigarettenindustrie ........................... 42

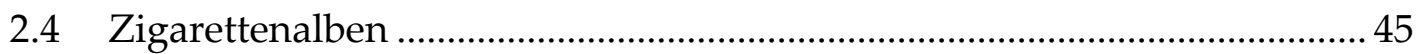

2.4.1 Publizierte Zigarettenalben ............................................................ 46

2.4.2 Zigarettenalben im Dienst der NS-Propaganda.............................. 48

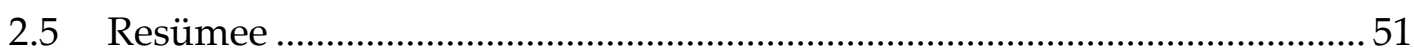

$3 \quad$ Massenpsychologie und Propaganda ..........................................................................55

3.1 Propaganda und Patriotismus ................................................................. 55

3.2 Psychotechnik - Massenpsychologie und Propaganda ............................. 57

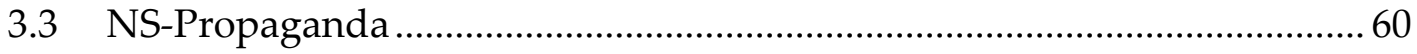

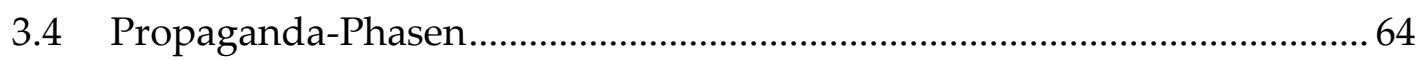

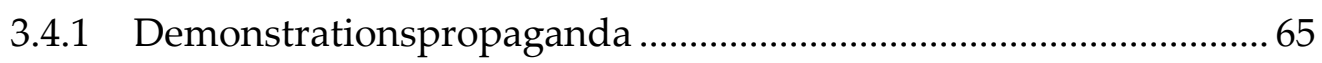

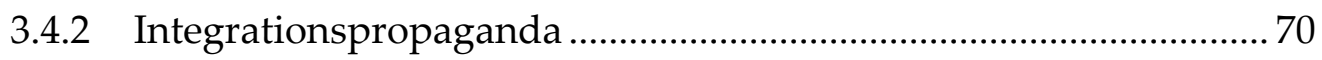

3.4.3 Kriegspropaganda ......................................................................... 79

3.5 Das Symbolsystem des Nationalsozialismus.............................................. 87

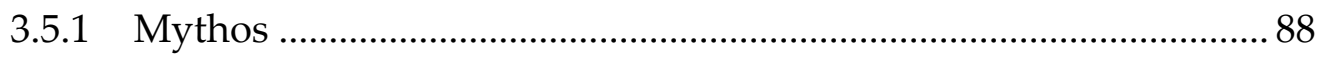

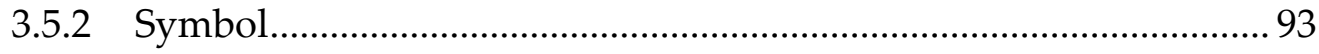

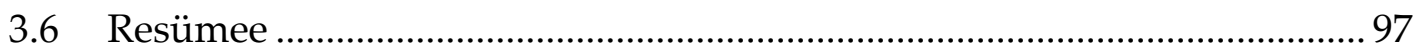


$4 \quad$ Zigarettenalben im Kontext politischer Ideologien..........................................100

4.1 Doms und der Oberschlesische Grenzkonflikt.......................................... 103

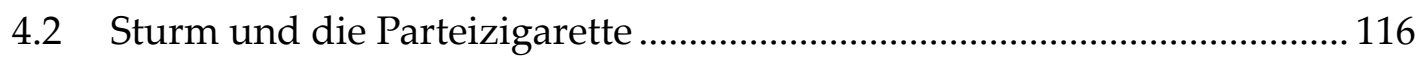

4.2.1 Zigarettenalben der Parteizigarette ............................................... 117

4.2.2 Auswirkungen des Röhm-Putsches auf die Sturm-Alben ........... 130

4.3 Propaganda-Alben des linken Lagers................................................... 133

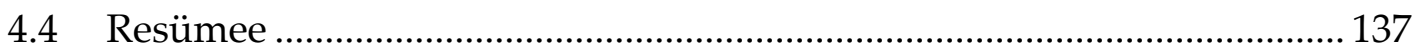

$5 \quad$ Technik und Mobilität in den Zigarettenalben .................................................... 140

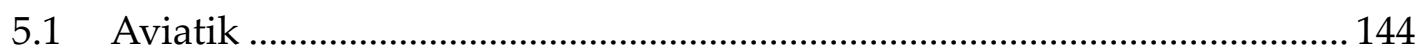

5.1.1 Luftfahrt zwischen Mythos, Moderne und Revanche................... 145

5.1.1.1 Wiederauferstehung der Kriegshelden ............................ 151

5.1.1.2 Triumph über die Schmach von Versailles........................ 170

5.1.1.3 Luftfahrt tut not ................................................................ 178

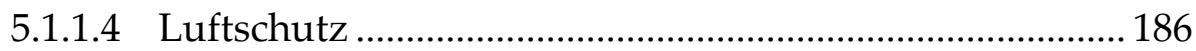

5.1.2 Usurpation durch das Hakenkreuz ........................................... 192

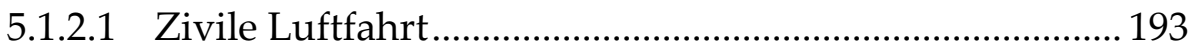

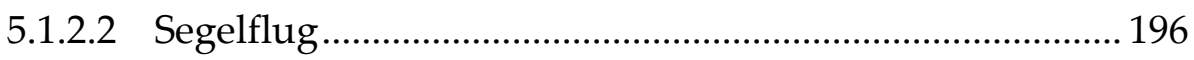

5.1.3 Integrationskräfte der Volksgemeinschaft ..................................... 205

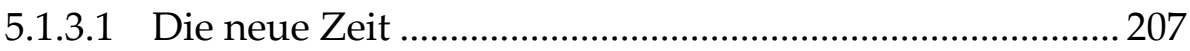

5.1.3.2 Amazonen der Luft und stählerne Krieger...................... 212

5.1.3.3 Die stille Front der Arbeiter................................................. 218

5.1.4 Zeppelin - Phönix aus der Asche..................................................... 222

5.1.4.1 Luftschiffe im Kriegseinsatz........................................... 225

5.1.4.2 Nationaler Opfergang ...................................................... 227

5.1.4.3 Zeppelin unter dem Hakenkreuz ..................................... 232

5.2 Nautik .................................................................................................................... 243

5.2.1 Romantische Verklärung der Seefahrt.......................................... 244

5.2.2 Untergang einer Epoche ............................................................. 245

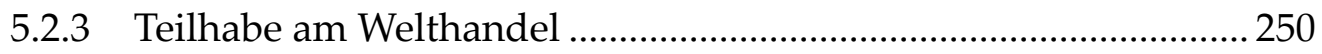

5.2.4 Bedingt einsatzfähige Kriegsmarine ............................................ 253

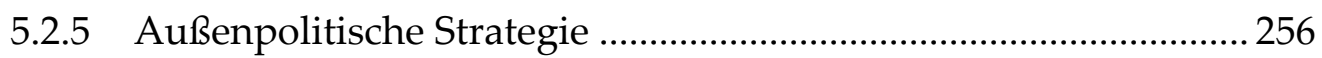

5.2.6 Vergessene Helden ............................................................................ 264 


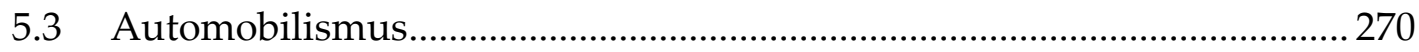

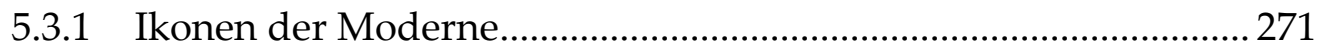

5.3.2 Deutsche Automobile - Meisterwerke der Präzision..................... 274

5.3.3 Jagen und Siegen ......................................................................... 285

5.3.4 Motorhelden an der Front ........................................................... 290

5.3.5 Die Straßen des Führers.............................................................. 294

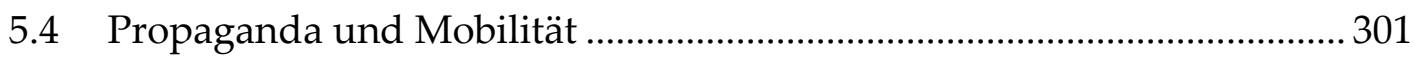

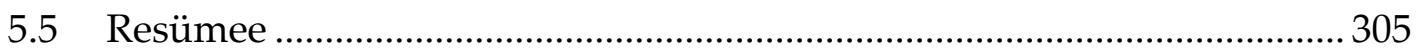

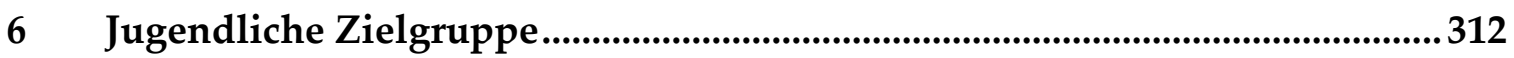

6.1 Zigarettenalben als Wissensquelle .......................................................... 313

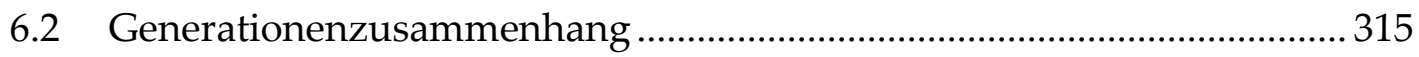

6.3 Vorbild Kriegsheld ................................................................................... 324

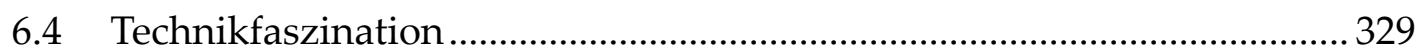

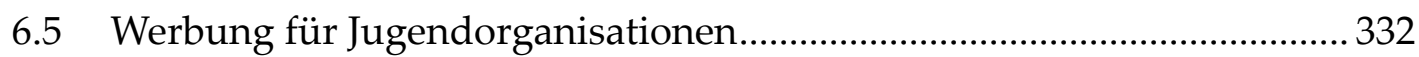

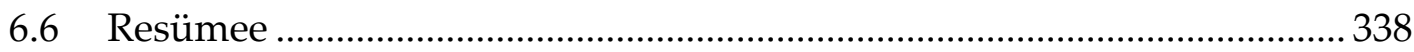

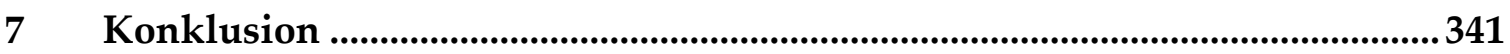

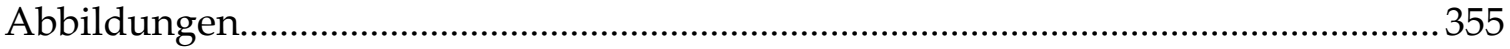

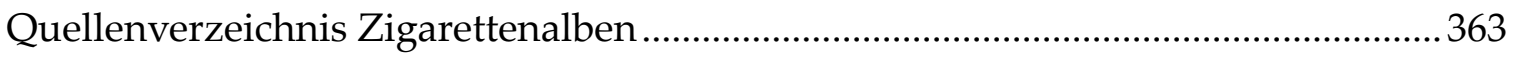

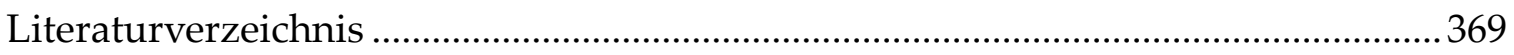




\section{Abkürzungsverzeichnis}

AVUS Automobil-, Verkehrs- und Uebungs-Straße

BATC Britisch American Tobaco Company

BDM Bund Deutscher Mädel

CI Corporate Identity

DAF Deutsche Arbeitsfront

DDP Deutsche Demokratische Partei

DLV Deutscher Luftsportverband

DPA Deutsches Propaganda Atelier

DZR Deutsche Zeppelin-Reederei

F.d.L Führer der Luftschiffe

Frhr. Freiherr

HJ Hitlerjugend

IG Interessengemeinschaft der deutschen Zigarettenhersteller

KdF Kraft durch Freude

KPD Kommunistische Partei Deutschlands

Ltn. Leutnant

MdR Mitglied des Reichstages

NSDAP Nationalsozialistische Deutsche Arbeiterpartei

NSFK Nationalsozialistisches Fliegerkorps

NSKK Nationalsozialistisches Kraftfahrerkorps

NSLB Nationalsozialistischer Lehrerbund

Oblt. Oberleutnant

OHL Oberste Heeresleitung

ONS Oberste Nationale Sportbehörde

OSAF Oberste SA-Führung

PLZ Produktlebenszyklus

RDO Reichsverband Deutscher Offiziere

RGBL Reichsgesetzblatt

RLB Reichsluftschutzbund

RLM Reichsluftfahrtministerium

RM Reichsmark

RMVP Reichsministerium für Volksaufklärung und Propaganda 


$\begin{array}{ll}\text { SA } & \text { Sturmabteilung } \\ \text { SS } & \text { Schutzstaffel } \\ \text { UDSSR } & \text { Union der Sozialistischen Sowjetrepubliken } \\ \text { UK } & \text { Unabkömmlich } \\ \text { VB } & \text { Völkischer Beobachter } \\ \text { WHW } & \text { Winterhilfswerk } \\ \text { WVZ } & \text { Wirtschaftliche Vereinigung der Zigarettenindustrie }\end{array}$

\section{Diagrammverzeichnis}

Diagramm 1: Themenspektrum der Zigarettenalben ............................................... 45

Diagramm 2: Publizierte Zigarettenalben von 1926 bis 1941 ....................................... 47

Diagramm 3: Publizierte Zigarettenalben mit NS-Themen von 1932 bis 1940 ............ 49

\section{Abbildungsverzeichnis}

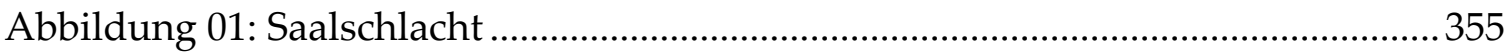

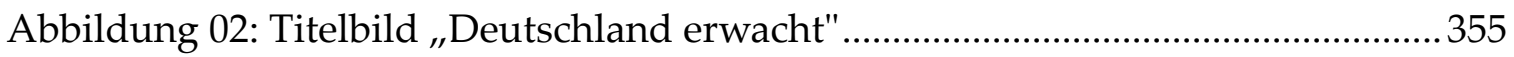

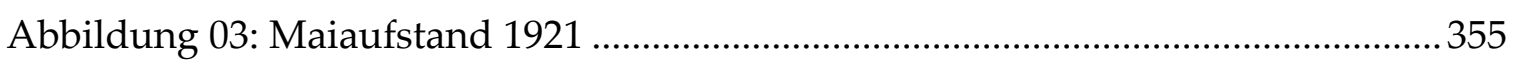

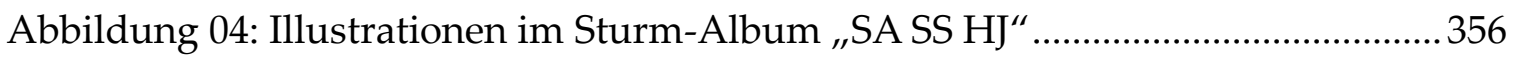

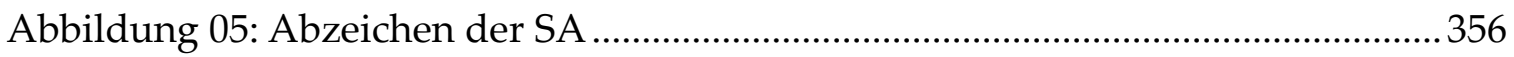

Abbildung 06: Chef des Stabes Viktor Lutze - Legende: „Stabschef Röhm“ ............. 357

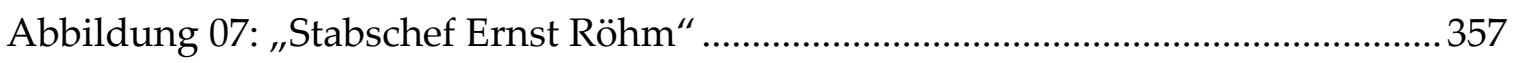

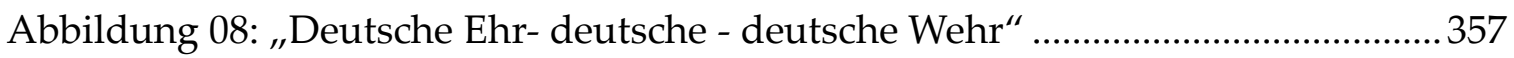

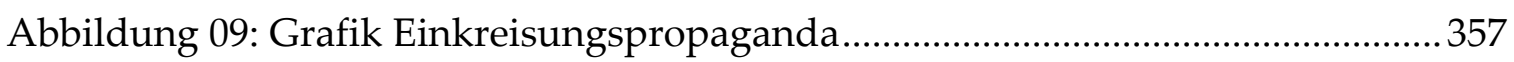

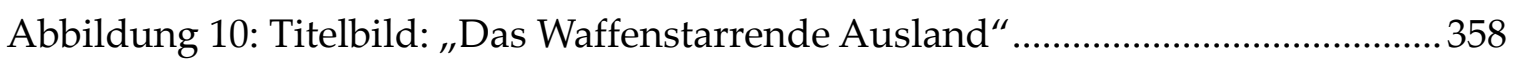

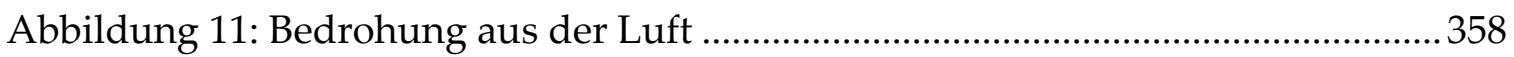

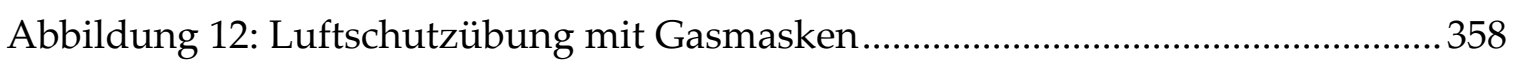

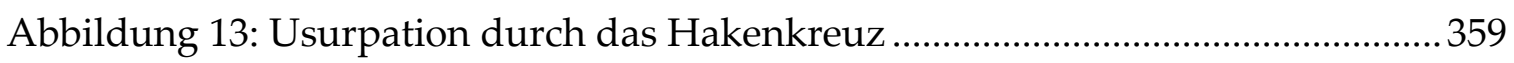

Abbildung 14: Titelbild "Das deutsche Volk muß ein Volk von Fliegern werden"... 359

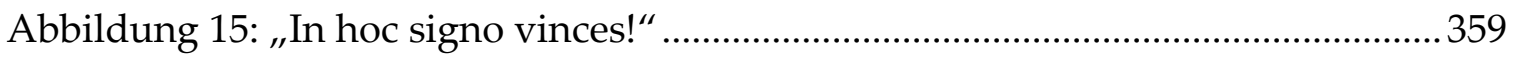

Abbildung 16: Luftschiff „Graf Zeppelin“ über Nürnberg ..........................................360 
Abbildung 17: Internationale Automobilausstellung in Berlin 1935...........................360

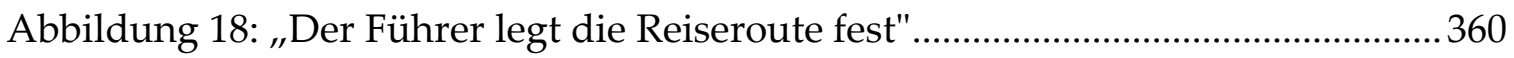

Abbildung 19: „Der Führer fördert durch sein Beispiel die Luftfahrt“ ....................... 361

Abbildung 20: Schwerkriegsbeschädigte des Ersten Weltkrieges ................................ 361

Abbildung 21: Hitler-Jugend bei gemeinnützigen Aufgaben .....................................361

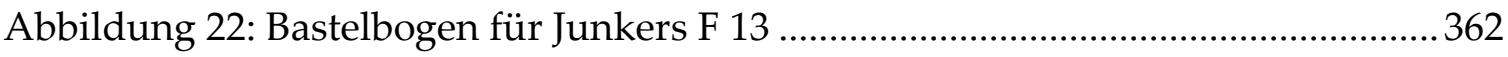

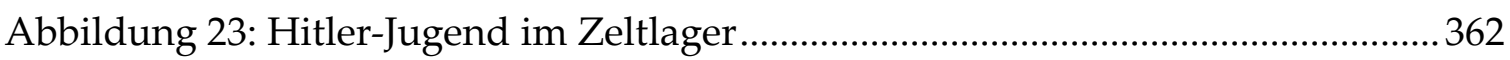




\section{Einführung}

Der Forschungsgegenstand ,Zigarettenbild' mag bei oberflächlicher Betrachtung einige Irritationen hervorrufen. Auf den zweiten Blick stellen die kleinen Reklamebilder aber einen reichhaltigen Fundus für unterschiedliche Wissenschaftsdisziplinen dar. Die scheinbar banalen Bilder sind seit den 2000er Jahren zunehmend Gegenstand historischer Forschung im Kontext von Popularisierung, Wissensvermittlung und Markentinggeschichte. Als Medium der Populärkultur reflektieren Sammelbilder die Vorstellungswelten ihrer Zeit und erlauben darüber hinaus einen Einblick, wie historische und zeitgenössische Themen im jeweiligen zeitgeschichtlichen Kontext imaginiert wurden. Sammelbilder sind seit dem späten 19. Jahrhundert ein weit verbreitetes Medium und Teil der visuellen Alltagskultur. Bis in die Mitte des 20. Jahrhunderts wurden sie als Marketinginstrument zur Kundenbindung- und Gewinnung eingesetzt. Mit zunehmender Verbreitung dieses Mediums wurden Alben ausgegeben, in denen das Konvolut der Bilder nach einem Ordnungssystem gesammelt werden konnte. Zahlreiche Themen fanden Aufnahme in das Repertoire der Sammelbilder, die eine breite Akzeptanz der seitens der Konsumenten fanden. ${ }^{1}$ Die Sammelbilder waren nicht nur ein vitales Instrument der Kundenbindung, sondern auch ein Medium populärer Wissensvermittlung. Exemplarisch dafür stehen die Bilderserien der Firmen Liebig, Stollwerck oder Reemtsma, die mit ihren Sammelwerken vielfältiges Wissen präsentieren. ${ }^{2}$

1 Etymologisch ist die Populärkultur eine gemeinverständliche Form der Kultur, die die Zustimmung der Masse findet. Vgl. Magnus, Gilbert (2011): „Die populäre Literatur als Textsorte? Eine Begriffsbestimmung." In: Agard, Olivier/ Helmreich, Christian/ VinckelRoisin, Hélène (Hg.): Das Populäre. Untersuchungen zu Interaktionen und Differenzierungsstrategien in Literatur, Kultur und Sprache. Göttingen: V\&R, S. 413

$2 \quad$ Eine ausführliche Analyse der Wissenspräsentation der Liebig- und Stollwerck-Bilder wurde von Henning Schweer vorgenommen. Schweer, Henning (2010): Popularisierung und Zirkulation von Wissen, Wissenschaft und Technik in visuellen Massenmedien. Eine grundlegende historische Studie am Beispiel der Sammelbilder der Liebig Company und der Stollwerck AG. Dissertationsschrift, Universität Hamburg 
Ende der 1920er Jahre erkannte die expandierende Zigarettenindustrie das Potential der Sammelbilder als Werbemittel, ${ }^{3}$ das sich in der folgenden Dekade zu einem vitalen Marketinginstrument dieser Branche entwickelte. Die Zigarettenalben erreichten Millionenauflagen und avancierten zu einem Medium der zeitgenössischen Populärkultur. Mit zunehmender Beliebtheit erfuhren die Zigarettenalben sowohl eine Professionalisierung als auch eine veränderte thematische Aufbereitung. Während die Alben bis zum Beginn der 1930er Jahre lexikalisch angelegt waren, gingen viele Zigarettenfabrikanten dazu über, die Alben mit reichhaltigem Textmaterial auszustatten, so dass die Zigarettenalben den Charakter von Bildbänden erhielten. Die Zigarettenalben waren keine preiswert produzierte Zugabe, sondern zeichneten sich oft durch inhaltlich profunde Texte und qualitativ hochwertiges Bildmaterial aus. ${ }^{4}$ Das Themenspektrum der Zigarettenbilder erstreckte sich über Folklore, Geschichte, Flora, Fauna, Unterhaltung, Militaria, Naturwissenschaft, Volks- und Völkerkunde bis zu Film und Sport.

Mit dem Erstarken der NS-Bewegung hielten ab 1932 nationalsozialistische Themen Eingang in die Zigarettenalben. Es wurden einige Sammelwerke publiziert, die sich monothematisch dem Nationalsozialismus widmeten. Die Anzahl der NS-Alben nimmt am Gesamtvolumen Zigarettenalben, die zwischen 1926 und 1941 publiziert wurden, nahmen mit 47 von insgesamt 651 Publikationen einen Anteil 7,22 Prozent ${ }^{5}$ ein. Der relativ geringe Prozentsatz wird durch die Auflagen kompensiert, die Millionenhöhe erreichten. Damit zählen die Zigarettenalben zu den erfolgreichsten und

3 Die Zigarettenbilder wurden um das Jahr 1924 auf dem deutschen Markt eingeführt. HIS PFR 491,08

$4 \quad$ Anm.: Da es sich bei den Zigarettenalben um ein kostspieliges Marketinginstrument handelte, waren viele kleinere Zigarettenfirmen gezwungen, Werke von minderer Qualität zu publizieren. (Das gilt insbesondere für Unternehmen, die dem linken politischen Spektrum zuzuordnen sind). Die Sammelwerke größerer Unternehmen waren sowohl inhaltlich als auch drucktechnisch hochwertig. Exemplarisch die Malerei-Alben der Firma Reemtsma.

$5 \quad$ Die Angaben basieren auf dem Katalog von Köberich. Köberich, Hartmut (2003): Köberich's Reklame- und Sammelbilder. Katalog zur Bewertung der Sammelalben aus der Zeit von 1872 - 1945, 4. Aufl., Rabenau: Lumdatal 
auflagestärksten NS-Publikationen, ${ }^{6}$ bis sie im Jahr 1941 aufgrund kriegsbedingter Ressourcenknappheit eingestellt wurden. ${ }^{7}$

In der vorliegenden Arbeit werden die Zigarettenalben mit nationalsozialistischen Inhalten einer Untersuchung unterzogen. Angesichts des ausgesprochen umfangreichen Quellenkorpus, der Milliarden an Einzelbildern umfasst, wird die Arbeit thematisch eingegrenzt, wobei der Bereich der Technik fokussiert wird. Die thematische Eingrenzung ist ferner der Dominanz der Technik geschuldet, die in den 1920er und1930er Jahren zentrales Thema gesellschaftlicher und politischer Diskurse war. Technische Themen sind daher prädestiniert, um Einblicke in die kollektiven Vorstellungswelten im Kontext des Nationalsozialismus zu erhalten. Neben den TechnikAlben werden ferner die Sammelbände einiger klein- und mittelständischer Unternehmen untersucht, die das Medium genutzt haben, um ihre individuellen propagandistischen Ziele einem breiten Publikum zu präsentieren.

\subsection{Fragestellungen}

Die populäre Massenkultur war integrierter Bestandteil des NS-Systems und wurde vom Regime sowohl mit dem Ziel eingesetzt, die Bevölkerung zu unterhalten als auch um die Volksgemeinschaft zu lenken und ihre Lebenswelt zu formen. Um die Bevölkerung zu indoktrinieren, bedienten sich die Propagandastrategen aller Sparten der audio-visuellen Kommunikation. Neben den klassischen Printmedien wie Illustrierte und Bildbände, die zeitgenössische Themen publikumsgerecht darboten, kamen auch moderne Medien wie Kino und Radio zum Einsatz. Das NS-Regime trieb die Entwicklung neuer Techniken zur medialen Informationsverbreitung daher voran und etablierte ein Mediensystem, das auf die Verbreitung von Populärkultur ausgerichtet war. ${ }^{8}$ Inwieweit das NS-Regime die populäre Massenkultur als Propagandainstrument

\footnotetext{
Vgl. Adam, Christian (2010): Lesen unter Hitler. Berlin: Galiani, S. $129 \mathrm{ff}$.

Vgl. Die Reemtsma-Zigarettenbilder wurden aufgrund der Respektfrist noch nach 1941 ausgeliefert. Vgl. HIS PFR 491,01 Reemtsma-Geschäftsleitung an die am Bilderschecksystem beteiligten Firmen, 18. August 1942

$8 \quad$ Würmann, Carsten/ Warner, Ansgar (Hg.) (2008): Im Pausenraum des 'Dritten Reiches'. Zur Populärkultur im nationalsozialistischen Deutschland. Bern/ Berlin: Peter Lang, S. 7
} 
eingesetzt hat, ist von der jeweiligen Intension abhängig. Während einige Produkte der reinen Unterhaltung und dem Eskapismus dienten, wurden andere Medien gezielt eingesetzt, um manipulativ auf die Bevölkerung einzuwirken. Da in der Zeit des Nationalsozialismus die strukturelle Kopplung zwischen Politik und Medien sehr eng und die Autonomie des Öffentlichkeitssystems vollständig aufgehoben war, ist von Interesse, inwieweit die Zigarettenalben Teil der auf Machtbildung ausgerichteten Kommunikationsprozesse waren und als Propagandamittel instrumentalisiert wurden.

In der vorliegenden Arbeit soll untersucht werden, wo die Zigarettenalben im Propaganda-Konzept des NS-Staates zu verorten sind. Im Unterschied zu anderen kommunikationswissenschaftlichen Konzepten, bei dem die Propaganda des Nationalsozialismus vielfach als dispositionales Konzept beschrieben wird und das Individuum einem Reiz-Reaktions-Schema folgt, wird in dieser Arbeit der sozial-psychologische Hintergrund betrachtet, vor dem die Propaganda ihre Wirkung entfaltet hat. In diesem Rahmen wird untersucht, inwieweit die Zigarettenalben in einen vielschichtigen Kommunikationsprozess eingebunden waren, aus dem die Rezipienten einen Nutzen generieren konnten. Dabei sollen die Motive des NS-Regimes sowie der Zigarettenhersteller, die Zigarettenalben als Propagandamedium zu instrumentalisieren, einer Betrachtung unterzogen werden. In diesem Kontext sollen ferner die Aktivitäten seitens der Rezipienten analysiert werden. Damit werden alle an dem Kommunikationsprozess beteiligten Gruppen in den Rahmen der Untersuchung einbezogen. So können Interaktionszusammenhänge sowie die Motive der Kommunikatoren umfassend analysiert werden. Dabei soll eruiert werden, ob sich die Propaganda Prädispositionen zunutze machte, um die Rezipienten in einen ideologisch geprägten Diskurs zu involvieren. In diesem Kontext wird auch das politische und gesellschaftliche Zeitgeschehen einer Betrachtung unterzogen. 
Da die Synchronisation von Politik und soziokulturellen Idealen charakteristisch für faschistische Systeme ist, ist ferner von Interesse, welche Bereiche der nationalen Kultur und Geschichte aufgegriffen und in den Zigarettenalben instrumentalisiert wurden, um Einfluss auf das kollektive Bewusstsein der Bevölkerung zu nehmen. In Anbetracht dieser Aspekte und der Tatsache, dass Ideologien eine symbolische Dimension haben, soll in der Arbeit erforscht werden, wie Ideologien in Mythen und Symbolen in dem Medium Zigarettenalbum sinnfällig wurden. In diesem Kontext soll eruiert werden, inwiefern Zigarettenalben aufgrund ihrer Bedeutungsdimensionen im damaligen medialen Diskurs einen spezifischen Zugang zur wissenschaftlichen Erforschung der Geschichte bieten.

Ein weiterer Fokus bei der Analyse liegt in der Betrachtung der deutschen Geschichte. In diesem Rahmen soll untersucht werden, ob historische Ereignisse neu bewertet wurden. Dabei ist von besonderer Relevanz, ob Geschichte in der semiotischen Welt mit Bedeutungen aufgeladen und als Sinnressource für die Propaganda instrumentalisiert wurde. Neben den historischen Aspekten soll ferner untersucht werden, inwieweit strategische Zielsetzungen des NS-Regimes in Bezug auf die zeitgenössische Innen- und Außenpolitik zum Gegenstand der Zigarettenalben wurden, respektive Berücksichtigung fanden.

Da sich die NS-Propaganda komplexer Kommunikationsstrategien bedient hat und nicht auf eine Ikonografie von Aufmärschen und Hakenkreuz reduziert werden kann, ${ }^{9}$ sollen die Methoden, die das NS-Regime eingesetzt hat, um die Bevölkerung in einen ideologischen Diskurs zu involvieren, einer Betrachtung unterzogen werden. Von besonderer Relevanz ist dabei die Funktion, die die Zigarettenalben einnahmen und wie diese in das Propaganda-System eingebunden wurden. Da das NS-Regime während seiner Präsenz auf der politischen Bühne unterschiedliche Zielsetzungen verfolgt hat, wie Machtergreifung- und Stabilisierung sowie Mobilisierung der

Vgl. Paul, Gerhard (1990): Aufstand der Bilder. Die NS-Propaganda vor 1933. Bonn: J.H.W. Dietz Nachf., S. 11 
Bevölkerung für kriegerische Auseinandersetzungen, ${ }^{10}$ soll vor diesem Hintergrund untersucht werden, in welcher Propagandaphase die Zigarettenalben zur Multiplikation der NS-Ideologie eingesetzt wurden.

Aufgrund der Inanspruchnahme des Marketinginstrumentes Zigarettenalbum soll ferner untersucht werden, inwieweit die Machthaber Strategien der Propagandaforschung aufgegriffen sowie Erkenntnisse der Gesellschafts- und Wirtschaftskommunikation für ihre Zwecke ausgewertet haben. Dazu zählen die Synergieeffekte zwischen Wirtschaftswerbung und politischer Propaganda, die während des Ersten Weltkrieges entstanden sind sowie die sozialpsychologischen Forschungen, die im Zuge der erfolgreichen Kriegspropaganda der Entente in der Nachkriegszeit initiiert wurden. Angesichts der Einflussnahme des NS-Regimes sollen die Motive identifiziert werden, die zu den kommunikationspolitischen Allianzen zwischen der Zigarettenindustrie und dem NS-Regime geführt haben. Da eine effiziente Wirtschafts- und Gesellschaftskommunikation nicht rein vertikal auf die ökonomischen und propagandistischen Zielsetzungen ausgerichtet werden kann, soll ferner untersucht werden, ob Wirtschaft und Machthaber gezwungen waren, kollektive Bedürfnisse der Verbraucher und Bildersammler bei der kommunikationsstrategischen Planung zu berücksichtigen. Im Umkehrschluss soll untersucht werden, ob Unternehmen die Zigarettenalben benutzt haben, um ihre eignen ideologischen Überzeugungen zu verbreiten. Da die Zigarettenalben als omnipräsentes Medium nicht nur von der erwachsenen Bevölkerung konsumiert wurden, sondern auch von Kindern, ${ }^{11}$ liegt ein weiterer Fokus dieser Forschungsarbeit auf der Analyse der Ansprache dieses Bevölkerungssegments. Dabei soll untersucht werden, ob die Zigarettenalben als strategisches Propagandainstrument eingesetzt wurden, um gezielt Kinder und Jugendliche für das NS-Regime einzunehmen und sie zu sozialem Handeln zu motivieren.

10 Vgl. Bussemer, Thymian (2000): Propaganda und Populärkultur. Konstruierte Erlebniswelten im Nationalsozialismus. Wiesbaden: DUV, S. 14

11 Kinder und Jugendliche zählten nach Aussage von Ph. Reemtsma zur primären Zielgruppe der Bildersammler. Vernehmung Ph. Reemtsmas in Bezug auf das NS-Zigarettenalbum Der Kampf um's Dritte Reich. Vgl. HIS PFR 230,35 Strafsache Reemtsma, 56. Verhandlungstag, 22. September 1948 


\subsection{Forschungsansatz}

Gegenstand der vorliegenden Forschungsarbeit sind Zigarettenalben im Kontext des Nationalsozialismus. Angesichts der Vielzahl an Publikationen und des breiten Themenspektrums der Alben war es erforderlich, das Quellenmaterial12 einzugrenzen. Für die Untersuchung wurden daher primär die Zigarettenalben herangezogen, die ihm Rahmen der Fragestellungen von Relevanz sind. Dazu zählen Alben mit eindeutigem NS-Hintergrund sowie die Zigarettenalben der Unternehmen, die ihre gesamte Marketingkommunikation auf die Semantisierung politischer Ideologien ausgerichtet haben.

Zur Analyse der propagandistischen Synergieeffekte von Produktwerbung und NS-Propaganda werden einleitend die zeitgenössischen Forschungen im Bereich der persuasiven Kommunikation wie Massenpsychologie und Propagandaforschung beschrieben. In diesem Kontext wird aufgezeigt, wie die nationalsozialistische Propaganda von diesen Erkenntnissen partizipiert hat. Um die Zigarettenalben im gesamten Spektrum der NS-Propaganda verorten zu können, werden die unterschiedlichen Phasen der Propaganda ${ }^{13}$ aufgezeigt sowie die Instrumente und Medien, die dabei zum Einsatz kamen.

Da sich die NS-Propaganda eines vielschichtigen Symbol- und Mythensystems bediente, werden im dritten Teil die Wirkung und die Relevanz von Mythen und Symbolen im Rahmen von Kommunikationsprozessen und Massenbeeinflussung dargelegt. Der Fokus liegt insbesondere auf den Mythen politischer Natur, da diese Teile des kollektiven Gedächtnisses einer Nation bilden und der Konstruktion von sozialen Identitätsräumen dienen. ${ }^{14}$ Von Bedeutung ist dabei die symbolische

12 Das Material entstammt öffentlicher und privater Quellen: Goethe-Universität Frankfurt/M. (Sammlung Köberich), Deutsche Nationalbibliothek Frankfurt/M. und Leipzig, Badische Landesbibliothek Karlsruhe, Familie Schweiger (Durmersheim), Privatsammlung des Verfassers.

13 Vgl. Bussemer (2000): Populärkultur, S. $13 f$.

14 Vgl. Assmann, Jan (1992): Das kulturelle Gedächtnis. München: C.H. Beck, S. 89 
Interaktion, die einen interpretativen ${ }^{15}$ Prozess in Gang setzte und es dem NS-Regime ermöglichte, in einen vielschichtigen Dialog mit der Bevölkerung zu treten.

Im vierten Kapitel werden die Zigarettenalben im Kontext politischer Ideologien betrachtet. Am Beispiel von klein- und mittelständischen Zigarettenfirmen werden die engen Verbindungen zwischen Propaganda und Wirtschaftswerbung einer Betrachtung unterzogen. In diesem Zusammenhang wird die semantische Anpassung von Firmen- und Produktnamen an politische Ideologien untersucht sowie die Instrumentalisierung der Zigarettenalben für spezifische Interessen einzelner Gruppen. Exemplarisch dafür ist die Firma ,Sturm', die ihre gesamte Wirtschaftskommunikation auf die Interessen der SA ausgerichtet hat.

Der Schwerpunkt des Forschungsansatzes konzentriert sich auf die Zigarettenalben mit technischem Inhalt wie Aviatik, Nautik und Automobilismus, die im fünften Abschnitt behandelt werden. Die Fokussierung auf den technischen Themenbereich beruht auf diversen Faktoren. Die Technik wurde positiv konnotiert und war verbunden mit einer gesellschaftlichen Utopie, die es dem Menschen ermöglichte, sich die Naturgewalten Untertan zu machen und seinen Lebensraum selbstbestimmt zu gestalten. Der nahezu grenzenlose Glaube an den Erfindergeist, der den Menschen befähigt, technische Utopien zu realisieren, ist auch Tenor vieler Zigarettenalben. Die Sammelalben boten die Möglichkeit, nicht nur dem menschlichen Erfindergeist zu huldigen, sondern waren auch mediales Parkett für die Industrienationen, ihre technischen Errungenschaften zu präsentieren. In Deutschland manifestierte sich der Glaube an die Realisierbarkeit von Utopien insbesondere in den „technischen Schlüsselinnovationen"16 wie dem Automobilismus und der Aviatik. Für Deutschland, das sich bereits seit der wilhelminischen Epoche ${ }^{17}$ vor dem Hintergrund technischer

\footnotetext{
15 Vgl. Renckstorf, Karsten (1977): Neue Perspektiven in der Massenkommunikationsforschung. Berlin: Volker Spiess, S. 27

16 Bauer (2004): 19. Jahrhundert, S. 108

17 Bereits in der wilhelminischen Epoche waren Wissenschaft und Technik sowohl Garant für die Eroberung der Weltmärkte als auch Ausdruck des Nationalstolzes, der von militärischem Kräftemessen - insbesondere mit England - verbunden war. Vgl. Schüler, Andreas (1990): Erfindergeist und Technikkritik. Stuttgart: Franz Steiner, S. 30
} 
Innovationen definierte, war dieser Aspekt von besonderer Relevanz. Die Technik wurde daher von Anbeginn von einer patriotrischen Codierung begleitet.

Da technische Themen Teil der Populärkultur ${ }^{18}$ waren, partizipierte das NS-Regime an der Technikfaszination der Bevölkerung und band sie in ihre Propagandastrategien ein. ${ }^{19}$ Darüber hinaus besaß die Technik angesichts des verlorenen Ersten Weltkrieges sozialpsychologische Bedeutung für das Kollektiv, denn technische Errungenschaften boten den Deutschen die Möglichkeit, das nationale Selbstbewusstsein zu stärken. Vor diesem historischen Hintergrund war die Technik nicht nur Prestigeobjekt für die deutsche Nation, sondern generierte auch zum Instrument der Vergeltung. Die Nationalsozialisten potenzierten diese Aspekte und machten sie zu einem zentralen Topos der Propaganda. Darüber hinaus war die Technik auch Identifikationsmoment für das NS-Regime selbst, denn der Nationalsozialismus definierte sich über Determinanten wie Dynamik, Fortschritt und Geschwindigkeit, die mit der Technik assoziiert wurden. Im kriegerischen Kontext verkörperte die Technik eine moderne Männlichkeit, die Leitbild der faschistischen Ideologie war. Diese Forschungsarbeit stützt sich daher primär auf die Zigarettenalben, die sich monothematisch mit den drei Ausprägungen der Technik - Aviatik, Nautik und Automobilismus - beschäftigen. Aufgrund der multithematischen Konzeption vieler Alben wurden auch Sammelbände in die Analysen einbezogen, die Technik und Mobilität thematisieren. Bei der Erforschung des Themas wurden sowohl Bilder als auch Texte einbezogen. Da die Majorität der Zigarettenalben die Charakteristika von Bildbänden aufweisen, liegt der Schwerpunkt auf der Analyse der Texte.

18 Vgl. Brockhaus, Gudrun (1997): Schauder und Idylle. München: Verlag Antje Kunstmann, S. 89

19 Anm.: Die Popularität der Technik manifestiert sich in der Vielzahl an Zigarettenalben. Siehe Diagramm 1 


\subsection{Forschungsstand}

Die Sammelbilder und Sammelalben als kulturelle Dokumentation gerieten in Vergessenheit und blieben von der Forschung unbeachtet. Erst seit jüngster Zeit sind sie in den Fokus wissenschaftlichen Interesses gerückt. Die Gründe dieser Vernachlässigung sind mannigfaltig und sind u.a. auf das immense, nahezu unüberschaubare Material zurückzuführen, dessen Dokumentation erst begonnen hat. Eine weitere Ursache für das Nischendasein des Sammelbildes ist das Image als banaler und trivialer Werbeträger sowie der Mangel an künstlerischem Anspruch der Bilder und Texte. Die weitgehende Ausklammerung der Populärkultur bei der historischen Forschung mag ebenfalls dazu beigetragen haben, dass die Sammelbilder- und Alben nicht als seriöser Forschungsgegenstand angesehen wurden.

Die Sammelbilder stehen erst seit gut einer Dekade im Fokus der historischen Forschung und das Terrain der Sammelbilder steht noch am Beginn seiner Entdeckung. So wurde auch die Epoche des Nationalsozialismus bei der Erforschung der Sammelbilder bislang keiner detaillierten Analyse unterzogen und wissenschaftlich aufgearbeitet. Da sich neben politischen, historischen und soziokulturellen Strömungen auch das aktuelle Zeitgeschehen in visuellen Medien manifestiert, ist das Sammelbild insbesondere im nationalsozialistischen Kontext von wissenschaftlicher Bedeutung. Neben einer überschaubaren Anzahl an Populärliteratur, die mit überwiegend gefälligen Motiven einen kleinen Ausschnitt in die Welt der Sammelbilder eröffnet, haben nur wenige Autoren einen kritischen und reflektiven Ansatz gefunden. Die bislang einzige Aufarbeitung und Katalogisierung des Bildmaterials wurde von B. Jussen vorgenommen. ${ }^{20}$ Damit erfolgte eine Anerkennung der Sammelbilder als bedeutender Fundus für historische und kunsthistorische Disziplinen. Im Rahmen dieser Forschungsarbeit wurden auch die Zäsuren in der Sammelbildkultur erfasst

20 Jussen, Bernhard (Hg.) (2007:) Atlas des historischen Bildwissens 2. Bilder der Jahre 1870-1970, 2. Aufl., Berlin: Directmedia Publ. Jussen, Bernhard (Hg.) (2002): Atlas des historischen Bildwissen. Liebigs Sammelbilder (Vollständige Serien 1 - 1138), Max-Planck-Institut für Geschichte (DVD). 
und die veränderte Kanonisierung und Präsentation der Sammelbilder erforscht. So wurde das visuelle Massenmedium als Forschungsgegenstand etabliert, der einen Einblick in das kulturelle Gedächtnis ermöglicht. Die Bildbestände eröffnen so einen Zugang für die Erforschung von Gedächtniskulturen vor dem Hintergrund sozialer und politischer Auseinandersetzungen. Damit kann erforscht werden, welche Vorstellungen in der jeweiligen Epoche dominierten und wie diese im zeitgeschichtlichen Kontext imaginiert wurden. An diese Grundlagenarbeit hat der Historiker J. Zeller angeknüpft. In seinem Buch „Bilderschule des Herrenmenschen“, ${ }^{21}$ wird aufgezeigt, wie Sammelbilder zur Legitimation der Kolonisierung beitrugen und Stereotypen etablierten. Die Historikerin Judith Blume hat mit ihrer Arbeit die Geschichte des Sammelbildes im kulturhistorischen Kontext von Konsums und Wissen erforscht und dargelegt, welche Relevanz das Medium im metapolitischen Diskurs hatte. ${ }^{22}$ Vera Zeichmann hat in ihrer Diplomarbeit die Hauptthemen der Zigarettenbilderalben herausgearbeitet sowie den Zeitraum der Veröffentlichung in Deutschland und Österreich. ${ }^{23}$ Die Sammelbilder im Kontext der nationalsozialistischen Propaganda wurden bislang nur peripher untersucht. Auch in der Sekundärliteratur der Kunstgeschichte, der Politik- und Kommunikationswissenschaft findet sich diese Thematik allenfalls als Randnotiz wieder.

21 Zeller, Joachim (2008): Bilderschule der Herrenmenschen. Koloniale Reklamesammelbilder. Berlin: Ch. Links, Schweer (2010): Popularisierung.

22 Blume, Judith (2019): Wissen und Konsum. Eine Geschichte des Sammelbildalbums 1860-1952. Göttingen: Wallstein Verlag

23 Zeichmann, Vera (2010): Werbemittel Sammelbild. Zigarettenbilderalben im Dienst der NS-Propaganda. Diplomarbeit Universität Wien 


\section{Sammelbilder im Kontext von Marketing und Propaganda}

Das Aufkommen des Reklame-Sammelbildes verläuft parallel zu den wirtschaftlichen und strukturellen Umwälzungen der industriellen Revolution, die eine Expansion der Massenproduktion eingeleitet und ein neues Verhältnis zwischen Mensch und Ware geschaffen hatte. Die evolutionären Veränderungen erforderten neue Kommunikationsstrategien, die in modernen Medien wie dem Sammelbild ihren Ausdruck fanden und zum Bestandteil der populären Alltagskultur wurden. Die Sammelbilder waren neben ihrer Funktion als Instrument der Wirtschaftskommunikation auch ein Medium, das sowohl kollektive Bedürfnisse als auch soziokulturelles, wirtschaftliches und politisches Zeitgeschehen reflektierte.

\subsection{Medium der Wissensvermittlung und des Marketings}

Die Genese des Sammelbildes liegt in den Devotional- und Andachtsbildern, die sich ab dem 14. Jahrhundert großer Beliebtheit erfreuten. ${ }^{24}$ Aus dieser Tradition heraus entwickelten sich Bilderbögen, die sich im 19. Jahrhundert als eigenständiges Medium etablierten und mit ihrem thematischen Kaleidoskop unterschiedliche Informationsbedürfnisse befriedigten. Die industrielle Herstellung und die arbeitsteilige Produktion erlaubten hohe Auflagen, so dass der Bilderbogen Teil der zeitgenössischen Aufgaben der Medien übernahm und zum charakteristischen Medium seiner Zeit wurde. ${ }^{25}$ Neben Unterhaltung, Belehrung und Informationen zu zeitgeschichtlichen Ereignissen wurde über das neue Massenmedium auch politische Propaganda und

$24 \quad$ Vgl. Nieke, Erdmute (2007): Religiöse Bilderbogen aus Neuruppin: Eine Untersuchung zur Frömmigkeit im 19. Jahrhundert. Bern/ Berlin: Peter Lang, S. 193f. Der Klerus erkannte die Suggestivkraft bildlicher Darstellungen. Es entstand ein schwunghafter Handel mit den kleinformatigen Bildern, die teilweise in Serien herausgebracht und in Andachtsbücher eingeklebt wurden. Spamer, A. (1930): „Das kleine Andachtsbild“. Zit. nach: Lorenz, Detlef (2000): Reklamekunst um 1900. Berlin: Reimer, S. 9

25 Vgl. Faulstich, Werner (2004): Medienwandel im Industrie- und Massenzeitalter. Göttingen: V\&R, S. 110f. Die Bilderbögen wurden sukzessive von den aufkommenden abgelöst. Die Verschiebung in der Medienlandschaft erfolgte mit dem Krieg 1870/71. Vgl. Wasem, Erich (1987): Das Serienbild. Medium der Werbung und Alltagskultur. Dortmund: Harenberg, S. 54 
Wirtschaftswerbung verbreitet. ${ }^{26}$ Die Bilderbögen beeinflussten maßgeblich das Geschichts- und Weltbild breiter Bevölkerungsschichten, in dem sie zur politischen Erziehung und Aufklärung beitrugen. In Form von Lehrbögen wurde Allgemeinwissen zu diversen Themen wie Flora und Fauna, Theater, Waffengattungen, Naturwissenschaft sowie Volkskunde vermittelt. Vereinzelt wurden auch militärische Ereignisse wie der Krieg 1870/71 popularisiert, mit dem Ziel, „das patriotische Treueempfinden zwischen Volk und Monarch“27 zu festigen. Nach der Reichsgründung im Jahr $1871^{28}$ sahen sich viele Markenartikelhersteller, die auf dem nationalen Markt operierten in der patriotischen Pflicht, dem deutschen Volk eine kollektive historische Kontinuität zu vermitteln. Deutsch-Nationale Attitüden beschränkten sich nicht nur auf Sammelbilder, sondern prägten viele Werbemittel an der Wende des 19. Jahrhunderts..$^{29}$

Die Sammelbilder entwickelten sich im Zuge der industriellen Revolution, ${ }^{30}$ die ab den 1840er Jahren auch das Deutsche Reich erfasste. Die Epoche war geprägt von sektoralem Wandel, technischen Neuerungen und wirtschaftlicher Expansion. ${ }^{31}$ Wechselseitige Einflussnahme von Industrie und Staat bildeten den Rahmen für einen signifikanten ökonomischen und gesellschaftlichen Wandel. ${ }^{32}$ Dieser leitete in den Jahren 1880 bis 1914 evolutionäre Veränderungen und Innovationen ein, die der

26 Vgl. Lorenz (2000): Reklamekunst, S. 12. Die politische Propaganda bediente sich bereits im 19. Jahrhundert Methoden der Wirtschaftswerbung. Vgl. Berghoff, Hartmut (2007): „Marketing im 20. Jahrhundert. Absatzinstrument - Managementphilosophie - universelle Sozialtechnik“. In: Ders. (Hg.): Marketinggeschichte. Die Genese einer modernen Sozialtechnik. Frankfurt/M./ New York: Campus, S. 53

$27 \quad$ Bilderbögen mit Motiven aus dem Krieg 1870/71 erreichten eine Auflage von zwei Millionen Exemplaren. Faulstich (2004): Medienwandel, S. 112

28 Vgl. Münkler, Herfried (2009): Die Deutschen und ihre Mythen, 2. Aufl. Berlin: Rowohlt, S. 17

29 Vgl. Reinhardt, Dirk (1993): Von der Reklame zum Marketing. Berlin: Akademie Verlag, S. 416

30 Die Epoche der Industrialisierung gilt als Abschnitt einer durchgängigen historischen Entwicklung mit relativ homogenen Strukturen und Erscheinungsformen. Vgl. Bauer, J. Franz (2004): Das „lange“ 19. Jahrhundert. Stuttgart: Reclam, S. 11

31 Vgl. Nonn, Christoph (2007): Das 19. und 20. Jahrhundert. Orientierung Geschichte, 2. Aufl., Paderborn: Ferdinand Schöningh, S. 36

32 Aufgrund fehlender Konzepte gab es im Kaiserreich jedoch keine gesamtwirtschaftliche Ordnungs-, Struktur und Konjunkturpolitik. Vgl. Ullmann, Hans-Peter (1995): Das Deutsche Kaiserreich 1871-1918, Frankfurt/M.: Suhrkamp, S. 175 ff. 
modernen Massenproduktion zum Durchbruch verhalfen. ${ }^{33}$ Die konfektionierte Massenware verlor, losgelöst vom Produzenten, ihre Identität und distanzierte sich zunehmend vom Endverbraucher. Angesichts der gleichartigen Massenprodukte und „Genussmittel kolonialen Ursprungs wie Kaffee, Kakao oder Tee“34, die auf dem Markt drängten, war es für die Produzenten daher von vitalem Interesse, ihre Produkte von denen der Konkurrenz zu differenzieren. ${ }^{35}$ Es mussten Kommunikationsstrategien entwickelt werden, die einen Dialog zwischen dem Produkt und dem Konsumenten ermöglichten. ${ }^{36}$ Das gelang, in dem die Markenartikel über den reinen Produktnutzen hinaus mit einem Mehrwert, mit dem der Konsument psychologische und soziale Bedürfnisse befriedigen konnte, versehen wurden. ${ }^{37}$ Der Konsum dieser Markenartikel bedeutete eine Abkehr von einem Existenz sichernden Konsum, hin zu ei-

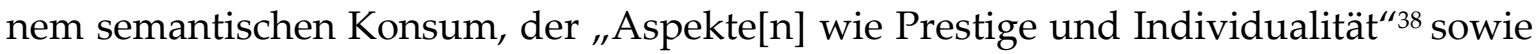
einen „Erlebnisfaktor “39 beinhaltete. Der Konsum dieses „symbolischen Mehrwerts“40 eröffnete neue soziale Identifikationsräume, der mit zunehmendem Massenkonsum in breite Gesellschaftsschichten diffundierte. Um den Mehrwert dieser Markenprodukte zu übermitteln, wurden mediale Vermarktungsstrategien in Form von Annoncen, Plakaten und Sammelbildern entwickelt.

Ein Vorläufer des klassischen Sammelbildes geht auf den französischen Kaufmann Aristide Boucicaut zurück, der um $1870^{41}$ in seinem Pariser Kaufhaus ,Au Bon Marché den Kindern seiner Kundinnen jeden Donnerstag ein Getränk und ein

33 Vgl. Teuteberg, Hans Jürgen (Hg.) (2004): Die Revolution am Esstisch. Stuttgart: Steiner, S. 132

$34 \quad$ Ilgen, Volker/Schindelbeck, Dirk (2006): Am Anfang war die Litfaßsäule. Illustrierte deutsche Reklamegeschichte. Darmstadt: Primus, S. 2

35 Vgl. Bruhn, Manfred (2014): Unternehmens- und Marketingkommunikation: Handbuch für ein integriertes Kommunikationsmanagement, 3. Aufl. München: Vahlen, S. 118

36 Der Philosoph und Soziologe Georg Simmel sah bereits 1890 Handlungsbedarf seitens der Hersteller, ihre Ware mittels Kommunikationsstrategien von den Konkurrenzprodukten zu differenzieren. Vgl. Simmel, Georg (1989): Über sociale Differenzierung - Aufsätze 1887-1890. Die Probleme der Geschichtsphilosophie. Frankfurt/M.: Suhrkamp, S. 229

37 Vgl. Bruhn (2011): Marketingkommunikation, S. 226

$38 \quad$ Kleinschmidt, Christian (2008): Konsumgesellschaft. Göttingen: V\&R, S. 11

39 Der Erlebnisfaktor ist ein Teil der Markenpersönlichkeit und stellt als „Erlebniswert der Marke ein wichtiges Konsumkriterium dar." Esch, Franz-Rudolf (2011): Strategie und Technik der Markenführung, 6. Aufl. München: Vahlen, S. 36.

40 Vgl. Torp, Claudius (2011): Konsum und Politik in der Weimarer Republik. Göttingen: V\&R, S. 20

41 Vgl. Ciolina, Erhard und Evamaria (2003): Reklamebilder. München: Weltbild, S. 10 
Bildpräsent offerierte. ${ }^{42}$ Kongenialer Ausdruck des Marketings wurden jedoch die Sammelbilder, die mit einem Produkt abgegeben wurden, denn sie verhalfen der Markenware aus der Anonymität und verliehen ihnen Persönlichkeit. Um 1900 begannen Markenartikelhersteller diverse Medien wie Oblaten, Kalender, Lesezeichen, Werbeheftchen, Kulissenbilder und Rechnungszettel für die Produktwerbung einzusetzen. Beliebtes Werbemittel waren ferner Serien von Reklamemarken mit Werbeaufdruck, die zum Verschließen von Umschlägen verwendet wurden. ${ }^{43}$ Im gleichen Zeitraum konnte sich das Kaufmannsbild in den Reihen der Werbeträger etablieren. Im Unterschied $\mathrm{zu}$ anderen Zugaben waren diese nicht an ein singuläres Produkt gekoppelt, sondern wurden von Einzelhändlern an die Kunden verteilt, um diese zu weiteren Einkäufen zu motivieren. ${ }^{44}$ Die Bilder konnten in prächtige Leeralben geklebt werden, die ab 1880 von Buchbindern für Fotografien, Postkarten oder Sammelbilder produziert wurden. ${ }^{45}$ Der Sammler konnte so das Sammelgut nach eigenen Ordnungskriterien in die Alben einordnen, bis Firmen ${ }^{46}$ dazu übergingen, die Bilder mit Seriennummern zu versehen. Dieses Ordnungssystem motivierte den Sammler in seiner Aktivität. Da sich ein Sammler aufgrund der homologen Struktur von Serien nur mit einer vollständigen Sammlung identifizieren kann, ${ }^{47}$ ist eine komplette Sammlung das Ergebnis einer Tätigkeit und „dem Sammler Grund zur Freude und zum

42 Der Zeitpunkt der Herausgabe der ersten Bilder ist nicht bekannt. Erhalten sind 438 Serien, die eine Auflage bis zu 400.000 erreichten. Vgl. Pieske, Christa/ Museum für Deutsche Volkskunde Berlin (1983): Das ABC des Luxuspapiers, Herstellung, Verarbeitung und Gebrauch 1860 bis 1930. Katalog zur Ausstellung des Museums für Deutsche Volkskunde Berlin, Staatliche Museen Preußischer Kulturbesitz. Berlin: Dietrich Reimer, S. 230

43 Vgl. Ciolina (2003): Reklamebilder, S. $17 f$.

44 Vgl. Ebd., S. 10. Die Abgabe war meist mit dem Kauf eines Artikels einer bestimmten Produktgruppe wie Kaffee, Kaffeesurrogat oder Haferflocken verbunden. Vgl. Pieske (1983): $A B C$, S. 232

45 Vgl. Ebd., S. 78. Auch Firmen begannen, eigene Alben auszugeben. Vorreiter war das Unternehmen Stollwerck, das ab 1897 prächtige Alben herausbrachte. Vgl. Weyers, Dorle/ Christoph Köck/ Landschaftsverband Westfalen-Lippe, Westfälisches Freilichtmuseum Detmold (Hg.) (1992): Die Eroberung der Welt. Sammelbilder vermitteln Zeitbilder. Bielefeld: Print und Kommunikation, S. 17

46 Haferkakao-Fabrik Hausen \& Co. war die erste Firma, die 1896 Serien publizierte. Vgl. Mielke, Heinz-Peter (1982): Vom Bilderbuch des kleinen Mannes. Köln: Rheinland, S. 118

47 Vgl. Baudrillard, Jean (2001): Das System der Dinge, 2. Aufl. Frankfurt/M./ New York: Campus, S. 116f. 
Stolz". ${ }^{48}$ Das Erschaffen eines ganzheitlichen Werkes ${ }^{49}$ veranlasste ihn daher, dem Produkt treu zu bleiben. Da die Sammelbilder nach 1900 auch Konsumgütern beigefügt wurden, die niedrigere Preissegmente bedienten, setzten sie einen Diffusionsprozess innerhalb der bürgerlichen Gruppierungen in Gang und ermöglichte auch dem Kleinbürgertum, sich den Wertekanon höherer Schichten zu eigen zu machen. Sammeln repräsentierte damit ",den Kult autodidaktischer Strebsamkeit“. ${ }^{50}$

Neben der Produkt-, Preis-, und Distributionspolitik wurde das Sammelbild als Kommunikationsinstrument Teil des Marketing-Mix, ${ }^{51}$ der das Ziel hatte, potentielle Konsumenten zu akquirieren und habitualisierte Käufer heranzuziehen. Das Erscheinen des Sammelbildes ist daher eng mit dem Aufkommen der Markenartikel $^{52}$ verbunden und damit medialer Wegbegleiter der modernen Konsumwelt. Nach der zeitgenössischen Definition waren Sammelbilder eine Wertereklame, die „Gewährung gegenständlich gebundener Vergünstigungen“53 bot. Die ersten Firmen, die in den 1870er Jahren Sammelbilder für ihre relativ hochpreisigen Produkte wie Schokolade, Kaffee oder Fleischextrakt auf den Markt brachten, orientierten sich bei der Themenauswahl an bürgerlichen Idealen und Werten. ${ }^{54}$ In Deutschland war der Schokoladenfabrikant Stollwerck Pionier auf dem Gebiet der Sammelbilder. Das Unternehmen orientierte sich an dem französischen Vorbild und setzte bald kurz nach der

Sommer, Manfred (1999): Sammeln - Ein philosophischer Versuch. Frankfurt/M.: Suhrkamp, S. 195

49 Vgl. HIS PFR 491,08 Lose, Otto (1953): Der Bilderdienst, S. 292

50 Bourdieu, Pierre (1987): Die feinen Unterschiede. Frankfurt/M.: Suhrkamp, S. 549

51 Der Marketing-Mix besteht aus den Marketinginstrumenten „Produkt-, Preis-, Vertriebs- und Kommunikationspolitik“. Vgl. Kotler, Philip/ Armstrong, Gary/ Saunders, John/ Veronica Wong (2003): Grundlagen des Marketing, 3. Aufl. München: Pearson Studium, S. 191. Das Marketing-Mix ist Teil des Marketing-Managements und Schnittstelle zwischen der strategischen Gesamtplanung und der operativen Maßnahmen im Markt. Die Marketinginstrumente entsprechend der Marktbedingung eingesetzt. Vgl. Pepels, Werner (2004): Marketing: Lehr- und Handbuch, 4.Aufl. München: Oldenbourg, S. 349

52 Vgl. Ilgen, Volker/ Schindelbeck, Dirk (1997): Jagd auf den Sarotti-Mohr. Frankfurt/M.: S. Fischer, S. 100

53 Redlich, Fritz (1935): Reklame - Begriff - Geschichte - Theorie. Stuttgart: Ferdinand Enke, S. 4

54 Die ersten Bilderserien, die im Kaiserreich ausgegeben wurden, hatten neben unterschiedlichen Wissensgebieten auch Genrebilder und Lebenswelten von Kindern zum Inhalt. Mielke verweist auch auf die Status bildende Funktion der Liebigbilder: „Sie künden von einer heilen, bürgerlichen Welt, in der jedem der soziale Status, der ihm zukommt, zugewiesen ist, dies versetzt mit jenem Optimismus, demzufolge das Glück allemal mit dem Tüchtigen sei“. Mielke (1982): Bilderbuch, S. 47 
Einführung jährlich bis zu 50 Millionen Bilder ab. Neben Stollwerck übernahmen weitere Markenartikelhersteller das Konzept der Sammelbilder, um ihre Waren mit Persönlichkeit und Mehrwert auszustatten. Dazu zählen Produkte, die auch noch heute auf dem Markt existieren wie „Erdal, Dr. Oetker, Knorr, Sarotti, Palmin oder Kathreiner“ ${ }^{25}$ Den größten Bekanntheitsgrad erreichten die Bilder der Liebig Company, die den Absatz ihres Fleischextraktes mit Bildzugaben förderte und um 1890 einen ungeahnten Sammelboom entfachte. ${ }^{56}$ Die Liebig-Alben waren lexikalische Bilderalben, die ein bürgerliches Bildungsideal transportierten. ${ }^{57}$ Die Liebig-Serien deckten ein sehr breites Wissensspektrum ab, wie Wissenschaft, Technik, Kultur, Geschichte, Volksund Völkerkunde sowie diverse Sparten der Unterhaltung. Im Unterschied zu anderen Firmen fanden aufklärerische Gedanken oder zeitgenössische Themen keinen Eingang in die Liebig-Bilder. Diese Zurückhaltung, insbesondere bei der Darstellung religiöser und patriotischer Sujets oder kriegerischer Auseinandersetzungen, ist dem internationalen Markt geschuldet, den Liebig beliefert hat. ${ }^{58}$

Das Sammelbild verdankte seine Effizienz nicht nur dem Zusatznutzen, sondern auch dem Sammeltrieb, der als inhärentes menschliches Bedürfnis eine zusätzliche Motivation zum Kauf darstellte. Das Sammeln, Ordnen und Sortieren ist tief in der menschlichen Psyche verankert und zeichnet sich durch außerordentliche Komplexität aus.

$55 \quad$ Ilgen/ Schindelbeck (1997): Sarotti-Mohr, S. 101

56 Vgl. Faulstich (2004): Medienwandel, S. 140. In der Zeit von 1872 bis 1940 brachte Liebig 1138 Serien heraus, die in der Regel aus 6 Bildern bestanden und teilweise Millionenauflagen erreichten. Auch das Liebig-Format von $11 \times 7 \mathrm{~cm}$ wurde sukzessive von vielen Firmen zum Standardmaß für Sammelbilder. Vgl. Faulstich (2004): Medienwandel, S. 142f. Einige Liebigforscher geben einen Erscheinungszeitraum von 1875 bis 1975 an. Vgl. Lorenz (2000): Reklamekunst, S. 17

$57 \quad$ Vgl. Mielke (1982): Bilderbuch, S.47. Die lexikalische Wissensaufbereitung hat ihren Vorläufer auch in den Intelligenzblättern, die ab dem 18. und 19.Jahrhundert enzyklopädisch angelegt wurden, um Wissen und Informationen systematisch zu ordnen. Die Intelligenzblätter hatten einen „Sammlungsauftrag“. Wüst, Wolfgang (2004): „Die 'Gelehrten Sachen' in den aufgeklärten Intelligenzblättern. Regionale Alternative oder Rezeption der 'großen' Enzyklopädie?“ In: Stammen, Theo/ Weber, Wolfgang E. J. (Hg.): Wissenssicherung, Wissensordnung und Verarbeitung. Das europäische Modell der Enzyklopädien. Berlin: Akademie Verlag, S. 390 Vgl. Mielke (1982): Bilderbuch, S.47 
Das Sammeln, befreit von der Notwendigkeit zur Lebenserhaltung, wurde zur Passion und diente der Befriedigung psychischer und intellektueller Bedürfnisse. ${ }^{59}$ Die Akkumulation von Wissen in Form von Sammlungen ist dabei sowohl ein kulturanthropologisches als auch ein entwicklungspsychologisches Phänomen und „gehört zum anthropologischen Grundbestand des Individuums". ${ }^{60}$

\subsection{Zigarettenbilder in Deutschland}

In den 1920er Jahren hatten einige deutsche Zigarettenfirmen nach amerikanischem ${ }^{61}$ und britischem Vorbild ${ }^{62}$ das Sammelbild als Marketinginstrument zur Kundenbindung für sich entdeckt und begannen, den Zigarettenverpackungen Bilder beizulegen. Die Bilder waren eine reine Zugabe. Der Firmenaufdruck befand sich auf der Rückseite und war nach dem Einkleben nicht mehr sichtbar. Selbst bei den Zigarettenalben wurde der Produkt- oder Firmenname nur in Ausnahmen ${ }^{63}$ auf den Einbänden oder in den Alben vermerkt. Die Anzahl der Zigarettenbilder pro Album war ausgesprochen variabel und betrug zwischen 6 und 1984 Bilder. ${ }^{64}$ Pionier des deutschen Zigarettenbildes war Friedrich Ladendorf, der mittels des Sammelbildes seine qualitativ minderwertigen Zigaretten in den 1920er Jahren erfolgreich auf dem Markt platzieren konnte. ${ }^{65}$

Entsprechend des Zeitgeistes nach 1918, der sich weitgehend vom Kriegsgeschehen des Ersten Weltkrieges distanziert hatte, wurden Zigarettenbilder nicht politisiert oder zur Verbreitung patriotischen Gedankengutes verwendet. Die Unternehmen

\footnotetext{
$59 \quad$ Vgl. Ebd., S. 9

$60 \quad$ Ilgen/ Schindelbeck (1997): Sarotti-Mohr, S. 9

61 Die ersten Zigarettenbilder wurden ab 1897 und primär für Seeleute herausgebracht. Vgl. Faulstich (2004): Medienwandel, S. 143

62 Die Angaben bezüglich der ersten Zigarettenbilder divergieren. Nach Aussage des Direktors des Reemtsma-Bilderdienstes Otto Lose kamen die ersten Zigarettenbilder im Jahr 1878 in Umlauf. Abgebildet waren Schauspieler und berühmte Schönheiten. Vgl. HIS PFR 491,08 Lose, Bilderdienst, S. 292

63 Beispiele: Abdulla (1932): Im Auto mit Abdulla durch die Welt, Bd. 3, Berlin. Bravour (1933): Bravour-Bilder Film und Sport. Berlin. Kosmos (1933/1934): Film Photos, Serie 1 und 2. Dresden

64 Lande (1934): Der Rattenfänger von Hameln, Dresden, 6 Bilder. Abadie (1928): Flaggen und Wappen der Welt, Bd. 1, 1984 Bilder.

65 Vgl. HIS PFR 491,08 Lose (1953): Bilderdienst, S. 294
} 
publizierten ausschließlich Bilderserien aus Bereichen der populären Alltagskultur, wie Film, schöne Frauen, Gesellschaft und Sport. ${ }^{66}$ Die starke Konkurrenz innerhalb der Branche, der geringe Preis der Zigaretten, die Nachfrage seitens der Konsumenten und der nicht zu unterschätzende Suchtfaktor des Nikotins, der über Klassenschranken hinweg breite Bevölkerungsschichten erfasste, steigerten die Nachfrage nach Zigarettenbildern, die ab $1932^{67}$ den Markt der Sammelbilder dominierten. 80 Prozent der Raucher sammelten Bilder. ${ }^{68}$ Die Anzahl der Alben hatte sich von 24 Alben im Jahr 1930 auf 93 Alben im Jahr 1931 mehr als verdreifacht und erreichte mit 162 Alben im Jahr 1933 seinen Rekord. ${ }^{69}$ Im Jahr 1935 ebbte die Nachfrage rapide ab, erhöhte sich lediglich im Jahr 1936 aufgrund der Olypiade, die in vielen Alben thematisiert wurde. Das Zigarettenbild wurde einige Jahre nach seiner Einführung vom Konsumenten als zum Produkt gehörende Leistung angesehen, wodurch das Beilagesystem eine Eigendynamik entfaltete. Da der Raucher das Sammelbild als eine „ihm in jedem Fall zustehende Zugabe "70 betrachtete, konnten sich die Zigarettenfirmen dem Zugabewesen auf dem hart umkämpften Zigarettenmarkt der 1930er Jahre nicht verweigern. Der Verkauf der Zigaretten wurde maßgeblich von der Beilage beeinflusst, so dass es den Unternehmen nicht möglich war, Zigarettenmarken ohne Zugabe auf dem Markt zu etablieren. Insbesondere dann, wenn Firmen im selben Preissegment miteinander in Konkurrenz standen, mussten sie Umsatzeinbußen verbuchen, wenn sie keine Bilder anboten. Aber auch mit Bildzugabe konnten Firmen in eine prekäre finanzielle Lage geraten.71 Während einige Zigarettenfabriken mit den Bildern den Absatz stei-

66 Vgl. Mielke (1982): Bilderbuch, S.137

67 Köberich (2003): Sammelbilder. Vgl. Ciolina, Evamaria/ Ciolina, Erhard (2007): Das Reklamesammelbild, 2. Aufl. Regenstauf: Battenberg, S. 12

68 Vgl. Lindner, Erik (2007): Die Reemtsmas. Hamburg: Hoffmann und Campe, S. 237

69 Köberich (2003): Sammelbilder

70 HIS PFR 491,08 Lose (1953): Bilderdienst, S. 294

71 Zu Beginn der 1930er Jahre wurden seitens der Zigarettenindustrie Reglements erlassen, um Konkursen durch „übersteigerter[n] Wettbewerb in Stickereien, Spitzen und anderen Beilagen insbesondere in der Klein- und Mittelindustrie" entgegenzuwirken. Die 1934 gegründete Wirtschaftliche Vereinigung der Zigarettenindustrie (WVZ) untersagte ihren Mitgliedern Beilagen für 3 1/3 Pfg.-Zigaretten, wenn die Zugaben mehr als 85 Pfg. pro Tausend Stück kosteten. Für Billig-Marken wurde ein generelles Reklame- und Beilageverbot erlassen. Vgl. HIS PFR 491,01 
gern konnten, ${ }^{72}$ gerieten andere Hersteller wie das Unternehmen Lande aufgrund der hohen Kosten dieser Marketingmaßnahme in wirtschaftliche Bedrängnis. ${ }^{73}$ Laut Wolfgang Ritter, Inhaber der Zigarettenfabrik Brinckmann, sind Beilagen nur dann effektiv, „wenn ein gewisser Schwellenwert überschritten wird, d.h. nur bei Marken mit großem Umsatz. Die Kosten zwingen den Hersteller dazu, die Werbung zu verringern “ ${ }^{74}$ In Anbetracht der Risiken und der Zusatzkosten ${ }^{75}$ beteiligten sich viele Firmen nur widerwillig an dem Beilagesystem.

Die Zigarettenfabrikanten versuchten daher vereinzelt, sich dem Zugabewesen zu entziehen. So hatte der Reemtsma-Konzern bei der Marke 'Juno' versucht, den Fokus auf die Qualität des Produktes zu lenken und warb mit dem Slogan: „Juno bringt Qualität und keine Bilder" ${ }^{76}$ Die Ablehnung gegenüber den Beigaben veranschaulicht auch eine Werbeanzeige der Waldorf-Astoria-Marke ,Oberst' im Völkischen Beobachter (VB). In der großformatigen Anzeige wird die Umsatzsteigerung der Marke auf die Empfehlung der begeisterten Kundschaft zurückgeführt, denn „Reklame und Zugaben allein schaffen's nicht!" ${ }^{\prime 77}$ Die Zigarettenfabrikanten sahen sich einem doppelten Konkurrenzkampf ausgesetzt, bei dem nicht nur die Qualität der Zigaretten, sondern auch die Zigarettenbilder über den wirtschaftlichen Erfolg einer Marke entschieden. „Der Verkauf geriet zeitweilig in ein Abhängigkeitsverhältnis zu diesem Werbemittel “, ${ }^{\prime 8}$ so Otto Lose, Direktor des Reemtsma-Bilderdienstes. Der Zigarettenfabrikant Philipp Reemtsma selbst hatte ein distanziertes Verhältnis zu den Bildern, da er der Sammeltätigkeit nichts abgewinnen konnte. ${ }^{79}$ Insbesondere für Reemtsmas

\footnotetext{
72 Vgl. HIS PFR 491,08 Lose (1953): Bilderdienst S. 294

Vgl. Lindner (2007): Reemtsmas, S. 151

Ritter, Wolfgang (1970): Die bessere Idee. Pfullingen: Neske, S. 90

Vgl. HIS PFR 491,08 Lose (1953): Bilderdienst, S. 294.

Die Alben wurden kostengünstig an die Konsumenten abgegeben und hatten mitunter den 7-8fachen Wert. Reemtsma-Geschäftsleitung, Rundschreiben Nr. 50, 12. Oktober 1933, Vgl. HIS PFR 491,01

76

Da die Konkurrenz in derselben Preisklasse mit Beilagen warb, musste Reemtsma nach sechs Wochen aufgeben und Bilder beifügen. Ritter (1970): Idee, S. 89

77 VB, 46. Jahrgang, 60. Ausgabe, Norddeutsche Ausgabe A, Erstes Beiblatt, Mittwoch, 1. März, 1933

78 HIS PFR 491,08 Lose (1953): Bilderdienst, S. 294

79 Vgl. HIS PFR 230,35 Strafsache Reemtsma, 56. Verhandlungstag, 22. September 1948
} 
Markentechniker Hans Domizlaff war das einzig legitime Mittel die Qualität der Ware: „Konkurrenzkampfmittel gegen Marken ist die größere Leistung und die bessere Marke“ ${ }^{80}$ Im Jahr 1932 musste er sich aber resigniert dem Marktgeschehen beugen, da sich die Konkurrenz dem „Teufel des Zugabewesens verschrieben habe“. 81 Ebenso kritisch äußerte sich Wolfgang Ritter, der sich widerwillig den Bedürfnissen der Konsumenten beugen musste: „Die Erfahrung hat gezeigt, daß die Bilderseuche etwa alle 30 Jahre wiederkehrt, und daß die Industrie nach einigen Jahren völlig ermattet mit dem Unsinn wieder aufhört. In diesem Zeitraum verschiebt sich aber das Bild des Umsatzes wesentlich". ${ }^{82}$

Die Zigarettenfabrikanten hatten den psychologischen Mehrwert der Sammelbilder nicht einkalkuliert, respektive unterschätzt. So sehr sich Reemtsma und andere Unternehmen auch gegen die Beilagen wehrten, bekamen die Bilder eine vitale marketingstrategische Relevanz, was aus der Korrespondenz des ReemtsmaVorstandes hervorgeht: „Die Bedeutung des Albenverkaufs ist Ihnen allen bekannt. Der Raucher, der ein Album gekauft hat, bleibt der Cigarette einmal bis zur Komplettierung seiner Sammlung, zum anderen infolge ihrer Qualität meist dauernd treu $[\ldots]^{\prime \prime}{ }^{83}$ Als Reemtsma den Stellenwert der Sammelbilder für die Kundenbindung erkannte, forcierte das Unternehmen den Vertrieb der Bilder, um neue Kundensegmente zu erschließen. ${ }^{84}$ Um die Distribution der Bilder zu vereinfachen und die Kosten zu reduzieren, empfahl Friedrich Ladendorf, den Reemtsma als Berater hinzugezogen hatte, ein Bilderschecksystem einzuführen. ${ }^{85}$ Anstelle der Bilder wurden den Packungen nummerierte Coupons beigefügt, die bei Einsendung gegen Bilderreihen eingetauscht werden konnten. Der Bilderscheck stellte eine Bezugsberechtigung dar, mit der der Sammler nicht mehr an bestimmte Serien gebunden war. Für 50 gebündelDomizlaff, Hans (2005, Erstausgabe 1939): Die Gewinnung des öffentlichen Vertrauens. Ein Lehrbuch der Markentechnik. Hamburg: Marketing Journal, S. 171

81 Jacobs, Tino (2008): Rauch und Macht. Göttingen: Wallstein, S. 131f.

82 Ritter (1970): Idee, S. 90

83 Reemtsma-Geschäftsleitung, Rundschreiben Nr. 50, 12. Oktober 1933, HIS PFR 491,01

84 Vgl. Ebd.

85 Vgl. HIS PFR 491,08 Lose (1953): Bilderdienst, S. 294
} 
te Einzel- und Doppelschecks erhielt der Sammler ein Bildpaket. Der Bilderscheck war derart erfolgreich, dass er eine "Art Monopolstellung in der Zigarettenwerbung" einnahm. Damit entfiel für den Konsumenten das müßige Sammeln einzelner Bilder und vereinfachte den Bildertausch sowie das Komplettieren einer Sammlung. ${ }^{87}$ Die Bilder waren aufgrund dieses Systems auch nicht mehr von der Größe der Zigarettenpackung abhängig. Die unterschiedlichen Bildformate erlaubten daher eine freie Gestaltung des Layouts, ${ }^{88}$ was den Zigarettenfabrikanten auch ermöglichte, die Alben als Bildbände anzulegen. So konnten sie einem Trend folgen, denn bebilderte Sachbücher waren in den 1930er Jahren zu beliebten Medien der populären Informationsvermittlung avanciert. ${ }^{89}$ Jahr 1932 wurde eigens für den Vertrieb der ReemtsmaSammelbilder der ,Cigaretten-Bilderdienst Bahrenfeld' gegründet, dem Direktor Otto Lose vorstand. Dieses System stellte nicht nur eine innovative Neuerung dar, sondern reduzierte aufgrund der vereinfachten Distribution die Kosten. Der Bilderdienst wuchs schnell zu einem großen Verlag mit 150 Angestellten heran. Die Zigarettenalben erreichten Millionenauflagen und die Reemtsma-Bilder wurden zum Synonym für Zigarettenbilder. ${ }^{90} \mathrm{Um}$ die Kosten weiter zu reduzieren, konnten sich Firmen, die der Interessengemeinschaft der deutschen Zigarettenhersteller (IG) ${ }^{91}$ angehörten, dem Reemtsma-Bilderschecksystem anschließen.

Bei den Sammelalben blieb Reemtsma seinem Qualitätsanspruch treu, denn minderwertige Zugaben hätten die Marken in Mitleidenschaft gezogen. Um das Marketinginstrument nicht zu beschädigen, mussten sich die Zigarettenfirmen, die dem Bilderschecksystem angeschlossen waren, strengen Regeln unterwerfen.92 Die Anzahl

86 HIS PFR 491,01 Artikel aus der „Deutschen Allgemeinen Zeitung“, 15. Mai 1942

87 HIS PFR 491,10 Cigaretten-Bilderdienst Hamburg Bahrenfeld - Was Ihnen der Bilderdienst bietet.

88 Vgl. HIS PFR 491,08 Lose (1953): Bilderdienst, S. 294

89 Vgl. Härtel, Christian (2004): Stromlinien - Wilfrid Bade. Eine Karriere im Dritten Reich. Berlin: be.bra, S. $125 \mathrm{f}$.

$90 \quad$ Vgl. HIS PFR 491,08 Lose (1953): Bilderdienst, S. $294 \mathrm{f}$.

91 Der IG waren große Firmen wie die BATC, Lande, Garbáty und Brinkmann angeschlossen sowie mittlere Firmen wie Greiling, Aurelia, Kyriazi, Muratti, Yramos und Sturm. Kleinproduzenten, wurden nicht zugelassen. Vgl. Lindner (2007): Reemtsmas, S. 148f.

92 Die Bilderschecks mussten von IG-Mitgliedern beim Bilderdienst bestellt werden. Das Urheberrecht blieb beim Reemtsma-Konzern, dem es ab 1935 als geschäftsführende Firma oblag, 
der Bilderserien wurde begrenzt, um die „Qualität der Serien, Bilder und Alben laufend zu steigern“. ${ }^{93}$ Neben hoher Druckqualität und guter Verarbeitung zeichneten sich

insbesondere die Reemtsma-Sammelalben durch anspruchsvolle Inhalte aus, für die „,sachverständige Schriftsteller und Künstler verpflichtet wurden“. ${ }^{94}$ Die Zigarettenalben besaßen ein so hohes Niveau, dass sie als Lehrmaterial eingesetzt wurden. „Die Schulen betrachteten diese Sammelwerke als wertvolle Hilfsmittel. Selbst Fachgelehrte benutzten unsere Materialalben oder unsere naturkundlichen Werke als gute Informationsquellen“. 95

Am 1. Oktober 1941 wurden die Sammelbilder auf Weisung der Reichsstelle für Papier und Verpackungswesen eingestellt, wobei laufende Serien bei Reemtsma noch bis Mai 1943 abgewickelt werden konnten. Die Einstellung beruhte neben dem kriegsbedingten Papiermangel ${ }^{96}$ auf den Engpässen bei der Roh- und Brennstoffversorgung, die sich ab Mitte 1941 gravierend auf die Zigarettenproduktion auswirkte. ${ }^{97}$ 1942 wurden 88 Zigarettenfabriken geschlossen und 350 von 500 Marken eingestellt. Im gleichen Jahr wurde die Raucherkarte eingeführt, was ein kontinuierliches Sammeln erschwerte oder Personen von vorn herein ausschloss. ${ }^{98}$ Im Jahr 1944 wurde die Einheitszigarette eingeführt.99 Marketingmaßnahmen waren damit obsolet.

für die technische Ausführung der Einheitsserien Sorge zu tragen. Vgl. HIS PFR 491,02 Reemtsma-Geschäftsleitung (Kurt Heldern) an die Geschäftsleitungen der Mitglieder der IG, 25. Juli 1936. Die Herstellung der Klischees und der Alben wurde von Reemtsma in Auftrag gegeben. Der Verkaufspreis und die Grammatur des Papiers waren ebenso vorgeschrieben wie das Layout der Rückseite, auf der die einzelnen Firmen lediglich ihre Marke und Tauschstelle aufdrucken konnten. Die Wahl der Druckerei blieb den Mitgliedern vorbehalten. Vgl. HIS PFR 491,01 Reemtsma-Geschäftsleitung, Mitteilung Nr. 6, 13. April 1935 HIS PFR 491,01 Rundschreiben Nr. 67, 27. Juli 1937

HIS PFR 491,08 Lose (1953): Bilderdienst, S. 294

Ebd. S. 295

Vgl. Boelcke: „Die deutsche Wirtschaft 1930-1945“, S. 257. Zit. nach: Rücker, Matthias (2000): Wirtschaftswerbung unter dem Nationalsozialismus. Frankfurt/M.: Peter Lang, S. 216.

Vgl. Merki, Christoph Maria (1998): Die nationalsozialistische Tabakpolitik. Vierteljahreshefte für Zeitgeschichte, Jg. 46, Heft 1. München: Oldenbourg, S. 34

Die Raucherkarte konnte von Männern ab 18 und Frauen ab 25 Jahren bezogen werden. Vgl. Lindner (2007): Reemtsmas, S. 234

Vgl. Merki (1998): Tabakpolitik, S. 37 


\subsection{Die deutsche Zigarettenindustrie}

Vor dem ersten Weltkrieg kämpften in Deutschland ca. 1000 Hersteller um die Gunst der Konsumenten. Die Zigaretten wurden in kleinen Manufakturen in Handarbeit hergestellt und auf regionalen Märkten vertrieben. Als ein Phänomen der Moderne konzentrierte sich der Konsum anfangs aber primär auf die Großstädte. In den 1920er Jahren eroberten Markenzigaretten sukzessive den Markt. Dresden, Berlin, Köln und Hamburg wurden zu Zentren der Zigarettenfabrikation, die zunehmend automatisiert wurde. ${ }^{100}$

Die Geschichte der deutschen Zigarettenindustrie ist im Wesentlichen die Geschichte des Reemtsma-Konzerns, der sich von einem Kleinunternehmen zum marktbeherrschenden Zigaretten-Tycoon entwickelte. Reemtsma begann als kleine Manufaktur Dixi, ${ }^{101}$ die 1910 mit sieben Angestellten für den regionalen Markt produzierte. In den folgenden Jahren expandierte das Unternehmen und firmierte zur Handelsgesellschaft, die sich ab 1919 ,B. Reemtsma \& Söhne`102 nannte. Von den drei Brüdern brillierte Philipp Reemtsma mit kaufmännischem Geschick. Durch Übernahmen etablierter Firmen ${ }^{103}$ mit gut eingeführten Marken expandierte das Unternehmen in den 1920er Jahren zum Branchenführer. ${ }^{104}$ Reemtsma konnte durch die Übernahmen und vertraglichen Verbindungen sein hochpreisiges Sortiment durch mittlere und preiswerte Marken zu einer breiten Angebotspalette ausbauen, was in krisengeschüttelten Inflationszeiten einen Wettbewerbsvorteil darstellte. ${ }^{105} \mathrm{Um}$ die anvisierte „kartellartige Interessengemeinschaft“106 vor der Konkurrenz zu verschleiern, erfolgten hinter den Kulissen diverse Übernahmen, darunter Bulgaria,

\footnotetext{
100 Vgl. Lindner (2007): Reemtsmas, S. 16f.

101 Vgl. Ebd., S. 14

102 Vgl. Ebd., S. 19

1031929 wurde die Interessengemeinschaft mit dem Unternehmen Neuerburg, dem die WaldorfAstoria, Halpaus und Zuban angeschlossen waren, gegründet. 1937 erfolgte die Fusion. Vgl. HIS PFR 491,02 „Das Volk“ 20.10. 1945 (Abschrift).

104 Vgl. Lindner (2007): Reemtsmas, S. 46

105 Vgl. HIS PFR 491,01 Kölnische Volkszeitung, 27. Juni 1938

Vgl. Rahner, Stefan (Hg.) (2010): Werbewelten made in Hamburg. 100 Jahre Reemtsma. Hamburg: Junius, S. 92 
Haus Neuerburg und Batschari, sowie eine Teilhaberschaft an Greiling und Garbáty. ${ }^{107}$ Reemtsma avancierte damit zum unangefochtenen Marktführer, der das gesamte Marktgeschehen kontrollierte. ${ }^{108}$ Der rasante Aufstieg der Reemtsma-Brüder beruhte neben unternehmerischem Geschick auf engen Verbindungen zu wichtigen Schaltstellen der Macht sowie auf fragwürdigen Praktiken. Reemtsmas rücksichtsloses Geschäftsgebaren und Betrugsaffären, mit denen sich der Konzern unter anderem immense Steuervorteile erschlich, ${ }^{109}$ brachten dem Unternehmen sowohl innerhalb der Branche als auch in der Öffentlichkeit einen schlechten Ruf ein. ${ }^{110}$

\subsubsection{Arrangement mit dem NS-Regime}

Auf dem hart umkämpften Zigarettenmarkt im Jahr 1932 waren Marketingmaßnahmen ein unerlässliches Instrument der Absatzförderung, bei dem Werbeanzeigen neben dem Zigarettenbild einen hohen Stellenwert besaßen, denn „für jeden Markenartikel“ bestand „zwingende Notwendigkeit, fortlaufend Propaganda zu treiben.“111 Der Pragmatiker Ph. Reemtsma schaltete daher auch Anzeigen in Zeitungen des EherVerlages, der im Besitz der NSDAP war. In einem Ermittlungsverfahren im Jahr 1947 rechtfertigte sich Reemtsma für sein Vorgehen: „Ich war in dem fraglichen Zeitpunkt der Auffassung, dass Hitler der kommende Mann sei, daher auch meine vorerwähnte Sorge. (Anm.: um Deutschlands Schicksal) Gleichwohl habe ich die Frage der Inseratverteilung nur nach rein kaufmännischen Gesichtspunkten beurteilt [...] Bemerken will ich, dass die Frage der politischen Richtung der Presse ohne Bedeutung für unsere Inseratenaufträge war. So haben wir die kommunistische Presse, [...] die uns ständig bekämpft hat, laufend mit Inseraten bedacht, bis zu ihrer Auflösung im März 1933. Denn wir wollten, dass auch die Kommunisten unsere Cigaretten rauchten. “112

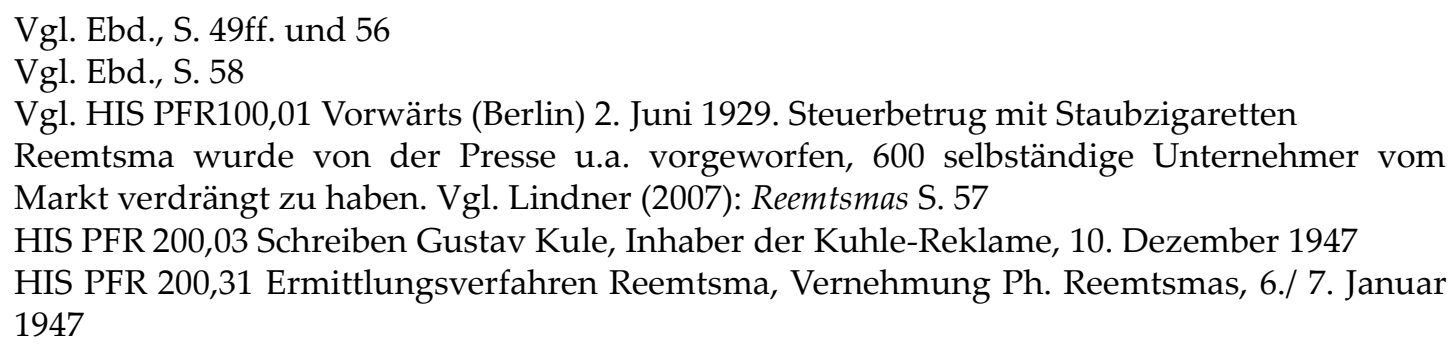


Die Inserate, die der in Verruf geratene Konzern in der nationalsozialistischen Presse schaltete, provozierten heftige Proteste seitens der Leserschaft. Insbesondere die Zigarettenfirma Sturm, die der SA nahe stand und die Parteiarmee finanziell unterstützte, opponierte lautstark gegen die Werbeanzeigen des Hamburger Konzern. ${ }^{113}$ Da es bis Mitte 1932 keine einheitlichen Direktiven für die NS-Presse gab, wurden die Reemtsma-Anzeigen von lokalen Blättern boykottiert, ${ }^{114}$ während sich Max Amann, der Verlagsleiter des Eher-Verlages, für Reemtsma aussprach, um den ausländischen und jüdischen Firmen nicht das deutsche Terrain zu ebnen. ${ }^{115}$ Da sich die NSDAP teilweise durch Inserate des Parteiverlages finanzierte,, ${ }^{116}$ war Reemtsma als einer der größten deutschen Inserenten ${ }^{117}$ ein unverzichtbarer Anzeigenkunde. Um eine Eskalation innerparteilicher Auseinandersetzungen zu beenden, wurde Hitler der Fall vorgetragen, der Ph. Reemtsma zu einem Gespräch lud. ${ }^{118}$ Die Nationalsozialisten, darunter auch Hitler, zeigten sich angesichts der leeren Parteikasse nicht minder pragmatisch. Hitler konnte aufgrund des bevorstehenden Wahlkampfes mit den kostspieligen ,Deutschlandflügen' auf die Reemtsma-Anzeigen im Völkischen Beobachter nicht verzichten und gestattete das Schalten der Werbung. ${ }^{119}$

Reemtsma musste sich jedoch weiterhin gegen Attacken von rechts wehren. Die Zigarettenfirma Sturm unternahm massive Angriffe gegen den Konzern, die nach der Machtergreifung insbesondere in Sachsen an Schärfe zunahmen. Reemtsma-Werbung wurde von SA-Mitgliedern auf die Straße geworfen und Gastwirte und Händler, die

\footnotetext{
113 Vgl. Lindner (2007): Reemtsmas, S. 85ff.

$114 \quad$ Vgl. Ebd., S. 82

115 Vgl. Sennebogen, Waltraud (2008): Zwischen Kommerz und Ideologie. München: Martin Meidenbauer, S. 204

116 Vgl. Tavernaro, Thomas (2004): Der Verlag Hitlers und der NSDAP. Die Franz Eher Nachfolger GmbH. Wien: Praesens, S. 33

117 Vgl. HIS PFR 100,01 Neueste Nachrichten (Berlin) 9.-15. Oktober 1932

118 Das Gespräch mit Hitler fand im Juli 1932 im Hotel Kaiserhof in Berlin statt. Laut Ph. Reemtsma hatte er zuvor zwei Einladungen Hitlers ausgeschlagen. Reemtsma hielt es „Brüning gegenüber nicht anständig“ mit Hitler in Verbindung zu treten. Vgl. HIS PFR 220,36 Ermittlungsverfahren Reemtsma, Vernehmung Ph. Reemtsmas, 6./ 7. Januar 1947

119 Vgl. Lindner (2007): Reemtsmas, S. 88. Laut Max Amann war Reemtsma 1932 der größte deutsche Inserent. Vgl. BArch, OPG, Reemtsma; Schreiben Max Amann, 8.8.1932. Zit. nach: Ebd., S. 90
} 
Reemtsma-Zigaretten vertrieben, wurden attackiert. Die Situation verschärfte sich zusehends, denn die NSDAP baute eine neue Drohkulisse auf. Ph. Reemtsma fand seinen Namen auf einer Korruptionsliste wieder, die in der Presse publik gemacht wurde. Im Hause Reemtsma war man sich bewusst, dass es angesichts eines bevorstehenden Strafverfahrens aussichtsreicher sei, sich prominenter Protektion zu bedienen, als auf einen fairen Prozess zu hoffen. Auf Betreiben seiner Mitarbeiter wandte sich Ph. Reemtsma an Hermann Göring. ${ }^{120}$ Göring war nicht nur aufgrund seiner Position als Preußischer Ministerpräsident eine gute Wahl, sondern galt als Verfechter einer kapitalistisch orientierten Wirtschaftspolitik in Kreisen der Industrie als adäquater Kooperationspartner. Auch Görings Opposition zum radikalen Flügel der NSDAP sowie seine Ablehnung gegen „unbefugte[r] Eingriffe“"121 der Partei oder Justiz, machten Göring zu einem gesuchten Ansprechpartner. Auch Görings angespanntes Verhältnis zur SA und ihres „Chef des Stabes“ ${ }^{122}$ Ernst Röhm kam bei der Unterredung mit Ph. Reemtsma deutlich zum Ausdruck: „Die Trommler sind wieder am Werk. [...] Röhm baut die SA aus, und dazu braucht er Geld und nochmals Geld $[\ldots]^{\prime \prime}{ }^{123} \mathrm{Ph}$. Reemtsma konnte bei Göring auch darauf hoffen, seine erprobte Lösungsstrategie in Form finanzieller Zuwendungen anwenden zu können. Göring gelang es, das Ver-fahren „,...] im Interesse des Wirtschaftsfriedens und zur ungestörten Aufbauarbeit in der Zigarettenindustrie niederzuschlagen [...]. ${ }^{\text {‘24 }}$ Für seine erfolgreiche Intervention erhielt er eine von ihm geforderte exorbitante Spende in Millionenhöhe. ${ }^{125}$ Reemtsma wurde nicht nur zur Kasse gebeten, sondern war gleichzeitig auch

\footnotetext{
$120 \quad$ Vgl. Jacobs (2008): Rauch, S. 116-119

121 Im Mai 1933 befürwortete Göring eine rein auf Effizienz ausgerichtete Wirtschaftspolitik, deren Erfolg nicht daran gemessen werde, ob vermeintliche Korruptionsaffären verfolgt würden. Relevant sei nur die Expansion der deutschen Wirtschaft. Vgl. Kube, Alfred (1987): Pour le Mérite und Hakenkreuz. Hermann Göring im Dritten Reich, 2. Aufl. München: Oldenbourg, S. 121

122 Vgl. Longerich, Peter (1999): Die braunen Bataillone. Augsburg: Bechtermünz, S.109

123 Aussage Ph. Reemtsmas am 31.5.1948, StLG Hbg. 14 Js 170/46, IV/50 f., HIS PFR 230,04. Zit. nach: Jacobs (2008): Rauch, S. 120. Die SA hatte unter Röhm ein reichhaltiges Waffenlager angelegt. Longerich (1999): Bataillone, S. 205

124 HIS PFR 100,03 Wirtschaftsnachrichten 12. Februar 1934

125 Im Jahr 1934 erhielt Göring drei Millionen RM. Vgl. Lindner (2007): Reemtsmas, S. 123. Es folgte eine Million jährlich, die bis 1944 ausgezahlt wurde. Hinzu kamen weitere Zuwen-
} 
dungen wie Antiquitäten und Hochzeitsgeschenke. Vgl. HIS PFR 250,02 Strafsache Reemtsma, 40. Verhandlungstag, Zeugenaussage Dr. Rüdiger, 16. August 1948. 
Nutznießer der Korruption, die der Herrschaftsstruktur des NS-Staates inhärent war. ${ }^{126}$ Die obskuren Geschäftspraktiken des Reemtsma-Konzerns waren nicht der alleinige Grund für die Angriffe von Seiten des Staates. Auch die Ablehnung der breiten NSDAP-Anhängerschaft gegenüber der wirtschaftlichen Machtfülle der Konzerne sowie die jüdischen Teilhaber und Mitarbeiter ${ }^{127}$ waren eine Achillesferse, die die Hamburger Firma angreifbar machte. Im Unterschied $\mathrm{zu}$ anderen Zigarettenunternehmen war Reemtsma darüber hinaus massiven Repressalien seitens der SA ausgesetzt, die mit der Firma Sturm, einem potenten Rivalen Reemtsmas, sympathisierte. So war es Sturm gelungen, mit „Unterstützung durch Dienststellen der NSDAP und der SA“128 Konsumenten der Reemtsma-Marken abzuwerben. Da Reemtsma insbesondere in der NSDAP-Hochburg ${ }^{129}$ Sachsen übel beleumundet war, wurden Reemtsma-Zigaretten von vielen nationalsozialistischen Konsumenten gemieden. Reemtsma musste hier beträchtliche Einbußen verbuchen. Der ambitionierte Geschäftsmann hatte aber ein vitales Interesse, das verloren gegangene Terrain zurück zu erobern.

Das Arrangement Reemtsmas mit dem NS-Regime beschränkte sich nicht nur auf das Schalten von Werbeanzeigen und üppiger finanzieller Zuwendungen, sondern erstreckte sich auch auf die Publikation von Zigarettenalben mit NS-spezifischen Themen. Einige der NS-Alben entstanden in direkter Kooperation mit dem Reichsministerium für Volksaufklärung und Propaganda (RMVP). Bereits im Jahr 1933 kam das RMVP auf Reemtsma zu, mit der Forderung, das Propaganda-Album

126 Vgl. Bajohr, Frank (2001): Parvenüs und Profiteure. Frankfurt/M.: S. Fischer, S. 142. Korruption wurde unterschiedlich geahndet. „Während manche „Hoheitsträger" auf Grund ihrer Stellung und politischer Protektion Narrenfreiheit genossen, sahen sich subalterne Beamte mit drastischen Disziplinarmaßnahmen konfrontiert." Ebd., S. 191

127 Vgl. Lindner (2007): Reemtsmas, S. 184

128 HIS PFR 200,04 Ermittlungsverfahren Reemtsma, Vernehmung Ph. Reemtsmas, 6. Juli 1947.

129 In Sachsen war die NSDAP bereits bei der Landtagswahl 1930 hinter der SPD zur zweitstärksten Partei aufgestiegen. 1932 gab es bereits 780 NSDAP-Ortsgruppen in Sachsen. Bei der Reichstagswahl im Juli 1932 erzielte sie 41,2 Prozent der Wählerstimme; auch die Mitgliederzahl der NSDAP war seit 1929 stetig gestiegen. Sächsisches Staatsarchiv/ Parteien, Organisationen und Verbände, NSDAP, 10.01.01 
DEUTSCHLAND ERWACHT. WERDEN, KAMPF UND SiEG DER NSDAP ${ }^{130}$ zu publizieren. Laut Otto Lose hatte das RMVP „mit feinem Spürsinn [...] die außerordentliche Verbreitung und Werbemöglichkeit unserer Bilder für eigene Zwecke einzufangen“131 erkannt. In der Folge entstanden insgesamt fünf Alben unter der Ägide Reemtsmas, die das NS-Regime propagierten. Die Alben Deutschland ERWACHT (1933), AdOlF HitLER. BILDER AUS DEM LeBEN DES FÜHRERS ${ }^{132}$ und RAUBSTAAT ENGLAND, ${ }^{133}$ kamen direkt aus dem Hause Reemtsma, während die Sammelbände KAMPF UM's DRITTE REICH ${ }^{134}$ und Der STAAT DER ARbeIT UND DES FRIEDENS ${ }^{135}$ in Zusammenarbeit mit der IG publiziert wurden. Die NS-Alben entstanden laut Aussage von Kurt Heldern, einem führenden Reemtsma-Mitarbeiter, in direkter Zusammenarbeit mit dem RMVP: „Der besondere Inhalt der Sammelalben „Kampf ums dritte Reich“, der „Staat der Arbeit und des Friedens" und „Deutschland erwacht“ brachte es mit sich, dass diese Alben mit Unterstützung des Propaganda-Ministeriums und der massgebenden Führer der Bewegung fertiggestellt wurden."136 Ministerialrat Hanke, ein enger Mitarbeiter von Goebbels, fungierte indirekt als Herausgeber. Er war maßgeblich für die thematische Zusammenstellung verantwortlich und lektorierte die Manuskripte von Wilfrid Bade, dem Leiter der Abteilung ,Zeitschriftenpresse und Schrifttum' im Propagandaministerium. Für die Zusammenstellung der Bilder wurde eigens Hitlers Leibfotograf und

130 Reemtsma (Cigaretten-Bilderdienst Hamburg-Bahrenfeld) (1933): Deutschland erwacht. Werden, Kampf und Sieg der NSDAP, Auflage 876 - 975 (Auswahl und künstlerische Durcharbeitung der Lichtbilder Heinrich Hoffmann, München. Texte: Wilfrid Bade und Sonderbeiträge div. Autoren). Hamburg-Bahrenfeld

131 HIS PFR 491,08 Lose (1953): Bilderdienst, S. 295

132 Reemtsma (Cigaretten-Bilderdienst Altona/Bahrenfeld) (1936): Adolf Hitler. Bilder aus dem Leben des Führers. (Auswahl und künstlerische Bearbeitung der Bilder Heinrich Hoffmann, München). Hamburg-Bahrenfeld

133 Reemtsma (Cigaretten-Bilderdienst Altona/Bahrenfeld) (1941): Raubstaat England. HamburgBahrenfeld

134 Zigaretten-Industrie (Gemeinschaftsausgabe, beteiligte Firmen: Bulgaria, Constantin, Delta, Jasmatzi, Josetti, Salem) (1934): Kampf um's dritte Reich. Eine historische Bilderfolge (Text von: L. von Schenkendorf, Truppenführer der SA, Berlin.. Die Auswahl und künstlerische Durcharbeitung der Lichtbilder Heinrich Hoffmann, München) o.O.

135 Zigaretten-Industrie (Gemeinschaftsausgabe, beteiligte Firmen: Bulgaria, Constantin, Delta, Jasmatzi, Josetti, Salem) (1934): Der Staat der Arbeit und des Friedens. o.O.

136 HIS PFR 491,01 Schreiben von Kurt Heldern an die WVZ. Heldern bezieht sich in diesem Schreiben auf die Alben: Kampf um's dritte Reich, Deutschland erwacht und Der Staat der Arbeit und des Frieden, 4. Juni 1934 
späterer „Reichsbildberichterstatter" ${ }^{\prime 137}$ Heinrich Hoffmann engagiert. Hoffmann lieferte das Bildmaterial für diverse Alben, darunter auch für die Bände Adolf Hitler, ${ }^{138}$ Deutschland erwacht ${ }^{139}$ und Kampf um's Dritte Reich, ${ }^{140}$ wofür er stattliche Honorare für sich verbuchen konnte. ${ }^{141}$

Aber auch Hitler selbst profitierte insbesondere an dem Sammelband ADOLF HITLER, der sich ausschließlich seiner Person widmete. Neben der Image-Werbung konnte er finanzielle Gewinne verbuchen, denn die Bildagentur Hoffmann, zahlte ihm stattliche Tantiemen. ${ }^{142}$ Bei der Produktion des Albums DeUTSCHLAND ERWACHT war Hanke während der gesamten Produktion als Berater tätig und führte gemeinsam mit Hoffmann die Verhandlungen mit Otto Lose. ${ }^{143}$ Der Hauptteil der Texte wurde von „führenden Publizisten der NSDAP“144 erstellt, wie Wilfrid Bade, dem Reichspressechef Otto Dietrich und sowie hochrangigen Mitgliedern des Parteikaders wie SA-Truppenführer Leopold von Schenkendorf, Joseph Goebbels und Baldur von Schirach. Reemtsma war nach eigenen Angaben insbesondere aufgrund seines Konkurrenten Sturm gezwungen, Alben mit NS-Themen zu publizieren, um die Bedürfnisse der nationalsozialistischen Klientel zu befriedigen. ${ }^{145}$

Die fünf NS-Alben waren nicht die einzigen, die unter der Ägide von Reemtsma entstanden sind. Die Firma Greiling, an der Reemtsma 40 Prozent der Anteile hielt, brachte zwischen 1932 und 1934 insgesamt vier Sammelwerke mit eindeutigem NS-Bezug heraus: MÄNNER UND EREIGNISSE unSERER ZEIT, Band. 1 und Band 2, ${ }^{146}$ Herz, Rudolf (1994): Hoffmann \& Hitler. Fotografie als Medium des Führer-Mythos. München: Klinghardt \& Biermann, S. 18

138 Vgl. HIS PFR 491,01 Reemtsma-Geschäftsleitung an die am Bilderschecksystem beteiligten Firmen, 10. Februar 1939

139 Vgl. HIS PFR 491,02 Otto Lose zur Entlastung von Hans Domizlaff, 24. August 1945, S. 2

140 Vgl. HIS PFR 230,35 Strafsache Reemtsma, 56. Verhandlungstag, 22. September 1948

141 Vgl. HIS PFR 230, 22 Für das Album Deutschland erwacht erhielt Hoffmann 500.000 RM.

142 Vgl. Schwarzwäller, Wulf C. (1998): Hitlers Geld. Wien: Ueberreuter, S. 174ff.

143 Vgl. Härtel (2004): Stromlinien, S. 133

144 HIS PFR 491,01 Heldern, 4. Juni 1934

145 Sturm war es auch durch massiven Einsatz der SA gelungen, Reemtsma große Marktanteile zu entziehen. Vgl. Lindner (2007): Reemtsmas, S. 71 und S. 81f.

146 Greiling (1934): Männer und Ereignisse unserer Zeit, Bd. 1 und 2. Dresden
} 
Das Neue Reich ${ }^{147}$ und 13 historische Tage. Reichsparteitag Der Arbeit. StaAtsbeSuCH Mussolinis. ${ }^{148}$ Hinzu kam das Album Die Deutsche WeHrmacht, ${ }^{149}$ das als Gemeinschaftsausgabe von der IG erstellt wurde. ${ }^{150}$ Die Bilder für die Zigarettenalben wurden über den Reemtsma Bilderdienst Bahrenfeld vertrieben. Die Anzahl der eingelösten Bilderschecks und Verkaufszahlen der NS-Alben sprechen für die große Resonanz seitens der Konsumenten. Die Sammelwerke erfreuten sich größter Beliebtheit und führten die Verkaufslisten an. Den höchsten Absatz konnte das Hitler-Album mit 2.388 460 Mio. Exemplaren verzeichnen, gefolgt von den beiden Olympia-Bänden OLYMPIA 1936 und DEUTSCHLAND ERWACHT. ${ }^{151}$

Aus der Publikation der NS-Alben erwuchsen Reemtsma keine wirtschaftlichen Nachteile, denn sie waren ein vitales Instrument der Kundenbindung- und Gewinnung. Der Umsatz konnte sogar beträchtlich gesteigert werden. ${ }^{152}$ Reemtsma konnte mit den NS-Alben von der Popularität des Regimes wirtschaftlich profitierten. Im Laufe einer Gerichtsverhandlung im Jahre 1948 rechtfertige Ph. Reemtsma die Publikation der NS-Werke als strategische Maßnahme gegen den Rivalen Sturm: „Die Aufgabe war also ausschließlich, in den Kreis einzudringen, der uns verloren gegangen war, und zwar an die Zigarettenfabrik Sturm. Dieser Kreis war durch Sturm infiziert und war dieser Propaganda bereits verfallen. Ich konnte diese Kreise selbstverständlich nicht zurückgewinnen mit Bildern, die die Konsumenten ablehnten. “153

\footnotetext{
$147 \quad$ Greiling (1933): Das Neue Reich. Dresden

148 Greiling (1938): 13 historische Tage 1937. Reichsparteitag der Arbeit. Staatsbesuch Mussolinis. Dresden

149 Zigaretten-Industrie (Gemeinschaftsausgabe, beteiligte Firmen: Alva-Yosma, Bergmann, Bulgaria, Eckstein, Garbáty, Greiling, Jasmatzi, Josetti, Kyriazzi, Lande, Salem, WaldorfAstoria, Yenidze) (1936): Die Deutsche Wehrmacht. o.O. Die beteiligten Firmen Bulgaria, Constantin, Delta, Jasmatzi, Josetti gehörten zum ReemtsmaKonzern. Vgl. Lindner (2007): Reemtsmas, S. 35

151 Reemtsma (Cigaretten-Bilderdienst Hamburg-Bahrenfeld) (1936): Die Olympischen Spiele 1936, Bd. 1, 1.607446 Exemplare. Reemtsma (Cigaretten-Bilderdienst Hamburg-Bahrenfeld) (1936): Die Olympischen Spiele 1936, Bd. 2, 1.593392 Exemplare. Reemtsma (1933): Deutschland erwacht, 1. 526736 Exemplare. HIS PFR 491,08 Lose (1953): Bilderdienst, S. 295

152 Vgl. Lindner (2007): Reemtsmas, S. 155

153 HIS PFR 230,35 Strafsache Reemtsma, 56. Verhandlungstag, 22, September 1948.
} 
Die Kooperation mit dem NS-Regime war Reemtsma-Konzern nicht politisch motiviert, sondern folgte rein unternehmerischen Interessen. ${ }^{154}$ So verurteilte ein Kritiker Ph. Reemtsma als Opportunisten: „Nach der Revolution entpuppte sich Philipp Reemtsma als Materialist und Egoist übelster Sorte. Jedes Mittel war und ist ihm heute noch recht, um sein Ziel zu erreichen. [...] Politisch ist Philipp Reemtsma demokratisch eingestellt und Mitglied der „Deutschen Staatspartei“. Er ist scharfer Gegner der nationalsozialistischen Bewegung. Soweit es jedoch im Interesse des Unternehmens liegt, versteht er es meisterhaft, sich den jeweiligen Verhältnissen nach aussen anzupassen $[\ldots]^{\prime \prime 155}$

Anhand der Quellen kann nachgewiesen werden, dass auch die kriegsbedingte Ressourcenknappheit an Arbeitskräften und Papier für Reemtsma eine weitere Motivation darstellte, mit den Machthabern zu kooperieren. Ein Mangel an Arbeitskräften hätte die Zigarettenproduktion nachteilig beeinflusst. ${ }^{156}$ Bei einer Rationierung des Papiers wäre das gesamte Bilderschecksystem zum Erliegen gekommen. Reemtsma und die angeschlossen Firmen hätten damit auf einen Teil der 13 Bilderserien, die bis $1943^{157}$ ausgeliefert wurden, verzichten müssen und wären zu Gunsten der Konkurrenz ins Hintertreffen geraten. Diese Vorteilnahme kann bei dem Sammelwerk RAUBSTAAT ENGLAND aus dem Jahr 1941 nachgewiesen werden. Die Anweisung zur Publikation des Albums kam direkt aus dem RMVP (ausführlich Kap. 3.4.3). Propagandaminister Goebbels verfolgte damit eine anti-britische Kriegspropaganda im S inne der Rademaeker-Bilder, die im Ersten Weltkrieg eine große Resonanz bei der britischen Bevölkerung gefunden hatten. ${ }^{158}$ Die Publikation des England-Albums

\footnotetext{
154 Ph. Reemtsma war Anhänger und Unterstützer demokratischer Parteien. Hitler hielt er für einen Wahnsinnigen, der Unheil über Deutschland bringen würde. Vgl. Ebd.

155 Gauleitung Altona vom 18. Mai 1932 über Ph. Reemtsma. Schreiben von Tetens zur Haftbeschwerde Ph. Reemtsmas vom 11. September 1947, HIS PFR 250,02.

156 Vgl. Lindner (2007): Reemtsmas, S. 236. Vgl. HIS PFR 491,08 Lose (1953): Bilderdienst, S. 295

157 Ebd.

158 Vgl. HIS PFR 491,02 Lose zur Entlastung von Hans Domizlaff, 24. August 1945
} 
sicherte Reemtsma signifikante Vorteile. Nach dem Verbot für die meisten Werbedrucksachen ${ }^{159}$ konnte der Hamburger Konzern die wenigen Ausnahmereglungen für sich beanspruchen und trotz kriegsbedingter Ressourcenknappheit die Arbeit des Bilderdienstes aufrecht erhalten. Als bei der Druckerei Gruner \& Sohn, die die Herstellung der Alben übernommen hatte, vom Arbeitsamt Arbeiterinnen abgezogen wurden, intervenierte Otto Lose erfolgreich bei dem für das England-Album zuständigen

Dr. Richter. ${ }^{160}$ Lose argumentierte mit der Bedeutung der Zigarettenbilder, die vom Oberkommando der Wehrmacht für die Truppenbetreuung als „kategorisch“161 angesehen wurden.

Ein weiteres vom Hause Goebbels propagiertes Werk konnte Lose jedoch abwehren. Die Fachuntergruppe Zigarettenindustrie reichte im Auftrag von Goebbels einen Vorschlag für ein neues Sammelwerk ein, das ganz auf die Zielgruppe der Frontsoldaten zugeschnitten werden sollte. Das Album sollte „Text von neuen Soldatenliedern [...] Karikaturen von Chamberlain usw. [...] ferner Aussprüche von bedeutenden Männern und Anekdoten, eventuell auch Geduldspiele ${ }^{\prime 162}$ beinhalten. Lose gelang es, das Anliegen ad absurdum zu führen, unter anderem mit dem Hinweis auf das bereits in Produktion befindliche Album RAUBSTAAT EnGLAND. Seine vehemente Ablehnung beruhte wohl auch auf dem Vorschlag des RMVP, die Papierressourcen auf das neue Album umzuverteilen. ${ }^{163}$

Die Bilderschecks für das Album RAUBSTAAT ENGLAND wurden von allen Firmen vertrieben, die der Gemeinschaft des Bilderdienstes angeschlossen waren. Neben den Unternehmen, an denen Reemtsma Anteile besaß, zählten dazu alle noch verbliebe-

\footnotetext{
159 Vgl. Die Reichsstelle für Papier und Verpackungswesen erließ am 14. März 1941 ein Herstellungsverbot für viele Werbedrucksachen. RAnz. 1941, Nr. 304 Zit. nach: Rücker, Matthias (2000): Wirtschaftswerbung unter dem Nationalsozialismus. Frankfurt/M.: Peter Lang, S. 216

160 Vgl. Lindner (2007): Reemtsmas S. 236

161 HIS PFR 491,02 Schreiben des Propagandaministerium (Dr. Wiebe). Lindner (2007): Reemtsmas, S. 236

162 HIS PFR 491,02 Schreiben von A. Thronicke (Leiter der Fachuntergruppe Zigarettenindustrie) an Reemtsma, 18. März 1940

163 Vgl. HIS PFR 491,02 Schreiben von Lose an A. Thronicke, 21. März 1940, S. 2
} 
nen größeren Produzenten, darunter die regimefreundliche Aurelia, der SturmNachfolger Union, die österreichische Austria ${ }^{164}$ sowie Kyriazi und Muratti, die von griechischen, respektive griechisch-armenischen Inhabern geführt wurden. Auch Greiling mit griechischem Mehrheitseigner zählte zu den Unternehmen, die Bilder dieses Propaganda-Albums vertrieben. Skurril mutet die Beteiligung der Britisch American Tobaco Company (BATC) ${ }^{165}$ an, die sich als Mitglied des Bilderdienstes ebenfalls an der anti-britischen Propaganda des NS-Regimes beteiligte. Der BATC hätte es freigestanden, das vertraglich vereinbarte Kündigungsrecht in Anspruch zu nehmen. ${ }^{166}$ Damit war die BATC auch an der Verbreitung der zwischen Juli 1936 und Juni $1943^{167}$ erschienen Bilder für das Hitler-Album beteiligt und an dem ebenfalls bis 1943 erschienenen NS-Album DEUTSCHLAND ERWACHT. ${ }^{168}$ Reemtsma und andere deutsche Zigarettenfirmen waren daher nicht die einzigen, die aufgrund wirtschaftlicher Interessen eine opportunistische Haltung einnahmen. Unabhängig von den direkten Forderungen des RMVP in Bezug auf die Publikation NS-spezifischer Sammelwerke, unterlagen Reemtsma und andere Zigarettenunternehmen der Einflussnahme des Regimes bei der inhaltlichen Aufbereitung der Alben. Sie waren gezwungen, sich den veränderten politischen Rahmenbedingungen zu beugen, denn mit der Machtergreifung der NSDAP war eine Säuberung und Gleichschaltung von Kunst und Literatur erfolgt. Der kulturelle Kahlschlag umfasste alle Bereiche der Kultur und damit auch alle Sparten der Literatur. Neben wissenschaftlichen Publikationen fielen auch Belletristik und Sachbücher der rigiden Zensur zum Opfer. Die schwarze Liste betraf nicht nur Bücher, deren Inhalte nicht mit dem Regime konform

164 Die Austria Tabakregie besaß von 1784 bis 1996 das Vollmonopol. Mach dem Anschluss Österreichs an das Deutsche Reich wurde sie in Austria Tabak AG umfirmiert und unterstand dem deutschen Finanzministerium. Lindner (2007): Reemtsmas, S. 198 Vgl. HIS PFR 491,02 Lose zur Entlastung von Hans Domizlaff, 24. August 1945 Vgl. Aurelia kündigte ohne die Einhaltung der Kündigungsfrist die Beteiligung am Bilderschecksystem. Vgl. HIS PFR 620,05. Schreiben des Inhabers der Aurelia AG Ernst K. Müller an die Reemtsma Geschäftsleitung, 14. Juni 1938

167 Vgl. HIS PFR 491,08 Lose (1953): Bilderdienst, S. 295

Vgl. HIS PFR 491,02 Lose zur Entlastung von Hans Domizlaff, 24. August 1945

Vgl. HIS PFR 491,08 Lose (1953): Bilderdient, S. 295 
gingen, sondern auch Autoren. ${ }^{169}$ Aufgrund der Gleichschaltung und der Kontrolle aller Publikationen, wurden auch einige Reemtsma-Alben zensiert. So wurden in den Jahren 1937 und 1938 einige Sammelwerke des Reemtsma-Konzerns beschlagnahmt oder verboten. Dazu gehörten die Alben Der StUMMe FILM ${ }^{170}$ und DeR TonfILM, ${ }^{171}$ die aufgrund der Mitwirkung jüdischer Filmschaffender zensiert wurden sowie das Album Moderne MALEREI, ${ }^{172}$ das wegen des Verstoßes gegen die „kulturellen Bestimmungen“173 des Dritten Reiches aus dem Repertoire genommen werden musste. Die Zigarettenindustrie war daher gezwungen, bei den Texten und Bildern der Sammelalben mit größter Sorgfalt vorzugehen. Inhalte, die der Ideologie zuwiderliefen, hätten ein Verbot der Publikation ${ }^{174}$ oder Repressalien zur Folge gehabt.

\subsubsection{Klein- und Mittelständische Zigarettenindustrie}

Aufgrund der Dominanz Reemtsmas konnten sich ab Mitte der 1920er Jahre nur wenige Zigarettenhersteller auf dem deutschen Markt behaupten. Neben dem Zigaretten-Tycoon waren es die BATC, Lande, Garbáty und Brinkmann, die zu den größeren Unternehmen zählten. Das Mittelfeld wurde von den Firmen Greiling, Aurelia, Austria, Kyriazi, Muratti und Yramos besetzt. Zum Mittelstand gehörte auch die Firma Sturm, die der SA nahe stand und die so genannte ,Parteizigarette' produzierte (ausführlich in Kap. 4.2.1). Die Zahl der Kleinproduzenten betrug lediglich

169 Vgl. Barbian, Jan-Pieter (2015): „Die Arbeits- und Lebensbedingungen der Schriftsteller“. In: Geschichte des deutschen Buchhandels im 19. und 20. Jahrhundert. Drittes Reich, Teil 1. Berlin: de Gruyter, S. 7-10. Dieser radikale Einschnitt in die deutsche Kulturlandschaft fand seinen exemplarischen Ausdruck in der Bücherverbrennung, der "Aktion wider den undeutschen Geist" am 10. Mai 1933. Ebd., S. 9

170 Reemtsma (Cigaretten-Bilderdienst Altona/Bahrenfeld) (1935): Vom Werden deutscher Filmkunst. 1. Teil: Der stumme Film. Hamburg-Bahrenfeld

171 Reemtsma (Cigaretten-Bilderdienst Altona/Bahrenfeld) (1936): Vom Werden deutscher Filmkunst. 2. Teil: Der Tonfilm. Hamburg-Bahrenfeld

172 Reemtsma (Cigaretten-Bilderdienst Altona/Bahrenfeld) (1932): Moderne Malerei. Vom Impressionismus bis zur Gegenwart. Hamburg-Bahrenfeld

173 HIS PFR 491,08 Lose (1953): Bilderdienst, S. 295

174 Das Album Mitglieder des deutschen Reichstages (1932) des Hamburger Unternehmens, Dimitriou' wurde verboten, ebenso die beiden Alben der linksgerichteten Zigarettenfabrik Solidarität. Solidarität (1933): Aus der Geschichte der Revolution. Berlin und Köpfe aus der Arbeiterbewegung aus dem gleichen Jahr. Köberich (2003): Sammelbilder 
3,6 Prozent. Es waren kleine Manufakturen, die keine Markenzigaretten herstellten und für regionale Märkte produzierten ${ }^{175}$

Neben Reemtsma gab es auch andere Zigarettenfabrikanten, die sich mit dem NS-Regime arrangierten, wie das Bremer Unternehmen Brinkmann. Brinkmann produzierte Tabak zum Selbstdrehen, bis es 1931 begann, Markenzigaretten herzustellen. Wolfgang Ritter, der 1933 die Firma von seinem Vater übernahm, trat drei Jahre später in die NSDAP ein, um seine Position an der Firmenspitze zu sichern. Eine Protektion seitens des Regimes stritt er später ab:176 „Das Ganze war eine rein defensive Maßnahme, um nicht eines Tages von den Nazis als Gesamtbetriebsführer abgesetzt zu werden. [...] Ein einfacher Parteigenosse konnte einen nennenswerten politischen Einfluß überhaupt nicht ausüben. Dazu musste man in meiner Stellung entweder Wehrwirtschaftsführer sein, oder zum Kreis der Freunde Himmlers gehören, oder Beziehungen zu den Größen wie Göring haben."177 Angesichts der exponierten Stellung seines Vaters Hermann Ritter, der als Deutsch-Nationaler Senator im Bremer NS-Senat saß und bei Reichsminister Speer zum Leiter des Produktionsausschusses Tabak aufgestiegen war, eine Aussage, die in Zweifel gezogen werden kann. Brinkmann gehörte zu den Profiteuren des NS-Regimes. Das Unternehmen wurde in der besetzten Ukraine mit 40.000 Hektar Anbaufläche für Tabak bedacht, was Wolfgang Ritter ermöglichte, die ,Ost-West-Gesellschaft Hansa' mit Sitz im ukrainischen Luzk zu gründen. ${ }^{178}$ Brinkmann war insgesamt weniger öffentlichen oder staatlichen Repressalien ausgesetzt als Reemtsma. Laut Wolfgang Ritter versuchte lediglich die SA gegen das Unternehmen zu agitieren. Ritter wurde vorgeworfen, seinen Umsatz auf Kosten der Kleinunternehmer zu machen. ${ }^{179}$ Brinkmann publizierte viele Alben mit NS-Hintergrund wie MäNNER IM DRITTEN ReICH. ${ }^{180} \mathrm{Zu}$ den NS-Publikationen gehörten auch Werke, die der Einkreisungspropaganda zuzuordnen sind, wie

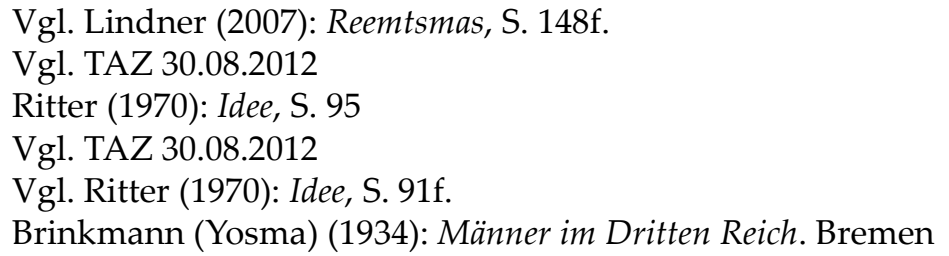


DAs WAFFENSTARRENDE AUSLAND, ${ }^{181}$ WIE DIE ANDEREN GERÜSTET SIND...! TROTZ VERTRAGLICHER ABRÜSTUNGSPFLICHT. ${ }^{182}$ Die BATC war der einzige internationale Konzern, der sich nach dem Ersten Weltkrieg auf dem deutschen Markt etablieren konnte. ${ }^{183}$ Der anfangs bescheidene Marktanteil von 0,3 Prozent im Jahr 1926 konnte durch die Übernahme von Haus Bergmann im Jahr 1932 auf knapp 10 Prozent gesteigert werden. ${ }^{184}$ Unternehmen mit jüdischen Inhabern wie Yramos und Garbáty, an denen Reemtsma 50 Prozent der Anteile hielt, konnten sich bis 1938 behaupten. ${ }^{185}$ Für die Mitgliedschaft in der IG hatte der jüdische Hintergrund keine Relevanz. Ausschlaggebend waren die gut eingeführten Markenzigaretten. ${ }^{186}$ Lediglich Ernst Müller von der Aurelia protestierte gegen die Aufnahme der jüdischen Fabrikanten. ${ }^{187}$ Garbáty konnte Anzeigen schalten und Sammelalben unter anderem mit „national-patriotischen“188 Hintergrund herausbringen wie die Die Deutsche WeHRMACHT. ${ }^{189}$ Erst gegen Ende der 1930er Jahre wurde die Lage prekär. Mangelnde Werbemöglichkeiten, Anfeindungen in der Presse und der Boykott nationalsozialistisch gesinnter Raucher hatten die Firma in eine wirtschaftlich desolate Lage gebracht. ${ }^{190}$ Im Verlauf des ArisierungsVerfahrens konnte Reemtsma einen Verkauf an die BATC verhindern, musste seine Firmenanteile aber abtreten. ${ }^{191}$

181 Brinkmann G.M.B.H. (1934): Das Waffenstarrende Ausland. (Text und sämtliche Abbildungen von F. Hohm. Verantwortlich für die Herausgabe Oberst a. D. von Struensee). Bremen Brinkmann (1934): Wie die anderen gerüstet sind...! Trotz vertraglicher Abrüstungspflicht. Bremen Vgl. Lindner (2007): Reemtsmas, S. 45

Vgl. HIS PFR 100,03 - Frankfurter Handelsblatt 16. März 1938

Vgl. Lindner, Erik (2007): „Garbáty. Eine Zigarettenfabrik in Pankow“. In: Biggeleben, Christof/ Schreiber, Beate/ Steiner, Kilian J.L. (Hg.): Arisierung in Berlin. Berlin: Metropol, S. 259

186 Vgl. Lindner (2007): Reemtsmas, S. 149

187 Vgl. Ebd., S. 255. Müller reichte seine Kündigung ein, die aber nach einer Verhandlung vor dem Kartellgericht zurückgenommen wurde. Vgl. Ebd., S. 149f. Vgl. HIS PFR 620,05

188 Lindner (2007): Garbáty, S. 254

189 Zigaretten-Industrie (Gemeinschaftsausgabe, beteiligte Firmen: Alva-Yosma, Bergmann, Bulgaria, Eckstein, Garbáty, Greiling, Jasmatzi, Josetti, Kyriazzi, Lande, Salem, Waldorf-Astoria, Yenidze) (1936): Die Deutsche Wehrmacht. o.O.

190 Vgl. Lindner (2007): Reemtsmas, S. 189

191 Vgl. Ebd., S. 190ff. Die Beteiligung Reemtsmas an Garbáty wurde erst 1936 bei einer Steuerprüfung bei Neuerburg bekannt. Vgl. Lindner (2007): Garbáty, S. 256 


\subsection{Zigarettenalben}

In der Zeit von 1926 bis 1943 wurden ca. $650^{192}$ Zigarettenalben publiziert. Da keine exakten Angaben über die Publikationen vorliegen, basiert die Berechnung auf den Daten des Kataloges von Köberich. Gut dokumentiert sind die Publikationen des Reemtsma-Konzerns. Im Zeitraum zwischen Januar 1932 bis Mai 1943 wurden von dem Bilderdienst des Unternehmens 4,13 Milliarden Bilder und 19 Millionen Alben mit Auflagen zwischen 500.000 und knapp 2,5 Mio. ausgegeben. ${ }^{193}$

\section{Themenspektrum Zigarettenalben 1926 - 1941}

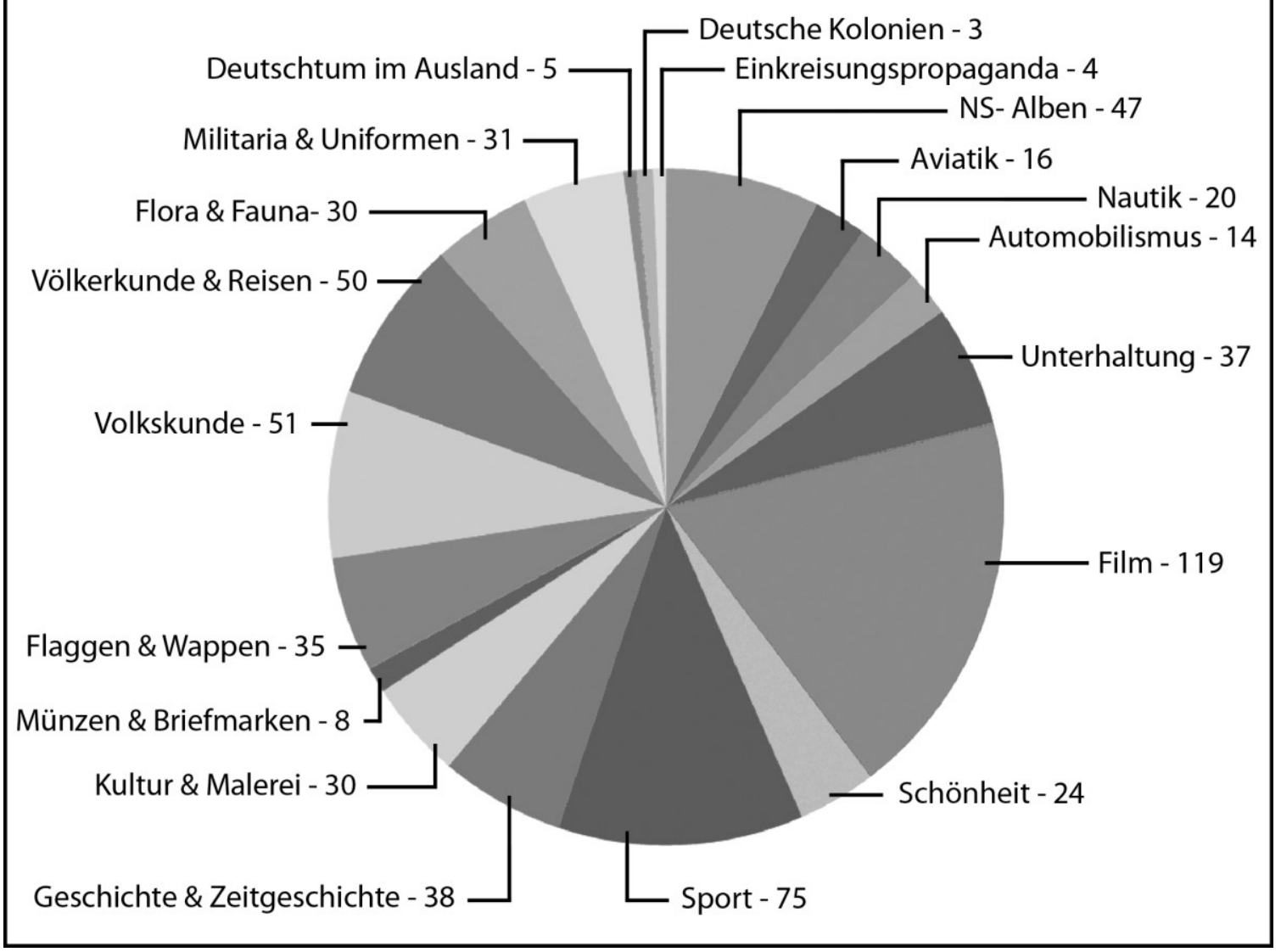

Diagramm 1: Themenspektrum der Zigarettenalben ${ }^{194}$

Köberich (2003): Sammelbilder

Vgl. HIS PFR 491,08 Anfrage vom 2. Juli 1979

Eigene Darstellung, nach Daten von: Köberich (2003): Sammelbilder 


\subsubsection{Publizierte Zigarettenalben}

Die reichhaltige Themenpalette der Zigarettenalben und ihre hohen Auflagen belegen, dass es sich um ein populäres Massenmedium handelte. Das Diagramm 1 gibt einen Überblick über die Themenvielfalt der publizierten Alben. Das Spektrum der Sammelwerke war weit gefächert und erstreckte sich über Kunst und Kultur, Sport, Film, Technik, Flora, Fauna, Geografie, Völkerkunde, Geschichte, Fahne, Flaggen, Militaria und Zeitgeschichte. ${ }^{195}$ Die Wahl der Themen sowie die Gestaltung der Bilder wurden von politischen, wirtschaftlichen, kunst- und zeitgeschichtlichen Aspekten beeinflusst. ${ }^{196}$ Das Spekturm zeigt, dass die Verbraucher Themen aus dem Unterhaltungs- und Technikbereich favorisierten (Diagramm 1). Film, Sport, Unterhaltung und schöne Frauen führten die Beliebtheitsskala mit 255 Alben an, gefolgt von Themen aus dem Technik- und Mobilitätsbereich, darunter Automobilismus, Nautik und Aviatik mit insgesamt 50 Alben. Auch Völkerkunde und Reisen (50 Alben) zählten zu den Themen, die vom Verbraucher favorisiert wurden. Das Interesse für die Zigarettenalben ist auf den Zeitraum zwischen 1926 und 1941 nicht gleichmäßig verteilt, sondern weist eine glockenförmige Verteilung auf.

Der Produktlebenszyklus (PLZ) der Alben zeigt, dass das Interesse der Konsumenten an dem Medium zeitlich begrenzt war (Diagramm 2). Der PLZ definiert u.a., wie lange ein Produkt oder eine Dienstleistung auf dem Markt verweilt. ${ }^{197}$

Köberich (2003): Sammelbilder. Wasem (1987): Serienbild, S. 53-129

Vgl. Ebd., S. 53-56

Produkte und Dienstleistungen haben eine zeitlich begrenzte Verweildauer auf dem Markt. Der Lebenszyklus durchläuft 5 Stadien: Produktentwicklung, Markteinführung, Wachstum, Reifephase, Auslaufen des Produktes. Vgl. Kotler et al. (2003): Marketing, S. 705f. Die Zeitspanne der Marktpräsenz, respektive die Phase, in der Gewinn erwirtschaftet wird, sind von der Akzeptanz des Kunden abhängig. Der Lebenszyklus ist bei der Produkteinführung nicht bekannt oder schwer einzuschätzen. Der Produktlebenszyklus kann durch nachträgliche Innovationen, Anpassungen an die Bedürfnisse der Konsumenten, Preispolitik oder Werbestrategien verlängert werden. Vgl. Ebd., S. 712f. 


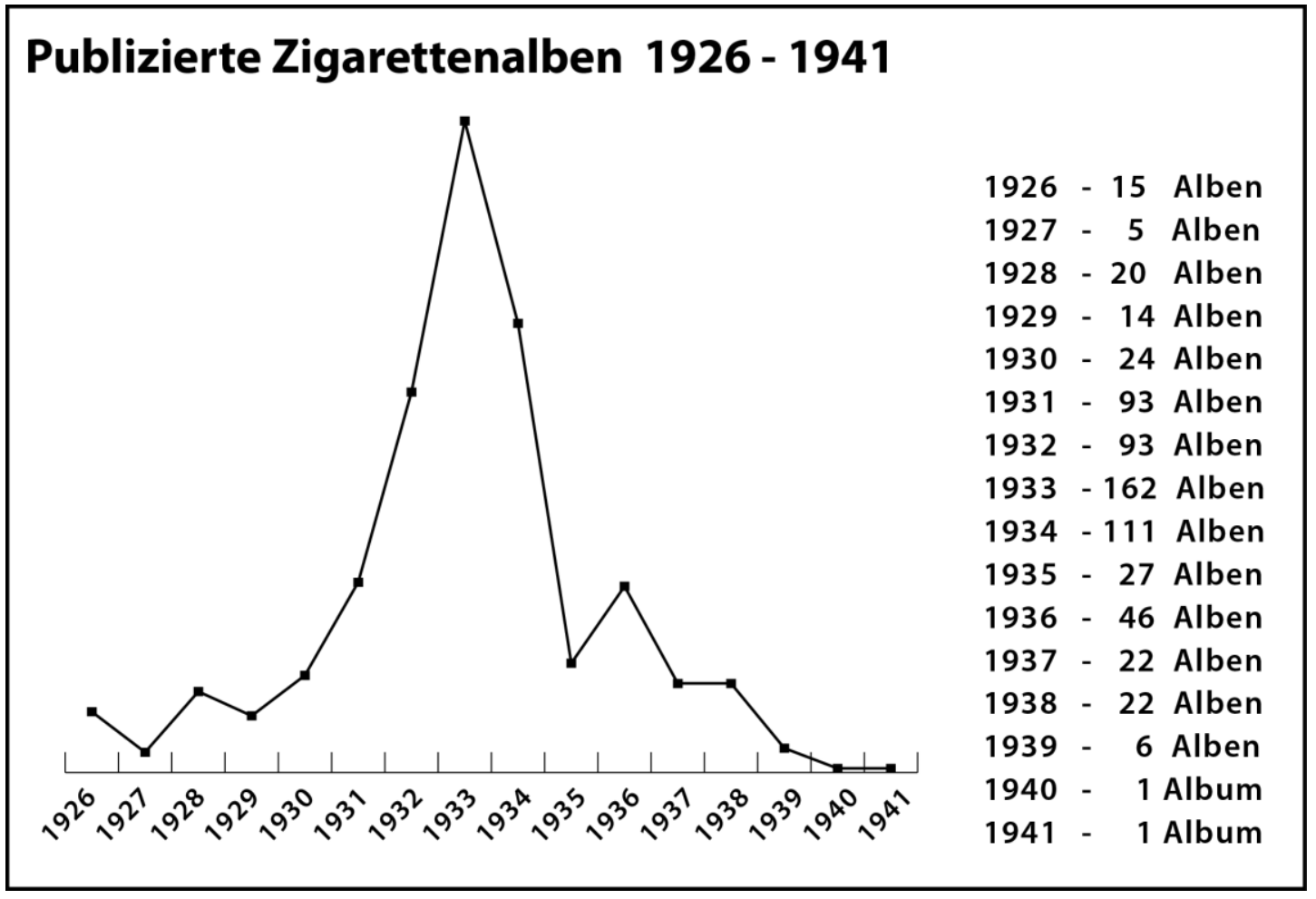

Diagramm 2: Publizierte Zigarettenalben von 1926 bis $1941^{198}$

Die Zigarettenbilder waren nach der Phase ihrer Einführung auf dem deutschen Markt um das Jahr 1926 immanenter Bestandteil des Marketings, bis sie 1941 aufgrund kriegsbedingter Ressourcenknappheit eingestellt wurden. Während ihrer Hochphase waren Zigarettenbilder ein vitales Instrument, mit dem insbesondere der Reemtsma-Konzern das Marktgeschehen kontrollieren konnte. ${ }^{199}$

Der PLZ der Zigarettenbilder wurde damit nicht aufgrund mangelnder Akzeptanz seitens des Konsumenten beendet, sondern durch äußere Faktoren. Der Abwärtstrend, der sich bereits Jahre vor der Einstellung der Zigarettenalben abzeichnete, deutet aber auf ein nachlassendes Interesse seitens der Konsumenten hin. Der kontinuierliche Auf- und Abstieg der Absatzkurve der Zigarettenalben weist die typische Charakteristik einer Modeerscheinung auf, die eine relativ kurze Marktpräsenz

\footnotetext{
198 Eigene Darstellung, nach Daten von: Köberich (2003): Sammelbilder

199 Vgl. Jacobs, Tino (2007): „Zwischen Intuition und Experiment. Hans Domizlaff und der Aufstieg Reemtsmas, 1921 bis 1932“. In: Berghoff (Hg.): Marketinggeschichte, S. 171
} 
anzeigt. ${ }^{200}$ Das stetige Wachstum in den 1920er Jahren erreichte seinen Höhepunkt zu Beginn der 1930er Jahre und ebbte ab 1936 wieder ab. Der marginale Anstieg der Publikation im Jahr 1936 ist der Olympiade geschuldet, die im gleichen Jahr in Berlin stattfand. Diese Analyse korrespondiert mit der Aussage einiger Zigarettenfabrikanten, die das Zigarettenbild als kurzlebige „Bilderseuche“ und wiederkehrenden „Unsinn“201 verdammt hatten.

\subsubsection{Zigarettenalben im Dienst der NS-Propaganda}

Ab dem Jahr 1933 drängten verstärkt Alben mit nationalsozialistischem Hintergrund auf den Markt. Neben Alben, die sich monothematisch der Genese der NS-Bewegung, ihrer Protagonisten, Organisationen und Uniformen widmeten, besetzten die NS-Alben auch populäre Themen wie Aviatik, Automobilismus und Nautik. Darüber hinaus wurden auch Alben publiziert, die vom Tenor der Einkreisungspropaganda geprägt waren. Einige Werke widmen sich monothematisch der Einkreisungspropaganda, die bis Mitte der 1930er Jahre integraler Bestandteil der NS-Propaganda war. Dazu gehören: DAs WAFFENSTARRENDE AusLAND, WIE DIE ANDEREN GERÜSTET SIND...! TROTZ VERTRAgLICHER AbrÜSTUNGSPFLICHT und EUROPA IN WAFFEN. ${ }^{202}$ Die Zigarettenindustrie war damit am Puls des gesellschaftlichen und politischen Zeitgeistes.

Der PLZ der monothematischen NS-Alben weist eine abweichende Form von dem er Zigarettenalben auf, die insgesamt zwischen 1926 und 1941 produziert wurden (Diagramm 3). Während die Kurve der Gesamtpublikationen einen gleichmäßigen glockenförmigen Verlauf aufweist, konzentriert sich der Absatz der NS-Alben auf die Jahre 1933-34 und folgt dann einem auffälligen, nahezu abrupten Abwärtstrend. Das im Jahr 1941 publizierte Album RAUBSTAAT ENGLAND wurde direkt vom

200 Ein PLZ kann nicht nur für Produkte oder Produktklassen herangezogen werden, sondern auch für Stile und Moden. Der typische Verlauf des PLZ bei einer kurzfristigen Modeerscheinung folgt einer Glockenform und hat eine relativ kurze Verweildauer auf dem Markt. Der „Gag“ ähnelt einer spitzen Kurve und hat eine sehr kurze Markpräsenz. Der Bedarf nimmt rasch zu, ebbt aber ebenso schnell wieder ab. Vgl. Kotler et al. (2003): Marketing, S. 708

201 Ritter (1970): Idee, S. 90

202 Borg (Vereinigte Tabak- und Zigarettenfabriken) (1934): Europa in Waffen. Ein Dokument in 180 Bildern, welches den Rüstungsstand der europäischen Armeen Ende des Jr. 1933 zeigt. Offenbach 
Propagandaministerium in Auftrag gegeben und ist das einzige Zigarettenalbum, das der Phase der Kriegspropaganda zuzuordnen ist. Es kann daher nicht als charakteristisches NS-Album betrachtet werden, das die NS-Ideologie verbreiten, sondern die Bevölkerung für den Krieg gegen England mobilisieren sollte (ausführlich Kapitel 3).

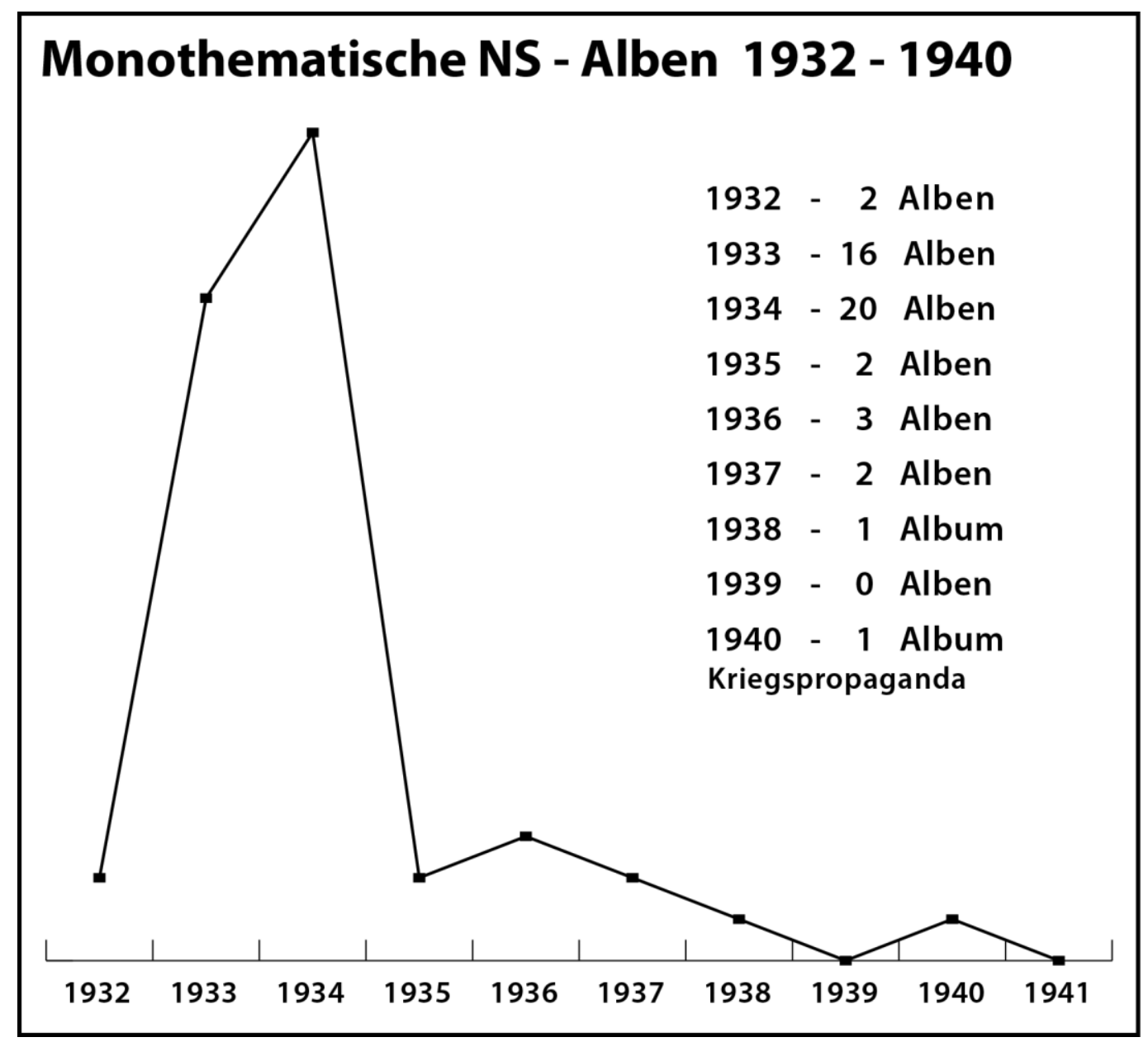

Diagramm 3: Publizierte Zigarettenalben mit NS-Themen von 1932 bis 1940203

Der PLZ der NS-Alben weist eine signifikante Absatzkurve auf, die eine kurzlebige Verweildauer auf dem Markt anzeigt. Die Nachfrage konzentriert sich auf einen kurzen Zeitraum und charakterisiert damit einen Artikel, der „lawinenartig eingeführt“ wird und nach einer großen Resonanz auf dem Markt „ganz schnell wieder aus der

203 Eigene Darstellung. In diese Berechnung wurden auch Alben einbezogen, die von verschiedenen Firmen zu unterschiedlichen Zeitpunkten publiziert wurden. Köberich (2003): Sammelbilder 
Mode “204 kommt, da er die Bedürfnisse der Zielgruppe langfristig nicht befriedigt. ${ }^{205}$ Der PLZ der NS-Alben zeigt, dass das Interesse der Bevölkerung an NS-Themen zeitlich sehr begrenzt war. In Anbetracht der zwölfjährigen Dauer des NS-Regimes umfasst der PLZ der NS-Alben einen geringen Zeitabschnitt, der dafür spricht, dass das Interesse der Bevölkerung an NS-Themen schnell gesättigt war. ${ }^{206}$

In der Tat war ein Rückgang des Interesses seitens der Bevölkerung bei der gesamten NS-Literatur zu verzeichnen. ${ }^{207} \mathrm{Um}$ den außerordentlichen, wenn auch nur temporären Erfolg der NS-Alben als Teil der Massenliteratur ${ }^{208}$ zu erklären, bietet es sich an, die während der NS-Zeit publizierte Literatur dieser Art als Vergleichsparameter heranzuziehen. Mangels statistischer Erhebungen ${ }^{209}$ können keine konkreten Angaben zur Auflagenstärke einzelner Literatursparten, insbesondere zur Massenliteratur, gemacht werden. Rückschlüsse auf die vom Leser favorisierte Lektüre im Dritten Reich können lediglich über die Verkaufszahlen erfolgen. Die Absatzzahlen weisen dabei eindeutige Tendenzen auf, die belegen, dass das propagierte NS-Schrifttum nur bedingt die vom Regime gewünschte Resonanz hatte und hinter vielen literarischen Sparten zurückstand. ${ }^{210}$ Führend in der Publikumsgunst waren populärwissenschaftliche Sachbücher, Lebenshilfen sowie populäre Unterhaltungsliteratur. ${ }^{211}$ Eine 1933 vom Börsenblatt durchgeführte Studie zum Leseverhalten von Jugendlichen konfron-

\footnotetext{
204 Typisch für diesen Lebenszyklus sind ,Gags', die einen kurzfristigen Hype befriedigen. Vgl. Kotler et al. (2003): Marketing, S. 708

205 Vgl. Ebd.

206 Viele Autoren, meist erfolglose Schriftsteller, folgten dem Zug der NS-Literatur und versuchten als Trittbrettbrettfahrer an dem Polittrend zu partizipieren. Die Flut an Konjukturschrifttum hatte aber bereits im Sommer 1933 den Buchmarkt derart überschwemmt, dass der Bedarf gesättigt war. Vgl. Härtel (2004 ): Stromlinien, S. 108. Dazu gehörten auch Publikationen der NS-Elite wie Goebbels. Vgl. Adam (2010): Lesen, S. 127. Die „Parteiamtliche Prüfungskommission zum Schutze des nationalsozialistischen Schrifttums" (PPK) wurde eingerichtet, um das Konjunkturschrifttum, das ab 1933 den Markt zu überfluten drohte, einzudämmen. Das Amt wurde von Phillip Bouhler geleitet. Barbian, Jan-Pieter (2015): „Die organisatorische, personelle und rechtliche Neuordnung des deutschen Buchhandels." In: Geschichte des deutschen Buchhandels im 19. und 20. Jahrhundert. Drittes Reich, Teil 1. Berlin: de Gruyter, S. 98

207 Vgl. Bussemer (2000): Populärkultur, S. 75

208 In der Auflistung der erfolgreichsten Buchtypen werden bewusst Romanhefte und Sammelalben einbezogen. Vgl. Adam (2010): Lesen, S. 85

209 Vgl. Ebd., S. 46

210 Vgl. Ebd., S. 86

211 Vgl. Ebd., S. 85 - 129
} 
tierte die NS-Kulturpolitiker mit der Erkenntnis, dass die von ihnen propagierte Bekenntnisliteratur hinter verfemten Autoren und klassischen Schmökern wie Kriminal- und Abenteuerromanen zurückstand. ${ }^{212}$ Der Markt für NS-Literatur war bereits 1933 gesättigt. ${ }^{213}$ Der zeitgenössische Publikumsgeschmack sowie das schnell nachlassende Interesse an NS-Literatur, respektive Konjunkturschrifttum korrespondiert mit den Zigarettenalben mit NS-Thematik.

\subsection{Resümee}

Sammelalben und bebilderte Medien zur Verbreitung von Werbung, Propaganda und Wissen können auf eine lange Tradition zurückblicken. Sie stehen in der Kontinuitätslinie der Massenmedien, die nicht nur Informationen und Wissen vermittelten, sondern auch Instrumente der politischen Erziehung waren. Mit dem Erstarken der NS-Bewegung begannen Zigarettenhersteller nationalsozialistische Themen in die Zigarettenalben aufzunehmen. Mit der Popularisierung des Nationalsozialismus folgten sowohl die Zigarettenindustrie als auch die Machthaber einer kommunikationspolitischen Kontinuität. Die Intention der Zigarettenproduzenten, die NS-Ideologie in ihre Marketingkommunikation einzubeziehen, war unterschiedlich motiviert, wobei rein wirtschaftliche Interessen im Vordergrund standen. Da nationalsozialistische Themen ab 1933 sehr populär waren, konnten die Unternehmen von diesem Trend profitieren. Bei den Inhalten der Zigarettenalben hatten die Bedürfnisse der Zielgruppe, also die der Bildersammler und Raucher, Priorität. Fehlentscheidungen hätten sich negativ auf den Absatz der Zigaretten ausgewirkt. Bei einem vitalen Instrument wie dem Zigarettenbild musste die Zigarettenindustrie die Bedürfnisse der Zielgruppe berücksichtigen und Themen der zeitgenössischen Politik in ihre Sammelwerke aufnehmen. Bei den Alben zum Zeitgeschehen mit eindeutigem NS-Bezug muss daher eine temporäre

212 Die durchgeführte Studie hätte in den Folgejahren aufgrund des verheerenden Ergebnisses für die NS-Kulturpolitik aller Wahrscheinlichkeit nach nicht durchgeführt werden können. Vgl. Ebd., S. 59

213 Vgl. Ebd., S. 128. Auch der Absatz von Hitlers ,Mein Kampf' war 1933 eingebrochen. Selbst $>$ Pflichtgeschenke< bei Vermählungen oder an Veteranen des Ersten Weltkrieges konnten die Zahlen kaum steigern. Erst die Ausgabe an die Wehrmacht brachte dem Eher-Verlag den gewünschten Erfolg. Ebd., S. 116f. 
Akzeptanz beim Sammler bis 1934 vorausgesetzt werden. Da viele Unternehmen dem Reemtsma-Bilderdienst angeschlossenen waren, konnten individuelle Präferenzen einzelner Unternehmen nicht immer Berücksichtigung finden. Mitunter wurden Sammelwerke von Firmen zum Verkauf angeboten, die nicht dem Bilderdienst angehörten. So wurden Alben nicht nur zwischen Firmen ausgetauscht, die in wirtschaftlicher Konkurrenz zueinander standen, sondern sich auch auf ideologischem Parkett bekämpften wie Sturm und Reemtsma. ${ }^{214}$ Die Beteiligung der Zigarettenindustrie an der NS-Propaganda war daher bis auf wenige Ausnahmen kein Ausdruck einer politischen Gesinnung, sondern war rein monetären Motiven geschuldet, respektive unternehmenspolitische Strategie.

Da die Sammelbilder als erfolgreiches Marketinginstrument eine Eigendynamik entfaltet hatten und der Konsument das Bild als eine zum Produkt gehörende Leistung betrachtete, konnten einzelne Unternehmen die Sammelbilder nicht vom Markt zurückziehen. Damit befand sich insbesondere Reemtsma in einem komplexen Abhängigkeitsverhältnis. Bei einer Einstellung der Sammelbilder wären nicht nur Kundensegmente an die Konkurrenz gefallen, sondern es hätte auch Repressalien seitens des Regimes zur Folge gehabt. Neben drohenden Prozessen, verbunden mit der efahr der Liquidierung des Unternehmens, wäre Reemtsma von der Zuteilung von Papier und Arbeitskräften ausgeschlossen worden. Ferner sah sich Reemtsma aufgrund der Sturm-Zigarettenfabrik gezwungen, die Bedürfnisse der nationalsozialistischen Konsumentengruppe zu befriedigen. Eine nationalsozialistische Gesinnung Reemtsmas und anderer Zigarettenfabrikaten kann aufgrund der Publikation von NS-Alben jedoch nicht nachgewiesen werden. ${ }^{215}$

Arthur Dressler (Inhaber der Firma Sturm) bot nach seinem Konkurs im Jahr 1935 Reemtsma sein Hindenburg-Album als Einheitsserie an: „Im Hinblick darauf, daß das behandelte Thema auch heute noch außerordentlich aktuell ist, glauben wir in der Annahme nicht fehlzugehen, daß sich dieses Werk und die dazu gehörenden Bilder vorzüglich für eine neue zu schaffende Einheitsserie eignen würde." HIS PFR 491,05 Schreiben von Dressler an Reemtsma, 23. März 1935

215 Ein evidenter Nachweis einer nationalsozialistischen Einstellung kann lediglich bei den Firmen Aurelia, Lande, Sturm erbracht werden. Vgl. HIS PFR 620,05 
Das NS-Regime zeigte sich nicht minder opportunistisch. Entgegen der eigenen Doktrin, die Macht der Konzerne zu begrenzen ${ }^{216}$ und jüdische Unternehmen vom Markt zu verdrängen, respektive deren Teilhaberschaft $\mathrm{zu}$ unterbinden, wurden Reemtsma besondere Konzessionen zugestanden. Das NS-Regime konnte aus der Zusammenarbeit mit Reemtsma Vorteile ziehen. Neben den finanziellen Zuwendungen, die insbesondere Göring für seine Protektion zuflossen, konnte die NSDAP von den Werbeanzeigen des Reemtsma-Konzerns finanziell profitieren. Die Einnahmen kamen der Partei bereits im Jahr 1932 bei der Finanzierung des kostspieligen Wahlkampfes mit Hitlers, Deutschlandflügen' zugute. Weitere Vorteile finanzieller Art bestanden in der Verbreitung der Propaganda über die Zigarettenalben und in der unentgeltlichen Nutzung der Distributionskanäle des Bilderdienstes. In Anbetracht der Ablehnung des Regimes gegenüber dem Tabak, erscheint die Inanspruchnahme der Zigarettenbilder für die eigene Propaganda als ausgesprochen disparat. Selbst der fanatische Tabakgegner Hitler, für den die Volksgesundheit absolute Priorität hatte, ${ }^{217}$ nutzte dieses Medium als Plattform zur Popularisierung seiner Person und konnte darüber hinaus stattliche Tantiemen für sich verbuchen.

\footnotetext{
216 Viele Zigarettenalben tragen den Vermerk: „Ring- und Konzernfrei“", bspw.: Orami (1933): Helden der Luft, Bd. 1 und 2. Dresden

217 Vgl. Merki (1998): Tabakpolitik, S. 28
} 


\section{Massenpsychologie und Propaganda}

Die politische Propaganda ist seit dem Aufkommen der Massenkommunikation Gegenstand zahlreicher Diskurse geisteswissenschaftlicher Disziplinen wie Politik, Soziologie, Psychologie und Kommunikationswissenschaft. Die gesellschaftliche Bedeutung der politischen Propaganda wurde seit 1900 kontrovers diskutiert und hat unterschiedliche Interpretationen erfahren, so dass „von einem einheitlichen Propagandabegriff kaum“218 gesprochen werden kann. Der Begriff Propaganda hat eine wechselvolle Geschichte und wurde im Laufe seiner Historie sowohl positiv als auch negativ konnotiert. ${ }^{219}$ Insbesondere im nationalsozialistischen Kontext wird die Propaganda mit nahezu diabolischer Beeinflussung der Massen assoziiert.

Die Propaganda ist als Strategie zur Beeinflussung kein Phänomen der Moderne, sondern bereits seit der Antike bekannt. Der Begriff Propaganda etablierte sich in der Neuzeit im Jahr 1622 mit der Gründung der Propaganda Kongregation „Congregatio de propaganda fide" durch Papst Gregor XV. Damit wurden alle Maßnahmen bezeichnet, die zur Verbreitung des christlichen Glaubens angewandt wurden.220 Im weitesten Sinne gilt Propaganda heute als kommunikative Strategie der Einflussnahme, die primär von Politikern und Werbetreibenden eingesetzt wird, um gewünschte Reaktionen bei der anvisierten Zielgruppe hervorzurufen oder um eine Idee zu implementieren. „Modern propaganda is a consistent, enduring effort to create or shape events to influence the relations of the public to an enterprise, idea or group". ${ }^{221}$

Die ersten sozialwissenschaftlichen Analysen gehen auf den Staatswissenschaftler Johann Plenge zurück, der in den 1920er Jahren zu einem maßgeblichen Wegbereiter Bussemer, Thymian (2005): Propaganda - Konzepte und Theorien. Wiesbaden: VS Verlag für Sozialwissenschaften, S. 13

219 Vgl. Bernays, Edward Miller/ Introduction: Mark Crispin (2005): Propaganda. New York: Ig Publishing, S. 48

220 Brockhaus Enzyklopädie (2006): Stichwort „Propaganda“. Band 22, 21. Aufl. Leipzig/ Mannheim: Brockhaus. S. 162,

22

Bernays (2005): Propaganda, S. 52
} 
für die Erforschung der Propaganda avancierte. ${ }^{222}$ Plenges Ansatz basierte auf der Tatsache, dass soziale Gemeinschaften durch Symbole interagieren und verortete die Propaganda daher „in der symbolischen Welt der Ideen und Metaphern“.223 Plenge und andere Wissenschaftler definierten die Propaganda als persuasive Kommunikation, mit der Massen beeinflusst werden. Die Propaganda ist damit nicht nur eine Technik, mit der Einfluss auf die Überzeugung von Individuen und sozialen Gruppen genommen werden kann, sondern im politischen Kontext auch Mittel der Macht.

\subsection{Propaganda und Patriotismus}

Deutsch-Nationale Attitüden prägten um 1900 viele Werbemittel, 224 darunter auch Sammelbilder. Im neu konstituierten Deutschen Reich war es von besonderer Bedeutung, dem sozialen Umfeld die eigene nationale Gesinnung zu demonstrieren. Die Nationalisierung der Konsumenten wurde von Industrie und Handel angefacht, die unterschiedliche Produktgruppen mit nationalen Symbolen bewarben, wobei sich die Insignien des Kaiserhauses besonderer Beliebtheit erfreuten. ${ }^{225}$ Damit konnte der Konsument mit dem Kauf eines Produktes eine „kraftvolle, freudige Bekennung zu einem gesunden Patriotismus“ ${ }^{226}$ zum Ausdruck bringen. Im Kaiserreich wurde die Bedeutung der Massenmedien nicht nur für die Produktwerbung erkannt, sondern auch für die Popularisierung von politischen Interessen. Als das Tirpitz'sche Flottenbauprogramm, für das Wilhelm II. große Sympathie hegte, beim Parlament auf Widerstand stieß, wurde eine Propaganda-Maschinerie in Gang gesetzt. Es erfolgte ein Machtkampf, der bewusst mittels der Medien in der Öffentlichkeit ausgetragen

222 Plenge avancierte zu einem maßgeblichen Wegbereiter für die Erforschung der Propaganda. In dem nach dem Ersten Weltkrieg gegründeten Staatswissenschaftlichen Institut an der Universität Münster sprach sich Plenge in seinen Vorlesungen für eine organisierte Propaganda aus. Vgl. Schäfers, Bernhard (1996). Soziologie und Gesellschaftsentwicklung: Aufsätze 1966-1996. Wiesbaden: Springer, S. 83ff.

223 Bussemer (2005): Propaganda, S. 27

224 Vgl. Reinhardt (1993): Reklame, S. 416

225 Die Schokoladenfabrik Stollwerck modellierte die kaiserliche Familie in Marzipan und die Zigarettenfirma Manoli brachte die Marke ,The Kaiser' auf den Markt. Vgl. Reinhardt (1993): Reklame, S. 416 
wurde. ${ }^{227}$ Die „öffentliche Meinung [...] war zu einem unentbehrlichen und manipulierbaren Instrument des politischen Kampfes geworden“ um sich gegen „Widerstände innerhalb des Regierungsapparates“228 $\mathrm{zu}$ behaupten.

Im Verlauf des Ersten Weltkrieges erkannte die Industrie den Propagandawert von Ideen und Ideologien. Als der nationale Stolz im Ersten Weltkrieg seinen Höhepunkt erreichte, fand die patriotische Hybris ihr Echo im Sprachgebrauch der Werbung und die Firmen wetteiferten darum, mit ihren Produkten Stellung zu beziehen. Die Produkte wurden mit nationalem Pathos semantisch aufgeladen, womit der Konsument in der Lage war, mit dem Kauf der Ware Flagge zu zeigen. An vorderster Front im Propaganda-Kampf stand die Zigarettenindustrie. Mit Aussicht auf ein Millionenheer potentieller Konsumenten wurden international oder mondän klingende Zigarettenmarken mit Namen deutscher Provenienz versehen oder aus der Taufe gehoben. Damit konnte der Konsument mit Marken wie „'Feldherr' [...] 'Deutsche Helden Cigarette' [...] oder 'Weltmacht'“229 seinen Patriotismus demonstrieren. Mit der Welle des Patriotismus eroberten Zigarettenmarken wie „General Goeben“230 oder „Ernst Udet $^{\prime 231}$ den Markt. Besonderer Beliebtheit erfreute sich der Chef der Heeresleitung Hindenburg, der im Laufe des Krieges Wilhelm II. als Identifikationsfigur abgelöst hatte. ${ }^{232}$ Die Werbetreibenden reagierten damit instinktsicher, denn der zunehmende Macht- und Prestigeverlust des Kaisers hätte sich auf die Produkte übertragen.

227 Vgl. Stöber, Gunda (1998): Pressepolitik und Notwendigkeit Zum Verhältnis von Staat und Öffentlichkeit im Wilhelminischen Deutschland 1890-1914. Stuttgart: Franz Steiner, S. 149

228 Deist, Wilhelm (1976): Flottenpolitik und Flottenpropaganda. Das Nachrichtenbüro des Reichsmarineamtes 1897- 1914. Stuttgart: Deutsche Verlagsanstalt, S.17

229 Tauchner, Paul (2004): „Politik und Industrie: Zigarettenmarken im historischen Rückblick.“ In: Meißner, Jörg/ Deutsches Historisches Museum (Hg.): Strategien der Werbekunst 1850-1933. Bönen: DruckVerlag Kettler, S. 109

$230 \quad$ Ebd., S. 108

231 Ebd., S. 109

232 Mit dem Namen ,Hindenburg' wurden nicht nur Genussmittel beworben, sondern auch die 7. Kriegsanleihe, für die er anlässlich seines 70. Geburtstages mit seinem Konterfei warb. Vgl. Kilian, Jette (2008): „Propaganda für die deutschen Kriegsanleihen im Ersten Weltkrieg.“ In: Wilke, Jürgen (Hg.): Massenmedien und Spendenkampagnen vom 17. Jahrhundert bis in die Gegenwart. Wien/ Köln: Böhlau, S.115 


\subsection{Psychotechnik - Massenpsychologie und Propaganda}

Nach dem Ersten Weltkrieg erlangte die Propaganda zunehmend an Bedeutung und avancierte zur Gesellschaftslehre. Anlass war die massenwirksame Kriegspropaganda der Entente, ${ }^{233}$ der es gelungen war, das deutsche Volk vor den Augen der Weltöffentlichkeit als kulturlose „Barbaren und Hunnen“234 zu diskreditieren. Den ausländischen Propagandastrategen wurde ferner unterstellt, die deutsche Kampfkraft unterminiert zu haben. ${ }^{235}$ General Ludendorff manifestierte in seinen 1919 publizierten Kriegserinnerungen den Gedanken von der Omnipotenz der gegnerischen Propaganda und prangerte das Versagen der deutschen Politik und Propagandaleitung an, ${ }^{236}$ die angesichts der gegnerischen Massensuggestion regelrecht paralysiert waren. Der Militärschriftsteller und Oberleutnant der Reichswehr Kurt Hesse forderte in seinem Buch „Der Feldherr Psychologos“,237 die Propaganda in einem zukünftigen Krieg als Waffe einzusetzen. Adolf Hitler führte den Erfolg der englischen „Greuelpropaganda“ auf „die glänzende Kenntnis der Primitivität der Empfindung der breiten Masse“ zurück, denn das gemeine Volk sei „in seiner überwiegenden Mehrheit so feminin veranlagt und eingestellt, daß weniger nüchterne Überlegung als vielmehr gefühlsmäßige Empfindung sein Denken und Handeln bestimmt. ${ }^{238}$

233 Die deutschen Soldaten haben der Übermacht an Mensch und Material nur aufgrund ihrer psychischen Stärke standhalten können. Der Zusammenbruch sei erst erfolgt, nach dem der Revolutionsgedanke das deutsche Heer moralisch desavouiert und die Heimatfront destabilisiert und revolutioniert hatte. Vgl. Ludendorff, Erich (1919): Meine Kriegserinnerungen. Berlin: E. S. Mittler, S. 290 - 303

234 Hitler, Adolf (1930): Mein Kampf, 2. Aufl. München: Frz. Eher Nachf., S. 199

235 Vgl. Hesse, Kurt (1922): Der Feldherr Psychologos. Ein Suchen nach dem Führer der deutschen Zukunft. Berlin: E. S. Mittler, S. 172

Vgl. Paul (1990): Aufstand, S. 28

236 Vgl. Ludendorff (1919): Kriegserinnerungen, S. 300 - 303. Die britische Kriegspropaganda formierte sich nach dem Ausbruch des Ersten Weltkrieges unter der Ägide unterschiedlicher Institutionen, wobei dem „War Propaganda Bureau im Wellington House“ die größte Bedeutung zukam. Eine Professionalisierung erfuhr die britische Propaganda im Jahr 1918 unter dem Direktor für Feindpropaganda Lord Northcliff. Wittek, Thomas (2005): Auf ewig Feind?: Das Deutschlandbild in den britischen Massenmedien nach dem Ersten Weltkrieg. München: Oldenbourg, S. $85-88$

237 Hesse (1922): Feldherr, S. 61-72

238 Hitler (1930): Kampf, S. 201 
Bei vielen Staatswissenschaftlern, Schriftstellern und Publizisten herrschte nicht nur Konsens darüber, den Krieg aufgrund verfehlter Propagandapolitik verloren zu haben, sondern auch, dass ein zukünftiger Krieg nur mit organisierter und auf psychologischen Erkenntnissen basierender gezielter Massenbeeinflussung gewonnen werden kann. Der Publizist Stern-Rubarth plädierte für den Einsatz der Propaganda als Waffe und „Mittel für eine Kriegsführung. “239 Die psychologischen Ansätze knüpften dabei an die im Jahr 1895 von Le Bon publizierte Arbeit ,Psychologie der Massen“ an. Le Bon definiert die Masse nicht als gewachsene soziale Gemeinschaft, sondern als „psychologische Masse“,240 mit einer veränderten kognitiven Informationsverarbeitung. Le Bon spricht der psychologischen Masse sowohl die Intellektualität ab, als auch die Kulturfähigkeit. Als Teil einer triebgesteuerten Masse würde sich der Mensch leidenschaftlicher und archaischer Emotionen hingeben, die ihn $\mathrm{zu}$ „Heldenmut oder Edelmut“ aber auch zu unsittlichen Taten und „blutigsten Grausamkeit“241 motiviert. Bildern, Worten und Redewendungen misst Le Bon bei der Beeinflussung besondere Relevanz zu und bezeichnet sie als "geheimnisvolle Macht",242 der die Massenseele zum Opfer fällt. Bilder und eingängige Worte stehen dabei stellvertretend für alle semantischen Ausdrucksformen, die in einfacher, plakativer Weise Informationen transferieren und die aktuellen Befindlichkeiten einer Masse ansprechen. So plädierte Goebbels später auch für den Einsatz einfachster Mittel, um die Massen zu beeinflussen: „Je einfacher und je primitiver, desto wirkungsvoller“. ${ }^{243}$ Die Propagandastrategen forderten einen Paradigmenwechsel von einer akademisch-formalgeprägten

\footnotetext{
239 Stern-Rubarth, Edgar (1921): Die Propaganda als politisches Instrument. Berlin: Trowitzsch \& Sohn, S. 4

240 Le Bon, Gustave (1982): Psychologie der Massen. Stuttgart: Kröner, S. 10

241 Ebd., S. $19 f$.

242 Ebd., S. 71f.

243 Goebbels, Joseph: „Wesen, Methoden und Ziele der Propaganda“. Rede auf der Sondertagung der Gau- und Kreispropagandaleiter anläßlich des 7. Reichsparteitags der NSDAP Nürnberg, Apollo-Theater, 16.9.1935. In: Heiber, Helmut (Hg.) (1991): Goebbels Reden 19321945. Düsseldorf: Gondrom, S. 238ff. In der Anleitung für die Gestaltung von politischen Plakaten wurde explizit Einfachheit gefordert, um „dem primitiven Empfinden der Massen“ zu entsprechen. Medebach, Friedrich (1941): Das Kampfplakat. Aufgabe, Wesen und Gesetzmäßigkeit des politischen Plakats, nachgewiesen an den Plakaten der Kampfjahre von 1918 bis 1933. Zeitung und Zeit. Schriftenreihe des Instituts für Zeitungswissenschaft an der Universität Berlin. Reihe A, Band 19. Frankfurt/M.: Moritz Diesterweg, S. 14
} 
Propagandastrategie, ${ }^{244}$ hin $\mathrm{zu}$ einer psychologisch strukturierten Massenbeeinflussung unter Verwendung visueller und suggestiver Kommunikationsmittel. Den Forschern war bewusst, dass sich die Massen nicht wie von Le Bon beschrieben, allein durch einfache Manipulationstechniken lenken lassen, sondern nur mittels komplexer persuasiver Kommunikationsstrategien beeinflusst werden können. Diese neue Ausrichtung der Propaganda wurde getragen von werbewissenschaftlicher und publizistischer Forschung, die in der Weimarer Republik zur Gesellschaftslehre avanciert war. Mit der Ausweitung der Reklame hatten psychologische Techniken zur Erforschung der menschlichen Psyche einen Innovationsschub erfahren und die erworbenen Erkenntnisse flossen in die Propagandaforschung ein, die daraufhin ebenfalls einen Professionalisierungsschub erfuhr. ${ }^{245}$ Vitales Interesse der Forscher lag in der Optimierung der Kommunikationsinstrumente, um die Suggestibilität der Rezipienten zu erhöhen. Die führenden deutschen Köpfe der Psychotechnik wie Johann Plenge und Edgar Stern-Rubarth plädierten für eine wissenschaftliche Erforschung der Propaganda sowie für „die psychologische Vertiefung des Verfahrens und seiner Wirkungen“ unter der bewährten Prämisse „deutscher wissenschaftlicher und technischer Arbeit“. ${ }^{246}$ Die Forschung hatte das Ziel, adäquate Repräsentationsformen für eine persuasive Kommunikation zur Beeinflussung der Massen zu entwickeln.

Das erwachende Interesse an der Propaganda wurde begleitet von einer Flut an populistischen Publikationen zur Erforschung der Massenseele und Willenslenkung, die einen maßgeblichen Einfluss auf das politische Geschehen hatten. Insbesondere politische Gruppierungen, die sich in der Weimarer Republik am rechten und linken Rand etabliert hatten, maßen der Propaganda eine allmächtige Wirkung bei und sahen in der Beeinflussung der Massen ein vitales Instrument, um ihre politischen Ziele

\footnotetext{
244 Vgl. Plenge, Johann (1922): Deutsche Propaganda. Die Lehre von der Propaganda als praktische Gesellschaftslehre. Bremen: Angelsachsen-Verlag, S. 27ff. Die sachliche, teils auf Argumentation basierende Propaganda verunglimpft Hitler als deutschen „Objektivitätsfimmel“. Hitler (1930): Kampf, S. 201

245 Vgl. Plenge (1922): Propaganda, S. 53

246 Stern-Rubarth (1921): Propaganda, S.106
} 
durchzusetzen. Insbesondere Hitler setzte sich mit Propaganda, Massenpsychologie und Reklame auseinander, die den damaligen Kenntnisstand wider gaben. ${ }^{247}$

\subsection{NS-Propaganda}

Die NS-Propagandastrategen hatten die Parallelen zwischen Werbung und Propaganda hinsichtlich der Kommunikationsstrukturen und der psychologischen Methodik erkannt. ${ }^{248}$ Joseph Goebbels hob 1930 die Bedeutung moderner Werbetechniken hervor und war bestrebt, in der neu konstituierten Propaganda-Abteilung der NSDAP an die Erkenntnisse der Reklame anzuknüpfen. Goebbels empfahl, „Werbemethoden zu studieren und sie [...] auszuwerten“, 249 denn „Ursachen und Erfolg der nationalsozialistischen Propaganda und Propagandakunst liegen [...] primär darin, daß die Reklame ihr schon den Weg bereitet hatte. “250 Die Propagandastrategen konnten nicht nur an die Werbe- und Propagandaforschung anknüpfen, sondern fanden auch geschulte Rezipienten vor, die die semantischen Bedeutungsebenen der Werbung und der Propaganda bereits verinnerlicht hatten. Nach der Reichgründung und insbesondere während des Ersten Weltkrieges hatten sie gelernt, die Symbolsprache der Werbung und der Propaganda zu decodieren.

Maßgeblichen Einfluss auf die nationalsozialistische Propaganda hatte Plenge, der bereits 1923 den ersten Kontakt mit der NSDAP hatte, als er von Goebbels aufgesucht wurde, um „Rat zu holen wie eine junge Partei und Bewegung mit Hilfe dieses Instruments der Propaganda Erfolg haben könne“ ${ }^{251}$ Plenge erwies sich dabei als wichtiger Ratgeber, in dem er eine Vielzahl an signifikanten „sinnstiftender Symbole

247 Hitler und Goebbels partizipierten an den Forschungen von Plenge. Später stritten sie die Adaption ab, um die Propagandaerfolge für sich zu beanspruchen. Vgl. Paul (1990): Aufstand, S. 26. Plenge klagte später mehrmals vergeblich seine Urheberschaft ein. 1934 wurde sein Institut für Propaganda-Forschung geschlossen. Er selbst wurde zwangsemeritiert. Vgl. Bussemer (2005): Propaganda, S. 124

Vgl. Reinhardt (1993): Reklame, S. 446

Vgl. Henkel (1934): Werbung, S. 97

249 Stark, G. (1930): Moderne politische Propaganda. 1. Heft der Schriftenreihe der Reichspropaganda-Abteilung. München: Verlag Frz. Eher Nachf., S. 4

250 Wirtschaftswerbung, 1934, Heft 13, S. 92. Zit. nach: Westphal, Uwe (1989): Werbung im Dritten Reich, Berlin: Transit, S. 21f.

251 Schäfers, 1967 b, S. 9. Zit. nach: Bussemer (2005): Propaganda, S. 123 
lieferte“ wie „die ,Ideen von 1914', das ,Hakenkreuz', den Begriff des 'Dritten Reiches' und der 'organisierten Volksgenossenschaft'“. ${ }^{252}$ Plenge wies dabei auf die Bedeutung einer organisierten und dauerhaften Strategie hin, „weil eine durchgeführte Propaganda, die planmäßig „energetische Imperative“ zu dauernder Wirkung verbreiten will, nur auf richtiger organisatorischer Unterlage möglich ist.“253 Die Relevanz einer zielgerichteten Strategie zur Massenbeeinflussung wurde von den Propagandaverantwortlichen der NSDAP erkannt und zielgerichtet verfolgt. So forderte Goebbels eine permanente Propaganda zur Sicherung der Macht: „Und wenn heute vielfach gefragt wird, ob die Propaganda denn, nachdem wir die Macht erobert hätten, überhaupt noch nötig sei, so ist das dieselbe dumme Frage wie die, ob die Partei noch nötig sei, da wir doch den Staat besitzen [...] Wenn aber hinter der Verwaltung nicht eine einheitliche, in sich geschlossene Volksmasse steht, dann wird die Lebensdauer einer Regierung nur von kurzem Bestand sein." ${ }^{254} \mathrm{~B}$ Um die Propaganda als legitimes Instrument $\mathrm{zu}$ etablieren, musste der Begriff im Bewusstsein der Öffentlichkeit neu konnotiert und in ein positives Licht gesetzt werden. ${ }^{255}$ In dem Vorwort des Albums Adolf Hitler unternimmt Goebbels den Versuch, die Propaganda positiv zu besetzen:

„Über den Begriff Propaganda herrscht in der ganzen Welt und auch heute noch in Deutschland eine Unmenge von Mißverständnissen, die, da sie so eingewurzelt sind und meistens auf Vorurteilen beruhen, nur schwer erklärt werden können. Dabei hat gerade das deutsche Volk seit Ende des Krieges in

\footnotetext{
252 Bussemer (2005): Propaganda, S. 124

253 Plenge (1922): Propaganda, S. 15

254 Goebbels (1991): Reden (Wesen, Methoden und Ziele der Propaganda, 1935), S. 231 „Die Propaganda hat nun wesentliche Charakterzüge, die - ob sie nun in einem revolutionären Kampf um die Macht oder in einem evolutionären Kampf um die Behauptung der Macht angewandt werden - immer die selben sind." Ebd., S. 233

255 Goebbels unterstreicht in seiner Rede auf der Sondertagung der "Gau- und Kreispropagandaleiter" am 16.9.1935 den Unterschied zwischen Reklame und Propaganda. Vgl. Ebd., S. 232. Die Differenzierung der beiden Begriffe wurde per Gesetz geregelt und vom Werberat mit Nachdruck überwacht. Zweite Verordnung zur Durchführung des Gesetzes über Wirtschaftswerbung v. 17.10 1933, RGBL, 1, 1933, 791. Zit. nach: Schmitz-Berning, Cornelia (2000): Vokabular des Nationalsozialismus, München: de Gruyter, S. 179
} 
dieser Beziehung einen Anschauungsunterricht genossen, wie er besser und eindringlicher gar nicht gedacht werden kann. ${ }^{256}$

Die NS-Propagandaleitung war sich darüber hinaus bewusst, dass sowohl der Weg zur Macht als auch ihre Erhaltung nur mit der Kontrolle aller Bereiche der Gesellschafts- und Wirtschaftskommunikation einhergehen konnte, denn „die psychologische Erfassung und Mobilisierung der Nation" war Basis der Herrschaft und ein Instrument „totalitärer Durchdringung aller gesellschaftlichen Strukturen.“257 So erfolgte eine „Erfassung, Mobilisierung und Gleichschaltung aller Lebensbereiche“. ${ }^{258}$ Mit der Gründung des RMVP am 13. März 1933 wurden alle Medien dem Ministerium unterstellt. Das NS-Regime erlangte damit das Informationsmonopol über die "geistige Führung der Nation“ ${ }^{259}$ und somit auch die Kontrolle über die gesamte Werbewirtschaft. ${ }^{260}$ Diese Kontrolle war auch wirtschaftspolitisch eine erforderliche Maßnahme, denn die zivile Wirtschaft wurde partiell auf eine planwirtschaftlich ausgerichtete Wehrwirtschaft umgestellt. ${ }^{261}$

256 Reemtsma (1936): Hitler, Vorwort von Joseph Goebbels, unpag.

257 Fest, Joachim (2006): Hitler. Eine Biographie, 9. Aufl. Berlin: Ullstein, S. 595

258 Bauer, Kurt (2008): Nationalsozialismus. Ursprünge, Anfänge, Aufstieg und Fall. Wien/ Köln: Böhlau, S. 277

259 Rücker (2000): Wirtschaftswerbung, S. 81

260 Die rasante Indienststellung der Werbewirtschaft hatte ihre Ursache nicht nur in den repressiven Maßnahmen seitens der Politik. Ohne homogene Konzeption befand sich die gesamte Werbewirtschaft nach dem Machtwechsel 1933 in einer starken Rezession und war somit empfänglich für die neue politische Ausrichtung. Der Deutscher Reklame-Verband begrüßte die Gründung des Propagandaministeriums und betonte die Notwendigkeit professioneller Werbung für den Neuaufbau des Staates. Vgl. Ebd., S. 82

261 Die Kontrolle über die Wirtschaftswerbung erlaubte dem NS-Regime einen Teil seiner Wirtschaftspolitik zu lenken, die jedoch keiner Doktrin folgte, sondern im Spannungsfeld zwischen Planwirtschaft und marktwirtschaftlichen Prinzipien stand. Dabei setzte sich ein vom Ordoliberalismus geprägter Wirtschaftskurs durch. Die Umlenkung des Konsums zu Gunsten der Rüstung wurde daher nicht in aller Konsequenz umgesetzt. Eine strikte Umlenkung hätte nicht nur eine Inflation provoziert, sondern auch den Unmut der Bevölkerung. Vgl. Ptak, Ralf (2004): Vom Ordoliberalismus zur Sozialen Marktwirtschaft. Stationen des Neoliberalismus in Deutschland. Wiesbaden: Springer, S. 69 - 72. Der reine Liberalismus wurde offiziell abgelehnt. In dem Album Adel der Arbeit wird er als Manchesterkapitalismus verdammt, da er jede staatliche Lenkung ausschließt und sich auf Kosten der Arbeiter bereichert. Vgl. Greiling (1934): Adel der Arbeit. Bilder aus dem Berufsleben des schaffenden deutschen Volkes. Dresden, S. 30 und 38. Mit der Machtübernahme wurde das auch Prinzip der Wehrwirtschaft verfolgt, die das Ziel hatte, die Volkswirtschaft bereits in Zeiten des Friedens auf einen Krieg vorzubereiten. Ziel war es, neben dem militärischen Bedarf auch den der Zivilbevölkerung zu sichern. Die Ressourcensicherung umfasste Ernährung, Rohstoffe sowie die Anpassung des Verkehrswesens. Volkmann, Hans-Erich (1979): „Die NS-Wirtschaft in Vorbereitung des Krieges." In: Deist, Wilhelm/ Messerschmidt, Manfred/ Ders./ Wette, Wolfram. Ursachen und 
Die Monopolisierung aller kommunikationspolitischen Maßnahmen erforderte weitere Restriktionen, denn als zu Beginn der 1930er Jahre Werbetreibende an der wachsenden Popularität des Nationalsozialismus partizipieren wollten, sah sich das NS-Regime angesichts des inflationären Gebrauchs und der Trivialisierung der nationalen Symbole gezwungen, dem Trend gesetzlich Einhalt zu gebieten. Die neuen Machthaber sahen in der Verquickung der Wirtschaftswerbung mit dem Führer oder mit Symbolen der nationalsozialistischen Bewegung eine gefährliche Erscheinung, die imstande war, die Person Hitlers oder die NS-Bewegung lächerlich zu machen. ${ }^{262}$ Damit die Ikonen des Dritten Reiches ihre Wirkungsmacht entfalten konnten, mussten die sakralen Symbole des Regimes ihre ontologische Dimension bewahren und der profanen Konsumwelt entzogen werden. ${ }^{263}$ So wurde bereits im Mai 1933 das „Gesetz zum Schutz der nationalen Symbole“264 erlassen. Die NSDAP konnte mit den Gesetzgebungen alle Maßnahmen ihrer Propagandastrategien disponieren und entsprechend ihren gesetzten Zielen auf die Rezipienten ausrichten und eine permanente Beziehung zur Bevölkerung aufbauen. Wenige Firmen waren von den Gesetzgebungen und Regelungen ausgenommen. Daimler-Benz und dem Zigarettenkonzern Reemtsma, ${ }^{265}$ Sturm und anderen kleinen Unternehmen der Branche war es erlaubt,

Voraussetzungen der deutschen Kriegspolitik. Militärgeschichtliches Forschungsamt (Hg.): Das Deutsche Reich und der Zweite Weltkrieg, Bd. 1. München: Deutsche Verlags-Anstalt, 208f. Vgl. Behrenbeck (1996): „,,Der Führer“. Die Einbindung eines politischen Markenartikels“. In: Diesener, Gerald/ Gries, Rainer (Hg.) (1996): Propaganda in Deutschland - Zur Geschichte der politischen Massenbeeinflussung im 20. Jahrhundert. Darmstadt: Primus, S. 68

263 Vor der Gefahr der Profanisierung hatte bereits Plenge gewarnt: , $[\ldots .$.$] man [soll] große$ Namen und große Dinge in der Propaganda nicht mißbrauchen, weil sie sonst ihre Heiligkeit, ihre unersetzliche Kraft verlieren. Die Entwertungspropaganda kann durch ihren Mißbrauch große Dinge und große Namen in den Staub des Alltags ziehen.“ Plenge (1922): Propaganda, S. 37

264 Sennebogen, Waltraud (2004): „Von jüdischer Werbung zu deutscher Werbung. Sprachregelung in der nationalsozialistischen Wirtschaftswerbung." In: Greule, Albrecht/ Dies. (Hg.): Tarnung - Leistung - Werbung. Untersuchungen zur Sprache im Nationalsozialismus. Frankfurt/M.: Peter Lang, S. 212

265 Vgl. Schug, Alexander (2007): „Hitler als Designobjekt und Marke. Die Rezeption des Werbegedankens durch die NSDAP bis 1933/34“. In: Berghoff (Hg.): Marketinggeschichte. S. 338. Die Verbindung von Daimler-Benz und Hitler ist ein klassisches "Co-Branding“. Bei einem Co-Branding werden zwei unabhängige Marken miteinander verbunden. Dabei müssen mindestens zwei „Identitäten eigenständiger Marken unter Berücksichtigung der zu Grunde liegenden gemeinsamen Leistung verbunden werden [...] ohne dass es zu Widersprüchen oder Konflikten zwischen dem Selbst- und dem Fremdbild kommt.“ Meffert, Heribert (2002): „Strategien des Markenmanagements.“ In: Ders./ Burmann, Christoph/ Koers, Martin (Hg.): 
NS-Symbole oder Vertreter des Regimes in kommunikationspolitische Strategien einzubinden.

\subsection{Propaganda-Phasen}

Propaganda kann nur dann erfolgreich sein, wenn ihre Inhalte und Paradigmen auf die Lebenswelt der Zielgruppe ausgerichtet und darüber hinaus die politischen und sozialen Rahmenbedingungen berücksichtigt werden. Da die sozialpsychologischen Faktoren in der Bevölkerung unterschiedlich segmentiert und einem stetigen Wandel unterworfen sind, müssen Publikumsansprache und Propagandainhalte entsprechend modifiziert werden. Goebbels mahnte angesichts der unterschiedlichen kulturellen Hintergründe der Großstädter und Landbewohner bereits 1930 für eine Ausdifferenzierung der Propagandastrategien.266 Zielgruppenadäquate Ansprache der Rezipienten war dabei ebenso von Relevanz wie die Auswahl der Medien und Propagandaformen. Auch Plenge nahm eine Unterscheidung vor und differenzierte unter anderem zwischen Demonstrations-, Wort- und Symbolpropaganda. Für Plenge galt die Demonstrationspropaganda als primitivste Form der Propaganda. Auch die Propaganda der Tat, die sich darauf beschränkt, Menschen mit politischen Verbrechen oder singulären Protestaktionen aufzurütteln,267 betrachtete er als niedere Form der Massenbeeinflussung. Dem Wort maß Plenge eine weitaus größere Bedeutung zu, da es zum Transfer von Ideen, Schlagworten und zur Gegenpropaganda eingesetzt werden kann sowie der Akquise und Bindung von Anhängern dient.268 Das NS-Regime war daher gezwungen, die Propagandastrategien durch operative Maßnahmen während der Phase der Machtergreifung, des Machterhalts und des Krieges neu zu justieren. Neben der veränderten Bedürfnislage der deutschen Bevölkerung in den 1920er und frühen 1930er Jahren waren auch die Intentionen der NSDAP einem Wandel unter

Markenmanagement: Grundfragen der identitätsorientierten Markenführung. Wiesbaden: Gabler, S. 151

266 Die "Großstadtbevölkerung" ist „politisch viel mehr verfeinert und hat eine ganz andere geistige Einstellung zu den Dingen.“ Stark (1930): Propaganda, S. 3

267 Vgl. Plenge (1922): Propaganda, S. 27

268 Vgl. Ebd., S. $27 f$. 
worfen. Waren vor 1933 alle Propagandaaktivitäten auf das Erlangen der Macht ausgerichtet, galt es danach, die Macht zu erhalten und das Regime zu stabilisieren. In der Phase von 1933 bis 1939 verfolgte die NSDAP darüber hinaus noch weitere Ziele, denn neben der Etablierung der Macht galt es, die Bevölkerung für einen geplanten Angriffskrieg zu emotionalisieren.

Mit dem Beginn des Krieges war eine erneute Anpassung erforderlich, denn nun bestand das vitale Interesse darin, die Bevölkerung für den Kriegseinsatz zu mobilisieren und darüber hinaus eine Akzeptanz für die kriegsbedingten Repressalien zu verankern. Das Regime musste bei der Öffentlichkeitsarbeit nicht nur eine Konvergenz zwischen den Repressalien und den eigenen Propagandazielen herstellen, sondern Sieg und Niederlage der deutschen Truppen mussten an die Stimmungslage der Bevölkerung angepasst und mit den außenpolitischen Gegebenheiten abgestimmt werden. Den Propagandaverantwortlichen war bewusst, dass sie sich bei der Massenbeeinflussung der Bevölkerung und der Legitimation gegenüber dem Ausland ausgefeilter Kommunikationsstrategien bedienen und den Gegebenheiten anpassen mussten. Die NS-Propaganda muss daher, wie von Thymian Bussemer ${ }^{269}$ exemplarisch darlegt, in unterschiedliche Phasen eingeteilt werden, wie in "politische Agitation und Parteienwerbung“ und in „Intergrations- und Kriegspropaganda.“270

\subsubsection{Demonstrationspropaganda}

Die Zeit der nationalsozialistischen Agitation und Parteienwerbung reicht von der Gründung der NSADP im Jahr 1920 bis zum Machtantritt im Januar 1933. Obwohl sich bis 1932 noch kein einheitlicher Propaganda-Stil herausgebildet hatte, ${ }^{271}$ war die NS-Propaganda ab dem Jahr 1921 ganz auf Demagogie und auf die „Rückeroberung der Masse“272 ausgerichtet, bei der insbesondere Hitler „auf die psychologische

Bussemer (2000): Populärkultur, S. 13

Ebd., S. 14

Vgl. Ebd., S. 15

Paul (1990): Aufstand, S. 37 
Wirkung des Terrors“273 setzte. Die Propaganda dieser Zeit war eine charakteristische „faschistische Mobilmachung der Öffentlichkeit“, ${ }^{274}$ die von einem militärischen und aggressiven Tenor geprägt war. Als Bühne für die Agitation dienten öffentliche Veranstaltungen und Propagandafahrten auf Lastkraftwagen, ${ }^{275}$ bei denen sich insbesondere die von Hitler gezielt eingesetzte SA als die Propaganda-Säule von Gewalt und Terror präsentierte. „Gegen die Faust setzte Adolf Hitler nicht den papierenen Protest der Bürgerlichen, sondern seine Faust: die SA.“"276 Gewaltaktionen auf der Straße und bei Veranstaltungen waren dem Selbstverständnis der SA nicht nur inhärent, ${ }^{277}$ sondern auch „von der NSDAP berechnet und kalkuliert.“278 Die „symbolische Eroberung der Straße in Form von Aufmärschen der uniformierten SA, die von Marschmusik begleitet wurden und Fahrten mit Lastkraftwagen, ${ }^{279}$ bei denen die Parteiarmee durch die Straßen raste und Flugblätter verteilte, demonstrierte einen militärischen wie kämpferischen Habitus. Diese Propaganda besaß nach Einschätzung der SA „eine außerordentliche Propagandawirkung", 280 die in rechtsgerichteten Kreisen der Bevölkerung verstärkt Zustimmung fand.281 Die physische Okkupation des Raumes war integrativer Bestandteil der demonstrativen Propaganda, die ihre psychologische Wirkung nicht verfehlte und „optisch das Reich“282 erdrückte. Victor Klemperer beschreibt eindringlich die Wirkung, die eine Massenkundgebung selbst

\footnotetext{
273 Ebd., S. 41

274 Loiperdinger, Martin (1987): Rituale der Mobilmachung. Opladen: Leske und Budrich, S. 130

275 Vgl. Ebd., S. 137. Vgl. Bley, Wulf (1934): SA marschiert. Leben und Kampf der brauen Bataillone. Berlin: Verlag Deutsche Kultur-Wacht, S. 17ff.

276 Bley (1934): SA, S. 22. Gewalt war dem Selbstverständnis der SA inhärent. Vgl. Reichardt, Sven (2007): „Totalitäre Gewaltpolitik?“ In: Hartwig, Wolfgang (Hg.): Ordnungen in der Krise. München: Oldenbourg, S. 392

277 Neben der Einschüchterung des politischen Gegners schweißte die Gewalt die Kampfbünde als Gemeinschaft zusammen. Vgl. Reichhardt, Sven (2009): Faschistische Kampfbünde. Gewalt und Gemeinschaft im italienischen Squadrismus und in der deutschen SA, 2. Aufl. Wien/ Köln: Böhlau, S. 135

278 Ebd., S. 120

279 Vgl. Thamer, Hans-Ulrich (1986): Verführung und Gewalt Deutschland 1933 - 1945. Berlin: Siedler, S. 63

280 Bley (1934): SA, S. 86. Reichhardt (2007): Gewaltpolitik, S. 391f.

281 Vgl. Paul, Gerhard (1989): „Die Nationalsozialisten.“ In: Lehnert, Detlef/Megerle, Klaus (Hg.) (1989): Politische Identität und nationale Gedenktage. Opladen: Westdeutscher Verlag, S. 256

282 Reichel, Peter (2012): Glanz und Elend deutscher Selbstdarstellung. Nationalsymbole in Reich und Republik. Göttingen: Wallstein, S. 181
} 
im Film besaß:,,Die Masse der SA-Leute vor ihm [Anm.: Hitler], das halbe Dutzend Mikrophone vor seinem Pult, das seine Worte an 600000 SA-Leute im ganzen Dritten Reich weitergeht - man sieht seine Allmacht und duckt sich. “283

Physische Einwirkung und psychische Erfahrbarkeit durch Gefühlsadaption wird bei der Demonstrationspropaganda minimiert, wenn sie in ein statisches Medium wie Bild und Text übersetzt wird. Bildbände und Zigarettenalben sind daher ein inadäquates Medium für diese Form der Propaganda. In den Alben wird lediglich Rekurs auf diese Phase genommen und als heroische Kampfzeit stilisiert. In dem Album der Firma Sturm Deutsche UnIformen: SA SS HJ wird die gesamte Spannbreite der aggressiven Propaganda-Instrumente beschrieben:

\begin{abstract}
„Der 4. November 1921 sollte der Tag der Bluttaufe der Sturmabteilung werden. An die 46 Getreuen richtete der Führer im Vorraum des Hofbräuhauses in München die historisch gewordene Ansprache:,,Ihr werdet heute zum ersten Male auf Biegen und Brechen der Bewegung die Treue halten müssen. Keiner von uns verläßt den Saal, außer sie tragen uns als Tote hinaus. Wer feige zurückweicht, dem reiße ich persönlich die Ehrenbinde herunter und nehme ihm das Abzeichen“. In blutiger Saalschlacht wurden 800 Marxisten, welche die Versammlung stören wollten, aus dem Saale geworfen." ${ }^{284}$

„Die SA marschierte, klebte Plakate, verbreitete ihre Lehre durch das Wort, drang in die übelsten Quartiere der Feinde, eroberte eine Feste der roten Gegner nach der anderen, belehrte das Spießertum und setzte sich dort zur Wehr, wo sie angegriffen wurde. “285
\end{abstract}

In dem Sammelband DEUTSCHLAND ERWACHT wird eine Saalschlacht illustriert, die das blutige Szenario wiedergibt: Eine raufende Menge schlägt mit geballten Fäusten, Stühlen und Bierkrügen aufeinander ein (Abb.1). ${ }^{286}$ Die Brutalität wird in dem Album szenisch in Wort und Bild geschildert und gleichsam heroisch verklärt:

\footnotetext{
283 Klemperer, Victor (1996): Ich will Zeugnis ablegen bis zum letzten. Tagebücher 1933 - 1941, 8. Aufl. Berlin: Aufbau-Verlag, S. 23

284 Sturm (1933): SA SS HJ, Dresden (Literaturbearbeitung: Oberführer von Calrshausen, Oberste SA-Führung, München. Bilder: Militärmaler Herbert Knötel, Berlin), erste Textseite. Die gewalttätigen Ausschreitungen werden durch eine Zeichnung veranschaulicht. Die Grafik illustriert eine Saalschlacht zwischen Marxisten und SA, bei der Stühle und Bierkrüge zu Bruch gehen.

285 Sturm (1933): SA SS HJ, vierte Textseite

286 Vgl. Reemtsma (1933): Deutschland erwacht, Kapitel: Des Führers erste SA, unpag.
} 
„Nicht in geheimen Konventiteln soll gearbeitet werden, sondern in gewaltigen Massenaufzügen und nicht durch Dolch und Gift oder Pistole, kann der Bewegung die Bahn frei gemacht werden, sondern durch die Eroberung der Straße." ${ }^{287}$

„Flugblätter und Plakate wurden ausgegeben. Die Farbe der Plakate war ein blutiges Rot, das unter allen Umständen auffallen mußte.“288

In dem Gros der Zigarettenalben wird die Gewaltbereitschaft der SA jedoch nicht thematisiert. Die Sturmabteilung wird als treue Garde des Führers dargestellt, die im Sinne der Bewegung agiert. Der Verzicht auf die visuelle Demonstration von Gewalt reflektiert die Neuausrichtung der NS-Propaganda nach 1933, denn mit dem Machtantritt hatten sich die Rahmenbedingungen für die NSDAP gewandelt. Da die Partei noch nicht vollständig in der Gesellschaft verankert war und drohte, aufgrund der fortbestehenden krisenhaften wirtschaftlichen Lage an Akzeptanz zu verlieren, ${ }^{289}$ war eine zivile Außenwirkung das Gebot der Stunde. Da Herrscher dem Volk entgegenkommen und Konzessionen machen müssen, können selbst faschistische Regime ihre Macht langfristig nicht auf Gewalt und Terror aufbauen, sondern müssen eine Akzeptanz in der breiten Bevölkerung schaffen. ${ }^{290}$ Entsprechend konnte auch das NS-Regime die Bedürfnislage des Volkes nicht unberücksichtigt lassen. Zur Stabilisierung der Macht musste sich das NS-Regime bei Regierungsantritt ferner den Rückhalt der „konservativen Eliten“291 sichern, die gemeinsam mit bürgerlichen Kreisen nach 1933 auf eine moderate autoritäre Herrschaftsstruktur hofften. ${ }^{292}$ Angesichts der

\footnotetext{
$287 \quad$ Ebd., S. 129

288 Ebd., S. 13

289 Der Stimmenanteil der betrug bei den Wahlen im Jahr 1933 lediglich 37,3 Prozent, wobei viele Protestwähler für die NSDAP votiert hatten. Vgl. Longerich (1999): Bataillone, S. 207

290 Die Propaganda musste daher auch im Bereich der populären Kultur Konzessionen machen und das Bedürfnis nach Unterhaltung und Zerstreuung berücksichtigen. Vgl. Evans, Richard J. (2006): Das Dritte Reich, Bd. 2/1. München: Deutsche Verlags-Anstalt, S. 161. Machtbeziehungen können weder auf Gewalt noch auf Konsens verzichten. Vgl. Foucault, Michel (2005): Analytik der Macht. Frankfurt/M.: Suhrkamp, S. 255

291 Nolzen, Armin (1986): „Der Durchbruch der NSDAP zur Massenbewegung seit 1929.“ In: Thamer (1986): Verführung, S. 49

292 Vgl. Longerich (1999): Bataillone, S. 208. 1933 waren die konservativen Minister noch in der Überzahl und die Regierung war bestrebt, der Öffentlichkeit ein Bild normaler Regierungstätigkeit zu vermitteln. Vgl. Thamer (1986): Verführung, S. 345
} 
gewalttätigen Ausschreitungen seitens der SA sehnten sich weite Teile der Bevölkerung nach Sicherheit und ein ruhiges politisches Fahrwasser. ${ }^{293}$

Unabhängig von den Bestrebungen Hitlers, die vitalen Ambitionen der SA, die nationalsozialistische Revolution voranzutreiben, zu unterbinden, ${ }^{294}$ wurde die demonstrative Propaganda der SA sowie ihre Ausschreitungen für das Regime inopportun. Am 14. Juli 1933 gab die NSADP offiziell bekannt, dass die Revolution abgeschlossen sei, was primär an die SA gerichtet war. ${ }^{295}$ Die Sturmabteilung erhielt ein neues Image und wurde der Öffentlichkeit als selbstlose Dienerin der Volksgemeinschaft präsentiert. Die veränderte Rolle, die der SA oktroyiert wurde, manifestiert sich in dem Album DeUTSCHLAND ERWACHT. Wurde die Kampfzeit in einem der ersten Kapitel noch nostalgisch verklärt, wird auf den letzten Seiten ein Mentalitätswandel in der Propaganda deutlich, der gleichzeitig den parteipolitischen Machtverlust der SA zugunsten der SS reflektiert. 296

„Schwer waren die letzten Jahre vor 1933 für die Sturmabteilungen gewesen. [...] Sie erzwangen sich gegen die Kommune und System das Recht auf die Straße. Sie waren unbewaffnet, aber sie siegten durch ihren Glauben, durch ihren fanatischen Entschluß, alle Zeit auch das Leben einzusetzen für Adolf Hitler und seine Idee. Als der 30. Januar gekommen war, endete nicht ihre Aufgabe. Sie blieben, was sie waren: die politischen Soldaten der Bewegung. Sie kämpften weiter, nur die Art des Kampfes wurde eine andere. [...] Es gibt keine Veranstaltung, keine Massenkundgebung, keinen Aufmarsch, der nicht gekennzeichnet ist durch die braune und schwarze Ordnungstruppe. [...] Eine Brandkatastrophe ist geschehen? - Die Braunhemden retten und helfen. Ein Anschlag auf die Sicherheit des Staates wird irgendwo noch versucht? Die SS

293 Vgl. Longerich (1999): Bataillone, S. 207. „Die Liquidierung der Obersten SA-Führung und die anschließende Parteisäuberung wurden, obwohl ein offenkundiger Rechtsbruch vorlag, von der Masse der Bevölkerung als Rückkehr des Regimes zur politischen Normalität und als Absage Hitlers an den politischen Radikalismus verstanden." Mommsen, Hans (1997): „Militär und zivile Militarisierung in Deutschland 1914 bis 1938." In: Frevert, Ute (Hg.): Militär und Gesellschaft im 19. und 20. Jahrhundert. Stuttgart: Klett-Cotta, S. 275

294 Vgl. Longerich (1999): Bataillone, S. 202

295 Vgl. Wette, Wolfram (1979): „Ideologien, Propaganda und Innenpolitik als Voraussetzungen der Kriegspolitik des Dritten Reiches." In: Deist, Wilhelm/Messerschmidt, Manfred/ Volkmann, Hans-Erich/ Ders./ Militärgeschichtliches Forschungsamt (Hg): Ursachen und Voraussetzungen der deutschen Kriegspolitik. Das Deutsche Reich und der Zweite Weltkrieg. Bd. 1. München: Deutsche Verlags-Anstalt, S. 147 Vgl. Fest (2006): Hitler, S. 414f. und S. 672. Vgl. Bauer (2008): Nationalsozialismus, S. $237 \mathrm{f}$. 
zerschmettert den Feind. Es soll gesammelt werden Geld oder Kleidung für die Bedürftigen des Volks, oder Altpapier, Altreifen oder was sonst, - die SA führt die Sammlung durch, allein oder mit anderen Gliederungen der Partei, denn auch sie ist ja eine Abteilung der Partei [...]“297

Das NS-Regime hatte erkannt, dass es seine Macht nicht dauerhaft sichern konnte, wenn es sich der aggressiven Demonstrationspropaganda bedient. Letztendlich müssen sich auch faschistische Bewegungen den Rückhalt im Volk sichern und können ihre Macht nicht nur auf „angstvolle Unterwerfung“ gründen, sondern sind auf ,'aktive Kooperation“298 angewiesen.

\subsubsection{Integrationspropaganda}

Der Wandel in der propagandistischen Außenwirkung des NS-Regimes beschränkte sich nicht nur auf das Erscheinungsbild der SA, sondern umfasste weite Bereiche des öffentlichen Lebens. Der ambitionierteste Verfechter eines Paradigmenwechsels in der Propaganda war Joseph Goebbels, der für eine Abkehr von der Demonstrationspropaganda, respektive für eine wohl dosierte aggressive Propaganda plädierte. ${ }^{299}$ Gleichzeitig war er sich der Relevanz permanenter propagandistischer Präsenz zur Erhaltung des NS-Regimes bewusst. „Die Frage, ob Propaganda denn im Dritten Reich überhaupt noch nötig sei, wird deshalb von uns mit einem knappen, aber kräftigen Ja beantwortet. Sie ist nötig wie das tägliche Brot, denn sie erhält den Staat und sie ist jene Kraft, die immerdar mit dem Staate das Volk verbindet. “300 Goebbels war überzeugt, dass Propaganda auch nach der Machtergreifung erforderlich sei, vor allem, um einen Grad an Begeisterung aufrecht zu erhalten. „Goebbels believed that propaganda would be necessary after the takeover the power, not only to mobilize mass support for the Völkischer Staat, but, more importantly, to maintain a level of

\footnotetext{
297 Reemtsma (1933): Deutschland erwacht, S. 131f.

298 Adorno, Theodor W. (1995): Studien zum autoritären Charakter. Frankfurt/M.: Suhrkamp, S. 13

299 „Man darf nicht immer trommeln." Goebbels (1991): Reden (Wesen, Methoden und Ziele der Propaganda, 1935), S. 238

300 Ebd., S. 231f.
} 
enthusiasm and commitment for its ideological foundations. “301 Goebbels sprach sich für eine integrative Propaganda aus, die sich primär Massenmedien der populären Kultur wie „Film, >leichte< Romane, Illustrierte“ und „Radio“302 bediente und „aus einer Kombination aus Unterhaltungsangeboten und Aufbaurhetorik" "303 bestand. Bussemer weist in diesem Zusammenhang auf die Ambivalenz der Integrationspropaganda hin, die sich zwischen banaler Unterhaltung und nazistischer Inhalte bewegte. 304

Mit der Instrumentalisierung der Populärkultur konnte das NS-Regime dem Bedürfnis des Massenpublikums nach Unterhaltung entgegenkommen und gleichzeitig das System stabilisieren. Aus kulturwissenschaftlicher Perspektive beschreibt Populärkultur ein breites Spektrum, das Formen der Unterhaltungskultur und Vergnügen umfasst und sich volkstümlicher Kommunikationsmittel- und Träger bedient. ${ }^{305}$ Populärkultur ist „Volkskultur“306 und damit prädestiniert, die Masse der Bevölkerung zu erreichen. Die populäre Kultur ist ein „Phänomen der modernen Massenkultur“307 und daher unmittelbar verbunden mit dem Aufkommen der Massenmedien. In dem Zigarettenalbum Vom WeRDEn DEUTSCHER FILMKUNST - DeR TONFILM wird der Einsatz des Films als charakteristisches Medium der Populärkultur für die Propaganda als herausragende Leistung des NS-Regimes gewürdigt.

„Ihre nächste Aufgabe erblickte die Regierung darin, den Film, dessen ungeheure Wirkungsmöglichkeit als Kultur- und auch als Propagandainstrument wohl in diesem Umfange noch keine Regierung zuvor erkannt hatte $[\ldots]^{\text {“308 }}$

301 Welch, David (2001): Propaganda and the German Cinema, 1933-1945. Oxford: Oxford University Press, S. 35

302 Bussemer (2000): Populärkultur, S. 77

$303 \quad$ Ebd., S. 17. Welch (2001): Propaganda, S. 35

304 Vgl. Bussemer (2000): Populärkultur, S. 17f.

305 Vgl. Bareither, Christoph/ Maase, Kaspar/ Bausinger, Hermann (Hg.) (2013): Unterhaltung und Vergnügung. Beiträge der Europäischen Ethnologie zur Populärkulturforschung. Würzburg: Königshausen \& Neumann, S. 20

306 Die Populärkultur hat sich als Volkskultur zwischen 1750 und 1800 entwickelt und geht mit dem Erscheinen der modernen Unterhaltungsliteratur einher. In Deutschland begann sich die Populärkultur ab Mitte 19. Jahrhunderts zu etablieren. Hügel (2003): Kultur, S. 5

$307 \quad$ Bareither et al. (2013): Unterhaltung, S. 11

308 Reemtsma (Cigaretten-Bilderdienst Altona/Bahrenfeld) (1936): Vom Werden deutscher Filmkunst. 2. Teil: Der Tonfilm. Hamburg-Bahrenfeld, S. 102 
Da Integrationspropaganda im Vergleich zur Demonstrations- und Kriegspropaganda weniger an ein Muster gebunden ist, konnte sie von der NS-Diktatur in „populäre Kulturmuster" integriert werden. Die Politik hatte erkannt, dass Suggestion ein vitales Instrument zur Manipulation darstellt, eine Erkenntnis, die mit zeitgenössischen Forschungen konform ging. So konstatierte der Philosoph Ernst Cassirer in den 1940er Jahren, „daß große Massen viel leichter durch die Gewalt der Einbildung bewegt werden, als durch reine physische Gewalt."309 Die Beeinflussung der Massen bewegte sich daher in der Phase zwischen Machtantritt und Kriegsbeginn zwischen Unterhaltung und subtiler Propaganda.

Die Populärkultur ermöglichte eine zielgruppenadäquate Kommunikation, mit der die Bevölkerung in den Propaganda-Diskurs eingebunden werden konnte. Diese Propaganda-Maxime wurde vor allem von Goebbels vertreten: „Weil wir die Sprache des Volkes sprachen, haben wir das Volk erobert! Und nur, wenn wir weiterhin die Sprache des Volkes zu sprechen verstehen, werden wir das Volk auch behalten können. “310 Die Manipulations- und Suggestionskraft der NS-Propaganda lag vor allem darin, dass sie populäre Themen aufgriff und in den gesellschaftlichen Kontext der Zielgruppen setzte. Damit können die sozialpsychologischen Bedürfnisse der Rezipienten berücksichtigt werden. Den Zielgruppen eröffnen sich so soziale wie psychologische Identifikationsräume, denen sie sich zugehörig fühlen. ${ }^{311}$ Die Bevölkerung wurde über die Populärkultur in einen permanenten „kommunikativen Diskurs“312 eingebunden. Angesichts der dauerhaften Anwesenheit staatlicher Indoktrination verhinderte die Indienstnahme der Populärkultur auch, dass die Propaganda

Cassirer, Ernst (2002 ): Vom Mythus des Staates. Hamburg: Meiner, S. 377

Goebbels (1991): Reden, S. 231

Vgl. Karmasin, Helene (2004): Produkte als Botschaften, 3. Aufl. München: Redline, S. 482f.

Bussemer (2000): Populärkultur, S. 18 
„dem modernen Tempo und dem modernen Zeitempfinden entspricht" ${ }^{\prime 313}$ und die Bevölkerung ihrer überdrüssig wurde. ${ }^{314}$

Ein weiterer signifikanter Vorteil der Populärkultur war, dass sie keinen, respektive nur einen marginalen imperativen Charakter hatte oder von den Rezipienten erst gar nicht als Propaganda wahrgenommen wurde. Diese subtile Form der Manipulation entsprach ganz dem Propagandaverständnis von Goebbels, der für eine Vermischung von Unterhaltung und Propaganda plädierte. Angelehnt an die Werbewirkungsforschung 315 wusste Goebbels, dass Propaganda nur dann ihre höchste Wirkungsmacht entfaltet, wenn die Manipulation auf subtile Weise erfolgt und der Rezipient sich der Beeinflussung nicht bewusst wird. „Das ist das Geheimnis der Propaganda: Den, den die Propaganda fassen will, ganz mit den Ideen der Propaganda zu durchtränken, ohne daß er überhaupt merkt, daß er durchtränkt wird. Selbstverständlich hat die Propaganda eine Absicht, aber die Absicht muß so klug und virtuos kaschiert sein, daß der, der von dieser Absicht erfüllt werden soll, das überhaupt nicht bemerkt. “316

Der Erfolg der Integrationspropaganda ist letztendlich auch darauf zurückzuführen, dass das NS-Regime aufgrund des Informationsmonopols die Inhalte bis zu einem Grad kontrollieren, aber gleichzeitig auch dem Bedürfnis nach bestimmten Unterhaltungsformaten- und Themen gerecht werden konnte. ${ }^{317}$ Eine Anpassung an den Geschmack des Massenpublikums ist nicht nur notwendig, sondern der Populärkultur inhärent, denn neben den technologischen Rahmenbedingungen muss ein

313 Goebbels, Joseph: „Die zukünftige Arbeit und Gestaltung des deutschen Rundfunks“. Ansprache an die Intendanten und Direktoren der Rundfunkgesellschaften. Berlin, Haus des Rundfunks, 25.3.33. In: Heiber (1991): Reden, S. 95

314 Goebbels konnte seine Forderungen nur sukzessive durchsetzen. Das Unterhaltungsangebot des Rundfunks konnte erst ab 1939 so gesteigert werden, dass es das Niveau der Weimarer Republik erreichte. Bei einem Überangebot an Reden und Berichten von NS-Veranstaltungen zeigte sich das Publikum gelangweilt und viele Hörer wechselten teilweise zu ausländischen Sendern. Vgl. Evans, (2006): Reich, S. 168f.

315 „Der Kaufmann muß unter allen Umständen - wenn er das Vertrauen seiner Kunden behalten will - vermeiden, den Käufer erkennbar zu beeinflussen." Domizlaff (2005): Gewinnung, S. 33

316 Goebbels (1991): Reden (Die zukünftige Arbeit und Gestaltung des deutschen Rundfunks, 1933), S. 95

317 Vgl. Bussemer (2000): Populärkultur, S. 18 
Massenpublikum vorhanden sein, dass das Angebot an Populärkultur konsumiert. ${ }^{318}$ Darüber hinaus muss populäre Kultur den Konsumenten Freiheiten zugestehen und Auswahlmöglichkeiten anbieten, zwischen verschiedenen Optionen wählen zu können, ${ }^{319}$ um die eigenen Bedürfnisse adäquat befriedigen zu können. Das RMVP war sich der Relevanz der Bedürfnisbefriedigung bewusst und wertete die Resonanz der Medienwirkung akribisch aus. Falls erforderlich, wurden Korrekturen vorgenommen, ${ }^{320}$ um die Propaganda den Bedürfnissen der Bevölkerung anzupassen. Die NSPropaganda war, ebenso wie die Zigarettenindustrie gezwungen, den Bedürfnissen der Zielgruppen Rechnung zu tragen. So konstatierte Ph. Reemtsma, dass ein Unternehmen den Wünschen der Konsumenten entsprechen muss, um sich auf dem Markt behaupten zu können: „Zunächst sind ja die Zigarettenbilder nicht der Ausdruck der eigenen Überzeugung des Zigarettenfabrikanten, sondern sind das, was die Konsumenten zu sammeln wünschen, zu sammeln pflegen. [...] Also handelte es sich ausschließlich um ein Vorgehen [Anm.: Publikation der NS-Alben] gegenüber den Nationalsozialisten-Konsumenten. Nun ist die Frage, wieweit kann überhaupt eine Zigarettenfabrik nach politischen Gründen abstimmen oder nicht, sie will ja Zigaretten verkaufen an alle Konsumenten von rechts bis links [...]“..321 Die NS-Propaganda-Alben hätten keine Resonanz gefunden, wenn die Sammelbilder den Geschmack des Publikums nicht berücksichtigt hätten.

\footnotetext{
318 Vgl. Ebd., S. 31

319 Vgl. Hügel (2003): Kultur, S. 6

320 „Systematische Rezipientenforschung und die permanente Rückkopplung von Massenkommunikation sind zu einem gewissen Maße NS-Erfindungen, die über das Fehlen des natürlichen Resonanzbodens einer demokratischen Öffentlichkeit hinweghelfen sollten." Rück-meldungen lieferten insbesondere „SD-Berichte Meldungen aus dem Reich bzw. die Lebensgebietsberichterstattung." Bussemer (2000): Populärkultur, S. 89. Um einen Markt erfolgreich bedienen zu können, müssen dem Werbetreibenden ausreichende Informationen über die Zielgruppe vorliegen. Vgl. Kotler et al. (2003): Marketing, S. 306 -337

321 HIS PFR 230,35 Strafsache Reemtsma, 56. Verhandlungstag, 22. September 1948. Vernehmung Philipp Reemtsmas zu den NS-Zigarettenalben.
} 
Reemtsma überließ bei der thematischen Auswahl nichts dem Zufall, sondern führte eine erfolgreiche Konsumentenforschung durch, um die Präferenzen der Zielgruppen auszuloten. Die anspruchsvollen Reemtsma-Alben zur Geschichte der Malerei ${ }^{322}$ sowie die naturkundliche Reihe AUS WALD UND FLUR ${ }^{323}$ entstanden auf Grund der Nachfrage seitens der Bildersammler. So wurden Marktanalysen betreffend der Sammelbilder, Anzeigen und Zigarettenmarken nach markt- und markenpolitischen Aspekten wie Parteizugehörigkeit durchgeführt. ${ }^{324}$ Die Marketingstrategien wurden explizit nach diesen Kriterien ausgerichtet und „bis ins Kleinste auf Wirkung und Erfolg durchdacht [...]“.325 Bei den Zigarettenbildern wurden der Umsatz der Serien und die Korrespondenz mit den Sammlern herangezogen, um „zuverlässige Rückschlüsse hinsichtlich der Begehrtheit bestimmter Themen“326 zu erhalten. Die Relevanz der Zielgruppe unterstreicht Otto Lose auch bei der Ablehnung eines vom Propagandaministerium verlangten Albums: „Dass wir mit unseren Bildern den Geschmack der Sammler und der Frontsoldaten treffen, beweist die ungeheure Zahl der Einsendungen $[\ldots]^{\prime \prime} .327$

Das RMVP bediente sich vieler psychologischer Techniken, die auch von der Zigarettenindustrie eingesetzt wurden und heute noch im modernen Marketing ihre Gültigkeit haben. Dennoch erlaubte die Integrationspropaganda keine völlige Konvergenz

322 Vgl. HIS PFR 491, 01 Mitteilung der Reemtsma-Geschäftsleitung an den Außendienst betreffend des Albums Die Malerei der Renaissance, 7. Oktober an den Außendienst, 7. Oktober 1938 Vgl. HIS PFR 491,01 Rundschreiben der Reemtsma-Geschäftsleitung an den Außendienst betreffend des Albums Aus Wald und Flur - Tiere unserer Heimat, 9. Februar 1939

324 Vgl. HIS PFR 491,05 Schreiben von Herbert Scheur an RA Dr. Fischer vom 12. Juli 1947 Parallel zu den Themen der Alben wurden die Anzeigen nach markenpolitischen Überlegungen geschaltet wie Parteizugehörigkeit, Verbreitung der Zeitung, Auflage und Anzeigenpreis. Vgl. HIS PFR 200,37 Schreiben von Herbert Scheuer an RA Fischer vom 12. Juli 1947 HIS PFR 200, 31 Schreiben des Inhabers der Kuhle-Reklame, 10. Dezember 1947. Für einen adäquaten Einsatz eines Marketinginstruments ist eine Analyse der Zielgruppe unabdingbar. Der Werbetreibende benötigt Kenntnisse über soziodemografische Merkmale wie Bildung, Einkommen, sowie über psychologische Faktoren wie Meinungen und Einstellungen. Vgl. Seebohn (2001): Werbepraxis, S. 251

326 HIS PFR 491,08 Otto Lose, „Der Bilderdienst“ 1953 S. 294f.

327 HIS PFR 491,2 Schreiben von Lose an die Fachschaftsgruppe Zigarettenindustrie Thronicke vom 21. März 1940 
zwischen dem Publikumsgeschmack und den eigenen Propagandaansprüchen, ${ }^{328}$ denn die stark von der amerikanischen Massenkultur geprägte Unterhaltungskultur ${ }^{329}$ wurde von weiten Teilen des rechten Flügels der Partei und von konservativen bürgerlichen Kreisen abgelehnt. ${ }^{330}$ Angesichts der unpolitischen Unterhaltungsangebote, die bereits in der Weimarer Republik zum Lebensstil gehörten, konnte sich das NS-Regime dem Massengeschmack aber nicht entziehen. ${ }^{331}$ Die nationalsozialistische Propaganda war zudem stark von der amerikanischen Werbung, die sich einer emotionalen Bildsprache bediente, beeinflusst. ${ }^{332}$ Alleine aufgrund der „Technik- und Medienverliebtheit“333 des NS-Regimes konnte die Kultur der USA nicht völlig negativ bewertet werden. Das Regime wusste beide Strömungen für sich zu nutzen und bediente sowohl national-volkstümliche als auch moderne Themen. ${ }^{334}$

Das breite Spektrum der Zigarettenalben zu reinen Unterhaltungsthemen reflektiert den Massengeschmack der Zeit. Insbesondere Alben über Film, Unterhaltung und Schönheit, die bereits vor 1933 beliebte Sujets waren, führen auch während der NS-Zeit die Themenliste an. Da die Propagandastrategen gezwungen waren, sich der Massenmedien der Kulturindustrie $\mathrm{zu}$ bedienen, waren sie ferner aus monetären

328 Goebbels konnte seine Forderungen, populäre Kulturangebote zu erhöhen, nur sukzessive durchsetzen. Das Unterhaltungsangebot des Rundfunks konnte erst ab 1939 so gesteigert werden, dass es das Niveau der Weimarer Republik erreichte. Bei einem Überangebot an Reden und Berichten von NS-Veranstaltungen zeigte sich das Publikum gelangweilt und wechselte teilweise zu ausländischen Sendern. Vgl. Evans, (2006): Reich, S. 168f.

329 Die amerikanische Unterhaltungsindustrie galt vielen als materialistisch und kulturlos. Vgl. Junker, Detlef (1999): „Die Kontinuität der Ambivalenz. Deutsche Bilder von Amerika, 1933 1945.“ In: Wala, Michael (Hg.): Gesellschaft und Diplomatie im transatlantischen Kontext. Stuttgart: Franz Steiner, S. 173

330 Goebbels stieß nicht nur in konservativen Kreisen auf Kritik, sondern musste seine Propaganda-Linie auch in den eigenen Reihen durchsetzen. So sprach sich Hitler für eine Trennung zwischen Organisation und Propaganda aus. Vgl. Welch (2001): Propaganda, S. 35

331 Vgl. Borsó, Vittoria/Liermann, Christiane/Merzinger, Patrick (2010): “Transfigurationen des Politischen. Von Propaganda-Studien zu Interaktionsmodellen der Medienkommunikation eine Einleitung“. In: Dies. (Hg.): Die Macht des Populären. Bielefeld: transcript, S. 11

332 Vgl. Ross, Cotey (2007): Visions of Prosperity. "The Americanization of Advertising in Interwar Germany." In: Swett, Pamela E./Wiesen, S. Jonathan/Zatlin, Jonathan R. (Hg.) Selling Modernity. Advertising in Twentieth-Century Germany. Durham/ London: Duke University Press, S. 66f.

333 Popp, Valerie (2008): „Aber hier war alles anders...”. Würzburg: Königshausen \& Neumann, S. 49

334 Vgl. Walsdorf, Hanna (2010): Bewegte Propaganda. Politische Instrumentalisierung von Volkstanz in den deutschen Diktaturen. Würzburg: Königshausen \& Neumann, S. 50 
Gründen gezwungen, dem Publikumsgeschmack Rechnung zu tragen. ${ }^{335}$ So wurde Wilfrid Bade, Verfasser illustrierter Sachbücher und Autor des Zigarettenalbums DEUTSCHLAND ERWACHT, vom Ullstein Verlag angehalten, für seine Publikationen gesellschaftspolitisch neutrale Bildberichte zu schreiben, „um die bei einer größeren Auflage unerlässliche Auflockerung zu erreichen. “336

Die Zigarettenalben wurden dieser Forderung gerecht. Die NS-Propaganda konnte selbst in monothematischen NS-Sammelbänden durch Unterhaltung populär gestaltet oder in multithematischen Werken dosiert werden. Die Visualisierung der Texte durch umfangreiches Bildmaterial trug ferner zu einer Auflockerung und $\mathrm{zu}$ einer erhöhten Emotionalität der Rezipienten bei. ${ }^{337}$ Inspiriert vom Film setzte das NS-Regime zunehmend auf eine visuelle Form der Wissensvermittlung und forcierte daher verstärkt die Publikation von Bildbänden. ${ }^{338}$ Exemplarisch dafür stehen die Werke von Wilfrid Bade. Die Bildbände „Das Hohelied vom Dritten Reich“,339 an dem Bade als Co-Autor beteiligt war, stehen exemplarisch für dieses Genre. Die Deutsche Illustrierte Verlagsgesellschaft hob die Besonderheit des Propaganda-Werkes hervor, das „die geschichtlichen Ereignisse des Jahres 1933“340 in ansprechender Weise schildert. Der Verlag warb mit den „neuartigen Linien der Berichterstattung“ und verwies auf die $[. .$.$] „knappe, filmartige“ und „ausdrucksvolle Form zu berichten.“ Der Verlag$ betonte ferner, dass damit ein Werk geschaffen wurde, das „zu einem für Jeden erschwinglichen Preis für alle deutsche Volksgenossen ein Album“341 geschaffen wurde. Der niedrige Kaufpreis trug damit, ebenso wie bei den Zigarettenalben, zu einer

335 Vgl. Maase, Kaspar (1997): Grenzenloses Vergnügen: der Aufstieg der Massenkultur 1850 - 1970. Frankfurt/M.: Fischer, S. 17

336 Härtel (2004): Stromlinien, S. $129 f$.

337 Vgl. Müller, Marion G. (2001): „Bilder-Visionen-Wirklichkeiten. Zur Bedeutung der Bildwissenschaft im 21. Jahrhundert.“ In: Knieper, Thomas/ Dies. (Hg.) (2001): Kommunikation visuell. Das Bild als Forschungsgegenstand-Grundlagen und Perspektiven. Köln: Herbert von Halem, S. 29

338 Vgl. Härtel (2004): Stromlinien, S. 129

$339 \quad$ Ebd., S. 125

340 Schreiben Dr. Selle-Eysler, vom 22.12.1933 (Durchschrift), Hoover, Bade, Box 2, Correspondence 1934 (R-Z). Zit. nach: Ebd.

$341 \quad$ Ebd., S. 126 
breiten Verbreitung in der Bevölkerung bei. Die illustrierten Bildbände, die Bild und Text miteinander verbanden, korrespondierten ganz mit dem Layout und der Art der Wissensvermittlung der Zigarettenalben, die insbesondere von dem Bilderdienst der Firma Reemtsma perfektioniert und von anderen Unternehmen übernommen wurde. $^{342}$ Exemplarisch ist der Sammelband DeUTSCHLAND BAUT AUF, ${ }^{343}$ der nicht nur illustrativ den Wiederaufbau Deutschlands schildert, sondern auch mit seinem reichhaltigen Themenspektrum die Interessen unterschiedlicher Zielgruppen bedient. In dem Album, das in Kleinserien verschiedene Themen aufgreift, werden neben den Errungenschaften in den Bereichen, Luftfahrt, Schiffbau, Automobilbau, Technik und Forschung auch bodenständiges Handwerk wie Brauereiwesen und Glockenguss sowie Landwirtschaft und deutsches Brauchtum beschrieben. In der Palette des deutschen Wiederaufbaus wird dem Bildersammler in den Kapiteln „Bauten des Dritten Reiches" und „N.S.-Gemeinschaft durch Kraft und Freude“ subtil vermittelt, dass der Wiederaufbau einzig und allein dem Dritten Reich zu verdanken ist. In das Spektrum reihen sich auch die Kapitel „Die Wehrmacht" und „Luftschutz" ein, Themen, mit denen Deutschlands Wehrhaftigkeit demonstriert, respektive die Notwendigkeit einer Wehrmacht veranschaulicht wird.

Auch die einschlägigen NS-Alben wie DEUTSCHLAND ERWACHT, KAMPF UM'S DRITTE REICH und AdOLF HITLER verbinden NS-Ideologie mit Unterhaltung. Die Alben bieten dem Bildersammler ein facettenreiches Potpourri, in dem die Historie der NSDAP, die Aufbruchsstimmung von 1933, Hitler als volksnaher Führer, die Leistungen des NSRegimes und die „Blutzeugen der Bewegung“344 in Szene gesetzt werden. Die biografischen Skizzen über Adolf Hitler, die dem Massenpublikum einen vermeintlichen Blick in das Privatleben des Führers geben, sind nach dem Vorbild von Homestories

\footnotetext{
$342 \quad$ Vgl. Ebd., S. 129

343 Monopol (1937): Deutschland baut auf. Dresden

344 Behrenbeck, Sabine (2011): Der Kult um die toten Helden. Nationalsozialistische Mythen, Riten und Symbole. Köln: sh Verlag, S. 140. Dem „Ehrentag der alten Kämpfer von 1929“ wird in dem Sammelband Bilddokumente unserer Zeit, Mappe 2 ein langes Kapitel gewidmet. Kosmos (1934): Bilddokumente unserer Zeit. Mit Sonderabteilung Deutsche Jugend - unser Stolzunsere Zukunft, Mappe 2. Dresden, S. 3 - 15
} 
verfasst, einem Genre, das sich seinerzeit großer Beliebtheit erfreute. ${ }^{345}$ Die Zigarettenalben kamen durch ihre moderne Aufbereitung der Intention des NS-Regimes, Propaganda unverdächtig, respektive wohldosiert in der Bevölkerung zu verbreiten, entgegen. Die Sammelbilder, die in einfacher Weise Informationen transportieren, waren ein besonders adäquates Instrument der Massenbeeinflussung. Sie sollten, wie Jost Henkel in seiner Dissertation von 1934 betont, „besonders auf die Psyche von Kindern und kindlichen Personen nicht ohne Eindruck" bleiben und eingesetzt werden, um die "geistig oft primitiven Massen zu bearbeiten“. ${ }^{346}$ Die Sammelbände waren daher das ideale Medium für die von Goebbels postulierte Form der Propaganda. Die Alben ermöglichen dem NS-Regime, suggestiv auf die Massen einwirken. Aufgrund der Beliebtheit des Mediums und der enormen Auflagenhöhe konnte die Propaganda in Segmente der Bevölkerung diffundieren. Das Zigarettenalbum wurde damit zu einem vitalen Instrument der Integrationspropaganda. ${ }^{347}$

\subsubsection{Kriegspropaganda}

Die Kriegspropaganda folgt anderen Regeln als die Integrationspropaganda, denn sie bedient sich verstärkt einem normativem Modell, das von Stereotypen geprägt ist, wie der Dämonisierung des Gegners, dem Potenzieren von Siegen sowie dem Herunterspielen von Niederlagen und Verlusten. ${ }^{348}$ Entsprechend war die NS-Propaganda

345 Autobiografien von Elly Beinhorn-Rosemeyer oder Biografien über die Görings erzielten hohe Auflagen. Die privaten Einblicke hatten wie bei Göring ",halbamtlichen Charakter" und waren Werke, die moderne Heldengeschichten erzählten. Beinhorn und Rosemeyer, die als Flieger und Rennfahrer Kultstatus besaßen, wurden zu Ikonen stilisiert, die der deutschen Jugend als Vorbild dienen sollten. Vgl. Adam (2010): Lesen, S. 100 - 104. Den Charakter einer Homestory hatte auch der Bildband „Hitler, wie ihn keiner kennt“ von Hitlers Leibfotografen Heinrich Hoffmann. Viele der Aufnahmen finden sich in den Sammelalben wieder. Hoffmann, Heinrich (1938): Hitler wie ihn keiner kennt. München: Zeitgeschichte-Verlag. Das Bildmaterial wurde mehrfach und in unterschiedlichen Medien publiziert und neu zusammengestellt. Vgl. Herz (1994): Hoffmann \& Hitler, S. 52

346 Henkel, Jost (1934): Die volkswirtschaftliche Bedeutung der Werbung (einschl. Zugabewesen und politischer Werbung). Düsseldorf: Bagel, S. 68f.

347 Härtel bezieht sich in seiner Analyse zu Bades Arbeit und zu den Alben der Firma Reemtsma ebenfalls auf die Propaganda-Phasen von Bussemer. Vgl. Härtel (2004 ): Stromlinien, S. 129

348 Vgl. Bussemer (2000): Populärkultur, S. 18. Die moderne Kriegspropaganda folgt einem Schema, das maßgeblich im Ersten Weltkrieg von der Entente festgelegt wurde, als Ausschreitungen des deutschen Militärs in Belgien potenziert und als Gräuelpropaganda verbreitet wurde. Vgl. Keegan, John (2004): Der Erste Weltkrieg, 3. Aufl., Reinbek bei Hamburg: Rowohlt, S. 128 
während des Zweiten Weltkrieges „rein vertikal organisiert“. ${ }^{349}$ Das NS-Regime war aufgrund der veränderten Rahmenbedingungen gezwungen, die Propaganda auf ihre eigenen Ziele auszurichten und konnte die Bedürfnisse der Bevölkerung, wenn überhaupt, nur noch bedingt berücksichtigen. Die unilaterale Kommunikation setzte der Interaktion zwischen dem Regime und der Bevölkerung massive Grenzen, so dass keine „Verstärkereffekte innerhalb der >Volksgemeinschaft $<“ 350$ möglich waren. In der Folge konnten die Rezipienten die Botschaften nicht mehr in ihre Lebenswelt inte grieren.

Die Kriegspropaganda ist „Teil von militärischer Taktik“,351 die sich gegen den Feind richtet und sie kann ihre Wirkungsmacht nur mit der Zustimmung der Bevölkerung entfalten. Die Kriegspropaganda war daher im Vergleich zur Integrationspropaganda entsprechend schwach aufgestellt und sah sich darüber hinaus mit ungünstigen Rahmenbedingungen konfrontiert. Die deutsche Bevölkerung war nicht nur kriegsmüde und gegen einen Krieg eingestellt, sondern war aufgrund der vorangegangenen Friedenspropaganda mehrheitlich davon überzeugt, dass Hitler keine kriegerischen Absichten verfolgt. ${ }^{352}$ Die Begeisterung für Hitler basierte maßgeblich auf dem Propaganda-Mythos, dass er ohne kriegerische Auseinandersetzung Deutschlands Ehre wiederhergestellt und einen wirtschaftlichen Aufschwung eingeleitet hatte. ${ }^{353}$ Dass eine ,jahrzehntelang betriebene Friedenspropaganda auch ihre bedenklichen Seiten hat", war sich Hitler bewusst, "denn es kann nur zu leicht dahin führen, daß sich in den Gehirnen vieler Menschen die Auffassung festsetzt, daß das heutige Regime an sich identisch sei mit dem Entschluß um dem Willen, den Frieden unter allen Umständen zu bewahren.“ Nach der Machtergreifung war es erforderlich, „das deutsche Volk psychologisch umzustellen und ihm langsam klarzumachen, daß es Dinge gibt, die, wenn sie nicht mit friedlichen durchgesetzt werden können, mit den Mitteln

\footnotetext{
349 Bussemer (2000): Populärkultur, S. 19

350 Ebd.

$351 \quad$ Ebd., S. 33

352 Vgl. Kershaw, Ian (1980): Der Hitler-Mythos: Volksmeinung und Propaganda im Dritten Reich. Stuttgart: Deutsche Verlags-Anstalt, S. 127. Vgl. Wette (1979): „Ideologien“, S. 26

353 Vgl. Kershaw (1980): Hitler-Mythos, S. 117
} 
der Gewalt durchgesetzt werden müssen. ${ }^{\text {354 }}$ Gleichzeitig befand sich die deutsche Bevölkerung in latenter Kriegsangst. Insbesondere nach dem Anschluss Österreichs, der Rheinlandbesetzung oder nach dem Bruch des Münchner Abkommens, fürchtete die Bevölkerung eine militärische Eskalation. ${ }^{355}$

Beim Kriegseintritt Englands stand die Propaganda daher vor der großen Herausforderung, die Bevölkerung emotional zu mobilisieren. Während der Einmarsch in die Tschechoslowakei und die Bildung der Protektorate Böhmen und Mähren von der Bevölkerung noch als Schutz deutscher Siedlungsgebiete betrachtet werden konnte, ${ }^{356}$ mangelte es dem NS-Regime an Argumenten für einen Krieg gegen England. Aufgrund Hitlers Kalkül, die Briten würden sich nach dem Einmarsch in Polen nicht auf einen Krieg mit Deutschland einlassen, ${ }^{357}$ war der Nährboden für eine anti-britische Propaganda nicht vorbereitet. Die für die Kriegspropaganda charakteristischen Kommunikationsstrategien wie die Erzeugung eines Feindbildes, die von Rechtfertigungen und Schuldzuweisungen begleitet werden, mussten daher kurzfristig in Gang gesetzt werden. Die Propaganda besaß daher nicht die Suggestions- und Überzeugungskraft der Integrationspropaganda. Das hilflose Agieren manifestiert sich in der eilig zusammengestellten Propaganda-Ausstellung „Raubstaat England“358 Ende des Jahres 1939. Die Ausstellung versuchte in einer historischen Retrospektive die Briten als räuberische Nation darzustellen, die sich durch Skrupellosigkeit ein Weltreich an-

\footnotetext{
354 „Völkischer Beobachter“, 11. November 1938. Zit. nach: Wette (1979): „Ideologien“, S. 133

355 Im Münchner Abkommen vom September 1938 hatte Hitler versichert, er würde nach der Besetzung des Sudetenlandes keine weiteren Territorialansprüche stellen. Der Bruch des Abkommens erfolgte bereits im März 1939. Vgl. Kuhn (2016): Flucht, S. 32

356 Vgl. Wedekind, Michael (2005): Ethnisch-soziale Neuordnungskonzepte im besetzten Europa (1939-1945) Forschungsperspektiven von Fallstudien zum Alpen-Adria-Raum In: Mackensen, Rainer/ Reulecke, Jürgen (Hg.) Das Konstrukt "Bevolkerung" vor, im und nach dem „Dritten Reich". Wiesbaden: VS Verlag für Sozialwissenschaften, S. 372

Hitler war sich der Gefahr, dass sich England nach einem Einmarsch in Polen nicht neutral verhalten würde, bewusst. 1939 sollte ein Eingreifen Englands aber in jedem Fall vermieden werden. Angesichts der geplanten Ostexpansion war ein Krieg gegen England und die Westmächte langfristig aber nicht vermeidbar. Eine kriegerische Auseinandersetzung mit England war für 1940/41, respektive 1943/44 eingeplant. Vgl. Messerschmidt (1979): „Außenpolitik und Kriegsvorbereitung", S. 674

358 Kivelitz, Christoph (1999): Die Propagandaausstellung in europäischen Diktaturen. Konfrontation und Vergleich: Nationalsozialismus in Deutschland, Faschismus in Italien und die UdSSR der Stalinzeit. Bochum: Winkler, S. 227
} 
geeignet und sich nun mit anderen Nationen gegen Deutschland verschworen hatte. ${ }^{359}$ Im gleichen Jahr wurde vom RMVP das Zigarettenalbum RAUBSTAAT ENGLAND ${ }^{360}$ bei dem Cigaretten-Bilderdienst Reemtsma in Auftrag gegeben. ${ }^{361}$ Das Album RAUBSTAAT ENGLAND ist das einzige Album, das der Phase der klassischen Kriegspropaganda zuzuordnen ist. Der Sammelband ist nach demselben Konzept aufgebaut wie die gleichnamige Propagandaausstellung. Die Bilder des Sammelbandes folgen keiner stringenten Gestaltungslinie, sondern sind eine Zusammenstellung aus Gemälden und Fotografien sowie Grafiken und Karikaturen, die die britische Kolonialpolitik anprangern. Für das RMVP besaß das Album besondere Relevanz, ${ }^{362}$ denn mit dem Vertrieb über den Bilderdienst Reemtsma konnte die Kriegspropaganda multipliziert und schnell in die Bevölkerung getragen werden.

In dem Album RAUBSTAAT ENGLAND manifestiert sich nicht nur die Problematik, die der Kriegspropaganda aufgrund ihrer vertikalen Ausrichtung inhärent ist, sondern auch der Umstand, die ohnehin wenig kriegsbegeisterte Bevölkerung für eine militärische Auseinandersetzung gegen England zu mobilisieren. Ferner hatte das Flottenabkommen von 1935 dazu beigetragen, dass die Friedensabsichten im Bewusstsein der deutschen Bevölkerung verankert waren. Darüber hinaus waren England und Deutschland durch eine gemeinsame Historie miteinander verbunden. Aufgrund der über Jahrhunderte gewachsenen Verbindung, die getragen wurde von militärischen Bündnissen und verwandtschaftlichen Beziehungen zwischen den beiden Monarchien, hatte sich im Bewusstsein der Deutschen kein ausgeprägtes Feindbild gegenüber England etabliert. ${ }^{363}$ Viele Deutsche waren daher mit einem anglophilen

\footnotetext{
359 Vgl., S. 227f.

360 Der Titel des Albums Raubstaat England stammt von Goebbels. HIS PFR 491,02 Aussage Lose, 24. August 1945, S. 3

361 Das Album Raubstaat England wurde erst im Jahr 1941 publiziert. P1040195 Nach den Aussagen von Direktor Lose hatte Reemtsma über ein Jahr lang versucht, die Herausgabe zu verhindern. Vgl. HIS PFR 491,02, Aussage Lose, 24. August 1945, S. 3

362 „Es wird daher hier größter Wert darauf gelegt, daß die Arbeiten an dem Bilderwerk keinerlei Behinderung erleiden." HIS PFR 409,02 Schnellbrief an Reemtsma vom RMVP, 3. April 1940

363 Das Bild der Deutschen gegenüber England war bis in das 19. Jahrhundert positiv besetzt. Die Briten waren vielfach Bündnispartner Preußens. Erst mit dem Burenkrieg und der Ablehnung der deutschen Flotten- und Kolonialpolitik entwickelten sich Ressentiments.
} 
Bild aufgewachsen, das in Teilen der Gesellschaft noch präsent war. Dem Autor des Albums, Ernst Lewalter, war diese Problematik offenbar bewusst, denn auf der ersten Seite unternimmt er den Versuch, das positive, im kollektiven Gedächtnis verankerte England-Bild zu revidieren und negativ zu belichten. ${ }^{364}$

\begin{abstract}
„Es klingt unwahrscheinlich, aber es ist wahrhaftig wahr: der Glaube an die meerbeherrrschende Sendung Englands wurde damals, am Anfang des zwanzigsten Jahrhunderts, vor einer Quartaner-Generation nach der anderen, vor lauter deutschen Buben verkündet! [...] Ist es nicht erstaunlich, daß niemand sich etwas dabei dachte? [...] Mögen solche Jugenderlebnisse auch im einzelnen recht verschieden gewesen sein, im ganzen wird man sagen dürfen, daß die deutsche Jugend vor dem Weltkriege in einer seltsamen, fast resignierenden Englandfrömmigkeit auferzogen wurde - aus der dann ein böses Erwachen folgte, als England sich gleich zu Beginn des Weltkrieges auf die Seite unserer Feinde stellte. [...] Heute will uns diese Stimmung ganz unfaßlich erscheinen, und wir fragen uns, wie jene Verblendung überhaupt möglich geworden ist. Die Dinge liegen verhältnismäßig einfach. Das liberale Bürgertum des Zweiten Reiches, die breite Schicht der "Gebildeten“ war von Haus aus zur Englandfreundlichkeit geneigt. “ ${ }^{365}$
\end{abstract}

Die antibritische Propaganda des Albums RAUBSTAAT ENGLAND baut sehr plakativ auf die Dämonisierung des Gegners auf. Kern der Agitation bildet der Vorwurf, England sei ein plutokratisch ausgerichtetes Herrschaftssystem, das von König Heinrich VII ${ }^{366}$ errichtet und unter nachfolgenden Machthabern ausgebaut wurde. Großbritannien wird vorgehalten, sich im Laufe von Jahrhunderten die Welt rücksichtslos untertan

Stöber, Rudolf (1998): Die erfolgverführte Nation: Deutschlands öffentliche Stimmungen 1866 bis 1945. Stuttgart: Franz Steiner, S. 192. Im politischen Diskurs war das Englandbild von Ambivalenz geprägt. Zu Beginn des Ersten Weltkrieges galt der Kampf gegen England nicht der Nation, der Bewunderung entgegengebracht wurde, sondern der puritanischen Bigotterie und den kleingeistigen Krämerseelen. Wende, Peter (2006): „Modell und Menetekel. Jacob Venedeys 'England'.“ In: Hein, Dieter/ Schulz, Klaus/Hildebrand, Andreas (Hg.): Historie und Leben: Der Historiker als Wissenschaftler und Zeitgenosse. München: Oldenbourg, S. 409

364 Der unerwartete Kriegseintritt Großbritanniens manifestiert sich auch in der Rücknahme des Films ,Kity und die Weltkonferenz'. Der Film wurde, obwohl ein Publikumserfolg, auf Geheiß des Außenministers Ribbentrop wegen vermeintlich positiver Darstellung britischer Politiker aus den Kinos zurückgezogen. Moeller, Felix (1994): „Blitzkrieg und die nationalsozialistische Filmpropaganda. Aus den Tagebuchaufzeichnungen von Joseph Goebbels 1939 bis 1941“. In: Daniel, Ute/ Siemann, Wolfram (Hg.): Propaganda. Meinungskampf, Verführung und politische Sinnstiftung 1789-1989. Frankfurt/M.: Fischer, S. 136

365 Reemtsma (1941): Raubstaat, S. 4f.

366 Bildunterschrift: „König Heinrich VII. (1473 - 1509), der erste Herrscher aus dem Hause Tudor, schuf die Grundlagen der britischen Plutokratie, indem er, mehr Krämer als König, den Staat den Interessen der Geschäftswelt dienstbar machte." Ebd. S. 13 
gemacht $\mathrm{zu}$ haben. Das Bildmaterial und die Begleittexte setzen die britische Geschichte in den Kontext von Raub, Versklavung und Unterdrückung, die es dem Land ermöglicht haben, zur Weltmacht aufzusteigen. Die Briten werden mit Verbalinjurien wie „Halsabschneider" als Volk diffamiert, das mit „unmenschlicher Grausamkeit“367 andere Völker unterdrückt. Lewalter differenziert dabei zwischen dem darwinistischen Recht des Stärkeren, der durch Eroberung eine „neue Weltkultur“ etabliert und dem kaltblütigen Plutokraten, der, von seiner Habsucht angetrieben, andere Völker unterwirft, ,"aber ohne überlegene Führung“368 und ohne eine Kultur zu schaffen. Der historische Abriss endet in der Gegenüberstellung des britischen und deutschen Kolonialsystems, wobei das Deutsche Reich retrospektiv als Kulturbringer stilisiert wird, während die Briten als machtgierige Ausbeuter dargestellt werden. ${ }^{369}$ England wird das vermeintlich moralische Recht abgesprochen, andere Länder zu unterwerfen. Dieser Vorwurf legitimiert gleichzeitig die deutsche Besetzung anderer Länder und impliziert eine moralische und kulturelle Überlegenheit Deutschlands.

Die Thematisierung der ehemaligen deutschen Kolonien reflektiert die Suche nach Argumenten, um die deutsche Bevölkerung von den imperialistischen Absichten Großbritanniens zu überzeugen. Angesichts der Tatsache, dass der Kolonialgedanke in der breiten Bevölkerung nie wirklich verankert ${ }^{370}$ und auch kein bedeutender Teil

\section{Ebd., S. 6}

Ebd.

Entsprechend lautet eine Bildunterschrift: „Von Deutschland gebaut - von England geraubt Der Sitz der deutschen Regierung in Windhuk (Deutsch-Südwestafrika). Wie wenig die Eingeborenen aller deutschen Schutzgebiete mit den fremden Mandatsregierungen einverstanden sind, geht aus unzähligen Schreiben und Aufrufen hervor, in denen es immer wieder heißt: „Tausende harren der Stunde, wo die große Mutter Deutschland sich ihrer Kinder wieder annehmen wird!“" Ebd., S. 121

370 Obwohl Deutschland die Kolonien nach den Statuten des Versailler Vertrages abtreten musste, stand eine Revision dieses Paragraphen nicht zur Diskussion. Die kolonialen Gruppen, die sich in der Weimarer Republik gründeten hatten, besaßen wenig Einfluss; auch die Mitgliederanzahl war überschaubar. Die koloniale Bewegung fand weder die Unterstützung der Regierung, noch das der breiten Bevölkerung. In der Weimarer Republik waren die Kolonien in den Medien kaum präsent. Vgl. Schmokel, Wolfe W. (1967): Der Traum vom Reich. Gütersloh: Sigbert Mohn, S. 15ff. Die Publikationen der ,Kolonialliteratur' stieg erst in den Jahren zwischen den Jahren 1933 und 1937 an und wurde 1941 wegen Papierknappheit fast eingestellt. Vgl. Ebd. S. 53 
des NS-Programms war, ${ }^{371}$ reflektiert der Rekurs auf die Kolonien einen ungelenken Versuch der Propaganda, die Bevölkerung gegen die Briten einzunehmen. Die Tatsache, dass lediglich drei Zigarettenalben zum Thema deutsche Kolonien publiziert wurden, spiegelt diesen Trend wider. ${ }^{372}$ Die Argumentationskette, mit der die Mobilmachung gegen England entfacht werden sollte, setzte sich aus Elementen zusammen, die außerhalb des Identifikationsraumes der deutschen Bevölkerung lagen. Am Ende des Sammelbandes RAUBSTAAT ENGLAND werden die Gründe für einen Krieg gegen England mit dem Kampf zweier Gesellschaftssysteme subsumiert:

„Nicht wie einst zu Tirpitz' Zeiten die Panzerschiffe, sondern die KdF.-Schiffe machten England zum unversöhnlichen Gegner Deutschlands. [...] Zum erstenmal in der Weltgeschichte hieß der Gegensatz nicht: Großmacht gegen Großmacht, sondern: Plutokratie gegen Sozialismus. “373

Divergierende politische Systeme, Neid auf deutsche KdF-Schiffe oder die menschenverachtende Sklavenhaltung der Briten im 18. Jahrhundert, ${ }^{374}$ besaßen jedoch nicht das Potential, um die deutsche Bevölkerung emotional zu involvieren und für einen Krieg gegen England zu mobilisieren. Vor dem anglophil geprägten Hintergrund der Bevölkerung hatte diese propagandistische Ad-hoc-Maßnahme zur geistigen

371 Der Kolonialgedanke wurde erst Jahre nach der Machtergreifung aufgegriffen und ideologisch gefärbt. Vgl. Ebd., S. 15. Die NSDAP richtete zwar ein Kolonialpolitisches Amt ein, betrieb aber keine weitreichende oder unterstützende Propaganda. Ebd., S. 53

Zigarettenalben, die sich monothematisch mit den deutschen Kolonien beschäftigen: Zigaretten-Industrie (Gemeinschaftsausgabe, beteiligte Firmen: Alva-Yosma, Bergmann, Bulgaria, Constantin, Eckstein, Garbáty, Greiling, Jasmatzi, Josetti, Kyriazi, Lande, Salem, WaldorfAstoria (1936): Deutsche Kolonien, o.O. Arosa (1933): Ehemalige deutsche Kolonien, Dresden. Niki (1933): Deutschlands ehemalige Kolonien, Dresden. Der Tenor jener Zeit lag mehr auf dem Deutschtum im Ausland: Lande (1934): Das Deutschtum im Ausland, Grenzdeutschtum, Bd. 1 und Deutschtum im Ausland, Europa, Bd. 2, Dresden. Der Kolonialismus wird in anderen Zigarettenalben nur marginal behandelt. Es kommen nur ,Kolonialhelden' vor wie LettowVorbeck oder Dr. Carl Peters, alias ,Hänge-Peter' (ein wegen Amtsmissbrauchs verurteilter Kolonialbeamter), der im NS-Staat zu neuen Ehren gekommen war. Schmokel (1967): Traum, S. 187. Der Kolonialismus war in vielen Alben, insbesondere zu Beginn des Jahrhunderts, ein zentrales Thema. Vgl. llgen, Volker/ Schindelbeck, Dirk (1997): Sarotti-Mohr, S. 110. Ausführlich dokumentiert auch in: Zeller (2008): Bilderschule der Herrenmenschen. In den KolonialAlben der 30er Jahre anderer Produktreihen steht das Thema unter dem Tenor des „Verlustschmerzes". Zeller (2008): Bilderschule, S. 231 Kolonial-Alben wurden desweiteren von der Oldenkott-Handelsgesellschaft (1933), Onno Behrends Tee Import (1934) und der Berliner Morgenpost (1941) publiziert. Vgl. Ebd., S. 231 - 240.

373 Reemtsma (1941): Raubstaat, S. 126

374 Vergleichbar ist der Vorwurf, der gegen die USA gerichtet war, dass die Gebäude in Washington D.C. von Sklaven errichtet wurden. Vgl. Bussemer (2000): Populärkultur, S. 18 
Umschulung kaum eine Basis. Aufgrund der holzschnittartigen Argumente war diese Art der Propaganda zu transparent, um bei der Bevölkerung auf Resonanz zu stoßen. Die mangelnde Überzeugungskraft des Albums wird von dem Direktor des Reemtsma-Bilderdienstes Lose bestätigt, der die Erfolglosigkeit auf die grob geschnitzte Kriegspropaganda zurückführte: „Im übrigen ist das Sammelwerk sowohl hinsichtlich der Bilder als auch hinsichtlich der Texte ausserordentlich schwach und wenig überzeugend. Von den Konsumenten wurde es als gewollte Zweckpropaganda empfunden. Umsatzmässig wurde es von der starken Organisation und den guten anderen Sammelwerken, welche im Rahmen des Schecksystems vertrieben wurden, mitgetragen. Werbemässig war es im Sinne einer Cigarettenreklame ein Misserfolg“. ${ }^{375}$

Der Auftrag zur Publikation wurde von Goebbels persönlich über das „PropagandaAtelier ${ }^{\star 376}$ in Berlin erteilt, das direkt dem RMVP unterstand. ${ }^{377}$ Lose betonte nach Kriegsende explizit, dass Bilder und Texte vom Propaganda-Atelier geliefert wurden und dass es Reemtsma trotz aller Einwände nicht gelungen sei, die Publikation des Albums zu verhindern. ${ }^{378}$ Wie massiv Reemtsma versucht hat, die Herausgabe des Albums zu verhindern, lässt sich aufgrund der Quellenlage nicht eindeutig klären. Der Papiermangel, wirtschaftliches Kalkül und persönliche Interessen können zur Kooperation beigetragen haben, denn das RMVP sicherte dem Unternehmen Unterstützung bei der Materialbeschaffung zu. ${ }^{379}$ Direktor Lose konnte die „staatspolitisch besonders wichtige Bedeutung" des Albums auch zum Anlass nehmen, um seine

375 HIS PFR 491,02 Lose zur Entlastung von Hans Domizlaff, 24. August 1945

376 HIS PFR 491,02 Lose zur Entlastung von Hans Domizlaff, 24. August 1945. Kivelitz (1999): Propagandaausstellung, S. 54

377 Das Deutsche Propaganda Atelier wurde am 11. Mai 1936 vom RMVP als GmbH gegründet. Dem DPA unterlag „die praktische Durchführung propagandistisch-künstlerischer Aufgaben im Sinne der vom Reichsministerium für Volksaufklärung und Propaganda verfolgten Grundsätze." BArch, R55/201, Aufgabenbereich des Deutschen Propaganda Ateliers, 1942, B1.89. Zit. Nach: Koch, Christian (2013): Das Deutsche Propaganda Atelier und die NSFeindpropaganda im Zweiten Weltkrieg. Norderstedt: BoD, S. 12

378 HIS PFR 491,02 Lose zur Entlastung von Hans Domizlaff, 24. August 1945, S. 4

379 Vgl. HIS PFR 491,02. Schreiben Loses an die Fachgruppe Zigarettenindustrie, Herrn Thronicke. 21. März 1940. Reemtsma publizierte noch Ende 1940 das anspruchsvolle Kunstalbum Malerei des Barock. Vgl. HIS PFR 491,02 Reemtsma-Geschäftsleitung an die am Bilderschecksystem beteiligten Firmen sowie anderer Abt. im Hause, 26. November 1940. 
UK-Stellung zu verlängern. ${ }^{380}$ Die Verteilung des Albums RAUBSTAAT ENGLAND wurde mit der Schließung des Bilderdienstes am 30. April 1942 eingestellt. ${ }^{381}$ Aufgrund der „Einlösepflicht“ ${ }^{\prime 382}$ wurden die Bilder jedoch noch nach 1942 an die Sammler ausgeliefert. 383

\subsection{Das Symbolsystem des Nationalsozialismus}

Die nationalsozialistische Propaganda beruhte nicht auf einer eingleisigen Kommunikation, die sich zwischen „suggestiven Führern und irrational geleiteten Massen abspielte“,,384 bei der die Empfänger reflexartig auf Informationen reagierten. Basis für die Propaganda war die symbolische Interaktion, die einen interpretativen Prozess in Gang setzte. ${ }^{385}$ Insbesondere während der Phase der Integrationspropaganda verstand es das NS-Regime in einen vielschichtigen Dialog mit der Bevölkerung zu treten. Es gelang, die Massen emotional zu involvieren und sozialpsychologische Identifikationsräume zu installieren. Die NS-Propaganda war sich der Wirkungsmacht symbolischer Interaktion bewusst und hatte erkannt, dass Völker und Gruppen ein "Produkt von Kommunikationsprozessen"386 sind, die durch Mythen und Symbole in Gang gesetzt werden können. Es "kann kein politischer Kult existieren und wirken" wenn er sich keiner "Mythen, Symbole und Rituale"387 bedient. Der Erfolg der NS-Propaganda basierte daher maßgeblich auf einem offenen System, das Mythen und Symbole einsetze. Gemeinsam mit der Rede stellten sie die Säulen der Massenbeeinflussung dar.

\footnotetext{
380 Vgl. HIS PFR 491,02 Schnellbrief an Reemtsma vom RMVP, 3. April 1940

381 Vgl. HIS PFR 491,02 Lose zur Entlastung von Hans Domizlaff, 24. August 1945, S. 5

382 Die Sammelbilder des Bilderdienstes wurden noch nach 1941 ausgeliefert. Vgl. HIS PFR 491,02 Reemtsma-Geschäftsleitung, 18. August 1942

383 Handstempelungen auf den Umschlägen, in denen die Bildergruppen versandt wurden, datieren von August 1942 und März 1943. Ein Umschlag trägt das Datum 14. Aug.1947. Vollständige Bildergruppen 68, 69, 70 und 71 des Werks 16, Raubstaat England. Originalumschläge des Cigaretten-Bilderdienstes Hamburg-Bahrenfeld Postfach 16. Privatbesitz des Verfassers. Die Stempel und Stempelfarbe der Jahre 1942 und 1947 sind identisch. Es kann sich hier um einen Kontrollstempel des Unternehmens, des Zigarettenhändlers handeln oder um eine Stempelung des Sammlers. Wenn die Bilder nach Kriegsende verteilt wurden, dann könnte es sich um Restbestände des Unternehmens handeln.

384 Bussemer (2000): Populärkultur, S. 43

385 Vgl. Renckstorf (1977): Massenkommunikationsforschung, S. 27

386 Hein, Heidi (2006): „Historische Mythos- und Kultforschung.“ In: Tepe, Peter/ Semlow, Tanja (Hg.): Mythos No. 2. Politische Mythen, Würzburg: Königshausen \& Neumann, S. 33 Hein (2006): Mythos- und Kultforschung, S. 40
} 
„Rhetoric, symbolism and myth are the interwoven trinity that has underpinned most propaganda programme (sic!) which is deficient in any these even though the individual propaganda text may be“. ${ }^{388}$ Mythen und Symbole waren Elemente, die in Form von Denkmalen, Feiern und Gedenktagen permanente Präsenz erhielten. ${ }^{389}$ Die NS-Propaganda setzte ein vielschichtiges und komplexes Symbolsystem ein und kann daher nicht auf eine Ikonografie reduziert werden, die sich auf Fackelzüge, Fahnen und Aufmärsche beschränkte. ${ }^{390}$

\subsubsection{Mythos}

Die Etymologie des Begriffes Mythos hat ihren Ursprung im Altgriechischen und bezeichnet sowohl „Wort und Sprache“,,391 als auch eine Erzählung religiöser Natur, in der Menschen mit der Götterwelt in Interaktion treten. Ein Mythos erzählt von essentiellen Dingen des Seins wie Geburt, Tod und Wiedergeburt oder von Heldenfiguren, die sich im Kampf gegen Götter, Naturgewalten und Tiere behaupten müssen. Der Mythos bringt „,bestimmte elementare Aspekte der menschlichen und übermenschlichen Existenz zum Ausdruck“ ${ }^{\prime 392}$ und verleiht ihnen eine symbolische Form. Er behandelt transzendente Themen und Sinnfragen, die den Menschen seit Beginn seiner Bewusstwerdung begleiten. ${ }^{393}$ Bei aller begrifflichen Vielfalt kann der Mythos als Mitteilungssystem betrachtet werden, das eine „heilige Geschichte“ erzählt, die sich in einer „primordialen Zeit“394 ereignet hat. In den Mythen wird die Historie aus der Zeit herausgelöst und „durch eine überzeitlich-präsentische Evidenzerfahrung überlagert". 395 Der Mythos entzieht sich jedem rationalen Diskurs, bleibt aber aufgrund

\footnotetext{
388 O'Shaughnessy, Nicholas J. (2004): Politics and Propaganda: Weapons of Mass Seduction, Manchester. Manchester University Press, S. 65

389 Vgl. Hein (2006): Mythos- und Kultforschung, S. 40

390 Vgl. Paul (1990): Aufstand, S. 11

391 Nöth, Winfried (2000): Handbuch der Semiotik, 2. Aufl. Stuttgart: J.B. Metzler, S. 410

392 Ebd.

393 Vgl. Ebd.

394 Eliade, Mircea (1988): Mythos und Wirklichkeit. Frankfurt am Main: Insel-Verlag, S. 15

395 Wodianka, Stephanie (2009): Zwischen Mythos und Geschichte: Ästhetik, Medialität und Kulturspezifik der Mittelalterkonjunktur. München: de Gruyter, S. 19
} 
seiner ontologischen Inhalte und Fragestellungen elementarer Gegenstand geisteswissenschaftlicher Disziplinen mit vielfältigen Deutungsansätzen. Der Mythos wird in den Kulturwissenschaften vor dem jeweiligen disziplinären Hintergrund interpretiert und ist „eine äußerst komplexe kulturelle Realität [...].“396

Im Kontext von Politik und Geschichte werden unterschiedliche Ansätze verfolgt, die $\mathrm{zu}$ differenzierten diskursiven Methoden anregen und $\mathrm{zu}$ divergierenden Theorien führen. Sozialhistorisch beschreibt der Mythos einen Prozess der "gesellschaftlichen Entwicklung“, während politische Mythen „der Ausdruck eines primären kollektiven Narzissmus“ sind und der „Selbstdarstellung einer Gesellschaft"397 dienen. Mythen sind als „Götter- und Heldengeschichten eines Volkes bzw. einer Kultur [...]"398 Geschichten, mit denen von „Generation zu Generation wachsendes Wissen weitergereicht “399 wird. Für Nationen oder soziale Gemeinschaften sind Mythen Teil des kulturellen und kollektiven Gedächtnisses, in denen „Erinnerungen an historische Ereignisse und Personen“400 gespeichert werden. Sie sind die Gestalt der Kultur, die der Gruppe soziale Identitätsräume bietet. ${ }^{401}$

Mythen besitzen einen Kern, der mit Narrationsvarianten modifiziert werden kann, die von „ausgeprägter marginaler Interpretationsfähigkeit“ sein können. „Diese Eigenschaften machen Mythen traditionsgängig: ihre Beständigkeit ergibt den Reiz, sie auch in bildnerischer oder ritueller Darstellung wiederzuerkennen, ihre Veränderbarkeit den Reiz der Erprobung neuer und eigener Mittel der Darbietung. " ${ }^{02}$ Ein Mythos

\footnotetext{
396 Eliade (1988): Mythos, S. 15

397 Jamme, Christoph (2013): „Mythos - Kulturphilosophische Zugänge.“ In: Krüger, Brigitte/ Stillmark, Hans-Christian (Hg.): Mythos und Kulturtransfer: Neue Figurationen in Literatur, Kunst und modernen Medien. Bielefeld: transcript, S. 20

398 Tepe, Peter (2013): „Terminologische Sensibilisierung im Umgang mit dem Mythos.“ In: Krüger Mythos, S. 30

399 Jamme (2013): Zugänge, S. 19

400 Subrt, Jirí/ Pfeiferová, Stepánka (2013): „Kollektives Gedächtnis und historisches Bewusstsein." In: Lehmann, René/ Öchsner, Florian/ Sebald, Gerd (Hg.): Formen und Funktionen sozialen Erinnerns. Wiesbaden: Springer VS, S. 53

401 Vgl. Assmann (1992): Gedächtnis, S. 89

402 Blumberg, Hans (2006): Arbeit am Mythos. Frankfurt/M.: Suhrkamp, S. 40
} 
bewahrt seinen Kern, der menschliche Erfahrungen und psychologische Vorgänge reflektiert, die mittels narrativer Varianten an gesellschaftliche Gegebenheiten angepasst werden können. Die Narrationsvarianten können darüber hinaus eine „selektive und erstarrte Interpretation der Vergangenheit“ zur Folge haben, weil einzelne historische Sachverhalte nicht mehr gemäß den Tatsachen interpretiert $[\ldots]^{“ 403}$ werden. „Durch seine semantische Struktur ermöglicht er immer neue Deutungsperspektiven, was besonders für veränderte gesellschaftliche Kontexte von Bedeutung ist, in denen er einen erheblichen Funktionswandel unterliegt. “404 Die narrative Vielfalt prädestiniert Mythen für eine mediale Aufbereitung für propagandistische Zwecke, denn der Mythos „visualisiert mythische Narration in sehr komprimierter Weise, sodass diese für den Menschen leicht einprägsam wird und gleichzeitig eine bestimmte politische Orientierung repräsentiert." 405

Mythen können gezielt in das kollektive Gedächtnis implementiert werden, wo sie gespeichert und vor einem kulturellen und zeitlichen Hintergrund als Identifikationsraum wiederbelebt und zur Stabilisierung einer Gesellschaft eingesetzt werden. Da sich in Mythen die Identitäten von Völkern und Nationen manifestieren, erfahren sie insbesondere dann eine Renaissance, wenn Gesellschaften in Krisenzeiten nach einer gemeinsamen Identität suchen, denn "[I]in allen kritischen Augenblicken des sozialen Lebens sind die rationalen Kräfte, die zum Wiedererwachen der alten mythischen Vorstellungen Widerstand leisten, ihrer selbst nicht mehr sicher." ${ }^{406}$ Durch den Mangel an numinoser Orientierung entsteht ein Bedürfnis nach säkularer Sinnstiftung, der durch Mythen, Symbole und politische Heilslehren kompensiert werden kann. „Sie stärken den Glauben der Gemeinschaft, denn durch die Rezeption der Mythen erhält eine soziale Gruppe oder Nation Zugang zu ihrer Geschichte, die sie sinnstiftend mit gegenwärtigen Ereignissen verbinden kann. Damit wird der Glauben

Hein (2006): „Kultforschung“, S. 31f.

Ebd.

Hein (2006): „Kultforschung“, S. 32

Cassirer (2002 ): Mythus. S. 364 
der Gemeinschaft gestärkt und das Zusammengehörigkeitsgefühl verfestigt.“ ${ }^{407} \mathrm{My}$ then hatten in vielen Phasen der deutschen Geschichte eine außerordentliche Relevanz. Insbesondere nach der Reichsgründung erlebten Mythen, die der jungen Nation einen Identifikationsraum boten, eine regelrechte Inflation. ${ }^{408}$ Nach dem Ersten Weltkrieg wurden Mythen in der Phase der Desorientierung zum nationalen Identifikationsraum. Den Mangel an numinoser Orientierung machten sich insbesondere die Nationalsozialisten zunutze. Sie okkupierten das nationale Mythenpantheon und machten ihn zum inhärenten Bestandteil ihrer Propaganda. „The power of myth is the power of narrative. Propaganda rejects intellectual challenge, and it seeks refuge in the structures of myth. [...] Myths are a culture's self explanation, and they are a key part of propaganda“. ${ }^{409}$ Die Nationalsozialisten kompensierten damit einen nationalen Identitätsverlust, denn die Weimarer Republik war mit ihrem „verfassungsidentifikatorischen Angebot" ${ }^{410}$ sehr rational geprägt. Sie besaß daher kaum identifikationsstiftendes Potential und bot wenig Raum für Mythenbildungen. Die Republik basierte nicht auf einer "nationalen Mythologie“, sondern trug die Lasten der Kriegsniederlage und des gescheiterten Kaiserreiches ${ }^{411}$ ohne einen Ausgleich an sinnstiftenden Identifikationsräumen zu bieten. Darüber hinaus hatte Weimar die Bedeutung von Mythen als vitalen Bestandteil zur Nationalbildung 412 nicht erkannt. In der Weimarer Republik herrschte daher ein Mangel an mythischer Geschichtsinterpretation, mit der die Demütigung der Nation kompensiert und einer "sinnhaften[r] Integration“413 zugeführt werden konnte. Die Nationalsozialisten hingegen waren sich der

\footnotetext{
407 Hein (2006): „Kultforschung“, S. 33

408 Mythen und Symbole wurden zu Repräsentanten der Nation und galten im Kaiserreich als Richtschnur. Ferner boten sie dem Bürgertum eine Möglichkeit der Teilhabe an dem politischen Geschehen, als es die Macht mit der erstarkten Arbeiterschaft teilen musste. Das rechte Lager zog sich hinter die alten politischen Mythen zurück und verwendete diese gegen die Republik. Vgl. Münkler (2009): Mythen, S. 17ff.

409 O'Shaughnessy (2004): Politics, S. 65

410 Fuge, Janina (2009): „Zwischen Kontroverse und Konsens.“ In: Schmid, Harald (Hg.): Geschichtspolitik und kollektives Gedächtnis. Göttingen: V\&R unipress, S. 131

411 Peukert, Detlev J. K. (1987): Die Weimarer Republik. Krisenjahre der klassischen Moderne. Frankfurt/M.: Suhrkamp, S. 16

412 Vgl. Assmann, Aleida (2006): Der lange Schatten der Vergangenheit. Erinnerungskultur und Geschichtspolitik. München: C. H. Beck, S.41

413 Schirmer, Dietmar (1989): „Politisch-kulturelle Deutungsmuster: Vorstellungen von der Welt der Politik in der Weimarer Republik." In: Lehnert/ Megerle (Hg.): Identität, S. 37
} 
Bedeutung der „politischen Mythen“ als „narrative Grundlage der symbolischen Ordnung eines Gemeinwesens“" ${ }^{414}$ bewusst und installierten ein vielschichtiges Mythen- und Symbolsystem.

Der Nationalsozialismus generierte sein Mythen- und Symbolsystem primär aus dem deutschen Heldentum und den getöteten Putschisten vom 9. November 1923, den ,Märtyrern der Bewegung،. ${ }^{415}$ Da die NS-Ideologie darüber hinaus stark von einem „heroischen Verlierergedächtnis“416 des Ersten Weltkrieges geprägt war, waren deutsche Kriegshelden fester Bestandteil des nationalsozialistischen Pantheons. ${ }^{417}$ Die Mythen und Helden fanden in Gedenktagen und Riten ihren symbolischen Ausdruck. Als zentrale Elemente der politischen Identifikation und Repräsentation entfalteten sie aufgrund ihrer Bedeutung eine vitale Dynamik. Der Chefideologe des NS-Regimes Alfred Rosenberg ${ }^{418}$ erkannte die dem Mythos inhärente Kraft, Menschen emotional zu mobilisieren: "Lebendig sind nur der Mythus und seine Formen, für die Menschen zu sterben bereit sind."419 Die Nationalsozialisten verstanden es, Mythen und Helden mittels „ikonischer Verdichtung“ ${ }^{\prime 20}$ neue Deutungsebenen zu verleihen, die sakralen Charakter besaßen. Sie wurden von der politischen Propaganda als emotionale Ressource zur Vitalisierung der nationalen Identität instrumentalisiert. Eingebunden in die politische Propaganda wurde der Mythos zum kommunikativen Element und zur „ideellen Mobilisierung von Massen.“ ${ }^{421}$ Mythen können besonders gut in die Gesellschaft implementiert und propagandistisch vereinnahmt werden, wenn sie durch

\footnotetext{
$414 \quad$ Münkler (2009): Mythen, S. 15

415 Vgl. Behrenbeck (2011): Helden, S. 86f.

416 Assmann (2006): Schatten, S. 67

417 Insbesondere für die Deutschnationalen wurden Mythen zu einem Instrument, mit dem die Niederlage des Ersten Weltkrieges kompensiert werden konnte. Vgl. Thimme, Annelise (1969): Flucht in den Mythos. Die Deutschnationale Volkspartei und die Niederlage von 1918. Göttingen: V\&R, S. 86

418 Rosenberg war „Beauftragter des Führers zur Überwachung der gesamten geistigen und weltanschaulichen Schulung und Erziehung der NSDAP." Sein ideologisches Gedankengut hatte er bereits in dem Werk „Der Mythus des 20. Jahrhunderts“ verkündet. Koop, Volker (2016): Alfred Rosenberg: Der Wegbereiter des Holocaust. Eine Biographie. Wien/ Köln: Böhlau, S. $274 \mathrm{f}$.

419 Rosenberg, Alfred (1930): Der Mythus des 20. Jahrhunderts. Eine Wertung der seelisch-geistigen Gestaltenkämpfe unserer Zeit, Aufl. 936-965 1942, München: Hoheneichen-Verlag, S. 638

420 Münkler (2009): Mythen, S. 15

421 Hein (2006): „,Kultforschung“, S. 31
} 
Narrationsvarianten den jeweiligen Bedürfnissen angepasst und über die Massenmedien verbreitet werden. "Social myth are perpetuated by propaganda, celebrated in film, ritual and print, and this has been a ceaseless activity. ${ }^{\text {}}{ }^{422}$

In Bezug auf massenmediale Verbreitung waren Zigarettenalben als omnipräsentes Massenmedium der 1930er Jahre prädestiniert, um für die Installation und Multiplikation von Mythen instrumentalisiert zu werden. Entsprechend wurden in den Sammelwerken Mythen, kriegerische Auseinandersetzungen, historische Ereignisse wie Gründungsmythen im Sinne der politischen Ideologie neu interpretiert und verbreitet. ${ }^{423}$ (Ausführlich Kap. 5)

\subsubsection{Symbol}

Das Symbol gilt als Sinnbild und Bedeutungsträger, das in den einzelnen wissenschaftlichen Disziplinen unterschiedlich interpretiert wird. ${ }^{424}$ Der Begriff wird daher im erkenntnis-, sprach- und zeichentheoretischen sowie im psychoanalytischen Kontext unterschiedlich besetzt. ${ }^{425}$ Neben Autoren, die das Symbol in ihren Konzeptionen als rein konventionelles Zeichen verstehen wie Pierce und Langer oder als ikonisches Zeichen beschreiben wie Hegel, ${ }^{426}$ erweitert Ernst Cassirer den Symbolbegriff um eine Bedeutungsebene. Für Cassirer besitzen Symbole, die dem Menschen in Mythen und der Kunst begegnen a priori keine Bedeutung, sondern erhalten diese erst in ihrem jeweiligen Kontext, denn „[I]ihr Gehalt geht rein und vollständig in der Funktion des Bedeutens auf.“ Die Deutung eines Symbols ist als Wahrnehmungserlebnis zu verstehen, bei dem sich das „Bewusstsein [...] bestimmte konkret-sinnliche Inhalte als

\footnotetext{
422 O'Shaughnessy (2004): Politics, S. 89

423 Exemplarisch in dem Album: Brinkmann (YOSMA) G.M.B.H. (1934): Alles für Deutschland 2000 Jahre deutsche Geschichte und deutsches Heldentum. (Textbearbeitung von M. Gutewort und Oberstleutnant Hänichen). Bremen

$424 \quad$ Vgl. Nöth (2000): Semiotik, S. 178

425 Symbole werden sowohl als konventionelle Zeichen verstanden als auch als Träger von Emotionen oder als komplexe Zeichen und Metaphern, die erst durch Konnotation mit Bedeutung aufgeladen werden. Vgl. Ebd., S. 179-184

426 Vgl. Ebd., S. 179ff.
} 
Ausdruck für bestimmte Bedeutungskomplexe“427 bildet. Nach dieser Interpretation besitzt die „symbolische Konnotation“ einen „emotionalen Gehalt“, ${ }^{228}$ der über die Bedeutung hinaus Vorstellungen wie Ideale und Ideen repräsentiert. „Ein Symbol definiert sich als ein Reiz, der für den Menschen eine erlernte Bedeutung und einen erlernten Wert besitzt" ${ }^{429}$ die er sich, durch Kommunikation aneignet. ${ }^{430}$ Als Sinnbild muss das Symbol daher erst mit Bedeutung aufgeladen werden, bevor es als Träger auf eine Sache, Idee oder Gedanken hinweist und seine vitale Suggestivkraft entfalten kann. Das Symbol gibt, sobald es aufgeladen ist, „in bildhafter, stark verkürzter Weise einen Sach- oder Handlungszusammenhang wider, den es letztendlich ersetzt. “431 Ein Symbol wird so zu einem „mit intersubjektiver Bedeutung behaftetes und deshalb über sich selbst hinausweisendes Zeichen. Dadurch ist es Toröffner und Trägermedium menschlicher Kultur. “432

Symbole erhalten ihre Bedeutung und ihren emotionalen Gehalt nicht nur über Schrift und Sprache, sondern können auch als Form Inhalte vermitteln. Als konnotatives Zeichen findet es seine Gestalt in grafischen Elementen wie Flaggen, Wappen oder Abzeichen. ${ }^{433}$ Im politischen Kontext können Symbole auch in Form von Denk- und Grabmalen Orte „der Aufbewahrung und Weitergabe von Bedeutung“434 werden. Gräber und Denkmale verweisen nicht nur auf Personen, sondern auch auf die Taten und Eigenschaften, die mit diesen Menschen assoziiert werden. Das Denkmal kann so

${ }_{427}$ Cassirer, Ernst (1964): Philosophie der symbolischen Formen, Erster Teil, Die Sprache, 4. Aufl., Darmstadt: Wissenschaftliche Buchgesellschaft, S. 42f.

428 So sind Hammer und Sichel nicht nur Symbole für kommunistische Gruppierungen, sondern das Symbol repräsentiert gleichzeitig die Ideale, die mit diesem Gesellschaftsentwurf verbunden sind. Vgl. Nöth (2000): Semiotik, S. 182

429 Rose, Arnold M. (1967): „Systematische Zusammenfassung der Theorie der symbolischen Interaktion“. In: Hartmann, Heinz (Hg.): Moderne amerikanische Soziologie. Stuttgart: Ferdinand Enke, S. 220

$430 \quad$ Vgl. Ebd., S. 221

431 Hein (2006): „Kultforschung“, S. 32

432 Gründer, René (2008): Germanisches (Neu-)Heidentum in Deutschland. Entstehung, Struktur und Symbolsystem eines alternativreligiösen Feldes. Berlin: Logos, S. 27

433 Vertreter der kulturwissenschaftlichen Interpretation legen bei der Deutung des Symbols sowohl eine arbiträre und konventionelle als auch eine gewohnheitsmäßige Definition zugrunde. Vgl. Ebd., S. 179

434 Fuchs, Max (2011): Die Macht der Symbole: ein Versuch über Kultur, Medien und Subjektivität. München: Herbert Utz, S. 28 
mit der Historie oder einem Ideal konnotiert werden, dass das Symbol repräsentiert. Denkmale werden "Haltepunkte für Memoria",435 als eine "symbolische Aufladung und Gedächtniskonstruktion", 436 die ein kollektives Erinnern bewirkt. Denkmale, mit denen eine Nation oder Gemeinschaft Verstorbener oder historischer Ereignisse gedenkt, können von Machthabern in einen Kontext gesetzt werden, der ihre Ideologie repräsentiert. Die Symbole können so zum Erhalt ihrer Macht beitragen oder diese legitimieren.

Der Stellenwert der Symbole als Mittel der Massenbeeinflussung wurde bereits in der Weimarer Republik von Propagandastrategen, Staatswissenschaftlern sowie Marketingfachleuten erkannt. Für Plenge war die Symbolpropaganda von besonderer Relevanz, da sie mit komplexen Vorstellungen verbunden ist, die in den Zeichen ikonisch verdichtet werden. Ein Symbol hat den „höchsten Propagandawert, weil es in gedrängtester Zusammenfassung schlagkräftig dem Wissenden so vieles sagt. “ ${ }^{437}$ Für Stern-Rubarth war das Symbol ein Instrument, mit dem Glaubensinhalte und politische Ideen in eine einfache visuelle Form gebracht werden können, unter der sich Gleichgesinnte zu einer politischen Gemeinschaft zusammenfinden. ${ }^{438}$ Der Markentechniker Hans Domizlaff, seines Zeichens verantwortlicher Werbefachmann bei Reemtsma und führender Marketingfachmann seiner Zeit, plädierte für eine Propagandastrategie, die auf einem Komplex aufeinander abgestimmter Kommunikationsmittel basiert. Domizlaff empfahl der Politik, sich Symbole in Form von „Wort, Schrift und Bild“ zu bedienen, also der "physischen Wirkungsmittel“, 439 die sich in der Welt des Konsums seit langem etabliert hatten. Damit würde nicht nur die Identifikation der Mitglieder gestärkt, sondern auch die Kontaktbrücke zum Rezipienten aufrecht erhalten. Domizlaff propagierte eine „Staats-Symbolik“ in Gestalt von „Titel,

435 Rader, Olaf A. (2007): „Legitimitionsgenerator Grab. Zur politischen Instrumentalisierung.“ In: Behrmann, Carolin/ Karsten, Arne/ Zitzlsperger, Philipp (Hg.) Grab - Kult - Memoria: Studien zur gesellschaftlichen Funktion von Erinnerung. Wien/Köln: Böhlau, S. 20

436 Ebd., S. 11

437 Plenge (1922): Propaganda, S. 29

$438 \quad$ Vgl. Stern-Rubarth (1921): Propaganda, S. 14

439 Domizlaff, Hans (1931): Propaganda-Mittel der Staats-Idee. Altona-Dithmarschen: Selbstverlag, S. 29 
Orden, Wappen, Fahnen, Uniformen, Aufzüge, feierliche Riten usw.“, mit der sich eine Volksgemeinschaft identifizieren kann. Domizlaff hielt diese simple Formensprache in einem aufgeklärten Zeitalter für „unwürdig“ und „Merkmale des Geltungstriebes und des Herdentriebes“, aber als Zeichen für "sichtbare Dokumentierung der Gemeinsamkeit“, die „für jede Propaganda, also auch für jede Parteipropaganda notwendig“440 ist. Das Symbol entführt den Betrachter in eine emotional aufgeladene Welt und entfaltet so seine Suggestivkraft. Das Symbol ist daher nicht nur bedeutendes Instrument der Massenbeeinflussung, sondern auch integrierter Bestandteil der Propaganda. „If myth are the heart of propaganda, symbolism is its outer garment indeed, to speak of propaganda devoid of symbolism is really to be speaking about some other phenomenon, for a propaganda bereft of symbol structures would be unintelligible as propaganda. ${ }^{441}$

Im Kontext der nationalsozialistischen Propaganda, die sich im Spannungsfeld zwischen Identität und Wir-Bewusstsein, politischem Ordnungssystem und Machtstrukturen bewegte, nahmen Symbole und Mythen eine zentrale Stellung ein. Die NS-Propaganda etablierte ein „Symbolssystem, das seine Inhalte in symbolischen Geschichten vermittelte. “442 Symbole wurden zur psychologischen Kraftquelle mit ontologischen Dimensionen und zur Projektionsfläche, die die Bedürfnisse der Volksgemeinschaft $\mathrm{t}^{443}$ reflektierte und Identifikationsräume herstellten. Zur Installation von Identifikationsräumen dienten auch konnotative Zeichen wie Erinnerungsorte und Abzeichen. Exemplarisch ist die Hakenkreuzfahne. Sie wurde zum „Kollektivsymbol“",444 mit dem sich die Bevölkerung als Gemeinschaft identifizieren konnte.

\footnotetext{
$440 \quad$ Ebd., S. 32. Vgl. Paul (1990): Aufstand, S. 165

441 O'Shaughnessy (2004): Politics, S. 100

$442 \quad$ Behrenbeck (2011): Helden, S. 27

443 Der Gedanke der Volksgemeinschaft war bereits seit der Reichsgründung ein gesellschaftliches Ideal völkischer Kreise. Sie war Voraussetzung dafür, dass Deutschland seinem ,Sendungsauftrag' als Kulturnation gerecht werden konnte. Vgl. Bergmann, Jürgen (1989): „,„Das Land steht rechts!“ Das „agrarische Milieu“““ In: Lehnert/ Megerle (1989): Identität, S. 186f. Der völkische Gedanke war eine Folge der Romantik des 19. Jahrhunderts, der sich u.a. vom Rationalismus ab- und dem Irrationalen zuwandte. Mosse, George L. (1991): Die völkische Revolution. Über die geistigen Wurzeln des Nationalsozialismus. Frankfurt/M.: Anton Hain, S. 21

Soeffner, Hans-Georg (2010): Symbolische Formung. Weilerswist-Metternich: Verlbrück, S. 36
} 
Die

Nationalsozialisten kompensierten mit diesem Zeichen den Mangel an nationaler Identität, der sich in der Weimarer Republik insbesondere in dem „Flaggenstreit“445 manifestierte. Die Bedeutung der Staats-Symbolik als psychologische Vitalität wird in dem Zigarettenalbum DEUTSCHLAND ERWACHT hervorgehoben:

„Die beginnende Organisierung machte ein Parteiabzeichen, eine Parteiflagge unabweisbar notwendig. Niemand wusste tiefer um die Bedeutung von Symbolen als Hitler. Eine Bewegung, eine Gemeinschaft, ein Volk, ein Staat ohne ein Symbol, an dem sich die Herzen entzünden, auf das sie alle ihre Sehnsucht, ihren Stolz, ihre Begeisterung richten können, ist leblos und damit wirkungslos. ${ }^{446}$

Politische Mythen und Symbole sind daher ein integraler Bestandteil von Geschichte, denen sich Gesellschaften insbesondere in Zeiten nationaler Identitätskrisen und sozialer Umbrüche bedienen. Sie können, multipliziert über Massenmedien, für politische Propaganda instrumentalisiert und zur Indoktrination sozialer Gruppen eingesetzt werden.

\subsection{Resümee}

Im Laufe ihrer Geschichte hat die NSDAP keine einheitliche Propaganda-Strategie verfolgt, sondern diese den politischen Zielen und der Stimmungslage der Bevölkerung angepasst. So wurde in der Phase vor 1933, als das Erlangen der Macht oberstes Ziel war, eine aggressive Demonstrationspropaganda betrieben. Unmittelbar nach Machtantritt erfolgte ein Paradigmenwechsel hin zur Integrationspropaganda, der sowohl den innen- als auch den außenpolitischen Erfordernissen geschuldet war. Das NS-Regime setzte bei der Integrationspropaganda kommunikationsstrategische Elemente der Populärkultur ein und bediente sich moderner Massenmedien. So konn-

\footnotetext{
445 Neben der Flagge mit den Farben Schwarz, Rot und Gold wurde auf das Drängen der im Ausland lebenden Deutschen die Handelsflagge aufgezogen. Sozialdemokraten und die linksliberale DDP warfen Reichskanzler Luther vor, die Verfassung verraten zu haben. In der Folge musste er 1926 zurücktreten. Weißmann, Karlheinz (1991): Schwarze Fahnen, Runenzeichen. Die Entwicklung der politischen Symbolik der deutschen Rechten zwischen 1890 und 1945. Düsseldorf: Droste Verlag, S. 78 
ten propagandistische Zielsetzungen und populäre Themen in den gesellschaftlichen Kontext der Zielgruppen gesetzt und die sozialpsychologischen Bedürfnisse der Rezipienten berücksichtigt, respektive befriedigt werden. Die Propagandastrategen erkannten schnell das Potential der Zigarettenalben. Da die Sammelalben ein beliebtes Massenmedium ihrer Zeit waren, konnte die Propaganda nicht nur an der Beliebtheit des Mediums partizipieren, sondern auch von seiner hohen Auflage.

Die Konnexion von Propaganda und Unterhaltung war auch kommunikationspsychologisch eine gelungene Strategie, denn so wurde nicht nur das Bedürfnis der Rezipienten nach Unterhaltung befriedigt, sondern die Propaganda wurde damit auch kaschiert und konnte suggestiv auf die Rezipienten einwirken. Da auch die Provenienz der Alben verschleiert und die staatliche Lenkung der NS-Alben kaum erkennbar war, konnte beim Konsumenten der Eindruck vermittelt werden, die Ideologie des Nationalsozialismus sei gesamtgesellschaftlicher Konsens. Das RMVP vermied es daher, auf seine direkte Mitarbeit und Einflussnahme bei den Zigarettenalben hinzuweisen. Neben diesen Vorzügen kam die mehrjährige Laufzeit sowohl der Intention der Wirtschaft als auch der des RMVP entgegen, denn beide Parteien waren auf langfristige sozialtechnische Maßnahmen zur Beeinflussung menschlichen Verhaltens angewiesen. Das Zigarettenalbum erfüllte die von Goebbels und Hitler postulierte Kontinuität, die dem Erfolg jeder kommerziellen und politischen Reklame zugrunde liegt.447 Die „zwingende Notwendigkeit“ bei Markenartikeln „fortlaufend Propaganda zu treiben“448 war sowohl Doktrin für die Zigarettenfabrikanten als auch für den NS-Staat.

Die Zigarettenunternehmen profitieren ihrerseits von der temporären Beliebtheit der NS-Alben. So hatten der Reemtsma-Konzern und der angeschlossene Bilderdienst diverse NS-Alben im Portfolio, die auf freiwilliger Basis publiziert wurden, um Marktanteile, respektive um nationalsozialistische Kundensegmente zu gewinnen.

\footnotetext{
447 Vgl. Hitler (1930): Kampf, S. 203

448 HIS PFR 2000,03 Schreiben Gustav Kuhle, Inhaber der Kuhle-Reklame vom 10. Dezember 1947
} 
Mit dem Aufgreifen sozialpolitischer Themen knüpfte die Industrie an Marketingstrategien an, die bereits während des Ersten Weltkrieges erfolgreich zum Einsatz gekommen waren. Da die Verbindung von Werbung und Politik der Bevölkerung vertraut war, traf diese Strategie auf geschulte Rezipienten, die die Botschaften leicht decodieren konnten. Damit entstand eine Gemeinschaftswerbung von Produkt und Politik, von deren Synergieeffekt beide Seiten profitierten. Durch die Kooperation entstanden jedoch vielschichtige Abhängigkeiten. Da die Autonomie des Öffentlichkeitssystems aufgehoben war, besaß das NS-Regime die rechtliche Legitimation, Publikationen $\mathrm{zu}$ zensieren oder $\mathrm{zu}$ verbieten. Die Zigarettenunternehmen waren daher gezwungen, sich bei der inhaltlichen Aufbereitung der Inhalte regimekonform auszurichten $^{449}$ oder, wie im Fall Reemtsma, den Forderungen des RMVP nachzukommen, propagandistische Werke zu publizieren.

Die Bausteine dieser Identifikationsräume waren Mythen und Symbole, die vom NS-Regime als Fundament ihres autoritären Systems installiert wurden. Aufgrund ihrer ikonischen Verdichtung bildeten die mythischen Narrationen eine politische Orientierung ${ }^{450}$ und dienten der Bevölkerung darüber hinaus als Sinnressource. Die Mythen und Symbole wurden Teil des kollektiven Gedächtnisses und gaben der sozialen Gemeinschaft eine kulturelle Identität. Sie wurden zur psychologischen Kraftquelle mit ontologischen Dimensionen und zur Projektionsfläche, die die Bedürfnisse breiter Bevölkerungsschichten reflektierte.451 Die Symbole des NS-Regimes bildeten ein Äquivalent zu den in der Wirtschaftswerbung verwendeten Markenzeichen, die Botschaften transferierten. Diese Botschaften waren der symbolische Mehrwert, mit dem Identifikationsräume für die Zielgruppen geschaffen wurden. So nutzen Wirtschaft und Politik die Suggestivkraft der Mythen und Symbole, um manipulativ auf die Empfänger einzuwirken und sie $\mathrm{zu}$ einem gewünschten Handeln zu provozieren.

\footnotetext{
449 Vgl. HIS PFR 230,35 Strafsache Reemtsma, 56. Verhandlungstag, 22. September 1948.

Vgl. HIS PFR 491,08 Lose (1953): Bilderdienst, S. 295

450 Vgl. Hein (2006): „Kultforschung“, S. 31f.

451 Vgl. Bergmann (1989): „Das Land“, S. $186 f$.
} 


\section{Zigarettenalben im Kontext politischer Ideologien}

Während die Zigarettenindustrie in der Propagandaschlacht des Ersten Weltkrieges lautstarke patriotische Töne angeschlagen hatte, um im zeitgenössischen Taumel des Nationalbewusstseins nicht aus dem Takt zu geraten, waren die Unternehmen in der Weimarer Republik verhaltener. Während im Weltkrieg die Namen der Zigarettenmarken in einer Welle chauvinistischer Semantisierung untergingen, fand in der folgenden Dekade keine Anpassung des Produktnamens an das politische Zeitgeschehen statt. Der Erste Weltkrieg war im öffentlichen Bewusstsein breiter Bevölkerungsschichten ohnehin nicht mehr präsent und patriotische Töne entsprachen nicht dem auf Pazifismus ausgerichteten Zeitgeist. 452 Die Tradition der Semantisierung von Ideologien, die sich im Kaiserreich als probates Instrument in der Werbung etabliert hatte, fand erst zu Beginn der 1930er Jahre wieder Eingang in die Wirtschaftskommunikation.

Die etablierte groß- und mittelständische Zigarettenindustrie, die ab Ende der 1920er Jahren das Sammelbild als Marketinginstrument für sich entdeckt hatte, setzte mit dem Erstarken der NSDAP ab 1933 auf den Synergieeffekt von Propaganda und Wirtschaftswerbung. Im Unterschied zur Zeit des Ersten Weltkriegs wurden die Namen der Zigarettensorten nicht verändert. Aus der Perspektive des Marketings eine folgerichtige Planung, denn eine Semantisierung des Firmen- oder Produktnamens hätte eine Anpassung der "ganzheitlichen Organisationskonzeption“ des Unternehmens, der „Corporate Identity“453 (CI), erforderlich gemacht. Bei einer Änderung der

452 Während einige rechtsgerichtete Ideologen eine Revision des Versailler Vertrages militärisch herbeiführen wollten, hatten andere Teile der Bevölkerung eine pazifistische Position bezogen. Der Völkerbund trug maßgeblich zur Verbreitung des pazifistischen Gedankens bei. Vgl. Wette, Wolfram (1991): Militarismus und Pazifismus. Auseinandersetzung mit den deutschen Kriegen. Bremen: Donat Verlag, S. 123

453 Die Corporate Identity umfasst: Corporate Behavior, Corporate Communication und das Corporate Design. Die CI beeinflusst daher u.a.: Führungsstil, Kommunikation, Öffentlichkeitsarbeit, Marketing und das Gestaltungskonzept. Vgl. Regenthal, Gerhard (2003): Ganzheitliche Corporate Identity. Form, Verhalten und Kommunikation erfolgreich gestalten. Wiesbaden: Gabler, S. 83 
sozialen oder politischen Verhältnisse wären die Unternehmen darüber hinaus Gefahr gelaufen, nicht mehr dem sozialpolitischen Umfeld spezifischer Bevölkerungsgruppen oder dem politischen Zeitgeist zu entsprechen. Eine Semantisierung erfolgte lediglich bei operativen Maßnahmen, wie bei der thematischen Ausrichtung der Zigarettenalben an den neuen politischen Zeitgeist. Die temporären Werbemaßnahmen, die sich an gesellschaftspolitischen Trends orientierten, konnten leicht in das Gesamtkonzept der verkaufsfördernden Maßnahmen integriert werden. Dazu zählten die Publikationen von Sammelalben mit propagandistischen Inhalten, die den Unternehmen auch die Möglichkeit boten, von der Popularität des NS-Regimes zu profitieren. Exemplarisch für die Semantisierung politischen Gedankengutes sind Alben wie ERWACHENDES DeUtSChlAND ${ }^{454}$ oder Deutschland ERWACHT (Abb. 2). Die Titel verweisen auf die letzten Zeilen des ,Sturmliedes` von Dietrich Eckart aus dem Jahre 1919455 und bringen damit die nationalsozialistische Gesinnung zum Ausdruck. Der appellative Ruf „Deutschland, erwache! erwache!“456 war Schlagwort der nationalsozialistischen Bewegung und prangte als Schlachtruf auf den Standarten der SA, ${ }^{457}$ die bei Aufmärschen vorangetragen wurden. ${ }^{458}$

Das einzige größere Unternehmen, das die gesamte Kommunikation auf die Politik ausgerichtet hat, war "Sturm'. Das mittelständische Unternehmen, das der SA nahe stand, hatte nicht nur den Firmennamen, sondern auch die Namen der Zigarettensorten dem paramilitärischen SA-Vokabular entnommen. im Unterschied dazu weist die Marketingstrategie bei vielen Vertretern der Kleinindustrie eine große Divergenz zu

$454 \quad$ Kameradschafts-Zigarettenfabrik (1933): Erwachendes Deutschland. Gera

455 Vgl. Hillesheim, Jürgen/Michael, Elisabeth (1993): Lexikon nationalsozialistischer Dichter Biographien, Analysen. Würzburg: Königshausen \& Neumann, S. 136

Das ,Sturm-Gedicht' wurde 1922 von Hans Gansser vertont und war frühes Kampflied der NS-Bewegung. Vgl. Schreckenberg, Heinz (2003): Ideologie und Alltag im Dritten Reich. Frankfurt/M.: Peter Lang, S. 49 Eckart, Dietrich (1934): „Sturmlied“. In: Gille, Hans (Hg.): Das Neue Deutschland im Gedicht. Bielefeld/Leipzig: Velhagen \& Klasing

457 Die Standarten hatten aufgrund ihrer Berührung mit der ,Blutfahne‘ den Nimbus des Sakrosankten. Vgl. Schmitz-Berning (2007): Vokabular, S. 113. Das Bild der kämpferischen wie machtpolitischen Demonstration eines SA-Aufzuges mit Standarten ziert den Schutzumschlag des Reemtsma-Albums Deutschland erwacht. Reemtsma (1933): Deutschland erwacht

$458 \quad$ „Deutschland erwache!“ war die beliebteste Parole, die bei Aufmärschen der SA vorgetragen wurde; meist in Verbindung mit "Juda verrecke!“. Schreckenberg (2003): Ideologie, S. 49. 
den größeren Unternehmen auf, denn hier wurde die CI auf das zeitpolitische Geschehen ausgerichtet. Firmennamen wie DEUTSCHE FrONT, KAMERADSCHAFTsZigARETTE und STANDARTE indizieren dabei nicht nur eine Anpassung an den Nationalsozialismus, sondern sprechen auch für eine nationalsozialistische Gesinnung der Inhaber. Das gleiche gilt für die Zigarettenunternehmen des linken Lagers. Auch diese Firmen haben eine vollständige semantische Anpassung an die sozialistische Ideologie vorgenommen. Mangels Archivalien können jedoch keine evidenten Nachweise zur politischen Gesinnung der Unternehmer erbracht werden. Die vollständige Ausrichtung der CI auf politische Ideologien war in der Kleinindustrie keine Randerscheinung, sondern wurde vielfach praktiziert. Die nachfolgende Auflistung ${ }^{459}$ gibt einen Überblick über die Vielfalt der Semantisierungen:

\section{Deutsche Front}

DIE BRAUNE MAPPE

\section{Kameradschaftszigarette}

DIE DEUTSCHE WEHRMACHT

ERWACHENDES DEUTSCHLAND 460

Neudeutsche Zigarette / Kios

RANG- UND GRADABZEICHEN DER SA

\section{Standard}

FAHNEN UND STANDARTENTRÄGER DES DEUTSCHEN REICHES 1871-1918

SYMBOLE UND ABZEICHEN DES DRITTEN REICHES

\section{Standarte und Steiger}

DEUTSCHLAND ERWACHT

SCHLESIEN IM DRITTEN REICH

SCHLESISCHE HEIMAT 1

UNSERE FÜHRER

\section{Köberich (2003): Sammelbilder}

460 Für den Sammelband Erwachendes Deutschland waren 180 Bilder vorgesehen, bekannt sind lediglich 69. Eine zweite Auflage erschien bei der Zigarettenfabrik Mahalesi. Album- und Bildbestand durch Bombenangriffe vernichtet. Köberich (2003): Sammelbilder 


\section{Verbands-Zigarettenvertrieb}

GEEINTE FRONT. STAHLHELM REICHSFÜHRERTAGUNG HANNOVER 1933

DEUTSCHE KRIEGER ALLER ZEITEN

\section{Wehrverbands-Zigarettenvertrieb}

GEEINTE FRONT 1

\section{Doms}

DER KAMPF UM OBERSCHLESIEN - 100 BILDER DEUTSCHER GRENZLANDSNOT U. DEUTSCHE GRENZLANDSTREUE

FÜHRER DER DEUTSCHEN WEHRMACHT IM WELTKRIEG 1914 - 1918

\subsection{Doms und der Oberschlesische Grenzkonflikt}

Eine besondere politische Fokussierung ist bei der in Schlesien beheimateten Zigarettenindustrie zu beobachten. Die Alben der Unternehmen Doms und Standarte widmen sich exklusiv regionalen Konflikten. Doms war ein in Schlesien ansässiges Unternehmen, dass Tabak und Kautabak produzierte. ${ }^{461}$ Das Album DeR KAMPF UM OBerschlesien - 100 BILDER Deutscher GRENZlandSNOT U. DEUTSCHE GRENZLANDSTREUE ${ }^{462}$ exemplifiziert die Synergie von Propaganda und Marketing sowie eine monothematische Konzentration auf ein regionales politisches Zeitgeschehen. Der Sammelband behandelt ausschließlich die Annexion Oberschlesiens durch Polen zu Beginn der 1920er Jahre und die daran anschließenden Insurrektionen. ${ }^{463}$ Nach den Bestimmungen des Versailler Vertrages musste Deutschland einen Teil Schlesiens an Polen abtreten, was von der deutschstämmigen Bevölkerung als oktroyiertes Diktat empfunden wurde. ${ }^{464}$ Trotz vorangegangener Abstimmung über die

461 Präsentation des Unternehmens im Album. Doms (1933): Der Kampf um Oberschlesien. 100 Bilder Deutscher Grenzlandsnot u. deutsche Grenzlandstreue. Ratibor

462 Doms (1933): Oberschlesien

463 Anm.: Der seit dem 10. Jahrhundert einsetzende deutsche Handels- und Siedlungsgeschichte im Osten Europas folgte die Annexion Schlesiens durch Friedrich II. und die „Polnische Teilung", bei der polnische Territorien an Preußen fielen. Vgl. Großbongardt, Annette/ Klußmann, Uwe/ Pötzl, Norbert F. (Hg.) (2011): "Chronik“. In: Die Deutschen im Osten Europas. München: Deutsche Verlags-Anstalt, S. 40f. Mit der Annexion fielen reiche Erz- und Kohlereservoire an die Preußische Krone. Die Rohstoffe wurden zur Basis für eine frühe Industrialisierung. Vgl. Gunkel, Christoph (2011): „Der Hunger der Monarchen“. In: Großbongardt et al. (Hg.): Die Deutschen, S. 64 
Staatszugehörigkeit im Jahr 1921, bei der 60 Prozent der Bevölkerung für den Verbleib bei Deutschland votierten, fielen im Jahr darauf 46 Prozent der Bevölkerung und 30 Prozent der Fläche und damit wirtschaftlich vitale Industriegebiete auf Anordnung der Alliierten an den polnischen Staat. ${ }^{465}$ Neben den Territorialverlusten bedeutender Industrieregionen barg die Minderheitenverschiebung Potential für nationale Differenzen. Der seit dem 18. Jahrhundert betriebenen „Germanisierungspolitik“ stand nach dem Ersten Weltkrieg eine „polnische Nationalbewegung“466 gegenüber, was eine chauvinistische Gemengelage provozierte, die von massiven beidseitigen paramilitärischen Auseinandersetzungen begleitet wurde. Angesichts der Versailler Bestimmungen sah sich die Regierung in Weimar jedoch gezwungen, Armee und Verwaltung nach der polnischen Machtübernahme zurückziehen. ${ }^{467}$ Die Region wurde daraufhin zum Aufmarschgelände für Freikorpsverbände, ${ }^{468}$ die, bar jeden „politischen Zukunftsinstinkts“, ${ }^{469}$ das annektierte Territorium zurückerobern wollten. Die Verbände, die sich unter dem „oberschlesischen Selbstschutz“470 zusammenfanden,

\footnotetext{
465 Vgl. Ebd., S. $155 f$.

466 Ebd., S. 154. Der Germanisierungsgedanke trat erstmals 1844 auf und wurde von Bismarck vorangetrieben. Vgl. Michalczyk, Andrzej (2010): Heimat, Kirche und Nation. deutsche und polnische Nationalisierungsprozesse im geteilten Oberschlesien (1922 - 1939). Wien/ Köln: Böhlau, S. 41 und S. 45

467 Vgl. Koch, Hannsjoachim W. (2002): Der deutsche Bürgerkrieg - Die Geschichte der deutschen und österreichischen Freikorps 1918-1923. Dresden: Edition Antaios, S. 248f. Der Abzug musste laut einer Anlage zu Artikel 88 des Versailler Vertrages binnen 14 Tagen erfolgen. Reichspräsident Hindenburg hatte zuvor veranlasst, dass das bedeutende Industriegebiet in jedem Fall zu verteidigen sei. Er zog Freiwillige, heimgekehrte Truppen von der Westfront und Freikorpsverbände zusammen, um eine Offensive gegen Polen zu starten. Vgl. Ebd., S. 246

468 Vgl. Koch (2002): Bürgerkrieg, S. 246. Zu den bekanntesten Freikorps zählten "Oberland", "Aulock", „Roßbach", „Heinz" und „Heydebreck“. Vgl. Ebd., S. 243

469 Schulze, Hagen (1969): Freikorps und Republik 1918 - 1920. Boppard am Rhein: Harald Boldt Verlag, S. 330

470 Von republikanischer Seite wurden die Freikorpsverbände aufgrund der außenpolitischen Gegebenheiten nicht anerkannt. Die Korps konnten 1918/19 noch legal agieren, wurden 1920/21 aber zu illegalen Verbänden. Korzetz, Ingo (2009): Die Freikorps in der Weimarer Republik: Freiheitskämpfer oder Landsknechthaufen? Marburg: Tectum Verlag, S. 45. Aufgrund der Aufstände, die in den Anfangstagen der Weimarer Republik in Deutschland aufflackerten, befand sich die Regierung in einer prekären Lage, denn zur Wiederherstellung der Ordnung musste sie auf Verbände der Freikorps zurückgreifen. Vgl. Thoms, Robert/ Poschanke, Stefan (2001): Handbuch zur Geschichte der deutschen Freikorps. Bad SodenSalmünster: MTM Verlag, S. 31. Die Westgrenze wurde 1925 im Vertrag von Locarno akzeptiert, Polen gegenüber sicherte die Regierung lediglich einen Gewaltverzicht zu. Vgl. Pieper (2011): Waisen, S. 156.
} 
wurden seitens der Weimarer Regierung nicht anerkannt. Die Bevölkerung Oberschlesiens fühlte sich als „Waisen von Versailles“471 von der Republik verraten und von der Nation vergessen. Gemeinsam mit Freikorpsverbänden und Frontheimkehrern formierte sich die Bevölkerung $\mathrm{zu}$ einem nationalen Widerstand, der zu bürgerkriegsähnlichen Auseinandersetzungen führte.

Das Bildmaterial des Albums DER KAMPF UM OBERSCHLESIEN bezieht sich nahezu ausschließlich auf das Bürgerkriegsgeschehen und die Repressalien, denen sich die deutsche Bevölkerung durch Polen sowie durch alliierte französische und britische Truppen ausgesetzt sah. Die Auswahl und Anordnung der Bildmotive stellen einen Aufruf an den Rest der Nation dar, der Drangsal und Okkupation entgegenzuwirken. In dem Album klagt die Bevölkerung, dass sie den polnischen Übergriffen schutzlos ausgeliefert und gezwungen war, die Verteidigung der Heimat in die eigenen Hände zu nehmen. Der Sammelband schwelgt in einem Rechtfertigungspathos, das dem Rezipienten eine moralische wie rechtliche Überlegenheit suggeriert und die militärische Rückeroberung der Heimat legitimiert. In dem Text- und Bildmaterial werden die zentralen Aspekte des militärischen Konfliktes und die prekäre Lage, in der sich die deutschstämmige Bevölkerung nach dem Ersten Weltkrieg katapultiert sah, mit eindringlichem Pathos geschildert.

„Das Problem Oberschlesien wurde erst nach der Revolution vom November 1918 konstruiert und der Verlust eines Teiles Oberschlesiens, der nie vorher gegnerisches Kriegsziel war, ist eine Folge der Novemberrevolution.

In dieser Stunde der höchsten Not, als die verzweifelten Hilferufe der bedrängten Bevölkerung ungehört verhallten und die ganze Provinz dem deutschen Vaterlande verloren $\mathrm{zu}$ gehen drohte, entschied wieder der ehemalige deutsche Soldat; er wollte lieber sterben, als ehrlos seine oder der Brüder Heimat fremder Willkür überlassen. Aus der großen Tradition deutscher Wehrhaftigkeit entstand eine freiwillige Truppe: der oberschlesische Selbstschutz.

$471 \quad$ Ebd., S. 153 
Es ist eine Ironie des Schicksals, daß einem deutschen Gebiet, von dem man im Reiche in den Tagen des Glücks, zu denen es durch seinen industriellen und wirtschaftlichen Reichtum so ungeheuer viel beigetragen hat, gar nichts wußte, zu allerhöchst, daß es südlich von Breslau liegt [...] daß gerade diesem verkannten Gebiet der Hauptteil an deutscher Nachkriegstragödie aufgebürdet wurde. [...] Der polnische Einbruch [und] eine schlagartig einsetzende polnische Propaganda bewirkten, daß die Söhne des Ostens unterWaffen blieben, unter einem Oberkommando zusammentraten und den "Grenzschutz Ost" formierten. ${ }^{\text {" }} 72$

Die Freikorpsverbände und Frontheimkehrer, die sich durch Rücksichtslosigkeit und Gewaltbereitschaft auszeichneten und den Ausschreitungen Vorschub leisteten, werden in dem Sammelband zu Helden verklärt. Um diesen Mythos emotional zu verstärken, wird die Republik desavouiert, womit eine gegenmythische Konfrontation erschaffen wird. Darüber hinaus wird der Rückzug der deutschen Truppen nach Kriegsende jenseits historischer Realität dargestellt. Die heimkehrenden Soldaten, die "sich im Zustand der Meuterei“473 befanden, werden in dem Zigarettenalbum zum unbesiegten und disziplinierten Heer, das die Heimat nach dem Schandfrieden von Versailles erneut verteidigen musste. Mit dieser Geschichtsklitterung wird in dem Album der Mythos des Freiheitskämpfers erschaffen, der unter Einsatz seines Lebens die Heimaterde verteidigt hat.

\begin{abstract}
„Als nach dem schmachvollen 9. November 1918 die feldgrauen Heeressäulen, in ihrem Mustergültigen Rückzug das erhabendste Bild ihrer Unbesiegbarkeit darstellend, den traurigen Weg zur armen irregeleiteten Heimat nahmen $[\ldots]$

Der polnische Einbruch in Posen, vage Nachrichten von einem Schacher um Schlesien bei den Versailler "Friedens-Aposteln“, eine schlagartig einsetzende polnische Propaganda bewirkten, daß die Söhne des Ostens unter Waffen blieben, unter einem Oberkommando zusammentraten und den „Grenzschutz Ost" formierten.
\end{abstract}

\footnotetext{
472 Doms (1933): Oberschlesien, Grenzland O-S im Kampf, ohne Bildnummern, unpag.

473 Koch (2002): Bürgerkrieg, S. 123. Vgl. Korzetz (2009): Freikorps, S. 27
} 
Hätte man damals in Berlin weniger Furcht besessen und mehr Mannesmut, zum wenigsten den gleiche realpolitischen Sinn wie die einstigen Feindmächte - das heißt, man hätte den Dingen hier unten freien Lauf gelassen und dem Selbstschutz nicht Halt geboten -, wer wird bezweifeln, daß das Deutschland den hohen Botschaftsrat, den Richter über Oberschlesiens Zukunft, vor vollendete Tatsachen gestellt und eine Teilung gar nicht erst zur Diskussion gekommen wäre?"“74

Die Freikorpsverbände werden zu heldenhaften Verteidigern Oberschlesiens verklärt und nehmen mit 16 von insgesamt 100 Bildern in dem Album eine exponierte Stellung ein. Im Unterschied dazu werden die Nationalisten, die auf polnischer Seite kämpften, „als Korfanty-Bande ${ }^{\star 475}$ beschrieben. Sie werden als undisziplinierte InsurgentenTruppe dargestellt, die vandalierend die deutsche Bevölkerung drangsaliert hat. Die Erschaffung des Feindbildes war Teil des Perzeptionsmanagements, mit dem die Bevölkerung emotionalisiert und das Gemeinschaftsgefühl der Oberschlesier gestärkt werden sollte. Um den Anspruch auf das Land zu legitimieren, wird in dem Album auf die Historie zurückgegriffen. Das Recht auf das Territorium wird mit der langen deutschen Siedlungsgeschichte begründet, in deren Verlauf das Land urbar gemacht und industrialisiert wurde. Die daraus gewachsene Heimatverbundenheit, geprägt von Brauchtum und Bodenständigkeit, wird im Text- und Bildmaterial mit patriotischer Diktion vorgetragen.

„Oberschlesien, des Reiches und Deutschtums wichtigster Posten im slawischen Südosten, trat in den Mittelpunkt der Weltpolitik, indem es in den Kampf gestellt wurde zwischen dem Recht des alten deutschen Vaterlandes und dem Unrecht fremder, historisch unbegründeter Ansprüche. ${ }^{476}$

Neben den Fotografien, die die deutschen Opfer und die Zerstörungen deutschen Kulturgutes im Zuge der paramilitärischen Auseinandersetzungen dokumentieren,

\footnotetext{
474 Doms (1933): Oberschlesien, Grenzland O-S im Kampf, ohne Bildnummern, unpag.

475 Ebd.

Korfanty hatte sich für einen friedlichen politischen Austausch mit der deutschen Bevölkerung ausgesprochen. Vgl. Shannon, Kasia (2006): „Etatismus und Wirtschaftsnationalismus in Ost-Oberschlesien“. In: Günther, Jutta/ Jajesniak-Quast, Dagmara (Hg.): Willkommene Investoren oder nationaler Ausverkauf?: Ausländische Direktinvestitionen in Ost-Mitteleuropa im 20. Jahrhundert. Berlin: Berliner Wissenschaftsverlag, S. 131 
befinden sich in dem Album vorgedruckte Illustrationen, die ein romantisch verklärtes Bild deutscher Kultur zeichnen. Das Spektrum der nostalgisch verklärten Grafiken umfasst die wirtschaftliche und kulturelle Traditionslinie, die während der deutschen Siedlungsgeschichte entstanden ist und eine historisch gewachsene Verbundenheit mit dem Land veranschaulichen soll. Das idyllische Szenario bildet einen Kontrapunkt zu den Fotografien, die die Repressalien und den Widerstand der deutschen Bevölkerung zum Inhalt haben. Die Gegenüberstellung der Bilder und Grafiken intensivieren im Auge des Betrachters das Leid und Elend der deutschen Bevölkerung (Abb. 3). Der Anspruch auf Oberschlesien als urdeutsches Siedlungsgebiet wird mit zahlreichen Abbildungen von Kultobjekten und Bauwerken untermauert, die als Medien die deutsche Historie und den deutschen Siedlungsraum visualisieren. Sie etablieren ein kulturelles Gedächtnis, das eine Zugehörigkeit zur oberschlesischen Heimat repräsentiert. Die kulturelle Verbundenheit mit der Heimaterde wird insbesondere mit der Heiligen Hedwig von Schlesien zum Ausdruck gebracht, die seit dem 13. Jahrhundert als fürsorgliche Landesmutter Oberschlesiens verehrt wurde. Als Ikone und „prägende Identifikationsfigur" ${ }^{477}$ diente sie auch als Motiv für ein deutsches Wahlplakat bei der Abstimmung im Jahr 1921, das als Fotografie in das Sammelalbum aufgenommen wurde. ${ }^{478}$

Neben sakralen Medien christlicher Provenienz befinden sich in dem Album mehrere Abbildungen von Denkmälern, die von der Bevölkerung für die gefallenen „Selbstschutzkämpfer“479 errichtet wurden. Sie symbolisieren nicht nur die Opfer, die für die Heimaterde erbracht wurden, sondern dienen auch der Kompensation eines kulturellen Identitätsverlustes, ${ }^{480}$ der mit der Annexion der Heimat verbunden war. Das Opfer der Freiheitskämpfer wird sakralisiert und erfährt in Denkmalen und Grabstätten seine symbolische Manifestation. Die Denkmäler erhalten damit eine Metaebene, die an

\footnotetext{
477 Hedwig von Schlesien galt im Mittelalter und nach dem Zweiten Weltkrieg als Friedensstifterin und Brückenbauerin zwischen Polen und Deutschen. Vgl. Schumann, Renata (2012): Hedwig von Schlesien - eine Frau für Europa. Görlitz: Bergstadtverlag, S. 8f.

478 Vgl. Doms (1933): Oberschlesien, Einleitung, ohne Bildnummern, unpag.

479 Doms (1933): Oberschlesien, Kapitel: Grenzland O-S im Kampf, ohne Bildnummern, unpag.

480 Vgl. Stoffels, Michaela (2011): Kriegerdenkmale als Kulturobjekte. Wien/Köln: Böhlau, S. 25
} 
ein gemeinsam erlittenes Leid erinnern und den Anspruch auf die Heimat konsolidieren. „[D]die urweltliche Kraft des Verbundenseins mit Blut und Boden“481 wird in dem Album zur Rechtfertigung für den Besitzanspruch auf das Grenzland, das viele Patrioten mit ihrem Leben verteidigt haben:

„Viele von ihnen aber auch deckt die Heimaterde, die sie mit ihrem Leib und ihr Leben geschützt haben. Das Opfer dieser Helden darf nicht vergessen werden!" 482

Die vor den Gedenkstätten vollzogenen Rituale wie Mahnwachen und Kranzniederlegungen erhalten eine „Identität stiftende Rolle“,"483 die das Kollektiv zu einer Schicksalsgemeinschaft zusammenschweißt. Die Trauer wurde damit „doppelt codiert", ${ }^{484}$ so dass die Trauerverarbeitung im Gefallenendenkmal eine „politische Vereinnahmung“485 ermöglichte. Die Toten wurden zu einem Mahnmal für die Lebenden, die ihnen die moralische Pflicht auferlegten, den Kampf um die Heimat fortzuführen.

"General Hoefer in Groß-Strehlitz bei der Einweihung des Denkmals für die Gefallenen des Weltkrieges und des Kampfes um Oberschlesien im Jahr 1931 anläßlich der Gedenkfeier der 10. Wiederkehr des Abstimmungstages.

Grabmal der deutschen Opfer des Insurgenten-Aufstandes vom Mail 1921 in Krappitz.Denkmal der Gefallenen des Weltkrieges u. des Kampfes um Oberschlesien in Groß-Strehlitz, errichtet 1931.

Totenehrung und Feldgottesdienst am Denkmal der gefallenen Selbstschutzkämpfer in Beuthen im Juli 1933.“486

Die Darstellungen der Ausschreitungen und der heldenhafte Kampf der patriotischen Freikorpskämpfer, die die bedrängte Bevölkerung unter dem Einsatz ihres Lebens verteidigt hatten, münden in dem Bekenntnis zum Dritten Reich, das Oberschlesien als bedeutenden Teil der deutschen Nation betrachtet. Sakrale Heimatverbundenheit

\footnotetext{
481 Doms (1933): Oberschlesien, Kapitel: Grenzland O-S im Kampf, ohne Bildnummern, unpag. 482 Ebd.

483 Petermann, Sandra (2007): Rituale machen Räume. Bielefeld: transcript, S. 25

$484 \quad$ Stoffels (2011): Kriegerdenkmale, S. 25

485 Ebd., S. 26

486 Doms (1933): Oberschlesien, Kapitel: Grenzland O-S im Kampf, ohne Bildnummern, unpag.
} 
und Politik werden zu einer Synkrise, die in dem Album mit Pathos zum Ausdruck gebracht wird.

„Die Regierung des Dritten Reiches hatte es wie keine andere erkannt, daß ein Deutschtum, fest und zähe zum Vaterland stehend, erst dann Wirklichkeit werden würde, wenn zufriedenstellende Daseinsbedingungen geschaffen seien. Aus dieser Erkenntnis heraus, soziale Zufriedenheit zur Grundlage nationaler Festigkeit zu machen, betrachtet sie nun die Stärkung des Bauerntums durch Verwurzelung mit einer wirtschaftlich zufriedenstellende Scholle als ihre vornehmste Aufgabe hier im Osten. ${ }^{4} 487$

Hinter dem pathetisch-sakralen Tenor, mit dem das Glaubensbekenntnis zur ostdeutschen Scholle in dem Album KAMPF UM OBERSCHLESIEN vorgetragen wird, verbirgt sich eine subtile Propaganda zur Vorbereitung eines Angriffskrieges gegen Polen. Der deutsche "Ostimperialismus“, der ab 1933 seinen Anspruch mit der germanischen und mittelalterlichen Besiedlung der Ostterritorien legitimierte, benötigte symbolisches Rüstzeug für einen kommenden Feldzug. ${ }^{488}$ Zur Emotionalisierung des Rezipienten wird symbolisches Kapital in Gestalt kulturell bedeutsamer Stätte und historischer Bauwerke angehäuft, in denen sich Tradition und Heimatverbundenheit verdichten. Neben Schlössern und landestypischen Holzkirchen, wird dem Betrachter eine Galerie deutschen Kulturlebens unterschiedlicher Epochen präsentiert. Dazu zählen Burg Ottmachau und das Stadttheater in Kattowitz mit der Aufschrift „Deutschem Wort, deutscher Art". ${ }^{489}$

Hinter Heimatverbundenheit und Tradition verbargen sich handfeste wirtschaftliche Interessen, denn mit der Gebietsabtretung an Polen verlor Deutschland eine bedeutende Industrieregion ${ }^{490}$ mit reichhaltigen Bodenschätzen. Oberschlesien musste

\footnotetext{
487 Ebd., Bildunterschriften, ohne Bildnummern, unpag.

488 Exemplarisch steht dafür der geschichtsträchtige ,Deutschen Orden', der in der Marienburg bei Danzig verwurzelt war. Vgl. Schreckenberg (2003): Ideologie, S. 123

489 Doms (1933): Oberschlesien, Kapitel: Grenzland O-S im Kampf, ohne Bildnummern, unpag.

490 Das Zentrum der Schwerindustrie befand sich in dem Dreieck ,Kattowitz-Gleiwitz-Beuthen'. Diese sowie städtische Gebiete waren primär von Deutschen bewohnt, während der ländliche Raum überwiegend von Polen besiedelt war. Auf polnischer Seite standen gleichfalls ökonomische Interessen im Vordergrund, denn die bedeutenden Industrieanlagen befanden sich in deutscher Hand und die eigenen Bodenschätze gingen zur Neige. Vgl. Koch (2002): Bürgerkrieg, S. 244f. Die französische Besatzungsmacht war sehr daran gelegen, Deutschland ein wichtiges Industriegebiet abzunehmen. Vgl. Ebd. S. 247
} 
80 Prozent der Eisenerz- und 26 Prozent der Steinkohlevorkommen abgeben. Die Relevanz dieser bedeutenden Ressourcen wird dem Rezipienten anhand einer Karte, auf der Bergwerke, Hochöfen und Erzvorkommen in den abgetrennten Territorien abgebildet sind, plastisch vor Augen geführt. Zur Legitimation der Wiedereingliederung Oberschlesiens in die Grenzen des Reiches wird die tiefe Verbundenheit des traditionsbewussten deutschen Bauern herangezogen, die aber mit dem Verweis auf die reichhaltigen Bodenschätze und Industrieanlagen verknüpft wird. Damit wird über die Heimatverbundenheit eine Emotionalität erzeugt, mit der die eigentliche Intention, die Rückeroberung der wirtschaftlichen Ressourcen, kaschiert wird. Die nationale und kämpferische Gesinnung der Bevölkerung wird mit „der völkischen und sozialen Zusammensetzung des oberschlesischen Volkes“ begründet, das nicht tatenlos zusehen wollte, wie die "gigantischen Gruben- und Hüttenwerke [...] dem wehrlosen deutschen Volke“491 genommen werden. Die wirtschaftlichen Einbußen, die mit dem bedeutenden Industriegebiet verlorengingen, werden im Text explizit zum Ausdruck gebracht:

„Der oberschlesische Selbstschutz hat verhindert, daß wertvolle Industrieanlagen und unermeßliche Werte des Volksvermögens, ja vielleicht ganz Oberschlesien verloren gingen. ${ }^{492}$

Die eklektische Auswahl der acht Bilder auf der letzten Seite des Albums fasst die gesamte Argumentationskette zusammen. Zwischen dem Zeugnis deutscher Siedlungsgeschichte im Mittelalter, landestypischer Traditionen und Sakralbauten mischen sich Bilder von Industrieanlagen. Die Zusammenstellung der Bilder vermittelt dem Betrachter das Gesamtbild einer gewachsenen deutschen Tradition mit kulturell-sakralen Wurzeln, in die die industriellen Aspekte subtil einbezogen werden. Der Sammelband KAMPF UM OBERSCHLESIEN mündet in der Bekenntnis zum Dritten Reich

\footnotetext{
491 Doms (1933): Oberschlesien, Kapitel: Grenzland O-S im Kampf, ohne Bildnummern, unpag. 492 Ebd.
} 
und der damit verbundenen Hoffnung auf Revision des Versailler Vertrages ${ }^{493}$ und der Wiedereingliederung in das Reich. Die Beseitigung des so genannten polnischen Korridors, der Oberschlesien vom Reichsgebiet trennte, wird unmittelbar mit den neuen Machthabern verknüpft.

\begin{abstract}
„Es ist nur allzu verständlich, daß ein Volksteil, der wie kein anderer deutsches Nachkriegsschicksal erfahren hat, dessen wirtschaftliche und nationale Einheit durch einen Machtanspruch unverständlichster Art zerrissen wurde, sehnlich wie kein anderer im Vaterlande nach einem Retter aus leiblicher und seelischer Not Ausschau hielt. [...] Der Augenblick der vollsten Hingabe zur neuen Führung war gekommen, als mit dem Siege der nationalsozialistischen Bewegung Regierung und Volk eines geworden waren. ${ }^{494}$
\end{abstract}

Der Anspruch auf die deutschen Siedlungsgebiete im Osten wird auch in anderen Zigarettenalben thematisiert. In dem Album KAMPF UM'S DRITTE REICH wird am Beispiel Ostpreußens die Erwartungshaltung gegenüber Hitler und dem NS-Regime deutlich zum Ausdruck gebracht. Auch hier wird der Anspruch auf die Region mit dem historisch gewachsenen urdeutschen Ordensland ${ }^{495}$ mit seinem tief verwurzelten Bauern- und Brauchtum legitimiert. Der Sammelband bringt eine Forderung der Nationalsozialisten und nationalen Rechten, zum Ausdruck, die sich bereits in der Weimarer Republik vehement für die Rückeroberung der Ostgebiete mit kriegerischen Mitteln aussprachen. ${ }^{496}$ In dem Album KAMPF UM`S DRITTE REICH manifestiert

493 Im Oberschlesienkonflikt trafen „polnische Expansionspolitik und das Bestreben der Deutschen nach einer Revision des Versailler Vertrages" aufeinander, es konnte kein Konsens gefunden werden. Vgl. Sprenger, Matthias (2007): Landsknechte auf dem Weg ins Dritte Reich. $\mathrm{Zu}$ Genese und Wandel des Freikorpsmythos, Paderborn: Ferdinand Schöningh, S. 46

494 Doms (1933): Oberschlesien, Kapitel: Grenzland O-S im Kampf, ohne Bildnummern, unpag.

495 Der Gedanke der Ostexpansion war bereits in den 40er Jahren des 19. Jahrhunderts in nationalen Kreisen präsent und weist eine historische Kontinuität auf. Der ,Drang nach Osten wurde mit der deutschen Besiedlung legitimiert, die im Mittelalter erfolgt war. Die Kolonisation der Ostmark wurde sowohl wirtschaftlich als auch militärisch begründet, um sich von Galizien und dem ,russischen Polen' abzugrenzen. Vgl. Wippermann, Wolfgang (1981): Der deutsche Drang nach Osten. Ideologie u. Wirklichkeit e. polit. Schlagwortes. Darmstadt: Wissenschaftliche Buchgesellschaft, S. 84 - 89

496 „Doch der Friede, der den Betrug von 1918 bestätigte, hat das Problem des Krieges nicht gelöst, das sich erst durch den vorläufigen Abschluß des Krieges in seiner ganzen Dringlichkeit enthüllte: das große Bevölkerungsproblem Mitteleuropas, um dessentwillen noch im Frühjahr 1919 Frontkämpfer nach Osten marschierten.“ Wirths, Werner (1922): „Das Erlebnis des Krieges". In: Moeller, van den Bruck/ Gleichen-Russwurm, Heinrich von/ Boehm, Max Hildebert (Hg.): Die Neue Front. Berlin: Verlag Gebrüder Pätel, S. 78 
sich in der Person Hitlers die Hoffnung, vom Fremden Joch befreit zu werden. Diese Hoffnung wird mit einer Gläubigkeit an einen heilbringenden Führer verbunden.

„Der Nationalsozialismus kämpft seit seinem Bestehen den ewigen Kampf um Heimat und Muttererde. [...] Seit Jahren sieht Ostpreußen in Adolf Hitler den Retter, den deutschen Freiheitskämpfer, der allein dazu berufen ist, ihr Führer zu sein, und der sie nie und nimmer verlassen wird. [...] Schon oft ist er zu ihnen gekommen, schon oft hat er zu ihnen gesprochen [...] und sie haben sein Wort aufgenommen, wie man ein heiliges Vermächtnis aufnimmt. ${ }^{497}$

Im Unterschied zu den Zigarettenalben, die technische Themen aufgreifen wie Aviatik und Automobilismus, stehen hier nicht Erfindergeist und Modernität im Vordergrund, sondern das urwüchsige Deutschtum und der gottesfürchtige Bauer, ${ }^{498}$ der mit „Schwert und Pflug“499 seine Scholle verteidigt.

„Mit Mut und Gottvertrauen wird der ostpreußische, nationalsozialistische Bauer den Samen in die Furchen streuen und seine Scholle pflügen, wie es seine Väter taten. Der Gedanke an den Führer Adolf Hitler wird sie stets innerlich festigen, und ihr Glaube an ihn wird unvergänglich sein.“ ${ }^{400}$

In dem Album KAMPF UM OBERSCHLESIEN der Firma Doms wird die „Blut- und BodenIdeologie ${ }^{\text {“501 }}$ herangezogen, um den historisch gewachsenen Anspruch auf die „Rückeroberung des deutschen Kulturbodens im Osten“502 zu rechtfertigen. Die Propaganda wird damit auf die Zielgruppe der deutschstämmigen Bevölkerung zugeschnitten, um diese für die eigenen politischen Ziele zu gewinnen. Anstelle von Innovation und Technik, mit der das Regime in anderen Zigarettenalben seine Dynamik zum

497 Zigaretten-Industrie (1934): Kampf, S. 68

498 Mit der Hinwendung zum Bauern kommt die Ideologie Walter Darrés, Reichsminister für Ernährung und Landwirtschaft, zum Ausdruck. Er sah im Bauerntum den Lebensquell der arischen Rasse und die Möglichkeit, die Mischrassigkeit der Deutschen zu überwinden. Er wich damit von der biologischen Rassenkunde Hitlers ab. Vgl. „Das Bauerntum als Lebensquell“", 1928, in der Ausg. v. 1940, S. 356f.; 277ff. Zit. nach: Wolnik, Gordon (2004): Mittelalter und NS-Propaganda: Mittelalterbilder in den Print-, Ton- und Bildmedien des Dritten Reiches. Münster: LIT, S. 5

499 Schreckenberg (2003): Ideologie, S. 50

500 Doms (1933): Oberschlesien, Kapitel: Grenzland O-S im Kampf, ohne Bildnummern, unpag.

501 Schreckenberg (2003): Ideologie, S. 72

502 Jahrbuch der Hitlerjugend 1943 (Redaktionsschluss Juni 1942). Zit. nach: Schreckenberg (2003): Ideologie, S. 72 
Ausdruck bringt, wird die nationalsozialistische Politik in dem Sammelband von Doms mit Bauerntum und Bodenständigkeit verknüpft.

„Aber ebenso lehrt die geschichtliche Erfahrung, daß nur dort, wo zu den Errungenschaften der Kultur die urweltliche Kraft des Verbundenseins mit Blut und Boden trat, Dauer und Sieg zu finden sind. “503

Es lag keineswegs in Hitlers Intention, Deutschland zu einem Agrarstaat mit dem Bauern als „Urquell reiner deutscher $\mathrm{Kraft}^{\text {“504 }}$ umzufunktionieren, wie von dem „antimodernistischen“505 Flügel der NSDAP gefordert. Angesichts der Invasionspolitik und der damit verbundenen militärischen Aufrüstung war Hitler bestrebt, Forschung und Technik voranzutreiben. ${ }^{506}$ Bereits vor der Machtübernahme fokussierte die NS-Propaganda aber auch die Landbevölkerung. Die Propaganda konnte so die Bedürfnisse dieser Zielgruppe befriedigen und Anhänger mit dem Versprechen auf weitreichende Förderungen der Agrarwirtschaft für sich gewinnen.507 Aufgrund fehlender Quellen können keine Nachweise für eine nationalsozialistische Gesinnung des Unternehmens Doms erbracht werden. Das offene Bekenntnis zu Hitler und der Verweis auf die langjährige Gesinnungskonformität mit der nationalsozialistischen Politik sowie das Erscheinungsjahr des Albums zu Beginn der Machtergreifung, deuten auf eine hohe Affinität zum NS-Regime hin. Im Text wird auf die Treue und das Vertrauen der Oberschlesier verwiesen, die bereits vor der Machtübernahme erkannt hatten, dass die NSDAP die berechtigten Ansprüche des Volkes verteidigt. Das zweite von Doms publizierte Zigarettenalbum FÜHRER DER DEUTSCHEN WEHRMACHT IM WELTKRIEG 1914-1919 widmet sich dem preußischen Militärwesen. ${ }^{508}$

503 Doms (1933): Oberschlesien, Kapitel: Grenzland O-S im Kampf, ohne Bildnummern, unpag.

504 Voigt H., Johannes (1986): „Die TH Stuttgart während der Zeit des Nationalsozialismus“. In: Stöhr, Martin (Hg.): Von der Verführbarkeit der Naturwissenschaft. Frankfurt/M.: Haag + Herchen, S. 53

505 Die bedeutendsten Vertreter der Agrar-Utopie waren der SS-Führer Heinrich Himmler, Landwirtschaftsminister Walter Darré und NS-Ideologe Alfred Rosenberg. Nach der Machtergreifung wurden die Blut- und Boden-Ideologen von den Technokraten verdrängt. Vgl. Prinz, Michael (1994): „Die totalitäre Seite der Moderne“. In: Ders./ Zitelmann, Rainer (Hg.): Nationalsozialismus und Modernisierung, 2. Aufl., Darmstadt: Wissenschaftliche Buchgesellschaft, S. 18

506 Vgl. Voigt (1986): TH Stuttgart, S. 53

507 Vgl. Bauer (2008): Nationalsozialismus, S. 175

508 Doms (1934): Führer der deutschen Wehrmacht im Weltkrieg 1914 -1918. Ratibor, S. 1 
In dem Album werden imperiale Machthaber der ehemaligen Mittelmächte ${ }^{509}$ der Bildersammlung vorangestellt, was in den Zigarettenalben eine Ausnahme darstellt. Der Rekurs auf ehemalige Monarchien und der damit verbundene Untergang einer alten Weltordnung sowie die Reminiszenz an das preußische Militär zeugen von einer konservativen und monarchistischen Grundhaltung.

Der Sammelband DeR KAMPF UM OBERSCHLESIEN stellt unter den Zigarettenalben mit seiner Fokussierung eines regionalen zeit-politischen Konfliktes eine der wenigen Ausnahmen dar. Obwohl die Quellenlage keine Rückschlüsse auf die Verbreitung der Zigaretten des Unternehmens zulässt, kann bei einer Unternehmensgröße von 700 Mitarbeitern davon ausgegangen werden, dass sich die Distributionskanäle über die Region hinaus erstreckten. Es ist daher nicht auszuschließen, dass die Firma Doms das Zigarettenalbum DER KAMPF UM OBERSCHLESIEN gezielt eingesetzt hat, um Propaganda gegen den Vertrag von Versailles zu machen. Die Thematisierung des oberschlesischen Konfliktes bot Doms und der Bevölkerung, die sich als Opfer einer verfehlten Politik betrachteten, die Möglichkeit, mit dem Sammelband auf ihre Lage aufmerksam zu machen. Das Album wurde zum Sprachrohr für eine Bevölkerung, die sich von je her diskriminiert fühlte und „mißverstandenerweise diffamiert" wurde. Das Album ist daher aufgrund seines Text- und Bildmaterials der politisch motivierten Propaganda zuzuordnen.

509 „Die Herrscher der Mittelmächte im Weltkrieg 1914-1919“ .Wilhelm II, Franz Joseph I., Zar Ferdinand, Mehmed V. Doms (1934): Führer, S. 1. Anm.: Die Angaben sind historisch nicht korrekt, denn die Herrscher verloren bereits 1918 ihre Macht, darüber hinaus herrschte in Österreich ab 1916 Karl I.

Macek, Bernhard A. (2012): Kaiser Karl I.: der letzte Kaiser Österreichs. Erfurt: Sutton, S. 57. Auch der Begriff, Wehrmacht' und die zeitliche Einordnung sind inkorrekt. Das deutsche Heer existierte von 1971 bis 1918 und der Begriff ,Wehrmacht' wurde erst mit dem Wehrgesetz im Jahr 1935 eingeführt. Förster, Jürgen (2007: Die Wehrmacht Im NS-Staat: Eine Strukturgeschichtliche Analyse, Bd. 5. München: Oldenbourg, S. 26 Ebd. 


\subsection{Sturm und die Parteizigarette}

Aufgrund der Marktmacht Reemtsmas und der harten Konkurrenzkämpfe in den 1930er Jahren stellte die Neugründung einer Zigarettenfabrik ein nahezu aussichtsloses Unterfangen dar. Ein Fabrikant riskierte es dennoch, den Hamburger Konzern herauszufordern: Die Dresdner Firma Sturm. ${ }^{511}$ Im Jahr 1929 gründete Arthur Dressler, gemeinsam mit Franz Xaver Schwarz, dem Schatzmeister der NSDAP, die Zigarettenfabrik Sturm. Dressler konnte die Reichszeugmeisterei der SA und die NSDAP überzeugen, das Gründungskapital zu bezuschussen. Das restliche Kapital erhielt er von einem privaten Finanzier und einem jüdischen Bankier. ${ }^{512}$ Zwei Jahre später wurden Mitglieder der SA-Führungsriege, darunter Ernst Röhm, der inzwischen zum "Chef des Stabes der SA“513 avanciert war, zum Kommanditisten des Unternehmens. ${ }^{514}$ Die Firma Sturm hat insgesamt neun Zigarettenalben publiziert:

\section{Zigarettenalben der Firma Sturm}

FLAGGENSPRACHE DER WELT (beteiligt: Aladin) 1934

HINDENBURG (beteiligt: Dressler, Kios) 1933/34

SEEFAHRT TUT NOT (beteiligt: Dressler $\quad$ 1933/34

\section{Uniform-Serie}

ZEITALTER FRIEDRICHS DES GROßEN 1932

DEUTSCHE UNIFORMEN ZEITALTER DEUTSCHER FREIHEITSKRIEGE 1932

ZEITALTER DER DEUTSCHEN EINIGUNG 1864 - 1914, Bd. 1

ZEITALTER DER DEUTSCHEN EINIGUNG 1864 - 1914, Bd. 2

DEUTSCHE UNIFORMEN SA / SS / HJ 1933

VOLK ANS GEWEHR 1934

Vgl. Lindner (2007): Reemtsmas, S. 69

30.000 RM von der SA, den gleichen Betrag vom dem Bankier. Vgl. Ebd., S. $69 f$.

Longerich (1999): Bataillone, S. 109

Vgl. Jacobs (2008): Rauch, S. 115 


\subsubsection{Zigarettenalben der Parteizigarette}

Dresslers Marketingkonzept war ganz auf die SA zugeschnitten. Das SA-Emblem diente als Firmenzeichen und auf Anzeigen und Plakaten war ein SA-Mann abgebildet, der für die Zigarettenmarken warb. Der Firmenname ,Sturm war an das Vokabular der SA angelehnt, die ihren militärischen Gliederungen das Attribut „Sturm“515 voransetzte. Die Zigarettenmarken "Trommler", "Sturm", „Alarm" und „Neue Front“516 transferierten den paramilitärischen, durch Aggressivität geprägten Charakter der SA, die sich als Revolutionsarmee verstand und Gewalt als legitimes Mittel zur Durchsetzung der politischen Ziele betrachtete. Die mit aggressiver Semantik aufgeladenen Produktnamen wurden zum Propagandainstrument der Parteiarmee. Damit erhielt die Marke eine dichotomische Ebene, die dem Produkt einen symbolischen Mehrwert verlieh. ${ }^{517} \mathrm{Da}$ die CI die Identität und das Image einer Marke prägt, trägt sie zu einer „Identifikation der Mitarbeiter und Zielgruppen mit dem Unternehmen" ${ }^{518}$ bei. Der Raucher konnte mit dem Konsum der Sturm-Marken seine politische Gesinnung und die Solidarität mit der SA nach außen kommunizieren.

Zwischen der Sturm- Zigarettenfabrik und der SA entstand eine enge Kooperation. Bereits 1931 engagierten sich Ortsgruppen der NSDAP und die SA im gesamten Reich an Werbekampagnen für Sturm-Zigaretten. Als Gegenleistung wurde die Parteiarmee von Sturm finanziell unterstützt. ${ }^{519}$ Da die SA in die NASDP eingegliedert war und keine Mitgliedsbeiträge erheben konnte, war sie finanziell von der Partei abhängig. Die finanzielle Unterstützung verhalf der SA zu mehr Autarkie und gab Ernst Röhm

515 "Sturmkompanien“, „Sturmbataillone“ und "Sturmregiment". Werner, Andreas (1964): „SA und NSDAP. SA "Wehrverband", Parteitruppe“ oder "Revolutionsarmee“? Studien zur Geschichte der SA und der NSDAP 1920-1933“. Phil. Diss. Erlangen-Nürnberg. Zit. nach: Longerich (1999): Bataillone, S. 34

516 Lindner (2007): Reemtsmas, S. 73

517 Vgl. Torp (2011): Konsum, S. 20. Die symbolische Dimension einer Marke geht über den reinen Produktnutzen hinaus und kann vom Konsumenten auf die eigene Person übertragen werden. Marken können damit eine „Identitätsstiftende Wirkung“ entfalten und zu einem Mittel der Selbstverwirklichung werden. Burmann, Christoph/ Halaszovich, Tilo/ Hemmann, Frank (2012): Identitätsbasierte Markenführung, Wiesbaden: Springer Gabler, S. 2

$518 \quad$ Regenthal (2003): Corporate Identity, S. 77

519 Rösch, Mathias (2002): Die Münchner NSDAP 1925 - 1933. Eine Untersuchung zur inneren Struktur der NSDAP in der Weimarer Republik. München: Oldenbourg, S. 492 
einen größeren Aktionsraum. Pro 1000 verkaufter Zigaretten entrichtete das Unternehmen einen prozentualen Anteil an die Kasse der Parteiarmee. Zusätzlich leistete Sturm auch einen Beitrag an den Stab der SA, der damit seinen kostspieligen Fuhrpark finanzierte. ${ }^{520}$ Angesichts der treuen Konsumentengruppe und sowie des ausgeübten Konsumzwangs auf SA-Mitglieder ${ }^{521}$ konnte Sturm so sein Distributions- und Werbebudget entlasten und der SA beträchtliche Summen zukommen lassen. Schätzungen zufolge summierten sich die Beträge auf insgesamt 250000 RM jährlich. 522

Neben den finanziellen Zuwendungen konnte die SA auch von dem Zugabewesen der Zigaretten profitieren. Sturm warb nicht nur mit Sammelbildern, sondern auch mit Gutscheinen, ${ }^{523}$ die gegen Ausrüstungsmaterial eingetauscht werden konnten. Die SA-Angehörigen konnten aus einem umfangreichen Warenangebot auswählen, das sich von Fahrradwimpeln über BMW-Motorräder bis zur Feldküche erstreckte.524 Angesichts der prekären finanziellen Situation vieler SA-Mitglieder, die für ihre Ausrüstungsgegenstände persönlich aufkommen mussten, ${ }^{525}$ waren diese Gutscheine eine willkommene Unterstützung. Der Konsument wurde daher auf Einlegezetteln angehalten, die leeren Zigarettenschachteln nicht zu entsorgen: „Diese leere Packung bitte nicht wegwerfen! Geben Sie dieselbe einem SA- od. einem SS-Mann. Sie bereiten ihm auch mit der leeren Packung eine Freude u. unterstützen damit die gute Sache!“526

\footnotetext{
$520 \quad$ Vgl. Lindner (2007): Reemtsmas, S. 69ff.

521 Der Konsum von Konzernmarken, insbesondere von Reemtsma, war unter SA-Angehörigen unerwünscht und wurde bestraft. Beim Appell mussten die Taschen geleert und die Zigaretten vorgezeigt werden. Ebd.

522 Vgl. Ebd., S. 132

523 HIS PFR 200,12 Anzeige der Sturm-Zigarettenfabrik

524 Vgl. Ciolina (2003): Reklamebilder, S. 124

525 Die Mitglieder der NSKK und der SA-Motorstürme mussten für Ihre Fahrzeuge und deren Unterhalt selbst aufkommen. Vgl. Hochstetter, Dorothee (2005): Motorisierung und "Volksgemeinschaft". Das Nationalsozialistische Kraftfahrerkorp (NSKK) 1931-1945. München: Oldenbourg , S. 34 
Als mit dem „Gesetz über das Zugabewesen“ vom 12. Mai $1933^{527}$ Zugaben verboten wurden, musste Sturm von der Wertereklame Abstand nehmen und sich auf das Alben-Geschäft zurückziehen. Zeitgleich mit Reemtsma und anderen Zigarettenfirmen schloss sich Sturm dem Boom der Zigarettenbilder an. Die Firma Sturm hat, ebenso wie andere Unternehmen, ein reichhaltiges Repertoire an Zigarettenalben publiziert. Wider Erwarten hat Sturm als Produzent der ,Parteizigarette' kein Sammelalbum herausgebracht, das sich ausschließlich der NS-Bewegung widmet. Auch inhaltlich weisen die Alben kaum propagandistische Inhalte auf, sondern setzen den Fokus auf die deutsche Militärtradition. Lediglich das Album DeUTSCHE UNIFORMEN SA SS HJ ${ }^{528}$ zeugt von der Verbundenheit der SA mit dem Nationalsozialismus. In der Serie von insgesamt sechs Uniform-Alben ${ }^{52}$ wird die Geschichte des deutschen Heeres anhand detailreicher Zeichnungen mit teils szenischen Darstellungen illustriert. Sturm hat damit ein populärwissenschaftliches Sammelwerk geschaffen, das sich der Geschichte des deutschen Militärwesens widmet. Sturm zeichnet dabei eine Kontinuitätslinie von den Ursprüngen des deutschen Heeres im 17. Jahrhundert über die Freiwilligenverbände der Freiheitskriege, den Freikorps zur Zeit der Weimarer Republik bis zur Reichswehr und SA.

Die starke Akzentuierung der deutschen Militärhistorie eröffnet einen Interpretationszugang zu der spezifischen Themenwahl der Sturm-Zigarettenalben. Die aus der

527 Per Gesetz wurde untersagt, „im geschäftlichen Verkehr neben einer Ware oder Leistung eine Zugabe (Ware oder Leistung) anzubieten, anzukündigen oder zu gewähren.“ Henkel (1934): Werbung, S. 67

528 Sturm (1933): SA SS HJ, Dresden (Literaturbearbeitung: Oberführer von Carlshausen, Oberste SA-Führung, München. Bilder: Militärmaler Herbert Knötel, Berlin. Text-Zeichnungen: Kunstmaler Martin Claus, Dresden).

529 Sturm (1932): Zeitalter Friedrichs d. Großen. Dresden (Texte: Militärschriftsteller Dr. Martin Lezius. Bilder: Militärmaler Herbert Knötel, Berlin). Sturm (1932): Deutsche Uniformen Zeitalter deutscher Freiheitskriege, Dresden (Texte: Militärschriftsteller Dr. Martin Lezius. Bilder: Militärmaler Herbert Knötel, Berlin). Sturm (1933): Zeitalter der Deutschen Einigung 1864 1914, Album III, Bd. 1, Dresden (Texte: Militärschriftsteller Dr. Martin Lezius. Bilder: Militärmaler Herbert Knötel, Berlin). Sturm (1933): Zeitalter der Deutschen Einigung 1864 - 1914, Album IV, Bd. 2, Dresden (Texte: Militärschriftsteller Dr. Martin Lezius. Bilder: Militärmaler Herbert Knötel, Berlin). Sturm (1933): SA SS HJ. Sturm (1934): Volk ans Gewehr, AbschlußAlbum des Werkes „Deutsche Uniformen“, Dresden (Bilder: Militärmaler Herbert Knötel, Berlin) 
„Turn- und Sportabteilung“530 hervorgegangene SA war von Beginn an militärisch organisiert. Ab 1921 übernahmen nach einer Vereinbarung mit Hitler ehemalige Weltkriegsoffiziere der Marinebrigade Erhardt die Ausbildung und Finanzierung der Mitglieder. ${ }^{531}$ Mit dem Erstarken der NSDAP als politische Kraft in den Jahren 1929/30 verzeichnete die SA einen massiven Zuwachs und wurde zur schlagkräftigen Parteiarmee. ${ }^{532}$ Die Verbundenheit mit der preußischen Militärtradition ist primär auf die innere Struktur der SA zurückzuführen. Während das Rekrutierungsmuster der unteren Ränge einen hohen Anteil an Jugendlichen aufwies, ${ }^{533}$ setzte sich die Führungsebene maßgeblich aus Kriegsteilnehmern mit bürgerlichem Hintergrund zusammen, wobei die SA-Elite meist auf eine Berufsoffizier und/oder FreikorpsführerKarriere ${ }^{534}$ zurückblicken konnte. Die obere Hierarchieebene sah sich in der Tradition der kaiserlichen Armee mit dem entsprechenden Standesbewusstsein des preußischen Offiziers. ${ }^{535}$ Die „Hochachtung der SA-Führer für die kaiserliche Armee“536 kam

530 Ab 1920 begann sich die nationalsozialistische Sturmabteilung unter der Leitung von Emil Maurice zu konturieren. In den Anfängen war die SA ein Sammelbecken für Mitglieder der bayerischen Einwohnerwehren und der Angehörigen des Freikorps ,Brigade Erhardt'. Vgl. Longerich (1999): Bataillone, S. 22ff. Aus dem, Rollkommando' der NSDAP wurde am 3. August 1921 die "Turn- und Sportabteilung" der NSDAP in eine feste Organisationsform gebracht und am 5. Oktober, in "Sturmabteilung" umbenannt. Grossweiler, Kurt (2012): Kapital, Reichswehr und NSDAP. Köln: PapyRossa, S. 198

531 Vgl. Longerich (1999): Bataillone, S. 24. Longerich vertritt in diesem Zusammenhang die These, dass die Formierung der SA in ihren Anfängen primär auf die völkisch-nationalen Kräfte zurückzuführen ist und weniger auf das Betreiben Hitlers. Vgl. Ebd., S. 24f.

Vgl. Longerich (1999): Bataillone, S. 81. Der Ausbau der SA zur Parteiarmee löste Kontroversen innerhalb der NSDAP aus, die maßgeblich auf Kompetenzstreitigkeiten zwischen der Partei und der SA sowie der prekären Finanzlage der Parteiarmee beruhten. Ferner wurde die permanente Gewaltbereitschaft der SA zu einem Problem für die NSDAP, die sich mit zunehmendem politischem Einfluss den Anstrich von Legalität geben wollte. Vgl. Ebd., S. 149

533 Vgl. Ebd., S. 26 und S. 86

534 Unter den Freikorpsverbänden befanden sich viele ehemalige Offiziere. Viele Freikorpsverbände, darunter Teile der Freikorpseinheiten von Roßbach und Oberland, traten ab 1921 in die SA ein. Die Freikorpsverbände konnten in der Gesamtheit jedoch nicht in die NSDAP eingebunden werden. Vgl. Sprenger (2007): Landsknechte, S. 51 bis S. 57. In Anlehnung an die deutsche Heerestradition nannten sich einige Korps nach den Einheiten der Freiheitskriege, z.B. Freikorps Lützow. Vgl. Koch (2002): Bürgerkrieg, S. 65

535 Vgl. Longerich (1999): Bataillone, S. 144f. Zur oberen Führungsriege wurden Ränge aufwärts vom Standartenführer gezählt. Die Elite war zudem adeliger oder großbürgerlicher Herkunft. Bereits der 1918 gegründete RDO unter dem Vorsitz von General von Epp, dem auch Röhm angehörte, beschwor in seiner Satzung das Standesbewusstsein des deutschen Offiziers. Vgl. Röhm, Ernst (1930): Die Geschichte eines Hochverräters, 2. Aufl. München: Frz. Eher Nachf., S. 110f. 
insbesondere bei Ernst Röhm zum Ausdruck, der sich bei dem organisatorischen Aufbau der SA maßgeblich an den militärischen Vorbildern der Wilhelminischen Ära orientierte..$^{537}$

Die in den Alben skizzierte historische Kontinuität wird von der einheitlichen Gestaltung der Alben und Deckblätter unterstrichen. Die kompetenten Fachkräfte wie der Militärschriftsteller Dr. Martin Lezius und der Militärmaler Herbert Knötel, ${ }^{538}$ die Sturm für ihre Uniform-Serie verpflichtet hatte, sprechen für die Intention des Unternehmens, dem Sammler ein militärhistorisch fundiertes Kompendium des deutschen Heeres und seiner Traditionen zu vermitteln. Die detailreichen Illustrationen werden von umfangreichen Texten begleitet, die den preußischen Militärgeist propagieren. Im Unterschied $\mathrm{zu}$ anderen Zigaretten-Firmen, die eine historische Kontinuitätslinie von bedeutenden deutschen Persönlichkeiten bis zu Hitler ziehen, ${ }^{539}$ zeichnet Sturm im letzten Band eine Genealogie, die sich ausschließlich aus Führungspersönlichkeiten der deutschen Militärgeschichte zusammensetzt. Dazu zählen der Kurfürst Friedrich Wilhelm, dem Begründer des preußischen Heeres und Generaloberst von Seeckt, der Chef der Heeresleitung in den 1920er Jahren. ${ }^{540}$

537 Die SA wurde reichsweit in Obergruppen und Standarten eingeteilt, deren Regimenter die Nummern aus der Kaiserzeit erhielten. Vgl. Fest (2006): Hitler, S. 428

538 Herbert Knötel war Militärmaler und als Berater für Museen, Theater und Film tätig. Für Sturm erstellte er insgesamt 1440 Zeichnungen. Vgl. Hemmann, Thomas (2011): Die Lüneburger Bilderhandschrift aus den Jahren 1807 - 1808 in der Nachzeichnung von Herbert Knötel. Norderstedt: BoD, S. 30f.

539 Die charakteristische Genealogie umfasste Friedrich II., Bismarck, Hindenburg und endete bei Hitler. Beispiel das Album: Brinkmann (1934): Alles für Deutschland, Illustration nach dem Vorwort: „Männer machen Geschichte“, unpag. Diese Genealogie wurde auch in anderen Medien Publiziert, um eine historische Kontinuitätslinie im Bewusstsein der Bevölkerung zu verankern. Vgl. Cilleßen, Wolfgang (2002): „Altäre für das Vaterland“. Der Niederrhein als national-patriotische Denkmallandschaft. Wesel: Selbstverlag des Stadtarchives Wesel, S. 207

540 „Der Ruhmeskranz" von Sturm schließt „acht Führerpersönlichkeiten“ ein: „Friedrich Wilhelm, Der Große Kurfürst, General Scharnhorst, Generalfeldmarschall v. Wrangel, Graf Schlieffen, Generalfeldmarschall von Hindenburg, Admiral Scheer, Oberst v. LettowVorbeck, Generaloberst v. Seeckt". Sturm (1934): Volk ans Gewehr! Abschluß-Album des Werkes „Deutsche Uniformen“. Dresden, unpag. Von Seeckt wird fälschlicherweise als „Begründer und Organisator des neuen deutschen Heeres, unserer Reichswehr" bezeichnet. Von Seeckt war 1919 Chef des Truppenamtes (Tarnname für den laut Versailler Vertrag verbotenen Generalstab) und ab 1920 Chef der Heeresleitung. Von Seeckt stand nicht loyal zur Weimarer Regierung und sympathisierte mit dem Nationalsozialismus. Vgl. Wette, Wolfgang (2008): Militarismus in Deutschland. Geschichte einer kriegerischen Kultur. Darmstadt: Primus, S. $149 f$. 
Im Fokus der Uniform-Serie stehen die Freiwilligenverbände, die im Laufe der deutschen Geschichte im Namen der Freiheit für König und Vaterland ins Feld gezogen sind. ${ }^{541}$ Der heroische Tod der Kämpfer in den Reihen der Freiwilligenverbände während der Befreiungskriege gegen die französische Vorherrschaft in den Jahren 1813-1815 war „integrierter Bestandteil des patriotisch-nationalen Diskurses“, 542 der in den Sturm-Alben belebt wird. Die starke Fokussierung der Freikorps kann auf die Freikorpskarriere vieler SA-Mitglieder ${ }^{543}$ zurückgeführt werden, die sich in der Tradition der Freiheitskämpfer sahen ${ }^{544}$ und den Korpsgeist der historischen Verbände in die SA tragen wollten. Die SA sah sich als legitime Erbin dieser Tradition, ${ }^{545}$ die in der heiligen Pflicht stand, das Vaterland vor dem Weimarer System und den linksgerichteten Kräften zu verteidigen. In dem Sammelband DEUTSCHE UNIFORMEN - ZEITALTER DEUTSCHE FREIHEITSKRIEGE wird eine direkte Verbindung vom Kampf zur „Befreiung Deutschlands vom Franzosenjoch“ im Jahr 1812 bis zum „Versailler Friedensdiktat“546 gezogen. Damit wird ein Bezug zu den zeitpolitischen Ereignissen hergestellt. Mit der historischen Kontinuitätslinie wird ein heldenhaft verklärtes Bild der Freikorpsverbände als Verteidiger der Freiheit gezeichnet.

Die Helden der Freiheitskriege dienten damit der Mobilisierung der Kriegsbereitschaft und der Nationalisierung des deutschen Volkes. ${ }^{547}$ Damit wird eine

541 Die Sturm-Alben knüpfen damit an den Patriotismus der Freiwilligenverbände während der Zeit der Napoleonischen Freiheitskriege von 1813 - 1815 an. Der heroische Tod für König und Vaterland wurde in diesem Kontext verklärt. Vgl. Schulz, Maria (2012): „Für Gott, König und Vaterland. Erinnern und Erzählen für ein Massenpublikum“. In: Carl, Horst/ Planert, Ute (Hg.): Militärische Erinnerungskulturen vom 14. bis zum 19. Jahrhundert: Träger - Medien - Deutungskonkurrenzen. Göttingen: V\&R unipress, S. 314f.

$542 \quad$ Ebd., S. 315

543 Vgl. Bauer (2008): Nationalsozialismus, S. 99

544 Die Freiwilligen von 1813 wurden während der Kaiserzeit integraler Bestandteil deutscher Traditionsstiftung. Die Freiheitshelden wurden insbesondere den Jugendlichen in Massenmedien als Vorbilder präsentiert. Vgl. Schulz (2012): „Für Gott“, S. 322ff. Ranghöhere Weltkriegsoffiziere gingen zu den Freikorps auf Distanz, da sie keine Traditionslinie zwischen dem preußischen Heer und den Freiwilligenverbänden in der Weimarer Republik ziehen konnten. Vgl. Koch (2002): Bürgerkrieg, S. 45

546 Sturm (1932): Freiheitskriege, Zur Einleitung, unpag.

547 Vgl. Hagemann, Karen (1997): „Heldenmütter, Kriegerbräute und Amazonen. Entwürfe „patriotischer" Weiblichkeit zur Zeit der Freiheitskriege". In: Frevert, Ute (Hg.): Militär und Gesellschaft im 19. und 20. Jahrhundert. Stuttgart: Klett-Cotta, S. 175f. 
gesellschaftspolitische Utopie zum Ausdruck gebracht, ${ }^{548}$ die von einer zum Mythos verklärten Vergangenheit genährt wird, aus der das Volk Kraft für den Kampf schöpfen sollte. In dem Sammelband VOLK ANS GEWEHR! wird die Relevanz der militärischen Tradition als ideologische Kraftquelle unterstrichen:

\begin{abstract}
„So wurde ein Werk geschaffen, wie es vielleicht einzig in der vaterländischen Literatur dasteht. Jung und alt finden in ihm Anregung, es ist ein geistiges Rüstzeug für den Kampf um Deutschlands innere Erneuerung. „Ein Volk, das seine Vergangenheit haben will, verdient auch seine Zukunft", durch die Pflege ihrer Tradition sind wir aber in der Lage, auch die schweren Gegenwartsaufgaben, die uns noch bevorstehen, zu meistern." ${ }^{459}$
\end{abstract}

Mit der starken Fokussierung auf die Freiheitskämpfer wollte die SturmZigarettenfabrik mit ihren Uniform-Alben „dem deutschen Volke“ aber vor allem den "[uns] alten Soldaten und der heranwachsenden Jugend“ das „Große und Heldische der deutschen Geschichte “550 bewahren. In den Begleittexten werden soldatische Tugenden der preußischen Armee wie Opferbereitschaft, Gehorsam, Kameradschaft und Pflichterfüllung an die Rezipienten weitergegeben.

\begin{abstract}
„Seine Vorgesetzten, die für ihn sorgen, ihm mit gutem Beispiel vorangehen, ihn ermahnen, ihn liebevoll, mit Achtung und gerecht behandeln, muß er verehren und hoch schätzen und seine Kameraden lieben lernen [...] Er muß zu dem Vollgefühl sich erheben, daß der preußische Soldat der geborene und berufene Verteidiger seiner Fahne ist [... und] am Tage der Schlacht "seinen Feldherren begeistert fragen wird: „Herr, wo befiehlst du, daß wir sterben sollen?““ ${ }^{\prime \prime 51}$
\end{abstract}

\footnotetext{
548 Reichhardt weist auf den revolutionären Idealismus hin, der sich gegen die moderne Gesellschaft wandte, da diese Utopie auf Destruktion ausgerichtet war. Vgl. Reichhardt (2009): Kampfbünde, S. 34f.

549 Sturm (1934): Volk ans Gewehr! Einleitungstext: „Volk ans Gewehr“", unpag.

550 Sturm (1932): Zeitalter Friedrichs d. Großen (Texte: Militärschriftsteller Dr. Martin Lezius. Bilder: Militärmaler Herbert Knötel, Berlin). Dresden, Zum Geleit, unpag.

551 Sturm (1933): Zeitalter der Deutschen Einigung 1864 - 1914, Album III, Bd. 1 (Texte: Militärschriftsteller Dr. Martin Lezius. Bilder: Militärmaler Herbert Knötel, Berlin). Dresden, Zur Einführung, unpag.
} 
„Die Liebe zu König und Vaterland, deren Keim in jeder Soldatenbrust schlummert, muss erweckt und bei jeder Gelegenheit genährt werden. Sein erhabener Beruf [...] seine Ehre als preußischer Soldat [...] kann ihm nicht oft genug vorgehalten werden. ${ }^{\text {552 }}$

Mit dem zum Mythos überhöhten Opfertod der Angehörigen der historischen Freikorpsverbände wird eine symbolische Verbindung von Tod und Erneuerung“553 beschworen, der dem Faschismus inhärent war. Der Opfergedanke wurde von der SA adaptiert, denn sie sah sich in der Pflicht, den Tod der Soldaten und Freikorpskämpfer zu legitimieren, die andernfalls auf den „Schlachtfeldern des Weltkrieges umsonst gefallen“554 wären. Das preußische Militärwesen und die historischen Freikorpsverbände werden in den Uniform-Alben mit dem Geist von Gemeinschaft und Fürsorge verknüpft. In den Alben wird preußischen Generälen wie „Seidlitz" und „Zieten" sowie anderen hohen Militärs aufgrund ihrer vorbildlichen Fürsorge gegenüber den ihnen anvertrauten Soldaten Respekt gezollt. Die väterlichen Attribute wie „Papa“ Blücher oder „Soldatenvater“555 York implizieren eine patrimoniale Sorge der Offiziere gegenüber den einfachen Mannschaften. Auch hier zeichnet die Firma Sturm in ihren Alben die SA als Organisation, die sich diesen Tugenden verpflichtet fühlt. ${ }^{556}$ Damit bringt Sturm das Bedürfnis vieler SA-Angehöriger nach einem sozialpsychologischen Rückhalt zum Ausdruck, den sie in der Parteiarmee zu finden glaubten. Neben der sozialen Fürsorge durch ein „Netz von Unterstützungseinrichtungen",557 die die spärlichen staatlichen Zuwendungen kompensierten, bot die SA

552 Zitat: Friedrich Karl, Neffe Wilhelms des I., König von Preußen. Ebd.

553 Reichhardt (2009): Kampfbünde, S. 35

$554 \quad$ Bley (1934): SA, S. 14

555 Sturm (1932): Freiheitskriege, Einleitungstext, unpag.

556 Die Überwindung sozialer Schranken charakterisiert einen Anspruch, der von der OSAF als einziger Kontrapunkt zur kaiserlichen Armee postuliert wurde. Die einzige Kritik der SA-Führung an der kaiserlichen Armee waren die starren Hierarchien sowie die sozialen Unterschiede und der daraus resultierende Kadavergehorsam. Vgl. Reichhardt (2009): Kampfbünde, S. 573

557 Longerich (1999): Bataillone, S. 89. Zur Proletarisierung weiter Teile der Bevölkerung vgl. Fest (2006): Hitler, S. 157. Einen besonderen Stellenwert besaßen die „Sturmlokale“ der SA, die als „Sammelpunkte des kameradschaftlichen Lebens“ dienten. Bley (1934): SA , S. 97 
für eine Generation, für die „in den Materialschlachten des Weltkrieges [...] die bürgerliche Welt innerlich zusammengebrochen“558 war psychologischen Halt innerhalb einer kameradschaftlichen Gesinnungsgemeinschaft. Für viele junge SA-Männer, die aufgrund der Wirtschaftskrise keine Zukunftsperspektive sahen und massiv von sozialem Abstieg und Verelendung bedroht waren, besaß die Parteiarmee daher eine hohe Anziehungskraft. ${ }^{59}$ Sowohl die Fürsorgemaßnahmen als auch die permanenten Auseinandersetzungen bei Propagandaaktionen stärkten das Zusammengehörigkeitsgefühl und wurden zu einem vitalen Integrationsfaktor ${ }^{560}$ (Abb. 4).

In dem fünften Album der Uniform-Serie DEUTSCHE UNIFORMEN SA SS HJ wird die von den SA-Führern beschworene Hilfsbereitschaft gegenüber den Kameraden hervorgehoben, die in einer klassenlosen Schicksalsgemeinschaft auch das letzte Brot und die letzte Zigarette miteinander teilen. ${ }^{561}$ Die SA wird in den Zigarettenalben als Organisation dargestellt, die sich jenseits sozialer Hierarchien zu einer Gesinnungsgemeinschaft zusammengeschlossen hat, die im blinden Gehorsam an ihre Führer, ${ }^{562}$ getragen von Idealismus und ohne entsprechende Besoldung, für ihre Ideale kämpft hat. Damit werden in den Sammelalben die zentralen Elemente faschistischer Bewegungskul-

Ebd., S. 20. Die Kampfverbände boten den Mitgliedern in einer Zeit persönlicher, politischer und sozialer Desorientierung eine kollektive Sinnstiftung, einen strukturierten Alltag und das Versprechen auf politische Umwälzungen. Sprenger (2007): Landsknechte, S. 87 In dem Zigarettenalbum Rekrut Peter Müller wird der Werdegang eines SA-Mannes vom arbeitslosen und gesellschaftlichen Außenseiter zum Mitglied des NSKK beschrieben. Vgl. Aviatik (1937): Rekrut Peter Müller. Heiteres und Ernstes aus dem Soldatenleben (Idee, Dichtung und Entwürfe Franz Barth). Breslau

560 Vgl. Longerich (1999): Bataillone, S. 115

561 Sturm (1933): SA SS HJ, Textseite 5ff. Der Zusammenhalt der einfachen SA-Mitglieder war unterschiedlich motiviert und kann nicht vollständig geklärt werden. Neben den bescheidenen sozialen Zuwendungen und dem psychologischen Moment der Zuwendung innerhalb einer Gemeinschaft kann das bürgerkriegsähnliche Umfeld das Zusammengehörigkeitsgefühl gefestigt haben. Auch die bandenähnliche Mentalität der Kleingruppen und ihre enge Bindung an die Kleingruppenführer haben den Zusammenhalt gestärkt. Vgl. Longerich (1999): Bataillone, S. 137

562 Die starke Bindung an den Vorgesetzten korrespondiert mit dem Treueverständnis der Freikorpseinheiten, die ihrem Führer mehr Loyalität entgegenbrachten als der Regierung oder der OHL. Vgl. Koch (2002): Bürgerkrieg, S. 46. Die SA weist vergleichbare Strukturen auf. Die Loyalität einzelner Gruppierungen zu ihrem Vorgesetzten war größer als zu der SA als Gesamtorganisation. Vgl. Longerich (1999): Bataillone, S. 137 
tur $^{563}$ vermittelt. Das in den Sturm-Alben skizzierte Bild der väterlichen Beziehung zwischen dem einfachen SA-Mann und der Führungsriege steht im Widerspruch zu den realen Gegebenheiten, denn die Struktur der SA war von eklatanten Gegensätze zwischen der Obersten SA-Führung (OSAF) und den unteren Rängen geprägt. Die Heterogenität dieser Schichten provozierte permanenten Unmut, der weitreichende Konflikte heraufbeschwor. ${ }^{564}$

In den Sturm-Alben wird die SA im Gefüge der nationalsozialistischen Gruppierungen jedoch als klassenlose Gemeinschaft und vitale Kraft präsentiert, die unter Entbehrungen und unter dem Einsatz ihres Lebens gegen die Feinde des Volkes angetreten ist, um ein neues Deutschland zu schaffen. Die Alben reflektieren damit das Selbstverständnis der Parteiarmee, denn die SA betrachtete sich als „Repräsentantin des jungen Deutschland“. .55

\begin{abstract}
„Als Neubegründer der Liebe zur deutschen Scholle, des unbändigen Willens zur Freiheit, trat der Gewonnene dem alten als neuer Kämpfer zur Seite. Alle Schichten der Bevölkerung, ohne Unterschied der Kaste, des Ranges, des Bildungsgrades, strömten zusammen in der Erkenntnis der hehren Aufgabe, ein einiges, gesundes Deutschland zu schaffen. Viele Tote und Verwundete blieben auf dem Wege des Kampfes. ${ }^{\text {"566 }}$
\end{abstract}

„Die SA als Kämpferin und Rückgrat der Bewegung, als politische Soldaten des Führers, denen die erreichte Größe zu verdanken war und die mit Einsatz von Leben und Freiheit ihr Recht erstritten hatte, war nicht aus der Welt zu schaffen. [...] Nach wohldurchdachten Plänen des Führers wurde von dem mächtigen Arm der SA alle Arbeit für die Wahlschlachten geleistet. [...] An dieser Stelle muß des unbekannten SA-Mannes gedacht werden. Er ist es, der ohne Verlangen nach Ruhm und Anerkennung still und freudig seine Arbeit getan. ${ }^{\prime \prime}{ }^{67}$

563 Faschistische Bewegungen kennzeichnet im Wesentlichen eine geschlossene Gesinnungsgemeinschaft von schwach strukturierten Gruppen innerhalb einer stark strukturierten Organisation. Weitere Charakteristika sind radikale systemoppositionelle Haltungen sowie Loyalität der Anhänger, die primär auf Freiwilligkeit und nicht auf materielle Gratifikation beruht. Vgl. Reichhardt (2009): Kampfbünde, S. 32f.

564 Vgl. Longerich (1999): Bataillone, S. 144ff.

565 Reichhardt (2009): Kampfbünde, S. 574

566 Sturm (1933): SA SS HJ, Textseite 4

567 Ebd., Textseite 6 
Die in den Alben beschworene Gemeinschaft und Kameradschaft findet ihren symbolischen Ausdruck in den abgebildeten Orden, Abzeichen und Uniformen. Diese Symbole besaßen als „Unterscheidungs- und Zugehörigkeitszeichen“ eine zentrale Bedeutung „für die Kenntnis der Gruppenidentität“. ${ }^{568}$ Die NS-Parteiuniformen- und Abzeichen zeichneten sich durch sehr differenzierte Merkmale aus und führten beinahe zu einem regelrechten „Abzeichenfimmel“. ${ }^{569}$ Die Abzeichen ermöglichten über die Erkennung des Dienstgrades und der Abteilung hinaus eine Bestimmung der regionalen Zugehörigkeit ${ }^{570}$ (Abb. 5). Das Zeichensystem ermöglichte den Mitgliedern damit, sich einer Gruppe zuzuordnen, was das Zusammengehörigkeits- und Identitätsgefühl stärkte. ${ }^{571}$

Die Zigarettenalben der Firma Sturm weisen trotz der Nähe zum NS-Regime keine stereotype NS-Propaganda auf, wie sie in den Sammelbänden anderer Unternehmen zu finden ist. Die Distanz der Sturm-Zigarettenfabrik zu propagandistischen und parteikonformen Themen hat realpolitische Hintergründe. Seit der Eingliederung der SA als Parteiarmee in die NSDAP kam es zu diversen Konflikten, die sich zwischen 1932 und 1934 zuspitzten. Die SA war unter Ernst Röhm zu einem beutenden Machtfaktor angewachsen. Röhm hatte den Anspruch, die Parteiarmee als einzige militärische Organisation im neuen Staat zu etablieren. ${ }^{572}$ Röhms Ambitionen provozierten einen Konflikt mit Hitler und dessen Gefolgsleuten, die ihre eigene Position bedroht sahen. ${ }^{573}$ Der selbstbewusste Chef des Stabes forderte für seine „alten Kämpfer“ und für sich „die entscheidende Stimme. “574 Gleichzeitig wollte Röhm sein Massenheer zu einer „Zweiten Revolution“575 rüsten. Darüber hinaus hegte Röhm eine offene Aversi-

\footnotetext{
568 Schreckenberg (2003): Ideologie, S. 100

569 Reichhardt (2009): Kampfbünde, S. 579

570 Die Bilder in dem Uniform-Album SA SS HJ beschreiben die Abzeichen, die eine detaillierte Auskunft über Rang, Gebiet, Bann, Schar und Kameradschaft geben. Sturm (1933): SA SS HJ. Neben den äußeren Kennzeichen stärkten Rituale, Lieder und Mythen den Zusammenhalt und ließen eine regelrechte "Subkultur" entstehen. Longerich (1999): Bataillone, S. 116

571 Vgl. Sontag, Susan (2003): Im Zeichen des Saturn, 3. Aufl. Frankfurt./M.: S. Fischer, S. 120

572 Vgl. Longerich (1999): Bataillone, S. 209

573 Hitler beabsichtigte bereits im Februar 1933, die SA zu entwaffnen und um zwei Drittel zu reduzieren. Vgl. Fest (2006): Hitler, S. 650

574 Röhm (1930): Hochverräter, S. 319

575 Fest (2006): Hitler, S. 645
} 
on gegen die opportunistischen „Hakenkreuz-Biedermänner", ${ }^{576}$ deren vitales Interesse darin bestand, ihre Pfründe zu sichern. Das Bekenntnis zu Hitler korrespondiert mit der öffentlichen 'Führertreue' der SA und ihres Stabschefs. Die nach außen beschworene Loyalität wurde angesichts der Differenzen zu einer Phrase. Der Unmut über die Parvenüs und Profiteure des Systems provozierte Differenzen, die in den Sturm-Alben zum Ausdruck gebracht werden:

\begin{abstract}
„Wegen angeblicher Vergehen als Kleber von Plakaten, Verteiler von genehmigten Flugschriften verhaftet, oder als widersetzlich mit dem Gummiknüppel niedergehauen, büßte er oft mit Hingabe seine Freiheit oder erlitt an seiner Gesundheit nie wieder gutzumachenden Schaden. Nicht um eines Lohnes Willen, heute nach zehn Jahren des Kampfes noch immer einfacher SA-Mann, auch im Dritten Reiche abseits von Postenjägern stehend, war er es, auf dessen Schultern die Bewegung zur Macht getragen wurde. [...] Nun endlich war ihr Führer an der Stelle, die ihm gebührte, nun endlich hatte die SA eine große entscheidende Etappe erkämpft und hatte eine Wendung in der deutschen Geschichte hervorgerufen. Denn ohne SA wäre der gewaltige Sieg nicht zu denken. ${ }^{4577}$
\end{abstract}

Das Album DeUTSche Uniformen SA SS HJ betont zwar die Treue zu Hitler, verweist aber gleichzeitig auf die tragende Rolle der SA, die während der Kampfzeit Hitler und dem Nationalsozialismus den Weg zur Macht geebnet hat. ${ }^{578}$

„Mancher der braunen Kämpfer sollte seinen Führer nicht wiedersehen, da ihm das Schicksal für seine Überzeugung und Treue zum Führer den Heldentod bestimmt hatte. [...] Die nationalsozialistische Idee, getragen von der SA, konnte nur unter dem Schutze dieser Organisation bestehen. ${ }^{579}$

Das Album artikuliert damit einen Anspruch auf Anerkennung, der insbesondere von Ernst Röhm eingefordert wurde. Sein Ziel war es, dem deutschen Frontkämpfer die ihm zustehende Partizipation an der Macht zu erkämpfen und ihm auf politischen Parkett eine Stimme zu verleihen. ${ }^{580}$ Die Uniform-Alben der Firma Sturm verbreiteten

\footnotetext{
576 Marohn, Norbert (2011): Röhm. Ein deutsches Leben. Leipzig: Lychatz, S. 223

577 Sturm (1933): SA SS HJ, Textseite 7

578 Aus der Perspektive der SA hatte die Forderung nach Partizipation an der Macht ihre Berechtigung, denn die Parteiarmee hatte bis 1933 die Propaganda getragen. Vgl. Bussemer (2000): Populärkultur, S. 16

579 Sturm (1933): SA SS HJ, S. 4f.

580 Reichhardt (2009): Kampfbünde, S. 571
} 
damit eine politische Propaganda, die mit der Idee des Nationalsozialismus konform ging, aber eine Divergenz zur Parteilinie aufwies. Diese Haltung reflektiert die zeitgenössischen Differenzen zwischen der SA und der offiziellen Parteilinie. Sturm stellt die Zigarettenalben ganz in den Dienst der SA und geht mit der Öffentlichkeitsarbeit von Ernst Röhm konform, der sich nach der Machtergreifung mit der Publicity in eigener Sache gekonnt ins rechte Licht und Hitler in den Schatten stellte. ${ }^{581}$ Die für die NS-Alben anderer Unternehmen charakteristische Huldigung und Verehrung Hitlers findet in den Sturm-Alben nicht statt. Anstelle der devoten Ehrerbietung gegenüber dem Führer zollt Hitler im 5. Band der Uniform-Reihe der Parteiarmee Dank und Respekt:

\section{„Adolf Hitler an seine SA und SS am 9. April 1933 \\ [...] Und für diese lange Zeit, meine Kameraden, möchte ich euch (sic!) heute dafür danken, daß Ihr so treu und so brav hinter mir geblieben seid. Euch sei Dank dafür, daß Ihr nicht wankend geworden seid, daß Ihr mich in der Zeit nicht allein gelassen habt. Wenn Ihr damals gegangen wäret, niemals wäre Deutschland gerettet worden. Ihr habt das Recht, Euch durch Euren Mut und Eure Treue Beharrlichkeit als des Volkes und Vaterlandes Retter zu fühlen. " 582}

Der letzte Band der Uniform-Serie VOLK ANS GEWEHR, schließt mit dem Bekenntnis, dass die SA als bedeutende Organisation den politischen Kampf weiter führen wird. Der imperative Titel, der während der NS-Zeit die Jugend propagandistisch auf einen Krieg vorbereiten sollte, impliziert bereits eine Aufforderung zum Kampf. Der Text des Albums kongruiert mit dem politischen und ideologischen Selbstverständnis Röhms, der den politischen Kampf auf innenpolitischem Terrain weiterführen wollte.

„Die SA fühlt genau, daß ihre Arbeit noch nicht zu Ende ist, wenn auch der erste Abschnitt ihrer, weit über ein Jahrzehnt gehende Arbeit, zunächst erreicht ist. Die gebrachten Opfer weitgehender beispielgebender Selbstlosigkeit, die Verwundeten und Toten waren nicht umsonst. Sie sind nicht der Partei wegen gebracht, sondern für ein einheitliches freies Deutschland, in

\footnotetext{
581 Röhm startete 1933 eine Propaganda-Kampagne in eigener Sache und versuchte, den „Führer-Glauben“ auf die sich zu übertragen. Longerich (1999): Bataillone, S. 201 
welchem alle Stände ohne Unterschied ihrer Herkunft, Ihres Wissens und Könnens zusammenstehen gegen jeden Feind, der es wagen sollte, aufzustehen. ${ }^{\text {"583 }}$

„Die stolze Garde der SA ist Führerin der deutschen Jugend, um sie für den politischen Kampf zu stählen und zu erhalten. Sie ist und bleibt auch in der Entwicklung der Partei führend.“584

„Im Anfang war die SA. Sie hat das geschaffen, was sie schaffen wollte und getreu dem Befehle des Führers schaffen mußte. Sie hält an ihrer Aufgabe fest, daß zu sein, was ihre weitere Aufgabe ist: Erhalter und Wahrer der Revolution. Aus ihrem Willen wächst die ständige unversiegbare Kraft, zum Schluß wird die SA sein. ${ }^{\prime \prime}{ }^{85}$

Vor diesem Hintergrund war die von Sturm verbreitete politische Propaganda ein brisanter Multiplikator von Röhms umstürzlerischen Gedankengutes. Getragen von dem Bewusstsein, die militärische Macht in dem neuen Staate innezuhaben sowie der Führungsanspruch von Ernst Röhm, machte die SA zu einer latenten Bedrohung für die NS-Regierung. 586

\subsubsection{Auswirkungen des Röhm-Putsches auf die Sturm-Alben}

Die zunehmende Militarisierung der SA, das Kompetenzgerangel mit der NSDAP und die Differenzen mit der erstarkten SS sowie der von Röhm forcierte Kult um seine Person veranlassten Hitler, den lange vorbereiteten Schlag gegen die SA durchzuführen. Unter dem Vorwand eines von Röhm geplanten Putschversuches, wurden Röhm und Mitglieder der OSAF am 30. Juni 1934 verhaftet und liquidiert. ${ }^{587}$ Mit der Eliminierung Röhms verlor auch Dressler seine Protektion und der Konsumzwang der Sturm-Zigaretten für die SA-Angehörigen wurde aufgehoben. Der daraufhin

\footnotetext{
583 Ebd., Textseite 6

$584 \quad$ Sturm (1934): Volk ans Gewehr, Textseite 78

585 Ebd., Textseite 79

586 Das diktatorische NS-System hatte sich trotz Okkupation der Schaltstellen der Macht noch nicht ausreichend konsolidiert. In vielen Bevölkerungsteilen machte sich aufgrund der wirtschaftlichen Instabilität und Arbeitslosigkeit Unzufriedenheit breit. Die Parteiarmee wurde zum Herd potentieller Gefahr, denn viele hofften angesichts der rigiden Parteidiktatur, die oppositionelle Haltung der SA könnte der neuen Regierung etwas entgegensetzen. Vgl. Longerich (1999): Bataillone, S. 206ff. 
einsetzende dramatische Umsatzrückgang zwang Dressler, sein Unternehmen zu liquidieren. Da ein Teil des Umsatzes in die Kasse der SA geflossen war, verlor die Parteiarmee einen verlässlichen Finanzier. Mit dem Konkurs des Unternehmens kam der SA auch das Zigarettenalbum abhanden. Die SA verlor damit ein Medium, mit dem sie die revolutionären Elemente ihrer Bewegungskultur und die oppositionelle Haltung gegenüber der Partei verbreitet hatte.

Die Liquidation der SA-Führungsriege hatte nachhaltige Konsequenzen für Zigarettenfirmen, die NS-Alben publizierten. Ernst Röhm, der in vielen Sammelbänden erwähnt wurde und zu den "treuen Soldaten Adolf Hitlers“588 gezählt wurde, war über Nacht zur Unperson degradiert worden. Das Bild musste daher umgehend revidiert werden. Insbesondere für den Reemtsma-Konzern bestand Handlungsbedarf. Das Verhältnis zum NS-Regime war 1934 mehr als angespannt. Reemtsma wollte daher keinen Unmut seitens des Propaganda-Ministeriums heraufzubeschwören. Die Aktion gegen die SA löste bei Reemtsma hektische Betriebsamkeit aus, denn das Unternehmen hatte drei NS-Alben im Handel, die mit Bildern von Ernst Röhm bestückt waren. Die Publikation der Bilder musste aufgrund der veränderten politischen Lage umgehend unterbunden, respektive verhindert werden.

Die Reemtsma-Geschäftsleitung sah sich bereits am 2. Juli, drei Tage nach dem Sturz Röhms, gezwungen, die Außendienstmitarbeiter sowie die am Bilderdienst beteiligten Unternehmen über die erforderlichen strategischen Maßnahmen in Kenntnis zu setzen. Die Brisanz der Situation kommt in der Korrespondenz zum Ausdruck, in der der Sachverhalt vorsichtig umschrieben und die Problematik der Röhm-Bilder nur indirekt angesprochen wird:

„Rundschreiben No. 43

[...] aufgrund der jüngsten politischen Ereignisse, die Ihnen durch die Presse bekannt geworden sind, könnte Ihnen die Frage vorgelegt werden, ob wir die Serie „Kampf ums dritte Reich“ (soweit im Tauschwege noch diese Bilder 
verlangt werden) und die z.Zt. zur Ausgabe gelangenden Serien „Der Staat der Arbeit und des Friedens" und „Deutschland erwacht" weiter ausgeben. [...] Selbstverständlich werden wir diejenigen Bilder, deren Wiedergabe auf Grund der jüngsten Ereignisse nicht mehr in Frage kommen kann, durch neue Bilder ersetzen, die dem Propaganda-Ministerium in den nächsten Tagen zur Genehmigung vorgelegt werden. ${ }^{589}$

Gleichlautend an:

Josseti G.m.b.H., Berlin, Jasmatzi G.m.b.H., Dresden, Bulgaria G.m.b.H., Dresden, Yenidze G.m.b.H., Dresden.

[...] Zu Ihrer persönlichen Orientierung sei bemerkt, dass die Ausgabe der Bilder „Der Staat der Arbeit und des Friedens" naturgemäß keinen Schwierigkeiten unterworfen ist, weil wir die auszusortierenden Bilder einfach zurückhalten können. Bei Ausgabe der Serien Werk VIII auf Bilderschecks wird eine Verzögerung von wenigen Tagen unvermeidlich sein. Diese Verzögerung wollen wir aber nicht bekanntgeben, damit keine Unruhe im Einkauf der Händler und beim Konsumenten entsteht. [...] Wir bitten Sie, sich gegenüber zu erwartenden Versuchen der Konkurrenz eindeutig und klar auf den Standpunkt zu stellen, den das anliegende Rundschreiben No. 43 darstellt [... “4590

„[...] 1.) Die Unterbrechung in der Auslieferung des Albums: „Kampf ums Dritte Reich" wird mit sofortiger Wirkung aufgehoben. Eine Neuauflage dieses Werkes erfolgt nicht mehr, die Auslieferungsmöglichkeiten sind deshalb auf die vorhandenen begrenzt. [...]

2.) Sämtliche bei Ihnen lagernden Alben: „Der Staat der Arbeit und des Friedens" sind u n v e r z ü g 1 i c h, sorgfältig verpackt, an die Lieferantin, die Firma Gundlach, zurückzusenden [...]

3.) Die Sperre in der Auslieferung des Werkes: „Deutschland erwacht“ wird aufgehoben. “591

Die Verbreitung der Röhm-Bilder konnte nicht völlig verhindert werden, zumal sich zwei Alben bereits im Handel befanden. Das Album KAMPF UM's DRITTE REICH beinhaltet neben Bildern auch einen kurzen Textbeitrag über Röhm. In dem Abschnitt

589 HIS PFR 491,01 Reemtsma-Geschäftsleitung, Rundschreiben No. 43 an Außendienstmitarbeiter, 2. Juli 1934

590 HIS PFR 491,01 Reemtsma-Geschäftsleitung an die Unternehmen, die am Vertrieb der Bilder des Albums Der Staat der Arbeit und des Friedens beteiligt waren, 2. Juli 1934

591 HIS PFR 491,01 Reemtsma-Geschäftsleitung an die Leitung aller Frischdienst-Filialen, 7. Juli 1934 
wird der Stabschef der SA als "Träger altdeutschen Soldatengeistes", 592 beschrieben, der das Vertrauen des Führers nie enttäuscht hat. Bei dem Album DeUTSCHLAND ERWACHT war der zeitliche Aktionsradius derart begrenzt, dass lediglich die Bilder ausgetauscht werden konnten. Daher musste der Sammler in der Auflage von 200.000 bis $776.000^{593}$ das Konterfei des neuen ,Chef des Stabes` Viktor Lutze über die Bildunterschrift „Stabschef Ernst Röhm“594 kleben (Abb. 6). Erst in der dritten Auflage konnte eine Übereinstimmung von Text und Bild hergestellt werden. ${ }^{595}$ Bei dem Album DER STAAT DER ARBEIT UND DES FRIEDENS gelang es Reemtsma entgegen des Schreibens vom 2. Juli 1934 nicht, die Bilder rechtzeitig zurückzuziehen. Ein Album wurde von einem akribischen Sammler eigenständig editiert. Am Ende des Albums wurden die von Reemtsma aussortierten Bilder von Ernst Röhm auf separate Papierbögen geklebt. Die Bildlegenden wurden handschriftlich hinzugefügt „Stabschef Erst Röhm“596 (Abb. 7). Die Eigeninitiative des Bildersammlers indiziert, dass zumindest Teile der Bevölkerung das Manöver von Reemtsma durchschaut, respektive der Liquidierung Röhms und Teilen der OSAF ablehnend gegenüberstanden. Ein eindeutiger Nachweis dafür kann anhand des Quellenmaterials jedoch nicht erbracht werden.

\subsection{Propaganda-Alben des linken Lagers}

Der Synergieeffekt von politischer Propaganda und Verkaufsförderung wurde nicht nur von Firmen des rechten politischen Spektrums genutzt, sondern auch von Unternehmen, die dem kommunistischen Lager nahe standen. In Relation zu den Alben, die völkisch-nationales oder nationalsozialistisches Gedankengut propagierten, fällt die Anzahl von insgesamt fünf Publikationen mit linksgerichteten Ideologien gering aus.

\footnotetext{
$592 \quad$ Zigaretten-Industrie (1934): Kampf, S. 54

593 Köberich (2003): Sammelbilder

594 Aller Bemühungen zum Trotz, den politischen Ereignissen Rechnung zu tragen, wurde ein Bild in dem Album Deutschland erwacht (Röhmausgabe) aufgrund des Aktionismus seitens Reemtsmas übersehen. Über der Bildunterschrift „Der Führer und sein Stabschef“ sind Hitler und Röhm in einem Bild vereint. Reemtsma (1933): Deutschland erwacht (Röhm-Ausgabe), S. 52

595 Die 3. Auflage des Albums Deutschland erwacht begann mit 776.000. Köberich (2003): Sammelbilder

596 Zigaretten-Industrie (1934): Der Staat der Arbeit und des Friedens. o.O. Album aus der Sammlung Köberich, Goethe-Universität Frankfurt/M., Historische Fakultät.
} 
Die überschaubare Anzahl der Alben lässt sich auf die Verbote zurückführen, die 1933 von der NSDAP gegen andere Parteien und nicht regimekonforme Publikationen erlassen wurden. ${ }^{597}$ So wurden auch die Alben des linken Lagers nach der Machtübernahme verboten. ${ }^{598}$

\section{Zigarettenalben des linken politischen Lagers}

Eifro - Eiserne Front

DIE VORKÄMPFER DES SOZIALISMUS

POLITISCHE FÜHRER

\section{Solidarität}

\section{AUS DER GESCHICHTE DER REVOLUTION}

KÖPFE AUS DER ARBEITERBEWEGUNG

\section{Osten}

QUERSCHNITT VOM AUFBAU DER SOWJET-UNION

Nach der minderwertigen Bild- und Verarbeitungsqualität der Alben und der geringen Anzahl an Bildern zu urteilen, handelt es sich bei diesen Firmen um kleine Unternehmen, die trotz mangelnder finanzieller Ressourcen das Medium Zigarettenalbum für propagandistische Zwecke eingesetzt haben. In den Propaganda-Alben mit linksrevolutionärer Ideologie wird eine Kontinuitätslinie von den Bauernkriegen über die Französische Revolution bis zur Pariser Kommune hergestellt, mit dem Ziel, dem Rezipienten ein historisches Bewusstsein für eine sozialistische Staatsform zu vermitteln.

597 Die kommunistische Partei war faktisch bereits nach dem Reichstagsbrand ausgeschaltet. Das offizielle Parteiverbot erging am 31. März 1933. Gewerkschaften wurden im Mai 1933 zerschlagen. Andere Parteien wurden im Laufe des Jahres aufgrund der Befugnis des Ermächtigungsgesetzes aufgelöst. Bauer (2008): Nationalsozialismus, S. 211 - 214. Goebbels hatte bereits Ende Februar 193360 kommunistische und 71 sozialdemokratische Zeitungen verboten. Vgl. Kollmann, Michaela (2006): Schulbücher im Nationalsozialismus. Saarbrücken: VDM, S. 117 
„In unseren Tagen erwacht in der Masse der gesamten Bevölkerung ein brennendes Interesse für das Studium der Geschichte. [...] Revolutionen sind Marksteine der Geschichte, an denen das bisherige Gleichgewicht der miteinander ringenden Klassenkräfte endgültig gestört ist und in offener Schlacht ein neues Verhältnis zwischen den sozialen Kräften eines Volkes hergestellt wird. Weil eben in Revolutionen Größe und Richtung der sozialen Kräfte am deutlichsten zum Ausdruck kommen, gibt das Studium der Revolutionen am besten Aufschluß über jene Gesetze, die Vergangenheit, Gegenwart und Zukunft des sozialen Aufbaues der menschlichen Gesellschaft bestimmen. "599

Die Titel der Alben DIE VORKÄMPfER DES SOZIALISMUS, KÖPfE AUS DER Arbeiterbewegung und Aus DeR Geschichte DeR Revolution verweisen eindeutig auf einen sozialistischen Hintergrund. Mit dem Firmennamen 'Solidarität' wird eine der ethischen Prinzipien der Arbeiterbewegung aufgegriffen. ${ }^{600}$ Die Markennamen des Unternehmens wie ,Rote Sorte' und ,Kollektive'601 stellen einen semantischen Bezug zur kommunistischen Terminologie her. Die Zigarettenfirma Solidarität setzt zur Legitimation der Ideologie und des eigenen Machtanspruches die gleichen strategischen Mittel ein wie die Firmen, die rechtsgerichtetes Gedankengut propagiert haben. ${ }^{602}$ Die historischen Personen stehen bei Solidarität aber in der Genealogie revolutionärer Kräfte und folgen nicht dem Eklektizismus vieler Alben mit rechtsgerichteter Ideologie.

Ein weiterer signifikanter Unterschied besteht in den Inseraten, die sozialistische Literatur und Studienreisen nach Sowjetrussland bewerben. Das Schalten von Anzeigen für sowjetrussische Literatur zeugt nicht nur von einer Nähe zur UDSSR, sondern ist auch Teil der sozialistischen Ideologie, die Bildung und Kultur zur Doktrin erhob. ${ }^{603}$ Die Fixierung auf Sowjetrussland reflektiert das enge Verhältnis zwischen

599 Solidarität (1933): Aus der Geschichte der Revolution. Berlin, Einleitungstext, unpag.
600 Vgl. Metz, H. Karls (1998): „Solidarität und Geschichte“. In: Bayertz, Kurt (Hg.): Solidarität
Begriff und Problem. Frankfurt/M.: Suhrkamp, S. 172-177
Werbung in dem Album: Solidarität (1933): Revolution, unpag.
602 Die KPD bediente sich vergleichbarer Propagandastrategien wie die NSDAP. So gehört die
Einkreisungspropaganda ebenso zum Propagandarepertoire wie Heilsversprechen mit reli-
giösem Tenor. Vgl. Hoppe, Bert (2007): In Stalins Gefolgschaft. Moskau und die KPD 1928-1933.
München: Oldenbourg, S. 129
Vgl. Markovic, Predrac J. 2006): „Vom sozialistischen Realismus bis zum sozialistischen Äs-
thetizismus: Die merkwürdige Entwicklung der ästhetischen Ideologie der jugoslawischen
Kommunisten“. In: Richter, Angela/ Beyer, Barbara (Hg.) Geschichte (ge-)brauchen. Literatur 
der Kommunistischen Partei Deutschlands (KPD) und der UDSSR, die einen großen Einfluss auf die deutschen Kommunisten besaß. Pro-russische Verlautbarungen waren daher seit der Gründung der KPD inhärenter Bestandteil der Propaganda. ${ }^{604}$ Im Unterschied zur NS-Propaganda, die darauf ausgelegt war, bei den Zigarettenbildern suggestiv auf den Rezipienten einzuwirken und nicht offiziell in Erscheinung zu treten, warben die Alben des linken Lagers offen für den Sozialismus.

Die Zigarettenfirmen, die das sozialistische Lager vertreten haben, stellten sich, ebenso wie viele Firmen der Zigarettenkleinindustrie, die der NS-Ideologie nahe standen, ganz in den Dienst der Propaganda. Die Ausrichtung aller Marketingstrategien auf die sozialistische Ideologie kommt besonders bei dem Unternehmen ,Eifro’ zum Ausdruck. Der Firmenname deutet nicht nur auf eine sozialistische Provenienz hin, sondern greift darüber hinaus ein zeitpolitisches Ereignis auf. ,Eifro' ist die Abkürzung für „Eiserne Front", 605 einer Gegenbewegung zu der von Alfred Hugenberg im Jahr 1931 initiierten „Harzburger Front“, bei der Wehrverbände und rechte Parteien wie die NSDAP zu einem gemeinsamen Kampf gegen die Weimarer Republik mobilisiert werden sollten. ${ }^{606}$, Eifro' hat sich damit ganz in den Dienst der sozialistischen Idee gestellt. Die Marketingstrategie der Vertreter der Kleinindustrie war damit vollständig auf das politische Zeitgeschehen ausgerichtet. Die Raucher beider politischer Lager fanden in den Zigarettenmarken nicht nur einen Identifikationsraum, sondern konnten ihre politische Haltung durch den Konsum der Produkte nach außen transferieren.

und Geschichtskultur im Staatssozialismus: Jugoslawien und Bulgarien. Berlin: Frank \& Timme, S. 33

604 Vgl. Hoppe (2007): Gefolgschaft, S. 129

605 Bauer (2008): Nationalsozialismus, S. 175

606 Ebd., S. 172 


\subsection{Resümee}

Ab dem Jahr 1933 begann die Zigarettenindustrie NS-Themen in ihre Zigarettenalben aufzunehmen. Eine Semantisierung der Marken- oder Firmennamen fand bei Vertretern des Groß- und Mittelstandes jedoch nicht statt. Ihre Strategie war ausschließlich auf den Aufbau von Marken auf der Basis einer stringenten CI ausgerichtet. Die Konzessionen an den politischen Zeitgeist wurden lediglich bei operativen Maßnahmen wie der Publikation von Zigarettenalben gemacht, die darauf abzielten, den Bedürfnissen der Konsumenten zu entsprechen. ${ }^{607}$ Im Unterschied zu den größeren Unternehmen war die Verbreitung nationalsozialistischen Gedankengutes bei einigen Vertretern der Kleinindustrie keine operative Maßnahme, sondern folgte einer strategischen Planung.

Die Ausrichtung der gesamten Markentingstrategie auf eine politische Ideologie erfolgte nicht nur bei Manufakturen des rechten, sondern auch bei allen bekannten Unternehmen des linken politischen Lagers. ${ }^{608}$ Diese haben sowohl die Firmen- als auch die Markennamen der Zigaretten dem sozialistischen Vokabular entnommen. Die Zigarettenalben dieser Kleinunternehmen fokussierten entsprechend ihrer linksrevolutionären Ausrichtung ausschließlich sozialistische Themen. Die Semantisierung spricht für die Intention der Firmen, mit Instrumenten der Wirtschaftskommunikation Front gegen die Propaganda rechtsgerichteter Kräfte zu machen. Die Kommunikationspolitik der Zigarettenfabrikanten, die dem linken politischen Spektrums zuzuordnen sind, weisen damit Parallelen zu den Strategien des rechten Lagers auf. Obwohl neben den Zigarettenalben kein weiteres Quellenmaterial über die Kleinunternehmen der beiden Lager zur Verfügung steht, weisen die ideologisch-politischen Semantisierungen aller Kommunikationsinstrumente darauf hin, dass die Unternehmensziele nicht nur von wirtschaftlichen Motiven geprägt waren, sondern auch von

\footnotetext{
607 Ausnahme bildet das Unternehmen Reemtsma, das direkt von RMVP instruiert wurde, zwei Alben mit NS-Themen, respektive Kriegspropaganda zu publizieren. 
propagandistischen. Die Zigarettenalben waren dabei ein bedeutendes Medium, mit dem die Ideologien propagiert wurden.

Eine besondere Stellung nehmen die in Schlesien ansässigen Unternehmen ein. Diese haben ihre Sammelwerke vielfach monothematisch auf den zeitgenössischen Schlesienkonflikt ausgerichtet. Die Untersuchungen indizieren, dass die Oberschlesischen Firmen für sich und die ansässige Bevölkerung, die sich als Waisen von Versailles vom Rest des Reiches isoliert fühlten und sich als Opfer der Weimarer Politik betrachteten, die Zigarettenalben als Sprachrohr für den regionalen Grenzkonflikt eingesetzt haben.

Im Spektrum der Unternehmen, die ihre Marketingstrategien in den Dienst ihrer Ideologie gestellt haben, ist die Firma Sturm in vielfacher Hinsicht eine Ausnahme. Als einziges mittelständisches Unternehmen hat Sturm bewusst das Marketingkonzept ganz auf eine politische Semantisierung ausgerichtet und auf die SA und die nationalsozialistischen Anhängerschaft zugeschnitten. Die Relevanz der Namen als bedeutungstragende Zeichenfunktionen kommt bei Sturm besonders zum Tragen. Da neben dem Firmen- auch die Markennamen dem SA-Vokabular entnommen waren, besaßen sie eine starke symbolische Dimension, die den Konsumenten soziale Identifikationsräume bot und gleichzeitig die Identität der SA-Angehörigen stärkte. Mit den Zigarettenalben konnte Sturm seinen Mitgliedern und Sympathisanten einen Identifikationsraum einer eigenen faschistischen Bewegungskultur vermitteln. In den Zigarettenalben von Sturm kommt darüber hinaus das Selbstbewusstsein der Parteiarmee zum Ausdruck, die ihr Recht auf Partizipation an der Macht einfordert. Die Sturm-Alben nehmen im Unterschied zu den NS-Alben anderer Unternehmen auch keine devote Haltung gegenüber Hitler ein. Die Zigarettenalben reflektieren damit den Konflikt zwischen den revolutionären Kräften um Ernst Röhm und der NSDAP.

Das Marketing-Konzept von Sturm war nur bis 1934 erfolgreich, denn nach dem Röhm-Putsch wurde der Konsumzwang der Sturm-Zigaretten für die SA-Mitglieder aufgehoben. Der Inhaber Dressler verlor jegliche Protektion und musste Konkurs anmelden. Der dramatische Rückgang der Konsumenten kann anhand fehlender Quel- 
len nicht eindeutig nachgewiesen werden. Dennoch kann angenommen werden, dass sich viele Raucher, insbesondere aus den Reihen der SA, nach Aufhebung des Konsumzwangs aufgrund der mangelnden Qualität der Zigaretten, anderen Marken zuwandten. Eine weitere Ursache für den Konsumentenrückgang kann auf die starke Zeichenfunktion der Sturm-Marken zurückgeführt werden. So ist nicht auszuschließen, dass sich Konsumenten angesichts der politischen Machtverschiebung zu Gunsten des Hitler-Flügels demonstrativ von Sturm distanzieren wollten. 


\section{Technik und Mobilität in den Zigarettenalben}

Der Technik-Diskurs des Dritten Reiches war von einer Ambiguität geprägt und bewegte sich zwischen Blut- und Bodenideologie und visionären technischen Innovationen. Die Traditionalisten und Kulturpessimisten, die das Althergebrachte nahezu mythisch verklärten, standen Modernisierern gegenüber, die von den technischen Möglichkeiten fasziniert waren. ${ }^{609}$ Mit dem von Goebbels geprägten Begriff „,stählerne Romantik“610 konnte der „reaktionäre[r] Modernismus“611 die divergierenden Ideologeme zu einer NS-Weltanschauung zusammenfassen. Diese Ambivalenz war charakteristisch für die Zeit des Nationalsozialismus und nicht nur der Ausdruck von divergierenden Strömungen ${ }^{612}$ innerhalb der NSDAP. Sie reflektierte auch die Einstellung der Bevölkerung, die sich zwischen archaisch-mythischer Retroversion und einem visionären, positiven Technikglauben bewegte. Der Nationalsozialismus vertrat beide Strömungen und bediente damit sowohl die Erwartungshaltungen der Traditionalisten als auch die der Modernisierer. Die Akzeptanz dieser divergierenden sozialpolitischen Richtungen war primär einem taktischen Kalkül geschuldet, denn so konnte die Popularität beider Anschauungen für die jeweilige propagandistische Zielsetzung einsetzen werden. 613

Die Faszination für den technischen Fortschritt war ein Trend, der bereits um 1900 eingesetzt hatte und zwei Dekaden später seinen Höhepunkt fand. ${ }^{614}$ Die Technik wurde positiv konnotiert und war verbunden mit einer gesellschaftlichen Utopie, die

609 Agrarromantik und Modernisierung mündeten bereits in der spätwilhelminischen Zeit in eine Kulturkritik, die sich in der Weimarer Republik zuspitzte. Vgl. Peukert (1987): Republik, S. 22f. Der Technikdiskurs bewegte sich zwischen Kulturkritik und einer positiven Rezeption der Moderne, die geprägt war von Massenmedien, Unterhaltung und Technikbegeisterung. Junker (1999): „Kontinuität“, S. 173

610 Brockhaus (1997): Schauder, S. 88

611 Nassen, Ulrich (1987): Jugend, Buch und Konjunktur 1933-1945. München: Wilhelm Fink, S. 10

612 Der ,Kulturkampf' wurde auch innerparteilich ausgefochten, insbesondere zwischen Goebbels und Alfred Rosenberg, der sich mit Vehemenz gegen technische, künstlerische und soziale Ausprägungen der Moderne aussprach. Brockhaus (1997): Schauder, S. 86ff.

613 Vgl. Ebd., S. 87

614 Der Erste Weltkrieg war sowohl „Katalysator für Technikschock und- akzeptanz", leitete aber einen "Modernisierungsschub im Lebensalltag der zwanziger Jahre“ ein. Becker, Sascha (2013): Spiel, Technik und Krieg. Marburg. Tectum Verlag, S. 69 
es dem Menschen ermöglichte, sich die Naturgewalten Untertan zu machen und seinen Lebensraum selbstbestimmt zu gestalten. Der nahezu grenzenlose Glaube an den Erfindergeist, der den Menschen befähigt, technische Utopien zu realisieren, ist auch Tenor vieler Zigarettenalben, wie in WUNDER DER TECHNIK IN GEGENWART UND ZUKUNFT ${ }^{615}$ und WUNDER AUS TECHNIK UND NATUR:616

\begin{abstract}
„Die technische Geisteswelt hat es verstanden, ungeheure Naturgewalten zu meistern und deren Kräfte der Menschlichkeit untertan zu machen, so daß man wohl behaupten kann, die Ohnmacht gegen Naturgewalten im wesentlichen [sic!] überwunden zu haben.“617

„Den Wundern der Natur stehen die vom Menschen geschaffenen gegenüber. Es ist in hohen Grade reizvoll, das Gesicht unserer Großindustrie kennenzulernen, in ihre gewaltigsten Werkstätten zu blicken und Kenntnis von den Höchstleistungen zu erhalten.“618
\end{abstract}

In Deutschland manifestierte sich der Glaube an die Realisierbarkeit technischer Utopien insbesondere in den „technischen Schlüsselinnovationen"619 wie dem Automobilismus und der Aviatik. Für Deutschland, das sich bereits seit der wilhelminischen Epoche ${ }^{620}$ vor dem Hintergrund technischer Innovationen definierte, war dieser Aspekt von besonderer Relevanz. Die Technik wurde daher von Anbeginn von einer chauvinistischen Codierung begleitet. Mit der patriotischen Konnotation konnte das NS-Regime auch reaktionäre Kreise und konservative Teile der Bevölkerung für sich einzunehmen. Die Technik wurde so von dem Negativ-Image, deutsches Kulturgut und Traditionen zu untergraben, befreit. ${ }^{621}$ Deutschland präsentierte sich als Nation,

615 Aviatik (1934): Wunder der Technik in Gegenwart und Zukunft. Breslau, Serie 2, Bild 7/ Serie 11, Bild 62 und 64/ Serien Raumschiffe und Raketenflugzeuge. In diesem Album werden zeitgenössische technische Errungenschaften visionären Entwürfen von Weltraumraketen, Nur-Flügel-Passagierflugzeugen und Stratosphärenflugzeugen gegenübergestellt und als realisierbare Utopien betrachtet.

616 Eckstein (1932): Wunder aus Technik und Natur. Dresden

617 Aviatik (1934): Zukunft, Vorwort, unpag.

618 Eckstein (1932): Wunder, Vorwort, unpag.

619 Bauer (2004): 19. Jahrhundert, S. 108

620 Bereits in der wilhelminischen Epoche waren Wissenschaft und Technik sowohl Garant für die Eroberung der Weltmärkte als auch Ausdruck des Nationalstolzes, der von militärischem Kräftemessen - insbesondere mit England - verbunden war. Vgl. Schüler, Andreas (1990): Erfindergeist und Technikkritik. Stuttgart: Franz Steiner, S. 30

621 Vgl. Brandt, Dina (2008): „„,Und die Welt sah, was deutscher Geist”. Der deutsche Zukunftsroman im 'Dritten Reich'." In: Würmann, Carsten/ Warner, Ansgar (Hg.) (2008): Im Pausen- 
die in der Lage war, technische Höchstleistungen $\mathrm{zu}$ vollbringen. Insbesondere nach dem verlorenen Ersten Weltkrieg boten die technischen Errungenschaften Deutschland die Möglichkeit, sich auf internationalem Parkett zu etablieren ${ }^{622}$ und das nationale Selbstbewusstsein zu stärken. In dem Zigarettenalbum DIE WELT IN BILDERN aus dem Jahr 1929 kommt der Stolz der Nation auf die technischen Leistungen exemplarisch zum Ausdruck:

„In der Geschichte der Technik steht Deutschlands Name strahlend an erste Stelle. Da liest Du die Zeitungsnotiz: Siam bestellt deutsche Lokomotiven; in Dublin wird ein Riesenkran mit einem 26-Meter-Radius errichtet - von Deutschen; [...] Tatsachen sind mehr als Ruhmredigkeit. [...] Aber daß es deutsche Leistungen, Erstleistungen waren, das bleibt; und das ist das Wesentliche. Nicht nur für uns, sondern für die ganze Welt.“623

Aufgrund der territorialen Verluste und des Kriegsschuldartikels des Versailler Vertrages $^{624}$ wurden Wissenschaft und Technik aber auch in den Kontext von Remilitarisierung und Vergeltung gesetzt. Die Technik war nicht nur „nationales Prestigeobjekt“, sondern diente auch der „Steigerung des militärischen Droh- und Vernichtungspotentials“.625 Sie wurde „Mittel zur Macht.“626 Der Gedanke der Remilitarisierung war unter dem Postulat von Wissenschaft und Technik bereits in der Weimarer

raum des 'Dritten Reiches'. Zur Populärkultur im nationalsozialistischen Deutschland. Bern/ Berlin: Peter Lang, S. 133. Exemplarisch für die patriotische Konnotation ist der Zukunftsroman ,Detatom'. Held des Werkes ist der deutsche Ingenieur Helo Thorwaldt, der sich als patriotischer Genius auszeichnet. Ebd., S. 127ff.

${ }^{622}$ Vgl. Fritzsche, Peter (2007): „Historical Time and Future Experience”. In: Hartwig (Hg.): Ordnungen, S. 161. Fritzsche weist besonders auf die Globetrotter-Flüge von Günther Plüschow und Marga von Etzdorf hin: „[...] aviation allowed Germany to feel at home in the postwar world." Ebd.

623 Josetti (1929): Die Welt in Bildern, Album 4, Berlin. Kapitel: Deutsche Technik, unpag.

624 Artikel 231, ,[...] Deutschland erkennt an, daß Deutschland und seine Verbündeten als Urheber für alle Verluste und Schäden verantwortlich sind, die den Verbandsregierungen und ihre Staatsangehörigen infolge des Krieges erlitten haben, der ihnen durch den Angriff Deutschlands und seiner Verbündeten aufgezwungen wurde." Delbrück, Hans (früher Sachverständige [sic!] für die Schuldfrage bei der Deutschen Friedensdelegation in Versailles) (1921): „Allgemeine Bestimmungen“. In: Lersner, Freiherr von, MdR (Hg.): Versailles! Volkskommentar des Friedensdiktates von Versailles. Berlin: Verlag für Politik und Wirtschaft, S. 50 Behrmann, Jörn (1986): „Grundlagenforschung im totalitären Staat”. In: Stöhr, Martin (Hg.): Verführbarkeit, S. 24 Esposito, Fernando (2011): Mythische Moderne. München: Oldenbourg, S. 224 
Republik ein Szenario in völkisch-nationalen Kreisen und in Teilen des Militärs. ${ }^{627}$ Nach dem Selbstverständnis dieser Gruppierungen war der Mensch auf den Schlachtfeldern des Ersten Weltkrieges mit der Technik eine Symbiose eingegangen, die sich nach dem Krieg auch in der Zivilgesellschaft manifestierte. An die Stelle der Soldaten traten Piloten und Rennfahrer, die das Erbe der metallischen Krieger ${ }^{628}$ übernahmen. Sie wurden zu Helden einer neuen Zeit stilisiert und avancierten zum Idealbild der Jugend. ${ }^{629}$ Wie der von Ernst Jünger und den Futuristen propagierte 'Neue Mensch', der "den Rhythmus und den Takt des Lebens bestimmte“, ${ }^{630}$ war die Technik dynamisches Element, das sich zwischen „utopischem Entwurf und politischer Anschauung“631 bewegte. „Die Technik, s o $1 \mathrm{~d}$ a t i s c h g e m e i s t e r t, verdient keineswegs die Unterstellung, daß sie das Leben mechanisiert und entseelt. Sie kann es vielmehr seelisch potenzieren und entfalten. “ ${ }^{362}$

In der nationalsozialistischen Ideologie wurde die Technik zur metaphysischen Kraft, die deutsche Werte generierte und der Nation eine verheißungsvolle Zukunft versprach. Für die Modernisierer unter den Nationalsozialisten galt die Technik als vitaler Impuls für Deutschlands Zukunft. „Aber gestützt auf die unendliche Kraft der Technik werden wir diese neue bessere Wirklichkeit, dieses neue herrliche Deutschland in der Einheit von Glaube, Sitte und Kultur herbeiführen, und getrost dürfen wir schon heute in fester Zuversicht, in unbedingter Gewißheit unseres baldigen Sieges

627 Vgl. Lemke, Bernd (2005): Luftschutz in Großbritannien und Deutschland 1923 bis 1939. Zivile Kriegsvorbereitungen als Ausdruck der staats- und gesellschaftspolitischen Grundlagen von Demokratie und Diktatur (Hg.): Militärgeschichtliches Forschungsamt München: Oldenbourg, S. 36f.

628 Ernst Jünger bezeichnet die Jagd- und Kampfflieder als „Stahlgestalten“ als „Helden des modernen Schlachtfeldes". Jünger, Ernst (1922): Der Kampf als inneres Erlebnis. Berlin: E.S. Mittler \& Sohn, S. 74

629 Das apokalyptische Zerstörungspotential der Technik hatte die bürgerliche Lebenswelt aus den Angeln gehoben und einen neuen Menschen hervorgebracht. Für Ernst Jünger war der Soldat hinter dem Maschinengewehr im zivilen Leben ein Arbeiter, der hinter seiner Maschine der Welt ein neues Gesicht verlieh. Vgl. Fritzsche (2007): „Historical Time“, S. 159

630 Esposito (2011): Moderne, S. 317

631 Wedemeyer-Kolbe, Bernd (2004): Der neue Mensch. Würzburg: Königshausen \& Neumann, S. 19

${ }_{632}$ Metzsch, Horst von (1935): Schlummernde Wehrkräfte. Neue soldatische Blickfelder. Oldenburg/ Berlin: Gerhard Stalling, S. 91 
singen $[\ldots]^{\text {“633 }}$ Für den Historiker Günther Gründel war die Technik Ausdruck der Dynamik des neuen Zeitgeistes. „Sie ist positiv, erfolgreich, sie ist sachlich und zuverlässig und entspricht außerdem unserer Dynamik. " ${ }^{634}$ Die Technik und ihre Helden, die zum Inbegriff eines neuen faschistischen Ideals ${ }^{635}$ wurden und eine gesellschaftliche und politische Neuorientierung transferierten, fanden Eingang in die Populärkultur ${ }^{636}$ wie Technikromane, Sachbücher637 und Zigarettenalben. Sie wurden zum Vehikel einer „manipulativen Propaganda“,"638 die dazu eingesetzt wurde, „um die gesamte Bevölkerung zu konditionieren.“639

\subsection{Aviatik}

Um 1900 begann der ewige Traum des Menschen von der Eroberung der Luft Konturen anzunehmen. Da die Überwindung von Zeit und Raum zur „Disposition der Moderne" "640 gehörte, wurde insbesondere die Luftfahrt zum Ausdruck für Fortschritt und Innovationkraft. Es setzte ein Wettstreit um flugtechnische Innovationen und Rekorde ein, der zunehmend auf internationalem Parkett ausgetragen wurde. Der aviatische Diskurs wurde von Kunst und Literatur ${ }^{641}$ adaptiert und fand, insbesondere im Schatten der beiden Weltkriege, zunehmend Eingang in die Populärmedien ${ }^{642}$ wie Romane, Illustrierte und Zigarettenalben.

633 Schwerber, Peter (1930): Nationalsozialismus und Technik. Geistigkeit der nationalsozialistischen Bewegung. Nationalsozialistische Bibliothek/ Heft 21. München: Frz. Eher Nachf., S. 63

634 Gründel, E. Günther (1932): Die Sendung der jungen Generation. Versuch einer umfassenden revolutionären Sinndeutung der Krise. München: Beck, S. 142. Bewegung, Beschleunigung und Dynamik sind Eigenschaften, die in der Moderne verankert sind. Alkemeyer, Thomas (1996): Körper, Kult und Politik. Frankfurt/M./ New York: Campus, S.50

635 Vgl. Esposito (2011): Moderne, S. 422

636 Vgl. Fritzsche (2007): Historical Time, S. 159

637 Adam (2010): Lesen, S. 87 und 97

638 Esposito (2011): Moderne, S. 422

639 Mumford, Lewis (1984): Mythos der Maschine. Kultur, Technik und Macht. Frankfurt/M.: Fischer Verlag, S. $619 \mathrm{f}$.

640 Asendorf, Christoph (1997): Super Constellation - Flugzeug und Raumrevolution. Die Wirkung der Luftfahrt auf Kunst und Kultur der Moderne. Wien/ Köln: Springer, S. V

641 Vgl. Behringer, Wolfgang/ Constance Ott-Koptschalijski (1991): Der Traum vom Fliegen. Zwischen Mythos und Technik. Frankfurt/M.: S. Fischer, S. 437f.

In der Zeit von 1914-1918 wurden ca. 50 populäre Bücher über den Luftkrieg und die Flieger publiziert. Esposito (2011): Moderne, S. 167

642 In der Weimarer Republik fand in allen Medien eine enorme Popularisierung der Flugtechnik statt. Vgl. Kehrt, Christian (2010): Moderne Krieger. Paderborn: Ferdinand Schöningh, S. 200 


\subsubsection{Luftfahrt zwischen Mythos, Moderne und Revanche}

Der erste Band Die EROBERUNG DER LUFT ${ }^{643}$ der Firma Garbáty eröffnet mit einer Retrospektive auf den archaischen Menschheitstraum vom Fliegen, der von mythischen Narrationen geprägt ist. Der Rückgriff auf mythologische Figurationen wird mit romantisch anmutenden Zeichnungen wie der Ikarus-Figur des LindenthalDenkmals ${ }^{644}$ visualisiert. Das Streben des Menschen nach der Beherrschung der Luft illustriert Garbáty mit einer Metamorphose, bei der sich Vögel in Flugzeuge verwandeln sowie mit einer märchenhaft anmutenden weiblichen Silhouette, die ihre Hände sehnsuchtsvoll nach den Sternen ausstreckt. ${ }^{645}$

„Der uralte Wunschtraum vom Menschenflug, vor wenigen Jahrzehnten noch als Utopie bezeichnet, ist dank der unermüdlichen Forschungsarbeit vieler hervorragender Männer zur Wirklichkeit geworden. Etwas völlig Neues, nämlich die Eroberung des Luftraumes ward damit erreicht. “646

Garbátys Adaption der anthropomorphen Ikarus-Figur verweist nicht nur auf die Verbindung zwischen Mythos und Gegenwart, sondern reflektiert auch die Spannungen und Widersprüche an der Schwelle der Epoche um 1900. In dieser Zeit wurde das Individuum mit rasanter Geschwindigkeit in die Moderne katapultiert und musste sich zwischen Vergangenheit und Gegenwart, technischem Fortschritt und Tradition, permanent neu orientieren. Der Mensch sah sich zum ersten Mal in der Historie einer Fülle an Möglichkeiten ausgesetzt, die von ihm die „Selbstgestaltung von Lebensprozessen“647 forderte. Für die Pioniere der Luftfahrt wie Graf Zeppelin bot die Moderne eine Möglichkeit, die „göttliche Unordnung“ zu offenbaren und die

\footnotetext{
643 Garbáty (1932): Die Eroberung der Luft, Bd. 1. Berlin-Pankow

644 Lilienthal-Denkmal von Peter Breuer (Friedhof in Berlin-Lichterfelde). Vgl. Höhler, Sabine (2001): Luftfahrtforschung und Luftfahrtmythos. Frankfurt/M./ New York: Campus, S. 106

645 Vgl. Garbáty (1932): Eroberung, Bd. 1, Einleitungstext, unpag.

646 Ebd.

647 Lindenberg, Christoph (1985): Die Technik des Bösen. Zur Vorgeschichte und Geschichte des Nationalsozialismus, 3. Aufl. Stuttgart: Verlag Freies Geistesleben, S. 70. Mit der Moderne geht eine technisch-wissenschaftlich Handhabung des Lebens einher, die den Menschen zum Selbstgestalter seines Geschickes macht.
} 
Welt individuell zu gestalten. Mittels der Luftfahrt war der Mensch nicht mehr "Anhängsel an einen Spielball der Lüfte“, sondern konnte selbstbestimmt den Weg wählen, „,der ihn zum gewollten Ziel tragen soll“. ${ }^{648}$

Der Erste Weltkrieg, der technische Innovationen hervorbrachte aber gleichzeitig auch die apokalyptische Zerstörung der Technik offenbarte, forderte die Gesellschaft mehr denn je heraus, sich angesichts der Schattenseiten der technischen Errungenschaften im Spannungsfeld zwischen Fortschrittsglauben und Retroversion zu orientieren. ${ }^{649}$ Die aus den Fugen geratene Welt brachte eine gesellschaftspolitische Instabilität hervor, die zu Beginn der 1930er Jahre in eine Krise kulminierte. Für die aufgeklärten Teile der Gesellschaft, die in den neuen Möglichkeitswelten eine Chance für ein selbstbestimmtes Handeln sahen, war der Aufbruch in die Moderne von einem optimistischen Tenor begleitet. ${ }^{650}$ Dieser Optimismus kommt in dem Album DiE EROBERUNG DER LUFT zum Ausdruck. Die hoffnungsvolle Erwartungshaltung gegenüber der Zukunft manifestiert sich bei Garbáty in der Luftfahrt, die von einem demokratischen und völkerverbindenden Gedanken ${ }^{61}$ geprägt ist. Die Ambitionen Garbátys liegen in „kulturellen Bestrebungen“ auf der Basis der Völkerverbindung. Die Eroberung der Luft wird hier als "gewaltige Idee“652 angesehen, die Welt zu entdecken.

648 Zeppelin, Ferdinand Graf (1908): Die Eroberung der Luft. Ein Vortrag gehalten im Saale der Sing-Akademie zu Berlin am 25. Februar 1908. Stuttgart: Deutsche Verlags-Anstalt, S. 4

649 Nach dem Ersten Weltkrieg schwand in Teilen der Bevölkerung die Technikbegeisterung, denn der Krieg hatte die zerstörerische Kraft der Technik offenbart. Auch Katastrophen wie der Untergang der Titanic sowie die modernen Produktionstechnologien des Taylorismus trugen zu einem Negativ-Bild der Technik bei. Vgl. Mühl-Benninghaus, Wolfgang (2004): „Das Bild der Technik in den audiovisuellen Medien“. In: Pichol, Karl/ Weber, Wolfhard/ Bluma, Lars (Hg.): Technikvermittlung und Technikpopularisierung. Historische und didaktische Perspektiven. Münster: Waymann, S. 217f.

650 Nach Bruno Latour unterschieden sich moderne von traditionellen Gesellschaften zu Beginn des 20. Jahrhunderts durch die Möglichkeiten der Erneuerung vor dem Horizont selbstbestimmter Handlungsoptionen. Vgl. Höhler (2001): Luftfahrtforschung, S. 71f.

651 Insbesondere die deutsche Friedensgesellschaft vertrat die Ansicht, dass eine Revision des Versailler Vertrages unter dem Tenor der Völkerverständigung von statten gehen sollte. Vgl. Klein, Fritz (2001): „Versailles und die Linke“. In: Krumeich, Gerd (Hg.): Versailles 1919 Ziele - Wirkung - Wahrnehmung. Essen: Klartext, S. 321f.

652 Garbáty (1932): Eroberung, Bd.1. Einleitungstext, unpag. Der pazifistische Gedanke ist Teil der Logik der Mobilitätstechnik. Die Mobilität war mit der Hoffnung verbunden, durch wirtschaftlichen und kulturellen Transfer kriegerische Auseinandersetzungen vermeiden zu können. Vgl. Woschech, Anke (2012): Technikfunktionen im frühen deutschen Tonfilm, S. 250 
„Die gewaltige Idee dieses Dienstes an der Verbindung der Völker auf dem Luftwege ist wach und wird immer neu belebt [...] Wir erwarten von der Luftfahrt nicht nur den Bau von Flugzeugen verschiedenster Typen, sondern die Erfüllung großer volkswirtschaftlicher und kultureller Aufgaben. [...] Bei der Erschaffung unserer verschiedenen Bilderserien haben wir uns stets von kulturellen Bestrebungen leiten lassen und damit in weitesten Raucherkreisen Anerkennung gefunden. ${ }^{653}$

Text und Gestaltung der beiden Aviatik-Alben der Firma Garbáty unterstreichen den positiven Blick auf die Luftfahrt, der in eine moderne, aufgeklärte Welt weist. Garbáty setzt die Luftfahrt nicht in den Kontext historischer Ereignisse oder gesellschaftspolitischen Zeitgeschehens und verzichtet in den kurzen Begleittexten gänzlich auf nationale Untertöne. Der Fokus liegt auf den flugtechnischen Innovationen sowie auf der nationalen und internationalen Entwicklung der Passagier- und Sportmaschinen. Die Militärflugzeuge werden nur marginal und im Rahmen einer Gesamtschau der flugtechnischen Errungenschaften ohne verbales Säbelrasseln aufgelistet. Die Farben der Grafiken und Gestaltungselemente sind frei von Kontrast und Dynamik ${ }^{654}$ und bewegen sich in einer Skala von rosa und blauen Pastelltönen, die mit dem harmonischen und neutralen Tenor der Begleittexte korrespondieren.

Der Flug in Richtung Utopia folgt jedoch einem retrograden Kurs, denn die positive Erwartungshaltung gegenüber der Zukunft ist mit einer Numinosität verbunden. Bei Garbáty kann die moderne Luftfahrt nur dann neue Horizonte erobern, wenn sie durch „weitschauende Führer“, die Prosperität, Kultur und Völkerverständigung im Blick haben, „immer neu belebt“655 wird. Die real gewordene Utopie des Fliegens rbindet sich hier mit „utopischen Erwartungen von Wundertaten“ mit denen „,materielle Sicherheit und mentale Geborgenheit" ${ }^{\prime 656}$ verbunden sind. Die bei Garbáty artikulierte Sehnsucht nach Arkadien reflektiert das desolate wie instabile gesellschaftspolitische Gefüge der Nachkriegszeit. Der Verlust traditioneller Strukturen, politische

\footnotetext{
653 Garbáty (1932): Eroberung, Bd.1. Einleitungstext, unpag.

654 Vgl. Böhringer, Joachim/ Böhler, Peter/ Schlaich, Patrick (2008): Kompendium der Mediengestaltung für Digital- und Printmedien, Bd. 1, 4. Aufl., Berlin/ Heidelberg: Springer-Verlag, S. 77

655 Garbáty (1932): Eroberung, Bd.1. Einleitungstext, unpag.

656 Thamer (1986): Verführung, S. 158.
} 
Instabilität, die als schmachvoll empfundenen Bedingungen des Versailler Vertrages und die Weltwirtschaftskrise ließen eine Perspektiv- und Orientierungslosigkeit entstehen, in der das Individuum aus einem historischen Kontinuum herausgelöst und in ein orientierungsloses Vakuum katapultiert wurde. ${ }^{657}$ Daraus entstand eine diffuse Erwartungshaltung, die verbunden war mit dem Wunsch nach einer sinnstiftenden gesellschaftspolitischen Macht, angeführt von einer Führerfigur. Bei völkischen und antidemokratischen Traditionalisten ${ }^{65}$ stand die Führerfigur unter dem Tenor einer messianisch-religiösen Heilserwartung hoch in Kurs und wurde in „Phasen tiefer Umbrüche“"659 wie in der Zeit der Weimarer Republik besonders genährt. ${ }^{660}$ Der Führergedanke steht bei Garbáty nicht im nationalsozialistischen Kontext, sondern transferiert eine gesellschaftliche Utopie, die die Sehnsucht nach einer Ordnung zum Ausdruck bringt, die in der Zukunft verortet wird. ${ }^{661}$

657 Vgl. Lindenberg (1985): Technik, S. 71. In der Weimarer Republik hatte die konservative Revolution von rechts keine konkreten Vorstellungen oder Ziele bezüglich einer neuen Gesellschaftsordnung. Die rechten Gruppierungen verloren sich in divergierenden politischen Utopien. Thamer (1986): Verführung, S. 149ff.

Der Führergedanke war bereits in national-konservativen Kreisen der Weimarer Republik verankert. Die Wurzeln des Führermythos reichen zurück in monarchistische und militärische Traditionen, die sakrale Vorstellungen von einer politischen Führerfigur propagierten. Vgl. Thamer (1986): Verführung S. 158. Die politische Rechte hatte sich in der Weimarer Republik hinter politische Mythen verschanzt. Diese Mythen wurden mit Erwartungen verbunden, die dem demokratischen Gedanken von Weimar entgegenstanden und das Verlangen nach einer Führerfigur hervorriefen. Münkler (2009): Mythen, S. 19. Der Gedanke an einen Führer als Erlöser wird von Kurt Hesse formuliert. Das deutsche Volk würde sich nach einem Führer sehnen, der ",eine eigentümliche Gewalt" ausübt und „Herrscher der Seelen“ ist. Hesse (1922): Feldherr, S. 206

659 Thamer (1986): Verführung, S. 158. Hitler hatte das Vakuum an transzendentalen Zielen und Utopien erkannt, die die Sehnsucht nach einer Führerfigur zum Ausdruck brachten. Vgl. Fest (2006): Hitler, S. 399. "Der Ruf nach Führerschaft erscheint nur, wenn ein kollektiver Wunsch eine überwältigende Stärke erreicht hat und wenn anderseits alle Hoffnungen, diesen Wunsch auf gewöhnliche und normale Weise zu erfüllen, fehlgeschlagen sind. [...] Er steht vor den Augen der Menschen in konkreter, plastischer und individueller Gestalt. Cassirer (2002): Mythus, S. 365

660 Mit dem Zusammenbruch des Kaiserreiches und dem Erstarken der Arbeiterbewegung hatte sich das konservative Bürgertum hinter politische Mythen zurückgezogen und in der Zeit der Weimarer Republik eine Erwartungshaltung entwickelt, die an eine Führerfigur geknüpft war. Vgl. Münkler (2009): Mythen, S. 19

661 Ernst Bloch differenziert zwischen einer zeitlichen Utopie, die in der Zukunft verortet ist und einer geografischen, die in glücklichen Gefilden angesiedelt wird. Die utopischen Wunschvorstellungen können dabei sowohl von dem Gedanken der Freiheit als auch von einem Bedürfnis nach Ordnung geprägt sein. Vgl. Bloch, Ernst (1980): Abschied von der Utopie? Vorträge. Frankfurt/M.: Suhrkamp, S. 53 
„Die gewaltige Idee dieses Dienstes an der Verbindung der Völker auf dem Luftwege ist wach und wird immer neu belebt durch weitschauende Führer. Wir erwarten von der Luftfahrt nicht nur den Bau von Flugzeugen verschiedenster Typen, sondern die Erfüllung volkswirtschaftlicher und kultureller Aufgaben. Auch wir wollen unser Teil zur Erreichung dieses im Interesse der Allgemeinheit liegenden Zieles beitragen und bringen deshalb Luftfahrtbilder unter dem Titel: „Die Eroberung der Luft“ heraus.“662

Garbátys Gesinnungsneutralität lässt sich auf die jüdische Herkunft zurückführen und dem Umstand, dass er zu Beginn der 1930er Jahre seine Marketing-Maßnahmen autark durchführen konnte. Garbáty hielt sich in Bezug auf nationalsozialistische Propaganda zurück und publizierte erst im Jahr 1936 das Album Die DEUTSCHE WEHRMACHT ${ }^{663}$ im Verbund mit dem Zigaretten-Bilderdienst Dresden. Im Unterschied zu den Firmen, die sich an der staatlichen Propaganda orientieren oder beteiligen, verzichtet Garbáty auf ideologische Inhalte, Revanchismus oder dem Evozieren patriotischer Emotionen. Die Darstellung der technischen Innovationen im Bereich der Flugtechnik ist frei von Opferkult, chauvinistischem Pathos und Heldenverehrung. Der Zeitgeist der Alben ist geprägt von der Hoffnung der Weimarer Jahre, Deutschland durch wirtschaftliche Expansion zu stabilisieren.664

In den Alben anderer Zigarettenfirmen wird die Heilserwartung in Gestalt einer Führerfigur explizit in den nationalsozialistischen Kontext gesetzt. In dem Sammelband DAS NEUE REICH wird die Erwartungshaltung in Bezug auf eine neue Führung exemplarisch zum Ausdruck gebracht. Die Ankunft des sehnlichst erwarteten Führers in der Gestalt Hitlers, der das Volk aus dem politischen Chaos und der zerrütteten kollektiven Seelenlage befreit, wird als eine segensreiche Fügung des Schicksals begrüßt:

\footnotetext{
662 Garbáty (1932): Eroberung, Bd.1. Einleitungstext, unpag.

663 Zigaretten-Industrie (1936): Wehrmacht. Garbátys Firmenanteile waren inzwischen in Reemtsma-Besitz. Lindner (2007): Reemtsmas, S. 56 - 59 und 109. Das Album weist einen eindeutigen Charakter einer Informations- und Werbebroschüre für die neu gegründete Wehrmacht auf. Neben der Erläuterung zum Rekrutierungsverfahren werden die einzelnen Waffengattungen und ihre Aufgaben sowie der Soldatenalltag beschrieben.

664 Vgl. Wirsching, Andreas (2006): „Politische Generationen, Konsumgesellschaft, Sozialpolitik. Zur Erfahrung von Demokratie und Diktatur in der Zwischenkriegszeit und Nachkriegszeit" ${ }^{\prime \prime}$ In: Doering-Manteuffel, Anselm (Hg.): Strukturmerkmale der deutschen Geschichte des 20.Jahrhunderts. München: Oldenbourg, S. 51f.
} 
„Nach dem großen Völkerringen brachte die verderbliche NovemberRevolution von 1918 über Deutschland Jahre des Niedergangs und Zerrissenheit. Fast schien es, als ob einmütiger deutscher Geist für alle Zeit verloren wäre, als in der Stunde höchster Not unserem Volke ein Retter erstand. Adolf Hitler [...] Diesen gewaltigen Erleben unserer Zeit-Geschichte ist dieses Buch gewidmet mit dem Mahnruf unseres Führers und Kanzlers: Du bist nichts Dein Volk ist alles! “665

Im ersten Album der beide Bände HELDEN DER LuFT der Firma Orami steht die Luftfahrt für den „Aufbruch der deutschen Nation im Frühjahr 1933“.666 Die Realisation einer neuen politischen Utopie wird der neuen nationalsozialistischen Führung zugeschrieben, die ihre Visionen zum Wohl der Nation realisiert und die „lebenswichtigsten Fragen des deutschen Volkes wieder in sein Bewußtsein“"667 gerückt hat. Die neuen Führer in Gestalt von Hitler und Göring werden dem Bildersammler auf großformatigen Porträts präsentiert, die der Bildersammlung vorangestellt sind.

„[Anm.: Die Bedeutung der Luftfahrt] fand ihren organisatorischen Ausdruck in der Errichtung des Luftfahrtministeriums unter der Leitung des Pour-lemérite-Fliegers, Ministerpräsidenten Göring und in dem Ausbau des deutschen Luftsportwesens. " ${ }^{\prime 68}$

Das Album HELDEN DER LuFT Bd.1 eröffnet wie Garbáty mit einer Retrospektive auf die archaischen Wurzeln des Fliegens und ihrer Helden, die hier aber eine semantische Verschiebung in den Kontext der Opferbereitschaft erfahren. Entsprechend generiert Ikarus zum prometheischen Heroen, der den Göttern das Privileg des Fliegens entreißt und für dieses hohe Ziel sein Leben opfert. ${ }^{669}$ Während Garbáty den Sammler in kurzen Begleittexten zum Bildmaterial über Mythen und Pioniere der Luftfahrtgeschichte informiert, werden bei Orami die Leistungen der Helden aus der Mythologie und der Luftfahrthistorie mit aller Dramatik geschildert. Die mythischen Helden werden zu auserwählten Charakteren stilisiert, die, allein getrieben von ihrem

\footnotetext{
665 Greiling (1933): Reich, Einleitungstext, unpag.

666 Orami (1933): Helden der Luft, Bd. 1. Dresden, Zur Einleitung, unpag.

667 Ebd.

668 Ebd.

669 Der Flugpionier wurde in der Frühzeit der Moderne nicht mehr ausschließlich als gescheiterter Ikarus betrachtet, der für seinen Frevel die Strafe der Götter erfährt, sondern als positive Leitfigur, mit der sich die intellektuelle Schicht der Bevölkerung identifizieren konnte. Vgl. Behringer/ Ott-Koptschalijski (1991): Traum, S. 246.
} 
Glauben, weder Tod noch soziale Ausgrenzung fürchten, um einer Idee zum Sieg zu verhelfen.

\begin{abstract}
„Waghalsig versuchte er [Anm. Ikarus] den besonnenen Vater zu übertrumpfen und büßte sein verwegenes Tun mit dem Tode. So ist sein Flug eigentlich die erste Pioniertat auf diesem Gebiete. [...] Das vorliegende Werk macht den Versuch [...] Menschen und Taten vorzuführen, die sich begeistert, voll unerschütterlichem Glauben an den Enderfolg, mit ihrem Wissen und Können für die Idee des Fliegens eingesetzt haben. ${ }^{\prime 670}$
\end{abstract}

Die Alben der Firmen Garbáty und Orami reflektieren die unterschiedlichen Ausprägungen des zeitgenössischen Technik-Diskurses, der geprägt war von Fortschrittsoptimismus, dem Unbehagen an der Moderne und der Sehnsucht nach einer Gemeinschafts-Utopie, die getragen wurde von einer Erlöserfigur. Die restaurative Sehnsucht reflektiert dabei den gesellschaftspolitischen Zeitgeist, der sowohl von einem nationalistischen und antidemokratischen als auch von einem völkerverbindenden Gedanken der Weimarer Jahre geprägt war.

\title{
5.1.1.1 Wiederauferstehung der Kriegshelden
}

Neben dem historischen Abriss über die Entwicklung der Flugtechnik stehen die gefallenen Kampf- und Jagdflieger des Ersten Weltkrieges, die ihr Leben für das Vaterland geopfert haben, im Fokus vieler Aviatik-Alben. Die Porträts der Flieger sind dem Zeitgeist der Kriegsjahre entsprechend von Individualität geprägt ${ }^{671}$ und weisen selten die Konformität des Soldaten und Offiziers auf, dessen Persönlichkeit hinter einer Uniformität zurücksteht. Die Uniformen sind uneinheitlich und repräsentieren zum Teil den pompösen wilhelminischen Stil. ${ }^{672}$ Auf den Fotografien sind die Flieger

\footnotetext{
670 Orami (1933): Helden, Bd. 1, S. 3 und 5

671 Ebd., S. 17-21

672 Uniformen umgeben den Körper mit militärischen Attributen und vermitteln Ordnung und Gruppenzugehörigkeit. Während des Ersten Weltkrieges wurde der pompöse Stil der Uniformen des Kaiserreiches an die militärischen Bedingungen des modernen Krieges angepasst. Vgl. Diehl, Paula (2005): Macht Mythos Utopie. Berlin: Akademie Verlag, S. 64f. Leutnant von Bülow posiert nicht nur mit seinem Schoßhund, sondern präsentiert sich auch in einer mit Kordeln und Knebelknöpfen besetzten Uniform. Orami (1933): Helden der Luft, Bd. 1, Dresden, S. 19, Bild 110. Oberltn. Freiherr v. Althaus. Orami (1933): Helden der Luft, Bd. 2, S. 7, Bild 24
} 
kaum in der klassischen Porträtpose abgebildet. Sie präsentieren sich in der Haltung des verwegenen Hasardeurs und Abenteurers und bedienen dabei das Klischee der zeitgenössischen Medien des Ersten Weltkrieges, die die Fliegerasse zu heroischen Ikonen stilisiert hatten. ${ }^{673}$ Die Protagonisten posieren mit lässig angewinkelten Ellenbogen oder mit Händen in den Taschen ${ }^{674}$ und produzieren sich leger, frei von straffer militärischer Haltung. Die individuell geprägte Selbstdarstellung wird durch persönliche Accessoires wie Hund, Spazierstock oder Zigarette unterstrichen, womit sie sich von den anonymen ,Feldgrauen' in den Schützengräben unterscheiden. Die dekorativen Elemente bewirken eine "Ausdehnung der Persönlichkeit", ${ }^{675}$ wodurch den Fliegern ein breiter Raum für die Darstellung ihrer Individualität zugestanden wird. Ambiente und Habitus verleihen den Porträts eine charismatische wie elitäre Note, ${ }^{676}$ die jene mythische Helden und Abenteurer charakterisiert, die sich von der Gemeinschaft ${ }^{677}$ abheben und einen Lebensweg jenseits manifester Ordnungssysteme beschreiten. Die Weltkriegs-Flieger repräsentieren damit eine aristokratische Ahnenreihe und "Deutsches Heldentum"678 die in der Tradition des romantischen Heldenideals germanischer Mythen steht.

673 Der Fliegerheld verkörperte während des Krieges noch eine „für das Bürgertum geschaffene Identifikationsfigur", die später in dem Kollektiv der Nation aufging. Vgl. Esposito (2011): Moderne, S. 262f.

674 Mit den Händen in den Taschen präsentieren sich: Ltn. Allmenroeder, Bild 101, Oblt. Wolf, Bild 104, Ltn. Voß, Bild 106, Ltn. Böhme, Bild 109, Ltn. Kleine, Bild 108, Rittmeister von Richthofen, Bild 114. Orami (1933): Helden, Bd. 1. In Bd. 2 posieren insgesamt zehn Flieger in dieser Pose. Orami (1933): Helden, Bd. 2, S. 5 - 9

675 Für den deutschen Philosoph und Soziologen Simmel ist das persönliche Eigentum Ausdruck und Äußerung des Ichs, das dem eigenen Willen gehorcht. Simmel, Georg (2008): Individualismus der modernen Zeit. Frankfurt/M.: Suhrkamp, S. 250

676 Die Flieger des Ersten Weltkrieges pflegten ihr Image als verwegene Fliegerhelden durch dekadentes und elitäres Gebaren. Dieser Habitus machte sie zu Ikonen einer wachsenden Medienindustrie. Vgl. Esposito (2011): Moderne, S. 237

677 Fliegerasse wurden bereits im Weltkrieg durch mediale Inszenierungen zu „überindividuelle[n] Figuren" stilisiert. Kehrt (2010): Krieger, S. 92. Während der "gewöhnliche Sterbliche“ innerhalb seiner Gemeinschaft verweilt, bricht der Heros in unbekannte Welten auf, die jenseits des Horizontes liegen. Campbell, Joseph (2011): Der Heros in tausend Gestalten. Berlin: Insel Verlag, S. 91

678 Diese Heldeninterpretation, in der der Held nicht aus dem Volk stammt, sondern nur von edler Abstammung sein kann, hatte in der wilhelminischen Epoche Konjunktur. Der imperiale wie antidemokratische Gedanke stand im Widerspruch zum modernen Industriestaat. Der Entwurf dieser germanisch geprägten mythologischen Ahnengalerie wurde insbesondere von dem Germanisten Gustav Roethe propagiert. Vgl. Schulz, Petra Maria (2004): Ästhetisierung von Gewalt in der Weimarer Republik. Münster: Westfälisches Dampfboot, S. 72 
Die Rückbesinnung auf die Fliegerasse impliziert eine ideologische Hinwendung zum rechten Lager, denn „[D] der Kriegsheld versprach Souveränität sowohl für das Individuum als auch für die Nation. Seine Bilder wurden für viele politische Zwecke verwendet - vor allem im rechten Spektrum - und ermöglichten die Anknüpfung an ein nationalistisches Ideal. “679 In den Aviatik-Alben werden die Leistungen der Flieger jenseits der realen Historie zu übermenschlichen Taten verklärt, wie ein Kampfeinsatz des Fliegers Oswald Boelcke, der derart heroisiert wird, dass dem Leser eine Herkulestat suggeriert wird, bei der er während eines einzigen Einsatzes 40 Gegner680 bezwungen haben soll.

\begin{abstract}
„Die feindlichen Flieger schwirren in der Luft wie Hornissen. Unsere schwachen Fliegerkräfte können zunächst nicht gegen sie aufkommen. Erst allmählich wird unsere Abwehr in der Luft wirksam. Ein einzelner Mann leistet sie, Hauptmann Boelcke, der selbst 40 feindliche Flugzeuge abschießt. Er verunglückt am 26. Oktober tödlich. “" ${ }^{81}$
\end{abstract}

Die Flieger des Ersten Weltkrieges nahmen im Gegensatz zu den Kriegern anderer Waffengattungen, die einen anonymen Tod in den Schützengräben fanden, eine exponierte Stellung ein. ${ }^{682}$ Der Kampfflieger repräsentierte einen neuen Kriegertypus, der individuelles Heldentum und moderne technische Kriegsführung miteinander vereinte. Der Flieger wurde zu einem technikbeherrschenden Ikarus, der sich mit Todesverachtung dem Zweikampf stellte und als „Ritter des Pour le Mérite“683 und

\footnotetext{
679 Diehl (2005): Macht, S. 63

680 Oswald Boelcke errang bis zu seinem Tod im Jahr 1916 insgesamt 40 dokumentierte Luftsiege. Vgl. Johannes, Werner (2009): Knight of Germany. Havertown: Casemate, S. 6. Der Text erweckt den Eindruck, als handele es sich um einen einzigen Luftkampf.

681 Brinkmann (1934): Alles für Deutschland, S. 91

682 „Der massenhafte Tod auf den Schlachtfeldern taugte nicht für die Inszenierung eines personalen Heldenmythos". Schilling, René (2002): "Kriegshelden“ Deutungsmuster heroischer Männlichkeit in Deutschland 1813-1945. Paderborn: Ferdinand Schöningh, S. 253

683 Orami (1933): Helden, Bd. 1, S. 16. Von 72 Pour-le-Mérite-Trägern fielen 27. Vgl. Bilderdienst Dresden (Reemtsma, Gemeinschaftsausgabe) (1937): Der Weltkrieg, o.O. Rubrik: Der Große Krieg in Zahlen, unpag. Der ,Pour le Mérite' ist ein Verdienstorden, der auf den ,Ordre de la générosité zurückgeht, von König Friedrich II. eingeführt und für besondere militärische Verdienste verliehen wurde. Vgl. Fuhrmann, Horst (1992): Pour le Mérite. Über die Sichtbarmachung von Verdiensten. Sigmaringen: Thorbecke, S. 31 und 34
} 
romantischer Einzelkämpfer ${ }^{64}$ mit der Technik eine Symbiose einging. Die neuen Krieger sind in einigen Zigarettenalben mit ihren Flugzeugen abgebildet ${ }^{685}$ und versinnbildlichen mit der Symbiose von Mensch und Maschine die Dynamik der Moderne. Die Inkarnation des modernen Kriegers, der der alten Zeit davonfliegt, wird in dem Album DeUTSCHE HELDEN ausdrucksvoll beschrieben.

„Hoch über den zerstampfenden und zermalmenden Materialschlachten focht der Flieger im ritterlichen Kampfe, und die Alten daheim im Vaterlande standen erschüttert und fassungslos vor diesem neuen Heldentum. Die Jugend aber zählte die Luftsiege der Größten in dieser verwegenen Schar [...]“686

Die Fliegerhelden des Ersten Weltkrieges waren als mediale Fixsterne in der Weimarer Republik aufgrund der pazifistischen Grundstimmung ${ }^{687}$ weitgehend erloschen. In der Weltkriegsliteratur, die in den 1930er Jahren wieder an Konjunktur aufgenommen hatte, wurde das vergessene Andenken an die Kriegshelden bedauert. So konstatiert der ehemalige Kapitänleutnant von Buttlar Brandenfels in seinen Kriegserinnerungen ,Zeppeline gegen England' nüchtern, dass der einstige Kriegsheld und Führer der Luftschiffe Peter Strasser „im deutschen Volke wenig bekannt“688 sei. Das Kriegsgeschehen mit seinem Heldentum und Opfertod, einst Inbegriffe nationaler Identität und Tradition, waren in der Weimarer Republik aus dem öffentlichen Leben so gut wie eliminiert. 689

684 Der Jagdflieger verkörperte den ritterlichen Helden und Abenteuer und war „Objekt romantischer Sehnsucht“. Mosse, George L. (1997): Das Bild des Mannes. Zur Konstruktion der modernen Männlichkeit. Frankfurt/M.: Büchergilde Gutenberg, S.155

685 Vgl. Orami (1933): Helden, Bd. 1, S. 20ff.

686 Kyriazi (1933): Deutsche Helden. (Bilder bearbeitet und zusammengestellt von der Firma Propaganda-Högner, Dresden. Die historischen, zeitgeschichtlichen Texte schrieb Prof. Dr. R. Rolle). Cairo/ Hamburg. Kapitel: Deutschland im Weltkrieg, 1914-1918, Unsere Fliegerhelden, S. 41

687 Vgl. Jünger (1922): Kampf, S. 36. Der Pazifismus umfasste unterschiedliche Richtungen wie Völkerverständigung, Antimilitarismus und Absage an die antidemokratischen Strömungen. Politisch hatten die pazifistisch ausgerichteten Organisationen und Parteien aber nur einen geringen Einfluss. Vgl. Wette (1979): „Ideologien“, S. 85ff.

688 Treusch von Buttlar Brandenfels, Horst Frhr., Kapitänleutnant (1931): Zeppeline gegen England, 2. Aufl., Zürich/ Leipzig: Amalthea-Verlag, S. 10

689 Der Niedergang der Kriegshelden manifestiert sich u.a. in dem dramatischen Rückgang der Auflage der Richthofen-Autobiografie. Während sich der „Der Rote Kampfflieger" während des Weltkrieges noch eine halbe Million mal verkaufte, sank die Auflage in der Weimarer Republik auf 26.000. Wenzel, Richard, Richthofen - Flieger. Dem Gedächtnis des großen Fliegers und seines heldenhaften Geschwaders, Karlsruhe 1930; Vgl. Wasner, Adolf (1924): 
Dieser Umstand wird auch in dem Zigarettenalbum DeR WeLTKRIEG 1914-18 der Firma ASS aus dem Jahr 1932 beklagt:

„,'Kriegsbilder? Da schlägt ja keiner den anderen tot auf diesen Bildern“, wird es vielleicht heißen." ${ }^{690}$

Weimar sah sich bei der Rezeption der Gefallenen des Ersten Weltkrieges mit divergierenden Erwartungen konfrontiert. Während die Politik und breite Kreise der Gesellschaft eine distanzierte Haltung einnahmen, forderten militärische Verbände und konservative Kreise der Bevölkerung eine Erinnerungskultur in Bezug auf die Gefallenen und Veteranen. Die einzelnen Lager fanden jedoch keinen Konsens, das Andenken an die Kriegsteilnehmer zum integrierenden Bestandteil des kulturellen Gedächtnisses zu etablieren. Da die Weimarer Republik nach dem Ersten Weltkrieg ihre Identität und politische Legitimation nicht aus den Gefallenen des Krieges schöpfen konnte, war eine positive Sinnstiftung deutscher Soldaten kaum möglich. ${ }^{691}$ Die kollektive Entfremdung, die in der Weimarer Republik zugenommen hatte, bot national-konservativen Kreisen einen optimalen Nährboden zum Einpflanzen nationaler Mythennarrationen. ${ }^{692}$ Ernst Udet, Fliegerheld des Ersten Weltkrieges, bringt das soziale wie psychische Vakuum der Veteranen in seiner Biografie zum Ausdruck und begrüßt, dass die Flieger unter der Fahne der nationalsozialistischen Machthaber wieder eine emotionale Heimat gefunden hätten. „[...] Sie wollten nichts wissen von den harten Tugenden des Soldaten, Kameradschaft, Pflichterfüllung und dem Geist des letzten Opfers. Wir waren fremd unter ihnen [...] mein eigenes Leben ist unwesentlich geworden, ist eingeströmt in den Fluß unseres gemeinsamen deutschen

"Schweidniz und unsere Richthofen“. Leipzig. Zit. nach: Schilling (2002): Kriegshelden, S. $289 f$.

690 ASS (1932): Der Weltkrieg 1914-18, München. Zum Geleit!, unpag.

691 Vgl. Kaiser, Alexandra (2010): Von Helden und Opfern, Frankfurt/M./ New York: Campus, S. 13. Erst im Jahr 1924 sah sich die Republik veranlasst, den Kriegstoten mit einer behelfsmäßigen Feier zu gedenken. Der Weimarer Regierung gelang es nicht, eine Gedenkstätte für die Gefallenen zu errichten. Der einzige Neubau war das Tannenbergdenkmal. Vgl. Hattenhauer, Hans (2006): Deutsche National Symbole, 4. Aufl. München: Olzog, S. 227f.

692 In der Weimarer Republik bestand ein großes Bedürfnis nach sinngebenden Mythen, was zu einem regelrechten „Weimarer Mythensyndrom“ führte. Dazu gehören die Nibelungen-Saga ebenso wie die Legende der „im Felde unbesiegten“ deutschen Armee. Dörner, Andreas (1996): Politischer Mythos und symbolische Politik. Der Hermannmythos: zur Entstehung des Nationalbewußtseins der Deutschen. Reinbek bei Hamburg: Rowohlt, S. 229 
Schicksals. Wir sind Soldaten ohne Fahne gewesen. Wir haben unsere Fahne wieder aufgerollt. Der Führer gab sie uns zurück." 693 Der Verlust der psychologischen wie sozialen Wurzeln, die einst in den soldatischen Tugenden verankert waren, wird auch in den Zigarettenalben wie HELDEN DER LUFT artikuliert:

„Diese Männer, an Kampf und Tod gewohnt, stahlhart und unbeugsamen Willens, standen nach Kriegsende vor ganz anderen Lebensaufgaben. Die meisten waren noch jung. Sie alle mußten sich einem völlig neuen Leben einordnen. ${ }^{\text {}} 694$

Der Diskurs des Ersten Weltkrieges wurde in der Weimarer Republik stark von der nationalen Rechten geprägt, die das Vakuum nationalen Heldentums beklagte und sich in der Nachfolge der Kämpfer des Weltkrieges sah. ${ }^{695}$ Der Kult um die Fliegerhelden und ihres Opfergangs wurde von einem kleinen Teil der Gesellschaft wie Veteranen, Wehrverbänden und Kriegervereinen aufrecht erhalten. ${ }^{696}$ Das preußische Wertesystem, das von Gehorsam und Opferbereitschaft geprägt war und von den Anhängern der völkischen Ideologie und den Veteranen als Inbegriff nationaler Zusammengehörigkeit galt, wurde von einschlägigen Medien völkisch-nationaler Provenienz eingefordert. Das NS-Regime kam der Forderung dieser Stimmen nach, die auf die Würdigung der Kriegstoten und Veteranen bestanden ${ }^{697}$ und förderte bewusst die Fliegerliteratur, die die Helden des Weltkrieges verherrlichte und wieder in das Bewusstsein der Öffentlichkeit brachte. So wurde von staatlicher Seite ein Preis für ein Buch ausgelobt, „das den Gedanken des Fliegens schöpferisch gestaltet und seine Bedeutung für das völkische Leben aufzeigt.“ Den Preis erhielt der Tatsachenroman „Der F.d.L Führer der Luftschiffe“, der das Leben von Peter Strasser heroisch verklärt.

693 Udet, Ernst (1935): Mein Fliegerleben. Berlin: Ullstein, Ausklang, unpag.

694 Orami (1933): Helden, Bd. 2, S. 5

695 "The bitter disappointment of defeat in 1918, the unrest alienation in the wake of the Spartacist revolution, and the political turmoil of the Weimarer Republic resulted in a spirit of pessimism and unease in Germany. The stress led to an assault on traditional political, social, and cultural values, which further alienated the nationalists. The memory of the heroic fallen was an issue that united conservatives and the radical right [...]" Baird, Jay W. (1990): To die for Germany: heroes in the Nazi pantheon. Bloomington: Indiana University Press, S. 4.

696 Schilling (2002): Kriegshelden, S. 300

697 Sie wollten das Andenken im Symbol des „unbekannten Soldaten“ lebendig halten, denn „[E]er lebt unverändert in der kleinen feldgrauen Schar, die seine Ehre durch die trüben Jahre trug." Foertsch, Hermann (1934): Der deutsche Soldat. Leipzig: Seemann, S. 4f. 
Das Geleitwort schrieb Hermann Göring, der die Leistungen der „MarineLuftschiffer" als die „eindrucksvollsten“ Leistungen „deutschen Soldatentums“698 lobte. Damit wurden auch die Zigarettenalben zum willkommenen Medium, um die Kriegshelden wieder in das kollektive Bewusstsein zu rücken. Angesichts der Geschichtsvergessenheit gegenüber dem Ersten Weltkrieg wird den Veteranen in den Alben nicht nur eine Stimme verliehen, sondern es wird auch versucht, eine gedächtnisstiftende Erinnerungskultur für nachfolgende Generationen zu etablieren.

„Wohl die meisten Kriegsteilnehmer besitzen das oder jenes Kriegsbuch, vielleicht auch ihre Regimentsgeschichte, doch gerade die Jugend soll daran erinnert werden, was ihre Väter und Großväter während des Weltkriegs mitgemacht und ertragen haben. ${ }^{\prime 699}$

Insbesondere die Fliegerasse von einst erfuhren in der Populärkultur eine Wiederauferstehung. Mit dem Jagd- und Kampfflieger, behaftet mit der Aura des opferbereiten Kriegers, konnten das rechte politische Lager und die alten militärischen Eliten einen Heldenkult aufleben lassen, der an die preußische Tradition anknüpfte. ${ }^{700}$ Der Flieger, der für Volk und Vaterland den Heldentod gestorben war, wurde sowohl Sinnbild für den Einzelnen als auch für das Kollektiv und war damit prädestiniert, von der rechten Propaganda vereinnahmt zu werden. ${ }^{701}$ Im Dritten Reich sollten die Helden wieder für heilige Reliquien wie Freiheit, Recht und Ehre kämpfen, Werte, für die die Flieger ihr Leben auf dem Altar des Vaterlandes geopfert hatten. Damit fand eine „[...] Verla-

698 Goote, Thor (1938): Der Führer der Luftschiffe. Mit einem Geleitwort vom Oberbefehlshaber der Luftwaffe Generalfeldmarschall Hermann Göring, Frankfurt/M.: dbg, Einleitungstexte, unpag. Ausgelobt wurde der Preis vom Oberbürgermeister der Stadt Frankfurt/M., die Auswahl wurde u.a. getroffen von der Reichsstelle zur Förderung des deutschen Schrifttums, dem Pressechef des Reichsluftfahrtministeriums und Oberst Loerzer im RLM. Reunion (1933): Reunion-Weltkriegsbilder 1914-1918. Obercunnersdorf. Zur Einführung! unpag.

700 Vgl. Schilling (2002): Kriegshelden, S. 293f. In dem Album Uniformen im neuen Deutschland wird explizit auf die preußische Tradition der neu gegründeten Wehrmacht verwiesen: „Im Soldatentum des Dritten Reiches verbinden sich der Geist und Ethos der alten preußischdeutschen Armee mit der Beherrschung neuzeitlichen militärischen Könnens [...] und mit der Bejahung nationalsozialistischer Weltanschauung." Aviatik (1936): Uniformen im neuen Deutschland. Wehrmacht. Breslau, S. 3. Der Preußenkönig Friedrich II. wurde in der NS-Zeit aus dem Kontext der Historie genommen und zum Inbegriff deutscher wie soldatischer Tugenden wie Ehre, Pflichterfüllung, Disziplin und Gehorsam. Vgl. Wegner, Bernd (2008): Hitlers politische Soldaten: Die Waffen-SS 1933-1945, 5. Aufl. Paderborn: Ferdinand Schöningh, S. 64 Vgl. Diehl (2005): Macht, S. 63 
gerung der Deutung des Soldatentodes von victima zum sacrificium, vom sinnlosen Sterben im Krieg zum sinnvollen Heldensterben und Opfertod“702 statt.

Da sich Deutschland nach dem Ersten Weltkrieg selbst als Opfer betrachtete, das der Willkür der Siegermächte hilflos ausgeliefert war, konnte das empfundene Unrecht nur auf der Basis von „Opferbewußstsein" ${ }^{\prime 703}$ restauriert werden, denn auch verlorene Kriege können nationalen Stolz provozieren und Demonstrationen von „Heldentum und Opferbereitschaft" ${ }^{\prime 704}$ zur Folge haben. Mit dem Aufleben des Heldenkultes unter den Nationalsozialisten wurden die Fliegerasse zu stellvertretenden Erlöserfiguren stilisiert. Sie sollten einer aus den Fugen geratenen Zeit einen Wertekanon verleihen und der ersehnten Zeitenwende eine positive Richtung geben. Die Fliegerhelden konnten damit die leer gewordene Nische numinoser Heilsbringer besetzen. In dem Sammelband Helden DeR Luft Bd. 1 werden sie zu Helden, die, aus Historie herausgelöst, den kollektiven Narzissmus der Gesellschaft befriedigen.

„Einzelne Namen sind im Gedenken des Deutschen Volkes unvergänglich eingebrannt. Hell leuchtenden Sternen gleich sind Immelmann, Boelcke, Richthofen unvergessen, um dessen Tod sich Legenden bildeten, die im Volke umgehen, wie es deutsche Art um deutsche Helden ist. Aber keiner von allen soll vergessen sein." 705

In den Zigarettenalben, die sich propagandistisch in den Dienst des Nationalsozialismus stellen, wird die Opferbereitschaft der Fliegerasse zur Apotheose stilisiert. Ihr Opfer steht nicht mehr ausschließlich im Kontext des Krieges, sondern im Dienst für die Gemeinschaft. ${ }^{706}$ Der Flieger, der seine Einzelseele für die Zukunft seines Volkes gegeben hatte, ${ }^{707}$ wurde von der NS-Politik vereinnahmt und Teil der „völkischen

\footnotetext{
$702 \quad$ Kaiser (2010): Helden, S. 32f.

703 Assmann (2006): Schatten, S. 65

704 Kühner, Angela (2008): Trauma und kollektives Gedächtnis. Gießen: Psychosozial-Verlag, S. 155

705 Orami (1933): Helden, Bd. 1, S. 16

706 Im dem Katalog „Die Pflichten des deutschen Soldaten“ heißt es: „Die Ehre des Soldaten liegt im bedingungslosen Einsatz seiner Person für Volk und Vaterland bis zur Opferung seines Lebens", gezeichnet von Reichspräsident von Hindenburg und Reichswehrminister Blomberg. In: Aviatik (1936): Uniformen, S. 2 
Ethik ${ }^{\prime 708}$ Die Fliegerhelden, die in den Kontext von Opfer und Leid gesetzt wurden, konnten so als Ressource einer künftigen Volksgemeinschaft dienen.709 Ziel war es, eine von Idealen geprägte Volksgemeinschaft heranzuziehen, die auf Verzicht und Opferbereitschaft basierte..$^{710}$

Der Kampf- und Jagdflieger erfährt damit eine semantische Verschiebung vom individuellen Hasardeur zur Heldenfigur, der sich in ein Kollektiv einfügt und altruistisch für die Gemeinschaft opfert. In dem Sammelband HeLDEN DER LUFT wird den „Toten Pour-le-mérite-Helden der Luft" ein eigenes Kapitel gewidmet. Die besondere Hervorhebung des Pour le Mérite weist eine eindeutige Tendenz zum rechten politische Lager auf, denn diese Auszeichnung wurde in der Weimarer Republik nicht vergeben und erst von den Nationalsozialisten wieder eingeführt. ${ }^{711}$ In dem Sammelband Deutsche Helden erhalten die Kampfflieger die Aura des Numinosen. Ihre Namen sind in die Ehrentafel des Volkes eingraviert und sie werden mit dieser Ehrung in das nationale Pantheon aufgenommen:

„Die 240 Bilder gehen hinaus in ernster, harter Zeit. Sie sollen in uns die Erinnerung stärken an die Helden, die einst in schweren Tagen Willen und Kraft einsetzten und ihr Leben hingaben für Ihres Vaterlandes Freiheit, Recht und Ehre. ${ }^{\text {712 }}$

Die toten Helden werden als Träger einer kulturellen Identität zu einem vitalen Bestandteil des nationalen Bewusstseins, denn „[J]jedes Land hat seine Helden“ deren Namen „mit ehernen Lettern in aller Herzen geschrieben stehen:“713 Das Bedürfnis der Menschen nach Helden, die mit ihrem Opfer eine Vermittlerrolle zwischen der

\footnotetext{
708 Behrenbeck (2011): Helden, S. 65

709 Vgl. Assmann (2006): Schatten, S. 65

710 Vgl. Winckler, Lutz (1985 ): Studie zur gesellschaftlichen Funktion faschistischer Sprache, 4 . Aufl. Frankfurt/M.: Suhrkamp, S. 74f.

711 In der Weimarer Republik stand man Orden ablehnend gegenüber; Ordensverleihungen waren verboten. Erst im Jahr 1924 wurde die „Freie Vereinigung der Ritter des Ordens Pour le Mérite“ zugelassen. Fuhrmann(1992): Pour le Mérite, S. 51

712 Kyriazi (1933): Helden, Vorwort, unpag.

713 Orami (1933): Helden, Bd. 1, S. 9
} 
sakralen und profanen Welt besetzen, ${ }^{714}$ beweist die Vielzahl an Textpassagen in den Zigarettenalben, in denen die dargebrachten Opfer zu heiligen Taten stilisiert werden.

„Sie [Anm.: die Bilder] sollen in uns die Erinnerung stärken an die Helden, die einst in schweren Tagen Willen und Kraft einsetzten und ihr Leben hingaben für ihres Vaterlandes Freiheit, Recht und Ehre. Immer in den Leidenszeiten des Unglücks erwachte in einem sittlich starken Volke die Kraft nationalen Heldentums, und wer im Anblick dieser Bilder die deutsche Vergangenheit durchdenkt, dem wird der freudige Glaube das Herz erheben, daß Führer und Helden auch unser Volk wieder aufwärts leiten werden zu Glück und Größe. ${ }^{\text {715 }}$

„Gefallen für Deutschland, gestorben den Fliegertod um das deutsche Volk! Nicht umsonst. [...] Ihr Tod sei unser Vorbild: Das Leben für Deutschland!" ${ }^{\prime 716}$

„Unser aufrichtiger Wunsch begleitet alle unter uns weilenden Lufthelden, daß sie noch lange und erfolgreich zum Segen des Deutschen Volkes tätig sein mögen, dessen leuchtende Vorkämpfer sie einstmals gewesen sind.“717

„[... die] deutschen Truppen bewiesen in diesen Kämpfen ihre militärische Tüchtigkeit und ihre Opferwilligkeit für den großen Gedanken an ein gemeinsames Vaterland. “"

Der verlorene Krieg und die Restriktionen des Versailler Vertrages hatten ein kollektives Trauma zur Folge, das geprägt war von der Ohnmacht gegenüber den Siegermächten, denn sie konnten die Geschichte schreiben - eine Geschichte, die von den Verlierern nicht akzeptiert und verarbeitet werden konnte. ${ }^{719}$ Es trat eine Verweigerung ein, die historischen Ereignisse zu akzeptieren. In den Zigarettenalben werden die Flieger herangezogen, um einen Gegenentwurf zu einer inakzeptablen historischen Tatsache zu schaffen. ${ }^{720}$ Die Flieger werden zu Protagonisten eines nationalen

714 Das Opfer ist Bestandteil des religiösen Bewusstseins, es hebt den Gegensatz zwischen Mensch und Gott auf und schafft eine Verbindung zum Heiligen. Vgl. Cassirer, Ernst (2010): Philosophie der symbolischen Formen. Zweiter Teil. Das mythische Denken, Hamburg: Meiner, S. $266 f$.

715 Kyriazi (1933): Helden, Vorwort, unpag.

716 Orami (1933): Helden, Bd. 1, S. 16

717 Orami (1933): Helden, Bd. 2, S. 6

718 Kyriazi (1933): Deutsche Helden. Vorwort, unpag.

719 Vgl. Assmann (2006): Schatten, S. 70

720 Der Mythos des im Felde unbesiegten deutschen Soldaten war Konsens in der gesamten Parteienlandschaft. Vgl. Schivelbusch, Wolfgang (2001): Die Kultur der Niederlage. Berlin: Rowohlt, S. 242 
Mythos, deren heldenhafte Taten angesichts der Kriegsniederlage im vermeintlich ungleichen Kampf potenziert werden.

„Deutschlands Flieger blieben im Weltkrieg unbesiegt. Die letzten Konstruktionen unserer Kampfflugzeuge waren denen der Feindmächte weit überlegen. ${ }^{\prime \prime}{ }^{721}$

„Das Material der Rohstoffquellen, die uns immer spärlicher flossen, entschied schließlich den ungleichen Kampf." ${ }^{\prime 722}$

„Daß uns gegenüber der Feind, dem eine ungeheuer große Industrie zur Seite stand, hier stets der Erzeugungsmenge nach im Vorteil war, liegt auf der Hand, wenn wir ihm auch, was die Güte des Menschen- und Maschinenmaterials anbelangt, wohl ebenbürtig, vielleicht sogar überlegen waren. ${ }^{4723}$

„Daß die junge Flugzeugwaffe im Kriege den Gegner schwer geschädigt hat, das beweist wohl am besten die Tatsache, daß dieser im Versailler Vertrage uns jede militärische Verwendung von Flugzeugen verboten hat. Die Ruhmestaten unserer Kriegsflieger aber werden nie vergessen sein. ${ }^{\prime 724}$

"In schweren und bitteren Kämpfen und vor allem durch die hohen Leistungen unserer Fliegertruppe hat die Entente die deutschen Luftstreitkräfte kennen und fürchten gelernt. Die Furcht wuchs ins Unermeßliche und fand erst durch den Friedensvertrag von Versailles, den diktatorischen Machtanspruch, eine Milderung. ${ }^{\prime 725}$

Vor dem Hintergrund des Kriegsschuldartikels und des verlorenen Krieges war die „Gedächtnisstrategie aus der Perspektive der Verlierer eher auf Selbstauratisierung und Mythenbildung ausgerichtet" ${ }^{\prime 726}$ als auf Völkerverständigung. Die kollektive Entfremdung, die in der Weimarer Republik zugenommen hatte, bot national-konservativen Kreisen einen optimalen Nährboden zum Einpflanzen

721 Austria (1934): Taschenbuch der Luftwaffe, Bd. 1. München (Vorwort von Ing. B. u. H. Von Römer, München), Texte zu den Bildern 1-4, unpag. In dem Album Der Weltkrieg werden Human- und Material-Ressourcen bilanziert. Die Daten bescheinigen dem Deutschen Reich eine erfolgreiche Abschussquote. Insgesamt 6811 abgeschossenen Flugzeugen stehen dem eigenen Verlust 4053 Maschinen gegenüber. Bilderdienst Dresden (1937): Weltkrieg, Kapitel: Der Große Krieg in Zahlen, unpag.

722 Orami (1933): Helden, Bd. 1, S. 16

723 Reunion (1933): Weltkriegsbilder, Serie VII: Flieger, unpag.

724 Ebd.

725 Brinkmann (1934): Waffenstarrende Ausland, S. 36

726 Rheinhart Koselleck. Zit. nach: Assmann (2006): Schatten, S. 70 
nationaler Mythennarrationen. Damit sollte das deutsche Volk gleich einer Schicksalsgemeinschaft $\mathrm{zu}$ einem Revisionismus gegen das "Schanddiktat von Versailles ${ }^{\text {“727 }}$ zusammengeschweißt werden. Um das angeschlagene Selbstbewusstsein der Nation wieder aufzurichten wurde der Mythisierungsprozess um die toten Helden vorangetrieben. Um eine positive kollektive Erinnerung der Deutschen wiederherzustellen erfuhren die Fliegerhelden mediale Wiederauferstehung, wobei verstärkt Medien der Populärkultur wie Zigarettenalben eingesetzt wurden. Exemplarisch dafür ein Textbreitrag in dem Sammelband HELDEN DER LUFT:

„Eines Tages werden auch die letzten Fesseln fallen. Wir werden dann den Weg bis zum leuchtenden Ziele vollenden können, der uns gewiesen wurde von den Pionieren der Luftfahrt. “728

Die Metamorphose der einstigen Fliegerasse zu legendären Heldenfiguren folgt einer dem Mythisierungsprozess immanenten Logik. Um die Fliegerhelden in das kollektive Gedächtnis des Volkes zu implementieren, mussten ihre individuellen Eigenschaften, die sie in einem historischen Kontext erworben und unter Beweis gestellt hatten, abgelöst werden. Mircea Eliade hat die Notwendigkeit dieser Transformation aufgezeigt. Er vertritt die These, dass „[D]das Volksgedächtnis [...] ahistorisch“ und nicht im Stande ist, „,historische Ereignisse und Individualitäten festzuhalten. “" dann, wenn die toten Fliegerhelden in Archetypen transformiert werden, kann das heroische Selbstopfer der Kampfflieger in eine ontologische Vorstellungswelt transferiert und zu einer anderen Zeit repetiert werden. „[...] [J]jedes Opfer wiederholt das anfängliche Opfer und fällt mit ihm zusammen, koinzidiert mit ihm.“730 Der Transformationsprozess, den die Helden erfuhren, ermöglichte eine Erweiterung des nationalen Mythenrepertoires, womit der Flieger als Topoi in das kulturelle Erbe

Bauer (2008): Nationalsozialismus, S. 65

Orami (1933): Helden, Bd. 1, S. 10

Vgl. Eliade, Mircea (1984): Kosmos und Geschichte. Frankfurt/M.: Insel, S. 60

Ebd. S. 49 
integriert werden konnte. Ernst Jünger, dessen Schriften insbesondere im nationalkonservativen Lager Beachtung fanden, ${ }^{731}$ charakterisiert in der Anthologie ,Luftfahrt ist not!' den nationalen Mythos als vitale Quelle, aus der ein Volk mehr Kraft schöpfen kann als aus politischen Verlautbarungen: „Denn nur, was im inneren Bestande eines Volkes gesichert ist, wird sich auf die Dauer im äußeren Bestande erhalten können. Diese Sicherung im inneren Bestande ist eine der vorzüglichen Aufgaben gerade in unserer Zeit, in der uns auf so vielen Gebieten der Regsamkeit die Flügel beschnitten sind. "732 In dem Zigarettenalbum DeUTSCHE HELDEN wird die Bedeutung nationalen Heldentums exemplarisch artikuliert. Die psychologische Grundstimmung der deutschen Nation, die nach einer mythologischen Kraftquelle als Basis für die erlösende, glückverheißende Zukunft verlangte, wird mit nationalem Pathos artikuliert:

„Wer über die Gegenwart sinnt, der findet beim Anblick dieser Bilder Lehre, Trost und beglückende Ruhe; denn er schaut zurück in eine große Vergangenheit und gewinnt die Zuversicht, daß auch unsers Volkes Zukunft wieder groß und glücklich wird durch die Kraft deutschen Heldentums. ${ }^{\text {"733 }}$

Die Flieger wurden so zu einem vitalen Bestandteil des Nationalmythos und damit zu Garanten einer „kulturellen Homogenität“, die eine „gemeinsame Mission, ein gemeinsames Schicksal, eine gemeinsame Bestimmung "734 symbolisierten. Ihr Mythos erhielt eine numinose Kraft, die in Krisenzeiten ein großes „emotionales Echo“ erfuhr. Die Menschen gelangten zu der Überzeugung, dass ihr Opfer zur Erlösung führen wird. ${ }^{735}$ In dem Album DeUTSCHE HELDEN wird das Opfer des Helden zur emotionalen Vitalisierung, zum Glaubenselixier und zur Ressource für die Hoffnung auf eine gütige Schicksalswendung.

\footnotetext{
731 Vgl. Kiesel, Helmuth (2007): Ernst Jünger. München: Siedler, S. 286

732 Jünger, Ernst (1933): In Ders. (Hg.): Luftfahrt ist not! Leipzig: Vaterländischer Buchvertrieb Thankmar Rudolph, S. 8

$733 \quad$ Kyriazi (1933): Helden, Vorwort, unpag.

734 Baumann, Zygmunt (2005): Moderne und Ambivalenz, Hamburg: Hamburger Edition, S.109

735 Edelmann (1990): Politik, S. 160
} 
„Immer in den Leidenszeiten des Unglücks erwachte in einem sittlich starken Volke die Kraft nationalen Heldentums, und wer im Anblick dieser Bilder die deutsche Vergangenheit durchdenkt, dem wird der freudige Glaube das Herz erheben, daß Führer und Helden auch immer unser Volk wieder aufwärts leiten werden zu Glück und Größe. “736

Im Rahmen der „nazistischen Liturgie“737 war der Fliegerheld des Ersten Weltkrieges aufgrund seiner ihm zugeschriebenen Eigenschaften prädestiniert, einen Platz im NS-Pantheon einzunehmen und Teil der Erinnerungskultur zu werden. ${ }^{738}$ In den Zigarettenalben mit NS-Hintergrund erfuhren die Fliegerhelden eine entsprechende neue Konnotation. So konnten sie als transzendente Leitbilder in das kollektive Erbe des deutschen Volkes implementiert werden. Mit den Helden wurde eine Kohäsion zwischen "einer ruhmreichen Vergangenheit" ${ }^{\text {“739 }}$ und einer Zukunft geschaffen, aus der das deutsche Volk Hoffnung auf eine glückliche Zukunft ziehen konnte. In dem Album DeUtSCheR RUHM ${ }^{740}$ gehen die Fliegermythen als „Meisternarrationen“ in das kulturelle Erbe der deutschen Nation ein und werden Teil der ",Heroengalerie‘ und ,Leistungsschau“". ${ }^{741}$

In den Zigarettenalben generieren die Flieger zu Helden, die in die Reihe herausragender Persönlichkeiten aus Kunst, Wissenschaft, Forschung und Vertretern des NS-Regime eingegliedert werden. Diese Genealogie wurzelt in einem Heldenbild des 19. Jahrhunderts, das Personen aus der Historie mit Persönlichkeiten unterschiedlichster Disziplinen in der nationalen Heroengalerie verklärte. ${ }^{742}$ So stehen von Richthofen

\footnotetext{
$736 \quad$ Kyriazi (1933): Helden, Vorwort, unpag.

737 Friedländer, Saul (2007): Kitsch und Tod. Der Widerschein des Nazismus. erweiterte Auflage, Frankfurt/M.: Fischer, S. 51

738 Vgl. Sywottek, Jutta (1976): Mobilmachung für den totalen Krieg. Opladen: Westdeutscher Verlag, S. 90

739 „Die Pflichten des deutschen Soldaten, gezeichnet von Reichspräsident von Hindenburg und Reichswehrminister Blomberg". In: Aviatik (1936): Uniformen, S. 2

740 Bergmann (1933): Deutscher Ruhm, Bd. 1. Dresden

741 Hein-Kircher, Heidi (2011): „Überlegungen zum Verhältnis von Erinnerungsorten und politischen Mythen. Eine Annäherung an zwei Modebegriffe“. In: Tepe, Peter/ Semlow, Tanja (Hg.) (2011): Mythos No. 3. Mythos in Medien und Politik. Würzburg: Königshausen \& Neumann, S. 69

742 Als Helden galten nicht nur Gestalten aus der deutschen Mythologie, sondern auch aus der Kunst, Wissenschaft und Historie. Diese Einordnung steht für einen imperialen Anspruch des wilhelminischen Deutschland, die den demokratischen Bestrebungen der aufkommenden Industriegesellschaft entgegenstand. Vgl. Schulz (2004): Ästhetisierung, S. 72.
} 
und Boelcke mit Max Planck, von Humboldt und Friedrich Schiller in einer Ahnengalerie mit Hitler und von Papen. ${ }^{743}$ Mit dieser Kontinuitätslinie konnte das NS-Regime nicht nur die vermeintlichen Tugenden der Jagd- und Kampfflieger in das deutsche Mythenrepertoire eingliedern, sondern auch die eigene Machtposition legitimieren. ${ }^{744}$

Die Stilisierung der Fliegerasse zu Heroen der Nation erfährt in den Zigarettenalben eine ikonische Reduktion mit der höchsten Kriegs-Auszeichnung dem Orden ,Pour le Mérite', dem symbolischem Ausdruck vaterländischen Heldentums. Damit konnten auch die Kampf- und Jagdflieger, die den Ersten Weltkrieg überlebt und sich in der Wirtschaft und im Ingenieurbereich etabliert hatten, vom Nimbus dieser Auszeichnung partizipierten. Der Pour le Mérite verlieh ihnen über ihre Funktionen hinaus die Legitimation, eine exponierte Stellung innerhalb der NS-Volksgemeinschaft einzunehmen. In dem Album HeLDEN DER LUFT werden sie zu „Leitenden Köpfen der nationalen Luftfahrt“745 und gelten als „Männer, die gezeigt haben, daß sie nicht erst beweisen müssen, was sie dem Volke sein wollen“. ${ }^{746}$ Kampferprobt sei es ihnen nach dem Krieg gelungen, sich in das zivile Leben $\mathrm{zu}$ integrieren um „heute im Wirtschaftsleben unseres Deutschen Volkes tätig" ${ }^{\prime 777} \mathrm{zu}$ werden. Das Album rühmt sich, diesen Männern eine Stimme zu verleihen:

743 Bergmann (1933): Ruhm, Bd. 1, Neben der Luftfahrt werden ,Deutsche Helden' des Landheeres und der Marine vorgestellt. Ferner werden Persönlichkeiten aus anderen Bereichen aufgezählt, darunter: Otto v. Bismarck, Paul v. Hindenburg, Friedrich II., Freiherr v. Humboldt, Max Planck, Robert Koch, Friedrich v. Schiller, J.W. v. Goethe, G.E Lessing, Richard Wagner, L.v. Beethoven, Joseph Haydn, F. Fröbel, T. Mommsen.

744 Diese Genealogie folgt dem Heldenschema wilhelminischer Prägung, die Vorstellungen germanischer Provenienz von Kampf, Sieg und Untergang einbezog. Das Heldenbild reflektiert sowohl die gesellschaftspolitische Situation als auch den Herrschaftsanspruch der aristokratischen Elite. Vgl. Ebd., S. 73

745 Orami (1933): Helden, Bd. 1, S. 37

746 Ebd. und „Zur Einleitung“ . Neben Göring werden Bruno Loerzer Hauptmann a.D. Bruno Loerzer war Präsident des Deutschen Luftsportverbandes e.V. (Quelle) und Kapitän Christiansen, Pilot der DO X abgebildet. 
„[...] es ist uns gelungen, allen Freunden unserer Sammlung die Männer im Bilde zu zeigen, die einst gefürchtete Gegner waren und deren Taten unvergessen bleiben. [...] In ihrer Gesamtheit erwiesen sie sich als zähe und siegreiche Kämpfer. Sie haben das Leben (Anm.: nach dem 1. Weltkrieg) ebenso bezwungen wie einst den gleichwertigen Gegner. [...] Es sind Männer aus ihrer Mitte, die heute in der Führung der Nation stehen. ${ }^{\text {"748 }}$

Von dem Nimbus des Pour le Mérite partizipierte insbesondere die neue NS-Parteielite, denn diese Auszeichnung verlieh den Trägern innerhalb der nationalsozialistischen Hierarchie soziale Anerkennung. In den Texten kommt der Paradigmenwechsel zum Ausdruck, der sich während des NS-Regimes vollzogen hatte. Im Unterschied zum Kaiserreich war nicht mehr die Herkunft entscheidend, sondern die soldatische Leistung und die Bereitschaft, sich für das Vaterland aufzuopfern. ${ }^{749}$ In den Aviatik-Alben steht der „Richthofen-Nachfolger“750 Göring, exemplarischer Repräsentant des Drittes Reiches, im Zentrum der Heldenverehrung. Er konnte seinen Führungsanspruch nicht nur auf sakrale Meriten wie dem Pour-le-Mérite zurückführen, sondern auch auf seine Funktion als Kommandeur des legendären Jagdgeschwaders Richthofen. In militärischem Ornat ${ }^{751}$ und mit Orden dekoriert steht er als Reichsministers für Luftfahrt an prominenter Stelle am Beginn fast jeder Bildersammlung der Aviatik-Alben.752 In den Zigarettenalben werden ihm soldatische Attribute zugeschrieben, die ihn für sein hohes politisches Amt auszeichnen. Er wird in die

Ebd.

Vgl. Kehrt (2010): Krieger, S. 238

Göring wurde nach dem Tod Richthofens dessen Nachfolger. Vgl. Bewley, Charles (1956): Hermann Göring. Göttingen: Göttinger Verlagsanstalt, S. 29.

Als „Richthofen-Nachfolger“ gab Göring „das heilige Versprechen, daß dieses Geschwader einmal neu erstehen solle.“ Müllenbach, Herbert (1941): Eroberung der Luft. „Vom "fliegenden Menschen" zum "Großen Dessauer", 4. Aufl. München: Zentralverlag der NSDAP., Frz. Eher Nachf., S. 81

751 Göring ließ sich nahezu ausschließlich in Herrscherpose, Uniform und Orden abbilden. Ronge, Tobias (2010): Das Bild des Herrschers in Malerei und Grafik des Nationalsozialismus. Eine Untersuchung zur Ikonografie von Führer- und Funktionärsbildern im Dritten Reich. Berlin: LIT, S. 174

752 Greiling (1936): Wunder des Segelfluges. Dresden. Greiling (1934): Zeppelin Weltfahrten II., Dresden. Orami (1933): Helden, Bd. 1 
Genealogie der „Lebenden Pour-le-mérite-Helden der Luft“ aufgenommen und gilt als , „[...] erster Garant für den Kampf gegen sinnlose Knebelung.“753

„Hermann Göring Pour-le-mérite-Flieger des großen Krieges! - Schon damals, draußen im Feindesland, im fürchterlichen Ringen um Heimat und Herd zeigte er, daß er Entschlußkraft und einen unbändigen Mut in sich trug! - [...] Die größte Ehre wurde ihm zuteil, als er zum Führer der Staffel ausersehen wurde, die den Namen des größten deutschen Fliegerhelden, Richthofen, trug. "

„[In] Göring lebt der Geist unserer großen Flieger Richthofen und Boelcke, derselbe Geist, aus dem heraus 1920 die ersten Segelflieger auf die Wasserkuppe zogen mit dem festen Willen, die deutsche Luftfahrt durch alle Not aufrecht erhalten und im Geiste der großen Helden des Weltkrieges weiterzuarbeiten. ${ }^{\text {}} 755$

„Der Name Hermann Göring ist ein Programm - ein Programm, das kaum einer Erläuterung bedarf. Denn so steht er vor dem deutschen Volke, vor der ganzen Weltöffentlichkeit: ein begeisterter Soldat, ein glühender Revolutionär, ein eiskalter Politiker, ein energischer Staatsmann, ein mutiger Flieger. [...] Reichspräsident von Hindenburg ernannte ihn in seines soldatischen Wollens und Kämpfens zum General der Infanterie“756

Andere Honoratioren der Luftfahrt wie Bruno Loerzer, dem Präsidenten des Deutschen Luftsportverbandes e.V., werden zum „Vorbild für die junge FliegerGeneration“757 und gelten als Männer, die „unerschütterlich in ihren Entschlüssen, erfüllt vom Fanatismus ihrer hohen Aufgabe und sicher in ihren Zielen [...] an der Spitze ${ }^{\prime \prime 758}$ stehen.

„Immer wird ihnen das Deutsche Volk für ihre Taten Dank wissen. Sie werden der kommenden Generation stets leuchtendes Vorbild sein und bleiben. Es sind Männer aus ihre Mitte, die heute in der Führung der Nation stehen und sie zu strahlender Erneuerung führen wollen, erfüllt von altem Flieger- und Kämpfergeist, dem kein Ziel zu hoch und keine Mühe zu niedrig ist, wenn es ums Ganze geht. “759

\footnotetext{
753 Orami (1933): Helden, Band 1, S. 37

$754 \quad$ Zigaretten-Industrie (1934): Kampf, S. 54

755 Greiling (1936): Wunder, Kapitel: Wie wird man Flieger? unpag

756 Brinkmann (Yosma) (1934): Männer im Dritten Reich. Bremen, S. 12, Bild 6

757 Bergmann (1933): Ruhm, S. 21

758 Orami (1933): Helden, Bd. 1, S. 37

759 Orami (1933): Helden, Bd. 2, S. 5
} 
Die gefallenen Flieger des Ersten Weltkrieges erfuhren durch Reminiszenzen in Form von Namensgebungen und Gedenktagen im nationalsozialistischen Feiertagskalendarium eine Wiederauferstehung. ${ }^{760}$ Sie wurden Teil der Erinnerungskultur, denn die Feier ermöglicht eine „Vergegenwärtigung fundierender Vergangenheit". Die Gedenkfeier für die Kriegshelden wirkt auf die soziale Gemeinschaft sowohl „gedächtnisstiftend“ als auch "transzendent-magisch", da sie die Verbindung mit dem Heiligen ermöglicht und „Krisenbewältigungsmechanismen in Gang“ bringt“761

Die Erinnerungsorte und Gedenktage werden auch in den Zigarettenalben vielfach thematisiert, wobei der populärste deutsche Flieger Manfred von Richthofen im Fokus steht. Als „Achill der Lüfte“ wird er "Allgemeingut des deutschen Volkes“.762 In dem Sammelband DIE DEUTSCHE WEHRMACHT erfährt der einstige Fliegerheld bei der Einweihung des Jagdgeschwaders „Richthofen“ durch Hitler am „Tag der Luftwaffe“763 eine Wiederauferstehung. Die Feierlichkeiten, wie die Gedenkfeier anlässlich seines Todestages, werden dem Bildersammler als klerikale Veranstaltung in Text und Bild vor Augen geführt.

„Alljährlich am 21. April, dem Todestag Manfred von Richthofens, feiert die Wehrmacht und mit ihr das ganze Volk den „Tag der Luftwaffe“. An ihm stellt in allen Standorten des Reiches die Luftwaffe die Ehrenwachen. ${ }^{\text {“764 }}$

760 Eine vergleichbare Liturgie fand bei den Feierlichkeiten am 9. November, bei denen den „Märtyrern der Bewegung“ gedacht wurde, statt. Auch hier war die "Wiederholung des Opferganges" zentraler Bestandteil des Ritus. Die Helden, die ihr Leben geopfert hatten, erlebten wie bei einer kultischen Handlung eine Wiederauferstehung. Sie wurden dabei zu Rettern und „Wächter“ der Nation. Behrenbeck, Sabine (2000): „Durch Opfer zur Erlösung. Feierpraxis im nationalsozialistischen Deutschland“. In: Dies./ Nützenadel, Alexander (Hg.): Inszenierungen des Nationalstaates. Politische Feiern in Italien und Deutschland seit 1860/71. Köln: SH-Verlag, S.158ff. Wulf, Christoph/ Zirfas, Jörg. In: Dies. (Hg.) (2004): Die Kultur des Rituals. Paderborn: Wilhelm Fink, S.18

762 Kosmos (1937): Deutsche Männer, Deutsche Taten! Dresden, Kapitel: Rittmeister Manfred von Richthofen, unpag.

763 Zigaretten-Industrie (1936): Wehrmacht, Bild 265, unpag.

764 Ebd., Bild 266 
Das letzte Bild ${ }^{765}$ der Sammlung zeigt Richthofens Grabstätte, die von einer Ehrenwache flankiert wird. Der im klassizistischen Stil gehaltene Gedenkstein vor dem Hintergrund einer Baumreihe unterstreicht die „säkularisierte Religion des Nationalsozialismus“, die antike und christliche Motive sowie „einheimische Landschaften“766 miteinander verband. Aufgrund der exponierten Platzierung der Aufnahme am Ende des Albums erhält die Gedenkstätte eine symbolische Erhöhung. Richthofens unsterbliche Aura wirkt damit wie ein abschließendes Versprechen, mit dem das Schutzpatronat für die Wehrmacht und das deutsche Volk besiegelt wird.

„Das Grab Richthofens auf dem Invalidenfriedhof in Berlin ist die heiligste Gedächtnisstätte der Luftwaffe. Im Geist ihres größten Vorkämpfers dient sie dem Schutz von Volk und Reich. ${ }^{\text {} 767}$

Mit der Wiederbelebung der Fliegerhelden folgt das Album DIE DEUTSCHE WEHRMACHT der staatlich verordneten Doktrin, den Richthofen-Mythos zu propagieren und zu verbreiten, um dessen traditionsstiftende Funktion ${ }^{768} \mathrm{zu}$ verstärken. Die rituelle Wiederholung der Feier bewirkt die "Herstellung kultureller Kohärenz", womit der Ritus nicht nur sinnstiftend ist, sondern dem vergangenen Geschehen auch ein Muster" ${ }^{\prime \prime 69}$ verleiht. Die Denkmäler erhalten damit eine Metaebene, die an ein gemeinsam erlittenes Leid und Opferbereitschaft erinnert. Die Gedenkfeier wird in dem Sammelband zum Symbol historischer Kontinuität und Stabilität, die der traumatisierten Nation gemeinsame Werte und Hoffnung vermitteln soll. Die Rituale, die vor den Gedenkstätten vollzogenen werden, beschwören eine gemeinsame Geschichte ${ }^{770}$ und erfüllen eine Identität stiftende Funktion, ${ }^{771}$ die das Kollektiv zu einer

766 Mosse, George L. (1993): Gefallen für das Vaterland. Nationales Heldentum und namenloses Sterben. Stuttgart: Klett-Cotta, S. 132. Historismus war die bevorzugte Architektur für die Gedenkstätten der Krieger des Ersten Weltkrieges. Behrenbeck (2011): Helden, S. 336. Die klassische Bauweise wurde vom Nationalsozialismus bewusst eingesetzt um eine „identitätsstiftende Umgebung“ mit Kontinuitätscharakter zu erschaffen. Bartetzko, Dieter (1985): Illusion in Stein. Stimmungsarchitektur im deutschen Faschismus. Ihre Vorgeschichte in Theater- und Film-Bauten. Reinbek bei Hamburg: Rowohlt, S. 33

767 Zigaretten-Industrie (1936): Wehrmacht, Bild 270, unpag.

768 Kehrt (2010): Krieger, S. 224

769 Assmann (1992): Gedächtnis, S. 89f.

770 Vgl. Kühner (2008): Trauma, S. 193 
Schicksalsgemeinschaft zusammenschweißt. So wurden Bezugspunkte eines „kulturellen Gedächtnisses“772 etabliert, die die Verbundenheit des Volkes mit der Geschichte und ihren Helden festigte. Die traumatisierte Nation erhielt mit den Ritualen und Gedenkstätten einen Raum für die kollektive Identität. ${ }^{773}$ Richthofens Gedenkstätte wurde auch ein symbolischer Ort der Trauer, in den die „libidinöse Energie“774 des Verlustes einging. Diese Energien, die sich in der Heldenverehrung konzentrierten, konnten dann zur „symbolischen Mobilmachung“ der Bevölkerung eingesetzt werden. ${ }^{775}$

\subsubsection{Triumph über die Schmach von Versailles}

Der Versailler Vertrag hat wie kein anderes Ereignis das politische Geschehen in der Weimarer Republik geprägt. ${ }^{776}$ Der Vertrag wurde in allen Teilen der Gesellschaft breit rezipiert und der Diskurs fand große mediale Verbreitung in politischen Schriften, historischen Analysen, Schulbüchern und Massenmedien. Die Friedensbedingungen und der Kriegsschuldartikel wurden von der überwiegenden Mehrheit der Bevölkerung als schmähliches Schanddiktat empfunden, das auch in allen Regierungskreisen auf Ablehnung stieß.777 Die Bestimmungen des Vertrages wurden gleichgesetzt mit

771 In der erinnernden Rückbindung an die Toten vergewissert sich die Gemeinschaft ihrer Identität. Vgl. Assmann (1992): Gedächtnis, S. 63.

772 Petermann (2007): Rituale, S. 25ff.

773 Kühner (2008): Trauma, S. 189

774 Behrenbeck (2011): Helden, S. 140

775 Schilling, René (2006): „Reichswehr, Wehrmacht und nationale republikanische Rechte“. In: Epkenhans, Michael/ Militärgeschichtliches Forschungsamt Potsdam (Hg.): Die Suche nach Orientierung in deutschen Streitkräften 1871 bis 1990. Norderstedt: BoD, S. 35.

776 Vgl. Cornelißen, Christoph (2001): ",Schuld am Weltfrieden“: Politische Kommentare und Deutungsversuche deutscher Historiker zum Versailler Vertrag 1919-1933“. In: Krumeich: Versailles 1919, S. 237

777 In der Forschung herrscht Konsens darüber, dass der Versailler Vertrag von der gesamten Bevölkerung in der Weimarer Republik abgelehnt wurde. Auch im Parlament herrschte unter den Parteien vom rechten bis linken Spektrum Konsens. Lediglich der Revisionismusgedanke war in den politischen Lagern unterschiedlich ausgeprägt. Vgl. Lorenz, Thomas (2008): „Die Weltgeschichte ist das Weltgericht!" Der Versailler Vertrag in Diskurs und Zeitgeist der Weimarer Republik. Frankfurt: Campus S. 40ff.

Vgl. "Nationalversammlung", 7. Sitzung, 14. Februar 1919, Bayerische Staatsbibliothek, Münchner Digitalisierungszentrum, Verhandlungen des Reichstages Bd.: 326. 1919/20, Berlin 1920, 4 J.publ.g. 1142 y, A-326, urn:nbn:de:bvb 12-bsb00000010-0 
Erniedrigung und Schikane einer ganzen Nation. Insbesondere der Kriegsschuldartikel und die Gebietsverluste wurden als „Schandfleck auf dem Schilde unserer Ehre und [als] ein Makel in den Augen der Kulturwelt" ${ }^{\prime 778}$ empfunden. Die Restriktionen des Vertrages hatten eine gedemütigte Nation mit einem zerstörten Selbstbild hinterlassen. ${ }^{779}$ Das kollektive wie individuelle Gedächtnis der Deutschen war daher ein "typisches Verlierergedächtnis“, das von Scham und Schmach geprägt war ${ }^{780}$ und ebenso an der deutschen Seele nagte wie die ökonomische Misere der Nachkriegsjahre. ${ }^{781}$ In der historischen Rezeption konservativer Historiker wurde der Versailler Vertrag „politisch-moralisch“ interpretiert, wobei „der Begriff der deutschen "Ehre“ immer wieder in den Mittelpunkt gerückt wurde“. Die Debatten um den Versailler Vertrag mündeten in Rechtfertigungspathos für Revisonsansprüche. ${ }^{782}$ Die Erinnerungskultur der Deutschen richtete sich daher auf eine verheißungsvolle Zukunft, die verbunden war mit dem Gedanken der Revanche. Insbesondere das rechte politische Lager forderte die Wiederherstellung der Ehre Deutschlands. ${ }^{783}$ Der Begriff der Ehre war von Beginn an der NS-Ideologie inhärent. Für den NS-Ideologen Alfred Rosenberg war sie das germanische Zentrum und Schicksalsnerv der deutschen Geschichte, für die jedes Opfer gebracht werden musste. Für Rosenberg war die Ehre ein Charakterzug der germanischen Rasse und stellte ein kulturelles Erbe dar, das im Nationalsozialismus wieder auflebte. ${ }^{784}$ Für Göring galten „Ehre und

\footnotetext{
778 Stahl, Friedrich (1927/ Neuaufl. 1986): Der Versailler Vertrag vom 28. Juni 1919 als ein Instrument der Ausbeutung, Erniedrigung und Schikanierung Deutschlands. Bremen: Faksimile-Verlag, S. 59 ff.

779 Vgl. Assmann (2006): Schatten, S. 67f.

780 Vgl. Ebd., S. 66f.

781 Vgl. Schivelbusch (2001): Niederlage, S. 283. „Nicht genug, daß der Frieden von Versailles Deutschland wirtschaftlich und finanziell zu Grunde richtet und völlig macht: Wir sollen auch ehrlos werden.“ Lersner, Freiherr von, MdR (1921): „Strafbestimmungen“, S. 49 Der bedeutendste Vertreter der konservativen Historiker war Hermann Oncken, der 1933 in seiner Arbeit den Versailler Friedensvertrag als „Verkrüppelung“ der deutschen Nation betrachtete. Cornelißen (2001): Schuld: S. 242

783 Die Schuldfrage wurde insbesondere von den deutschen Eliten als ehrenrührig empfunden. Vgl. Mommsen, Wolfgang J. (2004): Der Erste Weltkrieg. Anfang vom Ende des bürgerlichen Zeitalters. Frankfurt/M.: S. Fischer, S. 203

$784 \quad$ Vgl. Rosenberg (1930): Mythus, S. 658
} 
Freiheit“ als die „Lebensgrundlagen eines Volkes“, die nach der nationalsozialistischen Revolution ${ }^{785}$ wiederhergestellt wurden.

Diese völkisch-nationalistische Betrachtung des Ehrbegriffes wird von den Zigarettenalben adaptiert. Der Verlust der Ehre wird mit einem Angriff auf die Souveränität des Kollektivs gleichgesetzt, dem versagt wird, sich mit Verteidigungsmaßnahmen gegen feindliche Angriffe wappnen zu können. „Ehre, Freiheit und Vaterland!“786 stehen daher in den Alben an oberster Stelle des Wertesystems, für die selbst das eigene Leben geopfert werden muss.

„Heute herrscht eine Meinung darüber, daß uns für die Erhaltung des Friedens kein Opfer zu groß ist, wenn es nicht unsere Ehre und Freiheit verletzt. Das deutsche Volk ist darum aber auch bereit, zur Abwehr eines Angriffs das Letzte einzusetzen. ${ }^{\prime 787}$

„Es ist ein bitterarmes Land [Anm. Deutschland], das zäh und stolz um seine Geltung ringt und sich in diesem Wollen unter der Führung deutscher Männer wiedergefunden hat: Deutschland! Es gilt, nicht nachzulassen und der Welt immer wieder das schreiende Unrecht, dass sie verschuldet hat, vor Augen zu führen, bis das befreiende Werk vollendet ist. "

In dem Album DeUTSChLAND BAUT AUF wird die Wiederherstellung der Ehre mit dem Wiedererlangen der Wehrhaftigkeit des deutschen Volkes verbunden. Mit reduzierter Bildsprache wird dem Rezipienten vor Augen geführt, dass die Ehre maßgeblich mit Hilfe der Luftwaffe, die unter nationalsozialistischer Herrschaft erstarkt ist, wiederhergestellt wurde. Hier wird ostentativ eine archaische Ehrauffassung proklamiert. Ehre wird mit Schande gleichgesetzt, die nur im Kampf wiederhergestellt werden und „durch Blut getilgt werden“ kann. „Die Waffen müssen den Ehrenfall entscheiden.“789 In dem Kapitel „Die Wehrmacht“ schwebt eine Flugstaffel in Pfeilformation

\footnotetext{
785 Göring, Hermann: „Ehre und Freiheit“. Aufsatz im Völkischen Beobachter zum Reichsparteitag im September 1935. In: Gritzbach, Erich (1938): Hermann Göring. Reden und Aufsätze, München: Franz Eher Nachf. S. 188

786 Reunion (1933): Das Deutsche Volk muß ein Volk von Fliegern werden. Ein Sammelwerk deutscher Gleit-, Segel-, Sport- und Verkehrsflugzeuge. Obercunnersdorf, S. 17

787 Monopol (1937): Deutschland baut auf. Dresden, Kapitel: Luftschutz, unpag.

788 Orami (1933): Helden, Bd. 2, S. 31

789 Weinrich, Harald (1971): „Mythologie der Ehre“. In: Fuhrmann, Manfred (Hg.): Terror und Spiel. Probleme der Mythenrezeption. München: Wilhelm Fink, S. 342
} 
über vier Hakenkreuzfahnen, ${ }^{790}$ die das Motiv dominieren (Abb. 8). Die Gleichsetzung zwischen Wehrhaftigkeit und Ehre wird in der Bildunterschrift in einem einprägsamen Slogan konzentriert:

\section{„Deutsche Ehr - deutsche Wehr.}

Die Wiedergewinnung der deutschen Ehre durch die neuentstandene Wehrmacht war der große historische Hintergrund des Reichsparteitages der Freiheit 1936. ${ }^{\text {791 }}$

Die neuen Machthaber werden dem Bildersammler sowohl als Heilsbringer präsentiert, die die Scharte des Ehrverlustes wieder auswetzen, als auch als verantwortungsbewusste Staatsmänner, die die Bedeutung der Luftwaffe zum Schutz der Bevölkerung erkannt haben. Hitler prangerte bereits in 'Mein Kampf' angesichts der „schmachvollen Erniedrigung“ des Friedensvertrages die Weimarer Regierung an, keinen, „männlichen Trotz und zornigen Hass[es]“ genährt zu haben und fordert „Wir wollen wieder Waffen!“792 Hitlers Haltung wird in dem Album KAMPF UM'S DRITTE REICH als „Trutzspruch“ an exponierter Stelle platziert. Unter dem Porträt Hitlers, der seine Arme trotzig verschränkt, heißt es:

„[...] Ihr seid die Schande von Millionen!

Euch trifft der Fluch von Lebenden und Toten! -

Ihn aber fandt' der Himmel uns zum Boten $[. . .]^{\text {“793 }}$

Die Kriegsniederlage, die politischen Unruhen und das Erstarken kommunistischer Parteien brachten in der Weimarer Republik eine Grundstimmung hervor, die von

790 Hakenkreuzfahnen waren wichtiger Bestandteil der NS-Liturgie. Er war nicht nur dominantes Gestaltungselement, sondern diente auch der Emotionalisierung. Kühberger, Christoph (2006): „Emotionaler Rausch: Zu den Mechanismen der Gefühlsmobilisierung auf faschistischen und nationalsozialistischen Festen“. In: Klimó, Árpád von/ Malte, Rolf (Hg.): Rausch und Diktatur. Inszenierung, Mobilisierung und Kontrolle in totalitären Systemen. Frankfurt/M./ New York: Campus, S. 181

791 Monopol (1937): Deutschland, Kapitel: Die Wehrmacht, unpag. Die Zigarettenfirma Kosmos hat ein Album mit gleichnamigem Slogan publiziert: Kosmos (1935): Schutz und Wehr für Friede und Ehr. Dresden

792 Hitler (1930): Kampf, S. 715

793 Zigaretten-Industrie (1934): Kampf, S. 61. Ausdruck dieser Haltung war u.a. die „Trutztrophe“ der Nationalhymne: „Deutschland, Deutschland über alles, Und im Unglück nun erst recht.“ Hattenhauer (2006): Symbole, S. 86 
Unsicherheit geprägt war. Diese Gemengelage wurde begleitet von einem Gefühl des sozialen und kulturellen Werteverfalls. Das Selbstbild der Deutschen, das sich seit dem 19. Jahrhundert als Kulturvolk begriff und aus seinen kulturellen Leistungen seine Selbstidentifikation zog,794 musste vor der Welt behauptet werden. Die Identifikation der aufstrebenden Industrienationen war derart mit modernen Innovationen verbunden, dass eine Abkoppelung vom technischen Fortschritt als Ausgrenzung aus dem Kreise der Kulturnationen empfunden wurde.795 Die Leistungen der deutschen Wissenschaft gehörten zur „letzten Bastion des bürgerlichen deutschen Nationalstolzes“. Für den Nationalsozialismus, der in Teilen „die Technik als Schöpferin der Zivilisation“796 betrachtete, besaß die Restauration des Images als Kulturnation besondere Relevanz. Dieser Status Deutschlands wird in den Zigarettenalben mit Vehemenz verteidigt und eingefordert.

„Damit hat der Führer die unerträgliche Schande [Anm.: Einkreisungspolitik] von uns genommen, daß unserem großen Kulturvolk mit einer stolzen Geschichte das heilige Recht genommen sein sollte, die Heimat mit der Waffe zu verteidigen. ${ }^{\prime 797}$

„Deutschland ist das Vaterland eines Volkes, das mit Stolz sagen kann: Die Welt weiß, wie tüchtig wir sind! - Adolf Hitler, der Führer, ist aus diesem olke entstanden. Er wird das Volk den Weg zur Freiheit führen und im Bewußtsein deutscher Fähigkeit und Stärke von der Welt fordern: „Räumt Deutschland wieder den Platz ein, der ihm infolge seines Fleißes und seines Könnens zukommt! ““798

794 Vgl. Lörke, Tim (2010): Die Verteidigung der Kultur: Mythos und Musik als Medien der Gegenmoderne. Würzburg: Königshausen \& Neumann, S. 126. Insbesondere nach dem verlorenen Krieg fühlten sich die Deutschen mehr denn je berufen, das „neu interpretierte geistige Preußentum, siegreich in einer moralisch verfallenen Zeit" in die Welt hinauszutragen. Kuehnemund, Richard (1946): Psychologisch-Historischer Hintergrund im deutschen Sendungsbewusstsein, Monatshefte, Vol. 38, No. 8, Madison: University of Wisconsin Press, S. 500 Für Hitler gehörten die arische Rasse und damit das deutsche Volk zu den wahren Kulturgründern der Welt. Vgl. Hitler (1930): Kampf, S. 322. „,...] bei der kritischen und vorurteilslosen Durchdringung dieses Kulturideals erkennen wir klar, daß sich durch alle Teilgebiete der Kultur wie ein roter Faden die Technik als Schöpferin der Zivilisation unverkennbar hindurchwindet [...]." Schwerber (1930): Nationalsozialismus, S. 3

797 Monopol (1937): Deutschland, Kapitel: Die Wehrmacht, unpag.

798 Zigaretten-Industrie (1934): Kampf, S. 55 
„Deutschland hat es verstanden, die Hemmungen [Anm. des Versailler Vertrages] durch wissenschaftliche Forschungsarbeit auszugleichen - mehr noch, die Einschränkungen zu einem erheblichen Fortschritt zu gestalten. [...] Es ist unbestreitbar, dass die deutschen Flugzeuge sowohl bezüglich der grundlegenden konstruktiven Ideen, als auch hinsichtlich ihrer Betriebssicherheit mit an erste Stelle in der gesamten Welt stehen $[\ldots]^{\prime \prime 799}$

Die Restauration des hohen kulturellen Niveaus war, insbesondere vor dem Hintergrund des Versailler Vertrages, gesamtgesellschaftlicher Konsens, wobei die politischen Lager von divergierenden Motiven angetrieben wurden. Während Vertreter demokratischer Gesinnung mit den Errungenschaften der Moderne wirtschaftliche und kulturelle Ziele im Blick hatten, wurde der technische Fortschritt vom rechten Lager in den Dienst einer revisionistischen Politik gestellt. Bereits 1929 wird die Technik mit anderen kulturellen Leistungen Deutschlands gleichgesetzt:

„Und so ist die deutsche Technik im Grunde vielleicht nur eine Abart der deutschen Dichtung. Wie das Dichten, ist die Technik das Ringen, ein Letztes und Höchstes zu formen und auszudrücken. ${ }^{\text {" }} 800$

Vor dem Hintergrund des Versailler Vertrages wurde die Luftfahrt Projektionsfläche nationaler Wiederauferstehung.801 Zur Wiederherstellung der Ehre und nationaler Größe wird in den Zigarettenalben vielfach auf die herausragenden Leistungen verwiesen, die von deutschen Technikern und Ingenieuren im Bereich der Flugtechnik erbracht wurden. Innovationen werden damit zum „Triumph der Schmach“802 mit dem das Versailler Trauma überwunden werden sollte - ein Aspekt, der vielfach in den Technik- und Aviatik-Alben repetiert wird. Der deutschen Nation wird dabei eine besondere Affinität zur Technik zugeschrieben, eine Eigenschaft, die bereits vor der Machtübernahme genährt und unter den Nationalsozialisten zum nationalen Mythos

Ebd., S. 23

Josetti (1929): Welt, Album 4, unpag.

Vgl. Woschech, Anke (2012): „Technikfunktionen“. In: Fraunholz/ Ders. (2012): Technology, S. 250

802 Assmann (2006): Schatten, S. 66 
und zum Bestandteil der kulturellen Identität gemacht wurde. ${ }^{803}$ Die technische Vormachtstellung auf internationalem Parkett wird in den Zigarettenalben vielfach eingefordert:

„In der Geschichte der Technik steht Deutschlands Name strahlend an erster Stelle [...] Das Volk der Dichter und Denker auch das der großen Techniker? Gewiß, denn kein Wissen ist ohne Spekulation und Phantasie zu erwerben." ${ }^{04}$

„Gerade die Leistungen unseres deutschen Vaterlandes, die zur Entwicklung der Technik das höchste beitragen, beweisen unser Recht auf Gleichberechtigung und geben uns die Gewißheit, daß wir auch in Zukunft teilhaftig sein werden des höchsten Ruhms im Wettkampf des technischen Könnens." ${ }^{\text {805 }}$

Die Darstellung der deutschen Leistungen im Bereich der Aviatik erstreckt sich vom Segel- und Kunstflug, über den zivilen Luftverkehr bis zur technischen Forschungsarbeit. Die Autoren der Zigarettenalben schwelgen in Superlativen, wenn es darum geht, deutsche Errungenschaften zu schildern. Um die einzigartigen Fähigkeiten der Wissenschaftler zu unterstreichen, wird die Technik nahezu metaphysisch konnotiert. Die deutschen Konstruktionen werden zum „Wunder der Technik, das kaum noch zu überbieten“806 ist. Die flugtechnischen Errungenschaften stehen dabei nicht nur stellvertretend für den Wiederaufstieg der deutschen Nation, ${ }^{807}$ sondern die Technik wird zugleich von ihrem Negativ-Image, deutsches Kulturgut und Traditionen zu untergraben, befreit. 808

In dem Album HeLDEN DER LuFT wird das "Geheimnis der deutschen Flugerfolge“ 809 auf die akribische wissenschaftliche und methodische Forschung zurückgeführt, die Deutschland befähigt, eine Führungsposition auf dem Gebiet der Luftfahrt einzunehmen. Auf den begleitenden Bildern werden Versuchsanlagen, Techniker und

803 Nach der Auffassung der Nationalsozialisten konnten die Kulturleistungen der Moderne nur von dem Arier, dem „Prometheus der Menschheit“, erschaffen werden. Hitler (1930): Kampf, S. 317

804 Josetti (1929): Welt, Album 4, Kapitel: Deutsche Technik, unpag.

805 Aviatik (1934): Zukunft, Vorwort, unpag.

806 Greiling (1937): LZ 129 Hindenburg. Zeppelin Weltfahrten III. Dresden, Kapitel: Bauzeit, unpag.

807 Vgl. Woschech (2012): Technikfunktionen, S. 250

808 Vgl. Brandt (2008): Und die Welt sah, S. 133

809 Orami (1933): Helden, Bd. 2, S. 23 
Fluggeräte durch untersichtige Aufnahmen ${ }^{810}$ hervorgehoben, einer Perspektive, die Dynamik und Überlegenheit vermittelt und dem Betrachter die Omnipotenz deutscher Technik vermitteln soll. Die akribischen technischen Forschungen und Entwicklungsarbeiten, die in der „Deutschen Versuchsanstalt für Luftfahrt“811 durchgeführt wurden, werden im dem begleitenden Bildmaterial szenisch dargestellt. Damit wird dem Betrachter suggeriert, die deutsche Technik könne jegliche „Gefahren der Moderne bannen.“" ${ }^{12}$ Das Album präsentiert stolz innovative Fluggeräte wie die „DO X“, das seinerzeit größten oder die "He 70“, ${ }^{813}$ das damals schnellste Flugzeug der Welt. Die Präsentation innovativer deutscher Flugtechnik findet auch in dem Sammelband WUNDERWERK DER TECHNIK IN GEGENWART UND ZUKUNFT IHREN exemplarischen Ausdruck. Hier werden dem Bildersammler die ,Nur-Flügler ${ }^{\prime 814}$ und die ersten Flugzeugtypen mit Raketenantrieb ${ }^{815}$ vor Augen geführt, die die Überlegenheit deutscher Ingenieurskunst bezeugen sollen. Die Luftfahrt wird in den Zigarettenalben ebenso, wie in anderen Medien der zeitgenössischen Populärkultur zur "deutschen Wiedergeburt" nach einer Leidenszeit und eine „wunderbare Wirklichkeit". ${ }^{816}$

810 Kameraeinstellung unterhalb der normalen Augenhöhe. Vgl. Böhringer et al. (2008): Mediengestaltung, S. 70. Diese Perspektive war ein beliebtes suggestives Stilelement, mit dem die Technik erhöht wurde und "den Betrachter unterwarfen“. Day, Uwe (2005): Silberpfeil und Hakenkreuz. Autorennsport im Nationalsozialismus. Berlin: be.bra, S. 107. Die Untersicht war eine charakteristische Aufnahmetechnik der NS-Zeit. Die Bilder gewannen damit an Wirkungsmacht. Vgl. Stambolis, Barbara (2016): „Der Film „Junge Adler“ (1944) in Generationellen Kontexten“. In: Dies./ Köster, Markus (Hg.): Jugend im Fokus von Film und Fotografie. München: V\&R unipress, S. 230

811 Orami (1933): Helden, Bd. 2, S. 23

812 Mosse (1997): Bild, S. 156

813 Orami (1933): Helden, Bd. 1, S. 14f. Bilder 79, 80, 85, 86 und Großaufnahme der DO X, ohne Bildnummer, unpag.

814 Aviatik (1934): Zukunft, Serie 2, unpag.

815 Ebd., Serie 12, unpag.

816 Schultze-Pflaelzer, Gerhard (1938): Die Luftschmiede von Dessau. Berlin: Theodor Weicher Verlag, S. 316f. 


\subsubsection{Luftfahrt tut not}

Nach dem Ersten Weltkrieg war sich das Militär der Bedeutung der Luftfahrt als „Waffe des Zukunftskrieges“ im Rüstungswettstreit gegen England und Frankreich bewusst. ${ }^{817}$ Auch für den Chef der Heeresleistung von Seeckt, der bereits 1920 das „Fliegerreferat" gegründet hatte, war die Luftwaffe in einem künftigen Krieg eine unverzichtbare Waffengattung. ${ }^{818}$ Als die Nationalsozialisten im Jahr 1932 an der Regierung beteiligt wurden, forderte Göring bereits ein Luftfahrtministerium. ${ }^{819}$

In vielen Zigarettenalben wird die Notwendigkeit der Luftfahrt unter dem Deckmantel der Selbstverteidigung eingefordert. Die Dringlichkeit findet in der PropagandaPhrase ,Luftfahrt tut not' ihren Ausdruck. Der Slogan wird in den beiden Alben HeLDEN DER LUFT mehrfach repetiert und durch exponierte Platzierung im Layout und mit typografischen Auszeichnungen ${ }^{820}$ in den Fokus der Aufmerksamkeit gesetzt wird.

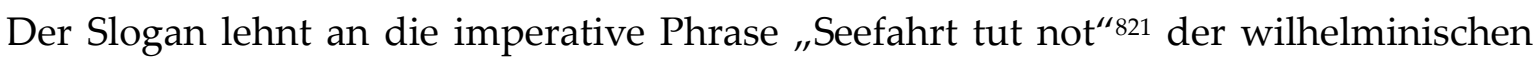
Flottenaufrüstung zur Durchsetzung deutscher Großmachtträume an. Da dieser Ausspruch symbolisch besetzt war, konnte das NS-Regime bei der Adaption von einer entsprechenden Rezeption beim Leser und Sammler ausgehen. Die insgeheim anvisierte Aufrüstung konnte so auf subtile Weise vermittelt werden. Mit der permanenten Wiederholung befolgt das Album das „zweite Grundgesetz für die Werbewirkung", das von Schultze-Pflaelzer aufgestellt wurde. Seinen Erkenntnissen nach kann ein Schlagwort gleich einer "suggestiven Formel“ ${ }^{\text {“22 }}$ durch Wiederholung aufgeladen werden.

\footnotetext{
817 Vgl. Stahl (1927): Versailler Vertrag, S. 67

818 Vgl. Budraß, Lutz (1998): Flugzeugindustrie und Luftrüstung in Deutschland 1918 - 1945. Düsseldorf: Droste, S. 101

819 Vgl. Ebd., S. 293

820 Um die Aufmerksamkeit des Lesers zu fokussieren werden Textpassagen mit einem fetten Schriftschnitt hervorgehoben. Vgl. Runk, Claudia (2006): Grundkurs Typografie und Layout. Bonn: Galieo Design, S. 101

821 Der Ausspruch „Navigare necesse est, vivere non“ wird Plutarch Pompeius zugeschrieben. Der Titel wurde von Gorch Fock als Titel seines Romans "Seefahrt ist not" wiederbelebt. Köller, Wilhelm (2004): Perspektivität und Sprache. Zur Struktur von Objektivierungsformen in Bildern, im Denken und in der Sprache. Berlin: de Gruyter, S. 693

822 Schultze-Pflaelzer, Gerhard (1923): Propaganda, Agitation, Reklame. Eine Theorie des gesamten Werbewesens. Berlin: Georg Stilke, S. 148f.
} 
In vielen Aviatik-Alben wird Deutschland als mittellose Nation dargestellt, die nach dem Ersten Weltkrieg der Despotie der Siegermächte zum Opfer gefallen ist. Das Land wird als friedfertige Nation beschrieben, die ihrer Wehrhaftigkeit beraubt und der Willkür angrenzender Staaten ausgesetzt ist. Die Völkergemeinschaft wird angeprangert, „ein ganzes Volk wehrlos gemacht und der Willkür aller ausgesetzt“" ${ }^{\text {"23 }} \mathrm{zu}$ haben. Während andere Länder nach dem Krieg das Luftfahrtwesen als „Machtfaktor“ ausbauen konnten, sei „Deutschland völlig ausgeschaltet“ ${ }^{\prime 824}$ worden.

\footnotetext{
„Deutschland ist im Herzen Europas von allen Seiten her angreifbar. ${ }^{\text {" } 25}$

"In all diesem Wahnsinn einer von Ängsten geschüttelten Welt gibt es ein Land, das nichts von den Erzeugnissen solch raffinierter Kriegstechnik besitzt und sich gegenwärtig nicht einmal gegen diese Hölle des Todes schützen kann. Ist es das Paradies, ein Märchen- oder Traumland? -

Nein! - Es ist ein bitterarmes Land [...] Deutschland!“826
}

Die vermeintliche Bedrohung, der Deutschland ausgesetzt ist, wird in den Zigarettenalben zu Beginn der 1930er Jahre mehrfach als Bühne des Unheils inszeniert. Die Militärflugzeuge anderer Nationen werden zu „Todesbote[n]“, ${ }^{227}$ die drohen, das deutsche Volk zu vernichten. Die Gefahr, die von übermächtigen Luftstreitkräften europäischer Länder ausgeht, wird in einigen Alben mittels Tabellen ${ }^{828}$ und Schaugrafiken dargestellt, die veranschaulichen sollen, „wie wehrlos Deutschland gegenüber feindlichen

\footnotetext{
823 Muratti (1934): Brennpunkte des deutschen Sports. Zwischen den Olympischen Spielen, Bd. 1. Berlin, S. 44

824 Austria (1934): Luftwaffe, Bd.1, unpag.

825 Ebd., Text zu den Bildern 5 - 8, unpag.

826 Orami (1933): Helden, Bd. 2, S. 31

827 Ebd., Bild Nr. 178, S. 32

828 Die Stärke der internationalen Luftrüstung vom Stand Herbst 1936 wird in einer Tabelle aufgelistet. Deutschland wird dabei ausgespart. Damit werden dem Leser eine Stärke der ausländischen Luftwaffen und eine vermeintliche eigene Wehrlosigkeit suggeriert. Vgl. Zigaretten-Industrie (1936): Wehrmacht, Kapitel: Die Luftwaffe, unpag.
} 
Fliegerangriffen ist" ${ }^{\prime 29}$ (Abb. 9). Angesichts der massiven Aufrüstung im großindustriellen Maßstab läuft diese Darstellung den realen Gegebenheiten zuwider. ${ }^{830}$ Die Luftwaffen der an Deutschland angrenzenden Staaten, die in den Alben als potentielle Aggressoren dargestellt werden, waren in den 1930er Jahren nicht für einen kriegerischen Einsatz gerüstet. ${ }^{831}$ Deutschland war technisch und zahlenmäßig überlegen. ${ }^{832}$

In den Zigarettenalben wird mit dieser „Einkreiungspropaganda“833 die geforderte Rearmierung zum Schutz der Zivilbevölkerung vor den verheerenden Angriffen einer feindlichen Armada legitimiert. In den Texten und Bildern wird eine Luftflotte eingefordert, damit das Volk gegen feindliche Aggressoren geschützt werden kann. Die Darstellung geht mit der offiziellen Leitlinie der NS-Regierung zu Beginn der 1930er Jahre konform, die als Alibi für die Wiederaufrüstung ein Bedrohungsszenario errichtet hatte.

829 Borg (Vereinigte Tabak- und Zigarettenfabriken) (1934): Europa in Waffen. Ein Dokument in 180 Bildern, welches den Rüstungsstand der europäischen Armeen, Ende des Jr. 1933 zeigt. Offenbach, S. 28. Vergleichbare Schaugrafiken und Tabellen in dem Album: Brinkmann (1934): Waffenstarrende Ausland, S. 9, 19, 23, 32 und 35

Bereits Ende 1932, nach dem Scheitern der Genfer Abrüstungskonferenz, fühlte sich die Regierung nicht mehr an die Bestimmungen des Versailler Vertrages gebunden. Vgl. Ottmer, Hans-Martin (1991): „Skandinavien in der deutschen marinestrategischen Planung der Reichs- bzw. Kriegsmarine“. In: Bohn, Robert/ Elvert, Jürgen/ Rebas, Hain/ Salewski, Michael (Hg.): Neutralität und totale Aggression. Nordeuropa und die Großmächte im Zweiten Weltkrieg. Stuttgart: Franz Steiner, S. 56. Die operativen Kriegsplanungen bezogen sich auf einen Zweifrontenkrieg gegen Polen und Frankreich, respektive der Sowjetunion und Frankreich. Ein Krieg mit England wurde „wie ein Tabu ausgeklammert.“ Die Marine forderte daher ab 1933 eine ausreichende Waffenstärke, um gegen Frankreich operieren zu können. Ebd., S. 57

831 Großbritannien hatte aufgrund seiner stagnierenden Wirtschaft die Rüstungsausgaben beschränkt. In die Luftstreitkräfte wurde erst im Jahr 1935/36 angesichts der deutschen Wiederaufrüstung investiert. Vgl. Schmidt, Rainer F. (2002): Die Außenpolitik des Dritten Reiches 1933 - 1939. Stuttgart: Klett-Cotta, S. 37.

832 Deutschlands Rüstungsindustrie produzierte unter Hochdruck und besaß mit 5.800 Maschinen im Vergleich zu den ehemaligen Kriegsgegnern bedeutend mehr Flugzeuge. Frankreich: 2.000, Großbritannien: 4.200, Italien: 3.000 und USA: 3.250. Lediglich die UDSSR verfügte mit 8.000 über mehr Flugzeuge. Mit einem Investitionsvolumen von 802 Millionen RM lag Deutschland an der Spitze. Vgl. Budraß (1998): Flugzeugindustrie, S. 376

833 Sywottek (1976): Mobilmachung, S. 194. Die Einkreisung Deutschlands (insb. von den vier Großmächten England, Frankreich, Österreich-Ungarn und Russland) diente bereits 1914 als Argument für die Kriegsteilnahme. Nach dem Ersten Weltkrieg war diese Gefahr nahezu eliminiert, denn England war mit dem Versailler Vertrag befriedigt, Österreich-Ungarn existierte nicht mehr und von schwachen Nachfolgestaaten ging keine Bedrohung aus. Russland hatte sich mit der Gründung der Sowjetrepubliken außerhalb des europäischen Systems platziert. Das Deutsche Reich war daher besser positioniert als vor dem Krieg. Haffner, Sebastian (1987): Von Bismarck zu Hitler. München: Kindler, S. 180f. 
„Dieser Zustand ist unerträglich und würdigt unser Vaterland zu einem Staat zweiter Klasse herab. Das gesamte deutsche Volk will den Frieden, aber gerade deshalb muß es Sicherheitsmaßnahmen zum Schutze seiner Zivilbevölkerung ergreifen, und eine ausreichende und leistungsfähige VerteidigungsLuftflotte fordern. “834

„Das Flugwesen hat in den letzten Jahren eine ungeahnt rasche Entwicklung erfahren. Besonders die Heeres-Luftflotten bilden heute einen wichtigen Machtfaktor. Sie sind nach dem Weltkriege hauptsächlich von Frankreich, England, Italien und den Vereinigten Staaten immer weiter ausgebaut worden, während Deutschland völlig ausgeschaltet wurde. Wir besitzen nicht einmal Flugzeuge für die Landesverteidigung und sind jedem Angriff schutzlos preisgegeben." ${ }^{235}$

„Kein Militärflugzeug wurde Deutschland belassen und kein einziges darf Deutschland bauen. Dieser unwürdige Zustand besteht seit Kriegsende. Inzwischen schritt die Entwicklung der Heeresluftfahrt des gesamten Auslandes mit atemberaubendem Tempo fort und schuf eine Waffe, deren gewaltiges Ausmaß in Bezug auf Anzahl und Leistungen noch nicht zu übersehen ist. [...] Demgegenüber darf Deutschland, trotz seiner geographisch ungünstigen Lage weder Flugzeuge bauen, noch besitzen. “836

Diese Einkreisungspropaganda korrespondiert mit der offiziellen Propagandastrategie des NS-Regimes zu Beginn der 1930er Jahre. So beteuerte Hermann Göring die friedlichen Absichten des NS-Regimes, forderte aber gleichzeitig eine Luftwaffe zur Verteidigung gegen potentielle Aggressoren: „Deutschland will andere Länder nicht überfallen; es wünscht aber auch selbst nicht überfallen zu werden.[...] Solange andere Mächte über Bombenflugzeuge verfügen, muß Deutschland eine Fliegerei besitzen, die die Sicherheit und das Leben der Nation garantiert. [...] Während die anderen Mächte um uns in Waffen starren, Tausende schwerer Angriffsflugzeuge besitzen, die bereitstehen, Deutschland im Augenblick zu vernichten, verzichten wir auf die Angriffswaffe $[\ldots]^{\varkappa 837}$

Austria (1934): Luftwaffe, Bd. 1, unpag.

Ebd.

Brinkmann (1934): Waffenstarrende Ausland, S. 36

Göring, Hermann (1934): „Der alte Fliegergeist lebt“. Rede zum Abschluß des Deutschlandfluges am 24. Juni 1934. In: Gritzbach (1938): Reden, S. $122 f$. 
Die Einkreisungspropaganda hatte eine derartige Relevanz, dass sie in drei Zigarettenalben zum zentralen Thema gemacht wurde: EUROPA IN WAFFEN. EIN DOKUMENT IN 180 BILDERN, WELCHES DEN RÜSTUNGSSTAND DER EUROPÄISCHEN ARMEEN, ENDE DES JHR. 1933 ZEIGT, WIE die ANDEREN GERÜSTET SIND...! TROTZ VERTRAGLICHER AbRÜSTUNGSPFLICHT $^{838}$ und DAS WAFFENSTARRENDE AUSLAND. ${ }^{839}$ In diesen Sammelbänden wird dem Bildersammler vor Augen geführt, wie wehrlos Deutschland angesichts hochgerüsteter Aggressoren ist. Bereits auf dem Titelbild DAS WAFFENSTARRENDE AusLAND sind die kanonen eines Schlachtschiffes demonstrativ auf den Betrachter gerichtet (Abb. 10).

Die Alben, die alle im Jahr 1934 publiziert wurden, folgen der offiziellen Propagandadoktrin und beteuern, trotz heimlicher Aufrüstung, die Friedensabsichten Deutschlands.

„Deutschland will den Frieden und braucht den Frieden. Aber es soll nicht unwissend über die Rüstung der anderen hinweggehen, sondern ganz Deutschland muß sich darüber klar sein, weshalb es Sicherheit verlangen und fordern muß. Dieses Werk soll zur Kenntnis der Weltrüstung dienen und dazu beitragen, den Schleier über die Wettrüstung der anderen und deren Werkzeuge zu lüften. ${ }^{\text {8 }} 40$

„Eine Unmenge startbereiter Flugzeuge steht jenseits der Grenze, die mühelos unser wehrloses Vaterland nach allen Seiten und Richtungen hin überfliegen und, ohne besondere Höchstleistungen vollbringen $\mathrm{zu}$ müssen, fast alle Städte für einen Bombenangriff erreichbar machen. ${ }^{\circledR 841}$

„... und die anderen

Staaten wetteifern untereinander, ihren Rüstungsstand zu erhöhen. Geradezu Rekorde werden in den Rüstungsausgaben aufgestellt. Und warum dies alles? Um sich vor einem bis zum Nichts abgerüsteten Staat zu schützen? Dieses Bildwerk zeigt deutlich, mit welchen Kampfwaffen die europäischen Mächte ausgerüstet sind.

rüsten weiter ${ }^{\prime 842}$

\footnotetext{
838 Brinkmann (1934): Wie die anderen gerüstet sind...!

839 Brinkmann (1934): Das Waffenstarrende Ausland. (Text und sämtliche Abbildungen von F. Hohm. Verantwortlich für die Herausgabe Oberst a. D. von Struensee). Bremen

840 Ebd., Einleitung, unpag.

$841 \quad$ Ebd., Ausland, S. 37

842 Borg (1934): Europa in Waffen, erste Textseite, unpag.
} 
Die Einkreisungspropaganda reflektiert die janusköpfige Politik des NS-Regimes zu Beginn der Machtergreifung. Psychische Mobilmachung und technische Aufrüstung wurden getarnt, während gleichzeitig pazifistische Signale in Richtung Ausland gesandt wurden. ${ }^{843}$ In den Sammelalben der Jahre 1933 bis 1934 werden die Autoren nicht müde, ein Bedrohungsszenario zu zeichnen, dem das friedfertige Deutschland wehrlos ausgeliefert ist:

„Wird das Ausland endlich einsehen, daß Deutschland den Frieden will? Werden unsere ehemaligen Feinde endlich begreifen, daß wir nur die Freiheit wollen, und Arbeit, und unser täglich Brot!? - Der Führer Adolf Hitler sprach im Namen des ganzen deutschen Volkes! “844

„Die Welt erstarrt in Waffen. Tausende von Flugzeugen nennen die Großmächte ihr eigen. [...] Es gilt, nicht nachzulassen und der Welt immer wieder das schreiende Unrecht, das sie verschuldet hat, vor Augen zu führen [...] Die Regierung hat diese Tatsache einwandfrei erkannt und die Dinge berufenen Händen anvertraut.“ ${ }^{485}$

Die mit vorgebrachten Klagen gegenüber der Weltgemeinschaft, die den Tenor der Alben zu Beginn der 1930er Jahre beherrschen, werden ab 1935 sukzessive durch aggressive Töne abgelöst. Eine Geheimhaltung in Bezug auf die Luftrüstung war ohnehin nicht mehr geboten, denn Hitler hatte bereits am 9. März 1934 die Weltöffentlichkeit offiziell von dem Aufbau einer Luftwaffe in Kenntnis gesetzt, ${ }^{846}$ nachdem die britische Regierung die wachsende deutsche Kriegspropaganda und die Luftrüstung angeprangert hatte. Zwei Jahre danach, am 1. März 1936, wurde die deutsche Luftwaffe offiziell aus der Taufe gehoben. ${ }^{847}$ In den Alben Uniformen im neuen Deutschland Wehrmacht aus dem Jahr 1936 und 13 historische Tage aus dem Jahr 1937 werden die

843 Vgl. Sywottek (1976): Mobilmachung, S. 49.

Das RLM finanzierte ab 1933 nicht nur alle Neuentwicklungen, sondern erließ Vorgaben bezüglich der Konstruktionen und Produktionsplanung. Damit konnte das NS-Regime die Aufrüstung gezielt planen. Lorenzen, Till (2010): „Unternehmerische Handlungsspielräume der Bayerischen Motoren Werke im Flugzeugmotorenbau 1933-1940“. In: Heusler, Andreas/ Spoerer, Mark/ Trischler, Helmuth (Hg.) (2010): Rüstung, Kriegswirtschaft und Zwangsarbeit im "Dritten Reich". München: Oldenbourg, S. 20f.

$844 \quad$ Zigaretten-Industrie (1934): Kampf, S. 85

845 Orami (1933): Helden, Bd. 2, S. 31

846 Vgl. Fest (2006): Hitler, S. 698

847 Vgl. Göring, Hermann: „Luftfahrttechnik und Luftfahrtforschung“. Rede vor der Akademie der Luftfahrtforschung am 1. März 1938. In: Gritzbach (1938): Reden, S. 304 
Friedensbeteuerungen zwar aufrecht erhalten, aber Deutschland wird nicht mehr als wehrlose Nation dargestellt, sondern als wehrhafter Staat, der seit der Gründung der Wehrmacht gegen feindliche Angriffe gewappnet ist. Die Zigarettenalben wurden so ein subtiles wie publikumswirksames Massenmedium, mit dem der Staat seine Wehrhaftigkeit über die Grenzen hinaus zur Schau stellen konnte. Entsprechend werden in den Alben insgesamt aggressivere Propagandatöne angeschlagen.

"Aufgaben und Ziele der Wehrmacht sind eindeutig und klar: Innerhalb der deutschen Grenzen soll sie eine harte Erziehungsschule zu Manneszucht und Wehrbereitschaft sein; nach außen ein starkes Bollwerk zum Schutze deutscher Arbeit und deutschen Lebens. [...] Sie dienen ja nur einer einzigen großen Aufgabe: der Erhaltung und Sicherung des deutschen Friedens. ${ }^{1848}$

„Durch die sich entwickelnde deutsche Wehr aber ist es nicht nur möglich geworden, dem Deutschen Reich nach außen hin die Freiheit zu erringen [...] Vor allem konnten wir dadurch unserem Volke in einer Zeit der Unruhe und der allgemeinen Unsicherheit den Frieden bewahren. Es sind noch nie die Völker vom Frieden gesegnet worden, die schwach waren, sondern immer nur jene, die stark gewesen sind. Daß aber Deutschland heute wieder stark ist, dankt es in erster Linie seinen Soldaten! Deutschland hat euch lieb und vor allem: es ist stolz auf euch. Denn es sieht in euch die Träger einer unvergänglichen, ruhmvollen Vergangenheit.“849

„Der Tag [Anm. der Wehrmacht] hat den Beweis erbracht, daß in knappen fünf Jahren nationalsozialistischer Staatsführung eine Wehrmacht entstanden ist, die einen der sichersten Garanten des europäischen Friedens darstellt. “850

In den Alben Uniformen IM NeUen Deutschland und Die DeUtsche WeHRMacht wird die Wehrhaftigkeit Deutschlands in Gestalt einer waffenstarken Wehrmacht mit allen Waffen, Einheiten präsentiert. Uniformen, Rang und Abzeichen der einzelnen Waffengattungen verdeutlichen, dass Deutschland über eine durchorganisierte und gut ausgerüstete Armee verfügt. Die ostentative Demonstration der Wehrhaftigkeit korrespondiert mit den Signalen, die ab den Jahren 1935/36 in Richtung Ausland

\footnotetext{
848 Aviatik (1936): Uniformen, Vorwort, S. 3

849 Greiling (1938): Historische Tage, Begleittext zu den Bildern 94-97, unpag.

850 Ebd., Begleittext zu den Bildern 90-93, unpag.
} 
gesandt wurden, denn nach der Gründung der Wehrmacht und der damit verbundenen massiven Aufrüstung wurde die Kampfkraft der deutschen Nation vor der Weltöffentlichkeit nicht mehr geheim gehalten.

In dem Sammelband UNIFORMEN IM NEUEN DEUTSCHLAND wird die Wehrmacht zum sichtbaren Zeichen einer „innenpolitischen Gesundung von Staat und Volk“851 und zu einem Symbol gegen die Demütigung von Versailles. Entsprechend werden aggressivere Propagandatöne angeschlagen.

„Die befreiende Tat des Führers und Reichskanzlers vom 16. März 1935 bildet einen entscheidenden Abschnitt in der Geschichte des deutschen Heerwesens. Das Gesetz zum Aufbau der Wehrmacht, dem das Wehrgesetz vom 21. Mai 1935 folgte, setzte einen Schlußstrich unter das entehrendste und ungerechteste Friedensdiktat der neuen Geschichte. Die fesseln von Versailles fielen. Der innenpolitischen Gesundung von Staat und Volk, die der Nationalsozialismus mit seiner Machtübernahme einleitete, konnte nunmehr auch die wehrpolitische Befreiung der Nation folgen.

Die kleine Reichswehr des Weimarer Staates, zahlenmäßig und technisch begrenzt und gehemmt [...] aber dennoch eine Organisation von höchstem sittlichen und militärischen Wert, gehört heute der Vergangenheit an." ${ }^{\text {852 }}$

In diesem Sammelband wird die Wehrmacht zum Inbegriff für die Wiederherstellung der Ehre und Heer, Kriegsmarine und Luftwaffe werden zum Symbol psychischer wie physischer Stärke. ${ }^{853}$ Insbesondere die Luftwaffe, die für Göring als das Schwert der Rache $^{854}$ galt, mit dem die Fesseln des Versailler Vertrages gesprengt werden sollten, wird zum Synonym für das Wiedererlangen nationaler Autonomie.

Aviatik (1936): Uniformen, Vorwort, S. 3

Ebd.

Ebd.

„Mir schwebt vor, eine Luftwaffe zu besitzen, die, wenn einmal die Stunde schlagen sollte, wie ein Chor der Rache über den Gegner hereinbricht.“ Göring, Hermann: „Kameradschaft, Pflichterfüllung und Opferbereitschaft". Ansprache vor 1000 Fliegerleutnants am Tage ihrer Vereidigung in Berlin am 20. Mai 1936. In: Gritzbach (1938): Reden, 242f. Hass und Vergeltung waren von Beginn an Bestandteil der nationalsozialistischen Rhetorik. Hitler prangert angesichts der "schmachvollen Erniedrigung" des Friedensvertrages die Regierung an, keinen „zornigen Hass" genährt zu haben und forderte „Wir wollen wieder Waffen!" Hitler (1930): Kampf, S. 714f. 
„Die Luftwaffe ist als Kind des technischen Zeitalters die jüngste aller Waffengattungen. Der Schandvertrag von Versailles hatte sie uns ganz genommen, bis sie Adolf Hitler nach der Erlangung der Wehrfreiheit zu einem besonderen Teil der Wehrmacht gestaltete. Am 26. Februar 1935 befahl der Führer die Aufstellung der Luftwaffe neben dem Heer und Kriegsmarine für den 1. März 1935.“855

Die Parade der Luftfahrttechnik, die in den Zigarettenalben präsentiert wird, suggeriert nicht nur dem Sammler die waffentechnische Überlegenheit und Innovationskraft des deutschen Volkes, sondern ist auch an die Adresse der potentiellen Gegner gerichtet. Angesichts der Restriktionen des Versailler Vertrages war die mediale Zurschaustellung der neusten Waffentechnik ein politisch inopportuner Schachzug. Da der Aufbau einer Wehrmacht gegen die Versailler Bestimmungen verstieß, provozierte das NS-Regime nicht nur Irritationen auf diplomatischem Parkett, sondern auch militärische Reaktionen. Die Befürchtung, das Ausland könnte mit militärischen Mitteln intervenieren, wurde nicht nur vom Auswärtigen Amt geäußert, sondern auch von der Reichswehr. In breiten Teilen der Bevölkerung stieß die „Wiederherstellung der Wehrhoheit" hingegen auf ein positives Echo. ${ }^{856}$ Die Zigarettenalben boten dem Regime damit eine subtile Plattform für eine Waffenschau. Damit wurde nicht nur der deutschen Bevölkerung das Potential der deutschen Kampfkraft demonstriert, sondern die Zurschaustellung war auch an das Ausland adressiert.

\subsubsection{Luftschutz}

Nach dem Ersten Weltkrieg fürchtete die deutsche Regierung militärische Übergriffe seitens der Nachbarstaaten und leitete erste Maßnahmen zum Luftschutz ein. Mit dem systematischen Aufbau wurde aber erst mit dem Machtantritt der Nationalsozialisten begonnen, ${ }^{857}$ denn ihnen war bewusst, dass ein ausreichender Luftschutz im Kriegsfall dringend erforderlich war. Die Maßnahmen sollten nicht nur der

\footnotetext{
855 Aviatik (1936): Uniformen, Kapitel: Die Luftwaffe, S. 29

856 Bauer (2008): Nationalsozialismus, S. 291

857 Vgl. Lemke (2005): Luftschutz, S. 100
} 
Demoralisierung der Bevölkerung entgegenwirken, ${ }^{858}$ sondern auch wichtige Industrieanlagen schützen. ${ }^{859}$ Bei der Errichtung von flächendeckenden Luftschutzeinrichtungen stand das NS-Regime kommunikationspolitisch vor diversen Herausforderungen, denn „,[M]man hegte Befürchtungen, daß Luftschutzmaßnahmen im In- und Ausland als Kriegsvorbereitungen gedeutet werden könnten.“"860 Da der Luftschutz integrierter Bestandteil der geheimen Wiederaufrüstung und Mobilmachung war und Deutschland nach den Statuten des Versailler Vertrages lediglich passive Schutzmaßnahmen erlaubt waren, musste der Aufbau eines organisierten Luftschutzes vor der Weltöffentlichkeit legitimiert werden. Um keine außenpolitischen Konflikte zu provozieren, wurden die Luftschutzmaßnahmen als Kompensation für mangelnde militärische Kräfte ausgelegt. ${ }^{861}$ Auf innenpolitischem Terrain wollte das NS-Regime die kriegsmüde Bevölkerung, die einen Luftkrieg fürchtete, nicht verunsichern. ${ }^{862}$ Die Schutzmaßnahmen wurden daher als Weiterführung der in der Weimarer Republik aufgebauten Luftschutzvereine ${ }^{863}$ als Selbstschutz gegen Industrieunfälle und Havarien getarnt. ${ }^{864}$ Der Luftschutz unterstand dem RLM, das aber bis 1939 nicht offiziell in Erscheinung trat. Stattdessen wurden die Aufgaben an den Reichsluftschutzbund (RLB) übertragen, der als eingetragener Verein einen zivilen Charakter hatte. Der Aufbau des Luftschutzes und die Ausbildung der Luftschutzhelfer wurden auf den

858 Vgl. Teetzmann, Otto (Hg.) (1934): Luftschutz. Die deutsche Schicksalsfrage. Mit einem Geleitwort von Reichsminister der Luftfahrt und preußischen Ministerpräsidenten Hermann Göring. Berlin: Schönfeld's Verlagsbuchhandlung, S. 22 Vgl. Lemke (2005): Luftschutz, S. 102

860 Ebd., S. 313

861 Vgl. Ebd., S. 100f.

862 Vgl. Ebd., S. 312. Allzu eifrige Redner, die öffentlich von der Rache für Versailles sprachen und einen Luftschutz für einen geplanten Rachefeldzug plädierten, wurden von offiziellen Stellen zur Raison gebracht. Ebd., S. 313. Der Leiter des RLB, SS-Oberführer Teetzmann, vertrat eine rigorose Haltung, die von der offiziellen Propaganda abgelehnt wurde: „Der Wille zum Luftschutz und der Kampf um die Luft sind ohne einander nicht denkbar, sie bilden eine geistige Einheit. [...] Luftschutz ist die Schicksalsfrage der Deutschen, denn sie ist der Gradmesser, in wie weit die Bevölkerung zusammensteht und die gleiche Weltanschauung teilt." Teetzmann (1934): Schicksalsfrage, S. 255f.

863 Vgl. Brinkhus, Jörn (2007): „Ziviler Luftschutz im „Dritten Reich“. Wandel seiner Spitzenorganisation“. In: Süß, Dietmar (Hg.): Deutschland im Luftkrieg. München: Oldenbourg, S. 30 
unteren Ebenen von Zivilisten getragen und organisiert, 865 die für „Aufklärung und Werbung für den Luftschutz in der Bevölkerung“866 sorgten.

In den Aviatik-Alben wird der Luftschutz vielfach thematisiert. In dem Sammelband HELDEN DER LUFT wird den Rezipienten die Relevanz des Luftschutzes in apokalyptischen Szenarien in Gestalt von Gasangriffen, ${ }^{867}$ Bomben- und Raketeneinschlägen vor Augen geführt. ${ }^{868}$ Unter das Lemma „Luftschutz tut not!“869 wird im begleitenden Bildmaterial mit dem Horrorszenario eines Luftkampfes eine Drohkulisse errichtet, in der „Vögel des Todes"870 bedrohlich am Himmel schweben (Abb. 11). Um die Notwendigkeit des Luftschutzes zum Wohl der Bevölkerung zu rechtfertigen, wird das Bedrohungsszenario potenziert, in dem Deutschland als wehrlose Nation dargestellt wird, die den Aggressionen waffenstarrender Mächte hilflos ausgeliefert ist. Das Album HELDEN DER LuFT beendet die dramatischen Schilderungen eines zu befürchtenden Angriffskrieges mit dem Verweis auf den Reichsluftschutzbund e.V. „in den einzutreten jedes Deutschen Pflicht sein sollte, denn „Luftschutz tut not.““871 Eingerahmt von Bombengeschwadern alliierter Streitkräfte, die Zerstörung und Vernichtung bringen und die Welt in den Abgrund stürzen, wird der Bevölkerung das Schreckensbild einer düsteren Prophezeiung gezeichnet:

„In all diesem Wahnsinn einer von Ängsten geschüttelten Welt gibt es ein Land, das nichts von den Erzeugnissen solch raffinierter Kriegstechnik besitzt und sich gegenwärtig nicht einmal gegen diese Hölle des Todes schützen kann. [...] Technik und Wissenschaft haben sich in den Dienst des Todes gestellt. Unermeßliches Grauen und Verderben würde die Erde beherrschen und

\footnotetext{
865 Vgl. Ebd., S. 252ff.

866 Satzung zur Gründung des RLB: BA-MA, R 43 II/1295, RK 5904/33 vom 9. 5.1933, §2. Zit. nach: Ebd. Laut Presse-Abteilung des RLB wurden bis 1934 11/4 Million Zivilisten im Luftschutz unterwiesen. Teetzmann (1934): Schicksalsfrage, S. 230f. Giftgas war ein einkalkuliertes Risiko, zumal das NS-Regime den Einsatz von Giftgas vor Kriegsbeginn in Betracht gezogen hatte. Vgl. Teetzmann (1934): Schicksalsfrage, S. 58

868 Orami (1933): Helden, Bd. 2, S. 31 - 34

869 Ebd., S. 31

870 Bildlegende: „Die Vögel des Todes kommen drohend herangeflogen“. Orami (1933): Helden, Bd. 2, S. 31, Bild 172

$871 \quad$ Ebd., S. 31
} 
verwüsten, wenn diese Mittel ihren vernichtenden Zwecken preisgegeben würden. Das Blut erstarrt in den Adern, wenn man sich die Folgen ausmalt." ${ }^{\text {" }} 72$

Der Luftschutz wird nicht nur in den Aviatik-Alben thematisiert, sondern auch in Zigarettenalben, die ein Deutschlandbild unter nationalsozialistischer Herrschaft zeichnen. Exemplarisch ist der Sammelband DeUTSCHLAND BAUT AUF, der dramaturgisch in Kleinserien aufgeteilt ist und sich in einer Serie ganz dem Luftschutz widmet. In dem gleichnamigen Kapitel wird dem Bildersammler die potentielle Kriegsgefahr in Gestalt feindlicher Bomber vor Augen geführt (Abb. 12). Die Illustrationen zeigen Rettungsmaßnahmen, die durch den RLB erfolgen wie das Löschen nach einem Angriff mit Brandbomben, dem Bergen und Versorgen von Verletzten sowie eine Gasmaskenübung. ${ }^{873}$ Im Begleittext wird die Bedeutung des Luftschutzes artikuliert, verbunden mit der Aufforderung, sich an der Heimatfront im Luftschutz zu engagieren. Der Luftschutz wird zur patriotischen Pflicht.

„Heute herrscht eine Meinung darüber, daß uns für alle Erhaltung des Friedens kein Opfer zu groß ist, wenn es nicht unsere Ehre und Freiheit verletzt. Das deutsche Volk ist darum aber auch bereit, zur Abwehr eines Angriffs das Letzte einzusetzen. Der Luftschutz macht die daheim bleibenden Männer und Frauen zu Soldaten der Heimat. Sie werden an der zweiten Front mit gleichem Mut zu kämpfen haben wie der Soldat im Felde. Der Luftschutz der Heimat ist somit zu einem wichtigen Teil der Landesverteidigung geworden, zumal Deutschland durch die Luftwaffe stärker bedroht ist als irgendein anderes Land. “874

Das Album VORWÄRTS DURCH EIGENE KRAFT! 875 widmet dem Luftschutz ebenfalls ein eigenes Kapitel. Der Abschnitt trägt die Überschrift „Luftschutz ist Selbstschutz",876 dem Slogan, mit dem das NS-Regime für den RLB war. Die Phrase ist aufgrund der reduzierten Aussage plakativ und einprägsam. Die Wiederholung des Slogans in den

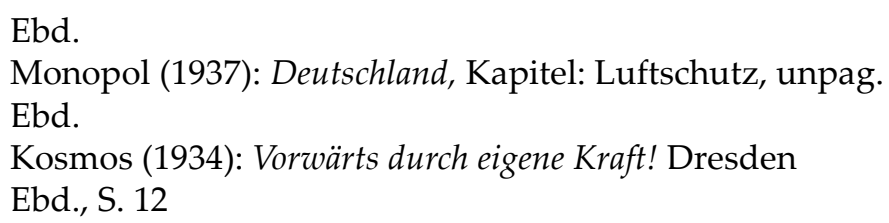

Ebd.

Monopol (1937): Deutschland, Kapitel: Luftschutz, unpag.

Ebd.

Kosmos (1934): Vorwärts durch eigene Kraft! Dresden

Ebd., S. 12 
Textpassagen impliziert, dass er als suggestive Formel im Bewusstsein der Rezipienten verankert werden sollte.

\section{„Luftschutz ist Selbstschutz}

Rings ist Deutschland von hochgerüsteten Mächten umgeben. Alle diese Staaten besitzen mächtige Flugzeuggeschwader, die binnen kürzester Frist über ganz Deutschland ihre verderbenbringenden Bomben abwerfen können. Wir besitzen keinerlei Abwehrwaffen. Lediglich durch den passiven Luftschutz können wird den möglichen Gefahren begegnen. ${ }^{\text {"877 }}$

„Reichsluftfahrtminister Göring [...] hat die umfassende Organisation des Reichsluftschutzbundes geschaffen und durch seine über das ganze Reich verbreiteten Ortsgruppen den Gedanken „Luftschutz ist Selbstschutz“ in alle Kreise der Bevölkerung hineingetragen. Überall in deutschen Landen ist dieser Gedanke durch eine große Aufklärungs- und Propaganda-Welle, durch Abwehr-Übungen, durch Anlage von Luftschutzkellern und durch Vorbereitung anderer Schutzmaßnahmen in die Tat umgesetzt worden. ${ }^{\text {" } 78}$

Um die Bevölkerung für ein Engagement im RLB zu animieren, wendet das Sammelwerk die gleichen Mechanismen wie das Album DeUtSCHLAND BAUT AUF an. Die Einkreisungspropanda wird von einem Horrorszenario begleitet, mit dem das Zerstörungspotential feindlicher Waffen veranschaulicht werden soll. Die Dringlichkeit der Schutzmaßnahmen wird von Fotos, die Übungen bei Gas- Brand- und Phosphorbombenangriffen $^{879}$ zeigen, mit aller Dramatik zum Ausdruck gebracht. Um die Drohkulisse $\mathrm{zu}$ intensivieren werden Exponate von Fliegerbomben gezeigt, die in „allen Städten zur Aufklärung der Bevölkerung aufgestellt “ ${ }^{\star 280}$ wurden. Um die Bevölkerung zum Eintritt in den RLB zu animieren, werden Fotografien von Zivilisten gezeigt, die für den RLB selbst auf der Zugspitze werben: „Skipatrouille wirbt für den Eintritt in den Reichsluftschutzbund am Schneefernerhaus auf der Zugspitze.“

Ebd., S. $13 f$.

Ebd., S. 14

Vgl. Ebd., S. 13f.

Ebd., S. 12 
Eine andere Aufnahme zeigt jugendliche Radfahrer in einem urbanen Raum, die Passanten vor einem Fliegerangriff warnen: „Fliegeralarm! Radfahrer warnen die Bevölkerung. ${ }^{\prime 881}$

Das Album VORWÄRTS DURCH EIGENE KRAFT! spricht mit der Werbung für den Luftschutz gezielt die Zielgruppe der Jugendlichen an, womit der Sammelband an den „Erlaß des Reicherziehungsministeriums“882 anknüpft, der auf Initiative des RLM ergangen war. Das Ministerium wollte gezielt die Jugend für Luftschutzmaßnahmen, die integrierter Bestanteil der militärischen Mobilmachung waren, gewinnen. Um den Gedanken des zivilen Luftschutzes zu verbreiten, hatte das RLM bereits ab 1933 die Erziehung der Jugend zur Wehr- und Schutzgemeinschaft als Teil der schulischen Ausbildung eingeleitet. ${ }^{883}$ „[Der] „zivile Luftschutz ist ein Teil der 'totalen Mobilmachung'; er ist kein Katastrophenschutz, keine Organisation zur Verminderung der Kriegsgefahren für den einzelnen, sondern er ist Ausdruck des Wehrwillens und der Selbstbehauptung eines großen Volkes.“ ${ }^{884}$

Die Werbung für den RLB, die in den Zigarettenalben betrieben wird, korrespondiert mit den offiziellen Propagandamaßnahmen, die ab 1933 eingeleitet wurden. In den Alben wird lediglich der Aspekt des technischen Hilfsdienstes im Rahmen von Havarien oder Naturkatastrophen ausgeklammert. Die Zigarettenalben arbeiten ausschließlich mit der Drohkulisse der Einkreisungspropaganda und dem patriotischen Appell, Dienst an der Heimatfront zu leisten. Die Thematisierung des Luftschutzes in den Zigarettenalben kann als unterstützende Maßnahmen zur Akquise von Freiwilligen betrachtet werden, denn die offizielle Propagandaarbeit von

\footnotetext{
881 Ebd.

882 Sywottek (1976): Mobilmachung, S. 76

883 Vgl. Meyer, Erich/ Sellien, Ewald/ Borowietz, Willibald (1934): „Schule und Luftschutz“. Im Auftrage des Reichsministeriums für Luftfahrt verfaßt. München 1934. Zit. nach.: Ebd.

884 Sellien, Ewald (1935): „Der Wehrgedanke im Luftschutz“. In: Monatsschrift für höhere Schulen, 34. Bd., 1935, 271-277, zit. S. 273, zit. nach: Ebd.
} 
staatlicher Seite stieß in der Bevölkerung auf wenig Resonanz. Obwohl der Luftschutz von der Propaganda zur "Schicksalsfrage des deutschen Volkes“" ${ }^{\text {"855 }}$ gemacht wurde, waren die Kampagnen nur bedingt erfolgreich, was maßgeblich auf die AntiKriegsstimmung der Bevölkerung zurückzuführen war. ${ }^{886}$

\subsubsection{Usurpation durch das Hakenkreuz}

In den Zigarettenalben, die ab dem Jahr 1933 erschienen sind, werden die technischen Errungenschaften vom NS-Regime durch das Hakenkreuz symbolisch in Besitz genommen. Die Wunderwerke der Technik verschmelzen mit den Insignien des Regimes zu einer Symbiose. Beliebtes und häufig repetiertes Motiv in den Sammelalben ist der Bildausschnitt eines Seitenruders mit Hakenkreuz (Abb. 13). ${ }^{887}$ In Anbetracht der Tatsache, dass die Flaggenfrage im Jahr 1933 noch nicht geklärt war und die Hakenkreuzfahne noch neben der schwarz-rot-weißen Reichsflagge gehisst wurde, ${ }^{888}$ wird mit der Platzierung des Hakenkreuzes auch ein politisches Statement gesetzt. Diese symbolische Inbesitznahme suggeriert dem Betrachter auf eindringliche Weise, dass das NS-Regime die Entwicklung der Flugtechnik vorangetrieben hat und weiterentwickeln wird. Die symbolische Inbesitznahme konzentriert sich auf die Errungenschaften im Bereich der Aviatik und umfasst alle flugtechnischen Sparten wie Luftschiffe, Segelflugzeuge und die zivile Luftfahrt.

\footnotetext{
885 Teetzmann (1934): Schicksalsfrage, S. 39

886 Vgl. Lemke (2005): Luftschutz, S. 314

887 Kosmos (1933): Bilddokumente unserer Zeit, Bd. 1. Dresden. Bildlegende: „Die neuen Hoheitszeichen am Luftschiff Graf Zeppelin“, S. 47

888 Reichsflaggengesetz vom 15. September 1935 (RGBL. S. 1145): „Artikel 1 Die Reichsfarben sind Schwarz-Weiß-Rot. Artikel 2 Reichs- und Nationalflagge ist die Hakenkreuzfahne. Sie ist zugleich Handelsflagge." Auf dem ,Reichsparteitag der Freiheit' in Nürnberg wurde die Hakenkreuzfahne zur National- und Handelsflagge erklärt. Hattenhauer (2006): Symbole, S. 57f.
} 


\subsubsection{Zivile Luftfahrt}

Nach dem Ersten Weltkrieg war Deutschland laut den Statuten des Versailler Vertrages nicht nur der Aufbau einer Luftwaffe untersagt, ${ }^{889}$ sondern auch die Entwicklung und der Bau von Motorflugzeugen für den zivilen und sportlichen Bereich. Für den zivilen Flugverkehr wurden die Restriktionen in den 1920er Jahren jedoch aufgehoben. Ausschlaggebend war der Beitritt Deutschlands in den Völkerbund und der Vertrag von Locarno, der eine Entspannung einleitete, die 1926 zum „Pariser Luftfahrtabkommen“ führte. Deutschland war damit der „Aufbau einer zivilen Luftfahrt" und die Einrichtung eines Luftschutzes, der sich auf „passive Bodenmaßnahmen“890 beschränkte, gestattet. Mit der außenpolitischen Normalisierung erhielt die Luftfahrt in der Weimarer Republik staatliche Förderungen, ${ }^{891}$ woraufhin die Luftfahrtindustrie einen Aufschwung nahm wie kaum ein anderer Industriezweig. So konnten im Rahmen der international aufblühenden zivilen Luftfahrt auch in Deutschland kleine Fluggesellschaften entstehen, die sich 1926 zur Deutschen ,Luft Hansa' zusammenschlossen. Die flugtechnischen Entwicklungen verliefen rasant und waren von Innovationen geprägt, so dass Deutschland auf internationalem Parkett gegen die Konkurrenz bestehen konnte. ${ }^{892}$ Insbesondere die Luft Hansa konnte sich schnell etablieren ${ }^{893}$ und ab 1933 im Weltflugverkehr eine bedeutende Rolle einnehmen. ${ }^{894}$

Mit ihrem Machtantritt übernahmen die Nationalsozialisten die Lenkungshoheit über den gesamten zivilen Luftverkehr, womit die Luftfahrt für viele Zwecke instrumentalisiert werden konnte. Mit der zivilen Luftfahrt konnte das NS-Regime seine

889 Versailler Vertrag „Abschnitt III: Luftstreitkräfte Artikel 198: Deutschland darf Luftstreitkräfte weder zu Lande noch zu Wasser als Teil seines Heerwesens unterhalten. Kein Lenkluftschiff darf beibehalten werden." Draeger, Hans (Vorwort) in Verbindung mit dem Arbeitsausschuß Deutscher Verbände herausgegeben für Volk und Jugend (1933): Der Vertrag von Versailles. Die Grundursache der deutschen Not. Berlin: Heinrich Beenken „Der Türmer", S. 29. Vgl. Bauer (2008): Nationalsozialismus, S. 290

$890 \quad$ Lemke (2005): Luftschutz, S. 106

891 Vgl. Ebd.

892 Vgl. Budraß (1998): Flugzeugindustrie, S. 21

893 Vgl. Erfurth, Helmut (2011): Luftfahrt im Dritten Reich. Ziviler Flugverkehr und Luftwaffe 19331945. München: GeraMond, S. $10 f$.

$894 \quad$ Vgl. Ebd., S. 7 
friedlichen Ambitionen zur Nutzung der Luftfahrt unter Beweis stellen, während hinter den Kulissen die technischen Errungenschaften und Entwicklungen rigoros für militärische Zwecke in Besitz genommen wurden. ${ }^{895}$ Die Erkenntnisse aus der zivilen Luftfahrtforschung mussten unmittelbar nach der Machtübernahme dem Reichsluftfahrtministerium (RLM) zur Verfügung gestellt werden. Selbst die Lufthansa unterstand ab 1933 dem RLM und musste wirtschaftlich unrentable Strecken zugunsten „militärischer Dringlichkeiten“896 aus ihrem Flugplan streichen. Das RLM finanzierte ab 1933 nicht nur alle Neuentwicklungen, sondern erließ Vorgaben bezüglich der Konstruktionen und Produktionsplanungen. Damit konnte das NS-Regime die Aufrüstung gezielt planen. ${ }^{897}$ Obwohl die zivile Luftfahrt während des Dritten Reiches international Furore machte, hatte die Luftrüstung Priorität. 898

In der Außendarstellung nutzte das NS-Regime die zivile Luftfahrt auch als Aushängeschild, um sich vor der eigenen Bevölkerung als moderne und fortschrittliche Partei zu präsentieren. Dieses Image wurde medial verbreitet, wobei auch die Zigarettenalben als omnipräsentes Medium der Zeit genutzt wurden, um dieses Bild zu vermitteln. In dem Sammelband HELDEN DER LUFT werden sowohl die Innovationen und Infrastrukturen sowie die diplomatischen Aktivitäten, die den Aufbau einer internationalen Luftfahrt ermöglicht hatten, in den Kontext einer eigenen Erfolgsbilanz gesetzt.

„Weiter geht die Entwicklung. [...] Deutsche überfliegen die Weltmeere. Eckener [...] führt unsere Luftschiffe in alle Welt, Junkers Maschinen sind Zeugen deutschen Könnens in fernen Ländern [...]. Die Lufthansa wird friedlicher

895 Der Luftfahrtpionier und Gründer des gleichnamigen Flugwerks Hugo Junkers musste bereits 1933 ein Patentabkommen unterzeichnen, das dem Regime einen kostenlosen und uneingeschränkten Zugriff auf technische Entwicklungen sicherte. Zwei Jahre später musste er unter dem Druck des Reichsluftministeriums vom Amt des Aufsichtsratsvorsitzenden der Luft Hansa zurücktreten und stand Ende 1933 unter polizeilicher Aufsicht. Vgl. Erfurth (2011): Luftfahrt, S. 35f.

896 Ebd., S. 38. Mit der Kontrolle über die zivile Luftfahrt und der Neubesetzung der Führungsspitze der Luft Hansa mit Erhard Milch änderte sich die Schreibweise in „Lufthansa“. Ebd.

897 Lorenzen (2010): „Handlungsspielräume“, S. 20f.

898 Vgl. Erfurth (2011): Luftfahrt, S. 7 
Bote und erschließt weitere Luftstraßen einem gesicherten Verkehr. Es geht aufwärts. Wir nennen heute mit Stolz das schnellste und das größte Verkehrsflugzeug unser eigen. DO X, das Riesenflugboot, setzte die Welt in Staunen, unsere Luftschiffe sind Vorbild. “899

In dem Band HeLDEN DER LuFT wird die Bedeutung des „Volkskanzlers“ bei der Entwicklung der zivilen Luftfahrt explizit hervorgehoben. In dem Kapitel „Die leitenden Köpfe der Nationalen Luftfahrt" wird Hitler zur zentralen Figur der deutschen Luftfahrt stilisiert. Diese gehobene Position wird dem Bildersammler auch visuell durch die Gestaltung des Layouts suggeriert. Sein Porträt befindet sich, leicht erhöht, zwischen dem von Göring und Bruno Loerzer, dem Präsident des Deutschen Luftsportverbandes. ${ }^{900}$ Die Autoren des Albums verweisen auf Hitlers „gigantische Arbeitsleistung “901 ohne die es der Luftfahrt nicht möglich gewesen wäre, Spitzenleistungen zu erzielen. Das Bild Hitlers als leitende Kraft der Luftfahrt wird nicht nur in den Aviatik-Alben genährt. In dem Sammelband AdOLF HitLer wird er zum Pionier und Förderer der deutschen Luftfahrttechnik stilisiert und als visionärer Führer inszeniert, der früh das Potential dieser Technik erkannt und protegiert hatte, als andere der Flugtechnik noch mit Skepsis begegneten.

„Die großen schweren Wahlkämpfe der damaligen Zeit verlangten von dem Führer größte Ausnutzung der Zeit, und so bediente sich der Führer auch des Flugzeuges; allerdings zu einer Zeit, wo man dem Flugverkehr noch Mißtrauen entgegenbrachte. ${ }^{4902}$

Dem Rezipienten wird ein technikaffiner Führer präsentiert, der Kenntnis vom aktuellen Stand der Forschung besitzt und darüber hinaus auch das wirtschaftliche Potential der Technik erkannt hat, mit der Deutschland zu Freiheit und Prosperität gelangen wird. In dem Album KAMPF UM'S DRITTE REICH aus dem Jahr 1933 wird Hitlers Technikbegeisterung ein eigenes Kapitel gewidmet. In dem Kapitel „Adolf Hitler und die Technik“ heißt es:903

\footnotetext{
899 Orami (1933): Helden, Bd. 1, S. 10

$900 \quad$ Ebd., S. 37

901 Ebd.

902 Reemtsma (1936): Hitler, S. 16

903 Zigaretten-Industrie (1934): Kampf, S. 55
} 
„Von je her bringt der Führer allen Gebieten der Technik sein besonderes Interesse entgegen. Aufmerksam verfolgt er jeden Fortschritt und ist bemüht, sich möglichst selbst vom Wert und Nutzen der Dinge zu überzeugen. [...] Auf dem Gebiete des Flugwesens ist der Führer zu Hause. Er hat den Wert des Flugzeuges kennengelernt! [...] Er spricht mit diesem und jenem über Entwicklungsmöglichkeiten, Wirtschaftlichkeit und Nutzen. [...]Immer wird der Führer ein Freund des Fortschritts auf technischem Gebiet sein." ${ }^{\prime 904}$

In den Sammelbänden werden die Innovationen der deutschen zivilen Luftfahrt vom Nationalsozialismus für die eigene Propaganda ebenso in Besitz genommen wie andere flugtechnische Errungenschaften. Die technischen Innovationen, die in der Weimarer Republik erbracht wurden, werden dabei gänzlich verschwiegen.

\subsubsection{Segelflug}

Der Segelflug hatte sich in Deutschland im Zuge der Technikbegeisterung bereits zu Beginn des 20. Jahrhunderts etabliert. Aufgrund der Versailler Bestimmungen, die bis 1926 den Motorflug in allen Bereichen verboten, erhielt der Segelflug massiven Auftrieb, denn auch andere Flugsportler waren gezwungen, auf den Segelflug auszuweichen. Da sich die sportlichen und flugtechnischen Ambitionen auf den motorlosen Flug konzentrierten, gelangen den deutschen Segelfliegern in der Zeit der Weimarer Republik beachtenswerte Pionierflüge und Rekorde. ${ }^{905}$ Neben den sportbegeisterten Segelfliegern fokussierten auch militärische Kreise den Segelflug, denn diese waren sich der Bedeutung des Flugzeuges für künftige kriegerische Auseinandersetzungen bewusst. ${ }^{906}$ Da Deutschland aufgrund der Restriktionen des Versailler Vertrages die Basis für flug- und waffentechnische Innovationen entzogen war und das Land drohte, gegenüber anderen Nationen ins Hintertreffen zu geraten, bot der Segelflug adäquaten Ersatz, um flugtechnische Grundlagenforschung im Bereich der Funk- und Strömungstechnik sowie der Konstruktion voranzutreiben. ${ }^{907}$

\footnotetext{
$904 \quad$ Ebd.

905 Vgl. Riedel, Peter (1984): Vom Hangwind zur Thermik. Erlebte Rhöngeschichte 1927-1932. Stuttgart: Motorbuch Verlag, S. 17. Vgl. Erfurth (2011): Luftfahrt, S. 22

906 Kehrt (2010): Krieger, S. 214

907 Vgl. Braun, Hans-Joachim (1995): „Britische und deutsche Luftrüstung in der Zwischenkriegszeit". In: Hansen, Ernst Willi/ Schreiber, Gerhard/ Wegner, Bernd. Militärgeschichtliches Forschungsamt (Hg.): Politischer Wandel, organisierte Gewalt und nationale Sicherheit:
} 
Nach dem Machtantritt der Nationalsozialisten wurde die geheime Wiederaufrüstung massiv vorangetrieben. ${ }^{908}$ Forschung und Entwicklung konzentrierten sich verstärkt auf den Segelflug, der zur wichtigen Basis für die aeronautische Forschung und die Ausbildung künftiger Piloten und Techniker wurde. Zur Tarnung der geheimen Aufrüstung wurden alle Flugsportvereine, darunter auch der Modell- und Segelflugverband im Deutschen Luftsportverband e.V., zusammengeführt. Damit konnte der Fliegernachwuchs unter der Ägide dieser Tarnorganisation ausgebildet werden. Arno Kehrberg, ab 1937 Chef des Stabes des Fliegerkorps, offenbarte unumwunden, dass der Gründung des DLV politisches Kalkül zugrunde lag, um die wahren Motive der Wiederaufrüstung zu verschleiern. „Die DLV.-Gründung in dieser Vereinsform war jedoch nicht etwa ein Organisationsfehler, sondern eine aus außenpolitischen Gründen bedingte Notlösung. Man darf nicht vergessen, daß der Führer zwar von Anfang an als Ziel die Beseitigung des Versailler „Friedensvertrages“ gesetzt hatte, daß aber 1933 dieser Vertrag noch äußerlich Geltung besaß." ${ }^{909}$ Bis zur Gründung der Wehrmacht und der offiziellen Bekanntmachung der Luftwaffe im Jahr $1935^{910}$ sollte das Luftrüstungsprogramm mit Tarnorganisationen geheim gehalten werden. Neben dem DLV zählte dazu auch das Nationalsozialistische Fliegerkorps (NSFK), das bereits 1931 von der NSDAP gegründet wurde. ${ }^{911}$ Die geheime Wiederaufrüstung wurde von einer psychologischen Mobilmachung der Jugendlichen begleitet, die

Beiträge zur neueren Geschichte Deutschlands und Frankreichs. München: Oldenbourg, S. 183. Bereits 1920 begann das Heereswaffenamt Ingenieure für die Waffenentwicklung zu verpflichten. Anlass waren der Grenzkonflikt mit Polen und die Ruhrbesetzung. Ab 1924 wurde eine Wehrwirtschaftsorganisation etabliert und ab 1926 begann eine enge Zusammenarbeit zwischen Industrie und Heereswaffenamt. Vgl. Hansen (1978): Reichswehr, S. 45-87. Es entstand eine geheime militärische Zusammenarbeit mit der Sowjetunion, die Gelände zur Verfügung stellte, auf dem mit Waffen und Kampfstoffen geübt werden konnte, die laut des Versailler Vertrages verboten waren. Die Initiative der Wiederaufrüstung ging maßgeblich vom Befehlshaber der Reichswehr General von Seeckt aus. Haffner (1987): Bismarck, S. 183 Der Segelflug war im Dritten Reich wesentlicher Bestandteil der Kriegsvorbereitungen. Vgl. Hormann, Jörg-M. (1988): Elite im Dritten Reich. Garbsen: Info-Verlag, S. 5 Kehrberg, Arno (NSFK Brigadeführer und Chef des Führungsamtes des NS-Fliegerkorps) (1942): Das Nationalsozialistische Fliegerkorps - die Vorschule der deutschen Flieger. Berlin: Verlag Anton Schuhmacher, S. 1

910 Vgl. Bauer (2008): Nationalsozialismus, S. 291

911 Das NSFK wurde 1932 als Verein eingetragen und stand bis zum Röhm-Putsch unter der Leitung der SA. Vgl. Cordts, Georg (1988): Junge Adler. Vom Luftsport zum Flugdienst 1920 1945. München: Bechtle, S. 39 und S. $42 \mathrm{ff}$. 
bereits 1933 gezielt in Gang gesetzt und von öffentlichen Stellen, wie Schulämtern, delegiert wurde. ${ }^{912}$ Die Remilitarisierung war in völkisch-nationalen Kreisen und in den Reihen ehemaliger Militärs Konsens und galt als „weltanschauliche Erziehungsaufgabe.“913 Der pädagogische Auftrag zur Wehrhaftmachung, insbesondere im Flugwesen, erfolgte auf Anweisung des „Kriegs- und Luftfahrtministerium“. Der Lehrauftrag wurde an die Referate „Luftschutz und Luftfahrt“ und an die Vertreter des NS-Lehrerbundes weitergeleitet. ${ }^{914}$

Die Politik der Geheimhaltung und der psychologischen Mobilmachung spiegelt sich in der Art und Weise wider, wie der Segelflug in den Zigarettenalben dargestellt wird. In den Sammelbänden, die bis 1935 publiziert wurden, wird der Segelflug nicht in den Kontext der Aufrüstung gesetzt. Im Fokus stehen die Schaffenskraft der Ingenieure und Techniker sowie die Erfolge der deutschen Segelflieger. Der Flugsport und die erbrachten Leistungen werden dabei vor dem Hintergrund des Versailler Vertrages rezipiert. Die Erfolge der Segelflieger stehen exemplarisch für den Willen des deutschen Volkes, denn ihnen sei es aller Widerstände zum Trotz gelungen, Rekorde aufstellten. Die Erfolge werden zu Leistungen stilisiert, die nur ein „hochstehendes Volk“915 erbringen kann. Dabei werden mangelnde finanzielle Ressourcen sowie die Restriktionen als innovative Triebfeder ausgelegt, die Deutschland zur Spitzenforschung angetrieben hätten. Um über die demütigenden Bedingungen des Versailler Vertrages zu triumphieren, erweist man sich den „versklavenden Maßnahmen“916 gegenüber als dankbar, da sie den Erfindergeist des deutschen Volkes herausgefordert hätten.

\footnotetext{
912 Vgl. Sywottek (1976): Mobilmachung, S. $73 f$.

913 Herbst, Ludolf (1982): Der totale Krieg und die Ordnung der Wirtschaft. Die Wirtschaft im Spannungsfeld von Politik, Ideologie und Propaganda 1939-1945. Stuttgart: Deutsche Verlagsanstalt, S. 47

914 Vgl. Ebd. S. 75. Hohe Militärs wie Horst von Metzsch und Hans Mundt forderten bereits 1934 und 35 den Luftschutz zum Bestandteil des Wehr- und Erdkundeunterrichts zu machen. Heske, Henning (2015): Und morgen die ganze Welt: Erdkundeunterricht im Nationalsozialismus. Norderstedt: BoD, S. 243f.

915 Muratti (1934): Brennpunkte, Bd. 1. Berlin, S. 44

916 Ebd.
} 
„Hier hat es sich erwiesen, daß alle Fesseln und Bindungen auf dem Papier nicht imstande sind, ein hochstehendes Volk auf dem Wege der Zivilisation zurückzuhalten, solange ein Gedanke lebt, solange man nicht den Geist tötet. Nie wäre der Segelflugsport zu seiner Spitzenleistung in der Welt gelangt, wenn nicht die Not [...] Pate gestanden hätte. “917

„Der Wahnwitz des Vertrages von Versailles machte dem Deutschen Volke eine Entwicklung des Luftwesens, wie sie anderen Völkern möglich blieb, zunichte. [...] Der Segelflug erlebte in Deutschland einen Aufschwung, der im Tatendrang mutiger Männer verankert war. Bald horchte die Welt auf." ${ }^{\prime 918}$

Der Segelflug wird in den Alben nicht nur zum patriotischen Aushängeschild, mit dem der Leistungswille und der Erfindergeist des deutschen Volkes unter Beweis gestellt werden. Das NS-Regime benutzt die Sammelalben auch, um die Errungenschaften des Segelfluges für sich zu beanspruchen. Es schreibt sich die Erfolge ebenso auf die eigene Fahne wie die des Motorfluges.

„Mit berechtigtem Stolz kann heute das Deutsche Volk aufblicken und voll Vertrauen erwarten, daß gerade auf dem Gebiete der Luftfahrt, das zum National- und Volksgut werden soll, Herrliches geleistet wird. [...] Der Volkskanzler gehört zu denen, die die ungeheure Bedeutung des Flugzeuges voll erkannt haben. ${ }^{\prime 919}$

„Die nationale Regierung erkannte die große Bedeutung, die der Luftfahrt, dem Flugsport und dem Luftschutz für den Aufbau des nationalen Deutschland und seiner Sicherheit zukommt. “920

„Die Pioniere des Segelfluges haben ihre Aufgabe erreicht. Sie haben durchgehalten, bis ein Adolf Hitler dem deutschen Volke die Wehrhoheit wieder gab und damit die Möglichkeit, die Tradition eines Richthofen und eines Boelcke nicht nur im Geiste, sondern auch in der Tat fortsetzen zu können.“921

„Nicht zuletzt hat an diesem machtvollen Aufschwung die straffe Führung der deutschen Luftfahrt Anteil, die seit Gründung des Dritten Reiches in Händen von Hermann G ö r i n g liegt. Erst als 1933 alle Kräfte, die in der Luftfahrt tätig waren, unter einheitlicher Führung zusammengefaßt wurden, erst da wurde die Luftfahrt wirklich Sache des ganzes Volkes [...] ${ }^{\mu 922}$

Ebd.

Orami (1933): Helden, Bd. 1, S. 24

Ebd., S. 37

Ebd., Zur Einleitung, unpag.

Greiling (1936): Wunder, Kapitel: Wie wird man Flieger?, unpag.

Ebd., Einleitung, unpag. 
Der Segelflug wurde vom NS-Regime auch dazu benutzt, Nachwuchs für die Luftwaffe und den flugtechnischen Ingenieurbereich $\mathrm{zu}$ akquirieren. Aufgrund der Geheimhaltungspolitik in Bezug auf die Wiederaufrüstung war es für das NS-Regime inopportun die Nachwuchsakquise für die Luftwaffe ostentativ zu betreiben. Das Anwerben künftiger Piloten und Luftfahrttechniker musste subtil erfolgen. In den Zigarettenalben, die vor 1935 erschienen sind, werden die wahren Ambitionen entsprechend verschleiert. Die Sammelbände korrespondieren mit der offiziellen Doktrin der Geheimhaltung. Text- und Bildmaterial stehen nicht im militärischen Kontext, sondern sind darauf ausgelegt, die Jugend für den Segelflug zu begeistern. Der Sammelband HELDEN DER LUFT aus dem Jahr 1933 beschreibt in einfacher Sprache die Technik des Segelfluges und versucht, die Faszination dieser Sportart zu übermitteln. Das begleitende Bildmaterial in Form von Fotografien zeigt, wie Jugendliche in lockerer Atmosphäre dem Flugsport nachgehen. Die Luft- und Landschaftsaufnahmen vermitteln den Eindruck von Freiheit und Abenteuer. ${ }^{923}$

Das Album TASCHENBUCH DER LUfTWAFFE aus dem Jahr 1934 wendet die gleichen Methoden an, um die Jugendlichen für sich einzunehmen. In erzählerischer Form werden technische Hintergründe vermittelt und das begleitende Bildmaterial suggeriert dem Betrachter ein spannendes Abenteuer inmitten Gleichgesinnter. Das Album ist damit ganz auf die jugendliche Zielgruppe zugeschnitten. Der Bildersammler erhält sowohl einen spannenden Eindruck vom Segelflug als auch sachlich gehaltene Einblicke in die aeronautischen Grundlagen. Die Intensionen des Sammelbandes werden bereits im Vorwort deutlich artikuliert:

„Die Begeisterung unserer Jugend für das Flugwesen ist sehr groß und sicher wird dieses kleine Sammelwerk dazu beitragen, in Vielen Lust und Liebe für die Fliegerei zu wecken." ${ }^{\text {29 }}$

923 Orami (1933): Helden, Bd. 2, Kapitel: Das entschleierte Geheimnis des Segelfluges, S. 35-37. Exemplarisch Bild 205: Flugzeug, aufgenommen im Gegenlicht, inmitten einer kleinen Wolkenformation mit der Unterschrift: „Der Sonne entgegen.“ 
„Die großen Erfolge im Motorflugzeugbau sind nicht zuletzt auf die gewonnenen Erfahrungen im Segelflug zurückzuführen [und dienen] zur Heranbildung eines Stammes tüchtiger Konstrukteure, Flieger und Facharbeiter $[\ldots]^{\prime \prime} 925$

Während die Akquise in den Alben bis zur Gründung der Wehrmacht noch als reines Freizeitzeitabenteuer getarnt wurde, werden die Jugendlichen ab dem Jahr 1935 offen dazu animiert, eine fliegerische Ausbildung anzustreben. In dem Sammelband Wunder DES SEGELFLuges aus dem Jahr 1935 erfolgt ein Paradigmenwechsel hin zur direkten Nachwuchswerbung. Das Album hat den didaktischen Charakters eines Lehrbuches, das die potentielle Zielgruppe in den Segelflug einführt. In dem Sammelband werden den Jugendlichen nicht nur die spannenden Aspekte des Segelflugsports nahegebracht, sondern es werden gleichzeitig auch die Stationen der Ausbildung aufgezeigt.

„Wie wird man Flieger?

Der Zweck dieses Buches wäre nicht erfüllt, wenn nicht in den jungen Menschen, die diese Bilder gesammelt haben, jetzt der Wunsch erweckt wäre, selbst mitzutun, selbst das Steuer eines Flugzeuges zu führen. Deshalb sei noch der Weg aufgezeigt, der die flugbegeisterte Jugend zu ihrem Ziele führt. [...] Wer Flugsport betreiben will, ganz gleich ob Segelflug oder Motorflug, muß in die Reihen der Fliegerstürme des Deutschen Luftsportverbandes eintreten. Überall im deutschen Reiche, auch in den kleinsten Orten, bestehen heute Ortsgruppen des DLV.“926

Das Album skizziert explizit den Karriereweg vom Modellbau bis zum Dienst in der Reichsluftwaffe. Der jugendliche Bildersammler erfährt, wie er in den NS Organisationen eine Ausbildung zum Flieger erhalten kann:

„Der Deutsche Luftsportverband [kann] seinen Nachwuchs aus der Hitlerjugend entnehmen, wo bis zum 14. Lebensjahre in den Modellbauarbeitsgemeinschaften des Deutschen Jungvolkes, dann in den Luftsportscharen der Hitler-Jugend die jungen Leute, die sich zum Flugwesen hingezogen fühlen, bereits ihr Vorbild in fliegerischen Dingen, zuerst in Modellbau, dann auch in

\footnotetext{
925 Ebd., Text zu den Bildern 100 - 102, unpag.

926 Ebd.
} 
Flugzeugbau und Gleitflugschulung erhalten. Mit Erreichung des 18. Lebensjahres tritt der Flieger-Hitlerjunge in den Fliegersturm des Deutschen Luftsportverbandes über. Aus dem Fliegersturm steht dann dem jungen Piloten oder Fliegerhandwerker der Weg zur Reichsluftwaffe offen, ein Ziel, das sicherlich jedem deutschen Jungen vor Augen schwebt, der an der Fliegerei interessiert ist.“927

Hinter dem sportlichen und spielerischen Charakter des Segelfluges verbargen sich rigide pädagogische Maßnahmen, mit denen die Jugendlichen im Sinne der NS-Volksgemeinschaftsideologie zu Soldaten erzogen werden sollten. Die sportlichen Aktivitäten hatten über die vormilitärische Erziehung hinaus psychologische Funktionen, denn damit sollten die Jugendlichen lernen, sich in die nationalsozialistische Gemeinschaft einzugliedern und Gehorsam und Disziplin zu üben. ${ }^{928}$ Der militärische Aspekt, der sich hinter der flugsportlichen Ausbildung verbarg, wird in dem Album WUNDER DES SEGELFLUGES deutlich im Geleitwort von Bruno Loerzer artikuliert:

„Der deutsche Segelflug ist ein besonders wichtiger Faktor in der Erziehung der deutschen Fliegerjugend geworden. Der deutsche Junge, der sich auf fliegerischem Gebiet betätigen will, sei es im Sport oder Beruf, muß erst durch diese Schule harter Gemeinschaftsarbeit gehen, um den Beweis für seine Begabung und seinen Charakter abzulegen. Die deutsche Fliegerei muß die beste Jugend in sich aufnehmen, wenn sie ihre hohen und schweren Aufgaben für die Nation erfüllen soll. [...] Vorliegendes Sammelwerk ist geeignet, die Alten und die Jungen für die deutsche Luftfahrt zu interessieren und sie zu tätiger Mithilfe anzuregen. Bruno Loerzer “929

Die offizielle Doktrin der Geheimhaltung wurde vom NS-Regime nicht stringent verfolgt. Das Aviatik-Album DAS DEUTSCHE VOLK MUß EIN VOLK VON FLIEGERN WERDEN ${ }^{930}$ schert aus der offiziellen Propagandarichtlinie aus. Das im Jahr 1933 publizierte Album verfolgt nicht nur eine ostentative Rekrutierung, sondern präsentiert die Luftfahrttechnik als Instrument der Vergeltung. Der prosaische Titel, der mit der Unterschrift Hermann Görings gezeichnet ist, verweist nicht nur auf die ideologische Provenienz des Albums, sondern auch auf die Motivation der Herausgeber. Mit dem

\footnotetext{
927 Greiling (1936): Wunder, Kapitel: Wie wird man Flieger? unpag.

928 Vgl. Kliem, Konstantin (2007): Sport in der Zeit des Nationalsozialismus. Saarbrücken: VDM Verlag, S. 5

929 Greiling (1936): Wunder, Geleitwort, unpag.

930 Reunion (1933): Volk von Fliegern, Einleitungstext Kapitel: A. Gleit-und Segelflugzeuge, unpag.
} 
imperativen Slogan ${ }^{931}$ warb das Regime Nachwuchs für die Fliegerausbildung und später für die Luftwaffe. Für das Jahr 1933, als sich die Propaganda noch in Zurückhaltung übte und sich Deutschland vor der Weltöffentlichkeit als wehrlose und friedliebende Nation präsentierte, glich der Titel einer Offenbarung der tatsächlichen Motivation. In der Tat lautete die Propaganda-Devise bis 1935, sich in Bezug auf Luftschutz und Luftrüstung in Zurückhaltung zu üben. Göring hatte mit seiner unmissverständlichen Forderung, die Deutschen müssten „ein Volk von Fliegern“ werden, die offizielle Propaganda-Richtlinie ignoriert. 932

Die Gestaltung des Einbandes weist eine reduzierte wie plakative Kriegspropaganda mit vielschichtiger Symbolsprache aus (Abb. 14). Das Layout wird im unteren Viertel von einem schwarzen Balken abgeschlossen auf dem in weißen Lettern das Thema des Albums angezeigt wird: „Ein Sammelwerk deutscher Gleit-, Segel-, Sport- und Verkehrsflugzeuge.“ Das Cover wird von einer Deutschlandkarte dominiert, auf der die Territorien, die nach den Statuten des Versailler Vertrages abgetreten werden mussten, farblich hervorgehoben sind. Im Zentrum der Karte sticht das NSFK-Abzeichen ${ }^{933}$ mit Hakenkreuz und stilisierter Ikarusfigur deutlich hervor. Die Farbgestaltung ist von intensiven Hell-Dunkel- und Komplementärkontrasten geprägt, die neben einer großen Signalwirkung auch Dynamik vermitteln. Der Rand der Karte ist in einem leuchtenden Rot gehalten, einer Farbe, die Aggressivität sowie „Kampf und Erregung " ${ }^{\prime 934}$ signalisiert. Neben den Farben Schwarz und Weiß des Textfeldes hebt sich das Dunkelblau, mit dem das Reichsgebiet gekennzeichnet ist, sehr intensiv von den Gebieten, die aufgrund der Bestimmungen des Versailler Vertrages abgetreten werden mussten. Dazu zählen Elsass-Lothringen, Oberschlesien sowie der ,polnische Korridor', der Ostpreußen und Danzig vom Reichsgebiet trennten. Diese in hellem Gelb

\footnotetext{
931 Mit Görings Ausspruch wurde auf Plakaten geworben, Entwurf: A.E. Wuttke, Berlin, DHM, P 96/1595

932 Vgl. Lemke (2005): Luftschutz, S. 313

933 Vgl. Kehrberg (1942): Fliegerkorps, Tafel zwischen den Seiten 25 und 26, unpag.

934 Winkelmann, Rita (2013): Was bedeuten Farben in den Bildern? Einführung in die Farbanalytische Ikonographie. Nordhausen: Traugott Bautz , S. 119
} 
markierten Gebiete suggerieren dem Betrachter die „blutenden Grenzen“,935 die in das Herz der deutschen Nation gerissen wurden. Mit dieser Gestaltung wird die anvisierte Okkupation der durch den Versailler Vertrag verlorenen Gebiete grafisch vorweggenommen.936 Derartig gestaltete Landkarten waren ein bewusst gewähltes Stilmittel, das auch in anderen Medien wie Lehrbüchern und Propagandafilmen als Instrument zur emotionalen Mobilisierung des Betrachters eingesetzt wurde. ${ }^{937}$ Das Fliegerabzeichen mit Hakenkreuz suggeriert, dass die Rückeroberung unter der Ägide des Regimes und mit der Hilfe der Luftwaffe gelingen wird. Der Rücktitel folgt dem Design der Vorderseite, der jedoch noch minimalistischer gestaltet ist. Im Zentrum befindet sich lediglich das Fliegerabzeichen, das einzelnstehend den Blick des Betrachters auf sich zieht. Im unteren Bereich steht die Aufforderung: „Werdet Mitglied im Deutschen Luftsport-Verband“. Text und Grafik erhalten in ihrer Gemeinsamkeit einen stark imperativen Charakter.

Der Inhalt des Albums Das DeUtsche VolK MUß EIN VOLK VON FLIEGERN WERDEN ist jedoch moderat gehalten und verzichtet auf demonstratives Säbelrasseln. Der Sammelband ist primär auf den Segelflug ausgerichtet, über den Jugendliche für die Fliegerausbildung gewonnen werden sollen: „Die beste Vorschule für den Motorflug ist der Segelflug. " ${ }^{938}$ Bilder, Zeichnungen und Texte des Albums bedienen darüber hinaus das Bedürfnis der jugendlichen Zielgruppe nach einem spannungsreichen

Wuttke, Gerhard (1933): „Unsere blutenden Grenzen“. In: Kreisgruppe Breslau des Nationalsozialistischen Lehrerbundes, i.A. Wolfgramm (Hg.): Schriften zu Deutschlands Erneuerung, Nr. 3, 5. Aufl. Breslau: Verlag Heinrich Handel, Titelseite und S. 3

936 Auf der Shell-Wetterkarte befindet sich der ,Polnische Korridor' entgegen der politischen Realität bereits innerhalb der deutschen Grenzen. Vgl. Gries, Rainer/ Schindelbeck, Dirk/ Ilgen, Volker (1995): Ins Gehirn der Masse kriechen. Werbung und Mentalitätsgeschichte. Darmstadt: Wissenschaftliche Buchgesellschaft, S. 37. Der ,Polnische Korridor' bezeichnete das Gebiet (Westpreußen und Teil Pommerns), die nach dem Ersten Weltkrieg an Polen abgetreten werden mussten und Ostpreußen sowie Danzig vom Reichsgebiet trennte. Lersner, Freiherr von, MdR (1921): „Deutschlands Grenzen“, S. 12 Vgl. Wuttke, Gerhard (1933): „Die Schmach von Versailles“. In: Kreisgruppe Breslau des Nationalsozialistischen Lehrerbundes, i.A. Wolfgramm (Hg.): Schriften, Nr. 2, Titelseite 
Abenteurer und Gemeinschaftserlebnis inmitten der Natur. In salopper, zielgruppenadäquater Sprache schildert der Autor des Albums die Ausbildung als spannendes Erlebnis.

„Die enge Verbundenheit des Segelfliegers mit der Natur, den Ereignissen und Verhältnissen im Luftraum machen das Fliegen ohne Motor zum Erlebnis und zum schönsten Sport [...]“939

„Einfach und leicht gebaut, der Pilot sitzt frei und lustig unter den Tragflächen. Vor sich den Steuerknüppel und die Seitensteuer, mit deren Hilfe er "die Kiste durch die Gegend schaukelt “. ${ }^{440}$

Die inhaltliche Aufbereitung und Akquise, dieses Sammelbandes korrespondieren daher mit der subtilen psychologischen Mobilmachung, die bis 1935 betrieben wurde.

\subsubsection{Integrationskräfte der Volksgemeinschaft}

Die NS-Propaganda hatte unterschiedliche Intentionen, die alle das Ziel verfolgten, die Bevölkerung ideologisch in einer Volksgemeinschaft zu intergieren. Dazu zählte das Implementieren neuer Werte wie soldatische Tugenden, Blut- und Bodenideologie, Fortschrittsglaube, Arbeitsethos oder die Vermittlung des religiös besetzten Glaubens an Deutschlands Zukunft und Wiederaufstieg. ${ }^{941}$ Aufgrund der Heterogenität der Gesamtzielgruppe Bevölkerung, respektive ,Volksgemeinschaft', ${ }^{\prime}{ }^{442}$ musste die NSIdeologie auf unterschiedliche Zielgruppen zugeschnitten werden. Die Propaganda, die an die Volksgemeinschaft gerichtet war, „war Zielgruppenpropaganda“ ausgerichtet, um unterschiedliche Teile der Bevölkerung anzusprechen." ${ }^{\prime 943}$ Zentrales Thema der NS-Propaganda war die „Erneuerungsideologie“,944 einem Begriff, der Goebbels

\footnotetext{
939 Ebd.

940 Ebd., S. 3

941 Vgl. Reeken, Dietmar von/ Thießen, Malte (Hg.) (2013): >Volksgemeinschaft< als soziale Praxis. Paderborn: Ferdinand Schöningh, S. 21

942 Die Utopie einer Volksgemeinschaft wurzelt nicht in der nationalsozialistischen Ideologie, sondern entstammt völkischen Bewegungen der Kaiserzeit, die nach der Kriegsniederlage als faschistische Utopie eine breite Anhängerschaft fand. Vgl. Esposito (2011): Moderne, S. 266

943 Nolzen, Armin (2013): „Nationalsozialismus und >Volksgemeinschaft< Plädoyer für eine operative Semantik“. In: Reeken, Dietmar von/ Thießen, Malte (Hg.): >Volksgemeinschaft< als soziale Praxis. Paderborn: Ferdinand Schöningh, S. 54

944 Ein symbolischer Akt der ,Erneuerungsideologie‘ war die Machtübergabe von Hindenburg an Hitler am Tag von Potsdam, an dem sich der neue Geist mit dem preußischen Geist verei-
} 
zugeschrieben wird und unmittelbar mit dem Einleiten einer neuen Zeit verbunden wurde. Die Zeitenwende wurde von Erlösermotiven begleitet, die Deutschland aus seinem kollektiven Trauma befreien sollte. In den Zigarettenalben werden diese Motive vielfach vor dem Hintergrund des Versailler Vertrages in Szene gesetzt. Mit Bildern, die sich einer religiös-mythischen Formensprache bedienen, werden Emotionen vieler Teile der Bevölkerung angesprochen, die sich nach einer erlösenden Führerfigur sehnten. Die Propaganda befriedigte damit ein „nicht befriedigtes Bedürfnis nach verheißungsvollen politisch-sozialen Utopien“. ${ }^{945}$ Eines der primären Ziele der NSPropaganda war die Mobilisierung der Bevölkerung für einen Angriffskrieg. Da die kriegerischen Absichten bis Ende der 1930er Jahre geheim gehalten und mit einer Friedensrhetorik kaschiert wurden, musste dennoch ein ideologischer Unterbau für eine psychologische Mobilmachung geschaffen werden. Das geschah vor allem mit der Neukonnotation des Kriegers, der zum Ideal erkoren wurde. Der neue Kriegertypus wurde zum „nationalen Symbol“, das von der politischen Rechten okkupiert wurde, denn es vermochte die „Maskulinität in das Alltagsleben zu transzendieren“. Die Krieger verkörperten „das faschistische Ideal der Männlichkeit“946 und sie avancierten zu den „Schöpfern der Grundlage des Dritten Reiches“.947 Eine weitere Zielgruppe innerhalb der Volksgemeinschaft war der Arbeiter. Ebenso wie der Krieger, erfuhr auch er eine neue Wertung, die in den Kontext soldatischer Tugenden gesetzt und von Pflichterfüllung und Opferbereitschaft geprägt war. Das neue Arbeitsethos war Teil der nationalsozialistischen Sozialutopie, die eine klassenlose Volksgemeinschaft propagierte. In den Zigarettenalben erhalten Arbeiter und Krieger im Kontext der Aviatik einen besonderen Stellenwert und ihre Rollen innerhalb der Volksgemeinschaft werden facettenreich thematisiert.

nigte. Kroll, Frank-Lothar (1998): Utopie als Ideologie. Paderborn: Ferdinand Schöningh, S. 286 und 300

945 Paul (1990): Aufstand, S. 13

946 Mosse (1997): Bild, S. 203

947 Volksbund Deutsche Kriegsgräberfürsorge e. V. (Hg.): „Dienst am Menschen - Dienst am Frieden“. Volksbund Deutsche Kriegsgräberfürsorge e. V. 1919 - 2009. Kassel, 2009, S. 38f. Zit. nach: Koch, Jörg (2013): Von Helden und Opfern. Darmstadt: WBG, S. 119. Gerhard Schultze-Pflaelzer reklamierte in seinem Aviatik-Roman das Erbe der Kampfflieger für das Dritte Reich. Schultze-Pflaelzer (1938): Luftschmiede, S. 317 


\subsubsection{Die neue Zeit}

In den Zigarettenalben wird das Bedürfnis der Gemeinschaft nach Erlösung instrumentalisiert, das sich aufgrund der Kriegsniederlage und des ,Schandfriedens' in breiten Teilen der Bevölkerung eingestellt hatte. ${ }^{948}$ Die Wunde des kollektiven Traumas und die Überwindung der Schmach konnten nur durch „Stärke und Überlegenheit" kompensiert werden ${ }^{949}$ und mit der Hoffnung auf eine neue Zeit, die das Schicksal der Nation zum Guten wendet. Eines der Erlösermotive der Zeitenwende war der nächtliche Fackelzug durch das Brandenburger Tor am 30. Januar 1933 anlässlich des Wahlsieges der NSDAP. In den Zigarettenalben wird der Fackelzug als Schlüsselmotiv vielfach zitiert. Die symbolische Relevanz dieser Inszenierung wird in dem Album KAMPF UM'S DRITTE REICH exemplarisch in einer großformatigen Fotografie zum Ausdruck gebracht. Das Bild unterscheidet sich nicht nur durch das größere Format von den anderen Bildern der Sammlung, sondern auch aufgrund der exponierten Platzierung auf einer Einzelseite. Die symbolische Bedeutung wird pathetisch-religiös aufgeladen, wodurch die Szenerie einem sakralen Tenor erhält:

„,,Durch die dunkle Nacht marschieren wir / Ins Herz des Vaterlandes ein - - / Allmächtiger Gott wird danken dir! - / Jetzt wird die Zukunft Freiheit sein! ““950

Ein anderes Motiv für die Zeitenwende ist die symbolische Machtübergabe von Hindenburg an Hitler, dem einzig legitimen, „apostolischen Nachfolge[r]“,951 am Tag von Potsdam. Die berühmte Demutsgeste Hitlers gegenüber Hindenburg vor der

\footnotetext{
948 Kollektive Neurosen und Traumata, sowie Bedrohungen fördern das Bedürfnis nach Erlösung.

Vgl. Behrenbeck (2011): Helden, S. 45

949 Vgl. Assmann (2006): Schatten, S. 66f.

$950 \quad$ Zigaretten-Industrie (1934): Kampf, unpag.

951 Bullok, A. (1961): „Hitler“, S. 266. Zit. nach: Hoegen, Jesko von (2011): „Der HindenburgMythos. Genese, Inhalte und Funktionen des Personenkults um Paul von Hindenburg.". In: Tepe/ Semlow (Hg.): Mythos No. 3, S. 123. Der Tag von Potsdam wurde von der politischen Rechten und von den Nationalsozialisten propagandistisch als sakrales Ereignis ausgeschlachtet. Dazu zählte der politische Journalist und Werbetheoretiker Schultze-Pfälzer. Die Seele Potsdams als „preußisches Heiligtum“ sollte auch „über der Nationalen Wiedergeburt schweben." Schultze-Pflaelzer, Gerhard (o. J., um 1934): Deutsche Geschichte 1918-1933. Vom Zweiten zum Dritten Reich. Berlin: Otto Stollberg, S. 323
} 
Potsdamer Garnisonskirche wurde zum Akt der ,Erneuerungsideologie' und zu Beginn der Machtübernahme variantenreich inszeniert. ${ }^{952}$ In dem Album KAMPF UM'S DRITTE REICH wird der historische Akt in dem Kapitel „Die neue Zeit“953 mit vielschichtiger Symbolik in Szene gesetzt. Die kleine Bilderreihe wird mit der „,,Taufe des Flugzeuges „Generalfeldmarschall von Hindenburg““ eröffnet. Mit dieser Namensgebung wird die Stafette des alten Preußens an Hitler weitergegeben. Eine weitere Aufnahme des Abschnittes zeigt Hitler, der bei einem seiner Deutschlandflüge einer Maschine entsteigt. ${ }^{954}$ Die Überleitung von Tradition in eine verheißungsvolle Zukunft, die durch das Flugzeug als Symbol der neuen Zeit repräsentiert wird, wird durch die Anordnung der Bilder suggestiv visualisiert.

In dem Sammelband HELDEN DER LUFT wird die Zeitenwende mit vergleichbaren Motiven in Szene gesetzt. Das Album schließt im letzten Kapitel mit einer Aufnahme von Hindenburg ab, der von Göring flankiert wird. Das Bild und die Bildunterschrift "Alte und neue Zeit sind wieder verbunden“955 vermitteln dem Rezipienten eine historische Kontinuität, die von einer ruhmreichen Vergangenheit in eine hoffnungsvolle Zukunft führt. Die Aufnahme wird von einem in Untersicht aufgenommenen Flugzeug dominiert, darüber weiterer Flugzeuge, die am Himmel schweben. Dazu heißt es: „Flieger! Die Zukunft liegt in der Luft“. ${ }^{956}$ Das Motiv und die Dramaturgie der Aufnahme suggerieren auch hier, dass der Führer die Nation mittels der Aviatik in eine hoffnungsvolle Zukunft führen wird. Hitler wird zum Führer, der, versehen mit sakralen Weihen des Himmels, zum Heilsbringer des deutschen Volkes stilisiert

952 Mit der symbolischen Adaption des Hindenburg-Mythos, der gleichzeitig die militärischen Tugenden wie Ehre, Treue und Opferbereitschaft repräsentierte, konnte sich Hitler als legitimer Nachfolger inszenieren. Vgl. Bullok (1961): Zit. nach: Hoegen (2011): „HindenburgMythos“, S. 123. Die symbolträchtige Inszenierung wird in den Zigarettenalben mehrfach thematisiert: „Dieser Händedruck heiligt, ein jeder spürt es, das neue Reich mit dem Segen einer jahrtausendealten Tradition." Reemtsma (1933): Deutschland, Kapitel: Der Tag von Potsdam, S. 88 - 92

953 Zigaretten-Industrie (1934): Kampf, S. 80

954 Ebd.

955 Orami (1933): Helden, Bd. 2, S. 37

956 Ebd. 
wird, ${ }^{957}$ der „eine radikale Verwandlung der Wirklichkeit“958 und eine neue, sakrale Zeit einleitet. Hinter der optimistischen Zukunftsperspektive, die in den Zigarettenalben propagiert wird, verbirgt sich ein apokalyptischer Gedanke, der von einer dem Nazismus immanenten negativen Transzendenz geprägt ist. Nach diesem Verständnis können Erlösung und Zeitenwende nur nach einem Untergang erfolgen.959 Der mythische Protagonist, der vom Himmel auserwählte Führer, ${ }^{960}$ fordert das „Selbstopfer“961 des Einzelnen und die Katastrophe heraus, ohne die es keine Erlösung für die Gemeinschaft geben kann. Das Selbstopfer für ein heiliges Werk „ist Voraussetzung des Triumphes“962 über die Schmach erlittener Demütigungen, denn nur mit dem Opfer des eigenen Lebens für eine göttliche Sache kann Erlösung erfolgen. ${ }^{963}$

Untergang und Opfer manifestieren sich in den Zigarettenalben in einer apokalyptisch besetzten Symbolsprache wie dem Begriff "Morgenrot", 964 der vielfach zitiert wird. Das ,Morgenrot' ist die morbide Metapher eines Gedichtes von Wilhelm Hauff. 965 Sie steht für die Schicksalsergebenheit eines Soldaten, der sich schwermütig

957 Gedicht „An den Führer“ von E. von Schenkendorf: „An den Führer/ Führe uns! In deinen Händen/ Liegt das Schicksal von Millionen,/Die in deinem Herzen wohnen,/ Denen du ein Glaube bist. -/ Gott hat dir die Kraft gegeben,/ Einzig deinem Volk zu leben,/ Das für dich der Pulsschlag ist!“ In: Zigaretten-Industrie (1934): Kampf, S. 42

958 Vondung, Klaus (2013): Deutsche Wege zur Erlösung. Formen des religiösen Nationalsozialismus. München: Wilhelm Fink, S. 121.

959 Bärsch, Claus-Ekkehard (2002): Die politische Religion des Nationalsozialismus. München: Wilhelm Fink, S. 140

960 Nach dem politischen Glaubensbekenntnis von Goebbels war Hitler der inkarnierte Erlöser, der Wunder bewirken konnte: „Ihnen gab ein Gott zu sagen, was wir leiden. Sie faßten unsere Qual in erlösende Worte, formten Sätze der Zuversicht auf das kommende Wunder.“ Goebbels, Joseph, „Die Führerfrage“. In: Ders., die Revolution, 6. Zit. nach: Bärsch (2002): Religion, S. 180

961 Das Selbstopfer basiert auf einer archaischen Weltanschauung. Kriegs- und Schutzgötter wurden gestärkt, damit sie dem Volk Kraft verleihen konnten. Grabner-Haider, Anton/ Strasser, Peter (2007): Hitlers mythische Religion. Theologische Denklinien und NS-Ideologie. Wien/ Köln: Böhlau, S.167

962 Behrenbeck (2011): Helden, S. 110

963 Vgl. Cassirer (2010): Formen, Zweiter Teil, S. 266

964 Orami (1933): Helden, Bd. 2, S. 38

965 Hauff, Wilhelm (2015): „Reiters Morgenlied“. In: Guth, Karl- Maria (Hg): Gedichte. Berlin: Contumax-Hofenberg, S. 12 
den eigenen Tod vor Augen führt. Das romantische Gedicht erhält im NS-Kontext eine semantische Verschiebung und wird zum Inbegriff einer durch nationale Blutsbande zusammengeschweißte Gemeinschaft, für die der Einzelne heldenhaft unter Aufopferung des eigenen Lebens in Kampf und Tod zieht. Die Neuinterpretation der Metapher, die jetzt auch für eine Wiederauferstehung nach Leid und Tod steht, wurde zum viel zitierten Bestandteil des nationalsozialistischen Vokabulars. Das Sprachbild „Siehst du im Osten das Morgenrot“ fand im Lied der Hitler-Jugend „Volk ans Gewehr!“966 seine größte Verbreitung. In dem Sammelband KAMPF UM'S DRITTE REICH wird in einer szenischen Darstellung der Ablauf eines Volkstrauertages pathetisch geschildert. Das Lied „Morgenrot, Morgenrot, - leuchtest mir den frühen Tod...“967 leitet dabei eine Ansprache Hitlers ein. Als Synonym für Untergang und Wiederauferstehung steht der Begriff ,Morgenrot' auch im gleichnamigen Kriegsfilm symbolisch für den Untergang der deutschen U-Bootflotte im Ersten Weltkrieg. In dem Zigarettenalbum VOM WERDEN DEUTSCHER FILMKUNST - DER TONFILM wird der Film als ein „Werk zur Erinnerung und Mahnung, zum Glauben und zur Wiedergeburt!“ Der morbide Tenor des Films, der die Seelenlage eines ganzes Volkes verkörpert, wird mit dem Satz: “Leben können wir Deutsche vielleicht schlecht [...] aber sterben können wir jedenfalls fabelhaft" ${ }^{\prime 968}$ zum Ausdruck gebracht. In dem zweiten Band des AviatikAlbums HeLDEN DER LuFT wird das ,Morgenrot' mit dem Slogan ,Luftfahrt tut not!' in den Kontext der Luftfahrt und der Erneuerungsideologie gesetzt, die durch Hindenburg und Hitler symbolisiert wird.

\footnotetext{
966 Pardun, A. (1933): „Volk ans Gewehr!“ In: Kreisgruppe Breslau, i.A. Wolfgramm (Hg.): Schriften, Nr. 9 Deutsche Jugend heraus! Ausgewählt und bearbeitet von Otto Fröhlich und Herbert Laube, unpag. Das Lied „Siehst Du im Osten das Morgenrot" [Anm. Volk ans Gewehr!] wurde an Schulen gesungen und gehörte zum Standardrepertoire bei NS-Aufmärschen. Vgl. Schreckenberg (2003): Ideologie, S. 51

967 Rede Adolf Hitlers am Volkstrauertag, dem 12. März 1933. In: Zigaretten-Industrie (1934): Kampf, S. 66

$968 \quad$ Reemtsma (1936): Filmkunst-Tonfilm, S. 82
} 
„Wir stehen an einer Wende. Morgenrot leuchtet über Deutschland. Das deutsche Volk hofft voll Vertrauen, daß sein Führer und seine Mitarbeiter ihren Weg siegreich vollenden werden. [...] Der ehrwürdige Reichspräsident v. Hindenburg als Vertreter der starken Vergangenheit hat sich mit Adolf Hitler, dem Führer des neuen, jungen Deutschlands verbunden, und mit dem Segen des Himmels wird das große Werk gelingen.

Dazu gehört auch die Beherzigung der alten Mahnung:

\section{$>$ Luftfahrt tut not!<" 969}

Das Endzeit-Szenario, das im Kontext von Leiden, Opfer und Erlösung steht, folgt einem sakralen Schema christlicher Prägung, das von einer Hoffnung auf Erlösung begleitet wird. Opfer und Leiden erhalten damit eine religiöse Dimension. ${ }^{970}$ Die Implikation der christlichen Religion war der NS-Ideologie inhärent. Ihr lag ein „mythisch strukturiertes Geschichtsbild“971 zugrunde, dem zu Folge eine Erlösung nur dann erlangt werden kann, wenn ihr eine Krise und Katastrophe vorausgeht. Exemplarisch für die Implikation christlicher Motive ist das letzte Bild des Sammelwerkes, das ein Flugzeugseitenruder zeigt, das mit einem Hakenkreuz gekennzeichnet und mit der sakrosankt konnotierten Bildunterschrift „In hoc signo vinces!“972 versehen ist (Abb. 15). Der Ausspruch wird Kaiser Konstantin zugeschrieben, dem der Legende nach am Vorabend einer wenig aussichtsreichen Schlacht der Sieg im Zeichen des Christogramms verkündet wurde. ${ }^{973}$ Die ikonische Verdichtung der Symbole verkündet eine Zeitenwende und verheißt eine göttliche Siegesverkündung nach einem Kampf mittels der Luftwaffe unter nationalsozialistischer Ägide. Die Aviatik erfährt eine vielschichtige symbolische Besetzung mit numinoser Dimension.

\footnotetext{
969 Orami (1933): Helden, Bd. 2, S. 38

970 Durkheim, Émile (2007): Die elementaren Formen des religiösen Lebens. Frankfurt/M.: Verlag der Weltreligionen, S. 458f.

971 Behrenbeck (2011): Helden, S. 110

972 Ebd.

973 Vor der siegreichen Schlacht gegen Maxentius im Jahr 312 erschien Kaiser Konstantin das Christogramm, verbunden mit den Worten "In hoc signo vinces“. Eusebius/ Translation: Maier, Paul L. (1999): The Church History. Grand Rapids: Kregel Academic, S. 305f. Die Vision und ihre christliche Interpretation im Sinne des himmlischen Beistandes wurde erst Jahre nach der Schlacht hinzugefügt. Leeb, Rudolf (1992): Konstantin und Christus. Berlin: de Gruyter, S.135f.
} 
Die Omnipotenz des NS-Regimes wird dem Betrachter auch mit gestalterischen Stilmitteln, wie untersichtige Aufnahmen, visuell vermittelt. In dem Sammelband HELDEN DER LuFT, erfährt die Dominanz des NS-Regimes durch diese Aufnahmetechnik eine symbolische Erhöhung. Ein Flugzeug, das in extremer Untersicht aufgenommen wurde, blickt erhaben in Richtung Himmel. Mit der Bildunterschrift „Gesicht der Zeit" ${ }^{\prime 9}{ }^{974}$ wird dem Betrachter nicht nur die Macht des Regimes plastisch vor Augen geführt, denn die Aufnahme suggeriert den Aufbruch in die vom Regime proklamierte „Neue Zeit“. ${ }^{975}$

\subsubsection{Amazonen der Luft und stählerne Krieger}

Das Bild des Kriegshelden als individueller Einzelkämpfer erfuhr nach dem Ersten Weltkrieg eine Transformation. Sieger waren diejenigen, die das Stahlgewitter überlebt und sich in einen technischen Krieger verwandelt hatten. ${ }^{976}$ Insbesondere die Flieger, die mit ihrer Maschine eine Symbiose eingegangen waren, hatten aufgrund ihrer Kampferfahrung im metallischen Krieg eine Initiation zur „modernen Männlichkeit" ${ }^{\prime 977}$ erfahren. In Anlehnung an den Futurismus generierte der Flieger zur Verkörperung von „Maskulinität, der Gewalt, der Geschwindigkeit und des Todes.“978 Der Flieger wurde zur Ikone, die Ernst Jünger als Vertreter einer neuen Rasse betrachtete. ${ }^{979}$ Für Jünger war die Aviatik Ausdruck moderner technischer Kriegsführung und „die schärfste Ausprägung einer neuen Männlichkeit", die „sich bereits im Kriege angedeutet hat“. ${ }^{980}$ Der moderne technische Krieg wurde zur „Domäne der Männlichkeit, der Abenteuer und Anerkennung. ${ }^{981}$ Der Flieger war der Inbegriff des

\footnotetext{
974 Orami (1933): Helden, Bd. 2, S. 38, Bild 216

975 Ausführlich Kap. 5.1.9

976 Vgl. Schnatz, Jörg (2013): Söhne von Kriegen und Bürgerkriegen. Generationalität und Kollektivgedächtnis im Werk Ernst Jüngers 1920-1965. Würzburg: Ergon, S.180

977 Mosse (1997): Bild, S. 203

978 Höhler (2001): Luftfahrtforschung, S. 113

979 Vgl. Jünger (1922): Kampf, S. 22f.

$980 \quad$ Jünger (1933) : Luftfahrt, S. 8f.

981 Schneider, Wolf (2014): Der Soldat - ein Nachruf. Reinbek bei Hamburg: Rowohlt, S. 275
} 
Kriegers. Er wurde zum faschistischen Ideal erkoren und stellte eine ideologische Basis für das Dritte Reich dar. ${ }^{982}$

Für das NS-Regime symbolisierten insbesondere die Flieger „die Ideale des deutschen Helden in ihrem Kampfeswillen, in ihrer Unerschrockenheit und ihrem Draufgängertum“. Das Ideal wurde insbesondere von Göring propagiert und stand für den „neuen Fliegergeist“. ${ }^{983}$ Der neue Kriegertypus, der eine stählerne Maskulinität ausstrahlte wurde zur Inkarnation des deutschen Helden, der „Kampfeswillen, in ihrer Unerschrockenheit und ihrem Draufgängertum“ 984 verkörperte, wurde vielfach medial verbreitet und auch in den Zigarettenalben als erstrebenswertes Vorbild verherrlicht. Der moderne Kämpfer wurde zum „Vorbild männlicher Kraft“" ${ }^{\text {" } 985}$ und erhielt die Konturen des technischen Kriegers mit stählernen Nerven. ${ }^{986}$ Die Aviatik und die damit verbundenen Eigenschaften wie „Tapferkeit und Mut“ wurden den Männern zuerkannt, waren „maskuline Monopole.“987 Die Aviatik ist daher männlich konnotiert und „,in der symbolischen Ordnung der Moderne verankert“ ${ }^{988}$ Eine weibliche Besetzung wird daher a priori ausgeschlossen.

Die Rolle der Frauen fällt in den Aviatik-Alben entsprechend bescheiden aus, wobei aber ein Paradigmenwechsel zu verzeichnen ist, der sich nach 1933 eingestellt hat. In

982 Gerhard Schultze-Pflaelzer reklamierte in seinem Aviatik-Roman das Erbe der Kampfflieger für das Dritte Reich. Schultze-Pflaelzer (1938): Luftschmiede, S. 317

983 „Im letzten Jahre habe ich betont, daß in Zukunft für die Anerkennung und Belohnung fliegerischer Leistung nicht mehr die überzüchtete Einzelleistung maßgebend sein soll. [...] Es kommt heute im nationalsozialistischen Deutschland darauf an, daß niemand als Einzelgänger da und dort hinläuft. Endlich ist das Volk zusammengefaßt zu einer Geschlossenheit, die allein die Kraftquelle für zukünftige Leistungen ist.“. Göring: „Fliegergeist”. In: Gritzbach (1938): Reden, S. 121

984 Vgl. Ritli, Martin (Wissenschaftlicher Mitarbeiter und Regisseur der UFA-Kulturabteilung) (1938): Flieger Funker Kanoniere. Berlin: Schützen Verlag, S. 59. Der gleichnamige Propagandafilm kam 1937 in die Kinos. Vgl. Stambolis, Barbara (2016): „Junge Adler“, S. 225 Aviatik (1936): Uniformen, S. 2

986 Vgl. Szczepaniak, Monika (2011): Militärische Männlichkeiten in Deutschland und Österreich im Umfeld des Großen Krieges. Würzburg: Königshausen \& Neumann, S. 35. Auch Hindenburg wurden diese Eigenschaften zugeschrieben: "Seine stahlharten Nerven haben die Belastungsprobe [...] ertragen." Brinkmann (1934): Alles für Deutschland, S. 82f.

987 Metzsch (1935): Wehrkräfte, S. 162

988 Szczepaniak (2011): Männlichkeiten, S. 8 
den Alben der frühen 1930er Jahre stehen die Fliegerinnen noch gleichberechtigt unter Hervorhebung ihrer besonderen Leistungen neben ihren männlichen Mitstreitern. Die Fliegerinnen werden bar jeder weiblicher Attribute in ihrer vollständigen Fliegermontur wie Fliegerkappe- und Brille ${ }^{989}$ dargestellt und gleichen in der Darstellung den männlichen Piloten. Die Fliegerinnen werden als mutige und moderne Frauen dargestellt, die wie eine asexuellen Mensch-Maschine mit ihrem Flugzeug 'verwachsen' sind:

„Frl. Liesel Bach, die deutsche Kunstflugmeisterin, ist der Typ des beherzten deutschen Sportmädels. Mit ihrer Maschine verwachsen kennt Liesel Bach keine Schwierigkeiten. Eine würdige Repräsentantin deutscher Flugkunst. “990

„Deutsche Flieger-Königinnen - Liesel Bach, Thea Rasche, Elly Beinhorn. Drei kernige deutsche Mädchen, Heldinnen der Luft. Liesel Bach, Kunstflugmeisterin von Deutschland. Thea Rasche, weltberühmt durch ihren Versuch, unter der Brooklin-Brücke hindurch zu fliegen. Rechts Elly Beinhorn, die reizende Hannoveranerin, deren Afrikaflug und späterer Weltflug die Bewunderung der Welt erregten.“991

Das Zigarettenalbum BERGMANNS BUNTE BÜCHER II aus dem Jahr 1932 spiegelt die Frauenrolle in der Weimarer Republik wider, die in Teilen von Modernität geprägt war. Die Fliegerin Elly Beinhorn wird gemeinsam mit Gerhard Fieseler, einem Flugpionier, Weltkriegsveteranen und Kunstflieger in einer Zigaretten-Werbung mit lockerem Strich illustriert. Beinhorn trägt die gleiche Kurzhaarfrisur und Fliegermontur wie Fieseler und ist in ihrem Habitus von ihrem männlichen Begleiter nicht zu unterscheiden. Das einzige weibliche Attribut sind ihre Schuhe.

„Elly Beinhorn Sportlehrerin und Fliegerin (aus Hannover), Weltenbummlerin auf 80 PS Argus Klemm-Maschine. Erfolgreich bei "Gildehof"Flugveranstaltungen der Haus Bergmann Zigaretten-Fabrik A-G. “992

\footnotetext{
989 Gruppenfoto mit Liesel Bach, Thea Rasche (Kostüm), Elly Beinhorn. Bulgaria-Sport-Photos. Dresden, S. 36, Bild Nr. 243

990 Liesel Bach mit Kurzhaarschnitt und in männlicher Kleidung. Bulgaria (1932): Bulgaria-SportPhotos, S. 36, Bild Nr. 239

991 Bulgaria (1932): Bulgaria-Sport-Photos, S. 36, Bild Nr. 243

992 Haus Bergmann (1932): Bergmanns bunte Bücher, Buch 2, 21.-22. Aufl. Dresden. Kapitel: SportKarikaturen, Bild Nr. 2 und Zigarettenwerbung auf der gegenüberliegenden Seite, unpag.
} 
Diese Darstellung reflektiert die Rolle der Frau, die in der Kriegszeit und der Weimarer Republik einen gesellschaftlichen Wandel erfahren und sich weitestgehend von ihren traditionellen Strukturen losgelöst hatte. ${ }^{993}$ Dennoch gelang es in der Weimarer Republik nur wenigen Frauen in die Domäne der Männlichkeit vorzudringen. Weibliche Piloten blieben meist aufgrund der ökonomischen Zwänge eine Randerscheinung. Ab 1930 wurden Frauen mit dem Wiedererstarkenden der deutschen Luftfahrt von den Luftfahrtgesellschaften als Werbeträger entdeckt ${ }^{994}$ und Fliegerinnen wie Thea Rasche oder Elly Beinhorn errangen mit ihren fliegerischen Leistungen und Rekorden eine enorme Publizität.

Mit dem Machtantritt der Nationalsozialisten erfuhr die Frau als Fliegerin einen Wandel, der aber sukzessive von statten ging, denn die Rolle der Frau konnte nach 1933 nicht völlig revidiert werden. Die Position der Frau als Fliegerin unterlag verschiedenen Einflüssen, die maßgeblich von den militärischen Ambitionen des Regimes abhängig waren, denn die Geschlechtertrennung manifestierte sich in der deutschen Gesellschaft auch über den Kriegsdienst. ${ }^{995}$ Insbesondere reaktionäre Kreise forderten eine Differenzierung der Geschlechter. Es musste den Männern vorbehalten bleiben, die Kriegsniederlage zu kompensieren, denn die „nationale Niederlage war auch Niederlage der Männlichkeit.“"996 Während bis 1934 keine Differenzierung zwischen den Geschlechtern herrschte, verlagerte sich die Förderung im Rahmen der vormilitärischen Fliegerausbildung zugunsten der Männer. ${ }^{997}$ Nachdem das NSFK ab

\footnotetext{
993 Die Fliegerinnen selbst betrachteten sich jedoch nicht als emanzipatorische Speerspitze und distanzierten sich von der Frauenbewegung. Vgl. Zachmann, Karin (2004): Mobilisierung der Frauen: Technik, Geschlecht und Kalter Krieg in der DDR. Frankfurt/M.: Campus, S. 162

994 Vgl. Zegenhagen, Evelyn (2007): "Schneidige deutsche Mädel": Fliegerinnen zwischen 1918 und 1945. Göttingen: Wallstein, S.165

995 Die Differenzierung der Geschlechter wurde durch Waffenfähigkeit definiert, die nur den Männern zugesprochen wurde. Vgl. Frevert, Ute (1997): „Das Militär als „Schule der Männlichkeiten". Erwartungen, Angebote, Erfahrungen im 19. Jahrhundert". In: Frevert (Hg.): Militär, S. 171

996 Schilling (2002): Kriegshelden, S. 313. Im Zuge der Freiheitskriege (1813-1815) hatte sich ein „patriotisch-wehrhafter Männlichkeitsentwurf“ in Preußen etabliert. Der Frau oblag die "patriotische Frauenpflicht", deutsche Sitte und Kultur im familiären Umfeld zu bewahren. Hagemann, Karen (1997): Heldenmütter, Kriegerbräute und Amazonen. Entwürfe „patriotischer" Weiblichkeit zur Zeit der Freiheitskriege. In: Frevert (Hg.): Militär, S. 185 Zegenhagen (2007): Mädel, S. 156f.
} 
1937 die Nachfolge des Luftsportverbandes übernommen hatte, war nur diese Organisation für die vormilitärische Ausbildung der angehenden Piloten zuständig. Frauen waren dabei ausgeschlossen. Lediglich bekannte Fliegerinnen wurden beim NSFK angestellt. 998

Mit dem Beginn des Krieges setzte aber eine „zunehmende Verflechtung der geschlechtsspezifischen Lebenswelten von Männern und Frauen [...]“ ein ${ }^{999}$ und die Differenzierung zwischen Männer- und Frauenarbeit wurde teilweise aufgehoben. ${ }^{1000}$ So war das RLM das einzige Ministerium, das Frauen in helfenden Funktionen zuließ. ${ }^{1001}$ Die Mehrheit der Fliegerinnen ging dem Luftsport aber in Vereinen nach. Für das Gros der Fliegerinnen war eine weiterführende Flugausbildung überflüssig, da Frauen von der militärischen Laufbahn als Pilotinnen ausgeschlossen waren. In dem Album HELDEN DER LUFT wird dieser Aspekt deutlich artikuliert:

,[...] aber das Segelfliegen hat noch einen höheren Sinn. Es ist eine ausgedehnte Eignungsprüfung und Vorstufe für das Fliegen überhaupt und führt zu einer Auslese von bestqualifizierten Flugzeugführern für die gesamte Luftfahrt. Für Frauen ist diese Auslese nicht nötig, wir beschäftigen sie nicht im Flugwesen - schließlich hat die Luft keine Balken. Es ist uns immer noch schrecklich, eine Frau in Gefahr zu sehen und sie Verletzungen ausgesetzt zu wissen. " ${ }^{1002}$

In den Aviatik-Alben, die ab 1933 erschienen sind, beherrschen männliche Piloten den Himmel. Lediglich in dem Sammelband HELDEN DER LuFT wird den weiblichen Piloten in dem Kapitel „Amazonen der Luft“1003 eine Plattform geboten. Die Frau, die als Fliegerin in die Domäne der Männer einbricht, wird mit der Bezeichnung 'Amazone' relativiert. Mit der Verschiebung in die Sagenwelt der Antike ${ }^{1004}$ werden sie

\footnotetext{
998 Vgl. Ebd.

999 Steinbacher, Sybille (Hg.) (2007): Volksgenossinnen: Frauen in der NS-Volksgemeinschaft. Göttingen: Wallstein Verlag, S. 24

1000 Buggeln, Marc/ Wildt, Michael (2014): In: Dies. Arbeit im Nationalsozialismus. München: de Gruyter, S. XXX

1001 Vgl. Zegenhagen (2007): Mädel, S. 163

1002 Orami (1933): Helden, Bd. 1, S. 2

1003 Ebd., S. 30

1004 Als Amazonen (Mondfrauen) wurden in der Antike bewaffnete Priesterinnen bezeichnet. Vgl. Ranke-Graves, Robert von (1960): Griechische Mythologie. Quellen und Deutung, Bd. 1. Hamburg: Rowohlt, S. 322f.
} 
in die Palette der „weiblichen Stereotypen“1005 eingereiht. Damit konnte der Typ der modernen Frau als temporäres Phänomen betrachtet und musste nicht in das gesellschaftlich sanktionierte Frauenbild integriert werden. In dem Album HELDEN DER LUFT kommt die Ambivalenz der Frau als Fliegerin besonders zum Ausdruck. Den Pilotinnen wird aufgrund ihrer Leistungen Respekt gezollt und sie werden in die „Garde der Luft" ${ }^{\prime 1006}$ aufgenommen, jedoch nicht in die kriegerische Welt, in der maskuline Tugenden gefordert werden.

Die „Heldinnen der Luft“ ${ }^{\prime 1007}$ werden mit femininer Semantik porträtiert und ihre Passion zum Fliegen wird mit weiblicher Emotionalität begründet. Anstelle kriegerischer Attribute werden sie inoffensiv als „lustige Gesellen“ bezeichnet, die „sich in den Lüften tummeln“. ${ }^{1008}$ Die Fluglehrer erweisen sich den Frauen gegenüber als Ritter der Luft der besonderen Art, denn „für den Mann ist es immer noch schrecklich, eine Frau Gefahr und Verletzungen ausgesetzt zu sehen.“ Die Frauen danken der „Ritterlichkeit“ ihrer männlichen Kollegen und schätzen es, wenn sie für zu „kostbar gehalten werden“ um bei einer Bruchlandung „verunstaltet“1009 zu werden. Aller Bewunderung zum Trotz wurden die weiblichen Flieger als latente Bedrohung angesehen, 1010 die ebenso viel Irritation hervorriefen wie die Amazonen in der Antike. Die Furcht vor der weiblichen Konkurrenz am Himmel kommt in einer Textpassage des Albums deutlich zum Ausdruck:

1005 Mosse (1997): Bild, S. 22. Der Stereotyp der Amazone ist vergleichbar mit den Charakteren im Film jener Zeit. In dem Zigarettenalbum, Vom Werden deutscher Filmkunst' wird die Typisierung der weiblichen Rollenfächer auf das Bedürfnis des Publikums zurückgeführt, Rollenklischees authentischen Charakteren vorzuziehen. Die Darstellerinnen waren daher festgelegt auf Rollen wie „Der Backfisch“, „Die Naive“, „Das Girl“, „Das süße Mädel“, „Die Frauliche“, „Die mondäne Frau“ oder "Der Vamp“. Reemtsma (Cigaretten-Bilderdienst Altona/Bahrenfeld) (1935): Vom Werden deutscher Filmkunst. 1. Teil: Der stumme Film. Hamburg-Bahrenfeld, S. 123-129

1006 Orami (1933): Helden, Bd. 1, S. 30

1007 Ebd., S. 32

1008 Ebd., S. 30

1009 Ebd., S. 32

1010 Ebenso wie die männlichen Flieger wurde der Typus der ,neuen Frau' durch den Ersten Weltkrieg hervorgebracht. Obwohl die Fliegerin eine Minderheit darstellte, wurde sie von den Männern als Bedrohung angesehen. Vgl. Mosse (1997): Bild, S. 20 
„Den Männern mag es eine Beruhigung sein, daß es immerhin nur einigen wenigen vorbehalten bleibt, der Flugpassion zu leben. [...] die Männer werden doch nicht in der Angst leben müssen, daß ihnen die Frauen eines Tages einfach davonfliegen. ${ }^{\text {1011 }}$

Die Zigarettenalben reihen sich damit in die populären Medien ein, die die männliche Jugend für die Luftfahrt mobilisieren und die Frauen auf eine Rolle als Fliegerfrauenund Mütter reduzierten wollten. ${ }^{1012}$ Diese Geschlechtertrennung wurde in der Zeit des Nationalsozialismus jedoch nicht konsequent verfolgt. Diese Ambivalenz manifestiert sich in den Fliegerinnen, die einen hohen propagandistischen Wert für die Außendarstellung des NS-Regimes besaßen, ${ }^{1013}$ denn sie transferierten das Image einer progressiven und modernen Nation. So zollt selbst die Firma Aurelia, das einzige Unternehmen, das nachweislich mit dem NS-Regime konform ging und das Vorwort vieler Alben mit „Heil Hitler!“ zeichnete, der Fliegerin Elly Beinhorn Respekt.

„Elli Beinhorn. Die deutsche Fliegerin Elli Beinhorn, die durch ihre weltumspannenden Flüge, die sie in mehrere Erdteile führten, bekannt wurde. " 1014

Die fliegenden Frauen stehen in den Zigarettenalben zwischen der tradierten Frauenrolle und der propagierten Modernität ${ }^{1015}$ und repräsentieren die Doppelwertigkeit der Moderne. Hier kommt die Ambivalenz der Frauenrolle im NS-Regime zum Ausdruck, die keine signifikante Uniformität aufweist ${ }^{1016}$ und maßgeblich von der Binarität von Fortschritt und Tradition geprägt war.

\subsubsection{Die stille Front der Arbeiter}

Mit der Neuinterpretation der Kriegshelden wurde auch die Rolle des Arbeiters neu rezipiert. Entsprechend den „Tugenden des nationalsozialistischen neuen Menschen“ hatte der Arbeiter die Pflicht, sich ebenso wie der Soldat, ,einzugliedern und notfalls

\footnotetext{
1011 Orami (1933): Helden, Bd. 1, S. 30

1012 Vgl. Kehrt (2010): Krieger, S. 236

1013 Vgl. Zegenhagen (2007): Mädel, S. 300

1014 Aurelia (1934): Film und Sport im Buntbild. Dresden, Bild Nr. 156, S. 26

1015 Vgl. Kehrt (2010): Krieger, S. 237

1016 Zur Ambivalenz der Frauenrolle im Drittes Reich ausführlich: Bavaj, Riccardo (2003): Die Ambivalenz der Moderne im Nationalsozialismus. München: Oldenbourg, Kapitel III, 1, Familie und Stellung der Frau
} 
aufzuopfern“. ${ }^{1017}$ Damit entstand eine „Gleichsetzung von Frontsoldatentum und Arbeitertum und, von Fliegern und Industriearbeitern [...]. ${ }^{\lrcorner 1018}$ Wie der Soldat, der im Schützengraben für sein Vaterland Opfer erbracht hatte, musste der Werktätige sein Opfer an der Arbeitsfront erbringen. ${ }^{1019}$ Als Soldaten der Arbeit wurden die Werktätigen durch die Propaganda aufgewertet und „Arbeit adelt“ wurde zum gängigen Slogan und "gesellschaftliches Ideal“ ${ }^{1020}$ Der Arbeiter trat die Nachfolge des Soldaten als Teil einer anonymen Gemeinschaft an und zeichnete sich aus durch „Kameradschaft und Disziplin. “1021 Der Arbeiter wurde zum Leitbild einer faschistischen Utopie, wie sie Ernst Jünger in dem Vorwort „Luftfahrt ist not!“ charakterisiert: „Der Weg, der durch die heroischen Landschaften des Krieges führte, zieht sich auch durch die nüchternen Gefilde der Arbeit fort, und hier wie dort ist es das Fliegerherz, das der Tätigkeit ihren eigentlichen Wert verleiht.. ${ }^{1022}$

Das nationalsozialistische Arbeitsethos wurde in den Medien der Populärkultur verbreitet wie den Zigarettenalben. ${ }^{1023}$ Die zunehmende Militarisierung der Arbeit ${ }^{1024}$ kommt in dem Sammelband DeR STAAT DER ARBEIT UND DES FrIEDENS exemplarisch zum Ausdruck. Die Arbeit erfährt eine semantische Verschiebung in die Welt des Krieges. So wird ein Arbeitsprogramm zur "Arbeitsschlacht“, ${ }^{1025}$ bei der wie auf dem

\footnotetext{
1017 Vondung, Klaus (1988): Die Apokalypse in Deutschland. München: DTV, S. 390

1018 Esposito (2011): Moderne, S. 293

1019 Das Opfer des Helden erhielt nach 1933/34 eine andere Bedeutung. Das Selbstopfer bezog sich nicht nur auf den Kampf, sondern stand für „die persönlichen Einschränkungen im täglichen Leben, die jeder Volksgenosse für den Aufbau des neuen Reiches zu bringen hatte [...]" Behrenbeck, (2011): Helden, S. 245

1020 Wette (1979): „Ideologien“, S. 149

1021 Wiedemann, Gerhard (1935): „Arbeiter und Student“. In: Gruber, Walter (Hg.): Volk ans Gewehr. Das Buch vom neuen Deutschland, 3. Aufl. Berlin: Nibelungen-Verl., S. 296

1022 Jünger (1933): Luftfahrt, S. 9

1023 Die Arbeit war Thema in insgesamt acht Sammelalben. (inklusive Zigarettenalben) Vgl. Scharnberg, Harriet (2014): „Arbeit und Gemeinschaft. Darstellungen „deutscher" und „jüdischer" Arbeit in der NS-Bildpropaganda“. In: Buggeln/ Wildt (2014): Arbeit, S. 175. Unter den Sammelalben befinden allein vier Zigarettenalben, die sich monothematisch mit der Arbeit beschäftigen: Greiling (1934): Adel der Arbeit. Zimmer (1934): Bildwerk vom deutschen Arbeitsdienst. Dresden. Aurelia (1933): Deutsche Zunftwappen. Die Adelszeichen deutscher Arbeit sowie Zigaretten-Industrie (1934): Staat

1024 Marszolek, Inge (2014): „Vom Proletarier zum „Soldaten der Arbeit““. In: Buggeln/ Wildt (Hg): Arbeit, S. 224

1025 Zigaretten-Industrie (1934): Staat, S. 93
} 


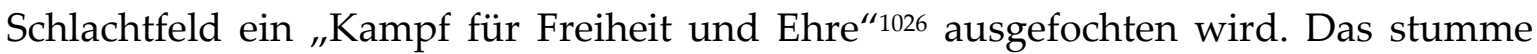
und bescheidene Heldentum wird auch den Akteuren abverlangt, die im Schatten der großen Fliegerhelden stehen. In dem Album HELDEN DER LUFT wird der „Stillen Front" ${ }^{\prime 1027}$ der Flugkapitäne, Technikern und Arbeitern, die hinter den Kulissen mit ihrem technischen Können und verantwortungsbewusster wie „unermüdlicher Pflichttreue “1028 ihren Dienst verrichten, Respekt gezollt. Sie werden damit in die Reihe der Forscher und Flugpioniere eingegliedert, die die Flugtechnik unter größten Opfern und unter Einsatz ihres Lebens entwickelt und vorangebracht haben, ohne in die Annalen der Geschichte einzugehen.

„Es gibt auf diesem Gebiete [Anm. Forscher in Theorie und Praxis] viele Opfer, die auf der Strecke bleiben, die nie bekannt werden, weil Andere, Erfolgreichere ihr Werk vollenden. Ihr Heldentum muß stumm sein. Wird aber das Drama in seinen Einzelheiten bekannt, so zeigt sich das Heroische ihrer Leistung. [...] Der Raum reicht nicht zu, alle zu nennen, aber wir wollen die Aufmerksamkeit auf diese fliegenden Arbeiter und Forscher gelenkt haben $[\ldots]^{\prime \prime} 1029$

Die Helden der Luft steigen herab und werden zu Arbeitern, die sich anonym in den Dienst der Gemeinschaft stellen. Sie werden zum Bindeglied einer faschistischen Massengesellschaft, zum „Mythos eines neuen, nicht-bürgerlichen Menschen“, der seine Individualität aufgibt. ${ }^{1030}$ Mit dem Appell an die Opferbereitschaft wird die Arbeit um eine magische Dimension erweitert. Mit der Entsagung wird dem Arbeiter vermittelt, er besäße eine numinose Kraft, die zum Wohl der Volksgemeinschaft beiträgt. Das Opferbewusstsein erhält damit eine psychologisch-magische Dimension,

1026 Ebd., S. 97. Nach dem Versailler Vertrag wurde Ehre „zum Ausdruck der abstrakten Gemeinschaft, des Vorranges des Kollektivs, zur Norm des $>$ Neuen Menschen $<<$, des Arbeiters und Soldaten im Dienste der Gemeinschaft [...]“. Speitkamp, Winfried (2010): Ohrfeige, Duell und Ehrenmord. Stuttgart: Reclam, S. 176

1027 Orami (1933): Helden, Bd. 1, S. 34

1028 Ebd., S. 33

1029 Orami (1933): Helden, Bd. 2, S. 15

1030 Vgl. Voskuhl, Adelheid, „Ernst Jünger“. In: Fraunholz/ Woschech (2012): Technology, S. 37f. Im Dritten Reich gehörten die Vertreter der Luftfahrtforschung zur wissenschaftlichen Elite. Die Heroisierung des Arbeiters verschleiert daher die wahren gesellschaftlichen Realitäten, denn das selbstlose Opfer wurde lediglich dem Arbeiter abverlangt. Vgl. Hormann (1988): Elite, S. 5 und 14f. 
denn es ist verbundenen mit dem "Verzicht, den das Ich sich auferlegt “, ${ }^{1031}$ um ", sein Mana [sic!], sein Besitz an physikalisch-magischer Gewalt und Wirksamkeit“1032 zu stärken. Hitler selbst beanspruchte für sich die Vorreiterrolle des neuen Arbeitertypus, der aus den Schützengräben des Ersten Weltkrieges hervorgegangen war. Dabei verstand er es, sich geschickt in dieser Rolle zu inszenieren - ein Mythos, der in den Sammelbänden genährt wird, wie in dem Album KAMPF UM'S DRITTE REICH:

„,'Achte den Arbeiter, und du achtest dein Volk!“ Diesen Grundsatz hat sich der Führer Adolf Hitler von Jugend auf zu eigen gemacht. Nur zu gut kann er das Los des deutschen Arbeiters verstehen. Er kann und wird es nie vergessen, was es heißt, durch tägliche mühselige Handarbeit sein Brot verdienen zu müssen [...] Wer wagt zu vergessen, daß Hunderttausende deutscher Arbeiter für ihr Vaterland gefallen sind?“"1033

Das neue Arbeitsethos war Teil der nationalsozialistischen Sozialutopie, die eine klassenlose Volksgemeinschaft propagierte. Der neue Tenor wird in vielen Zigarettenalben propagiert, wie in dem Band ADEL DER ARBEIT. Hier wird der Werktätige zum Teil einer klassenlosen Gemeinschaft und Deutschland zum „Reich der Arbeit. “1034

„Im deutschen Volk gibt es keine Sonderrechte mehr, die nicht durch entsprechende Leistungen begründet sind [...]. Über allem steht das Wohl des gesamten Volkes. Die Aufgaben, die im Interesse der Gesundung und Stärkung des deutschen Volkes bewältigt werden müssen, sind riesengroß. Sie können nur gelöst werden, wenn jeder einzelne sich restlos unterordnet, und wenn jeder die ihm übertragenen Aufgaben mit Sorgfalt und Fleiß ausführt. “1035

Der deutsche Arbeiter, wird, ebenso wie der Soldat zum Helden stilisiert, der sich zum Wohl der deutschen Nation unterordnen und jedes Opfer erbringen muss.

\footnotetext{
1031 Cassirer (2010): Formen, Zweiter Teil, S. 261

1032 Ebd., S. 262

1033 Zigaretten-Industrie (1934): Kampf, S. 48

1034 Greiling (1934): Adel, Einleitungstext, unpag.

1035 Ebd.
} 


\subsubsection{Zeppelin - Phönix aus der Asche}

Als sich im Jahr 1900 der erste Zeppelin in die Luft erhob, wurde die fliegende Zigarre als obskures Objekt eines exzentrischen Grafen bestaunt. Der populäre Höhenrausch, den das Luftschiff bereits wenige Jahre später erreichen sollte, lag noch jenseits des Horizontes, denn die Konstruktionen des Grafen Zeppelin stießen in ihren Anfängen bei staatlichen Stellen auf wenig Resonanz. Zeppelin gelang es nur mit Mühe, Ausdauer und Hartnäckigkeit, seine Unternehmungen zu finanzieren, wobei er ebenso viel Erfindergeist bewies wie bei seinen aeronautischen Entwicklungen. Mit Lotterien, Eingaben an staatliche Stellen, einem verzweifelten Spendenaufruf an die deutsche Nation und mit dem Einsatz seines Privatvermögens konnte der energische Graf seine Luftschiffe in der Luft halten. ${ }^{1036}$ Die Wende im Bewusstsein der Öffentlichkeit wurde erst durch eine Katastrophe herbeigeführt, bei der das Luftschiff LZ 4 im Jahr 1908 nach einer Deutschlandfahrt über Echterdingen explodierte und vollständig ausbrannte. Der Schicksalsschlag offenbarte, „wie tief das Nationalgefühl im ganzen deutschen Volke bei dieser Gelegenheit aufgerüttelt worden ist" ${ }^{1037}$ Graf Zeppelin avancierte nach dem Unglück zum daedalischen Volkshelden, zum kulturbringenden

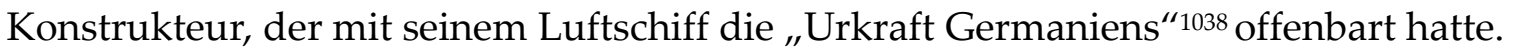

Angesichts der prometheischen Tat, für die der Graf jedes Opfer gebracht hatte um Deutschland mit dem Wunderwerk der Technik den gebührenden Platz im Kreis der Kulturvölker zu erobern, sah sich das Volk nach der Katastrophe seinerseits in der patriotischen Pflicht, mit einer 'Volksspende' den Opfergang zu beschreiten. Während fünf Jahre zuvor der „Notruf zur Rettung der Luftschiffahrt“1039 auf Ignoranz gestoßen war und nur die klägliche Summe von 15.000 RM ${ }^{1040}$ eingebracht hatte, kam mit der freiwilligen Volksspende die immense Summe von rund 6 Millionen RM ${ }^{1041}$

\footnotetext{
1036 Vgl. Reinicke, Helmut (1998): Deutschland hebt ab. Köln: PapyRossa, S. 10f.

1037 Hamburger Nachrichten, 9. August 1908, zit. nach: Reinicke (1998): Deutschland, S. 35

1038 Ebd., S. 106

1039 Ebd., S. 26

1040 Vgl. Ebd., S. 11

1041 Reinicke (1998): Deutschland, S. 35
} 
zusammen. Die nationale Kollekte und die darauf einsetzende Begeisterung retteten den Grafen vor dem finanziellen Ruin und bescherten dem Zeppelinwerk einen enormen Aufschwung, der 1909 zur Gründung der Luftschiff-Zeppelin GmbH und zu gefüllten Auftragsbüchern führte. Zur zahlungskräftigen Klientel zählte neben privaten Eignern auch das Kriegsministerium, das die Bedeutung der Luftschiffe für militärische Einsätze erkannt hatte. ${ }^{1042}$

Die Katastrophe generierte zum „Wunder von Echterdingen“,1043 zum göttlichen Fingerzeig, durch den das deutsche Volk lernte, „mit Trümmern umzugehen“1044 und begann, sich als Einheit zu begreifen. Die überwältigende Anteilnahme und das hohe Spendenaufkommen verhalfen den Deutschen nicht nur zu dem Bewusstsein, sich als Nation zu empfinden, die in Treue fest zusammenstand, sondern auch als ein Volk wahrzunehmen, von dem eine vitale Innovationskraft ausging. Um dem deutschen Nationalbewusstsein Nahrung zu geben, wurde die Spendenaktion von den Medien öffentlichkeitswirksam als ,Volksspende' verklärt, denn die Summe der ,Opfergabe' steuerte lediglich einen geringen Anteil zum gesamten Spendenaufkommen bei, das maßgeblich von der Wirtschaft und Finanzwelt erbracht wurde. ${ }^{1045}$ Mit der Spendenaktion konnte der Menschheitstraum von einem lenkbaren Luftschiff realisiert werden, mit dem Deutschland die Führungsposition im Bereich der Luftfahrt erobern $^{1046}$ und sich als Volk der Dichter, Denker und kühnen Techniker identifizieren konnte. Mit der Spende konnte der Zeppelin, der nicht nur Symbol für Deutschlands „Größe und Macht" war, sondern auch „Ruhm und Ehre“1047 verkörperte, wiederauferstehen. Durch die Katastrophe gingen der Graf und sein Luftschiff in das deutsche Nationalbewusstsein ein und erfuhren eine ungeahnte Popularisierung, die sich als

\footnotetext{
1042 Vgl. Ebd., S. 12

1043 Ebd., S. 26

1044 Ebd., S. 36

1045 Die ,Volksspende' war ein Begriff, mit dem der Spenden- und Einheitsgedanke leicht unter das Volk gebracht werden konnte. Das aufgeflammte Nationalbewusstsein wurde verglichen mit der Kriegserklärung Napoleons III. an Preußen im Jahr 1870 oder mit dem Tode Bismarcks. Vgl. Knäusel, Hans G. (2003): Mythos Zeppelin. Oberhaching: Aviatik, S. 13f.

1046 Vgl. Reinicke (1998): Deutschland, S. 68

1047 Knäusel (2003): Mythos, S. 13
} 
„Gratismehrwertheckung (sic!) ins Deutsch-Nationale“1048 verkehrte. Der Zeppelin wurde fester Bestandteil der Kultur- und Reklameindustrie und fand von der Zigarettenmarke über Schmuck bis zum Dekorationsutensil Eingang in die Wohnstuben und in das deutsche Mythenrepertoire.

Im Zeppelin manifestierte sich weitaus mehr als nur ein sichtbares Symbol deutschen Erfindergeistes und Einigkeit. Mit dem Luftschiff wurde der Glaube an eine Rettung aus einer hoffnungslosen Situation verbunden. Damit verfestigte sich der Glaube, dass eine Nation gerettet werden kann, wenn sie bereit ist, Opfer zu erbringen. Die Volksspende wurde ein „ideologisches Unternehmen par excellence.“1049 Der Nexus von Katastrophe und Opfer generierte zum deutschen Mythos, der gleichzeitig zu einem Lernprozess fataler Art wurde, denn das schichtübergreifende kollektive Opfer in Form der Volksspende wurde ein "pervertiertes Identifikationsmodell“, ${ }^{1050}$ das sich spätere Machthaber im Verlauf der deutschen Geschichte zunutze machten. So konnten die Nationalsozialisten auf das internalisierte „Pathos des Opferns“1051 zurückgreifen und insbesondere während der Kriegszeit erfolgreich an die Opferbereitschaft des Volkes appellieren. In dem Album 13 HISTORISCHE TAGE wird die Opferbereitschaft des deutschen Volkes gelobt, wobei der Unterton des Textes der Volksmasse eine Lenkbarkeit unterstellt.

„Es ist erstaunlich, wie leicht manche Schwierigkeit überwunden wird, wenn es gelingt, Vernunft und Opferbereitschaft zu mobilisieren! Vernünftig und opferbereit ist das deutsche Volk, und es läßt sich bei allen wichtigen Fragen von der Partei mobilisieren, weil es Vertrauen hat zu seiner Führung. ${ }^{1052}$

\footnotetext{
1048 Reinicke (1998): Deutschland, S. 12

1049 Ebd., S. 34

1050 Mit der Volksspende wurde die bürgerliche und proletarische Revolution mit den gescheiterten Forderungen nach Freiheit, Gleichheit und Brüderlichkeit auf populistische Art kompensiert. Ebd., S. 40

1051 Ebd.

1052 Greiling (1938): Historische Tage, Begleittext zu den Bildern 103-106, unpag.
} 
Die Luftschiffe nehmen in den Aviatik-Alben einen großen Stellenwert ein. Die Firma Greiling, die bereits die Reihe HELDEN DER LUFT publiziert hatte, widmete dem Luftschiff die Trilogie Zeppelin-WeltFahrTen. ${ }^{1053}$ Die Ambitionen des Unternehmens lagen darin, „die Bedeutung des Luftschiffgedankens weitesten Kreisen verständlich zu machen. "1054 Im Fokus der Alben stehen neben den Weltfahrten die Geschichte und die Entwicklung der Luftschifffahrt sowie „ausgesucht interessante[n] KriegsEpisoden“, wobei die Bedeutung der Luftschiffe im Kontext des Krieges hervorgehoben wird. Neben der Zeppelin-Trilogie ZePPELIN WeLtFAHRTEN, ist der Zeppelin Gegenstand vieler Zigarettenalben unterschiedlicher Themenbereiche und steht häufig im Kontext von NS-Propagandaaktionen wie Parteitage oder der Eröffnungsfeier der Olympiade 1936, bei der das Luftschiff als Requisit eingesetzt wird.

\subsubsection{Luftschiffe im Kriegseinsatz}

Im Ersten Weltkrieg kamen Luftschiffe unter dem Befehl der Marine zum Einsatz. Angriffsziel war Großbritannien. Angesichts nächtlicher Feindfahrten, schlechter Witterungsbedingungen und mangelnder Navigationstechnik gelang es jedoch nicht, strategisch bedeutsame Einrichtungen zu treffen. ${ }^{1055}$ Die Feindfahrten forderten stattdessen ausschließlich zivile Opfer und hatten rein psychologische Wirkung. ${ }^{1056}$ Die zu Beginn des Krieges als ,Wunderwaffe' gepriesenen Luftschiffe besaßen weder strategische noch kriegsentscheidende Relevanz. Nach 1916 verloren die starren Luftschiffe an Bedeutung, da sie von den beweglichen Flugzeugen leicht in Brand gesetzt werden

1053 Greiling (1933): Zeppelin Weltfahrten I. Buch. Dresden. Greiling (1934) Weltfahrten II. Greiling: (1937) LZ 129 Hindenburg. Zeppelin Weltfahrten III. Dresden

1054 Breithaupt, Kapitänleutnant a.D., Referent für Zeppelin-Fragen im Reichsluftfahrtministerium. „Das Luftschiff im Weltluftverkehr“. In: Greiling (1934): Weltfahrten II, unpag.

Das Anliegen, den Zeppelin-Gedanken wiederaufleben zu lassen, entsprach dem Geist der Zeit, der primär von wirtschaftlichen Intentionen getragen wurde. So forderte Korvettenkapitän Martin Dietrich 1927, dass „der Gedanke der Luftgeltung [...] in das deutsche Volk hineingetragen werden“ muss. Dietrich, Martin (1927): „Der deutsche Transozeanluftverkehr“. In: Die Luftwacht 1927/9, S. 499. Zit. nach: Woschech (2012): „Technikfunktionen“, S. 251

1055 Vgl. Knäusel (2003): Mythos, S. 33f.

1056 Vgl. White, Jerry (2015): Zeppelin Nights. London in the First World War. London: Vintage Books, S. 170 
konnten. ${ }^{1057}$ Die Luftschiffe, die die Feinfahrten überstanden, wurden teils am Boden in Brand gesetzt oder erlagen widrigen Wetterverhältnissen. ${ }^{1058}$ Während die Marine weiterhin Zeppeline einsetzte, musterte das Heer die Luftschiffe aus, da sie eine zu große Angriffsfläche für den Feind boten. ${ }^{1059}$ Durch den medialen Filter der Kriegspropaganda wurden der deutschen Bevölkerung die Lufteinsätze jedoch als „[E]erfolgreiche Zeppelinangriffe ${ }^{\prime 1060}$ verkauft.

Im zweiten Band der Zeppelin-Trilogie von Greiling wird das Luftschiff subtil in den Kontext des Krieges gesetzt, in dem auf die Epoche der Luftschiffe in der Vor- und Nachkriegszeit verwiesen wird. Das begleitende Bildmaterial illustriert den Einsatz der Luftschiffe im Ersten Weltkrieg. Die dramatischen Schilderungen der Feindfahrten werden von Fotografien mit teils dramatischen Motiven und nahezu morbider Ästhetik begleitet. Nachtaufnahmen eines brennenden Luftschiffes, Bombenangriffe und Flakscheinwerfer sowie Stahlgerippe ausgebrannter Schiffe ${ }^{1061}$ vermitteln dem Betrachter die zerstörerischen Auswirkungen der Kampfeinsätze.

„Um bei vollständiger Dunkelheit Anhaltspunkte für die Orientierung zu gewinnen, mußten von Zeit zu Zeit Leuchtbomben abgeworfen werden. Bild Nr. 2 zeigt den Aufschlag einer oder auch zwei Sprengbomben, die während einer solchen nächtlichen Angriffsfahrt abgeworfen wurden. [...] Dann aber entflammte ein Bündel von Scheinwerfern fast gleichzeitig auf und sobald ein Scheinwerfer das Luftschiff erfasst hatte, richteten sich auch die anderen Lichtkegel darauf, um den Abwehr-Batterien das Ziel zu beleuchten. (Bild Nr. 3) “1062

Da die Luftschiffe angesichts der Flugzeuge an Bedeutung verloren hatten, ${ }^{1063}$ stellen diese Kriegsschilderungen lediglich Reminiszenzen an vergangene Zeiten dar.

\footnotetext{
1057 Vgl. Kleinheins, Peter (1994): LZ 120 „Bodensee“ und LZ 121 „Nordstern“. Luftschiffe im Schatten des Versailler Vertrages. Friedrichshafen: Zeppelin-Museum, S. 9f.

1058 Vgl. Knäusel (2003): Mythos, S. 33f. Deutschland besaß insgesamt 78 Schiffe, davon verloren: 26 durch Feindeinwirkung, 14 durch Unwetter, 12 durch Brand und Explosionen, 17 wurden außer Dienst gestellt, 9 blieben übrig. Vgl. Buttlar (1931): Zeppeline, S. 202

1059 Vgl. Ludendorff (1919): Kriegserinnerungen, S. 305

1060 Extrablatt, Hamburgischer Correspondent, 25. August 1916. Zit. nach: Knäusel (2003): Mythos, S. 39

1061 Greiling (1934): Weltfahrten II, Kapitel: Kriegs-Luftschiffahrt, unpag.

1062 Ebd.

1063 Vgl. Knäusel (2003): Mythos, S. 108
} 


\title{
5.1.4.2 Nationaler Opfergang
}

Mit dem Start des ersten Zeppelins nach dem Ersten Weltkrieg erlebte das Luftschiff in der Weimarer Republik eine Renaissance und fand erneut Eingang in die Alltagskultur wie den Zigarettenalben. Die Relevanz des Luftschiffes kommt bei der Firma Greiling zum Ausdruck, die dem Zeppelin eine Serie von insgesamt drei Bänden widmet. Die Alben ZEPPELIN-WELTFAHRTEN weisen den gleichen nationalen und patriotischen Tenor auf wie die Aviatik-Serie des Unternehmens HELDEN DER LUFT. Mythen-Narrationen sowie die Exploration deutscher Schaffenskraft angesichts der Repressalien des Versailler Vertrages werden in den Zeppelin-Alben ebenso thematisiert wie die Fliegerhelden, die als identitätsstiftende Ikonen eine Kohäsion zwischen Vergangenheit und Gegenwart schaffen. In den ZEPPELIN-WELTFAHRTEN werden die Marineluftschiffer zu Vorbildern für nachfolgende Generationen installiert wie die Jagd- und Kampfflieger in den Alben HELDEN DER LUFT. Entsprechend wird ihnen in den WeLtFAHRTEN ein Ehrenplatz in der Galerie der deutschen Heroen zugewiesen.

\begin{abstract}
„Rund die Hälfte aller Luftschiffer ist im Weltkrieg gefallen. Man hat in den folgenden Jahren keine Zeit gefunden, viele Worte darüber zu verlieren, aber über ihre Taten lassen sich die Worte des deutschen Flieger-Ehrenmals setzen: $>$ Wir toten Flieger bleiben Sieger durch uns allein.

Volk, flieg du wieder, und du wirst Sieger sein! $\ll<1064$
\end{abstract}

Neben den Luftschiffern wird, im Unterschied zu anderen Aviatik-Alben über den Motorflug, den zerstörten Luftschiffen die gleiche Ehre zuteil wie den gefallenen Marine-Luftschiffen, denn auch sie werden in die Genealogie der 'Gefallenen' aufgenommen. Den Marine-Luftschiffern und ihren Zeppelinen wird hier eine besondere Ehrung in Form einer Gedenktafel zuteil. Ihre Namen sind in einen Karton mit goldener Schmuckfarbe gestanzt und heben sich als Gedenkstätte en miniature deutlich vom Gesamtlayout ab. Mit dem Gold, Sinnbild des Sakrosankten und Kostbaren, ${ }^{1065}$

\footnotetext{
1064 Greiling (1933): Weltfahrten I, Kapitel: Kriegs-Luftschiffe, unpag.

1065 Schmitz, Hermann (2013): Die mittelalterliche Malerei in Soest: Zur Geschichte des Naturgefühls in der deutschen Kunst. Staufen: Omena, S. 34f.
} 
werden die Opfer der Luftkämpfe der profanen Welt enthoben und steigen als Heroen in den nationalen Heiligenschrein auf.

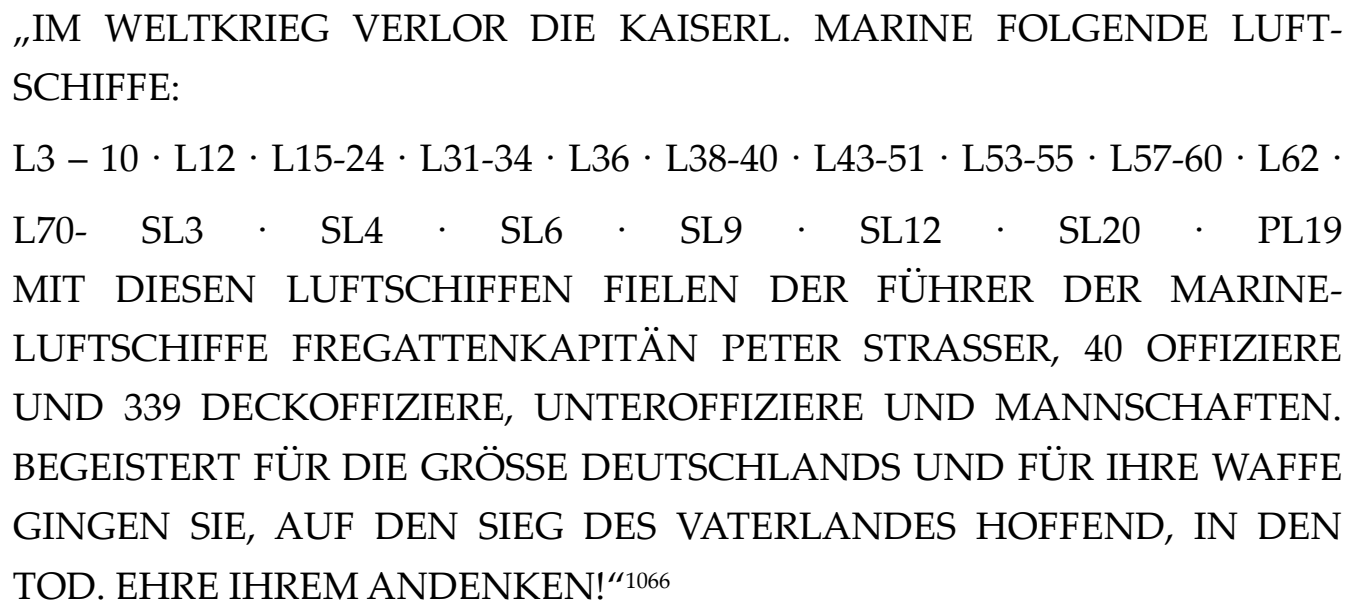

Diese besondere Anerkennung offenbart den Stellenwert, den der Zeppelin in der deutschen Mythologie errungen hatte. In ihm hatten sich Innovationskraft, Einigkeit und der Glaube an Wiederauferstehung nach einem Schicksalsschlag zu einem vitalen Symbol verdichtet. In den Texten der Zigarettenalben kommt die Symbolkraft zum Ausdruck, die das Luftschiff auf sich vereint hatte.

\begin{abstract}
„Die Entwicklung der Zeppelin-Luftschiffahrt steht mit goldenen Lettern in Deutschlands Geschichte. Zeppelin ist das Luftschiff unseres Volkes und Stolz der Nation. Der älteren Generation soll unsere Sammlung die gemeinsamen großen Erlebnisse der Friedens- und Kriegsjahre in Erinnerung rufen und der Jugend soll sie zeigen, welche Taten unbeugsamer Wille und unermüdlicher Schaffensgeist zu vollbringen vermögen. ${ }^{\text {} 1067}$
\end{abstract}

Die wechselvolle Historie des Zeppelins erfährt in der Weltfahrten-Trilogie eine narrative Umgestaltung, bei der die Dramaturgie der Helden,- Opfer- und Wiederauferstehungsgeschichte jedoch erhalten bleibt. Der ursprüngliche Mythos bewahrt damit seinen Ursprung sowie seine Grundstruktur und wird zur Matrix, die auf das Zeitgeschehen übertragen wird. Die Rollen des ursprünglichen Zeppelin-Mythos werden neu interpretiert und mit anderen Protagonisten besetzt. Die Opferbereitschaft des deutschen Volkes und der Glaube an eine Wiederauferstehung werden der

\footnotetext{
1066 Greiling (1934): Weltfahrten II, unpag.

1067 Greiling (1933): Weltfahrten I, Geleit, unpag.
} 
NS-Ideologie angepasst. In der Weltfahrten-Trilogie werden die Beharrlichkeit des Grafen, die Ignoranz der Regierung sowie die schicksalhafte Katastrophe aufgegriffen und auf das zeitgenössische Geschehen übertragen. Das Unglück und die Volksspende werden aus der Zeit herausgelöst und auf eine ontologische Ebene transferiert, womit Leid und Opfer, die sich im Zeppelin-Mythos manifestiert hatten, zum inhärenten Nukleus der deutschen Historie erklärt werden. Die Geschichte der Luftschifffahrt, die von Erfolg, Niedergang und Wiederauferstehen geprägt ist, wird in der Zeppelin-Trilogie zum Spiegelbild deutscher Tragik. Der „Opfertod“ wird, als integrierter Bestandteil des „Zeugungsmythos“, 1068 zur Voraussetzung für den Neubeginn und somit zum Symbol der Hoffnung für den Wiederaufstieg Deutschlands. Die deutsche Nation, die sich nach dem Ersten Weltkrieg in einer desolaten wirtschaftlichen, politischen und sozialpsychologischen Lage befand, erhielt mit dem Zeppelin einen Mythos, mit dem sie „die Angst vor dem Kommenden symbolisch zu verarbeiten ${ }^{\prime \prime} 1069$ vermochte.

„Wir wollen hier nicht die Geschichte der Zeppeline erzählen, die hier beginnt, wir wollen das Drama sehen. Es ist das Drama des deutschen Volkes auch.“1070

„Die Geschichte der Entwicklung der deutschen Zeppelin-Luftfahrzeuge ist keine ruhige Erzählung, die im breiten Strom dahinfließen kann. [...] sie war ein Drama, das sich von Akt zu Akt steigert. Man kann von dem Drama des deutschen Zeppelin-Gedankens sprechen. ${ }^{\prime 1071}$

Der Zeppelin-Mythos, der eine glückverheißende Zukunft für die deutsche Nation symbolisierte, wurde nach dem Ersten Weltkrieg zum wegweisenden politischen Mythos und zum Glaubenselixier für eine nationale Auferstehung. Menschen trachten danach, schicksalhafte Geschehnisse nicht nur aktiv anzugehen. Zur Wiedererlangung ihrer psychischen Stabilität benötigen sie ein symbolisches System, mit dem sie Ereignissen einen Sinngehalt zuweisen können. ${ }^{1072}$ Da die Symbolik des ZeppelinMythos bereits im kulturellen Gedächtnis verankert war, evozierte er eine

\footnotetext{
1068 Schirmer (1989): „Deutungsmuster“, S. 47

1069 Vondung (1988): Apokalypse, S. 12.

1070 Greiling (1937): Weltfahrten III., Vorwort, unpag.

1071 Ebd.

1072 Vondung (1988): Apokalypse, S. 12.
} 
vergleichbare Perzeption wie zu Beginn des Jahrhunderts. ${ }^{1073}$ Das NS-Regime konnte zu Beginn der Machtergreifung daher auf diese Sinnressource zurückgreifen und den Zeppelin in den eigenen Mythen-Kontext integrieren. Entsprechend werden der Zeppelin und seine Konstrukteure in den Alben zu Sinnbildern des Wiederaufstiegs.

\begin{abstract}
„Wir wollen den Pionieren der Luftfahrt ein ehrendes Andenken weihen und würdige Erben sein, die nicht bei den heutigen Erfolgen rasten! Deutschlands Zukunft liegt in seiner geistigen Führerstellung und der Wille, sie zu halten, stärke unseren Glauben an Deutschlands Zukunft!“1074
\end{abstract}

„Eine Fahrt wird beendet, die über weite Strecken des Reiches führte, die in bunten Wechsel die Heimat, ein neues Deutschland, eine geeinte Nation zeigte. ${ }^{\prime 1075}$

In dem zweiten Band der Zeppelin-Trilogie wird dem Jahrestages des Unglücks von 1908 gedacht, gefolgt von der direkten Überleitung zum Elend der Nachkriegszeit. Damit gelingt eine Adaption des Mythos, mit dem die Katastrophe wiederbelebt wird. Die im Unglück kulminierte Apokalypse verweist auf einen Tiefpunkt, der die Hoffnung auf einen Neubeginn verspricht. ${ }^{1076}$ Der kollektive Opfergang zur Rettung des Zeppelins, der im Jahr 1927 sein Echo in einer zweiten Volksspende fand, wird erneut zum Symbol der deutschen Einigkeit, Schaffenskraft und Wiederauferstehung. Das Unglück von Echterdingen wird zur Phönix-Metapher, mit dem das Kollektiv der Volksgemeinschaft ein Symbol erhält, in dem sich der Glaube an Wiederaufstieg und Fortschritt manifestiert. Damit wird mit der Wiederholung des Unheils in periodischen Abfolgen die Geschichte aufgehoben, womit das Leiden als Teil einer kosmischen Unabdingbarkeit empfunden werden kann. Herfried Münkler legt dar, dass die Renaissance der politischen Mythen eine Reaktion des konservativ und national gesinnten Bürgertums auf den Verlust an Kompensationsmöglichkeiten nach

\footnotetext{
1073 Graf Zeppelin selbst betrachtete seine Fahrt mit dem Luftschiff als Symbol für den Aufbruch der Nation in eine bedeutungsvolle Zukunft: „vorbei [...] an der Hohenzollernburg, dem Wahrzeichen von Deutschlands herrlicher Wiedergeburt und verheißungsvoller Zukunft". Zeppelin (1908): Eroberung, S. 27

1074 Greiling (1933): Weltfahrten I, Geleit, unpag.

1075 Greiling (1934): Weltfahrten II, Kapitel: Deutschland-Fahrt am 1. Mai 1933, unpag.

1076 Vgl. Vondung (1988): Apokalypse, S. 319
} 
dem Zusammenbruch von 1918 war. Mit der Repetition erfährt der Zeppelin-Mythos eine Wiederholung, die eine „periodische Erneuerung der Zeit“1077 einleitet, weil alles im Prinzip der Wiederholung wiederkehrt. In der Zeppelin-Trilogie werden Katastrophe und Wiederaufstieg mit einer sakralen Beschwörung in das Bewusstsein gerufen und der Zeppelin wird zum Symbol der Erlösung.

„Am 5. August 1933 war der 25. Jahrestag des Unglücks von Echterdingen, jener Tag, an dem das Werk Zeppelins verloren zu sein schien. Aber das deutsche Volk war sich einig im Glauben an die Zukunft und der Wille der Nation führte zum Sieg der Idee. ${ }^{1078}$

„Erst durch die neue Volksspende in Deutschland [...] konnte 1927 mit dem Bau des 'Graf Zeppelin' begonnen werden. [...] Das neue Luftschiff machte seine große historische Ozeanüberquerung mit Fahrgästen - die erste in der Weltgeschichte - [...] Mit der Überfahrt des $>>$ Graf Zeppelin $<<$, dann mit der ersten Weltreise war wieder ein neuer Sieg erfochten. ${ }^{1079}$

Die Firma Greiling folgt mit ihrer Zeppelin-Trilogie der ideologischen Leitlinie der politischen Rechten, die nach dem Ersten Weltkrieg die innere Geschlossenheit des deutschen Volkes zum zentralen Thema der nationalen Propaganda machte. Die Katastrophe von Echterdingen und der Niedergang des Zeppelinwerkes werden zur Katharsis, die für die Genese der Volksgemeinschaft als unerlässlich angesehen wurde.

„Aus den Trümmern und Opfern bitterer Kriegs- und Nachkriegsjahre entstand das Meisterwerk deutscher Technik. [...] Möge es auch von einem Volke künden, so einig im Glauben, so stark im Wollen, um das schlimmere Echterdingen der Zwietracht und Niederlage zu überwinden und Deutschland emporzuführen in das Licht einer besseren Zukunft. ${ }^{\text {"1080 }}$

\footnotetext{
1077 Mittels der Archetypen können historische Personen und Ereignisse aus der Geschichte herausgelöst werden. Danach kann die "profane Zeit" aufgehoben und eine "periodische Erneuerung der Zeit" eingeleitet werden. Eliade (1984): Kosmos, S. 66

1078 Greiling (1934): Weltfahrten II, Text nach Göring-Porträt, unpag.

1079 Greiling (1937): Weltfahrten III, Vorwort, unpag.

1080 Greiling (1934): Weltfahrten II, Text nach Göring-Porträt, unpag.
} 
Die düstere Philosophie der „Zerstörung“ wird hier in eine „Mittel-Zweck-Relation gesetzt“, denn nur durch „Umwendung und Zerstörung kann die Erlösung in dem kommenden Reich gelingen."1081 Dieser Prozess steht äquivalent zur Auffassung von Goebbels, der „Leid und Schmerzen einer gemeinsam erlittenen Not" als Basis der „deutschen Einheit“1082 betrachtete. Kern und Ursprung des Zeppelin-Mythos werden in den Zigarettenalben beibehalten, während die Erzählung an sich im Sinne der Propaganda variiert wird und $\mathrm{zu}$ einer kraftvollen Sinnressource wird. Die narrative Variation ist dabei nicht von Relevanz, denn „[O]obwohl der Mythos Ursprung und gegenwärtiges Ergebnis narrativ verknüpft, ist im Mythos der Ursprung wichtiger als die Genese. Kontinuierliche oder diskontinuierliche Entwicklungen zwischen Ursprung und Ergebnis sind nicht von besonderem Interesse. “1083

\subsubsection{Zeppelin unter dem Hakenkreuz}

Die NS-Propaganda adaptierte die Erfolge des Zeppelins ebenso wie die der motorisierten Flugzeuge. In der Weltfahrten-Trilogie wird die Renaissance der Luftschiffe dem Verdienst der neuen Regierung zugeschrieben, wobei die Initiativen Dritter in den Schatten gestellt werden. Angesichts der Tatsache, dass im Jahr 1928 der erste Transozeanflug in der Geschichte der Luftschifffahrt unter republikanischer Leitung realisiert wurde, eine gezielte Verfremdung der Historie. Mit dieser Narrationsvariante konnte das NS-Regime den Wiederaufstieg des Zeppelins für sich verbuchen und propagandistisch verwerten. ${ }^{1084}$ Für die Leiter der Zeppelin-Gesellschaft wie Korvettenkapitän Martin Dietrich und Dr. Eckener, stand die Wiederaufnahme der Luftschifffahrt nach dem Ersten Weltkrieg jedoch nicht im politischen Kontext. Für ihn war der globale Transozeanverkehr der Zeppeline sichtbares Symbol für deutsche

\footnotetext{
1081 Bärsch, Claus-Ekkehard (2004): Der junge Goebbels. Erlösung und Vernichtung. München: Wilhelm Fink Verlag, S. 48

1082 Goebbels postulierte drei Schritte zur Etablierung der Volksgemeinschaft. Neben einem gemeinsam erlittenen Leid, muss die Not auch auf seelischer Dimension erfolgen. Erst dann kann sie das Bedürfnis nach Erlösung generieren. Vgl. Bärsch (2002): Religion, S. 124

1083 Pandel, Hans-Jürgen (2010): Historisches Erzählen. Schwalbach/Ts.: Wochenschau Verlag, S. 66

1084 Den Luftschiffen maß Hitler keine besondere Bedeutung zu. Das Regime erkannte jedoch die außerordentliche Relevanz der Giganten als Prestigeobjekt. Vgl. Knäusel (2003): Mythos, S. 108
} 
Spitzenleistung und Ausdruck kultureller Schöpferkraft, mit der sich die Nation identifizieren konnte. ${ }^{1085}$

Die Wiederbelebung des Zeppelingedankens nach dem Ersten Weltkrieg wird in der Weltfahrten-Trilogie primär der Initiative Dr. Eckeners und der Volksspende von 1927 zugeschrieben, die es Deutschland ermöglicht hatten, das erste Nachkriegsluftschiff zu konstruieren. Der unermüdliche wie selbstlose Einsatz des Grafen Zeppelin wird damit auf dessen Nachfolger Dr. Eckener transferiert, dem es durch persönliches Engagement gelungen war, auf internationalem Parkett für den Einsatz des Zeppelins im transatlantischen Linienverkehr zu werben. Die Bemühungen seitens der Republik, die zivile Luftschifffahrt voranzutreiben und entgegen den Bestimmungen des Versailler Vertrages gegenüber den Siegermächten durchzusetzen, ${ }^{1086}$ werden in dem dritten Band der Trilogie marginalisiert. Der staatliche Zuschuss zur Spendenaktion fällt der neuen Erzählvariante sogar ganz zum Opfer und findet keine Erwähnung. ${ }^{1087}$ Stattdessen wird die Regierung angesichts des unermüdlichen Einsatzes von Dr. Eckener als „gleichmäßig stumpf “ ${ }^{\prime 1088}$ verunglimpft.

„Nun erhob sich aber - der Reichstag hätte nicht viel getan, wie er nie viel für den Zeppelin-Gedanken getan hat - das deutsche Volk. Die Tragik des Geschickes wurde von arm und reich begriffen [...]. ${ }^{\prime 1089}$

Die Weltfahrten-Trilogie folgt damit der ideologischen Leitlinie der politischen Rechten, die nach dem Ersten Weltkrieg Front gegen Weimar machte. Das Anprangern der republikanischen Politik war ein geschickter propagandistischer Schachzug. Um den eigenen Mythos zu stärken und emotional im Volk zu verankern, wurde der

1085 Vgl. Dietrich, Martin, „Der deutsche Transozeanluftverkehr“. In: Die Luftwacht 1927/9, S. 499. Zit. nach: Woschech, in: Fraunholz/ Dies. (2012): Technology, S. 250

1086 Eckener gelang eine Kooperation mit den USA. Das Luftschiff LZ 126 wurde zum „Friedensboten" und zum Zeichen der Völkerverständigung. Knäusel, Hans G. (2002): Zeppelin, 2. Aufl. Oberhaching: Aviatik Verlag, S. 73ff.

1087 Die Weimarer Regierung unterstützte den Bau und stellte finanzielle Mittel für den Bau des LZ 127 bereit. Vgl. Knäusel (2002): Zeppelin, S. 76. Auch die Bevölkerung leistete einen Beitrag. Bei der "Zeppelin-Eckener-Spende" kamen 2,5 Millionen Mark für das LZ 127 zusammen, das im Jahr 1928 „Graf Zeppelin“ getauft wurde. Ebd., S. 80

1088 Greiling (1937): Weltfahrten III, Vorwort, unpag.

1089 Ebd. 
ungeliebten Republik die Rolle des Antagonisten oktroyiert. Mit dem Desavouieren von Weimar konnte der eigene Zeppelin-Mythos etabliert und stabilisiert werden. Die "gegenmythische Konfrontation" war eine gelungene Strategie, mit der die Opponenten der Republik den „Überlegenheitsanspruch der Gegenseite mit eigenen politischen Mythen beantworten“ und „mehr Macht über die Vorstellungswelt der Menschen gewinnen“1090 konnten. Zur völligen Demontage Weimars wird den ehemaligen Siegerstaaten wie Großbritannien und den USA in dem Band ZEPPELIN WELTFAHRTEN III ein Verdienst an dem Bau des ersten Luftschiffes zuerkannt.

„Die amerikanische Forderung hat dann in der Tat das Werk des alten Grafen gerettet. [...] Erst durch eine neue Volksspende in Deutschland und das verständnisvolle Vorgehen des englischen Ministers für zivile Luftfahrt Sir Sefron Branker, der die Versailler Bestimmungen für die Verkehrsluftfahrt lockern half, konnte 1927 mit dem Bau des 'Graf Zeppelin' begonnen werden. ${ }^{1091}$

Eine weitere Inbesitznahme republikanischer Errungenschaften stellte die 'Hindenburg', das größte je erbaute Luftschiff dar, das mit seiner Größe, Leistung und Komfort alle bisherigen Dimensionen sprengte. Die Planung der 'Hindenburg' begann bereits im Jahr 1930 unter der Regie von Dr. Eckener. Als im Jahr 1936 das Luftschiff an die Deutsche Zeppelin-Reederei (DZR) übergeben wurde und zu ihrer ersten Fahrt startete, trug das Schiff noch die Werkstattbezeichnung D-LZ129. Den symbolträchtigen Namen 'Hindenburg' erhielt das Schiff erst 1936 vor dem Antritt zur großen Deutschlandfahrt mit dem Schwesterschiff 'Graf Zeppelin'. ${ }^{1092}$ In der Zeppelin-Trilogie fällt die erste Herstellungsphase einer geschickten Modifikation der Tatsachen zum Opfer. Die erste Bauphase unter republikanischer Leitung wird gänzlich verschwiegen. Der Text des Albums suggeriert, insbesondere durch den Hinweis auf das Hakenkreuz am Heck des Schiffes, das die 'Hindenburg' unter der Ägide des NS-Regimes erbaut wurde.

„Wer im Frühling des Jahres 1936 die alte Zeppelinstadt Friedrichshafen besuchte, konnte in den beiden großen Hallen zum erstenmal seit dem Welt-

\footnotetext{
1090 Münkler (2009): Mythen, S. 29f.

1091 Greiling (1937): Weltfahrten III, Vorwort, unpag.

1092 Vgl. Knäusel (2003): Mythos, S. 119
} 
kriege in der Geschichte der Zeppeline wieder zwei große Luftschiffe nebeneinander sehen. [...] Nun lag es in der neuen Halle „LZ 129“ - „Hindenburg“ bereit zur ersten Werkstättenfahrt. [...] Das neue Schiff aber brachte einem noch stärker zum Bewußtsein die Kleinheit des einzelnen Menschen und die Größe menschlichen Einsatzes und menschlicher Arbeit überhaupt. Auf dem weißen und roten Grund leuchtet das Hakenkreuz an der Schwanzflosse, die Fahne des neuen deutschen Reiches." 1093

Die NS-Propagandamaschinerie hatte den Zeppelin-Mythos damit erfolgreich variiert und zu einem atavistischen Konstrukt für eine erlösende Utopie generiert und gleichzeitig mit dem eigenen Symbol, dem Hakenkreuz, verbunden. Hugo Eckener stimmte der symbolischen Okkupation durch das Hakenkreuz nur widerwillig zu und hielt sich mit seiner Kritik an den Propagandafahrten für das NS-Regime nicht zurück. ${ }^{1094}$

Mit der Adaption und Modifikation des Zeppelin-Mythos und der ihm inhärenten Phönix-Metapher konnte der Glaube installiert werden, dass sich ein geeintes Volk aus einer desolaten Lage befreien kann. Das „zyklische Bild, ein traditioneller konservativer Topos, übt im Angesicht der Niederlage“ nicht nur Trost aus, sondern nährt auch die Hoffnung auf eine bessere Zukunft. ${ }^{1095}$ Mit der Konnexion der Zeppeline mit dem NS-Regime gelingt „,[D]der Sprung aus einer historischen in eine neue Zeit, die nicht mehr vergeht; der salto mortale aus der Geschichte in den Mythos. "1096 Diese Mythen-Variante wird von Greiling in der Weltfahrten-Trilogie übernommen. Nach der neuen Lesart konnte sich der Zeppelin erst wieder in die Lüfte erheben, als „sich endlich nach der Machtergreifung Adolf Hitlers das Dritte Reich auch des Zeppelin-Gedankens annahm“1097 und mit der Gründung der DZR den Bau der 'Hindenburg' ermöglichte.

\footnotetext{
1093 Greiling (1937): Weltfahrten III Kapitel: Bauzeit, unpag.

1094 Eckener wurde vom NS-Regime nur verschont, da er zu dieser Zeit als die populärste Persönlichkeit der Welt galt. Ferner hatte Hindenburg Hitler das Versprechen abgenommen, Eckener zu schonen. Der heimischen Presse wurde aber untersagt, ihn namentlich zu erwähnen. Geschäftsführer der Zeppelin-Reederei wurde Ernst Lehmann, der seine Linientreue unter Beweis gestellt hatte. Vgl. Knäusel (2003): Mythos, S. 112f.

1095 Vgl. Dörner (1996): Mythos, S. 232

1096 Balister, Thomas (1996): „Die Tatpropaganda der SA. Erfolg und Mythos“. In: Diesener/ Gries (Hg.): Propaganda, S. 32

1097 Greiling (1937): Weltfahrten III, Vorwort, unpag.
} 
Die Wiederauferstehung des Zeppelins wird in der Weltfahrten-Trilogie mit entsprechender sakraler Semantik aufgeladen. Der Ausspruch Graf Zeppelins „Man muß das wollen, man muß daran glauben, dann wird es gelingen!“1098 wird wie ein Glaubensbekenntnis repetiert und Görings Geleitwort zum Stapellauf der 'Hindenburg' kommt einer religiösen Zeremonie gleich und wird zum „Weihespruch für die Fahrt des neuen Luftschiffes.“ 1099 „Wenn das neue Luftschiff die Halle verläßt, begleiten das Schiff die leidenschaftlichsten Wünsche des Ministeriums, der gesamten deutschen Luftfahrt und, ich kann wohl sagen, des ganzen deutschen Volkes. Alle Voraussetzungen sind gegeben für einen günstigen Start und Weiterentwicklung." ${ }^{1100}$ Aufgrund der mythisch konnotierten Technik-Historie des Luftschiffes ist der Zeppelin prädestiniert, von der NS-Ideologie vereinnahmt zu werden. ${ }^{1101}$ Mit emphatisch aufgeladener Bildsprache wird das Wunderwerk der Technik und deutschen Erfindergeistes mit „̈̈ther immanente[n] Metaphern"1102 beschrieben. Im zweiten Teil der WeltfahrtenTrilogie wird das Luftschiff 'Graf Zeppelin' zu einem mystischen Objekt, das in einem...:

„bläulich-weißen Licht noch magischer wirkt als am Tage. Es gibt keine Möglichkeit, in Bild und Wort den überwältigenden Eindruck zu vermitteln [...] ein Eindruck, der rätselhaft ist und unergründlich bleiben wird, denn kein anderes Luftfahrzeug vermag ähnliche Empfindungen zu wecken. " ${ }^{1103}$

Die fotografischen Aufnahmen stilisieren die Zeppeline in der Weltfahrten-Trilogie zu Wunderwerken der Technik und evozieren mit ihrer „ästhetischen Erhöhung“1104

1098 Greiling (1934): Weltfahrten II, Kapitel: Deutschlandfahrt am 1. Mai 1933, unpag. Greiling (1933): Weltfahrten I, Kapitel: Vorkriegs-Luftschiffe, unpag.

1099 Greiling (1937): Weltfahrten III, Vorwort, unpag.

1100 Rede Hermann Görings zum Start des Luftschiffes „Hindenburg“ in: Greiling (1937): Weltfahrten III, Vorwort, unpag.

1101 Da die Maschine das neue Weltbild repräsentierte, entstand ein Mangel an numinoser Orientierung, die durch mythologische Strukturen kompensiert wurde. Vgl. Mumford (1984): Maschine, S. 373

1102 Reinicke (1998): Deutschland, S. 71

1103 Beschreibung des Luftschiffes vor dem Start. Greiling (1934): Weltfahrten II, Kapitel: Deutschland-Fahrt am 1. Mai 1933

1104 Reinicke (1998): Deutschland, S. 71 
Emotionen von Stärke und nationaler Größe. ${ }^{1105}$ Die aerodynamische Stromlinienform der Luftschiffe trägt dazu bei, den Zeppelin als technische Errungenschaft im Geist der Zeit ästhetisch zu stilisieren. Das zeitgenössische Industriedesign wird eingesetzt, um den „Eindruck technischer Erhabenheit“ zu unterstreichen und gleichsam die „Potenz des neuen Staates“1106 zu symbolisieren. Diese Ästhetisierung folgt einer "politischen Semantik", die ihre Wurzeln im völkischen Lager hat und ihren Ausdruck in der „Spannung von Archaik und Moderne“1107 findet. Über das Kultobjekt hinaus wird der Zeppelin in den Alben als Wunderwerk der Flugtechnik zum Symbol des Modernisierungsprozesses des Staates. Gleich einer „kollektiven Sinnressource $^{\text {"1108 }}$ wird es vom NS-Regime okkupiert zum Gradmesser des kulturellen Standards der deutschen Nation.

In einem eigenen Kapitel wird der Bau der 'Hindenburg' im Detail beschrieben. Die Untersicht, in der viele Bilder aufgenommen sind, unterstreicht die Größe der Konstruktionen. Das gewaltige Stahlgerüst des Luftschiffes 'Hindenburg' wächst vor dem Auge des Betrachters in schwindelerregender Weise ins Gigantische. Die Monteure, die neben dem Luftschiff optisch auf ein Minimalmaß reduziert werden, machen das Luftschiff zu einem ehrfurchtgebietenden Symbol der neuen Zeit. Anhand von Schaugrafiken werden die außergewöhnlichen Dimensionen des neuen Luftschiffes mit beeindruckenden Zahlen belegt. ${ }^{1109}$ Der Betrachter erhält darüber hinaus einen Einblick in das Ambiente des Schiffes, das durch Luxus und Komfort besticht. Auf knapp 30 Bildern wird die Ausstattung des weitläufigen Promenadendecks, des Lesezimmers, der Bar und anderer Gesellschaftsräume im Detail beschrie-

1105 Die Luftbildaufnahmen wurden bereits 1925 vom Deutschen Werkbund eingesetzt, um eine neue Perspektive vom Vaterland zu vermitteln. Vgl. Ewald, Erich (1925): „Deutschland aus der Vogelschau. Landschaft und Siedlung im Luftbild“, S. 5. Zit. nach: Kehrt (2010): Krieger, S. 202

1106 Ebd., S. 223. Der Zeppelin faszinierte die Zeitzeugen insbesondere durch seinen überwältigenden Anblick, hinter dem die Begeisterung für die Technik zurückstand. Meighörner, Wolfgang (2003): Pioniere des industriellen Designs am Bodensee. Friedrichshafen: Robert Gessler, S. 51

1107 Dörner (1996): Mythos, S. 252

1108 Kehrt (2010): Krieger, S. 49. Der Zeppelin war Ausdruck für technische Überlegenheit mit der sich das deutsche Volk identifizierte. Vgl. Weyers/ Köck (1992): Eroberung, S.35.

Greiling (1937): Weltfahrten III, Faltblatt am Ende des Albums 
ben. ${ }^{1110}$ Die elegante Stromlinienform und das im Bauhausstil gehaltene Interieur zeugen von einer Modernität, die auf der Höhe der Zeit ist. ${ }^{1111}$ Um den Luxus für den Rezipienten auch taktil erfahrbar zu machen, sind dem letzten Zeppelin-Album Zugaben beigelegt. So konnte der Bildersammler nicht nur anhand der Aufnahmen das Ambiente bestaunen, sondern auch die Fahrkarte von Friedrichshafen nach Lakehurst in die Hand nehmen und in der erlesenen Speise,- Wein- und Barkarte blättern. Mit einer Hindenburg-Büste als Teil der Innendekoration ${ }^{1112}$ wird der Namenspatron des Luftschiffes zitiert, womit eine subtile Verbindung zur deutschen Historie hergestellt wird. Das Luftschiff 'Hindenburg' wird so zum Symbol einer Zeitenwende in Deutschlands Geschichte, die von einem modernen, wie fortschrittlichen Staat kündet, dessen Leistungen von der Welt anerkannt werden.

Viele Nationalsozialisten, darunter auch Hitler, standen den Luftschiffen ambivalent gegenüber, erkannten aber den enormen Prestige- und Propagandawert.1113 Die gewaltigen und erhaben anmutenden Zeppeline, die elegant schwebend den Globus umrundeten, waren für das Dritte Reich ein Werbeträger par excellence. Die Luftschiffe wurden zu einem bedeutenden Requisit der NS-Propaganda, das bei den von Goebbels inszenierten NS-Veranstaltungen bewusst eingesetzt wurde. Der Zeppelin, der symbolisch nicht nur für technische Innovation stand, sondern auch für Wiederauferstehung und deutsches Nationalbewusstsein, wurde integraler Bestandteil des nationalsozialistischen Glaubenssystems und zum bedeutenden Requisit des NS-Feiertagsreigens. Bei populistisch gestalteten NS-Massenveranstaltungen wie dem 1. Mai oder den Reichsparteitagen in Nürnberg ${ }^{1114}$ war der Zeppelin ausdrucksstarker Kultgegenstand, der nationale Größe und politische Macht demonstrierte. Insbeson-

\footnotetext{
1110 Ebd., Kapitel: Vollendet, unpag.

1111 Bei der Innenausstattung orientierte sich der verantwortliche Designer Breuhaus am modernen Flugzeugbau sowie am Bauhaus-Design Marcel Breuers. Vgl. Meighörner (2003): Pioniere, S.62

1112 Greiling (1937): Weltfahrten III, Bild Nr. 41, unpag.

1113 Vgl. Knäusel (2003): Mythos, S. 108

1114 Flugzeuge, Zeppeline und Hakenkreuzfahnen sollten die Zeitenwende dokumentieren. Musikalische Untermalung und Lichtinszenierungen trugen zur Emotionalisierung der Volksmassen bei. Vgl. Reichel, Peter (2006): Der schöne Schein des Dritten Reiches. Hamburg: Ellert \& Richter Zeitgeschichte, S. 268-271
} 
dere die 'Hindenburg' wurde von der NS-Propaganda mannigfaltig eingesetzt, wie beim Wahlkampf zur Reichstagswahl am 29. März 1936, bei dem Hakenkreuze und Propagandamaterial von den Luftschiffen aus abgeworfen wurden. ${ }^{1115}$

Die herausragende Bedeutung und die vitale Symbolkraft des Zeppelins beweist die Vielzahl an Motiven in den Zigarettenalben ${ }^{1116}$. Insbesondere in den Aviatik-Alben stößt der Sammler auf ein wiederkehrendes Motiv. Dabei wird deutlich, wie sehr der Zeppelin vom NS-Regime symbolisch in Besitz genommen wurde. In den ZEPPELIN WELTFAHRTEN kommt die Usurpation des Zeppelins durch das Dritte Reich besonders zum Ausdruck, wie bei der Beschreibung einer Zeppelin-Fahrt anlässlich einer Maifeier.

„Überall Aufmärsche und Ansammlungen zu Ehren der Arbeit, überall leuchten Fahnen als Symbole der nationalen Erhebung, ein festlich geschmücktes Land und festlich gestimmte Menschen - Deutsche - die das Luftschiff begrüßen und stürmischer begrüßen, je weiter der Tag vorrückt." ${ }^{1117}$

Noch eindrucksvoller ist die Schilderung der Deutschlandfahrt des Luftschiffes 'Hindenburg' im Jahr 1936. Die Fahrt wird zu einem nationalen Spektakel, das bis ins Detail choreografiert ist. Die Reise beginnt über dem Bodensee, über dem sich die Luftschiffe 'Hindenburg' und 'Graf Zeppelin' begegnen. Mit diesem Zusammentreffen wird die vielbeschworene historische Kontinuität zwischen einer glorreichen Vergangenheit und der neuen Zeit symbolisch in ein malerisches Bild gesetzt:

„Nach einer Minute taucht die Fläche des Bodensees wie ein silberner Spiegel auf. [...] Über dem Bodensee findet dann diese großartige Begegnung in der Geschichte der Luftfahrt statt.“1118

\footnotetext{
1115 Der dreitägige Flug war eine von Goebbels befohlene Propaganda-Fahrt, die von Eckener missbilligt wurde. Vgl. Knäusel (2003): Mythos, S. 110f.

1116 Greiling (1934): Männer, Bd. 1, Bild 150, Bildlegende: „Luftschiff ,Graf Zeppelin’ über dem Reichsparteitag 1933 in Nürnberg“", unpag. Greiling (1933): Reich, Bilder 71, 74 und 131, unpag. Aurelia (1933): Führer und Volk im dritten Reich. Reichsparteitag Nürnberg. Erster deutscher Erntedanktag und andere wichtige Tage. Dresden, Bilder 60 und 101, unpag.

1117 Greiling (1934): Weltfahrten II, Kapitel: Deutschland-Fahrt am 1. Mai 1933, unpag.

1118 Greiling (1937): Weltfahrten III, Kapitel: Luftschiff marsch! unpag.
} 
Im Verlauf dieser Deutschlandfahrt steuert die 'Hindenburg“" symbolträchtige Stationen an. Bereits die Fahrt in den Osten des Reiches nach Königsberg und Ostpreußen impliziert mit der Überquerung des polnischen Korridors eine sinnbildliche Rückeroberung der abgetretenen Gebiete. Über dem kurischen Haff kommt es zu einer erneuten Begegnung der beiden Luftschiffe. Sie kreisen gemeinsam unter den Klängen des Horst-Wessel-Liedes über dem symbolträchtigen Tannenberg-Denkmal.1119

\begin{abstract}
„Unter den Heilrufen der Menschenmenge rings um das Landungsfeld hebt sich der Gigant in sein vorbestimmtes Element. [...] Zwei große Schleifen ziehen die beiden Luftschiffe über der Stadt, während aus dem Lautsprecher Marschweisen mit Wahlparolen wechseln. [...] LZ 129 besucht den Sieger von Tannenberg, dessen Namen er trägt, an seiner letzten Ruhestätte. [...] Unter den Klängen des Horst-Wessel-Liedes entfernen sich die beiden Luftschiffe wieder von der Gedenkstätte. ${ }^{\prime 120}$
\end{abstract}

Auf ihrer Route überfliegt die ,Hindenburg' bedeutende deutsche Städte wie Hamburg, Berlin und Nürnberg, sowie nationalsozialistische Sakralstätte wie die Festtribüne in Nürnberg oder das Aufmarschgelände in Berlin-Tempelhof. ${ }^{1121}$ Dieser Reiseabschnitt wird dem Bildersammler mit eindrucksvollen Luftaufnahmen und szenischen Beschreibungen detailreich vor Augen geführt. In dem Sammelband ALLES FÜR DEUTSCHLAND schwebt der Zeppelin auf einem Bild am Reichsparteitag in Nürnberg im Jahr 1933 als „Wahrzeichen deutscher Technik"1122 über den Kolonnen der SA, SS und der Reichswehr. Die Bedeutung des Luftschiffes und seine symbolische Relevanz innerhalb der nationalsozialistischen Ikonengalerie zeigt eine Illustration in dem

1119 Mit dem Tannenberg-Denkmal sollte der gleichnamigen Schlacht und ihren Opfern gedacht werden. Die Planung begann 1919, die Grundsteinlegung erfolgte 1924 in Anwesenheit von Hindenburg und Ludendorff. Architektonisch knüpfte es an den Stauffer Heinrich II. an, mit dem im Mittelalter die deutsche Ostexpansion unter dem Deutschen Orden begann. Im Jahr 1934 bestimmte Hitler das Denkmal zu Hindenburgs Grabstätte. Um das Denkmal wurde die Landschaft zur ",Germanisierung“" von "Landschafterfahrung“ umgestaltet. Tietz, Jürgen (1997): „Das ostpreußische Tannenberg-Nationaldenkmal“. In: Institut Norddeutsches Kulturwerk (Hg.): Das Denkmal im nördlichen Ostmitteleuropa im 20. Jahrhundert. Politischer Kontext und nationale Funktion. Lüneburg: Verlag Norddeutsches Kulturwerk, S. 42 - 65

1120 Greiling (1937): Weltfahrten III, Kapitel: Luftschiff marsch! unpag.

1121 Greiling (1934):Weltfahrten II, Bilder 139 bis 144 und 156. Die Staationen des Luftschiffes sind: Bremen, Hamburg, Nürnberg und Berlin.

1122 Im Zentrum der Illustration steht der Zeppelin, flankiert von wehenden Hakenkreuzfahnen. Brinkmann (1934): Alles für Deutschland, S. 103 
Album Deutschland HOCH ZU EHREN - VON HERMANN DEM CHERUSKER BIS ZUM „JA“ AM 12. Nov. 1933. Der Grafiker hat in einer Zeichnung zum Reichsparteitag mehrere Symbole aus dem Fundus der deutschen Geschichte in einem Motiv zusammengeführt: Die Abbildung zeigt Nürnberg mit dem Sinwell-Turm der Kaiserburg, der Reiterstatue Wilhelm I., flatternde Hakenkreuzfahnen im Vordergrund sowie das Luftschiff Graf Zeppelin, das über der Szenerie schwebt. ${ }^{1123}$ (Abb. 16) Der untere Bereich wird ausgefüllt von jubelnden Uniformträgern, die ihre Arme zum Hitlergruß ausstrecken. In dieser Zeichnung werden viele Ikonografien, die das NS-Regime in die eigene Ideologie implementiert hat, in einer Synergie komprimiert. Zum einen ist die Burg ein Motiv, das nach der Reichsgründung das Geschichtsbild der Deutschen geprägt hat. Die Burg repräsentierte das mittelalterliche Kaiserreich und die wahre Größe und Einheit der deutschen Nation. ${ }^{1124}$ Die Nationalsozialisten hatten diese Bedeutung erkannt und die Burg als Sinnbild aufgegriffen. ${ }^{1125}$ Die steingewordene Manifestation einer ruhmvollen Vergangenheit setzt sich in der Statue Wilhelms I. fort, mit der ein Bezug zu preußischen Traditionen hergestellt wird. Die Retrospektive

1123 Brinkmann (1934): Deutschland hoch in Ehren. Von Hermann dem Cherusker bis zum "Ja" am 9. Nov. 1933, Bremen, S. 66. Das gleiche Bild befindet sich in dem Album: Brinkmann (1934): Alles für Deutschland, S. 103. Das Motiv findet sich auch als Foto in dem Album: Aurelia (1933): Führer, Bild 101, unpag.

1124 Bis Mitte der 1930er Jahre hatte das NS-Regime noch keine einheitliche Haltung gegenüber den deutschen Kaisern. Beispielhaft ist die Stellung von Barbarossa und Karl dem Großen, deren Traditionswürdigkeit in Zweifel gezogen wurde. Vgl. Wolnik (2004): Mittelalter, S. 111. Erst mit dem Russlandfeldzug änderte sich die Haltung insbesondere gegenüber Barbarossa. Hitler legitimierte seine Expansionspolitik mit den mittelalterlichen Kaisern und des Deutschen Ordens. Von ihnen leitete er das Recht ab, die Gebiete im Osten zu annektieren. Vgl. Clemens-Schierbaum, Ursula (1995): Mittelalterliche Sakralarchitektur in Ideologie und Alltag der Nationalsozialisten. Weimar: VDG, S. 44f.

1125 Mit der Gründung der Nationalstaaten „wandelten sich die Burgen von einem Herrschaftssymbol des Hochadels zu einem Nationalsymbol des niederen Adels und des Bürgertums." Vgl. Ottomeyer, Hans/ Atzbach, Rainer/ Lüken, Sven (Hg.) (2010): Mythos Burg. Eine Ausstellung des Germanischen Nationalmuseums Nürnberg. Dresden: Sandsteinverlag, S. 320. Im Dritten Reich wurde die Burg zum Wahrzeichen von Rittertum und Wehrhaftigkeit, bis sie letztendlich zur Ikone nationalsozialistischer Ideologie wurde, wie die Kaiserburg in Nürnberg, die als Kulisse für die Reichsparteitage ausgebaut wurde. Vgl. Ottomeyer et al. (2010): Burg, S. 364f. Otto Dietrich verband mit der Burg in Nürnberg als Aufmarschgelände die „tiefe Verbundenheit bester deutscher Tradition mit dem jungen, starken, in die Zukunft vertrauenden Geist unserer Zeit.“ Dietrich, Otto (1937): „Geleitwort", in: Hoffmann, Heinrich (Hg.): Der Parteitag der Arbeit. 75 Bilddokumente vom Reichsparteitag zu Nürnberg 1937. Berlin: Zeitgeschichte-Verlag, unpag. 
auf eine glorreiche Historie wird beflügelt durch den Zeppelin, der Wiederauferstehung, Einheit, Opfer und technische Innovationskraft symbolisiert. Die gesamten Sinnbilder werden durch die flatternden Hakenkreuzfahnen vom NS-Regime symbolisch in Besitz genommen. Die Ansammlungen der uniformierten SA und SS im unteren Bildbereich vermitteln nicht nur das Bild einer in sich geschlossenen Gruppe, die das Kollektiv repräsentiert, sondern auch die Staatsmacht, wodurch das Motiv eine „politisch-symbolische Dimension“1126 erhält. Diese symbolische Konzentration lässt die Inszenierung „in semantischen Sinn derart transformieren“,1127 so dass der Betrachter eine sinnliche Erfahrung von gesteigerter Intensität erfährt, die sich im Zeppelin manifestiert. Mit dieser eklektischen Anordnung werden Ikonen angehäuft, mit dem das NS-Regime seine Machtfülle und Dynamik zum Ausdruck bringt. „Als ein Symbol deutscher Einheit [Anm.: Reichsparteitag Nürnberg 1933] soll dieser Tag in der Erinnerung kommender Geschlechter bleiben. Denn Einigkeit umspannt endlich wieder, die Deutschen aller Stämme. Dem gibt auch der Parteitag der NSDAP in Nürnberg Ausdruck. Dort strömen die gewaltigen Kolonnen der SA und SS am Gedenktage zusammen. Darüber kreist in der Luft, als Wahrzeichen deutscher Technik, das Luftschiff „Graf Zeppelin“.“1128 Der Zeppelin war damit mehr als Werbeträger für das NS-Regime, sondern auch ein Objekt mit ontologischer Dimension, das viele Symbole in sich vereinte. Es war "symbolisches Kapital“, ${ }^{1129}$ dass die Staatsmacht zu nutzen wusste.

\footnotetext{
1126 Diehl (2005): Macht, S.168

1127 Habermas, Jürgen (2001): „Symbolischer Ausdruck und rituelles Handeln“. In: Melville, Gert (Hg.): Institutionalität und Symbolisierung. Köln: Böhlau, S. 61

1128 Brinkmann (1934): hoch in Ehren, S. 66

1129 Dörner (1996): Mythos, S. 17
} 


\subsection{Nautik}

In den Jahren 1930 bis $1934^{1130}$ wurden insgesamt 20 Zigarettenalben mit nautischen Themen publiziert. Die Bände haben primär lexikalischen Charakter oder bieten einen Überblick über Reedereiflaggen sowie nationale und internationale Schiffe. Im Unterschied zu den Aviatik-Alben, in denen der Erste Weltkrieg vielfach thematisiert wird, wird das Kriegsgeschehen in den Nautik-Alben nur marginal erwähnt. Im Zentrum stehen Geschichte und Entwicklung der nationalen und internationalen Seefahrt. Exemplarisch für diesen lexikalischen Aufbau ist der Sammelband VOM EINBAUM BIS ZUR EUROPA! ${ }^{1131}$ Der Betrachter erhält einen lexikalischen Überblick über die Entwicklungsgeschichte der deutschen Marine, wobei insbesondere Segelschiffe fokussiert werden. Die Bildlegenden enthalten kurze Textinformationen über Wasserverdrängung, Armierung, teilweise auch ihr Einsatz im Ersten Weltkrieg und die Ursache ihres Untergangs.

Die Seefahrt ist aufgrund ihrer langen, teils mit Legenden umwobenen Geschichte prädestiniert, mythologisch adaptiert zu werden. Mit ihr verbinden sich Sehnsucht nach der Ferne, Romantik und mythische Reisen, die die Protagonisten zu fernen Gestaden führen. In einigen Nautik-Alben wird diese Sehnsucht beschworen, die den Menschen seit je her angetrieben hat, sich aller Gefahren zum Trotz, den Naturgewalten zu stellen und die Meere jenseits des Horizontes zu erforschen. Im Vergleich zu den Aviatik-Alben, die primär die technischen Errungenschaften fokussieren oder in den Kontext des politischen Zeitgeschehens setzen, verharren viele Nautik-Alben in romantischer Verklärung der Seefahrt und retrograder Schwärmerei. ${ }^{1132}$

\footnotetext{
1130 Das Album Reunion (1938) Ruhmestaten der deutschen Marine. Obercunnersdorf wurde von Mahalesi im Jahr 1934 und im Jahr 1938 erneut von Reunion publiziert. Köberich (2003): Sammelbilder

1131 Kyriazi (1930): Vom Einbaum bis zur Europa. Cairo/ Hamburg

1132 Exemplarisch der Text eines Nautik-Albums: „Von Urzeiten an haben die weiten Flächen der scheinbar unbegrenzten Meere die Menschen hinausgelockt auf ihre Wellen und Wogen nicht nur bei Sonnenschein, sondern auch bei Sturm und Wetter." Brinkmann (1933): LloydFlottenbilder. Die Welthandelsflotte. Bremen, Vorwort, unpag.
} 


\subsubsection{Romantische Verklärung der Seefahrt}

Die romantische Perspektive, die viele Nautik-Alben prägt, reflektiert die Sehnsucht nach vergangenen Zeiten, denn die Schifffahrt hatte im 20. Jahrhundert einen strukturellen Wandel erfahren. Die Schifffahrt, einst Symbol für die Innovationskraft eines Landes, hatte ihre Stellung zugunsten anderer Technikbereiche wie der Motorisierung zu Land oder in der Luft verloren. Während mit dem Anbruch des technischen Zeitalters der kulturelle Standard einer Nation auch mit der Vorherrschaft auf den Weltmeeren einherging, konnte die Seefahrt als Flaggschiff des Fortschritts im 20. Jahrhundert nicht mehr gerecht werden. So konstatierte auch Ernst Jünger, dass die deutsche Nation ihr erwachendes Selbstbewusstsein im 19. Jahrhundert mit maritimen Errungenschaften zum Ausdruck bringen konnte. Als die Seefahrt im technischen Zeitalter ihre symbolische Strahlkraft verloren hatte, konnte sie die Sehnsüchte einer aufstrebenden Nation jedoch nicht mehr bedienen. Der technische Fortschritt verlangte nach neuen Mythen. ${ }^{1133}$

Als Kontinentalmacht hatte Deutschland in seiner Geschichte ohnehin keine weitreichenden Ambitionen, eine große Welthandels- oder Kriegsflotte aufzubauen. Die Deutschen konnten daher auch nicht auf eine lange maritime Tradition zurückblicken. ${ }^{1134}$ Der Begriff „Seegeltung“ trat erst in dem Moment auf, als die Deutschen eine „nationale Bewusstwerdung“1135 erfuhren. So besaß auch die Marine im Gefüge der

\footnotetext{
1133 Vgl. Jünger (1933) : Luftfahrt, S. 7f.

1134 Vgl. Wolz, Nicolas (2013): "Und wir verrosten im Hafen“. Deutschland, Großbritannien und der Krieg zur See 1914-1918. München: DTV, S. 133. Die deutsche Seefahrt erhielt ab dem 12. Jahrhundert eine große Bedeutung, als sich norddeutsche Städte zu wichtigen Handelsstädten entwickelten und einen regen Handel im Ostseeraum betrieben. Damit ging eine deutsche Besiedlung der Ostgebiete und Christianisierung der Slawen einher. Ab 1230 gingen die ersten Städte unter der Ägide von Kaufleuten eine Genossenschaft ein, die in der Gründung der Hanse mündete. Vgl. Hattendorf, John B. (2005): „Deutschland und die See: Historische Wurzeln deutscher Seestreitkräfte bis 1815. In: Rahn, Werner (Hg.): Deutsche Marinen im Wandel: Vom Symbol nationaler Einheit zum Instrument nationaler Sicherheit. München: Oldenbourg, S. 20ff.

1135 Rübner (2005): Konzentration, S. 25.

Erst im Zuge der Revolution von 1848 kam die Forderung nach einer „Reichsflotte“ auf. Die maritimen Ambitionen der Bevölkerung wurden durch die dänische Blockierung der deutschen Handelswege in Nord- und Ostsee bestärkt. Vgl. Duppler, Jörg (1992): „Revisionismus oder Weltmachtstreben? Maritimes Denken in der nationalsozialistischen Zeit“. In: Elvert,
} 
Streitkräfte kaum Relevanz und wurde bis in das Jahr 1888 von Offizieren des Heeres geleitet. ${ }^{1136}$ Erst Kaiser Wilhelm II. begann um 1900 im Zuge ambitionierter Großmachtträume mit dem Aufbau einer schlagkräftigen Flotte unter der Ägide von Konteradmiral Tirpitz. ${ }^{1137}$ Mit dem Slogan „Seefahrt tut not!“ wurde die wilhelminische Flottenpolitik vorangetrieben und Deutschland gelang es, vor dem Ausbruch des Ersten Weltkrieges die zweitgrößte Seestreitmacht aufzubauen. Bei allen Schiffsklassen wie Schlacht- und Panzerkreuzern, Torpedo- und U-Booten blieb England aber überlegen. ${ }^{1138}$ Nach dem Ersten Weltkrieg war die deutsche Flotte auf den Weltmeeren kaum noch präsent. Die Geschichte der deutschen Seefahrt fällt daher in den Zigarettenalben bescheiden aus. In dem Sammelband RUHMESTATEN DER DEUTSCHEN MARINE ${ }^{1139}$ wird das historische Niemandsland der deutschen Seefahrt unverhohlen als 300-jähriger „Zustand maritimer Ohnmacht" ${ }^{\prime 1140}$ beschrieben.

\subsubsection{Untergang einer Epoche}

Im Unterschied zur Luftwaffe bot die deutsche Kriegsmarine keinen fruchtbaren Nährboden für mythische Quellen, aus denen das Volk Hoffnung auf eine bessere Zukunft schöpfen konnte. Während des Ersten Weltkrieges kam die Marine kaum zum Einsatz. Die deutsche Kriegsflotte, die in einer großen Seeschlacht zu Ruhm und Ehre gelangen wollte, dümpelte in den Häfen ${ }^{1141}$ und hatte keine Möglichkeit, sich in

Jürgen/ Jensen, Jürgen/ Salewski, Michael (Hg.): Kiel, die Deutschen und die See. Stuttgart: Franz Steiner Verlag, S. 72. Am 14. Juni 1848 stellte die Bundesversammlung sechs Millionen Taler für den Aufbau einer Flotte bereit und legte damit den Grundstein zum Aufbau einer deutschen Marine. Rahn, Werner (2005). „Einführung.“ In Ders. (Hg.): Deutsche Marinen im Wandel: Vom Symbol nationaler Einheit zum Instrument nationaler Sicherheit. München: Oldenbourg, S.2. Der Aufbau der Flotte aber scheiterte. Die Gründung vieler Schifffahrtsgesellschaften erfolgte erst nach der Reichsgründung. Rübner (2005): Konzentration, S. 33

1136 Vgl. Wolz (2013): Verrosten, S. $26 \mathrm{f}$.

1137 Das erste Flottengesetz wurde 1897 im Reichstag verhandelt. Vgl. Bergien, Rüdiger (2005): „Flotte und Medien im Kaiserreich“. In: Rahn, Werner (Hg.): Deutsche Marinen im Wandel: Vom Symbol nationaler Einheit zum Instrument nationaler Sicherheit. München: Oldenbourg, S. 146

1138 Vgl. Wolz (2013): Verrosten, S. 44

1139 Reunion (1938) (zuvor publiziert von Mahalesi 1934): Ruhmestaten der deutschen Marine. Obercunnersdorf

1140 Reunion (1938) Ruhmestaten, S. 3

1141 Vgl. Wolz (2013): Verrosten, S. 135 
einem heroischen Kampf zu bewähren. ${ }^{1142}$ Viele Offiziere empfanden ihren Dienst daher als nicht heroisch. ${ }^{1143}$ Die wenigen Erfolge der deutschen Flotte zu Kriegsbeginn waren den U-Booten zu verdanken. ${ }^{1144}$ Die wenigen Einsätze der Marine waren kaum von Erfolg gekrönt oder besaßen keine Relevanz für den Verlauf des Krieges. Bei einem der ersten Gefechte erlitt die deutsche Flotte 1914 vor Helgoland eine schwere Niederlage, die sehr an der Ehre der Marine nagte und eine Missstimmung innerhalb der Bevölkerung provozierte. ${ }^{1145}$ Während die Fliegerasse einen ehrenvollen Kampf fochten, ${ }^{1146}$ musste die Marine um ihre Ehre fürchten. Erst mit der Skagerrak-Schlacht im Jahr 1916 konnte die deutsche Flotte mit einem Patt einen Achtungserfolg davontragen und einen temporären Prestigegewinn erzielen. ${ }^{1147}$

Neben dem Mangel an Meriten war die Marine Keimzelle revolutionärer Umbrüche, denn 1917 fand die erste Meuterei in der Geschichte der deutschen Marine statt,1148 wobei die Aufständischen in linksgerichteten Kreisen einen Rückhalt fanden. ${ }^{1149}$ Den Unruhen waren sinnlose Schikanen auf deutschen Kriegsschiffen und eine schlechte Versorgungslage der Matrosen vorausgegangen. ${ }^{1150}$ Der Ruf der Marine, die sich selbst als marode betrachtete, stand bei Kriegsende auf dem Spiel. ${ }^{1151}$ Die Offiziere wollten

1142 Vgl. Kiekel, Stefan (2007): Die Reichsmarine zwischen Küstenverteidigung und Weltmachtstreben. Militärgeschichte und Wehrwissenschaften Bd. 9. Bonn: Bernard \& Graefe , S. 15

1143 Vgl. Wolz (2013): Verrosten, S. 141. Viele Marineangehörige wechselten daher aus Langeweile oder mangelndem Kriegseinsatz freiwillig zu den U-Booten oder zu den Marineluftschiffern. Das Tirpitz-Konzept, sich mit den Briten in einer großen Seeschlacht zu messen, ging nicht auf, denn diese griffen wider Erwarten nicht in der deutschen Bucht an. Um eigene Verluste zu minimieren, ging die britische Admiralität zu einer "risikoloseren Fernblockade“ über. Vgl. Rahn (2005): „Strategische Optionen und Erfahrungen der deutschen Marineführung 1914 bis 1944“. In: Ders. (Hg.): Marinen, S. 201

1144 Vgl. Wolz (2013): Verrosten, S. 67

1145 Vgl. Ebd., S. 64ff.

1146 „Der Flieger, der den ritterlichsten Kampf der Zeit geführt hat.“ Foertsch (1934): Soldat, S. 12

1147 Vgl. Wolz (2013): Verrosten, S. 161ff.

1148 Die Unruhen reflektierten die „Kriegsmüdigkeit und Unzufriedenheit mit den bestehenden politischen und sozialen Verhältnissen" Angesichts der russischen Novemberrevolution und dem Kriegseintritt der USA brachen im April 1917 politische Streikwellen im Kaiserreich aus. Ebd., S. 192f.

1149 Vgl. Dähnhardt, Dirk (1978): Revolution in Kiel. Neumünster: Karl Wachholtz Verlag, S. 48

1150 Vgl. Wolz (2013): Verrosten, S. 203

1151 Vgl. Ebd. S. 225f. 
daher in einer letzten Seeschlacht, dem „Operationsplan 19“, zu einem letzten Gefecht antreten und im Namen der Ehre einen „symbolischen Gewinn“1152 erzielen. Die Matrosen der Kriegsflotte konnten sich mit dem Heroismus der Offiziere nicht identifizieren und verweigerten aufgrund des aussichtslosen Unterfangens und der laufenden Waffenstillstandsverhandlungen den Befehl zum Auslaufen. Von Kiel ausgehend breitete sich die Revolte auf andere Marinestützpunkte aus. ${ }^{1153}$ Am 19. November 1918 wurde die deutsche Flotte nach den Statuten des Waffenstillstandsabkommens im britischen Hafen Scapa Flow interniert.1154 Die Marineoffiziere, den endgültigen Ehrverlust vor Augen, versenkten die Kriegsflotte unter dem Befehl von Konteradmiral Ludwig von Reuter. ${ }^{1155}$

Da die Flotte militärisch keine Erfolge aufzuweisen hatte, war sie „in der öffentlichen Wahrnehmung zur Nebensächlichkeit" "1156 geworden. Zweifelhafte finanzielle Transaktionen der Marineleitung sowie Verbindungen einiger Angehöriger der neu erstandenen Reichsmarine zum Kapp-Lüttwitz-Putsch ${ }^{1157}$ trugen nach dem Krieg zu einem negativen Image bei und desavouierten den Status der Marine als nationales Symbol. ${ }^{1158}$ Wie von konservativen Offizierskreisen der Marine gefordert, ${ }^{1159}$ konnte

1152 Ebd., S. 233ff. Hinter der Rettung der Ehre standen auch eigennützige Motive, denn die Offiziere fürchteten, nach dem Krieg sowohl ihre eigene als auch die Reputation der Marine zu verlieren. Der „Flottenvorstoß war daher viel mehr [...] der Versuch, den Machtanspruch der Marine und die Stellung des Seeoffizierskorps zu erhalten.“ Groß, Gerhard P. (2005): „Eine Frage der Ehre? Die Marineführung und der letzte Flottenvorstoß 1918.“ In: Rahn (Hg.): Marinen, S. 300

1153 Vgl. Wolz (2013): Verrosten, S. 235-242

1154 Vgl. Ebd., S. 255

1155 Die Aktion erfolgte entgegen der Order der Reichsregierung und kurz vor Unterzeichnung des Versailler Vertrages. Vgl. Büttner, Ursula (2008): Weimar. Die überforderte Republik 19181933. Stuttgart, S. 125

1156 Wolz (2013): Verrosten, S. 227

1157 Die Folgen des Putsches waren für die Marine derart verheerend, dass sie kaum noch einsatzfähig war und kurz vor ihrer Auflösung stand; auch ihre Position innerhalb der Reichswehr war geschwächt. Vgl. Kiekel (2007): Reichsmarine, S. 19f.

1158 Neben einer Reihe von Skandalen geriet die Reichsmarine durch die ,Lohmann-Affäre' in der Öffentlichkeit in Misskredit. Vgl. Dreeßen, Carl (2000): Die deutsche Flottenrüstung in der Zeit nach dem Vertrag von Versailles bis zum Beginn des Zweiten Weltkrieges und ihre Darstellung und Behandlung im Nürnberger Prozeß von 1945/46. Diss. Universität Hannover. Hamburg: Mittler, S. $55 \mathrm{ff}$.

1159 Vgl. Nolte, Maik (2005): „...mit Anstand zu sterben verstehen.“ Flottenrüstung zwischen Tirpitzscher Tradition, strategischer Notwendigkeit und ideologischem Kalkül 1933 - 1943. Lübeck: Der Andere Verlag, S. 29. Die Marineoffiziere, einst vom Kaiser bevorzugt, zeichneten sich durch 
die deutsche Reichsmarine angesichts ihres desolaten Zustandes in der Weimarer Republik nicht als künftige Speerspitze zur Wiedererlangung der Ehre eingesetzt werden. Sie besaß nicht das symbolische Potential, um mythologisch aufbereitet zu werden.

Die Nautik-Alben reflektieren das desolate Bild der Marine, das sich im Bewusstsein der Öffentlichkeit manifestiert hatte. Das Titelbild des Albums RUHMESTATEN DER DEUTSCHEN MARINE visualisiert exemplarisch den Untergang der kaiserlichen Flotte. Die Illustration zeichnet ein apokalyptisches Bild eines untergehenden Flottenverbandes. Im Vordergrund befindet sich ein verzweifelter Marinepilot mit wehender kaiserlicher Flagge, der in den tosenden Wogen versinkt. Das Motiv visualisiert nicht nur den Untergang der Flotte, sondern auch den Ehrbegriff der konservativen Marineoffiziere, denn ein deutsches Kriegsschiff kapitulierte nicht: „Wo das eine nicht möglich war, musste das andere in Kauf genommen werden“. ${ }^{1160}$ Entsprechend ihres Ehrenkodex' ging die kaiserliche Flotte in dem Album mit wehender kaiserlicher Fahne unter:

\begin{abstract}
„Der letzte Mann
Über allen Ruhmestaten der deutschen Marine klingt hoch und her das stolze Lied von der Flagge, die der sterbende Pilot auf dem sinkenden Schiff noch hoch in seiner Rechten hält: „Ihr wollen wir unser Leben weihn, der Flagge Schwarz-Weiß-Rot!"“"1161
\end{abstract}

Im Unterschied zur Aviatik, deren Protagonisten in den Zigarettenalben heroisiert werden, wird weder die Ära der kaiserlichen Flotte vor dem Hintergrund heldenhafter Taten geschildert, noch wird die deutsche Marine insgesamt heroisch verklärt. Einzig die Firma Sturm hält die preußische Marinetradition in Ehren und versucht in

besondere Kaisertreue aus. Sie hielten das Andenken an die Monarchie bis in die Weimarer Republik in Ehren. Vgl. Wolz (2013): Verrosten, S. 277f.

1160 Siegen oder sterben war eine pervertierte Ehrauffassung, die auch Hitler begeisterte und die er später von seinen Truppen einforderte. Ebd. S. 218

1161 Reunion (1938): Ruhmestaten, Bild 120, S. 44 
ihrem Nautik-Album SEEFAHRT TUT NOT!1162 an eine vermeintlich heroische Zeit anzuknüpfen. Der Verfasser E. von Mantey, seines Zeichens Vizeadmiral a.D., beschwört in dem Album die Anfänge der deutschen Seefahrt von den Germanen bis zur Reichsgründung im Jahr 1871. Bereits der Titel SEEFAHRT TUT NOT!, der Slogan der wilhelminischen Flottenaufrüstung, impliziert eine ideologische Verbindung zu preußischen Herrlichkeiten mit ihren Großmachtträumen am Ende des 19. Jahrhunderts. Deutschland wird bei Sturm als Opfer feindlicher Mächte und innerer Feinde dargestellt, denen es jedoch nicht gelungen sei, die „Bismarcksche Schöpfung“"1163 zu zerschlagen. Mit antiquiertem Vokabular unternimmt Sturm den Versuch, überholte Traditionen und angestaubte Mythen wiederzubeleben, versäumt es jedoch, eine Brücke zur Moderne zu schlagen. Ebenso wie in ihren militärhistorischen Uniform-Alben werden mit dem Großen Kurfürsten ${ }^{1164}$ und Friedrich dem Großen die Protagonisten beschworen, die die preußische Traditionslinie repräsentierten. Sturm erkennt im Rahmen ihres populärwissenschaftlichen historischen Werkes die inhärente Kraft des Mythos, mit dem ein Volk mit seiner Geschichte verbunden werden kann, verharrt aber in vergangenen Großmachtträumen der wilhelminischen Epoche, die den Menschen keinen Identifikationsraum mehr boten.

Angesichts mangelnder Heldentaten der deutschen Kriegsmarine im Ersten Weltkrieg, beschränkt sich die Darstellung maritimer Großtaten in dem Album SEEFAHRT TUT NOT! auf die ,Emden'. ${ }^{1165}$ Die ,Emden' war ein kleiner Kreuzer, ${ }^{1166}$ der sich, völlig auf sich gestellt, auf verwegenen Kaperfahrten im Gelben Meer und der Südsee mit

1162 Sturm (beteiligt: Dressler) (1934): Seefahrt tut not! Die Entwicklung deutscher Seeschiffahrt von der Frühzeit bis 1871 (Texte: Militärschriftsteller Dr. Martin Lezius. Bilder: Militärmaler Herbert Knötel, Berlin). Dresden

1163 Sturm (1934): Seefahrt, Zum Geleit, unpag.

1164 Die Bedeutung der Kurfürstlichen Flotte wird in dem Text mehr als überbewertet, denn die kleine Flotte kann lediglich als abenteuerliches Unterfangen betrachtet werden, sich mit den Kolonialmächten des 17. Jahrhunderts zu messen. Die Flotte diente primär der Sicherung der Handelsfahrten in Nord- und Ostsee. Vgl. Heyden, Ulrich van der (2001): Rote Adler an Afrikas Küste. Die brandenburgisch-preußische Kolonie Großfriedrichsburg in Westafrika, 2. Aufl. Berlin: Selignow Verlag, S. 12f.

1165 Sturm (1934): Seefahrt, Zum Geleit, unpag.

1166 Vgl. Hubatsch, Walther (1975): Kaiserliche Marine. München: Lehmann, S. 256. 
Proviant und Kohlen versorgen musste. ${ }^{1167}$ Nach dem Untergang des Schiffes schlug sich die Mannschaft durch die arabische Halbinsel bis nach Konstantinopel durch, was der Mannschaft weltweite Publizität und dem Deutschen Reich eine gute Reputation einbrachte. ${ }^{1168}$ Der Ruhm der Emden, der im Ersten Weltkrieg als „Deutscher Lorbeer" galt und „Ewig in deutscher Unsterblichkeit"1169 stehen sollte, war in der Weimarer Republik in einen fernen Horizont gerückt. In den Nautik-Alben ist die ,Emden' allenfalls eine Marginale und wird nur von dem Unternehmen Sturm als nationale Ikone wiederbelebt.

„,"Emden!“ Dies Wort bedeutet nicht nur den Namen einer deutschen Stadt, die bei Gelegenheit in der Vorkriegszeit bei dem kleinen Kreuzer „Emden“ Patenschaft war, so liegt vielmehr in dem Worte Emden für uns Deutsche noch eine tiefere Bedeutung. [...] „Der Name Emden“ ist in der brandenburgischpreußischen Geschichte mit den Anfängen einer deutschen Kriegsmarine und einer kräftigen Überseepolitik untrennbar verbunden. " ${ }^{1170}$

Das Album SEEFAHRT TUT NOT! stillt daher lediglich romantische Emotionen und die Sehnsucht nach einer vergangenen Epoche. Sturm unternimmt den vergeblichen Versuch, preußische Herrlichkeiten wieder aufleben zu lassen.

\subsubsection{Teilhabe am Welthandel}

Da die deutsche Handelsflotte wichtiger Bestandteil der Reparationsforderungen des Versailler Vertrages war, musste Deutschland einen großen Teil seiner Handels- und einen Teil seiner Fischereiflotte an die Siegermächte übergeben. ${ }^{1171}$ Deutschland war daher nach 1919 von den Weltmeeren nahezu verschwunden.1172 Eine Konsolidierung erfolgte erst in den Jahren 1924 bis 1929.1173 Die Zigarettenalben mit nautischen

1167 Vgl. Lochner, R. K. (1982): Die Kaperfahrten des Kleinen Kreuzers Emden. Tatsachenbericht. München: Heyne Verlag, S. 32 und 71 bis 210

1168 „Wir machten überall einen guten Eindruck, daß wir in Arabien, überhaupt im Orient, große Propaganda für Deutschland machen und begeisterte Anhänger gefunden haben.“ Mücke, Hellmuth von (1915): Emden. Berlin: Scherl, S. 45

1169 Gedicht von Maria Weinand, in: Mücke (1915): Emden, S. 97

1170 Sturm (1934): Seefahrt, Zum Geleit, unpag.

1171 Vgl. Rübner (2005): Konzentration, S. 71f.

1172 Vgl. Büttner (2008): Weimar, S. 125

1173 Vgl. Rübner (2005): Konzentration, S. 129 
Themen, die in den Jahren zwischen 1930 bis 1933 publiziert wurden, setzen die deutsche Schifffahrt in den Kontext des internationalen Seehandels. Lediglich vier Nautik-Alben, ${ }^{1174}$ die zwischen 1933 und 1934 publiziert wurden, beschäftigen sich mit der deutschen Kriegsmarine: RUHMESTATEN DER DEUTSCHEN MARINE, LLOYDFlottenbilder - Deutsche Marine, Unsere Reichsmarine- Und HANDEls-FlotTen und SeEFAhrt tUT NOT! Die Marine steht in diesen Sammelbänden aber nicht im Kontext der Wiederaufrüstung, sondern wird mit der Sicherung der Küsten legitimiert, einzig mit dem Ziel, Deutschlands Prosperität zu maximieren. Das Bilderspektrum der Nautik-Alben, das neben der deutschen Flotte auch die Schiffe anderer Nationen zeigt, spiegelt den internationalen und ökonomischen Rahmen wider, in dem sich Deutschland einfügen wollte. Entsprechend wird auch der kriegerisch konnotierte Slogan ,Seefahrt tut not!', eine in den Aviatik-Alben variierte und viel zitierte Phrase, kaum angeführt. Der einstige Imperativ der Flottenaufrüstung findet nur marginale Verwendung und wird nicht militärisch konnotiert, sondern in einen ökonomischen Kontext gesetzt.

„Seefahrt tut not!

$\mathrm{Zu}$ keiner Zeit wirtschaftlichen Auf- und Ausbaues hat dieser Ausspruch mehr Geltung gehabt, als in unserer jetzigen Zeit. Die Seefahrt ist für das deutsche Wirtschaftsleben eine Notwendigkeit. Ohne Wirtschaft gibt es keine Weltbedeutung. ${ }^{1175}$

Im dritten Band der Lloyd-Reihe Lloyd-FlotTEnBILDER - Die WeLthandelsflotte aus dem Jahr 1930 wird der ökonomische wie kulturelle Stellenwert einer internationalen Seefahrt in den Mittelpunkt gestellt, wobei die Bedeutung für den Transfer von Kulturgütern besonders hervorgehoben wird.

„In regelmäßigen Fahrten durchfuhren Wasserfahrzeuge aller Art und der verschiedensten Größe die gewaltigen Meeresflächen, um dem lebensnotwendigen Austausch von Menschen und Waren dienstbar zu sein. Alle Weltteile sind an diesen Verkehr angeschlossen; alle Kulturvölker der Erde haben Anteil

1174 Reunion (1938): Ruhmestaten. Jasmatzi (1934): Unsere Reichsmarine. Aus dem Leben der Matrosen. Dresden, Sturm (1934): Seefahrt, Brinkmann (1932): Lloyd-Flottenbilder. Deutsche Marine. Bremen und Deuzig Zigarettenfabrik (1933): Unsere Reichsmarine- und Handelsflotten. Dresden Kyriazi (1930): Vom Einbaum bis zur Europa. Cairo/ Hamburg, Text: Seefahrt tut not! unpag. 
an dem Bestande an Ueberseeschiffen, die die Meere bevölkern [...] So steht die Welthandelsflotte in ihrer wechselvollen Gestalt und ihren zahllosen Auswirkungen als eines der mächtigsten Kulturgüter, die die Menschheit besitzt $[\ldots]^{\prime 1176}$

Die Konzentration des Albums auf die Handelsflotte reflektiert die Ambitionen der Weimarer Regierung, Deutschlands Weltgeltung auf der Basis des Welthandels und technisch ausgereifte Prestigeobjekte wiederherzustellen. ${ }^{1177}$ Das Album korrespondiert daher mit den politischen und ökonomischen Gegebenheiten. Deutschland war auf eine Handelsflotte angewiesen, um wichtige Güter, darunter Erdöl und Eisenerz, zu importieren. ${ }^{1178}$ Neben dem Import wichtiger Rohstoffe war die Handelsflotte bis in die 1930er Jahre wichtigstes Transportmittel für den Export und damit einer der Hauptdevisenbringer. ${ }^{1179}$ Entsprechend werden dem Bildersammler in den NautikAlben jener Zeit die technischen Errungenschaften deutscher Werften präsentiert wie in dem Sammelband VOM EINBAUM BIS ZUR EUROPA! aus dem Jahr 1930. Dazu gehören der Dampfer ,Cap Arcona', der mit rauchloser Ölfeuerung eine Innovation darstellte oder das ,Rotorschiff Buckau', das anstelle von Segeln von zwei rotierenden Zylindern angetrieben wurde. ${ }^{1180}$ Dazu kamen die Luxusliner ,Bremen' und ,Europa', die weltweites Aufsehen erregten. Der Stapellauf dieser beiden Prestigeobjekte wird in dem Album zum Grundstein einer neuen Flotte und gleichsam zu Flaggschiffen einer wiedererstarkten Nation.

„Unsere Handelsflotte war nach dem Kriege bedeutungslos geworden. Aus dem Nichts ist in wenigen Jahren wieder eine gewaltige deutsche Flotte entstanden, welche deutsche Güter nach allen Teilen der Erde befördert. Das außerordentliche Interesse, welches der Stapellauf der Riesendampfer „Bremen" und „Europa“, als die modernsten und schönsten Schiffe der Welt, nicht nur in der deutschen, sondern in der Weltpresse ausgelöst hat, stellt das Problem der Schiffahrt wieder in den Vordergrund des Interesses. " ${ }^{1181}$

Die repräsentativen Schiffe nehmen in den Alben jedoch keine exponierte Stellung ein,

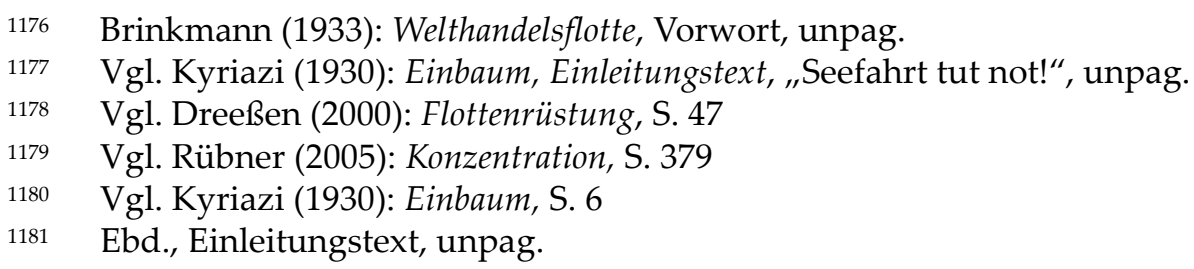


sondern reihen sich ein in das Spektrum der internationalen Schifffahrt. Die Texte beschränken sich auf marginale Sachinformationen zu den einzelnen Schiffen, wobei die Leistungen der deutschen Werften gegenüber anderen Nationen nicht explizit hervorgehoben werden. Exemplarisch dafür sind die Alben der Firma Brinkmann, deren Trilogie LlOYD FlOTtENBILDER neben einem Marine-Sammelband zwei Alben beinhaltet, die ganz im Zeichen des Welthandels stehen: DiE WeLTHANDELSFLOTTE1182 und REEDEREIFLAGGEN. ${ }^{1183}$

„Deutschland mit seinen langen Küsten, seinen engen Beziehungen zu den Überseeländern und seiner Lage im inneren Winkel der Nordseebucht ist auf die See angewiesen, auf Schiffahrt und Handel und deswegen auf Geltung im Auslande. Dazu soll unsere Flotte verhelfen. Hier in diesen Bildern wird uns vor Augen geführt, was Mannesmut und Tatkraft, freudige Opfertat und unbeirrte Ausdauer zu leisten im Stande sind."1184

Im Fokus der Nautik-Alben steht die Seefahrt im Kontext der wirtschaftlichen Konsolidierung Deutschlands. Die Sammelbände reflektieren damit die Ambitionen, die bereits während der Weimarer Republik vorherrschten. Der maritime Ruhm sollte auf Modernität und ökonomischen Erfolg aufgebaut werden und nicht auf die waffentechnische Überlegenheit einer Kriegsmarine.

\subsubsection{Bedingt einsatzfähige Kriegsmarine}

Die Reichsmarine nimmt in den Zigarettenalben eine marginale Stellung ein, wobei die Texte und Bilder einen realistischen Blick auf den Zustand der deutschen Kriegsschiffe werfen. In den Nautik-Alben der frühen 1930er Jahre werden die Schiffe der deutschen Kriegsmarine unverblümt als hoffnungslos überaltert präsentiert. Die in den Sammelwerken abgebildeten Schiffe vermitteln einen Eindruck von dem kläglichen Zustand der deutschen Kriegsflotte:

\footnotetext{
1182 Brinkmann (1933): Welthandelsflotte

1183 Brinkmann (1933): Lloyd-Flottenbilder. Reedereiflaggen der Welthandelsflotte. Bremen

1184 Brinkmann (1932): Lloyd-Flottenbilder. Deutsche Marine. Bremen, Vorwort, unpag.
} 
„Linienschiff „Hessen“, Stapellauf 1903. Es ist das älteste Linienschiff unserer Reichsmarine. “1185

„Linienschiff „Hannover“, Stapellauf 1905. Eines der ältesten Linienschiffe unserer Flotte, wurde 1924/1925 notdürftig modernisiert, genügt aber jetzt in keiner Weise mehr den militärischen Ansprüchen und wurde 1932 außer Dienst gestellt. “1186

„Linienschiff „Schleswig-Holstein“, Stapellauf 1906. Während des Krieges hat es mit Erfolg an der Skagerrakschlacht teilgenommen. Nach dem Kriege renoviert, ist es jetzt das erste Flottenflaggschiff der Reichsmarine. ${ }^{\prime 1187}$

„Minenräumbootsmutterschiff „Wittelsbach“. Diente kurz nach der Revolution als Mutterschiff der kleinen Minenräumboote, die auf ihm eingesetzt wurden. Hat sich wenig bewährt und wurde bald wieder nach einigen ungünstig ausfallenden Erprobungen außer Dienst gestellt."1188

In dem Album VOM EINBAUM BIS ZUR EUROPA! wird einigen Schiffen der deutschen Reichsmarine nur bedingte Modernität zuerkannt. Selbst Panzerkreuzern, dem ganzen Stolz der einstigen Flotte, wird ein bescheidenes Zertifikat ausgestellt. Der Panzerkreuzer ,Scharnhorst” wird als „Übergangstyp zur modernen Bauart“ angesehen und der Kreuzer ,v.d.Tann' wird laut Album „den Bedingungen des modernen Seekrieges weitgehend gerecht“. ${ }^{1189}$ Damit werden die realen zeitgenössischen Gegebenheiten reflektiert, denn aufgrund des Versailler Vertrages war die Anzahl der Neubauten der deutschen Kriegsschiffe und deren Tonnage auf ein Minimum begrenzt. ${ }^{1190}$ Insgesamt war die Reichsmarine technisch hoffnungslos überaltert. ${ }^{1191}$ Selbst in Nautik-Alben, die sich der deutschen Marine widmen, fällt das Lob über die Marine bescheiden aus. Sie wird als eine „neue kleine aber tüchtige Marine“

\footnotetext{
1185 Brinkmann (1932): Deutsche Marine, Serie 11, Bild 4, unpag.

1186 Ebd., Serie 9, Bild 2, unpag.

1187 Ebd., Serie 10, Bild 4, unpag.

1188 Ebd., Serie 14, Bild 6, unpag.

1189 Kyriazi (1930): Einbaum S. 8

1190 Im Versailler Vertrag wurde die Anzahl und Tonnage der Schiffe begrenzt: 10.000 Tonnen für Schlachtschiffe (6 Stk.), 6000 Tonnen für kleine Kreuzer (6 Stk.), 800 Tonnen für Zerstörer 12 Stk., 200 Torpedoboote (12 Stk.) Keine U-Boote. Die Mannschaften wurden auf 15.000 zu begrenzt. Draeger (1933): Vertrag von Versailles, S. 27f. 
präsentiert. Das Album zeigt keine Ambitionen, die Marine heroisch zu verklären, sondern möchte bei „manchem Beschauer der älteren Generation bunte Erinnerung an viele ernste, aber noch mehr frohe Stunden hervorrufen. "1192

Auch in den Zigarettenalben, die nach der Gründung der Reichsmarine publiziert wurden wie DEUTSCHLAND BAUT AUF aus dem Jahr 1937, wird ein realistisches Bild der Flotte gezeichnet. Gezeigt wird eine Marine, die unter Beachtung der Statuten des Versailler Vertrages bescheiden aufgerüstet hat, um Deutschlands Küsten verteidigen zu können. In der Kleinserie „Unsere junge Flotte“ wird ein recht bescheidenes Bild vom Arsenal der Marine gezeichnet. Auf demonstrative Zurschaustellung deutscher Waffentechnik, die unter nationalsozialistischer Ägide entstanden ist, wird gänzlich verzichtet. Mit Ausnahme des Segelschulschiffes, das nach ,Horst Wessel', ${ }^{1193}$ einem zum Märtyrer stilisierten Ikone der NS-Bewegung benannt wurde, werden Schiffe abgebildet, die noch während der Weimarer Republik erbaut, respektive vom Stapel gelassen wurden. Auch technische Neuerungen wie ein U-Boot werden nicht ostentativ in Szene gesetzt. Das Album möchte den Sammlern mit seinen Illustrationen „Freude und Erbauung an den Dokumenten deutschen Aufstiegs, des neuen und schönen Deutschlands Adolf Hitlers“"1194 schenken.

Im Unterschied zu Flugzeugen in den Aviatik-Alben erfahren die Schiffe und U-Boote in den Nautik-Alben keine symbolische Okkupation durch Platzierung der Hakenkreuzfahne. Exemplarisch stehen dafür die Kleinserien des Albums DEUTSCHLAND BAUT AUF. In den Kapiteln „Segelfliegerei“, „Ein Volk von Fliegern“ und „Die deutsche Post" sind Segelflugzeuge, Zeppeline und flugtechnische Anlagen ostentativ mit Hakenkreuzfahnen geschmückt. Insbesondere in der Serie „Die Wehrmacht" nehmen die Fahnen nicht nur eine dominante Stellung ein, sondern sind bei einem Bild singuläres

\footnotetext{
1192 Brinkmann (1932): Deutsche Marine, Vorwort, unpag.

1193 Behrenbeck (2011): Helden, S. 119

1194 Monopol (1937): Deutschland, Einleitungstext, unpag. Anm.: Der Sammelband zeigt in 6er-Serien einen Querschnitt aus Handwerk, Industrie und Verkehr, die Deutschland als modernen Staat zeigen, der technisch und wissenschaftlich auf der Höhe der Zeit ist. In die Serien mischen sich aber auch Waffengattungen der neu gegründeten Wehrmacht.
} 
Motiv. In den nautischen Serien „Unsere junge Flotte“, „Hamburg, das Tor zur Welt“, "Neubau der deutschen Handelsflotte", „Auf Helgen und Werften“ oder "Schiffbauversuchsanstalt" ist das NS-Parteiabzeichen nicht platziert. ${ }^{1195}$ Die Nautik-Alben unterscheiden sich damit maßgeblich von den Aviatik-Sammelbänden. Der Verzicht auf Usurpation der Marine und der Schifffahrt durch das NS-Regime sind nicht die einzigen Divergenzen, denn die Nautik-Bände vermeiden kriegerische Rhetorik, Heroismus oder Revanchismus und legen den Tenor auf den Wiederaufbau Deutschlands. Auch der Versailler Vertrag wird nicht instrumentalisiert, um eine Drohkulisse zum Aufbau einer Einkreisungspropaganda zu installieren. In den Nautik-Alben werden insgesamt verhaltene Töne angeschlagen: „Nicht klagen, wieder wagen!“1196

\subsubsection{Außenpolitische Strategie}

Die Zurückhaltung bei der Präsentation nautischer Errungenschaften ist primär der veränderten Rolle der Kriegsmarine geschuldet. Im Unterschied zur Luftwaffe war ihr Stellenwert für kriegerische Auseinandersetzungen eine zu vernachlässigende Größe. So musste auch Hitler Konzessionen an die Moderne machen, da er erkannte, dass selbst hochgerüstete Schlachtschiffe anderen Waffengattungen unterlegen sind und „angesichts der Entwicklung der Luftwaffe zur Bedeutungslosigkeit herabgesunken "1197 waren. Die Divergenz zwischen dem Stellenwert der Kriegsmarine und der Luftwaffe kommt in dem Album UNIFORMEN IM NEUEN DEUTSCHLAND deutlich zum Ausdruck. Die Bedeutung der Luftwaffe wird im Vergleich zur Reichsmarine als modernes Mittel der Kriegsführung und als Errungenschaft des technischen Zeitalters hervorgehoben, die Deutschland die Wehrhaftigkeit zurückgegeben hat. Während die Relevanz der Luftwaffe und der Wehrmacht als Symbol deutscher Wehrhaftigkeit hervorgehoben wird, wird die Reichsmarine in den Kontext ökonomischer Interessen gesetzt:

\footnotetext{
1195 Lediglich im Kapitel „Dieselmotoren überall“ trägt ein Schiff die Hakenkreuzfahne, die das Motiv aber nicht dominiert. Monopol (1937): Deutschland, unpag.

1196 Kosmos (1937): Deutsche, Kapitel: Das Ehrendenkmal der Deutschen Kriegsmarine, unpag.

1197 Jochmann (1941): Nr.16, S. 57f. Zit. nach: Nolte (2005): Anstand, S. 48f.
} 
„Der Schandvertrag von Versailles hatte sie (Anm.: die Luftwaffe) uns ganz genommen, bis sie Adolf Hitler nach Erlangung der Wehrfreiheit zu einem besonderen Teil der Wehrmacht gestaltete. [...] Damit war Deutschland in der Luft wieder frei." ${ }^{\prime 198}$

„Mit dem 16. März 1935 (Anm.: Flottenabkommen) wurde auch der Weg für den Aufbau einer den Lebens- und Handelsinteressen des deutschen Volkes entsprechende Flotte freigemacht. ${ }^{\prime 1199}$

Die Gründe für die mangelnde Präferenz der Kriegsschiffe, respektive die Fokussierung auf den Welthandel, ist ferner auf die politischen Rahmenbedingungen zurückzuführen, denn die Reichsmarine war in der außenpolitischen Konzeption der neuen Machthaber zu Beginn der 1930er Jahre eine Marginalie. Angesichts der Übermacht der Seemächte England, Japan und Nordamerika sollten die militärischen Kräfte auf die Landeroberung konzentriert werden. Hitlers Außenpolitik war vom Lebensraum im Osten und der Rassenpolitik geprägt. ${ }^{1200}$ Sein außenpolitisches Programm war zu Beginn der Machtergreifung auf ein Zweckbündnis mit England ausgerichtet, ${ }^{1201}$ auch um den hegemonialen Ambitionen Frankreichs entgegenzuwirken. ${ }^{1202}$ Nach der Gründung der Wehrmacht wurde das Bündnis mit Großbritannien durch ein Flottenabkommen gefestigt, das im Juni 1935 in Kraft trat. In dem Abkommen wurde der deutschen Flotte ein Verhältnis von 35:100 der Britischen Flottenstärke zuerkannt. Der U-Boot-Flotte wurden 45 Prozent zugestanden, wobei ein zukünftiger Gleichstand in Erwägung gezogen wurde. ${ }^{1203}$ Diese politische Linie korrespondiert mit der in den Zigarettenalben postulierten Außenpolitik, die bis zum Kriegseintritts Englands auf Ausgleich ausgerichtet war.

\footnotetext{
1198 Aviatik (1936): Uniformen, Kapitel: Luftwaffe, S. 29

1199 Ebd., Kapitel: Kriegsmarine, S. 21

1200 Vgl. Recker, Marie-Luise (2010): Die Außenpolitik des Dritten Reiches, 2. Aufl. München: de Gruyter, S. 59. Als England und Frankreich am 3. September 1939 dem Deutschen Reich den Krieg erklärten, lag kein Verteidigungsplan vor. Die Marine war weder vorbereitet und dem Gegner an Kampfkraft unterlegen. Vgl. Ottmer (1991): „Skandinavien“, S. 63

1201 Vgl. Dülffer (1973): Weimar, S. 207. Die Seerüstung hatte im „Stufenplan“ der NS-Politik eine nachgeordnete Rolle. Ebd. S. 216

1202 Vgl. Hitler (1930): Kampf, S. 696f.

1203 Vgl. Ottmer (1991): „Skandinavien“, S. 55
} 
„Aus der Reichsmarine der Nachkriegszeit, die zahlenmäßig und technisch ähnlichen Beschränkungen unterworfen war wie das Reichsheer, entstand die neue deutsche Kriegsmarine, deren Aufbau durch das deutsche-englische Flottenabkommen vom 18. Juni 1935 festgelegt wurde.“1204

Unabhängig von der außenpolitischen Strategie des NS-Regimes stand Deutschland noch unter der Beobachtung der Siegermächte. Laut Versailler Vertrag durfte Deutschland nur eine geringe Anzahl an Schiffen mit begrenzter Tonnage und Armierung zum Schutz seiner Küsten und Seeverbindungen nach Ostpreußen unterhalten. ${ }^{1205}$ Neben den politischen Rahmenbedingungen wäre es dem Staat aufgrund seiner chronischen Illiquidität auch nicht möglich gewesen, eine Flotte als Symbol deutscher Wehrhaftigkeit zu installieren. Deutschland besaß zu Beginn der 1930er Jahre weder die erforderliche Infrastruktur noch die Rohstoffe, ${ }^{1206}$ um eine schlagkräftige Kriegsflotte aufzubauen. Die Marine war bis 1937 noch relativ schwach aufgestellt und für einen Kriegseinsatz wenig gerüstet. ${ }^{1207}$

Auch Hitler hatte erkannt, dass die Kriegsflotte aufgrund mangelnder Förderung in der Vergangenheit und der überholten Kolonialpolitik für die Gestaltung seiner zukünftigen politischen Ziele nicht geeignet war. Hitler bewunderte zwar die Offiziere der deutschen Marine, stand der wilhelminischen Flottenpolitik jedoch ablehnend gegenüber und kritisierte sie bereits in ,Mein Kampf ${ }^{\prime}{ }^{1208}$ Hitler und die politische Rechte sahen Deutschlands zukünftige Prävalenz nicht in Übersee, sondern in der territorialen Ausweitung des Landes auf dem europäischen Kontinent. ${ }^{1209}$ In dem Album DEUTSCHLAND BAUT AUF wird die neue Reichsmarine als Waffengattung präsentiert, die einzig dem Schutz der Handelsinteressen dient. Entsprechend wird

\footnotetext{
1204 Aviatik (1936): Uniformen, Kapitel: Kriegsmarine, S. 21

1205 Vgl. Dreeßen (2000): Flottenrüstung, S. 46

1206 Vgl. Ebd. S. 47. Vgl. Ottmer (1991): "Skandinavien“, S. 61

1207 Vgl. Deist, Wilhelm (1979): „Die Aufrüstung der Wehrmacht”. In: Ders./ Messerschmidt, Manfred/ Volkmann, Hans-Erich/ Ders./ Militärgeschichtliches Forschungsamt. (Hg.): Ursachen und Voraussetzungen der deutschen Kriegspolitik. Das Deutsche Reich und der Zweite Weltkrieg. Bd. 1. München: Deutsche Verlags-Anstalt, S. 461

1208 Vgl. Hitler (1930): Kampf, S. 298 - 301

1209 Vgl. Ebd., S. 153
} 
auch Hitler in den Zigarettenalben als Staatsmann präsentiert, der den Aufbau einer deutschen Flotte primär vor dem Hintergrund ökonomischer Interessen betrachtet:

„Seit im Jahr 1919 die durch das Versailler Diktat abzuliefernde Flotte in Scapa Flow von deutschen Matrosen versenkt wurde, entbehren wir jedes wirksamen Küsten- und Handelsschutzes. Nach Wiedererlangung unserer Wehrhoheit ist der Bau von Kriegsschiffen sofort wieder aufgenommen worden. Durch das deutsch-englische Flottenabkommen von 1935 wurde die künftige Stärke der deutschen Kriegsmarine gegenüber der englischen auf 35 v.H. Festgesetzt. Auf den Werften wächst seitdem wieder eine Flotte heran, die unserer Seegeltung entsprechen wird. Schnelle, kampfkräftige Kriegsfahrzeuge mit modernster Armierung zeigen heute in unseren Marinehäfen Kiel und Wilhelmshaven die neue Flagge der Kriegsmarine. “1210

„Die Marine liebt Adolf Hitler besonders! -

Und, wenn er nur irgend kann, läßt er es sich nicht nehmen, an Bord eines Schiffes der Reichs- oder Handelsmarine zu gehen, um sich alles genauestens anzusehen. Er spricht mit diesem und jedem über Entwicklungsmöglichkeiten, Wirtschaftlichkeit und Nutzen. "1211

Die Nautik-Alben verzichten im Unterschied zu den Aviatik-Alben darauf, den Versailler Vertrag zu instrumentalisieren. Deutschland wird nicht als wehrlose Nation dargestellt, die mangels einer schlagkräftigen Marine den feindlichen Aggressoren ausgeliefert ist. Das Flottenabkommen, das Deutschland in die zweite Reihe der Seemächte verbannt hatte, wird in den Alben als Grundlage zur Wiedererlangung der Wehrhoheit betrachtet oder, wie im Sammelband ADOLF HiTLER, von Goebbels sogar als faire Vereinbarung gepriesen:

„Ein deutsches Volk, das wieder in der Lage ist, sein nationales Leben durch eigene Kraft zu beschützen, das seinen Flottenverband in einer ehrlichen $\mathrm{Ab}$ machung mit England auf einer national würdigen Höhe festgelegt hat $[\ldots]^{\text {“1212 }}$

Die Nautik-Alben reflektieren nicht nur den Pragmatismus des NS-Regime, die Flotte in den Dienst der ökonomischen Konsolidierung des Landes zu stellen, sondern auch die Einsicht, der britischen Flotte unterlegen zu sein. Die Texte vermeiden es daher, Großbritannien mit verbalem Säbelrasseln herauszufordern. Das taktische Kalkül, die

\footnotetext{
1210 Monopol (1937): Deutschland, unpag.

1211 Zigaretten-Industrie (1934): Kampf, S. 55

1212 Reemtsma (1936): Hitler, Kapitel: Der Führer als Staatsmann, von Joseph Goebbels, S. 54
} 
Seemacht nicht zu provozieren, manifestiert sich insbesondere in der Darstellung der U-Boote, die in den Alben lediglich eine Randnotiz darstellen. Angesichts der Tatsache, dass Deutschland das Potential der neuen Waffengattung erkannt hatte und im Zweiten Weltkrieg über eine schlagkräftige U-Boot-Flotte verfügte, ist die Abwesenheit der U-Boote in den Zigarettenalben auffällig. Die U-Boot-Waffe bleibt selbst in den Alben der 1936/37er Jahre eine Marginalie und wird nur mit kurzen Bildunterschriften vorgestellt.

„U-Boot-Flottille „Weddingen“. Bald nach Wiederherstellung der Wehrfreiheit erschienen auf See neue deutsche U-Boote. Laut Abkommen mit England kann deren Anzahl 45\% des englischen Besitzstandes betragen. ${ }^{\prime 1213}$

„U-Boot auf der Kieler Förde. Unsere ersten neuen U-Boote sind mit $250 \mathrm{t}$ kaum größer als „U 1“ von 1906. [...] Wir besitzen bzw. bauen jetzt neben den 250-t-Booten solche von 500 und 700 t. “1214

„U-Boot „U 26“. Erbaut 1936. Deschimag, Bremen. 712 t, 1/10,5 cm, 1Mg Flak, 6 Torpedorohre, 4 am Bug, 2 am Heck, Länge 71 m, Breite 6,2 m, Tiefgang 4,1 m, 40 Mann Besatzung. " 1215

Die Zurückhaltung bei der Präsentation deutscher U-Boote kann auch auf den technischen Rückstand zurückgeführt werden, denn im Unterschied zur Luftfahrt konnte das Militär nach dem Ersten Weltkrieg nur schwer an den internationalen Standard anknüpfen. Ebenso wie bei dem Aufbau der Luftwaffe wurde, ungeachtet der Restriktionen des Versailler Vertrages, bereits nach dem Ersten Weltkrieg mit der Konstruktion neuer U-Boote begonnen. Die widrigen Voraussetzungen schränkten die Ambitionen jedoch ein, denn aufgrund des Versailler Vertrages, der Deutschland den Besitz von U-Booten verbot, wanderten in der Zwischenkriegszeit viele bedeutende U-BootKonstrukteure in andere Bereiche ab. ${ }^{1216}$ Darüber hinaus waren sämtliche Anlagen und Werften zwischen 1918-19 von den Alliierten zerstört worden, so dass Deutschland bis 1935 nicht einmal in der Lage war, Reparaturarbeiten durchzufüh-

\footnotetext{
1213 Zigaretten-Industrie (1936): Wehrmacht, Bild 179, unpag.

1214 Ebd., Bild 175, unpag.

1215 Monopol (1937): Deutschland, Kapitel: Unsere junge Flotte, unpag.

1216 Showell, Jack Mallmann (2008): Die Geschichte der deutschen U-Boot-Waffe seit 1906. Stuttgart: Motorbuch, S. 88
} 
ren. ${ }^{1217}$ Die geheime Reichswehr versuchte dennoch, die Wiederaufrüstung voranzutreiben und baute nach dem Ersten Weltkrieg in den Niederlanden eine technische Versuchsanlage zur Weiterentwicklung der U-Boote auf. ${ }^{1218}$ Obwohl Maschinen und Werften den Anforderungen nicht völlig gerecht wurden und Personal erst angelernt werden musste, ${ }^{1219}$ konnte die U-Boot-Technik weiterentwickelt werden. 1935 verfügte Deutschland zwar über eine hervorragende U-Boottechnik, war aber nicht auf dem neusten technischen Stand. ${ }^{1220}$

Die maritime Politik der Nationalsozialisten war insgesamt widersprüchlich. Aufgrund eines fehlenden Grundkonzeptes konnte die deutsche Marine ihre Kapazitäten nicht ausschöpfen und war für einen See-Krieg wenig gerüstet. Auch die finanziellen Mittel zur Wiederaufrüstung waren begrenzt, denn bis 1935 war die Luftfahrt die Waffengattung, die am meisten gefördert wurde. ${ }^{1221}$ Einerseits wurde eine Hochseeflotte aufgebaut, anderseits wurden die Statuten des Versailler Vertrages nicht voll ausgeschöpft. ${ }^{1222}$ Der Chef der Marineleitung Raeder ging mit der Flottenpolitik Hitlers, der sich bereits vor Machtantritt gegen eine Flottenaufrüstung ausgesprochen hatte, nicht konform und fürchtete, in einem kommenden Krieg der französischen Flotte unterlegen zu sein. ${ }^{1223}$ Für ihn war die Marine ein unverzichtbarer Machtfaktor. Nach dem er Hitler von der Relevanz der Marine überzeugt hatte, wurde unter seiner Ägide im Jahr 1934 mit dem Aufbau der Flotte, darunter 72 U-Boote, für den Einsatz

\footnotetext{
1217 Vgl. Ebd.

1218 Vgl. Ebd., S. 83f.

1219 Vgl. Ebd., S. 88

1220 Wichtige Neuerung war die Einführung der Klassifizierung - wie „Typ U 93 oder UB 103“. Desweiteren wurden die Hydrauliksysteme optimiert und gegen die Drahtsteuerungen ausgetauscht. Ferner wurden die Diesel- und Elektromotoren verbessert und die Batterieleistung erhöht. Vgl. Ebd., S. 83f.

1221 Erst mit der Genehmigung des Z-Planes erhielt die Marine mehr Zuschüsse als Heer und Luftwaffe. Vgl. Ottmer (1991): „Skandinavien“, S. 61. Bis 1937/38 flossen die meisten Rüstungsausgaben in die Luftstreitmächte. Vgl. Ebd., S. 59

1222 Vgl. Salewski, Michael (1998) In: Elvert, Jürgen/ Lippert, Stefan (Hg.): Die Deutschen und die See: Studien zur deutschen Marinegeschichte des 19. und 20. Jahrhunderts, Band 1, Stuttgart: Franz Steiner, S. 223 
in der Ostsee, begonnen. ${ }^{1224}$ Erst im Jahr 1939 forderte Dönitz 100 U-Boote, die ständig im Atlantik im Einsatz sein sollten. ${ }^{1225}$

Für Raeder war das Flottenabkommen, ebenso wie für Hitler, lediglich temporär und wurde nicht als bindende Vertragsvereinbarung betrachtet. Hitler erklärte gegenüber der Marineleitung, dass die Bestimmungen bezüglich des Schiffbaus nur für die folgenden 5 Jahre gelten sollten. Diese Zeit sollte genutzt werden, um Schiffe und Anlagen zu planen, um bei einem späteren Wettrüsten einen logistischen Vorteil gegenüber England zu haben. Das Abkommen war für Raeder Mittel zum Zweck und diente nur dazu, den Aufbau einer deutschen Flotte außenpolitisch abzusichern. ${ }^{1226}$ Um dem Täuschungsmanöver Glaubwürdigkeit zu verleihen, wurden die Kapazitäten des Flottenabkommens nicht ausgeschöpft und die Zahl der genehmigten UBoote blieb unter den Möglichkeiten. ${ }^{1227}$ Die Schlachtschiffe ,Bismarck' und ,Tirpitz' wurden hingegen größer ausgelegt ${ }^{1228}$ und überschritten die im Versailler Vertrag vereinbarte Tonnage. Der Bau einer schlagkräftigen U-Boot-Flotte wurde erst im Rahmen des Z-Planes in den Jahren 1938/39 in Angriff genommen, denn die Marineleitung war sich bewusst, dass sie nicht gegen die britischen Kriegsschiffe bestehen konnte und setzte daher auf eine starke U-Boot-Flotte. ${ }^{1229}$ Theoretisch hätten U-Boote zur emotionalen Mobilmachung der Bevölkerung eingesetzt werden können, denn die moderne Waffengattung hatte sich im Ersten Weltkrieg als schlagkräftig erwiesen und genoss im Unterschied zu den anderen Seestreitkräften im Bewusstsein der Öffentlichkeit hohes Ansehen. ${ }^{1230}$ Der U-Boot-Krieg war von der deutschen Bevölkerung begrüßt

\footnotetext{
1224 Vgl. Deist (1979): „Aufrüstung“, S. 451ff.

1225 Vgl. Ottmer (1991): „Skandinavien“, S. 63

1226 Vgl. Rahn (2005): „Strategische Optionen und Erfahrungen der deutschen Marineführung 1914 bis 1944. In: Ders. (Hg.): Marinen, S. 215

1227 Vgl. Salewski (1998): Die Deutschen, S. 223

1228 Vgl. Ebd.

1229 Erst nach der teilweisen Mobilmachung der Tschechoslowakei im Mai 1938 wurde der Aufbau der Marine vorangetrieben. Insbesondere der Bau der U-Boot-Flotte wurde beschleunigt für den Fall, dass Frankreich und Groß Britannien nicht neutral blieben. Vgl. Deist (1979): "Aufrüstung", S. 465f.

1230 Vgl. Showell (2008): U-Boot-Waffe, S. 82

In weiten Teilen der Marine wurde die U-Boot-Flotte als unbedeutend betrachtet, eine Einstellung, die nach den ersten Erfolgen von Kapitänleutnant Otto Weddingen revidiert wer-
} 
worden, da er etwas von der maritimen Ohnmacht nahm. ${ }^{1231}$ Die deutschen U-Boote hatten sich als respektabler Gegner erwiesen. Großbritannien hatte während des Krieges das Potential der neuen Waffengattung höher eingeschätzt als das der deutschen Landstreitkräfte, zumal befürchtet wurde, die U-Boote könnten mit ihrer BlockadeStrategie den konventionellen Krieg in einen Wirtschaftskrieg ${ }^{1232}$ verwandeln. In zeitgenössischen Pressemeldungen wurde die Gefahr, die von der deutschen U-BootFlotte ausging, zum Ausdruck gebracht. ${ }^{1233}$ In den Zigarettenalben wird der U-BootKrieg des Ersten Weltkrieges lapidar als gescheitert betrachtet und die Erfolge werden den Hilfskreuzern zugesprochen. Diese Darstellung entspricht den realen Gegebenheiten nur bedingt. Die Hilfskreuzer wurden eingesetzt, um Blockaden zu durchbrechen und feindliche Schiffe aufzubringen. Aufgrund der geringen Anzahl an Hilfskreuzern war der erhoffte Erfolg, Großbritannien von der Rohstoff- und Lebensmittelzufuhr abzuschneiden, jedoch bescheiden. ${ }^{1234}$

„Wenn wir uns unserer Seekriegsführung im Jahr 1916 zuwenden, so ist zunächst zu konstatieren, daß der U-Boot-Handelskrieg infolge der eingeschränkten Bedingungen so gut wie ganz im Sande verläuft. - [...] Im Gegensatz zum versandeten U-Boot-Krieg lebt 1916 der Hilfskreuzerkrieg erfolgreich auf." 1235

den musste. Weddingen versenkte am 22. September 1914 drei britische Panzerkreuzer und stellte damit die Schlagkraft der neuen Waffengattung unter Beweis. Hubatsch (1975): Marine, S. 214

1231 Vgl. Wolz (2013): Verrosten, S. 172

1232 „Die strategische Grundauffassung des Krieges ist durch die deutsche U-Boote radikal verändert. [...] Wir waren uns der Tatsache bewußt, zu Lande schwach, zur See aber stark zu sein. Das Ende des Jahres 1917 aber sieht uns machtvoll zu Lande, während uns alle Gefahr zur See droht. Das verdanken wir nicht etwa dem Umstande, daß die Flotte irgendwie bei der Lösung der ihr gestellten Aufgabe versagt hätte. [...] Der weitere gewaltigere Umstand ist die Entwicklung des Unterseebootes als Hauptwaffe des Gegners gegenüber den Verbandsmächten. Damit hat der Krieg aufgehört, in erster Linie ein Kampf der Waffen zu sein, und ist zu einem Hungerkriege geworden. Beide Parteien sind darauf bedacht, durch Hunger die Übergabe zu erzwingen." Gardiner, Alfred, Daily Mail, 15.12. 1917. In: Kriegspresseamt. Auslandsstelle, Deutsches Reich (1918): Die Entwicklung des U-Bootkrieges seit Herbst 1917 im Urteil des Auslandes. Zusammengestellt in der Auslandsstelle des Kriegspresseamtes. Abgeschlossen a, 1. Februar 1918, Berlin: Reimar Hobbing Verlagsbuchhandlung, S. 3

1233 "Schreitet jedoch die Tonnageverminderung im gleichen Tempo wie bisher fort, so ist zu befürchten, daß England beim Friedensschluß sehr schlecht dastehen wird." Stockholms Dagblad vom 6.11. 1917. In: Kriegspresseamt. U-Bootkrieg, S. 23

1234 Vgl. Hubatsch (1975): Marine, S. 263f.

1235 Brinkmann (1934): hoch in Ehren, S. 59 
Den deutschen U-Booten gelang es zwar ebenso wenig wie den Luftstreitkräften, eine entscheidende Wendung im Krieg herbeizuführen, sie waren aber aufgrund der versenkten Tonnage erfolgreicher. ${ }^{1236}$ Trotz guter Reputation und den militärischen Erfolgen wird die U-Boote-Flotte in den Zigarettenalben nur marginal erwähnt oder erfährt eine völlig andere Darstellung als die Flieger-Staffeln.

\subsubsection{Vergessene Helden}

Mit dem Verzicht, maritime Errungenschaften zu instrumentalisieren, geht auch ein Paradigmenwechsel in Bezug auf die Helden-Narrativen einher. Marine-Angehörige, die während des Ersten Weltkrieges im Volk als Helden gefeiert und sogar auf internationalem Parkett Furore gemacht hatten, nehmen in den Zigarettenalben weder eine exponierte Stellung ein, noch werden sie zu Helden stilisiert, die sich für ihr Vaterland geopfert haben. Namhafte Persönlichkeiten wie Großadmiral von Tirpitz oder Graf Spee werden nicht archetypisiert oder verklärt. Die Taten der Kriegshelden des Ersten Weltkrieges wie von Mücke, von Müller, Graf Luckner oder Admiral Scheer werden nicht heroisiert, sondern relativ nüchtern geschildert.

„Im Zenit der Seekriegsführung dieses Jahres steht jedoch die SkagerrakSchlacht. Mit der Übernahme der Führung der Flotte durch Vizeadmiral Scheer am 13. Januar 1916 kommt frischer Zug in die Seekriegsführung. Scheer will den Gegner - die englische Flotte - aus ihrer Zurückhaltung aufstöbern, sie zur Schlacht zwingen. [...] Die Schlacht ist ein ausgesprochener Erfolg der deutschen Flotte, die, obwohl an Kräften unterlegene, der englischen Flotte die größeren Verluste zufügt. " ${ }^{1237}$

„Kapitänleutnant a. D. Helmut von Mücke Erster Offizier der „Emden“, erreichte nach der Zerstörung seines Schiffes bei den Keelinginseln (9. November 1914) den Hafen von Port Refuge und rettete sich mit den Resten seiner Mannschaft auf den Schoner "Ayesha", der ihm zur Flucht in die Heimat verhalf.“1238

1236 Für Ludendorff war der uneingeschränkte U-Boot-Krieg die einzige verbliebene Möglichkeit, den Krieg erfolgreich zu beenden. Vgl. Ludendorff (1919): Kriegserinnerungen, S. 245

1237 Brinkmann (1934): Deutschland hoch in Ehren, S. 59

1238 Brinkmann (1932): Deutsche Marine, Serie 4, Bild 3, unpag. 
„Fregattenkapitän Karl von Müller Kommandant der „Emden“. Der ruhmreiche Führer erhielt nach seiner Rückkehr aus englischer Gefangenschaft am 19. März den Orden „Pour le mérite.““1239

Die Angaben zu den Personen haben lexikalischen Charakter und beschränken sich auf persönliche Daten, Rang, Kommando und errungene Siege oder Niederlagen. Diese Divergenz zu den Aviatik-Alben zeichnet sich auch bei der Ansprache an die Jugend $a b$, denn es wird darauf verzichtet, die Marine-Helden als Vorbilder zu installieren. Die Gefallenen der Marine werden in den Nautik-Alben nicht instrumentalisiert, um ein Opferbewusstsein zu installieren. Die Sammelwerke veranschaulichen lediglich die Attraktivität der Seefahrt und verzichten darauf, die Jugendlichen für kriegerische Auseinandersetzungen zu mobilisieren. Texte, in denen die Jugend für die Seefahrt begeistert werden soll, stellen in den Nautik-Alben eine Rarität dar wie in dem Brinkmann-Album LloYd-FlotTEnBILDER. DeutSCHE MARINE:

„Möge es weiterhin unserer Jugend im Sinne des Seegedankens belehren und begeistern und sie anfeuern zu den Eigenschaften des echten Seemannes, zu Mut und Entschlossenheit, zu Pflichttreue und Kameradschaftlichkeit. " ${ }^{1240}$

Die Marine-Angehörigen, die während des Ersten Weltkrieges ebenso wie die Flieger Heldenstatus genossen, werden nicht mit Opfer und Leid konnotiert. Sie erfahren auch nicht die Helden-Metamorphose die sie, herausgelöst aus dem historischen Kontext, zu unsterblichen Ikonen des deutschen Mythenrepertoires macht. Die einzige Würdigung der gefallenen Marine-Angehörigen findet mittels Adaption eines Gefallenendenkmals statt. In dem Album Deutsche MäNner, Deutsche TATEN! wird die Errichtung des Ehrenmals der deutschen Kriegsmarine, ${ }^{1241}$ das am Tage derSkagerrakschlacht im Jahr 1936 eingeweiht und den gefallenen Seeleuten des Weltkrieges gewidmet ist, geschildert. In dem Album wird das Denkmal von dem NS-Regime

\footnotetext{
1239 Ebd., Serie 6, Bild 3, unpag.

1240 Ebd., Vorwort, unpag.

1241 Kosmos (1937): Deutsche, Kapitel: Das Ehrenmal der deutschen Kriegsmarine, unpag.
} 
okkupiert, denn der Text verschweigt dabei, dass mit dem Bau bereits 1927 begonnen wurde und die Errichtung auf private Initiative zurückging und nicht auf die des NSMarine-Bundes. ${ }^{1242}$

\section{„Das Ehrenmal der Deutschen Kriegsmarine}

An der Kieler Außenförde bei Laboe steht dieser Monumentalbau, der unseren tapferen todesmutigen Gefallenen zur See gewidmet ist. Von einzigartiger Eindringlichkeit und Schlichtheit getragen, wurde dieses Ehrenmal nach den Entwürfen des Architekten Munzer-Düsseldorf von dem NS-Marine-Bund errichtet und am Ehrentage der Deutschen Kriegsflotte, dem Tage der Skagerrak-Schlacht, 1936 durch einen Staatsakt feierlich eingeweiht. [...] Weit und wuchtig ragt dieses einzigartige Ehrenmal hinaus über den Strand, die Seeleute grüßend und mahnend: „Nicht klagen, wieder wagen!““1243

Die Okkupation kann auf die Monumentalität des Bauwerkes zurückgerührt werden, denn das Ehrenmal ging mit der nationalsozialistischen Architektursprache konform. Das imposante Denkmal war das Beispiel einer Staatsarchitektur, die während der Weimarer Republik vernachlässigt wurde und erst von den Nationalsozialisten aufgegriffen wurde. Im Mittelpunkt des Textes stehen auch nicht die Helden der Marine, sondern das Bauwerk. Mit der Okkupation des Denkmals hatte das NS- Regime "Zugriff auf den öffentlichen Raum", 1244 einer Forderung, die Hitler im Album AdOLF HITLER stellt:

„Unsere heutigen Großstädte besitzen keine, das ganze Stadtbild beherrschenden Denkmäler, die irgendwie als Wahrzeichen der ganzen Zeit angesprochen werden können. ${ }^{\prime 1245}$

Die Reminiszenz an die Gefallenen Marine-Angehörigen ist zurückhaltend und wird nicht vom gleichen Pathos begleitet, das den toten Fliegern zuteilwurde. Im

\footnotetext{
1242 Deutscher Marinebund e.V. (Hg.) (2004): Das Marine-Ehrenmal in Laboe „Für die Ewigkeit, zeitlos, klar...”. Hamburg: Convent Verlag S. 17. „Im Auftrage des früheren Bundes Deutscher Marine-Vereine, jetzigen Nationalsozialistischen Deutschen Marine-Bundes ist es gebaut worden." Einführungstext Generaloberst Raeder, Oberbefehlshaber der Kriegsmarine. Nationalsozialistischer Deutscher Marine-Bund (1936) (Hg.): Das deutsche Marine-Ehrenmal. Berlin: Marine-Verlag Heinrich Beenken, S. 2

1243 Kosmos (1937): Deutsche, Kapitel: Ehrenmal der Deutschen Kriegsmarine, unpag.

1244 Bartetzko (1985): Illusion, S. 49

1245 Reemtsma (1936): Hitler, Kapitel: Die Bauten des Führers, von Albert Speer, S. 77
} 
Unterschied zu dem Richthofen-Grab, dem Tannenberg-Denkmal oder dem „Ehrentempel der toten Helden vom 9. November 1923“1246 wird das Denkmal der Marine nicht zu einem Ort pathetischer Heldenverehrung. Im Vergleich zur Gedenkstätte Richthofens wird das Marine-Denkmal auch keinem Bedeutungswandel unterworfen und zur Kultstätte stilisiert, die die Hoffnung auf Wiederauferstehung nährt. Die Zitation der Inschrift „Nicht klagen, wieder wagen“ hat nicht den aggressiven Tenor, mit dem in den Aviatik-Alben die Luftwaffe bedacht wird. Mit der nahezu zaghaften Aufforderung, einen Neuanfang zu wagen, wird der Marine das Potential abgesprochen, zum Symbol für den Wiederaufstieg Deutschlands zu werden. Insgesamt wird den Marineangehörigen in den Zigarettenalben wenig Raum geboten. Wie in Abschnitt 5.2.2 dargelegt, war die Marine insgesamt schlecht beleumundet und die Marine-Helden verfügten aufgrund dessen nicht über das Potential, um die Rolle stellvertretender Erlöserfiguren einzunehmen.

Anders verhält es sich mit der U-Boot-Flotte und ihren Kommandanten, denn diese hätten das Potential besessen, vom NS-Regime instrumentalisiert zu werden. Die U-Boot-Helden von einst, wie „Weddingen“1247 und "Arnauld“1248 fanden nach dem Ersten Weltkrieg zwar als Paten und Namensgeber für U-Boot-Flotten Eingang in die Erinnerungskultur der Marine, erhielten aber nicht annähernd den Nimbus von Heldenfiguren wie die Flieger Richthofen oder Boelcke. Die U-Boot-Kommandanten hatten dem Gegner nicht nur empfindliche Verluste beigebracht. U-Boote waren eine Entwicklung des 20. Jahrhunderts und eine stählerne Waffe. ${ }^{1249}$ U-Boot-Fahrer verkörperten damit im Prinzip das Ideal des vom NS-Regime propagierten neuen Menschen. Sie waren ebenso wie die Flieger ,metallische Krieger` mit Nerven aus Stahl. ${ }^{1250}$ Die

\footnotetext{
1246 Kosmos (1937): Deutsche, Kapitel: Der Ehrentempel der toten Helden vom 9. November 1923, unpag.

1247 Deist (1979): „Aufrüstung“, S. 459

1248 Bogedain, Clemens (2016): Lothar von Arnauld de la Perière. Erfolgreichster U-Bootkommandant der Seekriegsgeschichte - ein vergessener „Kriegsheld“? Stuttgart: Franz Steiner Verlag, S. 148

1249 U-Boote galten ebenso wie die Flugzeuge als Vertreter neuer Waffensysteme, die sich im Ersten Weltkrieg bewährt hatten. Beide Waffengattungen waren daher auch laut Versailler Vertrag verboten. Vgl. Kiekel (2007): Reichsmarine, S. 17 
U-Boot-Fahrer genossen darüber hinaus im Unterschied zu den Angehörigen der Schiffs-Flotte in der Bevölkerung großes Ansehen ${ }^{1251}$ und die Mannschaften wurden als Helden verehrt. ${ }^{1252}$ U-Boot-Kommandanten wie Otto Weddingen, Otto Hersing und Lothar von Arnauld besaßen regelrechten Kultstatus. Die U-Boote und ihre Kommandeure erfüllten damit alle Voraussetzungen, um in den Zigarettenalben eine exponierte Stellung einzunehmen. Dennoch verzichten die Nautik-Alben gänzlich darauf, die U-Boot-Kommandanten in den Kontext von Pflichterfüllung und Opferbereitschaft zu setzen. In Zigarettenalben werden sie weder zu Helden stilisiert, noch der Jugend als nachahmenswerte Vorbilder präsentiert, sondern in lexikalischer Form aufgelistet und mit nüchternen Worten bedacht.

„Otto Hersing, Korv. Kapt. Seit 1909 Oblt. z. S., gehörte er 1914 als U-BootKommandant der Unterseebootabteilung in Kiel an. Im Weltkrieg führte er zuerst U 21. Später wurde er als Lehrer zur U-Boot-Schule befehligt u. war dann bis zum Kriegsende Chef der Front-U-Boot-Flottille. Für seine Leistungen wurde ihm der „Pour le mérite“ verliehen. “ ${ }^{1253}$

„Otto Weddingen, Kapitänleutnant, U-Boot-Kommandant. Mit U 9 unternahm er im Weltkrieg seine kühnen Fahrten und versenkte am 22.9. 1914 drei englische Panzerkreuzer, kurz darauf einen anderen englischen Kreuzer, dazu zahlreiche Handelsdampfer. Im März wurde er ein Opfer seines Heldenmutes." ${ }^{\prime 254}$

Lothar von Arnauld de la Perière steht dabei exemplarisch für die vergessenen U-Boot-Helden. Der Fregattenkapitän war nicht nur der erfolgreichste U-Bootkommandant während des Ersten Weltkrieges, ${ }^{1255}$ sondern gemessen an der versenkten Tonnage der erfolgreichste der gesamten Seekriegsgeschichte. ${ }^{1256}$ Für seine Erfolge erhielt er neben dem Pour le Mérite alle Auszeichnungen, die das Kaiserreich zu vergeben hatte. ${ }^{1257}$ Neben Hersing, Weddingen, Boelke und von Richthofen zählte

\footnotetext{
1251 Viele Marineangehörige wechselten aus Langeweile und mangelndem Kriegseinsatz freiwillig zu den U-Booten oder zu den Marineluftschiffern. Vgl. Wolz (2013): Verrosten, S. 141

1252 Vgl. Ebd., S. 182

1253 Kyriazi (1933): Helden, Bild 220, S. 53

1254 Ebd., Bild 221, S. 53

1255 Vgl. Bogedain (2016): Arnauld, S. 146

1256 Vgl. Ebd., Rücktitel

${ }_{1257}$ Vgl. Ebd., S. 106
} 
Lothar von Arnauld zu den bekanntesten Kriegshelden des Kaiserreiches ${ }^{1258}$ und sein Konterfei wurde auf Titelseiten und diversen Propaganda-Postkarten verbreitet. ${ }^{1259}$ Er zählte darüber hinaus zu den wenigen deutschen Militärs, dem sowohl von Untergebenen als auch von den Gegnern aufgrund seines korrekten und ritterlichen Verhaltens höchste Wertschätzung entgegengebracht wurde. ${ }^{1260}$ Lothar von Arnauld besaß damit alle Voraussetzungen, um von der NS-Propaganda in die Genealogie der Helden aufgenommen und vereinnahmt zu werden. In dem Album DeuTsCHE HeLDEN erfahren seine Leistungen, ebenso wie die anderer U-Boot-Kommandanten, lediglich eine minimale Würdigung. ${ }^{1261}$

„Lothar von Arnauld de la Perière, Freg. Kapt. Vor dem Kriege war er als Oblt. z. S. Adjutant im Admiralstab der Marine. April 1915 zur U-Boot-Schule kommandiert, kam er im Okt. z. 3. U-Boot-Flottille. Im Nov. wurde er Kommand. von U 35, das während einer einzigen Fahrt bis Cartagena (Spanien) 54 Schiffe mit 260000 t. Versenkte. Im Okt. 1916 erhielt er den „Pour le mérite“. Zuletzt führte er den U-Kreuzer „U 139“.“1262

Obwohl Arnauld in der Weimarer Republik in den Medien nicht mehr präsent war, ${ }^{1263}$ besaß er das Potential, um wie die Flieger Bruno Loerzer oder Hermann Göring als lebender Pour-le-mérite-Held eine mediale Wiederauferstehung zu erfahren und als Vorbild für Heldentum und Pflichterfüllung installiert zu werden. Die Divergenz zu den Helden der Luftfahrt kann daher darauf zurückgeführt werden, dass ein Krieg zur See in der Zeit der Publikation der Alben zwischen 1933 und 1934 nicht auf der strategischen Agenda des NS-Regimes stand. Zu dieser Zeit hatte die Ostexpansion Priorität. Darüber hinaus wollte das NS-Regime aufgrund mangelnder

\footnotetext{
1258 Vgl. Ebd.

1259 Vgl. Ebd., S. 105 und 163f.

1260 Vgl. Ebd., S. $140 \mathrm{f}$.

1261 Clemens Bogedain verweist in seiner Arnauld-Biografie auf das gleiche Sammelbild hin und bemerkt, dass der erfolgreichste U-Boot-Kommandant „,an kaum einer Stelle erwähnt“ wird. Ebd., S. 147 und 173

1262 Kyriazi (1933): Helden, Bild 223, S. 53

1263 Clemens Bogedain begründet die mangelnde Medienpräsenz auch mit dem zurückhaltenden Charakter Arnaulds, der sich im Unterschied zu anderen Kriegshelden während der Weimarer Republik nicht vermarktet hat und dem Umstand, dass Arnauld lediglich Handelsschiffe und keine prestigeträchtigen Angriffe auf Kriegsschiffe geführt hat. Vgl. Ebd., S. 146ff.
} 
Einsatzbereitschaft der deutschen Seestreitkräfte einen Krieg zu Beginn der 1930er Jahre mit England vermeiden. Da ein Seekrieg für einen späteren Zeitpunkt geplant war, sollte geheime Wiederaufrüstung der Marine vor der Weltöffentlichkeit geheim halten werden.

\subsection{Automobilismus}

Der Automobilismus wurde gegen Ende des 1900 Jahrhunderts zum Inbegriff des modernen technischen Zeitalters und zum Symbol für Mobilität, mit der der Mensch seine Individualität und Freiheit zum Ausdruck bringen konnte. Obwohl in Deutschland entwickelt, ${ }^{1264}$ galt das Automobil zu Beginn des 20. Jahrhunderts als elitäres Vehikel der Oberschicht, das in der breiten Bevölkerung auf Ablehnung stieß. Schlechte, kaum ausgebaute Straßen ${ }^{1265}$ sowie häufige Karambolagen mit Todesfolge $^{1266}$ trugen zum negativen Image bei. Bis in die Weimarer Zeit befand sich die deutsche Automobilindustrie aufgrund der Gegnerschaft innerhalb der Bevölkerung, verfehlter Politik und Fehlentscheidungen innerhalb der Branche in einem technischen Rückstand. ${ }^{267}$ Automobilunternehmen wie Mercedes, Benz oder Porsche, die später zu Großkonzernen mit Weltgeltung aufsteigen sollten, befanden sich nach der Inflation und der Weltwirtschaftskrise in einer wirtschaftlich prekären Lage. ${ }^{1268}$

\footnotetext{
1264 Bastian, Till (2005): High Tech unterm Hakenkreuz. Leipzig: Militzke, S. 19

1265 Vgl. Haubner, Barbara (2001): „Automobilismus im Kaiserreich. Auftakt zur Massenmotorisierung oder Freizeitvergnügen für Wohlhabende“. In: Boch, Rudolf (Hg.): Geschichte und Zukunft der deutschen Automobilindustrie. Stuttgart: Franz Steiner, S. 29. In dem Album „Deutscher Kraftfahrsport" wird auf die Widrigkeiten der Straßen, der Brennstoffbeschaffung und der Gefahren, die von Wild- und Haustieren auf den Landstraßen ausgehen, verwiesen. Werbegemeinschaft Saarlauterner Zigarettenfabriken (1937): Deutscher Kraftfahrsport, Teil 1, Wagen- und Motorradrennen, o.O., S. 10

1266 Vgl. Haubner (2001): „Automobilismus“, S. 33

1267 Vgl. Ebd. S. 43ff.

1268 Vgl. Reuß, Eberhard (2006): Hitlers Rennschlachten. Berlin: Aufbau Verlag, S. $15 \mathrm{ff} .1923$ befanden sich 63 Automobilunternehmen auf dem deutschen Markt, im Jahr 1930 ging die Zahl auf 17 zurück. Das bedeutendste Unternehmen war der Mercedes-Konzern, der sich 1926 mit den Benz-Werken zusammenschloss. Vgl. Day (2005): Silberpfeil, S. 47
} 


\subsubsection{Ikonen der Moderne}

Die Automobil-Alben, die vor 1933 publiziert wurden, stehen ganz im Zeichen der Moderne. Das Auto wird als Manifestation einer neuen Epoche gepriesen, das wie keine andere technische Errungenschaft den Aufbruch in ein neues Zeitalter symbolisiert. Der Kraftwagen wird zur Apotheose der Moderne schlechthin und Ausdruck eines Lebensrhythmus, der von Beschleunigung und Dynamik geprägt ist.

\section{„Warum Autobilder?}

Das Auto ist, ebenso wie die Zigarette, ein Symbol unserer Zeit. Fast gleichzeitig haben beide ihren erstaunlichen Siegeszug über den Erdball angetreten. [...] heute bedeuten Auto und Zigarette untrennbare Attribute des modernen Menschen. "1269

Dem Bildersammler werden technische Errungenschaften, Fahrleistungen und Rennsportveranstaltungen in einem internationalen Kontext präsentiert. Frei von nationalistischem Pathos werden in- und ausländische Automobile und Rennerfolge einander gegenübergestellt, wobei chauvinistische Obertöne oder kriegerische Rhetorik gänzlich ausgeklammert werden.

"Heute wetteifern die alte und die neue Welt in der Herstellung immer besserer Wagen. [...] Die fast allseitig angewandten amerikanischen Produktionsmethoden haben sich in aller Welt durchgesetzt; in der Frage des Geschmacks und der schönen Linienführung ist Europa aber tonangebend geblieben. ${ }^{\prime 1270}$

„Caracciola [...] Was andere nicht riskieren, führt er mit atemberaubender Sicherheit durch. In den bedeutendsten nationalen und internationalen Rennen der letzten Jahre führte Caracciola seine Mercedes-Benz-Maschinen zum Triumph. ${ }^{\prime 271}$

Der Engländer [Anm.: Major Segraves] erzielte Anfang 1929 am Strand von Daytona Beach mit seinem Wagen "Golden Arrow“ eine Geschwindigkeit von 372 Kilometern in der Stunde. ${ }^{1272}$

\footnotetext{
1269 Waldorf-Astoria (1931): Vom Segelwagen zum Achtzylinder. München, Einleitungstext 1270 Ebd.

1271 Josetti (1929): Welt, Album 4, S. 15

1272 Ebd.
} 
Die in- und ausländischen Fabrikate und Automobilsportler werden dem Rezipienten auf kleinformatigen Bildern präsentiert. Die Alben haben durchgehend lexikalischen Charakter und die Informationen beschränken sich auf rudimentäre Informationen, ${ }^{1273}$ wobei der Fokus auf der sachlichen Darstellung der technischen Spezifika sowie der Leistungen der Automobilsportler liegt. Charakteristisch sind die detailreichen Informationen und Konstruktionszeichnungen. Die Alben stehen damit in der Tradition einer technischen Wissensvermittlung, die bereits im 19. Jahrhundert in der Populärliteratur eingeführt und in der Weimarer Republik Bestandteil der bürgerlichen Bildungslektüre war. ${ }^{1274}$ Das Automobil-Album der Firma Garbáty DAS AUTO VON HEUTE ${ }^{1275}$ steht ganz in der Tradition dieser populären Wissensvermittlung. Der Sammelband präsentiert neben dem Bildmaterial auch ein plastisches Anschauungsmodell in Form einer Klappkarte mit einer Schaugrafik, auf der die Konstruktion eines Automobils anhand von 80 Items illustriert wird. Dem Bildersammler werden damit erste Grundlagen zum technischen Verständnis der Automobiltechnik vermittelt. ${ }^{1276}$

Mit dem Beginn der nationalsozialistischen Machtergreifung erfahren die AutomobilAlben einen Paradigmenwechsel. Neben der Wissensvermittlung konzentrieren sich die Sammelbände auf den deutschen Rennsport, der in einen nationalsozialistischen Kontext gesetzt wird. Der Übergang von der reinen Wissensvermittlung zur politischen Propaganda kommt in dem Album DAS AUTO VON HEUTE exemplarisch zum Ausdruck. Das Unternehmen Garbáty, dessen Aviatik-Alben DIE EROBERUNG DER LUFT aus dem Jahr 1932 noch von einem kulturellen und völkerverbindenden Gedanken

1273 Exemplarisch die Alben: Abdulla (1931): Automobile des bekanntesten Marken des In- und Auslandes, Bd. 1 und 2. Berlin und Abdulla (1932): Im Auto mit Abdulla durch die Welt, Bd. 3. Berlin 1274 Vgl. Faulstich (2004): Medienwandel, S. 110ff.

Vgl. Day (2005): Silberpfeil, S. 103. Bereits im 18. Jahrhundert war die populäre Wissensvermittlung zu technischen Themen verbreitet. Die Funktionsweisen technischer Geräte wurden in aufwändigen Schaubüchern illustriert. Popplow, Marcus, Popularisierung von Technik um 1700. Mühl-Benninghaus (2004): Technik S.195

1275 Garbáty (1934): Das Auto von heute, Berlin

1276 Mit der Darstellung technischer Details befriedigten auch Werbeabteilungen der Automobilkonzerne das Bedürfnis ihrer potentiellen Kunden nach technischem Wissen. Vgl. Day (2005): Silberpfeil, S. 106 
geprägt waren, macht in seinem Automobil-Album von 1934 Konzessionen an die nationalsozialistische Propaganda. Mit den Pastellzeichnungen und der minimalistischen Gestaltung bleibt sich Garbáty in Aufmachung und Gestaltung stilistisch treu. Die kleinformatigen Zeichnungen illustrieren das Spektrum vom Klein- und Großwagen bis zum Rennwagen. Das begleitende Textmaterial beschränkt sich auf Kurzinformationen zu den Herstellern, Motoren, PS und/oder Zylinder, die für Alben der Periode vor 1933 charakteristisch sind. Das Kaleidoskop der Fahrzeuge besitzt jedoch nicht mehr die Internationalität der Aviatik-Alben, sondern zeigt primär deutsche Fabrikate. Die Annäherung an das NS-Regime manifestiert sich in den beiden Zeichnungen am Beginn und am Ende der Bildersammlung. Die Illustration des Einleitungstextes zeigt eine Limousine vor der Kulisse des Brandenburger Tores. Die nächtliche Stimmung, die vom Licht einer Laterne erhellt ist, wird durch dunkle und kontrastreiche Farbgestaltung akzentuiert und verleiht dem Motiv eine bedrückende und bedrohliche Atmosphäre. Besonders prägnant ist das Rot der Hakenkreuz-Wimpel, die an den vorderen Kotflügeln des Wagens angebracht sind und sich deutlich von den gedeckten Farbtönen abheben, die die Illustration dominieren. Durch die visuelle Konnexion des Wagens mit dem Hakenkreuz wird die deutsche Automobiltechnik mit dem Nationalsozialismus codiert. Der Text preist die ästhetische Formgebung des Automobils und weist auf deutsche Solidität und Fortschrittlichkeit hin und transferiert damit das nationalsozialistische Arbeitsethos.

„Dieses „Auto von Heute“ in seiner technischen Vielfältigkeit und Schönheit zu zeigen, von deutschem Geist und deutscher Tatkraft zu künden und ein schöner Akkord zu sein im Hohelied der deutschen Arbeit, ist die Aufgabe dieser Bilder-Serie. ${ }^{\prime 1277}$

Die Symbiose aus Perfektion, Schönheit und Tatkraft verleiht der Technik eine ästhetische Erhöhung, womit Garbáty die politische Semantik des Nationalsozialismus bedient, mit der das Regime seine Macht und Dynamik zum Ausdruck brachte. 
Das Auto der Marke Daimler-Benz, das im Volksmund bereits als „Führerwagen“1278 bekannt war, stellt eine Assoziation mit Hitler her. ${ }^{1279}$ In Verbindung mit dem Brandenburger Tor wird eine Verbindung zur Staatsmacht erzeugt. Die visuelle Codierung wird in der abschließenden Illustration auf ein symbolisches Minimum reduziert, bei der der NS-Staat, Deutschland und das Automobil zu einer Symbiose verschmelzen. ${ }^{1280}$ In einem kleinen Bildausschnitt sieht der Betrachter lediglich das angedeutete Heck eines Automobils mit Deutschland-Kennzeichen, Berliner Nummernschild und Hakenkreuzfähnchen. Die Reduktion impliziert, dass der Rezipient bereits über das erforderliche Wissen verfügte, um die einzelnen Zeichen im nationalsozialistischen Kontext dekodieren zu können.

\subsubsection{Deutsche Automobile - Meisterwerke der Präzision}

Nach der nationalsozialistischen Machtergreifung wurde die Automobilwirtschaft zum Nukleus der Wirtschaftspolitik. Bereits im Februar 1933 erklärte Hitler die Automobilindustrie auf der Internationalen Automobil- und Motorradausstellung zur „Schlüsselindustrie“, ${ }^{1281}$ mit der die Volkswirtschaft angekurbelt werden sollte. ${ }^{1282}$ In der pathetischen Eröffnungsrede lobte er die „Meisterwerke von Präzision und auch ästhetischer Schönheit“"1283 und kündigte wirtschaftspolitische- und infrastrukturelle Maßnahmen zur Förderung der Automobilindustrie an. Mit der staatlichen Subventionierung konnte die Automobilindustrie einen signifikanten wirtschaftlichen Aufschwung verzeichnen. Diese Erfolge dürfen aber nicht darüber hinwegtäuschen, dass

\footnotetext{
1278 Day (2005): Silberpfeil, S. 111

1279 Die PR-Abteilungen von Daimler-Benz und auch Auto-Union versuchten, ihre Automobile mit kulturellen Codes zu besetzen. Ziel war eine „optimale mediale Verwertung.“ Ebd., S. 55

1280 Vgl. Ebd., S. 108

1281 König, Wolfgang (2004): Volkswagen, Volksempfänger, Volksgemeinschaft. $>$ Volksprodukte< im Dritten Reich. Vom Scheitern einer nationalsozialistischen Konsumgesellschaft. Paderborn: Ferdinand Schöningh, S. 152. Heidrun Edelmann vertritt die These, dass Hitler erst auf der Automobilausstellung 1933 zufällig die Automobilindustrie zum Wirtschaftsmotor erklärt hat. Zit. nach: Day (2005): Silberpfeil, S. 42

1282 Neben den staatlichen Subventionen erhielt die Industrie steuerliche Erleichterungen. Auch Straßenbau und Förderung sportlicher Veranstaltungen trugen zum Aufbau der Automobilindustrie bei. Vgl. Veröffentlicht im VB, Nr. 44, 13.2.1933. Zit nach: Domarus, Max (1965): Hitler. Reden und Proklamationen 1932 - 1945, Bd.1, erster Halbband. München: Süddeutscher Verlag, S. 208

Hitlerrede vor Automobilfabrikanten. VB, Nr. 44, 13.2.1933. Zit. nach: Ebd., S. 209
} 
die wirtschaftliche Expansion nur durch staatliche Eingriffe in den Markt, der Umlenkung des Binnenkonsums und von der Reduktion der Produktangebote getragen wurde. ${ }^{1284}$ Entgegen aller wirtschaftspolitischen Realität wird in den Zigarettenalben der Mythos von der wirtschaftlichen Expansion der Automobilbranche im Zeichen des Hakenkreuzes genährt.

\begin{abstract}
„Die laufend gestiegenen Umsätze der Kraftwagenindustrie geben der wachsenden Kaufkraft und dem Erfolg der Maßnahmen zur Förderung der Motorisierung beredten Ausdruck. Die Zulassungszahl der Kraftwagen ist 1936 auf 258800 gestiegen; dazu kommen 175900 Motorräder [...] Im Jahr 1932 betrug die Zahl der erzeugten Kraftwagen nur 48100 [...] $]^{{ }_{1285}}$
\end{abstract}

„Die Aufhebung der steuerlichen Sonderbelastung gab jedenfalls nicht nur dem Automobilverkehr, sondern auch dem Automobilbau einen ganz gewaltigen Auftrieb. Es gibt nur wenige Industrien, in denen die Belegschaft in einem gleich hohen Maße vermehrt werden konnte $[\ldots]^{\text {“1286 }}$

Ebenso wie bei der Flugtechnik wird die Förderung der deutschen Automobiltechnik in den Zigarettenalben ganz dem Nationalsozialismus zugeschrieben. Die Leistungen, die in der Weimarer Zeit erbracht wurden, werden in den Alben unterminiert. Gleichzeitig wird der Republik unterstellt, sich den Ambitionen der deutschen Automobilindustrie entgegengestellt zu haben.

\begin{abstract}
„Deutschland wandte sich in jener Zeit [Anm. 1920er Jahre] ganz vom Automobilrennen $a b$, weil seitens der Regierung keinerlei Verständnis für die Bemühungen der deutschen Automobilindustrie, ihre Weltgeltung wiederzugewinnen, zu erhoffen war." ${ }^{1287}$
\end{abstract}

Mit der Förderung der Automobilindustrie verfolgte das NS-Regime nicht nur wirtschafts- und arbeitspolitische Aspekte. Ein relevanter Faktor war die internationale Reputation, denn ebenso wie die Errungenschaften im Bereich der Luftfahrt wurde

\footnotetext{
1284 Der Konsum wurde von der Lebensmittelindustrie auf das Automobil verlagert. Damit sich jeder Volksgenosse ein Automobil leisten konnte, wurde die Tugend der Bescheidenheit propagiert. Die idealtypische nationalsozialistische Familie leistete sich keinen bourgeoisen Luxus, sondern übte Verzicht, um an der modernen technischen Errungenschaft partizipieren zu können. Vgl. König (2004): Volkswagen, S. 187. Vgl. Scherner, Jonas (2008): Die Logik der Industriepolitik im Dritten Reich. Stuttgart : Franz Steiner, S. 11

1285 Monopol (1937): Deutschland, Kapitel: Die deutsche Automobil-Industrie, unpag.

1286 Greiling (1934): Adel, Kapitel: Der Kampf gegen die Arbeitslosigkeit, unpag.

1287 Werbegemeinschaft (1937): Kraftfahrsport, S. 15
} 
die Kraftfahrzeugtechnik zum Ausdruck einer Kulturleistung, ${ }^{1288}$ mit der der deutschen Nation Weltgeltung verschafft werden sollte. Für Hitler galt die Länge des Straßennetzes als Gradmesser für die „Lebenshöhe“1289 von Völkern. Wilfrid Bade, federführender Autor des Albums DEUTSCHLAND ERWACHT, stilisiert den Kraftwagen in seinem Buch ,Das Auto erobert die Welt' zur Apotheose der Moderne und zum Symbol des Fortschritts, das maßgeblich von der deutschen Nation installiert wird. Für Bade war das Auto Teil der „nationalsozialistischer Wertphilosophie“, mit der insbesondere dem deutschen Menschen Unabhängigkeit und Würde verliehen wird. ${ }^{1290}$ Publikumswirksamer als nüchterne Zahlen in der Statistik der expandierenden Automobilindustrie waren Großveranstaltungen, denn sie boten dem NS-Regime die Möglichkeit, die Leistungen der deutschen Automobiltechnik auf internationalem Parkett zu präsentieren. Mit Rekordfahrten und Siegen auf internationalen Rennstrecken konnte die Automobilindustrie die technische Brillanz deutscher Ingenieurskunst unter Beweis stellen. In den Zigarettenalben, die nach 1933 publiziert wurden, wird daher dem Automobilsport im Vergleich zu den Personenkraftwagen ein weitaus größeres Podium geboten. Neben den deutschen Automobilen werden die deutschen Rennfahrer in das Rampenlicht gestellt und ihre Siege werden zu Siegen der gesamten Nation. ${ }^{1291}$ Die emotionale Adaption eines individuellen Sieges durch das Kollektiv ist dabei ein internationales Phänomen, auf das bereits in dem Album BERGMANNS BUNTE BÜCHER aus dem Jahr 1932 hingewiesen wird.

„Aber die großen Sportler aller Nationen haben das Glück, mit ihrem Lande identifiziert zu werden und Sieg und Niederlage bedeuten Sieg oder Niederlage des Landes. “ ${ }^{1292}$

\footnotetext{
1288 Für Hitler war die Straßenkilometer Gradmesser für die kulturelle Niveau eines Volkes. Vgl. Werlin, „Acht Jahre“, S. 316. Zit. nach: König (2004): Volkswagen, S. 152

1289 Domarus (1965): Hitler, S. 209

1290 Vgl. Bade, Wilfrid (1938): Das Auto erobert die Welt. Eine Biografie des Kraftwagens. Berlin: Zeitgeschichte-Verlag, S. 313

1291 Sporterfolge sind Ausdruck von Nationalismus und tragen zu einer positiven Identifikation mit der Nation bei. Vgl. Weiss, Hilde/ Reinprecht, Christoph (1998): Demokratischer Patriotismus oder ethnischer Nationalismus in Ost-Mitteleuropa? Wien/ Köln: Böhlau, S. 62 
Die deutschen Siege erfuhren im NS-Staat jedoch eine extrem chauvinistische Prägung. ${ }^{1293}$ Mit den Erfolgen des deutschen Kraftfahrsports konnten die psychischen Defizite, die an der Seele der Nation nagten, kompensiert werden, denn insbesondere vor dem Hintergrund des verlorenen Krieges wurde das Auto für die Deutschen ein „Symbol für nationale Identität“ ${ }^{1294}$ In den Zigarettenalben wird die Rennstrecke zur Arena, in der Deutschland seinen Anspruch auf Weltgeltung reklamiert.

„Der Anfang ist gemacht. Noch fahren viele unserer besten auf ausländischen Maschinen, bald werden sie alle deutsche Wagen steuern, und bald wird sich das Blättchen wenden, daß die Matadoren fremder Nationen hinter deutschen Motoren sitzen müssen, wenn sie siegen wollen. Dann erst stehen wir dort, wo der deutsche Motorsport sein Ziel sieht und wo wir ganz einfach hingehören. Nach unserer Kraft und nach unseren Leistungen. ${ }^{1295}$

„Wird es Stuck, werden es die Deutschen schaffen? Noch ist die Konkurrenz des Auslandes, das seinen Vorsprung im Bau von Rennmaschinen herausgeholt hat und nicht preisgeben will, zu groß. Aber Deutschland rückt nach. Ist im Laufe der Monate dieses verheißungsvollen Jahres 1934 schon aufgerückt. "Wir w e r d e n es schaffen", sagt sich der Laie, vom Gefühl der neuen Kraft eines neuen Deutschland durchflutet. „Wir m ü s s e n es schaffen“, sagt der Fachmann. “1296

Dieser sozialpsychologische, vom Nationalismus getragene Aspekt, bringt zum Ausdruck, was für die angeschlagene Kollektivseele nach der Kriegsniederlage und der Schmach des Versailler Vertrages von besonderer Relevanz war: Die Wiederherstellung der Ehre der Nation und dem damit verbundenen Anspruch auf Anerkennung als Kulturnation. ${ }^{1297}$

„Gerade Rennen und hier vor allem die Motorradrennen haben aber noch eine andere Aufgabe, die nicht technischer Art ist. [...] und weil andere Völker der Welt, deren kulturelles Niveau sicher nicht höher ist als dasjenige des deutschen Volkes, ihm in der Motorisierung noch weit voraus sind.

\footnotetext{
1293 „Ein Fahrer, der einen Weltrekord schafft [...] dient, wie sein Fahrzeug, als einer Spitzenleistung technischen und industriellen Könnens, der Weltgeltung seiner Nation." Otte, Reinhold, Kraftwagensport. In: ONS: 1935, S. 108. Zit. nach: Day (2005): Silberpfeil, S. 67

1294 Tauchner: 1996, S. 211. Zit. nach: Ebd., S. 36

1295 Muratti (1934): Brennpunkte, Bd. 1, S. 39

1296 Ebd.

1297 Vgl. Reichel (2006): Schein, S. 126
} 
Das deutsche Volk hatte unter den Folgen des großen Krieges mehr zu leiden als alle anderen Völker der Welt." ${ }^{1298}$

„Seit den Tagen im Mai 1934 wissen wir es: Wir sind wieder dabei. Deutsche Wagen, von deutschem Geist gezeugt, von deutscher Kraft gesteuert, haben sich durchgesetzt und ein altes Erbe wiedergewonnen, das in den Jahren der Stagnation beinahe leichtfertig vertan ward. “1299

Damit der Rennsport in das Zentrum der Motorisierungspropaganda gesetzt werden konnte, musste das NS-Regime einige Herausforderung bewältigen. Nach dem die deutsche Automobilindustrie in den Weimarer Jahren an Finanzkraft verloren hatte, konnten die technischen Innovationen nicht weiterentwickelt werden. Um auf internationalen Rennstrecken prestigeträchtige Siege einfahren zu können, mussten Forschung und Produktion von staatlicher Seite her subventioniert werden. Ohne finanzielle Unterstützung wären die führenden Automobilunternehmen weder ambitioniert noch wirtschaftlich in der Lage gewesen, sich gegen die internationale Konkurrenz zu behaupten. ${ }^{1300}$ So sicherte Hitler der Automobilindustrie bereits im Jahr 1933 staatliche Subventionen zur Entwicklung von Rennwagen zu. ${ }^{1301}$ Neben den Fragen der Finanzierung stand das Regime weiteren Hürden gegenüber, denn der Motorsport hatte den Nimbus des Elitären, der laut Volksmeinung nur von wenigen Lebemännern und Hasardeuren betrieben wurde. Darüber hinaus standen die Wettrennen in den 1920er Jahren aufgrund vieler Unfälle mit Todesfolge stark in der Kritik. ${ }^{1302}$ Die Propaganda-Abteilungen waren daher gefordert, das angeschlagene Image der Autorennen aus dem Kontext sinnloser Rennschlachten zu manövrieren. ${ }^{1303}$ Das Image „eines sinnlosen Jagens um den Sieg“1304 musste in den Rahmen internationaler Geltung und Forschungsarbeit gesetzt werden.

\footnotetext{
1298 Werbegemeinschaft (1937): Kraftfahrsport, S. 55f.

1299 Muratti (1934): Brennpunkte, Bd. 1, S. 39

1300 Vgl. Reuß (2006): Rennschlachten, S. $69 f$.

1301 Vgl. Ebd., S. 57

1302 Vgl. Ebd., S. 19ff.

1303 Vgl. Day (2005): Silberpfeil, S. 67

1304 Obscherningkat, 1933, S. 57. Zit. nach: Ebd.
} 
Die Zigarettenalben übernehmen den offiziellen Propaganda-Tenor und setzen die Rennsportveranstaltungen in den Kontext der Forschung und Erprobung neuer Techniken. Die Rennen werden zu Testfahrten deklariert, bei denen wichtige Erkenntnisse zur Optimierung der Personenkraftwagen gewonnen werden. Rennen und Überlandwettfahrten werden in den Alben zur „zwingenden Notwendigkeit“ da sie „Zuverlässigkeit und die Geschwindigkeit“ maximieren, um Deutschlands Automobilindustrie zur Weltgeltung zu verhelfen. ${ }^{1305}$

„Rennen steigerten die Zuverlässigkeit und die Geschwindigkeit. Es steht einwandfrei fest, dass das Kraftfahrzeug einzig und allein den Rennen seinen meteorhaften Aufstieg zum Weltwirtschaftsfaktor verdankt. Mit zwingender Notwendigkeit stellte sich bei den schweren Überlandfahrten jeder einzelne schwache Punkt heraus. Deutscher Erfindergeist schuf dann auch die zuverlässige Hochspannungszündung, die vor allem den Aufstieg des Fahrzeugmotors beschleunigte [...] Ist das Kraftfahrzeug nicht zum Wirtschaftsfaktor geworden, mit dem die größten Staaten der Erde rechnen müssen, und zwar nicht nur durch die Größe der zu seiner Erzeugung notwendigen Werksunternehmen und Arbeitsbeschäftigungszahlen, sondern vor allem durch seine Fahrleistung $[\ldots]^{\prime \prime 1306}$

„Die Rennen verloren nämlich nun ihren Sinn als technische Prüfungen[...] Deutschland wandte sich in jener Zeit ganz vom Automobilrennsport ab, weil seitens der Regierung keinerlei Verständnis für die Bemühungen der deutschen Automobilindustrie, ihre Weltgeltung wiederzugewinnen, zu erhoffen war. ${ }^{\prime 1307}$

Die Erfolge der deutschen Rennwagen sollten beweisen, dass nur auf den Rennpisten technisch relevante Erkenntnisse zur Weiterentwicklung der Motorenleistung gewonnen werden können. Entsprechend werden die deutschen Ingenieursleistungen, die in den 1930er Jahren unbestritten auf Weltniveau lagen, ${ }^{1308}$ von den Autoren der Sammelalben euphorisch in die Superlative katapultiert. Die deutschen Rennwagen

\footnotetext{
1305 Werbegemeinschaft (1937): Kraftfahrsport, S. 15

1306 Ebd., S. 10f.

1307 Ebd., S. 15

1308 Maier, Helmut (Hg.) (2002): „Einleitung“. In: Rüstungsforschung im Nationalsozialismus: Organisation, Mobilisierung und Entgrenzung der Technikwissenschaften. Göttingen: Wallstein, S. 17
} 
werden als „unerreicht geistvolle Konstruktion“1309 gepriesen, die Geschwindigkeiten erreichen, die an das Utopische grenzen.

„Die deutschen Rennwagen drückten die Weltrekorde über einen Kilometer und eine englische Meile mit stehendem Start in schwindelnde Höhe. Sie schossen vom Start weg, wie man sich das früher in technischen Romanen von Raketenfahrzeugen erträumte. “1310

„Die Fahrleistungen der deutschen Rennwagen stellten denn auch sämtliche bis dahin gemachten Erfahrungen mit Rennwagen auf den Kopf. Sie siegten nicht nur in allen wichtigen Straßen- und Bahnrennen. Sie holten schon im ersten Jahr ihres Auftretens, Herbst 1934, sämtliche mögliche Klassen- und Weltrekorde [...] Die Welt horchte auf! “1311

„Die Siege der deutschen Rennwagen, ferner zahlreiche auch von Adler und BMW erkämpfte Weltrekordleistungen brachten einen Gesamtsieg der deutschen Wissenschaft, der deutschen Technik, des deutschen Kraftfahrsports und damit der Gemeinschaftsleistung Deutschlands, dessen Siegeswille sich auch auf diesem Gebiet gegen jeden Gegner durchsetzte. ${ }^{1312}$

Deutsche Reifen, deutsche Kerzen, deutsche Kolben, deutsches Leichtmetall und noch Dutzende von Einzelteilen haben zu den Erfolgen beigetragen, die unsere Rennfahrer Caracciola, Rosemeyer, Stuck, von Brauchitsch und andere, betreut von der Obersten Nationalen Sportbehörde, errangen. ${ }^{1313}$

Die futuristisch anmutenden Rennwagen und Motorräder werden dem Rezipienten in dem Album DEUTSCHER KRAFTFAHRSPORT plastisch vor Augen geführt. Zur Akzentuierung der Innovationen werden den neuen Modellen die Konstruktionen der vergangenen Dekade gegenübergestellt, womit dem Bildersammler ein technischer Quantensprung deutscher Technik suggeriert wird.

„Nur ein Dutzend Jahre trennen uns von diesen Rennwagen, einem 2-LiterBugatti mit Achtzylindermotor und einem 2-Liter-Mercedes, mit achtzylindrigem Kompressor. Höchstgeschwindigkeit etwa 180 Kilometer. ${ }^{\prime 1314}$

\footnotetext{
1309 Werbegemeinschaft (1937): Kraftfahrsport, S. 22

1310 Ebd.

1311 Ebd.

1312 Ebd., S. 25

1313 Ebd.

1314 Ebd., S. 10
} 
Die stromlinienförmigen ${ }^{1315}$ Automobile, die alle Geschwindigkeitsrekorde brachen, erwecken den Eindruck einer manifest gewordenen Utopie, die nicht nur die kulturelle Leistung des deutschen Volkes repräsentiert, sondern auch die Überlegenheit des NS-Regimes symbolisiert.1316 Das charakteristische futuristisch anmutende stromlinienförmige Industriedesign der Rennwagen beruhte nicht nur auf physikalischen Erkenntnissen im Bereich der Strömungstechnik, sondern hatte einen gesellschaftspolitischen Hintergrund. Die neue Gestaltung war Ausdruck einer vom Technikoptimismus geprägten Epoche, in der sich Technik, Dynamik und Geschwindigkeit in einer neuen ästhetischen Form verbanden. In der Stromlinienform verschmolzen Ästhetik und Technik zu einer Symbiose, ${ }^{1317}$ die als utopische Vision in das kulturelle Bewusstsein einging. Die ideologische und künstlerische Provenienz der neuen Formgebung lag im italienischen Futurismus, der „die Faszination der Maschinenwelt nicht nur zum ästhetischen, sondern auch zum ideologischen bzw. politischen Programm" gemacht hatte.

Der Futurismus war von Anbeginn ",auch eine politische Bewegung“ und in seiner Spätzeit „durch aggressiven Extremismus“1318 gekennzeichnet. Futurismus und Faschismus verband eine gegenseitige Affinität, denn beide huldigten der Technik als Mittel zur Macht. Der Rennwagen wurde damit zur Inkarnation eines Maschinenmythos, in dem sich gesellschaftliche, politische und technische Dynamik vereinten.

1315 Die Stromlinie war eine vom Bauhaus verbreitete klare Gestaltungslehre und galt als perfekte, strömungsgünstige Gestaltung für einen Körper. $\mathrm{Zu}$ den ersten stromlinienförmig gebauten Autos zählten der Jaray und die "Tropfenwagen“ vom Rumpler. Vgl. Kieselbach, Ralf J. F. (1982): Stromlinienautos in Deutschland - Aerodynamik im PKW-Bau 1900-1945. Stuttgart: Kohlhammer, S. 190.

1316 Vgl. Day (2005): Silberpfeil S. 87

1317 Vgl. Giedion, Sigfried (1982): Die Herrschaft der Mechanisierung. Frankfurt/M.: Europäische Verlagsgesellschaft, S. 655

1318 Zenone, Daniela (2002): Das Automobil im italienischen Futurismus und Faschismus: seine ästhetische und politische Bedeutung. [WZB, Wissenschaftszentrum Berlin für Sozialforschung, Forschungsschwerpunkt Technik, Arbeit, Umwelt], Berlin: WZB, Forschungsschwerpunkt Technik, Arbeit, Umwelt, Abschnitt 11 
So erklärte Marinetti in seinem futuristischen Manifest „daß sich die Herrlichkeit der Welt um eine neue Schönheit bereichert hat: die Schönheit der Geschwindigkeit. "1319

In dem Album DeUTSCHER KRAFTFAHRSPORT werden Fahrer und Rennwagen, ebenso wie die Fliegerhelden mit ihren Flugzeugen, zu einer Einheit von Mensch und Maschine verdichtet und futuristisch in Szene gesetzt. Populäre Medien wie die Zigarettenalben machten die stromlinienförmigen Rennwagen zur Ikone und trugen zu ihrer Mythisierung bei. Die Symbiose von Technik und Ästhetik kommt insbesondere in dem Silberpfeil von Mercedes-Benz zum Ausdruck, der in dem Sammelband DEUTSCHER KRAFTFAHRSPORT als Inkarnation der Moderne in Bild ${ }^{1320}$ und Text als real gewordene Utopie verherrlicht wird. Als „populäre Ikone“1321 wurde er zum Mythos, der in das deutsche Kollektivbewusstsein einging und bis in die Gegenwart überlebt hat.

„Mit Hilfe einer ausgezeichnet durchkonstruierten, stromlinienförmigen Karosserie [war es möglich], eine unerhörte Geschwindigkeitssteigerung zu erzielen. [...] Die Welt horchte auf, als die Fahrgeschwindigkeiten und die erzielten Welt- und Klassenrekorde dieses Mercedes-Benz-Rennwagens auf der Reichsautobahn bekannt wurde. “1322

„Das sind die Rennwagen von heute, vollkommen stromlinienförmig verkleidet. Hier der Mercedes-Benz-Rennwagen, Sieger des Avusrennens 1937, mit einer Höchstgeschwindigkeit von 380 km. . ${ }^{1323}$

„Auto-Union-Rennwagen mit Stromlinienkarosserie für das Avusrennen; Höchstgeschwindigkeit von 380 km. ${ }^{\prime 1324}$

„Die einspurige Stromlinienlimousine, welche die $500 \mathrm{ccm}$ BMWKompressormaschine samt Fahrer Ernst Henne umschließt, vor dem Start vor einer Versuchsfahrt. “ ${ }^{1325}$

1319 Marinetti, Filippo Tommaso: Futuristisches Manifest von 1909. Zit. nach: Calvesi, Maurizio (1987): Der Futurismus. Kunst und Leben. Köln: Taschen, S. 7

1320 Vgl. Ebd., Bildlegenden auf den Seiten 11, 22 und 54 - 57

1321 Die Kraft griffiger visueller Bezeichnungen wurde ab 1933 forciert um die „ästhetische Formen in einer äußerst packenden, bildhaften Sprache zu erfassen.“ Day (2005): Silberpfeil, S. 21

1322 Werbegemeinschaft (1937): Kraftfahrsport, S. 5, Bildlegende, S. 61

1323 Ebd., S. 11, Bildlegende

1324 Ebd.

1325 Ebd., S. 5, Bildlegende 
Die Arbeit der Fahrer und Konstrukteure wird, ebenso wie in den Aviatik-Alben, mit dem soldatischen Wertekanon gleichgesetzt. Die Siege auf der Rennstrecke werden auf den außerordentlichen Gemeinschaftssinn der deutschen Mannschaften zurückgeführt, die, unabhängig von ihrem Status, zum Erfolg beigetragen haben. Die Rennfahrer werden den Werktätigen gleichgestellt und zu Helden der Arbeit stilisiert und $\mathrm{zu}$ „Ikonen des nationalen Arbeitswillens“. ${ }^{1326}$ Das vom NS-Regime geprägte Arbeitsethos des deutschen Arbeiters, das von „Sorgfalt“ und „Fleiß“1327 geprägt war, spiegelt sich in den Zigarettenalben wider. Neben den Arbeitern der 'Stirn' wird dem deutschen ,Arbeiter der Faust ${ }^{\prime 1328}$ gehuldigt, der im Hintergrund pflichtbewusst seine Arbeit verrichtet und damit ein Opfer für die Volksgemeinschaft erbringt. So wird nicht nur den Rennfahrern und Ingenieuren, die im Rampenlicht stehen gehuldigt, sondern auch den Mechanikern und Monteuren. Die Mechaniker, die im Schatten des Rennzirkus zum Erfolg beitragen, werden zur „Elite deutscher Arbeiter“1329 verklärt, die mit deutscher Wertarbeit Meisterwerke der Technik hervorbringen.

„Schnelligkeit und Sicherheit! - Dafür garantieren deutsche Erfinder, Techniker, Ingenieure und - der deutsche Qualitätsarbeiter! -“1330

„Deutsche Neukonstruktionen im Automobilbau setzten unsere kühnen Rennfahrer in den Stand, neue Höchstleistungen auf Bahnen und Landstraßen aufzustellen und die Qualität deutscher Wertarbeit zum Vergleich zu stellen. ${ }^{\prime 1331}$

Die Gleichstellung von Akademikern und Arbeitern, die ihre Potentiale in den Dienst der Volksgemeinschaft stellen um Wunderwerke deutscher Technik zu erzeugen, wird in dem Album Adolf HitLer besonders deutlich in Szene gesetzt. In dem Kapitel ,Der Führer und der deutsche Arbeiter` von Robert Ley wird die Wertschätzung Hitlers gegenüber dem deutschen Arbeiter gewürdigt. In dem Sammelband steht Hitler

\footnotetext{
1326 Ebd., S. 90ff.

1327 Greiling (1934): Adel, Einleitungstext, unpag.

1328 Auf die Gleichstellung von Akademikern und Arbeitern wird in den Alben vielfach hingewiesen: „Im Arbeitsdienst gibt es keinen Unterschied zwischen den Arbeiten der Stirn und der Faust." Greiling (1934): Adel, S. 80. Vgl. Reemtsma (1936): Hitler, S. 60.

1329 Automobilrevue, Frankfurt, Nr. 9, September 1937, 24. Zit. nach: Day (2005): Silberpfeil, S. 94

1330 Zigaretten-Industrie (1934): Kampf, S. 55

1331 Muratti (1934): Brennpunkte, Bd. 1, Kapitel: Höhepunkte des Deutschen Sportes
} 
vor einer Gruppe von Landarbeitern. Bild und Bildlegende - „[S]so bewegt sich ein Staatsmann unter Arbeitern“1332 - vermitteln das Image eines Führers, der ungeachtet seiner Stellung den Arbeitern und Bauern auf Augenhöhe begegnet. Das Bild suggeriert, dass der Führer nicht zwischen der Leistung der Ingenieure, Arbeiter und Bauern differenziert. ${ }^{1333}$ Mit der Verbindung von Bild und Text wird dem Rezipienten eine Interpretation im Sinne der nationalsozialistischen Ideologie vermittelt. Arbeiter und Landarbeiter werden den Akademikern gleichgestellt und $\mathrm{zu}$ geadelten Volksgenossen. In dem umfangreichen Begleittext auf der gleichen Seite wird die nationalsozialistische Arbeitsphilosophie, die auf den Säulen der Gleichstellung der Berufsstände und des selbstlosen Arbeitseinsatzes im Dienst der Volksgemeinschaft ruht, deklamiert.

„Dies lehrt aber der Führer: Du bist nichts, dein Volk ist alles. [...] Wer nicht arbeitet, verliert die Ehre in der Volksgemeinschaft. Arbeit schändet nicht, sondern adelt, gleichgültig, ob sie mit der Stirn oder mit der Faust geleistet wird. ${ }^{1334}$

In den Alben wird er als Führer beschrieben, der den Arbeiter wertschätzt und ihm auf persönlicher Ebene begegnet: „Wie gern drückt er dem deutschen Arbeiter die Hand!“1335 In dem Album KAMPF UM's DRITTE REICH wird Hitler sehnsuchtsvoll von Arbeitern erwartet und voller Inbrunst bejubelt, denn „Der deutsche Arbeiter liebt seinen Führer“. 1336

„Unter dem Hakenkreuzbanner reichen sich Arbeiter der Stirn und der Faust die Hand! Sie marschieren zusammen, sie kämpfen zusammen, sie leben zusammen, immer für das eine große Ziel, das „Deutschland“ heißt. “1337

\footnotetext{
1332 Vgl. Ebd.

1333 Die „Handreichung“ zwischen Arbeitern und „der nationalsozialistischen Parteiprominenz" war eine „beliebte Geste“. Mit ihr sollten demonstrativ Standesunterschiede aufgehoben werden. Scharnberg (2014): „Gemeinschaft", S. 174

1334 Reemtsma (1936): Hitler, S. 60

1335 Ebd., S. 49

1336 Ebd., Bildunterschrift, S. 48

1337 Zigaretten-Industrie (1934): Kampf, S. 49
} 
Dem Bildersammler wird damit subtil die sozialpolitische Utopie des Nationalsozialismus vermittelt, mit der die Volksgemeinschaft $\mathrm{zu}$ einer Produktionssteigerung motiviert werden sollte. „Die Volksgemeinschaft sollte eine Leistungsgemeinschaft sein, in der Führer und Geführte die ihnen zugewiesene Position bereitwillig auszufüllen hatten. ${ }^{\prime 1338}$

\subsubsection{Jagen und Siegen}

Nach dem Vorbild des italienischen Faschismus, der den Technikkult ${ }^{1339}$ als vitalen Bestandteil der Propaganda einsetzte, wurde der Rennwagen in Deutschland zum Symbol für die überragende deutsche Technik, die zukunftsweisend die Schallmauer der Utopie durchbricht. Der Nationalsozialismus verstand es, die Technikfaszination für sich zu vereinnahmen und zum Synonym für Fortschritt, Dynamik und Siegeswillen zu machen. Propaganda und Sportfunktionäre befreiten die Rennsportveranstaltungen mittels geschickter PR-Kampagnen vom Nimbus des Elitären und setzen sie in den Fokus von Fortschritt und Wirtschaft. ${ }^{1340}$ Dem NS-Regime gelang es, die öffentliche Aufmerksamkeit für den Motorsport zu gewinnen und als Teil der nationalsozialistischen Massenkultur ${ }^{1341}$ zu etablieren. Der Publikumserfolg der Autorennen wird in dem Album DEUTSCHER KRAFTFAHRSPORT auf die "gesunde“, beinahe genetische Veranlagung des Deutschen zum Automobil zurückgeführt, der die Technik als Instrument sportlicher Auseinandersetzungen internalisiert hat. Entsprechend vollmundig verkündet das Album: „Motorradrennen sind Volkssport geworden!“1342 Die Rennen wurden zu volkstümlichen Massen- und Propagandaveranstaltungen ${ }^{1343}$ par excellence, bei denen die Volksgemeinschaft bei Würstchen und Benzingeruch die

1338 Amenda, Lars (2013): „,Arbeitsmigration vs. >Volksgemeinschaft<?“ In: Reeken, Dietmar von/ Thießen, Malte (Hg.): >Volksgemeinschaft< als soziale Praxis. Paderborn: Ferdinand Schöningh, S. 293

1339 Mussolini ließ Autobahnen bauen, förderte heimische Automobilkonzerne und begründete 1927 die Rennsportveranstaltung ,Mille Miglia', Reuß (2006): Rennschlachten, S. 85f.

1340 „Auto-Rennen, einst ein privates Herrenfahrervergnügen, später Konkurrenzkampf der Autofirmen, jetzt zur Prestigefrage der Nationen." Stuck, Hans (1967): Tagebuch eines Rennfahrers. München: Moderne Verlags-GmbH, S. 100

1341 Day (2005): Silberpfeil, S. 11

1342 Werbegemeinschaft (1937): Kraftfahrsport, S. 49

1343 Vgl. Day (2005): Silberpfeil, S. 86 
Erfolge der deutschen Rennwagen und Fahrer feiern konnte. Das Album beschreibt das Motorsportrennen als „ein richtiges Volksfest, das schon am ersten Trainingstag seinen Anfang nimmt. “1344

Von den Rennsportveranstaltungen, bei denen deutsche Automobile brillierten und den Nimbus deutscher Technik mehrten, partizipierte sowohl die Automobilindustrie als auch das NS-Regime, denn neben der Wirtschaftswerbung ${ }^{1345}$ konnte der Staat die Rennen als Bühne für seine Propaganda benutzen und die Siege auf die eigene Fahne schreiben. Damit das Publikum in die Atmosphäre der Massenveranstaltung eintauchen konnte, wurde das Geschehen auf der Rennbahn in den populären Massenmedien wie den Zigarettenalben plastisch geschildert. So weht dem Bildersammler in dem Album BRENNPUNKTE DES DEUTSCHEN SPORTS regelrecht der Benzingeruch um die Nase, wenn er in das spannungsgeladene Geschehen einbezogen wird:

„Hunderttausende und mehr stehen jedesmal am Rande dieser mit Spannung geladenen 10-Kilometer-Strecke. An den Kurven stauen sich die Massen. Viele können nur blitzartig ein Bild, den Bruchteil eines Bildausschnittes erhaschen, aber die Menge steht gebannt und folgt mit Ohr und Hirn, vom Lautsprecher laufend unterbrochen, dem gewaltigen Kampf der Maschinen und Menschen. Wird es Stuck, werden es die Deutschen schaffen? Noch ist die Konkurrenz des Auslandes, das seinen Vorsprung im Bau von Rennmaschinen herausgeholt hat und nicht preisgeben will, zu groß." ${ }^{1346}$

Damit die Automobilrennen eine optimale Propagandawirkung entfalten konnten, wurden sie von staatlicher Seite her subventioniert, perfekt durchorganisiert und medial inszeniert. ${ }^{1347}$ Die Veranstaltungen besaßen für das Regime eine derartige Relevanz, dass die Oberste Nationale Sportbehörde (ONS) die Organisation der Rennen übernahm und die Fahrer bei internationalen Veranstaltungen begleitete.

\footnotetext{
1344 Werbegemeinschaft (1937): Kraftfahrsport, S. 50

1345 „Staatliche Propaganda und Wirtschaftswerbung waren weitgehend deckungsgleich.“ Day (2005): Silberpfeil, S. 91

1346 Muratti (1934): Brennpunkte, Bd. 1, S. 39

1347 Die Inbesitznahme des Automobilsports konnte nur mit einer strategischen Motorisierungspropaganda gelingen, die vollständig unter der Ägide des NS-Regimes stand. Entsprechend begann das Propagandaministerium, sich sukzessive in die PR- und Werbekampagnen der Automobilindustrie einzumischen, bis das RMVP 1938 gegen den Willen der Industrie die vollständige Kontrolle über alle Maßnahmen der Kommunikation anstrebte. Vgl. Day (2005): Silberpfeil, S. 62
} 
Die Rennsportveranstaltungen lagen damit ganz in nationalsozialistischer Hand. In dem Sammelband DeUTSCHER KRAFTFAHRSPORT wird dem Rezipienten die Okkupation der Rennsportveranstaltungen durch die ONS allerdings als Beistand und gönnerhafte Förderung vermittelt. Die Begleitung der ONS und des Führers des Nationalsozialistischen Kraftfahrerkorps (NSKK) Adolf Hühnlein ${ }^{1348}$ wird als selbstloser Einsatz für die deutschen Fahrer in Szene gesetzt.

\begin{abstract}
„Bei allen internationalen Tagungen entsendet die ONS Vertreter und bei allen großen internationalen Rennen, an denen deutsche Rennmaschinen oder deutsche Rennwagen beteiligt sind, werden die deutschen Rennmannschaften von Vertretern des ONS betreut. Häufig läßt es sich Korpsführer Hühnlein nicht nehmen, selbst anstrengende Reisen auf sich zu nehmen, um den deutschen Rennmannschaften bei schwerem Kampf für Deutschland draußen im Ausland einen Rückhalt zu bieten. [...]
\end{abstract}

Die NSKK-Männer, die hier eingesetzt sind, verrichten ihre Tätigkeit mit größtem Eifer, denn sie wissen, daß auch der Korpsführer häufig noch bis zu den spätesten Stunden mitarbeitet und Entscheidungen trifft, die für die Durchführung wichtig sind. [...] Der stolzeste Augenblick ist aber wohl nach der Veranstaltung gekommen, wenn Korpsführer Hühnlein dem Führer telegrafisch einen deutschen Sieg melden kann, einen Sieg, hinter dem nicht nur die motorsportlich Begeisterten stehen, sondern hinter dem ganz Deutschland steht, weil als Größtes Ergebnis der in den vergangenen vier Jahren geleisteten Arbeit schon verzeichnet werden kann, daß das ganze deutsche Volk den Gedanken der Motorisierung erfaßt hat." ${ }^{1349}$

Für das Regime waren die populären Massenveranstaltungen eine Werbeplattform, auf der der Gedanke der Motorisierung verbreitet werden konnte, denn jeder Volksgenosse sollte mit einem „KdF-Wagen“1350 an den wirtschaftlichen Errungenschaften des neuen Staates partizipieren. Das Automobil sollte nicht nur einer elitären Schicht vorbehalten sein. Gleichzeitig sollte die Binnennachfrage angekurbelt werden. Die

\footnotetext{
1348 Adolf Hühnlein, SA-Obergruppenführer, war Mitglied der Reichswehr, später des Blutordens. Er nahm am Hitler-Putsch von 1923 teil. Er gliederte im Auftrag Hitlers das 1931 als Abteilung der SA gegründete NSKK aus und etablierte es als eigenständige Organisation. Auf seine Weisung hin wurden auch alle Automobilclubs in das NSKK eingegliedert. Vgl. Reuß (2006): Rennschlachten, S. 91f.

1349 Werbegemeinschaft (1937): Kraftfahrsport, S. 56f.

1350 Der ,Volkswagen' sollte unter der Ägide der Organisation ,Kraft durch Freude' produziert werden. Schütz, Erhard/ Gruber, Eckhard (1996): Mythos Reichsautobahn. Berlin: Ch. Links Verlag, S. 142f.
} 
Propaganda förderte damit die „Faschisierung des Automobils“, ${ }^{1351}$ die mit der Einführung eines erschwinglichen Kraftwagens eingeleitet wurde. Das Automobil sollte nicht nur Ausdruck einer Sozialutopie werden, sondern auch Symbol für die Modernität des NS-Regimes sein. ${ }^{1352}$ Das Auto wurde Teil des nationalsozialistischen Wertekanons, der die Mobilitätsfreiheit als Instrument für gesellschaftliche Kohäsion propagierte.

„Auch der Automobilverkehr hat insofern eine Begünstigung erfahren, als man das Automobil nicht mehr, wie früher, als Luxusgegenstand ansieht, sondern als ein wichtiges der Allgemeinheit nützliches Verkehrsmittel. ${ }^{\prime 1353}$

In dem Album DeUtSCHER KRAFTFAHRSPORT wird die Förderung des Automobils als wirtschaftspolitische Maßnahme dem Bildersammler als Wohltätigkeit des Führers präsentiert. Diese Version entspricht dem offiziellen Propaganda-Tenor, denn Hitler wollte angesichts der geplanten Expansionspolitik die Akzeptanz für das Regime seitens der Bevölkerung durch die Anhebung des Lebensstandards sicherstellen. ${ }^{1354}$

„Gerade die Rennen [...] haben aber noch eine andere Aufgabe, die nicht technischer Art ist. Der Führer wünscht die Steigerung der Motorisierung des deutschen Volkes, weil diese dazu berufen ist, die Lebenshaltung angenehmer zu gestalten $[\ldots]^{\prime \prime} 1355$

Die Rennsportveranstaltungen wurden auch zur Bühne, auf der sich das NS-Regime inszenierte, in dem es die Siege der deutschen Fahrer symbolisch in Besitz nahm. In den Album DEUTSCHER KRAFTFAHRSPORT werden dem Bildersammler daher nicht nur „Deutscher Erfindergeist“1356 vor Augen geführt, sondern auch die Zeremonien, die die Rennen einrahmten:

\footnotetext{
1351 Zenone (2002): Automobil, Abschnitt 6

1352 Vgl. Bavaj (2003): Ambivalenz, S. 145

1353 Greiling (1934): Adel, S. 66

1354 Das Dritte Reich befand sich im Spannungsfeld zwischen Sozial- und Expansionspolitik. Geprägt von der Erfahrung des 1. Weltkrieges wollte Hitler eine materielle Notlage in Kriegszeiten vermeiden um keine soziale Unruhe zu provozieren. Vgl. Kershaw, Ian (1988): Der NS-Staat. Reinbek bei Hamburg: Rowohlt, S. 157

1355 Werbegemeinschaft (1937): Kraftfahrsport, S. 55

1356 Ebd., S. 11
} 
„Deutsche Rennen beginnen und enden mit der Flaggenhissung für Reich und Sieger, verbunden mit einem Aufmarsch eines Motorsturms des Nationalsozialistischen Kraftfahrerkorps, das der Träger des deutschen Motorsports ist. "1357

Mit den Insignien des Reiches in Form von Flaggen, Aufmärschen und musikalischer Untermalung generierten die Autorennen zu weihevollen Inszenierungen mit der Aura des Numinosen. Neben den Symbolen des Reiches sind in dem Album die Sieger mit überdimensionierten Kränzen aus Eichenlaub ${ }^{1358}$ abgebildet, einem Symbol der germanischen Mythologie. Mit diesem Attribut wurde nicht nur der Träger für seine individuelle Leistung geehrt, sondern auch die ganze Nation. Der Sieg des Sporthelden ging damit auf das Kollektiv über, weil sein Sieg zum Ruhm der ganzen Nation beitrug. Zur symbolischen Erhöhung dieser Auszeichnung wird dieser Art der Ehrung eine altgriechische Provenienz zugewiesen. In dem Sammelband Die OlymPISCHEN SPIELE 1936 wird auf die Verknüpfung von griechischer Antike mit der germanischen Mythologie hingewiesen:

„Mit dem [Anm.: Eichenkranz] wurde der antike Brauch der feierlichen Bekränzung würdig belebt, nationalisiert durch das gastgebende Land Deutschland, für das die Eiche das Symbol bodenverwurzelter Kraft und stolzen Mutes bedeutet. ${ }^{\prime 1359}$

Da die Zeremonien sowohl dem Individuum als auch dem Kollektiv galten und von einer intensiven Emotionalität geprägt waren, verbanden sie den Einzelnen mit seiner Nation. Die tiefe sozial-psychologische Bedeutung dieser Inszenierungen bringt die Flugpionierin und Frau des seinerzeit populären Rennfahrers Rosemeyer, Elly Beinhorn, zum Ausdruck, als sie sich in ihren Memoiren über die Taktlosigkeit des monegassischen Rundfunks entrüstete. Anstelle staatstragender Töne erklang nach einem Rennen Populärmusik, die den Wettkampf ihrem Empfinden nach ins Profane degradierte: „Musik - neckische Walzer und Liederchen nach diesem männlichen

\footnotetext{
$1357 \quad$ Ebd., S. 19, Bildunterschrift

1358 Bilder des Motorradsportlers Ernst Henne und des Automobilsportlers Bernd Rosemeyer, beide mit Eichenkranz. Ebd.

1359 Reemtsma (1936): Die Olympischen Spiele 1936, Bd. 2, Aufl. S. $164 f$.
} 
Kampf, der so viel für die Geltung unseres Landes bedeutete. ${ }^{\prime 1360}$ Die Rennen kamen damit dem Bedürfnis der Gesellschaft nach säkularer Sinnstiftung entgegen und versetzten die Zuschauer in den Zustand einer "tiefe[n] Frömmigkeit“. ${ }^{1361}$

\subsubsection{Motorhelden an der Front}

Für den Nationalsozialismus, der wie der italienische Faschismus das Ideal eines neuen Menschen propagierte „wurde das Automobil zum Politikum, zur Projektionsfläche von männlichem Besitzstreben und nationalen Potenzansprüchen. ${ }^{1362}$ Die individuellen Leistungen der Rennfahrer wurden kollektiviert und zu Gemeinschaftsleistungen, die für die Volksgemeinschaft erbracht wurden. Deutsche Rennfahrer wie Caracciola, Stuck, Lang, Rosemeyer oder von Brauchitsch wurden zu Helden stilisiert, die stellvertretend für die Nation Rennschlachten ausfochten. Die siegreichen Vertreter des Automobilsports transportierten die Ideale des Nationalsozialismus wie keine anderen Sport-Stars und waren, wie Victor Klemperer konstatiert, das „einprägsamste und häufigste Bild des Heldentums“. ${ }^{1363}$ Der Rennfahrer verkörperte den neuen Menschen, der sich durch Kühnheit, einem abgehärteten Körper und durch gestählte Nerven auszeichnete, Eigenschaften, die auch dem Soldaten abverlangt wurden. Autorennen waren, so der Sportfunktionär von Tschammer und Osten, „in jeder Form und

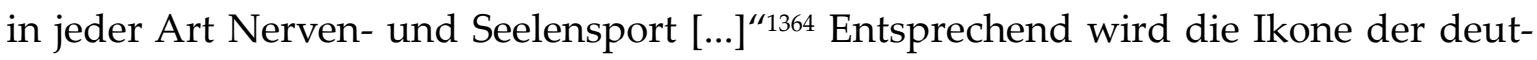
schen Rennfahrer, Bernd Rosemeyer, in dem Zigarettenalben in Szene gesetzt.

„Nach dem Siege kaum dem Rennwagen entstiegen, noch mit umgehängtem Eichenkranz, verlangt Bernd Rosemeyer nach einer Zigarette, die nach dem scharfen Kampf die Nerven beruhigt. ${ }^{\prime 1365}$

In dem Album DEUTSCHER KRAFTFAHRSPORT stehen die Sporthelden als Ikonen exemplarisch für den von der NS-Ideologie propagierten Helden. Dem Rennsportler werden

\footnotetext{
1360 Vgl. Rosemeyer-Beinhorn, Elly (1938): Mein Mann, der Rennfahrer. Der Lebensweg Bernd Rosemeyers. Berlin: Deutscher Verlag, S. 33

1361 Jünger, Ernst (2014) (Erstausgabe 1932): Der Arbeiter. Stuttgart: Klett-Cotta , S. 162

1362 Zenone, (2002): Automobil, Abschnitt 12

1363 Klemperer, Victor (2007): LTI Notizbuch eines Philologen, 22. Aufl. Stuttgart: Reclam, S.11

1364 Von Tschammer und Osten, Ist Autofahren Sport? In: AAZ, 20. Mai 1933, S. 5-6. Zit. nach: Day (2005): Silberpfeil, S. 66

1365 Werbegemeinschaft (1937): Kraftfahrsport, Bildunterschrift, S. 19,
} 
die gleichen Tugenden wie Opferbereitschaft und Pflichtgefühl abverlangt wie dem Soldaten. Sie sind die technischen Krieger, die sich durch Courage und Opferbereitschaft auszeichnen und „mit außerordentlichem Mut kämpfen." ${ }^{1366}$ Die Rhetorik wird in den Zigarettenalben von kriegerischen Metaphern begleitet: „Der deutsche Sport marschiert...!“1367 Die Automobilrennen wurden nach 1933 zu einem „Kampf“, der um jeden Preis gewonnen werden musste. Der kriegerische Tenor kennzeichnet daher die Alben, die ab 1933 publiziert wurden.

„Es kam das Dritte Reich. Die Initiative des Führers gab der deutschen Automobilindustrie den Rückhalt, um den aussichtslosen Kampf gegen die ausländischen Rennwagen neu aufnehmen zu können. “1368

Die Siege der deutschen Rennwagen werden in den Zigarettenalben mehrfach codiert, denn mit den Erfolgen auf internationalen Rennstrecken wurde das Potential der deutschen Technik nicht nur in den sportlichen Kontext gesetzt. Die herausragenden Leistungen auf dem Gebiet der Automobiltechnik werden dem Bildersammler wie Siege in einem Kampf präsentiert. Die ,Rennschlachten' werden damit zu einer mentalen Vorbereitung auf kriegerische Auseinandersetzungen, aus denen Deutschland aufgrund seiner technischen Überlegenheit und mentalen Stärke als Sieger hervorgehen wird. Die gelungene technische Aufholjagd suggerierte, dass die deutsche Technik auch auf den Schlachtfeldern dem Gegner überlegen ist. Klemperer weist auf die Konnexion zwischen Motorsport und Krieg hin, bei dem Rennfahrer und Soldat, Rennwagen und Panzer, fließend ineinander übergehen. „Sturzhelm und Maske des Rennfahrers werden zu einer zweiten Uniform des nazistischen Heldentums. [...] An die Stelle des Rennwagens tritt von 1939 an der Tank, an die Stelle des Rennfahrers der Panzerfahrer. (So nannte der Landser nicht nur den Mann am Steuer, sondern auch die Panzergrenadiere. $)^{\star 1369}$

\footnotetext{
1366 Ebd., S. 49

1367 Muratti (1934): Brennpunkte, Bd. 1, S. 35

1368 Ebd., S. 19

1369 Klemperer (2007): LTI, S.10ff.
} 
Die Nationalsozialisten sahen in der Automobilindustrie den Motor zur Wiederbelebung der Wirtschaft, erkannten aber gleichzeitig die militärische Relevanz der Kraftfahrzeugtechnik. Die staatliche Förderung der Automobilindustrie war nicht nur ökonomisch oder sozial- und machtpolitisch motiviert, sondern auch militärisch. ${ }^{1370}$ Das Regime hatte daher, ebenso wie beim Flugwesen, ein vitales Interesse daran, die Jugend für den Automobilsport zu elektrisieren und sie zum Eintritt in die MotorHJ ${ }^{1371}$ und das NSKK zu motivieren. „Für den Führer des deutschen Kraftfahrsports, Korpsführer Hühnlein, war dieser Sieg Rosemeyers gleichfalls eine freudige Genugtuung: denn wenn es Aufgabe einer weitsichtigen Sportführung ist, gerade die Jugend für große Taten zu begeistern und heranzuziehen, so war dieser Sieg eines jugendlichen Kämpfers des deutschen Motorsports für viele Zehntausende ein leuchtendes Beispiel, Mahnung und Ziel! "1372 „Eigenartig auch, daß diese Jugend den schwer kämpfenden Rosemeyer noch besser verstand als den umjubelten Sieger Rosemeyer.“1373 Rosemeyer, der mit seinem Rennwagen tödlich verunglückte, war daher nicht nur zu Lebzeiten ein Vorbild, sondern wurde nach seinem Tod zu einer nationalen Ikone, die der Jugend wie die Fliegerhelden des Ersten Weltkrieges als Idealbild für Kampf, Mut und Opferbereitschaft dienen sollte. „Sein Tod hat eine furchtbare Lücke hinterlassen. Aber wir wissen, dass dieses leuchtende Vorbild für eine kämpferische Jugend selbst einmal diese Lücke schließen wird, daß neue Streiter kommen werden, Jungens aus jenen Reihen, die heute symbolisch seinen Namen tragen $[\ldots]^{\prime \prime 1374}$ Fritz Todt, Generalinspekteur für das deutsche Straßenwesen in seinem Nachruf auf Bernd Rosemeyer: „Was kann es für die heutige Zeit Wertvolleres, für das

\footnotetext{
1370 Vgl. Flik, Reiner (2001): „Automobilindustrie und Motorisierung in Deutschland bis 1939“. In: Boch, (Hg.): Automobilindustrie, S. 80

1371 Vgl. Werbegemeinschaft (1937): Kraftfahrsport, S. 56

1372 Bretz, Hans (1938): Bernd Rosemeyer. Ein Leben für den deutschen Sport. Berlin: Wilhelm Limpert Verlag, S. 77

1373 Ebd., S. 91

1374 Ebd., S. 120
} 
persönliche Erleben Erfreulicheres geben als junge Menschen mit restlosem selbstverständlichem Einsatz, getrieben nicht aus Ehrgeiz, sondern aus Pflichtgefühl, jugendlichem Wagemut und aus der unbekümmerten Opferbereitschaft des Soldaten. ${ }^{\prime 1375}$

Das Album ReKRUt Peter MüLLeR ${ }^{1376}$ zeigt exemplarisch die Ambitionen des NS-Regimes, die Jugendlichen und junge Erwachsene über den Motorsport für den Militärdienst anzuwerben. Das Album, das wie ein Comic aufgebaut ist, skizziert in bunten Zeichnungen und in naiven wie ungelenken Versen den Werdegang des arbeitslosen Peter Müller, der beim NSKK seine Berufung als Fahrer findet und Fähigkeiten erlernt, die er in der Wehrmacht unter Beweis stellt. Müller steigt schnell zum Gruppenführer auf und wird ein respektiertes Mitglied der Gesellschaft, der durch seinen Aufstieg auch Erfolg beim anderen Geschlecht hat.

„Viel seinesgleichen konnte sehn man arbeitslos an Ecken stehn.

Und jeden Tag sah man ihn fast

Beim Arbeitsamt als Stempelgast.

In Reih und Glied, 's wunderbar, steht Peter in der Motorschar.

In jedem Sturmdienst steht er da.

Er schwärmt nur fürs NSKK.

Als Gruppenführer Müller - wichtig! -

fährt er entleg'ne Wege richtig.

Getarnt er 'ran zum Feinde schleicht, wie Ausbildung es ihm gezeigt.

Nicht lange sitzt er so allein.

Am schönsten plaudert sich's zu zwei'n.

Die Zeit ist schnell dahingegangen.

Schon will sein Herze Feuer fangen."1377

1375 Fritz Todt, Zit. nach: Rosemeyer-Beinhorn (1938): Rennfahrer, S. 203

1376 Aviatik (1937): Rekrut Peter Müller. Heiteres und Ernstes aus dem Soldatenleben. (Idee, Dichtung und Entwürfe Franz Barth). Breslau 


\subsubsection{Die Straßen des Führers}

Mit der Automobilindustrie wurde auch die verkehrstechnische Infrastruktur von der Propaganda vereinnahmt. Keine technische oder wirtschaftliche Leistung wurde derart mit dem ,Führer' in Verbindung gebracht, wie das Auto und die Autobahn. Von der Propaganda wurde, ebenso wie bei der Flugzeugtechnik, der Mythos eines visionären Führers installiert, der die Bedeutung des Automobils früh erkannt hatte. Das Image gründet unter anderem auf seiner pathetischen Rede bei der Eröffnung der Internationalen Automobilausstellung im Jahr 1933.1378 Für Hitler besaß die „Mobilitätspolitik“ außerordentliche Relevanz und das Automobil war ebenso wie im faschistischen Italien, eine „Freiheitsikone“, ${ }^{1379}$ die dem Menschen Unabhängigkeit

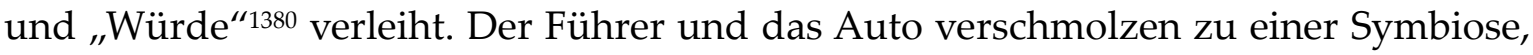
die durch eine geschickte massenmediale Verbreitung Eingang in das kollektive Bewusstsein fand. Wilfrid Bade hat maßgeblich zur Popularisierung dieses Mythos beigetragen. In seinem Buch ,Das Auto erobert die Welt' stilisiert er Hitler zum alleinigen Retter der deutschen Automobilindustrie: "gerettet durch Wort und Tat eines einzigen Menschen. “1381 Auch die Ikone des deutschen Rennsports Rosemeyer begrüßte die Machtergreifung wie eine Erlösung: „Wir schreiben das Jahr 1933! Es ist die Zeit der großen Wende, auch auf dem Gebiet des Motorsports“. ${ }^{1382}$

In den Medien wurde der Mythos von Hitler als Retter des Automobils so erfolgreich installiert, dass er schnell in das öffentliche Bewusstsein diffundierte. Als bedeutender Teil der Populärkultur trugen die Zigarettenalben dazu bei, das Image Hitlers als Förderer der Automobilindustrie zu festigen. In dem Album DeUTSCHER KRAFTFAHRTSPORT wird dieses Bild bereits im Eingangstext groß in Szene gesetzt.

\footnotetext{
1378 „Er benutzte diese Gelegenheit (Anm.: Internationale Automobilausstellung) um sich sogleich über ein Thema auszusprechen, das ihn so lange Jahre, während seines Kampfes um die Macht, in ruhigen Stunden immer wieder beschäftigt hatte." Bade (1938): Auto, S. 309f.

1379 Zenone, (2002): Automobil

1380 Bade (1938): Auto, S. 312f.

$1381 \quad$ Ebd., S. 316

$1382 \quad$ Bernd Rosemeyer. In: Bretz (1938): Rosemeyer, S. 42
} 
„Wir verdanken den Aufstieg des deutschen Kraftfahrtsports einzig und allein der Initiative des Führers, der bei der Machtübernahme sofort erkannte, daß die deutsche Kraftfahrzeug-Industrie in den Erfolgen der internationalen Kraftfahrsports einen Rückhalt brauchte, um der Welt gegenüber ihre technische Führerstellung dokumentieren zu können!"1383

„Dem Aufbruch der Nation folgte der Wiederanstieg des deutschen Kraftfahrtsports. Wenn er gelang, so nur durch die elementare Kraft, die der unbeugsame Siegeswille der nationalsozialistischen Freiheitsbewegung, von des Führers Hand sicher gelenkt, in ihm auszulösen vermochte. ${ }^{1384}$

„Deutschlands Rennwagen und des deutschen Reiches Straßen, beide auf persönliche Initiative des Führers entstanden und erbaut, sind als Schrittmacher des Kraftfahrzeuges und der Straßen der Zukunft anzugeben. “1385

In den Zigarettenalben wird Hitler nicht nur als Förderer der Automobilwirtschaft stilisiert, sondern auch als begeisterter Automobilist, der auf dem Gebiet der modernen Automobiltechnik bewandert ist. In dem Album AdOLF HiTLER inspiziert „Der Führer auf der Automobilausstellung 1935 in Berlin“ 1386 mit Kennerblick den Motor eines Automobils oder besichtigt bei einem „Besuch bei den Bayerischen Motorenwerken“ 1387 die Montagehalle des Unternehmens. Auf einem weiteren Bild wird Hitler, der wohlwollend einen Rennwagen begutachtet, zum Initiator des deutschen Rennsports stilisiert. Bilder und Texte suggerieren einen technikaffinen Führer, dem das deutsche Volk die erfolgreichen Rennwagen zu verdanken hat: „Der auf Anregung des Führers gebaute Mercedes-Benz-Rennwagen.“1388 Die Ikonografie der ,Führerschaft' in Bezug auf die Automobiltechnik wird in einer Aufnahme von der Automobilausstellung im Jahr 1935 par exellence in Szene gesetzt. Das in Untersicht aufgenommene Bild wird von einem Lenkrad im Vordergrund dominiert. Der Blick des Betrachters wird entlang der diagonal ausgerichteten Lenkstange auf Hitler als den

\footnotetext{
1383 Werbegemeinschaft (1937): Kraftfahrsport, Einleitung, unpag.

1384 Zitat Hühnlein, Ebd., S. 61

1385 Ebd.

1386 Reemtsma (1936): Hitler, S. 59

1387 Ebd., S. 60

1388 Ebd.
} 
„Protektor der Automobilindustrie“1389 gelenkt (Abb. 17). In dem Album wird, ganz im Sinne Hitlers, ein Konnex zwischen dem ihm und dem Symbol der Moderne erzeugt. Für Hitler „waren Automobile und Rennwagen funktionale Symbole, mit denen er das Image als moderner Staatsmann und weitsichtiger Verkehrspolitiker etablieren konnte. ${ }^{1390}$ Ebenso wie das Automobil wurde die Reichsautobahn den visionären Plänen Hitlers zugeschrieben. In dem Album AdOLF HITLER nährt Fritz Todt die Legende, in dem er die Pläne Hitlers zum Bau der Autobahn in die Zeit der Landsberger Haft datiert.

„Die Idee

Schon in der Festung Landsberg hat der Führer über die Notwendigkeit und seine Absicht gesprochen, dereinst einmal Straßen bauen zu lassen, die der technischen Leistungsfähigkeit des Kraftwagens voll entsprechen und die großzügig die einzelnen Gaue Deutschlands miteinander verbinden. “" 1391

Der Mythos von Hitler als dem Initiator der Reichsautobahn diffundierte durch mannigfaltige mediale Verbreitung in das Bewusstsein des deutschen Volkes und die „Straßen des Führers“1392 gehörten schnell zum Standardvokabular im Dritten Reich. Der Propaganda gelang es, den Mythos jenseits der historischen Realität zu installieren, denn die „Nur-Autostraßen“ gingen auf eine Planung von 1924 zurück, die auch aufgrund des Widerstandes seitens der NSDAP nicht realisiert werden konnte. ${ }^{1393}$ Ebenso wie die Reichsautobahn wurde auch die prestigeträchtige Vorzeigerennstrecke AVUS von der Propaganda in die Errungenschaften des NS-Regime eingereiht wie in dem im Album BRENNPUNKTE DES DEUTSCHEN SPORTS. „AVUS - das heißt Höchstleistung der Konstrukteure, der Straßenbauer, der Rennfahrer, der Organisatoren, der

1389 Ebd., S. 62. Diagonale Bildkompositionen können dem Inhalt eine Bedeutung geben, in dem sie „eine Bezogenheit auf ein Ziel, eine Entschlusskraft, eine mentale Ausrichtung" geben. Meyer, Guschti (2013): Sprache der Bilder, 2. Aufl. Leipzig: Seemann/ Henschel, S. 63

1390 Day (2005): Silberpfeil, S. 109

1391 Reemtsma (1936): Hitler, Kapitel: Adolf Hitler und seine Straßen, von Generalinspektor Dr.-Ing. Fritz Todt, S. 78

1392 Vgl. Schütz, Erhard/ Gruber, Eckhard (1996): Mythos Reichsautobahn. Berlin: Ch. Links, S. 7

1393 Vgl. Ebd., S. 9 f. 
Propagandisten. “"1394 Verschwiegen wird, dass der Bau bereits im Jahr 1912 begonnen und in der Weimarer Republik fertig gestellt wurde. ${ }^{1395}$

Hitler wurde zum Initiator der Reichsautobahn stilisiert, der mit seiner Arbeitsbeschaffungsmaßnahme tausenden von Volksgenossen ein Auskommen gesichert und den wirtschaftlichen Aufschwung des gesamten Verkehrswesens einleitet hat. Eines der bekanntesten Propaganda-Bilder jener Zeit ist der erste Spatenstich Hitlers am 23. September 1933, mit dem der Bau der Reichsautobahn eingeleitet wurde. Das Motiv wurde zur medialen Ikone des NS-Regimes und wurde im Original oder als Montage propagandistisch vielfach verwertet. Der Spatenstich ging als Gründungsmythos in die Geschichte der Autobahn ein. Die groß angelegte Inszenierung des historischen Spatenstichs wurde in Rundfunkbeiträgen, Propagandabroschüren, auf Postkarten oder auf dem Plakat zur Reichstagswahl von 1933 medial verbreitet. ${ }^{1396}$

Der Mythos von der Reichsautobahn wird vielfach in den Zigarettenalben übernommen, wobei die Weimarer Konzepte ebenso verschwiegen werden wie die vergleichsweise geringe Anzahl an Arbeitern, die auf den Baustellen gegen sehr geringe Entlohnung Schwerstarbeit leisten mussten. ${ }^{1397}$ Stattdessen wird der Mythos von Hitler als der Erbauer der Autobahn verbreitet, die Rekorde möglich machten. Das Album ADEL DER ARBEIT wird eingeleitet mit dem „Beginn der Arbeiten an einer Reichsautobahn“. ${ }^{1398}$ Das Motiv bedient den Stereotyp der Darstellungen von Arbeitskolonnen, die

\footnotetext{
1394 Muratti (1934): Brennpunkte, Bd. 1, S. 39

1395 Vgl. Kunze, Thomas/ Sommer, Rainer (1982): „Geschichte der Reichsautobahn“. In: Stommer (1982): Reichsautobahn, S. 22. Der Bau musste kriegsbedingt eingestellt werden, was die Freigabe für den Verkehr verzögerte. Ebd.

$1396 \mathrm{Zu}$ diesen Medien zählen: Die Fotomontage der Propaganda-Broschüre „Die Straßen des Führers", Wahlplakat von Heinrich Hoffmann: „Die Armee der Arbeit und des Friedens antwortet dem Führer mit: Ja!", Postkarte vom 25.9.1933: Erster Spatenstich 23.9.1936 1000 km Autobahn fertig." Ebd., S. 11f. und S. 44f. Die Aufnahme wurde auch als Montage als Plakat und Illustrierten-Titel verwendet. Herz (1994): Hoffmann \& Hitler, S. 262f.

1397 Vgl. Kunze, Thomas/ Stommer, Rainer (1982): „Geschichte der Reichsautobahn“. In: Stommer, Rainer (Hg.): Reichsautobahn: Pyramiden des Dritten Reichs: Analysen zur Ästhetik eines unbewältigten Mythos. Marburg: Jonas, S. 28 und 35. Bei der Reduktion der Arbeitslosenzahl hatte der Bau der Autobahn bis Ende 1934 lediglich einen Anteil von 2,3 Prozent. Vgl. Schütz/ Gruber (1996): Reichsautobahn, S. 38 Greiling (1934): Adel, Bild 1, S. 9
} 
in militärischer Formation mit ihrem Arbeitsgerät Parade stehen. ${ }^{1399}$ Die exponierte Stellung des Bildes reflektiert die propagandistische Relevanz, die der Arbeitseinsatz für das NS-Regime besaß. Im Textteil des Sammelbandes wird in dem Kapitel „Der Kampf gegen die Arbeitslosigkeit“ der Bau der Reichsautobahn als das „umfangreichste Projekt in der Arbeitslosenoffensive“1400 beschrieben.

„Gerade der Bau der Reichsautobahnen soll möglichst dem ungelernten Arbeiter Beschäftigungsmöglichkeiten bieten [...] Das Projekt der Reichsautobahnen stellt alle anderen Objekte in den Schatten [...] Durch die Entstehung der Reichsautobahnen werden neue Arbeitsmöglichkeiten entstehen, die man bisher nur ahnen kann $[\ldots]^{\mu / 1401}$

„Das war kein symbolischer Spatenstich, das war richtige Erdarbeit! Ein paar Arbeiter erkannten, daß der Führer wohl kaum aufhören werde, bevor der Haufen von 2 Kubikmetern nicht ordentlich ausplaniert sei. Sie sprangen mit ihren Schaufeln herbei, um zu helfen. So schippte der Führer mit ihnen [...] und auch von seiner Stirn die ersten Schweißtropfen auf die Erde fielen. " ${ }^{1402}$

Mit der ,Arbeitslosenoffensive' wollte die NS-Regierung nicht nur den sozialen Frieden sichern. Es war primär eine Propagandaoffensive, mit der mehrere Ziele verfolgt wurden. Die vermeintliche Wohltat sollte die Leistungsfähigkeit der Bevölkerung steigern und ein Gegenbild zu der Republik schaffen, denn die Arbeitslosigkeit in der Weimarer Republik galt „als das Signum der verunglimpften $>$ Systemzeit $<$ schlechthin“ ${ }^{1403}$ Nicht zuletzt war das Projekt Reichsautobahn auch als künftiges Streckennetz für Truppentransporte vitaler Bestandteil der infrastrukturellen Vorbereitung für einen Angriffskrieg. ${ }^{1404}$ Als Initialzündung für die Wirtschaft erreichte der Bau der

1399 Weitere Beispiele in: Reemtsma (1936): Hitler, S. 61 und Kosmos (1933): Bilddokument, Bd. 1, S. 70

1400 Greiling (1934): Adel, S. 66

1401 Ebd.

1402 Reemtsma (1936): Hitler, Kapitel: Adolf Hitler und seine Straßen, von Generalinspektor Dr.-Ing. Fritz Todt, S. 81f.

1403 Amenda, Lars (2013): „Arbeitsmigration vs. >Volksgemeinschaft<?“ In: Reeken, Dietmar von/ Thießen, Malte (Hg.): > Volksgemeinschaft< , S. 293

1404 Die Autobahn wurde kaum vom Militär benutzt, denn es setzte mehr auf die Reichsbahn. Eine militärische Nutzung erfolgte erst beim Einmarsch der Alliierten. Vgl. Schütz/ Gruber (1996): Reichsautobahn, S. 12. Ebenso wie die Autobahn war auch der Volkswagen" darauf ausgelegt, bei einem Krieg eingesetzt zu werden. Vgl. Bastian (2005): High Tech, S. 54 
Reichsautobahn bei weitem nicht die anvisierten Ziele. Die Maßnahme lieferte der Wirtschaft zwar Impulse, ${ }^{1405}$ besaß aber weder die Relevanz für einen wirtschaftlichen Aufschwung, noch trug der Bau zu einer Reduktion der Arbeitslosigkeit bei. Der Mythos Autobahn, der auch in den Zigarettenalben verbreitet wurde, steht damit in einem eklatanten Widerspruch zu den realen Gegebenheiten.

Einer der größten Werbeträger für das Automobil war Adolf Hitler selbst, denn das Automobil war Bestandteil des Führerimages. Das Auto diente Hitler als Requisit, mit dem er sich als modernen und dynamischen Staatsmanns repräsentieren konnte. Viele der Propaganda-Bilder, die Hitler stehend in einer Mercedes-Limousine zeigen, mit der er an jubelnden Volksmassen defiliert, fanden Eingang in die Sammelalben. ${ }^{1406}$ Bereits vor der Machtübernahme hatte eine Kooperation zwischen Mercedes-Benz und Hitler in Form von kostenloser Bereitstellung von Leihwagen, dem Gewähren von Rabatten und zahlreicher werbestrategischen Maßnahmen bestanden. ${ }^{1407}$ In dem Album KAMPF UM'S DRITTE REICH wird explizit auf die Verbindung zwischen Hitler und Mercedes verwiesen: „In seinem großen Mercedes-Wagen jagt der Führer von Ort zu Ort. “1408 In dem Album Das Auto vON Heute steht der „Wagen des Führers“ neben dem „Wagen des Reichspräsidenten“. ${ }^{1409}$ Bei diesen Automobilen wird, im Unterschied zu anderen Fabrikaten die in dem Sammelband präsentiert werden, auf die Produktinformationen verzichtet. Der ,Führerwagen' besaß als Ikone eine derartige Bekanntheit, dass er keine weitere Identifikation oder Beschreibung benötigte. Die Mercedes-Benz-Limousine und Hitler gingen eine Markensymbiose ein, die sich auch in der Bezeichnung „Führerwagen“ manifestierte, die Eingang in das Vokabular der

\footnotetext{
1405 Vgl. Schütz/ Gruber (1996): Reichsautobahn, S. 7

1406 Reemtsma (1933): Deutschland erwacht, S. 36, 61, 68, 144 und 149. Reemtsma (1936): Hitler: S. 54, 111, 121, 124 und 128. Zigaretten-Industrie (1934): Staat, S. 80

1407 Vgl. Schug, Alexander (2007): „Hitler als Designobjekt und Marke. Die Rezeption des Werbegedankens durch die NSDAP bis 1933/34“. In: Berghoff (Hg.): Marketinggeschichte, S. 339

1408 Zigaretten-Industrie (1934): Kampf, S. 50

1409 Garbáty (1934): Auto; Bilder 154 und 155, S. 21
} 
Zeit fand. Von dem Synergieeffekt profitierte nicht nur Hitler, sondern auch der Daimler-Benz-Konzern, der an der Popularität Hitlers partizipierte. ${ }^{1410}$ Die Zigarettenalben tragen dazu bei, diese Markensymbiose medial zu multiplizieren.

„Wenn seine (Anm.: Hitlers) Arbeit und seine Regierungsgeschäfte es ihm erlauben, dann sitzt der Führer auch heute nicht nur in seinem Amtszimmer, sondern fährt hinaus in das Land mitten unter das Volk. Dann sitzt er wieder in seinem Mercedes und taucht einmal hier, einmal dort auf $[\ldots]^{\prime \prime 1411}$

Bei den Bildern, die Hitler im Zusammenhang mit einem Automobil zeigen, wird auf ein wiederkehrendes Motiv zurückgegriffen: Hitler beim Lesen von Zeitungen, Büchern oder bei dem Studium von Landkarten. Dem Rezipienten wird damit das Bild eines belesenen, gut informierten Führers suggeriert, der sich unentwegt mit den Geschicken des Landes befasst. ${ }^{1412}$ Dieses populäre und von der Propaganda verbreitete Motiv wird auch in den Zigarettenalben vielfach zitiert. Im Kontext des Automobilismus wird Hitler meist mit sportlicher Lederkappe gezeigt, in das Studium von Landkarten vertieft. ${ }^{1413}$

„Schon in seinem ersten Wagen war sein Platz neben dem Fahrer. Heute, nach 15 Jahren, als Reichskanzler, ist er davon nicht abgegangen. Er legt auch die Reiseroute selbst fest $[\ldots]^{\prime \prime 1414}$

Das Kartenmaterial wird zum Requisit, mit dem sich Hitler als Führer präsentiert, der die Weisungshoheit inne hat und strategisch sein Ziel verfolgt. Eigenschaften, die vom Rezipienten auf das politische Handeln übertragen werden sollen und das Bild eines

1410 Das Wahlplakat (Hitler-Porträt von Heinrich Hoffmann) „Ja! Führer, wir folgen Dir!“ für die Reichstagswahl und Volksabstimmung am 12. November 1933. Das Bild war auch bei einer Sonderausstellung in der Mercedes-Zentrale ausgestellt. Vgl. Behrenbeck (1996): „Der Führer“, S. 62ff. Vgl. Schug (2007): „Hitler als Designobjekt“, S. 339. Die Auto Union, Konkurrent von Daimler-Benz, sicherte sich gleichfalls die Partizipation an der staatlichen Propaganda und warb mit dem Hakenkreuz. Damit entstand eine „Symbiose der Auto Union-Ringe mit dem Hakenkreuz". Day (2005): Silberpfeil, S. 91

1411 Reemtsma (1936): Hitler, Kapitel: Der Führer auf Reisen, von SS-Brigadeführer Julius Schreck+, S. 9 ff.

1412 Das Bild des belesenen Führers wird in dem Album mehrfach präsentiert. Reemtsma (1936): Hitler, Seiten: 11, 14, 16, 17, 36, 39, 43 und 129

1413 Reemtsma (1933): Deutschland erwacht, S. 71. Zigaretten-Industrie (1934): Staat, S. $79 f$.

1414 Reemtsma (1936): Hitler, Kapitel: Der Führer auf Reisen von SS-Brigadeführer Julius Schreck +, S. 16 
Führers vermitteln, der planvoll sein anvisiertes Ziel ansteuert und die Geschicke sei-

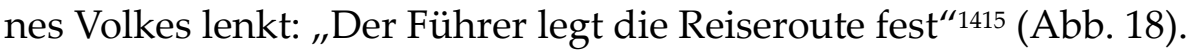

\subsection{Propaganda und Mobilität}

Bereits vor der Machtergreifung setzte die NS-Bewegung bei Propaganda-Aktionen und Wahlkämpfen wie keine andere politische Kraft auf Mobilität. Die Technik verhalf der NS-Bewegung zu einer „Erhöhung der physischen Geschwindigkeit“1416 und war Ausdruck von Dynamik, denn in der Geschwindigkeit manifestiert sich Macht, denn Geschwindigkeit ist immer auch eine Form "des Ereilens oder des Ergreifens. "1417 Für die NS-Bewegung war Mobilität ein Instrument auf dem Weg zur Macht und später zur Machterhaltung. In den Zigarettenalben wird vielfach auf die Relevanz des Flugzeuges und des Automobils verwiesen, denn diese Verkehrsmittel hatten maßgeblich dazu beigetragen, dem Nationalsozialismus zum Sieg zu verhelfen. In dem Sammelband KAMPF UM's DRITTE REICH werden das NSKK und die SA als „,starke Waffe“ und „vorwärtsstürmende Schwungkraft“ beschrieben, mit „der alleine unsere Idee zum Siege gelangen wird! - " 1418 In den Zigarettenalben wird die Etablierung des NSKK1419 als Organisation innerhalb der SA als folgerichtige Entscheidung betrachtet. Erst die Mobilität hätte es ermöglicht, aus den Wahlkampfschlachten als Sieger hervorzugehen. Technik und Mobilität werden in den Zigarettenalben zum Synonym für die Dynamik der NS-Bewegung. Die Alben betonen explizit die Bedeutung der motorisierten Organisation bei den Wahlkämpfen:

\footnotetext{
1415 Ebd., S. 11 und 15

1416 Ballister (1996): „Tatpropaganda“, S. 26

1417 Canetti, Elias (1996): Masse und Macht. Frankfurt/M.: Fischer, S. 335

1418 Aurelia (1933): Führer, S. 40

1419 Das NSKK entstand aus der Motor-SA, die bereits vor 1934 existierte. „Die Mitglieder waren verpflichtet, ihre Fahrzeuge auf Anordnung für Zwecke der NSDAP zur Verfügung zu stellen." Die Motorsportschulen waren im gesamten Reich verteilt. Die Ausbildung umfasste die "planmäßie fahrtechnische, sportliche wie weltanschauliche Nachwuchsschulung". Tümmler, Holger (2010): SA - SS - NSKK im "Führerstaat", Uniformen und Abzeichen. Wolfenbüttel: Melchior, S. 101
} 
„Bei den großen politischen Kämpfen um die Macht hat es sich gezeigt, daß der Führer durch die Motorisierung seiner Gefolgschaft allen seinen Gegnern weit voraus war. ${ }^{\prime 1420}$

"Und wenn der Wahltag anbrach, stand ein jeder auf seinem Posten. An vorderster Stelle stand der Mann vom Motorsturm! - Überall war er da! Überall wurde er verlangt. [...] Es galt, für die schnelle und einwandfreie Nachrichtenübermittlung zu sorgen; es galt, sofort einsatzbereit zu sein, wenn SA-Kameraden und zivile Parteigenossen von den politischen Gegnern überfallen wurden [...] Es galt, kranke und gebrechliche Volksgenossen abzuholen und zur Wahlurne zu bringen; - und schließlich galt es, am Abend die Wahlresultate auf schnellstem Wege den politischen Leitungen zu übermitteln.-“ 1421

„Schnelligkeit, Zuverlässigkeit und Pflichterfüllung sind grundsätzliche Eigenschaften der motorisierten SA! Auf sportlichem Gebiet leisten diese Kämpfer Adolf Hitlers Vorbildliches. Sie unternehmen es täglich, dem deutschen Volk und der ganzen Welt zu beweisen, daß deutsche Technik, deutsche Qualitätsarbeit und deutsches Können ihren alten, guten Ruf gewahrt haben. ${ }^{1422}$

Bei der Nutzung moderner Transportmittel wird explizit auf Hitler verwiesen, der dem Automobil auch unabhängig vom politischen Tagesgeschehen und Wahlkämpfen treu bleibt, um seinem Volk nahe zu sein.

„Die ewigen politischen Wahlen in Deutschland erfordern es, daß der Führer Adolf Hitler kreuz und quer durch das ganze deutsche Vaterland reist, um selber zum deutschen Volke zu sprechen und es zum Kampfe für den Nationalsozialismus, und damit für das Heimatland, aufzurufen. ${ }^{1423}$

„Noch nie hat ein führender Staatsmann sein Land und Volk so gründlich kennengelernt wie Adolf Hitler. [...] Schon am Anfang seiner Bewegung hat er weitschauend die Wichtigkeit schneller Transportmittel, besonders des Kraftwagens, erkannt und sich ihrer trotz der damals mehr als bescheidenen Mittel bedient. ${ }^{\prime 1} 1424$

\footnotetext{
1420 Reemtsma (1936): Hitler: Kapitel: Der Führer auf Reisen, von SS-Brigadeführer Julius Schreck +, S. 9

$1421 \quad$ Zigaretten-Industrie (1934): Kampf, S. 41

1422 Ebd.

1423 Ebd., S. 50

1424 Reemtsma (1936): Hitler: Kapitel: Der Führer auf Reisen, von SS-Brigadeführer Julius Schreck +, S. 9
} 
„Der Führer schätzt die Fahrt mit dem Kraftwagen über Land besonders, weil kein anderes Verkehrsmittel eine so enge Verbundenheit des Reisenden mit Volk und Landschaft ermöglicht $[. . .]^{\text {“1425 }}$

Das Automobil und das Flugzeug wurden zum Ausdruck der Dynamik des Nationalsozialismus, die von dem „Veränderungs- und Beschleunigungswillen[s]“1426 des Regimes zeugen sollten. Mehr noch als das Automobil war das Flugzeug Ausdruck für die Dynamik Bewegung, die insbesondere Hitler eine „mediale Omnipräsenz“1427 verlieh. In dem Album ADOLF HITLER wird Hitler als Förderer der Luftfahrt regelrecht in Szene gesetzt. Das Kapitel „Der Führer auf Reisen“ eröffnet mit einem Bild, auf dem Hitler dynamischen Schrittes einem Flugzeug entsteigt. ${ }^{1428}$ Unter dem Bild ein Kommentar von Julius Schreck: „Der Führer fördert durch sein Beispiel die Luftfahrt“ (Abb. 19). Hitler wird damit als visionärer Führer dargestellt, der sich dem schnelllebigen Rhythmus der Moderne anpasst und bei seinen Wahlkampftouren auch unter widrigen Bedingungen das Flugzeug genutzt hat um seinen engen Terminplan einzuhalten. ${ }^{1429}$ In dem Album KAMPF UM'S DRITTE ReICH wird in dem Kapitel „Der Führer auf großer Fahrt" der Deutschlandflug beschrieben, den er angesichts der wirtschaftlichen Not zum Wohl des Volkes ${ }^{1430} 1932$ angetreten hatte. Hitler wird dabei als

1425 Ebd., Kapitel: Adolf Hitler und seine Straßen, von Generalinspektor Dr.-Ing. Fritz Todt, S. 79

1426 Zigaretten-Industrie (1934): Kampf, S. 41

1427 Härtel (2004): Stromlinien, S. 130

1428 Reemtsma (1936): Hitler: Kapitel: Der Führer auf Reisen, von SS-Brigadeführer Julius Schreck +, S. 9

1429 Die vermeintliche Unerschrockenheit Hitlers wird in dem Text noch gesteigert, in dem widrige Flugverhältnisse plastisch geschildert werden. Hitler wird als furchtloser wie verantwortungsbewusster Führer präsentiert, der unter Einsatz seines Lebens jeden Termin wahrnimmt: „Wochenlang hindurch führt das Flugzeug von Stadt zu Stadt, ohne Rücksicht auf Wind und Wetter. Rückschauend auf diese Zeit, bekommt man ein leichtes Gruseln, erinnert man sich der zahlreichen Sturm-, Nacht-, und Nebelflüge. [...] Oft wurde dem Führer nahegelegt, den oder jenen Flug nicht zu unternehmen. Dann aber war immer seine Antwort: „Wenn die Notwendigkeit es verlangt, dann fliege ich auch bei Sturm." Reemtsma (1936): Hitler, S. 16f.

1430 Die Arbeitslosenzahl hatte mit knapp 30 Prozent einen Höhepunkt erreicht. Konzepte zur Wiederbelebung der Wirtschaft lagen bei Machtantritt bereits vor. Darunter auch Arbeitsbeschaffungsmaßnahmen in Form des Autobahnbaus oder der Trockenlegung von Sümpfen. Diese hatten lediglich propagandistischen Wert, denn die Entlohnung war kaum höher als die Arbeitslosenunterstützung. Die Maßnahmen gingen zulasten des Staatshaushalts und trugen zu der exorbitanten Überschuldung bei. Vgl. Thamer (1986): Verführung, S. 470 - 473 
dynamischer Mensch der Tat beschrieben, der handelt, wenn andere Politiker lediglich Versprechungen machen. ${ }^{1431}$ Der Deutschlandflug wird als innovative Form der Propaganda hervorgehoben, wobei Hitler als Führer präsentiert wird, der die Technik bewusst in seinen Dienst stellt.

„Bei der nächsten Wahl entwirft der Führer den größten Plan, der je für eine Wahlpropaganda entworfen wurde. Er beschließt mit dem Flugzeug über ganz Deutschland zu fliegen und binnen kürzester Frist an allen Orten des Vaterlandes vor dem deutschen Volke persönlich zu erscheinen und $\mathrm{zu}$ ihm $\mathrm{zu}$ sprechen. Die geniale Ausarbeitung dieses Planes zeugt von dem großen politischen Können des nationalsozialistischen Führers. Kein führender Politiker der Welt aber hat bisher ein derartiges Übermaß an geistigen und körperlichen Anstrengungen auf sich genommen $[\ldots]^{\prime \prime 1432}$

"Auf seinen Deutschlandfahrten war es einzig und allein dem Flugzeug zu verdanken, daß Adolf Hitler eine Wahlschlacht nach der anderen schlug, wie keiner es vor ihm je vermochte. - Schnelligkeit und Sicherheit! -“1433

In diesem Sammelband werden die wichtigsten Stationen des Deutschlandfluges aufgeführt, wobei der Fokus nicht auf den Inhalten der Wahlreden gesetzt wird, sondern auf die Anstrengungen der Reise, den Publikumszahlen sowie der jubelnden Zuhörerschaft. ${ }^{1434}$

„In einer Woche hat Adolf Hitler auf zweiundzwanzig Versammlungen gesprochen, und über 1 1/2 Millionen Menschen haben ihn gesehen und gehört. Kein Politiker der Welt hat bisher eine derartige Leistung vollbracht. Die Energie Adolf Hitlers ist einzig und allein bestimmend für den Erfolg der Bewegung. " 1435

Die Auswertung der Deutschlandflüge in den Zigarettenalben unterstreicht die propagandistische Bedeutung moderner Verkehrsmittel, die bereits 1932 eine Omnipräsenz Hitlers suggerierten und die Dynamik der Bewegung zum Ausdruck

\footnotetext{
1431 „Mit leeren Versprechungen ist kein Hunger zu stillen!“. Zigaretten-Industrie (1934): Kampf, S. 26

$1432 \quad$ Zigaretten-Industrie (1934): Kampf, S. 28

1433 Ebd., S. 55

1434 „Im Licht von fünftausend Fackeln verläßt Adolf Hitler diesen Ort und fährt zurück nach Berlin. Im Sportpalast harren seiner 20.000 Menschen. Weitere Tausende von Arbeitern erwarten ihn im Saalbau Friedrichshain. Wieder hat der Führer gesprochen und, den Jubel von Hunderttausenden im Ohr, begibt er sich zur kurzen Ruhe.“ Ebd., S. 29 
brachten. ${ }^{1436}$ Das Flugzeug diente Hitler nicht nur, um der Bevölkerung eine Allgegenwart zu suggerieren, sondern war Teil der Propagandainszenierung. Vor der Landung ließ er sein Flugzeug über dem Ort der Wahlkampfveranstaltung bei hell erleuchteter Kabine kreisen. Die "gespenstisch-dämonische Szene“ verlieh Hitler in den Augen der Zuschauer etwas Numinoses. ${ }^{1437}$

\subsection{Resümee}

Die Technikbegeisterung, die die Bevölkerung bereits seit dem Beginn des 20. Jahrhunderts erfasst hatte, manifestierte sich insbesondere in der Populärkultur. ${ }^{1438}$ Neben Technik-Romanen und Sachbüchern fand das Sujet auch Eingang in die Sammelalben. Die hohe Anzahl an Zigarettenalben, die sich technischer Themen angenommen hatten, belegt die anhaltende Faszination für die Errungenschaften der Moderne und reflektiert den gesellschaftspolitischen Technik-Diskurs der 1930er Jahre. Die größte Faszination ging von der Aviatik aus, die in den Zigarettenalben facettenreich thematisiert wird. In den Sammelwerken, die zwischen 1930 und 1933 publiziert wurden, stehen flugtechnische Errungenschaften symbolisch für den Aufbruch in die Moderne. Sie werden von einer positiven Erwartungshaltung sowie von einem völkerverbindenden Gedanken begleitet.

Ab dem Jahr 1933 erfolgte mit der nationalsozialistischen Machtübernahme eine Zäsur im technischen Diskurs, die sich auch in den Zigarettenalben widerspiegelt. So wird die Luftfahrt ganz in den Kontext der nationalsozialistischen Ideologie gesetzt, wobei ihre Protagonisten sowie flugtechnische Innovationen vollständig von der NS-Propaganda vereinnahmt werden. Die Propagandastrategen verfolgten dabei unterschiedliche Ziele. Durch die Okkupation konnte das NS-Regime Forschung, Innovationen und Flugzeugproduktion im Bereich des Motor- und Segelfluges sowie

\footnotetext{
1436 Die Flüge, die auf Hitlers Initiative erfolgten, wurden medial in Presse und Rundfunk angekündigt. Hitler wurde bei den Wahlveranstaltungen von seinem Fotografen Heinrich Hoffmann begleitet, der das Bildmaterial später verbreitete. Vgl. Paul (1990): Aufstand, S. 205 ff.

1437 Vgl. Domarus (1965): Hitler, S. 118

1438 Vgl. Brockhaus (1997): Schauder, S. 89
} 
der Luftschiffe für sich in Anspruch nehmen. Dem Rezipienten wurde suggeriert, dass die technischen Entwicklungen, die Deutschland zu Freiheit und Prosperität verholfen hatten, ausschließlich der Tatkraft der neuen Machthaber zu verdanken seien. Der wirtschaftliche Aufschwung im Flugwesen und die Innovationen, die bereits während der Weimarer Zeit gemacht wurden, werden verschwiegen oder unterminiert. Damit konnte die NS-Propaganda einen Gegenmythos zu Weimar lancieren und den eigenen Machtanspruch stärken. Ferner konnte der NS-Staat an dem Nimbus der Technik, der mit Bewegung, Dynamik und Modernität konnotiert war, partizipieren und das eigene Image prägen.

Die Luftfahrt und die technischen Innovationen waren darüber hinaus Manifestationen deutscher Schaffenskraft, mit der die Bevölkerung die Kriegsniederlage kompensieren konnte. Die Bedingungen des Vertrages, der Kriegsschuldartikel und der verlorene Krieg hatten ein kollektives Gedächtnis geformt, das von Scham und Schmach geprägt war. Vor diesem Hintergrund wurde die Luftfahrt zur Projektionsfläche für nationale Wiederauferstehung sowie Mittel zur Wiederherstellung der nationalen Ehre und zum Kompensationsinstrument der gedemütigten kollektiven Psyche. Da die Technik als Gradmesser für Kultur schlechthin betrachtet wurde, war sie auch ein Mittel, mit dem Deutschland das Image als Kulturnation für sich beanspruchen, respektive unter Beweis stellen konnte.

Die Aviatik wurde auch eingesetzt, um Werte der nationalsozialistischen Ideologie sowie eine neue sozial-politische Utopie zu vermitteln. So wurde mit den Fliegerassen des Ersten Weltkrieges ein neues Männlichkeitsideal geschaffen. Die Fliegerhelden des Ersten Weltkrieges stärkten die Integrationskraft der Volksgemeinschaft und vermittelten darüber hinaus soldatische Tugenden wie Kameradschaft, Pflichterfüllung und Opferbereitschaft. Die Aviatik wurde ferner Rahmen für die Erneuerungsideologie, wobei Flugzeuge zu Symbolen einer Zeitenwende generierten, die eutschland in eine verheißungsvolle Zukunft führen sollten. 
Der Versailler Vertrag war zentrales Thema der Zigarettenalben und bildete die Basis für unterschiedliche Propagandastrategien wie der Einkreisungspropaganda, bei der Deutschland als friedliebende Nation präsentiert wird, die von feindlichen Aggressoren bedroht wird. Die Bedrohung wird in den Luftwaffen anderer europäischer Staaten verortet, denen Deutschland schutzlos ausgeliefert ist. Die Wiederaufrüstung, die hinter den Kulissen vonstattenging, wird in den Zigarettenalben, die bis 1935 publiziert wurden, verschwiegen.

Dieser Tenor prägt die Zigarettenalben bis zur Gründung der Wehrmacht im Jahr 1935. In den Sammelbänden wird weiterhin die Friedensabsicht des NS-Regimes betont, während gleichzeitig auf das waffentechnische Potential der Wehrmacht verwiesen wird. Dabei wird insbesondere die Luftwaffe als moderne und starke Waffengattung präsentiert. Dieser Paradigmenwechsel korrespondiert mit der innen- und außenpolitischen Propagandastrategie des NS-Regimes. Während pazifistische Signale in Richtung Ausland gesandt wurden, sollte die eigene Bevölkerung sukzessive emotional für einen Krieg mobilisiert werden. Im Zusammenhang mit der Wiederaufrüstung wurden die Zigarettenalben ferner dazu benutzt, um für den Luftschutz zu werben. Als unverdächtiges Medium der Populärkultur konnte der NS-Staat über die Sammelalben Freiwillige für den Luftschutz akquirieren, ohne selbst in Erscheinung treten zu müssen.

Die Aviatik bot dem NS-Regime auch eine Plattform, von der aus ein retrograder Kurs in Richtung des Ersten Weltkrieges eingeschlagen werden konnte. Die Kriegshelden und Fliegerasse von einst erfuhren in den Zigarettenalben eine mediale Wiederauferstehung, in dem sie aus dem historischen Kontext herausgelöst und zu mythischen Heldenfiguren stilisiert wurden. Als Helden, die sich selbstlos für das Vaterland geopfert hatten, gingen sie in das deutsche Mythenrepertoire ein und wurden Teil des kollektiven Erbes, das an eine ruhmreiche Vergangenheit erinnern sollte. Mit den heroischen Vorbildern wurde eine gedächtnisstiftende Erinnerungskultur für nachfolgende Generationen geschaffen. Die zu Helden stilisierten Flieger wurden so in das 
kollektive Bewusstsein implementiert. Mit der Erinnerung an den Weltkrieg und der Auratisierung seiner Helden konnten soldatische Werte und Tugenden wie Kameradschaft, Pflichtbewusstsein und Opferbereitschaft in die Gesellschaft getragen und an die Jugend weitergereicht werden, mit dem Ziel, diese Generation emotional für einen künftigen Krieg zu mobilisieren. Die Zigarettenalben wurden so zu einem Medium, mit dem die Flieger- und Kriegshelden für die eigenen Propagandaziele vereinnahmt wurden.

Die Mobilisierung der Jugend war eines der primären Ziele, die das NS-Regime verfolgte. Die Propagandaverantwortlichen nutzten die Zigarettenalben, um die junge Generation für sich einzunehmen. Sie hatten die Technikfaszination, Flugbegeisterung und Abenteuerlust der Jugendlichen erkannt und warben in zielgruppenadäquater Sprache für den Segelflugsport. Da die Jugendlichen in den Flugsportvereinen über den Modellbau eine Flugausbildung erhielten, konnte das Militär gezielt Nachwuchs für die Luftwaffe heranziehen und auf gut ausgebildete Rekruten mit vormilitärischer Ausbildung zurückgreifen.

Die Luftschiffe nehmen in den Zigarettenalben einen besonderen Stellenwert ein. Der Zeppelin ist nicht nur ein zentrales Thema in den Aviatik-Alben, sondern auch Gegenstand von Sammelwerken, die im nationalsozialistischen Kontext stehen. Die Luftschiffe wurden vom NS-Regime usurpiert und zu imposanten Werbeträgern, mit denen die neuen Machthaber ihre Größe, Dynamik und Innovationskraft zum Ausdruck bringen konnten. Da der Zeppelin mit einer vielschichtigen Symbolik wie Opferbereitschaft, Einigkeit und Wiederauferstehung besetzt war, war das Luftschiff prädestiniert, um als kollektive Sinnressource genutzt zu werden. Der ZeppelinMythos blieb im Kern erhalten, wurde aber im Sinne des NS-Regimes modifiziert. Da der Zeppelin mit seiner Symbolik seit dem Beginn des 20. Jahrhunderts im kulturellen Gedächtnis der Deutschen verankert war, evozierte er die gleichen Emotionen wie zwei Dekaden zuvor. Für das NS-Regime war das Luftschiff daher ein vitaler politischer Mythos, der propagandistisch genutzt wurde. 
Im Unterschied zur Aviatik wird die Nautik in den Zigarettenalben nicht in den militärischen Kontext gesetzt. In den monothematischen Nautik-Alben, die fast ausschließlich zwischen 1930 bis 1934 publiziert wurden, stehen die nationale und internationale Seefahrt im Fokus. Diese Darstellung korrespondiert mit der politischen Strategie der Weimarer Republik, die die Schifffahrt ganz in den Dienst des wirtschaftlichen Wiederaufstiegs gestellt hatte. Mit der Machtergreifung erfolgte im Unterschied zur Aviatik kein Paradigmenwechsel, denn die Schifffahrt blieb im öffentlichen Diskurs bedeutender Faktor für die ökonomische Konsolidierung Deutschlands. Selbst die deutsche Kriegsmarine wird lediglich marginal erwähnt, wobei dem Rezipienten in den Alben eine überalterte Flotte präsentiert wird. Ein weiterer markanter Unterschied ist der Versailler Vertrag. Während das Vertragswerk im Kontext der Aviatik als ,Schandvertrag' thematisiert wird, mit dem Deutschland seiner Ehre und Wehrkraft beraubt wurde, wird es in nautischen Sammelwerken vollständig ausgeklammert. Das für die Aviatik-Alben charakteristische verbale Waffenklirren wird gänzlich vermieden und die Sammelwerke verzichten darauf, die Bevölkerung für kriegerische Auseinandersetzungen emotional zu mobilisieren. Auch die Kriegshelden von einst werden weder heroisiert noch zu Vorbildern für soldatische Tugenden. Selbst U-Boot-Kapitäne, die während des Ersten Weltkrieges großes Ansehen und Popularität genossen hatten, finden keine Aufnahme in das nationale Pantheon. Die Nautik und ihre Protagonisten werden, im Unterschied zur Aviatik, nicht zur Ressource sakraler Sinnstiftung oder zum Identifikationsmoment an dem das NS-Regime partizipierte.

Die Divergenz zwischen der Darstellung der Nautik und der Aviatik reflektiert die innen- und außenpolitische Strategie des NS-Regimes vor dem Hintergrund des geplanten Angriffskrieges. Da die strategische Kriegsplanung bis weit in die 1930er Jahre hinein auf eine Ostexpansion ausgerichtet war und das NS-Regime einen Krieg mit Großbritannien vermeiden wollte, war der Aufbau einer Drohkulisse, insbesondere auf dem maritimen Parkett, diplomatisch nicht angezeigt. Darüber hinaus besaß das NS-Regime weder die Finanzkraft noch die erforderlichen Rohstoffe, um eine 
schlagkräftige Kriegsmarine aufzubauen. Bei den Rüstungsausgaben hatte die Luftwaffe Priorität. Der Zeitraum der Publikation der Nautik-Alben, der sich bis auf eine Ausnahme auf die Jahre 1930 bis 1934 erstreckt, unterstreicht die mangelnde elevanz der maritimen Streitkräfte im Rahmen des vom NS-Regime anvisierten Angriffskrieges.

Bei den Automobil-Alben findet ab der nationalsozialistischen Machtergreifung eine vergleichbare Zäsur statt wie bei den Aviatik-Alben. Während die Sammelbände, die bis 1933 publiziert wurden, ganz in der Weimarer Tradition der Wissensvermittlung stehen und den Automobilismus in einem internationalen Rahmen betrachten, werden die Kraftwagen nach der Machtergreifung in den nationalsozialistischen Kontext gesetzt. Auffällig ist die Konzentration auf den deutschen Rennsport. Diese thematische Fokussierung folgt der propagandistischen Leitlinie des NS-Regimes, den Automobilsport zu popularisieren. Das NS-Regime konnte die Propaganda so mit einer populären Massenkultur verbinden und gleichzeitig auf nationalem wie intentionalem Parkett das Potential deutscher Technik demonstrieren. Die Autorennen wurden als ,Rennschlachten' in einen militärischen Kontext von Kampf, Opferbereitschaft und Heldentum gesetzt. Darüber hinaus gelang es der NS-Propaganda, die Rennfahrer als Inkarnation des stählernen Kriegertypus zu installieren. Da der Automobilismus die Apotheose der Moderne und der Dynamik darstellte, konnte das NS-Regime, ebenso wie bei der Aviatik, von dem Nimbus der Technik partizipieren und ihn zur Stärkung des eigenen Images nutzen. Die Machthaber setzten die Technik nicht nur als Requisit zur Selbstdarstellung ein, sondern auch als Mittel, ihre Propaganda zu verbreiten. Exemplarisch dafür sind die Deutschlandflüge Hitlers sowie die Einsatzbereitschaft der SA, die ohne Automobile an Effizienz eingebüßt hätte.

Technische Themen waren nicht nur aufgrund ihrer Beliebtheit prädestiniert, um von der NS-Propaganda vereinnahmt zu werden. Technik und Mobilität ermöglichten es dem NS-Regime auch, seine eigene Dynamik und Mobilität zum Ausdruck bringen, denn der „Mobilitätsappell“ bestimmte maßgeblich die "Selbstdarstellung und 
Werbekraft" ${ }^{\prime 1439}$ des NS-Regimes, dessen mediale Außendarstellung insgesamt von Modernität geprägt war. ${ }^{1440}$ Die Faszination für den technischen Fortschritt war ein gesellschaftlicher Trend, der bereits um 1900 eingesetzt hatte und sich in Deutschland zwei Dekaden insbesondere in den technischen Schlüsselinnovationen des Automobilismus und der Aviatik manifestierte. Die Technik bot mit ihren Facetten einen weiträumigen Hintergrund, vor dem das NS-Regime seine vielfältigen Propagandaziele realisieren konnte. Entsprechend erfährt die Technik in den Zigarettenalben, die nach 1933 publiziert wurden, eine neue Konnotation.

Die Gegenüberstellung der drei Technik-Sparten belegt, dass die Technik in mannigfaltiger Weise für die NS-Propagandaziele benutzt wurde. Die Adaption technischer Themen steht dabei in direktem Zusammenhang mit den militärischen Ambitionen und der damit verbundenen außen- und innenpolitischen Darstellung des NS-Regimes. Die Zigarettenalben aller drei Technik-Sparten werden dazu genutzt, pazifistische Signale auszusenden, wobei lediglich der Automobilismus und die Aviatik für die emotionale Mobilmachung der Bevölkerung und zur Nachwuchsakquise für das NSKK und NSFK instrumentalisiert werden. Bei der Mobilisierung ist jedoch nach 1935/36 ein eindeutiger Paradigmenwechsel zu erkennen. Die nachfolgenden Publikationen sind von einem aggressiven Tenor geprägt und die Zigarettenalben werden zur Plattform für die Demonstration militärischer Potenz.

\footnotetext{
1439 Thamer (1986):Verführung, S. 400

1440 Vgl. Sachse, Rolf (2006): „Zur Kontinuität von Bauhaus und Moderne im NS-Staat". In: Böhnigk, Volker/ Stamp, Joachim (Hg.): Die Moderne im Nationalsozialismus. Bonn: University Press, S. 13. In den Zigarettenalben ist die Agrarromantik eine Marginalie, die sich vereinzelt im Themenspektrum wiederfindet wie in Adel der Arbeit und Deutschland baut auf
} 


\section{Jugendliche Zielgruppe}

Das NS-Regime etablierte ein umfassendes Erziehungssystem mit dem die Jugend im Geist des Nationalsozialismus erzogen werden sollte. Die Indoktrination erfolgte nicht nur in der Schule und in den Jugendorganisationen HJ und BDM, sondern auch über Medien wie Bilderbücher, Jugendromane ${ }^{1441}$ und Filme, die „verschiedene Wahrnehmungsmuster von Politik und Gesellschaft"1442 anboten. Das Bildungskonzept konnte damit subtil in den Lebensalltag der Jugendlichen integriert werden. „Es waren die kleinen Dinge des Alltags - Schul- und Kinderbücher, Anstecknadeln und Kartenspiele -, die unauffällig politische Ideen [...] “1443 transportierten. Ein verbreitetes wie beliebtes Medium für den Wissenstransfer waren Bilderbücher, die den Jugendlichen deutsches Kulturgut vermittelten sollten wie Volkskunde, Naturlandschaften und Errungenschaften deutscher Ingenieurskunst. Der Nationalsozialistische Lehrerbund (NSLB) betrachtete die moderne Wissensaufbereitung als pädagogisch wertvoll und betonte die Bedeutung des Bilderbuches für die Volkserziehung. ${ }^{1444}$,So leitet das zukünftige Bilderbuch das deutsche Kind in der Richtung, wie später Schule und Hitlerjugend an ihm arbeiten und es erwächst und festigt sich der Grundstoff, aus dem einmal in ihm die nationalsozialistische Weltanschauung sich aufbaut, die uns alle als Deutsche eint und bindet." 1445

Da die Bilderbücher und Sammelalben viele Parallelen aufweisen, kann davon ausgegangen werden, dass die Motive, die das NS-Regime veranlasst hat, Sammelalben zur Indoktrination der Jugendlichen einzusetzen, identisch sind. Sammelalben und Bilderbücher hatten ein vergleichbares didaktisches Konzept zur Wissensaufbereitung

1441 Jugendromane wurden als Lernmedien außerhalb der Schule eingesetzt. Vgl. Merkel, Kerstin/ Dittrich, Constance (2011): „Jugendwissen III: Gesichte“. In: Dies. (Hg.): Spiel mit dem Reich. Nationalsozialistische Ideologie in Spielzeug und Kinderbüchern. Wiesbaden: Harrassowitz, S. 127

1442 Kessel, Martina: „Gewalt schreiben“. In: Hartwig (2007): Ordnungen, S. 249

1443 Merkel/ Dittrich (2011): „Allgegenwärtig und ganzheitlich. Die Ideologie des Nationalsozialismus in Kindheit und Jugendzeit“. In: Dies. (Hg.): Spiel, S. 9

1444 Wippler, Hugo (1936): Die volkserzieherische Bedeutung des deutschen Bilderbuches. Schulungsvortrag der Reichswaltung des NSLB. Erarbeitet im Auftrag und in Gemeinschaft mit der Jugendschriftenabteilung der Reichsverwaltung des NSLB. Leipzig: o.V., S. 6ff. 
und bedienten identische Themen. Auch bei der Aufbereitung technischer Themen, bei der die technischen Leistungen Deutschlands ${ }^{1446}$ besonders herausgestellt werden, bestehen eindeutige Parallelen.

Diese Übereinstimmungen sprechen dafür, dass das NS-Regime das pädagogische Potential der Zigarettenalben nutzte, um manipulativ auf die Jugendlichen einzuwirken. Die spielerische Form der Wissensvermittlung provozierte die Neugier der Jugendlichen, womit eine „didaktische Strategie" genutzt wurde, die auch "heute noch in vielen Werken zur populären Wissensvermittlung“1447 angewendet ist. Obwohl das Produkt Zigarette von Erwachsenen konsumiert wurde, die auch die Bilder sammelten, zählten auch Jugendliche zur Zielgruppe der Bildersammler, denn „[W]wer sammelte denn überhaupt die Bilder? Das waren die Kinder [...] “1448 Das NSRegime konnte daher auch bei den Zigarettenalben die Jugendlichen erreichen.

\subsection{Zigarettenalben als Wissensquelle}

Die Akkumulation von Wissen in Form von Sammlungen ist sowohl ein kulturanthropologisches als auch ein entwicklungspsychologisches Phänomen. Mit dem Sammeln von Bildern kann Wissen insbesondere bei Kindern auf spielerische Weise vermittelt werden. Der pädagogische Ansatz des Sammelns zur Wissensvermittlung wurde von den Sammelalben übernommen. Das „Sammeln und Memorieren [...] anhand der Sammelbilder orientierte sich dabei an ein ganzheitliches Konzept" bei dem Themen nicht separat vermittelt wurden, „sondern als Gesamtheit, die im Zusammenspiel zu einem Wissensschatz führ[t]en.“1449 Sammler „bewegen sich dabei in einem Raster von Wissensvorgaben“ und „verknüpfen unterschiedliche Sinnhorizonte

\footnotetext{
1446 Vgl. Geoffrey, Giles (2000): „Die erzieherische Rolle von Sammelbildern in politischen Umbruchzeiten“. In: Papenfuß/ Schieder (2000): Umbrüche, S. 250

1447 Schweer (2010): Popularisierung, S. 205

1448 HIS PFR 230,35 Strafsache Reemtsma, 56. Verhandlungstag, 22. September 1948. Aussage Ph. Reemtsma in Bezug auf das NS-Zigarettenalbum „Der Kampf ums Dritte Reich.“ 
miteinander [...]. ${ }^{\prime 1450}$ Das gespeicherte Wissen zirkuliert und kann erinnert und abgerufen und werden. ${ }^{1451}$ Durch das Zusammentragen von Artefakten und Sortieren nach Ordnungskriterien entsteht ein sinnhaftes Konvolut, das „ein veräußerlicht angewandtes sinnlich-wahrnehmbares Denken“ visualisiert. ${ }^{1452}$ Neben der Akkumulation von Wissen erfüllt das begleitende Bildmaterial eine "mnemotechnische Funktion“, die dazu beiträgt, dass begleitende Textinhalte über eine „visuelle Eselsbrücke“ besser memoriert werden können. ${ }^{1453}$ Mit der Visualisierung der Texte können neben den Lerninhalten auch Emotionen und Eindrücke vermittelt werden, die im Text nicht oder nur schwer artikuliert werden können.

Im zeitgenössischen Diskurs genossen die Zigarettenalben als Medium der Wissenszirkulation und Bildungsquelle großes Ansehen. Dabei wurden insbesondere die Ambitionen der Zigarettenfabrikanten gelobt, die mit ihren Sammelwerken Wissen in breite Bevölkerungsschichten getragen hätten. Besondere Anerkennung erhielten die Malerei-Alben der Firma Reemtsma, denn ihnen sei es mit den hervorragenden Reproduktionen gelungen, zur „Popularisierung der Kunst“1454 beizutragen. Der pädagogische Nutzen der Sammelalben war den Zigaretten-Produzenten bekannt. So wies der Cigaretten-Bilderdienst der Firma Reemtsma auf die didaktische Bedeutung des Sammelns hin: „Die Sammeltätigkeit ist eine notwendige Ergänzung unserer auf Wort und Wissen angelegten Bildung." ${ }^{1455}$ Der Direktor des Reemtsma-Bilderdienstes Lose

1450 Strobel, Matthias/ Dippel, Andrea (2011): Die Kunst des Sammelns. Phänomene des Ordnens, Archivierens und Präsentierens. Nürnberg: Verlag für moderne Kunst, S. 12

1451 Vgl. Erll, Astrid (2011): Kollektives Gedächtnis und Erinnerungskulturen, 2. Aufl. Stuttgart: J.B. Metzler, S. 186

1452 Auch das lateinische Wort für "Sammeln „colligere“ mit dem Stamm „legere“ (=lesen) schließt folglich die durch Sammeln erfolgte Visualisierung eines rationalen Denkvorgangs ein. Vgl. Mielke (1982): Bilderbuch, S. 9

1453 Vgl. Ballsteadt, Steffen-Peter (2006): „Didaktisches Design für Abbilder“. In: Gorbach, Rudolf Paulus (Hg.): Bilder lesen und erkennen. Ein Symposium der Typographischen Gesellschaft München. München: TGM, S. 18f. Die Theorie der „doppelten Codierung“ wurde von Pavio (1978) untermauert. Sie basiert auf Gedächtnisexperimenten, die bewiesen haben, dass der Mensch Bilder besser behalten und reproduzieren kann als Text. Vgl. Lewalter, Doris (1997): Lernen mit Bildern und Animationen. Studie zum Einfluß von Lernermerkmalen auf die Effektivität von Illustrationen. Münster: Waxmann, S. 57

1454 HIS PFR 491,02 Deutsche Allgemeine Zigarettenindustrie vom 15. Mai 1942

1455 Lichtwart, Alfred in: Broschüre Cigaretten-Bilderdienst-Hamburg-Bahrenfeld. Was Ihnen der Bilderdienst bietet - HIS PFR 491,10 
hob die Vorzüge der Sammelwerke als Medium der Wissensvermittlung hervor: „Weiterhin aber auch die mit der Drucktechnik zu beobachtende Neigung, das Wissen nicht durch umständliche und zeitraubende Lektüre, sondern durch das Betrachten mit kurzem erläuterndem Text zu erweitern. Geschichtliche, technische und naturwissenschaftliche Darstellungen als Thema dieser Serien lassen sich schwerlich so kurz und einprägsam veranschaulichen wie durch die Illustrationen einer Bilderserie. " ${ }^{1456}$ Die Komplementarität von Bild und Text ermöglichte daher eine auf die jugendliche Zielgruppe zugeschnittene Wissensvermittlung. Das Zusammentragen und Tauschen von Sammelbildern ${ }^{1457}$ setzte auch eine soziale Interaktion innerhalb einer Gruppe in Gang. Damit konnte sich das Wissen durch Wiederholungen im Gedächtnis der Empfänger verfestigten ${ }^{1458}$ und $\mathrm{zu}$ einem Teil des individuellen Identifikationsraumes werden. ${ }^{1459}$

\subsection{Generationenzusammenhang}

Da der Mensch im Rahmen seines Erfahrungshorizontes eingebunden ist, hat jede Generation ihren eigenen Blick auf die Vergangenheit. Innerhalb dieses historischen Zeitfensters wird der Einzelne von individuellen, subjektiv gefärbten Erlebnissen geprägt, die „Überzeugungen, Haltungen, Weltbilder, gesellschaftliche Wertmaßstäbe und kulturelle Deutungsmuster" erzeugen, ${ }^{1460}$ wobei bei einem Generationswechsel auch die Möglichkeit besteht, dass Erinnerungen verfestigt oder eliminiert werden. ${ }^{1461}$

Die Bedeutung des "Generationenzusammenhangs“1462 wurde in den 1930er Jahren insbesondere von Günther Gründel, ${ }^{1463}$ einem wortstarken Repräsentanten der neuen

\footnotetext{
1456 HIS PFR 491, 08 Otto Lose - Bilderdienst 1953, S. 292

1457 Vgl. Ciolina, Erhard und Evamaria (1985): Garantiert Aecht. Das Reklame-Sammelbild im Spiegel der Zeit. München: Edition Wissen und Literatur/ Flade u. Partner, S. 128

1458 Vgl. Assmann (2006): Schatten, S. 33

1459 Vgl. Ebd., S. 34

1460 Vgl. Assmann (2006): Schatten, S. 26

1461 Vgl. Ebd., S. 27

1462 Cornelißen (2001): „Schuld“, S. 256f.

1463 Der Weltkrieg und die Weltwirtschaftskrise werden als Folge eines geistigen Zusammenbruchs betrachtet, der um die Jahrhundertwende eingesetzt hatte. Als Hauptursache wurden „Kapitalismus, Liberalismus und Demokratie“ angeführt. Für Gründel war der Nationalsozialismus eine "großartige innerdeutsche Erscheinung", die in eine hoffnungsvolle Zukunft
} 
rechtsgerichteten Historikergeneration erkannt. Er konstatierte nüchtern, dass „eine frühe Erschließung der Kinderseele für das Große Ganze, für völkisches und gesellschaftliches [...] und für das kollektive Erleben“1464 von vitaler Relevanz sei. Die Verbindung zwischen den Generationen war für Gründel Voraussetzung für die Gestaltung der Gegenwart und der Zukunft, ${ }^{1465}$ was aber nur gelingen kann, wenn die Jugend in einer Gemeinschaft „einheitlicher Willens- und Wesensprägung“ zusammengeführt wird. Gründel propagierte eine neue Form der Literatur, eine „neue Dynamik in der jungen Dichtung“" durch die den Jugendlichen sowohl die kulturellen Wurzeln als auch der Wertekanon der „neuwerdenden Zeit“"1466 nahegebracht wird. Nur so könne das Individuum Teil einer „kollektiven Macht“1467 werden, die für ein gemeinsames Ziel kämpft. Neben Gründel und anderen rechtgerichteten Historikern forderten reaktionäre Kreise bereits in der Weimarer Republik, der Jugend über Bildung und Erziehung die Heroen aus deutscher Vergangenheit wieder in das Gedächtnis zu rufen, um „die zerrissene Verbindung zwischen dem heute und dem echten wahren Gestern unserer Geschichte wiederherzustellen [...]“. ${ }^{1468}$ Im Rahmen der Wissensvermittlung nahm die deutsche Geschichte daher einen besonderen Stellenwert ein. ${ }^{1469}$ Mit der deutschen Historie sollte den Jugendlichen sowohl eine Gruppenidentität vermittelt werden als auch eine Überleitung bieten, die ein Zusammenführen von Gegenwart und Zukunft ermöglichen. ${ }^{1470}$ So forderte auch Hitler einen Geschichtsunterricht, der sich maßgeblich darauf beschränkt, „eine Lehrmeisterin für

weist. Vgl. Gründel, E. Günther (1934): Jahre der Überwindung. Breslau: Wilhelm Gottl. Korn, S. 111

1464 Gründel, Günther. Zit. nach: Cornelißen (2001): „Schuld“, S. 256f.

1465 Vgl. Gründel (1932): Sendung, München, S. 63

1466 Ebd., S. 116

1467 Ebd., S. 13

1468 Ritter, Karl Bernhard (1922): „Religiöse Grundeinstellung der Jugend“. In: Moeller et al. (Hg.): Front, S. 95

1469 Im Unterschied zu anderen Lehrmaterialien wurden die Geschichtsbücher bis in die Kriegsjahre hinein aufwendig produziert. Vgl. Merkel/ Dittrich (2011): „Jugendwissen III: Geschichte. In: Dies. (Hg.) Spiel, S. 127

Subrt/ Pfeiferová (2013): „Kollektives Gedächtnis“, S. 51 
die Zukunft“ zu sein und dem Lernenden ermöglicht „,eine eigene Stellungnahme in den politischen Angelegenheiten seines Volkstums “1471 $\mathrm{zu}$ beziehen.

In den 1930er Jahren hatte das kollektive Gedächtnis aufgrund der epochalen Umwälzungen mehrere Brüche erfahren. Durch die Überschneidung von insgesamt vier Generationen mit sehr unterschiedlichem Erfahrungshintergrund waren die Jugendlichen in einem kulturellen Rahmen aufgewachsen, der sich grundlegend von dem der Erwachsenen unterschied. ${ }^{1472}$ Insbesondere das Kriegsgeschehen des Ersten Weltkrieges war im Gedächtnis der Jugend nicht mehr präsent, was eine kollektive Entfremdung zur vergangenen Generation zur Folge hatte. Ziel konservativer und rechtsgerichteter Kreise war es, den Ersten Weltkrieg im Bewusstsein der Jugend zu verankern. Mit der Wiederbelebung der Kriegserlebnisse sollten "Sinnhorizonte der Nachkriegsgesellschaft"1473 geschaffen werden. Von Seiten des Staates bestand ein vitales Interesse, das gesamte Bildungs- und Erziehungssystem auf ein Geschichtsbild auszurichten, das der jungen Generation das Weltkriegsgeschehen in Erinnerung rief.

Da sich ein kollektives Gedächtnis nicht aus sich selbst heraus entwickeln kann, benötigt es „Materialisierungen“, die den Bezug zur Vergangenheit herstellen. ${ }^{1474}$ Damit historische Ereignisse in die kollektive Erinnerungskultur aufgenommen werden können, müssen sie „objektiviert“ und „eine Form gewonnen haben.“ Damit das Wissen für das Kollektiv zum Bestandteil der Erinnerungskultur wird, muss es über Medien verbreitet werden, ${ }^{1475}$ denn „[O]ohne die Möglichkeit schriftlicher Speicherung hat das identitätsstiftende Wissen einer Gruppe keinen anderen Ort als das menschliche Gedächtnis. “1476

\footnotetext{
1471 Hitler (1930): Kampf, S. 468

1472 Peukert veranschaulicht den Generationenkonflikt anhand der politischen Identifikationsfiguren der jeweiligen Epoche. Er unterscheidet zwischen der Gründerzeit, der Wilhelminischen Zeit und der Frontgeneration sowie der „Überflüssigen Kriegsgeneration.“ Peukert (1987): Republik, S. 26ff.

1473 Schnatz (2013): Söhne, S. 13

1474 Berek, Mathias (2009): Kollektives Gedächtnis und die gesellschaftliche Konstruktion der Wirklichkeit. Wiesbaden: Harrassowitz, S. 84f.

1475 Vgl. Ebd., S. 90

1476 Assmann (1992): Gedächtnis, S. 56f.
} 
Das kollektive Gedächtnis muss dabei nicht durch Hochliteratur gespeist, sondern kann auch über Medien der Populärkultur vermittelt werden. Die Rezipienten differenzieren nicht zwischen Hoch- und Trivialliteratur, denn sie unterstellen den Populärmedien einen Wahrheitsgehalt und sprechen ihnen einen „Wirklichkeitsbezug“1477 zu. Gerade die „Trivialliteratur bedient sich symbolischer Ressourcen, die dem kulturellen Gedächtnis zuzuordnen sind. In ihr werden Mythen perpetuiert, kulturspezifische Sinnstiftungsschemata vermittelt.“1478 So können auch über die populären Massenmedien Mythen und Symbole transportiert werden, die manipulativ auf den Empfänger einwirken, womit Ideologien vermittelt und verfestigt werden. ${ }^{1479}$ Das gilt insbesondere dann, wenn mit fotografischem Material gearbeitet wird. Im Kontext historischer Ereignisse wird der Geschichte in diesem Medium ein „objektiver Status zugesprochen“, 1480 denn die Fotografie suggeriert dem Betrachter ein wahres Abbild der Wirklichkeit. ${ }^{1481}$

Die Bedeutung der Gestaltwerdung durch Texte mit begleitendem Bildmaterial wurde auch von den Herstellern der Zigarettenalben erkannt. Entsprechend wurden auch Bilder eingesetzt, um historisches Wissen in der Erinnerungskultur der Deutschen zu etablieren und ein Band zwischen den Generationen zu knüpfen. Bei der Darstellung des Ersten Weltkriegs, der im Fokus vieler Zigarettenalben stand, sollten Bilder „anspornender Zeuge einer großen Zeit!“1482 sein und über die Generationen hinweg eine identitätsstiftende Erinnerungskultur etablieren. Die mahnende Stimme der rechten Gruppierungen, die vor dem Vergessen des Weltkriegsgeschehens warnte, drang bis in die Sammelwerke:

\footnotetext{
1477 Erll (2011): Erinnerungskulturen, S. 189

1478 Ebd.

1479 Vgl. Assmann (2006): Schatten, S. 30

1480 Butzer, Günter (2009): „Medienrevolution. Zum utopischen Diskurs in den Medientheorien Kracauers und Benjamins". In: Grunert, Frank/ Kimmich, Dorothee (Hg.): Denken durch die Dinge. Siegried Kracauer im Kontext, München: Wilhelm Fink, S. 156

1481 Erll (2011): Erinnerungskulturen, S. 141. Die Zigaretten-Firma ASS weist den Sammler einleitend explizit auf die Echtheit ihrer Fotografien hin: „Die Firma Ass hat darauf verzichtet, solche gestellten Bilder zu bringen [...] Sie will echte Kriegsaufnahmen zeigen (...)“. ASS (1932): Weltkrieg, Zum Geleit!, unpag.

1482 Reunion (1933): Weltkriegsbilder, Zur Einführung! unpag.
} 
„Doch eine große Gefahr bringt das $>>$ Tempo $<<$ unseres Lebens in sich mit seinen kaleidoskopartig, fast möchte man sagen filmartig ständig wechselnden Bildern: die Erinnerung, sogar um Großtaten unseres deutschen Volkes, droht unterzugehen. Das aber darf nicht sein. Das was die ältere Generation in 4 1/2 langen Kriegsjahren 1914-1918 Großes geleistet hat, darf nicht vergessen werden $[\ldots]^{\prime \prime 1483}$

„Hat sie (Anm.: die Jugend) zum Lesen keine Zeit mehr, so sollte ihr doch wenigstens durch das Bild Einblick verschafft werden in jene großen Tage deutscher Geschichte, deutscher Schicksalswende. Diesem Zwecke wollen unsere Sammelbilder aus dem Weltkriege dienen. ${ }^{\prime 1484}$

„Beinahe 2 Jahrzehnte sind seit Anfang des Weltkrieges 1914-1918 vergangen. Langsam beginnt die Erinnerung an das große Weltgeschehen zu schwinden, da seine Hauptteilnehmer um fast 20 Jahre älter geworden sind. [...] $]^{\prime 1485}$

„Doch was nützt das geschriebene Wort und gedruckte Wort, wenn unsere junge Generation, die einer anderen Zeit entstammt, sich nicht auch ein Bild davon machen kann, wie es im Felde draußen gewesen ist. Um dem abzuhelfen und für eine möglichst große Verbreitung von wirklichen, echten Kriegsbildern zu sorgen hat sich die Firma „Zigarettenfabrik ASS Kom.-Ges. München“, entschlossen, ihren Zigarettenpackungen der neuen Marke „14-18“ solche Bilder beizulegen. ${ }^{1486}$

„Wohl gedenkt man noch dieses oder jenes wichtigen Ereignisses, aber die vielen Eindrücke im Bewegungskrieg und im Schützengraben [...] verblassen nach und nach im Gedächtnis und lassen nur noch schwache Umrisse erkennen. [...] So möge denn auch dieses Album ein kleines Erinnerungsmal sein an die große Zeit 1914-18.“1487

Aufgrund der distanzierten Haltung, die die Weimarer Republik zum Weltkriegsgeschehen eingenommen hatte, waren der Ersten Weltkrieg und seine Helden verblasst und ihr preußische Wertekanon aufgrund der pazifistischen Orientierung obsolet. Die noch im Kaiserreich populären Kriegshelden des Ersten Weltkrieges waren im Bewusstsein der Bevölkerung kaum noch präsent. ${ }^{1488}$ Auch das Militär besaß nicht

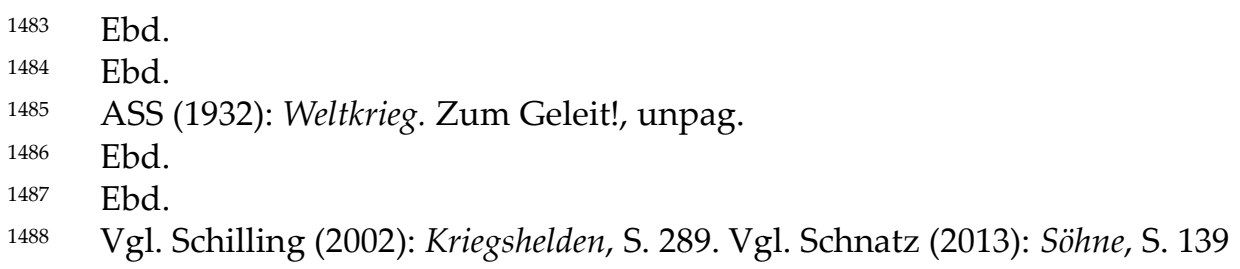


mehr den gesellschaftlichen Status wie zur Zeit des Kaiserreiches. ${ }^{1489}$ Mit dem Vergessen der Weltkriegsgeschichte und ihrer Protagonisten waren auch die soldatischen Tugenden, die geprägt waren von Pflichterfüllung und Opferbereitschaft für das Vaterland, nicht mehr das Ideal, das die deutsche Bevölkerung miteinander verband. Da der soldatische Wertekanon Basis für die emotionale Mobilmachung darstellte, war es für das NS-Regime von vitalem Interesse, den Ersten Weltkrieg im Bewusstsein der Jugend $\mathrm{zu}$ installieren. Eine Wiederbelebung der alten Werte konnte daher nur gelingen, wenn den Jugendlichen mit den Kriegserlebnissen eine Version des Krieges vermittelt wurde, die "Sinnhorizonte der Nachkriegsgesellschaft"1490 im Geist der NS-Ideologie schuf. Oberste Maxime des nationalsozialistischen Erziehungs- und Bildungssystem war daher die "politische Gesinnungsbildung“, 1491 die den Jugendlichen Werte wie Opferbereitschaft, Ehre, Kameradschaft und Gehorsam einprägen sollte. Da es sich dabei um Werte handelte, die das Fundament der NS-Ideologie bildeten, mussten das Geschichtsbild und der Erste Weltkrieg neu konnotiert und im kollektiven kulturellen Gedächtnis der nachfolgenden Generation verankert werden. In dem Album ALLES FÜr DeUTSCHLAND - 2000 JAHRE DEUTSCHE GESCHICHTE UND DEUTSCHES HELDENTUM ${ }^{1492}$ werden gemäß der propagierten Pädagogik ideologische Glieder zwischen den Generationen geknüpft.

„Opferbereitschaft und Wehrhaftigkeit, Treue und Pflichterfüllung sollen nach dem Willen des Führers die Grundlagen bilden zur wahren Volksgemeinschaft. „Du bist nichts, dein Volk ist alles!“ / „Alles für Deutschland“ / das soll der Leitgedanke dieses Werkes sein. Wie Deutschland aus tiefer Schmach immer wieder den Weg fand zu höchster Geltung im Weltgeschehen, das soll in den 360 Bildern aus deutscher Geschichte an uns vorüberziehen. Was in den Nachkriegsjahren unserer Jugend vorenthalten wurde, die Achtung vor nationaler Größe und heldischen Geist, das wollen wir helfen, weiter zu festigen. ${ }^{\prime 1493}$

\footnotetext{
1489 Vgl. Schilling (2002): Kriegshelden, S. 292

1490 Schnatz (2013): Söhne, S. 13

1491 Scholtz, Harald (2009): Erziehung und Unterricht unterm Hakenkreuz, Göttingen: V\&R, S. 10

1492 Brinkmann (YOSMA) G.M.B.H. (1934): Alles für Deutschland - 2000 Jahre deutsche Geschichte und deutsches Heldentum. (Textbearbeitung von M. Gutewort und Oberstleutnant Hänichen). Bremen

1493 Ebd., Vorwort, unpag.
} 
Zur Etablierung des neuen kollektiven Bewusstseins war es erforderlich, neben der jungen auch die Generation der Kriegsteilnehmer einzubeziehen. Mit der Erinnerung an den Ersten Weltkrieg und der Auratisierung seiner Helden konnten ihre Werte in die Gesellschaft getragen und an die Jugend weitergereicht werden. Der Wertekanon der wilhelminischen Gesellschaft, der geprägt war von Ehre, Pflicht und Opferbereitschaft für das Vaterland, der in der Weimarer Republik an Geltung verloren hatte, konnte damit restauriert werden. In den Zigarettenalben werden mit der Ehrung der Frontsoldaten und Kriegsveteranen auch die soldatischen Tugenden gelobt und hervorgehoben:

„So haben alle alten Frontsoldaten die Brücke zur jüngeren Generation geschlagen und bringen als beste Gabe die drei vornehmsten deutschen Soldatentugenden, erhärtet in hunderten von Schlachten, mit: „Treue, Tapferkeit und Kameradschaft." So sind auch die alten Frontkämpfer, vollzählig ins Dritte Reich, ins neue Deutschland, eingezogen. ${ }^{\text {"1494 }}$

„Oft hatte es in den Nachkriegsjahren geschienen, als seien die unerhörten Leistungen, die der unbekannte deutsche Soldat des Weltkrieges vollbracht hat, und die unermeßlichen Opfer besten deutschen Mannestums umsonst gewesen. Auch hier hat der nationalsozialistische Staat Wandel geschaffen und dem Frontsoldaten wieder die verdiente Ehrenstellung eingeräumt. “1495

Damit konnte das „Opfergedächtnis der Soldaten“ das „,in einer heroischen Semantik kodiert und die religiöse Bedeutung des Martyriums in sich aufgenommen"1496 hatte, als Teil des kulturellen Erbes in das kollektive Gedächtnis implementiert werden. Durch die Einbeziehung der Kriegsteilnehmer konnte sich das NS-Regime den Rückhalt dieser sozialen Gruppe sichern. Die Weltkriegsveteranen, die in der Weimarer Republik nicht den erwarteten sozialen Rückhalt und Anerkennung gefunden hatten, konnten sich mit den gefallenen Kriegskameraden identifizieren, denn der „tote Kamerad“ stand „symbolisch für die verlorene eigene Identität."1497 Mit ihren traumatischen Erfahrungen erfuhren die Veteranen darüber hinaus eine emotionale

\footnotetext{
1494 Ebd., S. 103

1495 Kosmos (1934): Bilddokumente, Mappe 2, S. 31

1496 Assmann (2006): Schatten, S. 73f.

1497 Behrenbeck (2011): Helden, S. 139
} 
Bindung untereinander, was das Gefühl der Gemeinsamkeit stärkte. ${ }^{1498}$ Die Werte der Frontgeneration wurden im NS-Staat symbolisch aufbereitet und die Kriegsteilnehmer erhielten die Anerkennung von der Gemeinschaft ${ }^{1499}$ (Abb. 20). In dem Album BILDDOKUMENTE UNSERER ZEIT wird den kriegsversehrten Frontsoldaten ein eigenes Kapitel gewidmet. Dabei wird explitzit darauf verweisen, dass die Leistungen und Opfer der Soldaten, im Unterschied zur Weimarer Zeit, gewürdigt werden ${ }^{1500}$ (Abb. 20). Reichsjugendführer Baldur von Schirach weist in dem Sammelband ADOLF HITLER auf die Missachtung der Kriegshelden seitens der Weimarer Republik.

„Männer, deren heldischer Einsatz im Weltkrieg die Jugend hätte verpflichten müssen, wurden von der Presse und darüber hinaus sogar von maßgebenden Männern der Regierung verspottet und beschimpft, und ungestraft konnte heldische Ideal als Ideal der Dummheit öffentlich verhöhnt werden. “1501

Die Heldennarrationen über Soldaten wurden verdichtet und als traditionsstiftende Heldentaten ${ }^{1502}$ in das Repertoire deutscher Mythen aufgenommen. Die „Pflicht des Opfers ${ }^{\prime 1503}$ wurde zu einem Teil des deutschen Bildungsideals, das bereits im Schulunterricht vermittelt wurde ${ }^{1504}$ und auch Eingang in die Populärliteratur wie den Sammelalben fand. George L. Mosse verweist auf den Einsatz visueller Medien durch die NS-Ideologen hin, über die den Jugendlichen der soldatische Pflichtkanon als erstrebenswertes Ideal vermittelt wurde. „,[...] sichtbare Bilder waren für die Herstellung einer Kontinuität zwischen beiden Kriegen von Bedeutung [...] auf denen die Deutschen immer wieder zu unterschiedlichen Pflichten angehalten"1505 und für kriegerische Auseinandersetzungen konditioniert wurden. „Die Erziehung des deutschen Volkes zu „Wehrhaftigkeit"“ im ,Dritten Reich' geschah nicht zuletzt durch den

\footnotetext{
1498 Vgl. Schnatz (2013): Söhne, S. 20

1499 Vgl. Assmann (2006): Schatten, S. 75

1500 Kosmos (1934): Bilddokumente, Mappe 2, S. 31

1501 Reemtsma (1936): Hitler, Kapitel: Der Führer und die deutsche Jugend, von Baldur von Schirach, S. 107

1502 Vgl. Schultz, Maria (2012): „Erinnern und Erzählen“, S. 324

1503 Vgl. Ortemeyer, Benjamin (2010): Mythos und Pathos statt Logos und Heros, 2. Aufl. Weinheim: Beltz, S. 352

1504 Reichsinnenminister Frick erließ bereits im Mai 1933 reichseinheitliche Richtlinien zur Neuordnung der Lehrpläne. Im Jahr 1940 wurde das Thema „Deutsches Heldentum im Weltkriege“" in die Geschichtslehrpläne aufgenommen. Schilling (2002): Kriegshelden, S. $316 \mathrm{ff}$. 
Heldenkult.“1506 Mit jedem Bild, das der jugendliche Sammler in sein Album klebte, rückten die im Sinne der NS-Ideologie neu konnotierte Mythen und Helden des Ersten Weltkrieges wieder in das individuelle Gedächtnis. ${ }^{1507}$

„So möge denn auch dieses Album ein kleines Erinnerungsmal sein an die große Zeit 1914-18, möge es dem alten Soldaten helfen, seine Kriegserlebnisse wieder fester zu gestalten, und der Jugend zeigen, was die Väter geleistet haben gegen eine Welt von Feinden. ${ }^{\prime 1508}$

„Die Sturm-Zigarettenfabrik in Dresden, nicht ein großer Buch- oder Kunstverlag, der doch eigentlich dazu berufen wäre, macht nun dem deutschen Volke, in erster Linie uns alten Soldaten und der heranwachsenden Jugend, die sich ein Herz für das Große und Heldische in unserer Geschichte bewahrt hat, das vorliegende Geschenk. ${ }^{1509}$

Die Zigarettenalben reihen sich in die zeitgenössische Weltkriegs-Literatur ${ }^{1510}$ und Propaganda-Medien ein, die Heldennarrationen aufgriffen, um Heldenmut sowie Tat- und Opferbereitschaft in das Bewusstsein der Jugendlichen zu infiltrieren. ${ }^{1511}$ Das Album BildDOKumente unSERER ZeIT, Mit SONDERABTEILUng DeutSCHE JugEND, 1512 das primär die Jugendorganisationen fokussiert, widmet sich in einem eigenen Kapitel der Ehrung der Invaliden Frontsoldaten des Ersten Weltkrieges. ${ }^{1513}$ In dem gleichen Band zieht Baldur von Schirach eine Kontinuitätslinie von den gefallenen Helden die im Geist der jungen Genration weiterleben:

1506 Behrenbeck (2011): Helden, S. 425

1507 "Das kommunikative Gedächtnis umfasst Erinnerungen, die sich auf die rezente Vergangenheit beziehen. Es sind dies Erinnerungen, die der Mensch mit seinen Zeitgenossen teilt. Der typische Fall ist das Generationen-Gedächtnis. Dieses Gedächtnis wächst der Gruppe historisch $\mathrm{zu}$; es entsteht in der Zeit und vergeht mit ihr, genauer: mit seinen Trägern." Assmann (1992): Gedächtnis, S. 50

1508 ASS (1932): Der Weltkrieg 1914-18, Zum Geleit! unpag.

1509 Sturm (1932): Zeitalter Friedrichs, Zum Geleit, unpag.

1510 Der Führer der Luftschiffe Peter Strasser wird von ehemaligen Angehörigen der Kaiserlichen Marine als vorbildlicher Held dargestellt. „Das Leben Peter Strassers konnte nur mit dem Heldentod abschließen, ehe alles zusammenbrach, was für ihn das Höchste gewesen war, die Pflichterfüllung". Von Trotha, Vizeadmiral a.D. Zit. nach: Buttlar (1931): Zeppeline, S. 7

1511 Die Kriegsgeneration des Ersten Weltkrieges galt vielen als Inkarnation des neuen Menschen. „Als Ziel der Erziehung gilt mit Recht der heroische Mensch [...]“ Weniger, Erich: „Gedanken über den Wert der Kriegserinnerung und Kriegserfahrung". In: Militärwissenschaftliche Rundschau, 2.Jg., 1937, 237f. Zit. nach: Ortemeyer (2010): Mythos, S. 354

1512 Kosmos (1934): Bilddokumente unserer Zeit. Mit Sonderabteilung Deutsche Jugend - unser Stolz unsere Zukunft, Mappe 2. Dresden

1513 Kosmos (1934): Bilddokumente, Mappe 2, S. 31 
„Wir grüßen unsere toten Kameraden, die in der „unsterblichen Gefolgschaft der Hitler-Jugend" mit uns marschieren, und geloben, in ihrem Geiste zu arbeiten und weiterzumarschieren in das Deutschland der Zukunft, dessen Träger wir Jungen von heute sein werden. Baldur v. Schirach. ${ }^{\prime 1514}$

Durch die mediale Aufbereitung erhielt der Erinnerungsprozess eine neue Dynamik, die es den Jugendlichen ermöglichte, die Vergangenheit in die eigene Lebenswelt zu integrieren. So wurde über die Zigarettenalben eine Verbindung zwischen Vergangenheit und Zukunft hergestellt, die gleichzeitig eine „Kontinuität zwischen den beiden Kriegen“ erzeugte und „die Ideale und Einstellungen des Ersten Weltkrieges am Leben ${ }^{\prime 1515}$ erhielt.

\subsection{Vorbild Kriegsheld}

Ziel des NS-Bildungssystems war es, die Mobilisierung für einen Krieg voranzutreiben. Rechtsgerichtete Kreise waren überzeugt, dass „ohne einheitliche nationalsozialistische Willensbildung [...] aller Aufwand an wehrbegeisterter Erziehung nutzlos vertan“1516 sei. Um die Jugendlichen für einen Krieg zu mobilisieren wurden Werte installiert, die über die Helden des Ersten Weltkrieges transportiert wurden. Die Kriegshelden von einst wurden zu Vorbildern, denen die Jugend nacheifern sollte. In vielen Zigarettenalben fordert Jugendführer Baldur von Schirach, dass die Jugend an „die Tradition der Front" ${ }^{\prime 1517}$ anknüpft soll und betont dabei explizit die erzieherische Bedeutung heroischer Vorbilder:

„Weiß nicht jeder Erzieher, daß eine Jugend großer und vor allem heroischer Vorbilder bedarf, um die Entwicklung nehmen zu können, die für das Volk notwendig ist? “ ${ }^{\prime \prime} 18$

\footnotetext{
1514 Kosmos (1934): Bilddokumente, Mappe 2, S. 70

1515 Mosse (1993): Gefallen, S. 227

1516 Metzsch (1935): Wehrkräfte, S. 130

1517 Reemtsma (1933): Deutschland erwacht, Kapitel: Die Hitlerjugend, Sonderbeitrag von Reichsjugendführer Baldur von Schirach, S. 58.

1518 Reemtsma (1936): Hitler, Kapitel: Der Führer und die deutsche Jugend, von Baldur von Schirach, S. 107
} 
Einzig und allein in der Front von einst sieht sie [Anm.: die HJ] die gedankliche Voraussetzung ihrer jungen Gemeinschaft. Sie ist nicht bündisch, sondern heroisch. Ihr Ziel ist nicht der kleine Bund, sondern die große Nation. ${ }^{1519}$

In den 1930er Jahren hatten insbesondere Jugendliteratur und Jugendfilme über Fliegerhelden Hochkonjunktur. ${ }^{1520}$ Mit der Abenteuermentalität, die der Fliegerliteratur inhärent ist, wurden Initiationsriten transferiert, die prädestiniert waren, die Begeisterung der Jugendlichen zu entfachen. Der Propaganda gelang damit, aufgrund der zielgruppengerechten emotionalen Ansprache, die Bedürfnisse der Bevölkerung $^{1521}$ und insbesondere die der Jugendlichen $\mathrm{zu}$ befriedigen. Beispielhaft waren Abenteuerromane wie "Segler durch Wind und Wolken“1522 oder „Me 109 der siegreiche deutsche Jäger", ${ }^{1523}$ einem Bildband von Heinrich Hoffmann, mit dem die Jugendlichen in einer Bilderfolge über den Segelflug zum Kampf in der Luftwaffe herangeführt werden sollten.

Viele Aviatik-Alben nehmen Rekurs auf die Fliegerhelden. Den Jugendlichen wird dabei die moralische Pflicht auferlegt, sich angesichts der Repressalien des Versailler Vertrages und der toten Kameraden dem Segelflug zu widmen. Dieser Tenor gleicht den öffentlichen Verlautbarungen Görings. In seiner Rede „Der Alte Fliegergeist lebt“

\footnotetext{
1519 Reemtsma (1933): Deutschland erwacht, S. 58

1520 Jugendbücher, in denen die Heldentaten der Kampfflieger verherrlicht wurden, erfreuten sich bereits während des Weltkrieges großer Beliebtheit. Die Flieger lieferten Vorbilder, denen die Jugend nacheifern sollte. Vgl. Esposito (2011): Moderne, S. 179

Manfred von Richthofen und Ernst Udet waren Ikonen. In den 1930er Jahren wurden diverse Flieger-Filme produziert, wie: „Flieg, deutscher Adler - flieg!“ (1939), „Vom Pimpf zum Flieger" (1941) „Flieger, Funker, Kanoniere“ (1937). Stambolis (2016): „Junge Adler“, S. 225

1521 Gudrun Wilcke betont, dass die Propagandastrategen der NSDAP sich der Bedeutung der emotionalen Ansprache des Volkes bewusst waren und die Propaganda gezielt darauf ausrichtete. Wilcke, Gudrun (2005): Die Kinder- und Jugendliteratur des Nationalsozialismus als Instrument ideologischer Beeinflussung, Frankfurt/M.: Peter Lang, S. 25

1522 „Segelflug ist ein Sport, ein herrlicher, männlicher königlicher Sport. Sport bedeutet Kampf und der Einsatz der Segelflieger es ist sein Leben. Jugend will kämpfen, sie will die gewaltigen Kräfte der Natur unter ihren Willen zwingen, sie sucht die Gefahr und stellt sich zum Kampf.“ Karlson, Paul (1933): Segler durch Wind und Wolken. Berlin: Ullstein, S. 84

1523 Hoffmann, Heinrich (Hg.) (1941): Me 109 der siegreiche deutsche Jäger. Entwicklung. Bau. Einsatz. München: Verlag Heinrich Hoffmann (in Zusammenarbeit mit der Messerschmidt A.G.)
} 
mahnt er an die „Pflicht, diesen Geist lebendig zu halten“ und von dem „Recht, unsere Helden zu ehren, sie der deutschen Jugend als Vorbild hinzustellen." ${ }^{1524}$

„[...] der Drang der Deutschen Jugend zum Fliegen war stärker, als die Fesseln, die uns banden. [...] Die Achtung vor unseren großen Fliegern des Weltkrieges steckt in jedem Deutschen [...] Die Opfer aber sollen, und werden auch nicht umsonst gewesen sein!" ${ }^{1525}$

Die Propaganda verfehlte ihre Wirkung nicht, denn die Jugend war vom Fliegen fasziniert und viele strebten eine Laufbahn als Pilot an. ${ }^{1526}$ Die Jugendlichen Rezipienten erhielten über die Fliegermythen ein Ordnungsmodell, das mit dem gesellschaftspolitischen Leitlinien konform ging. Damit konnte „[D]die moralische Ordnung mit den moralischen Notwendigkeiten des wirklichen Lebens in der Zeit, hier und jetzt, Schritt halten“1527 und internalisiert werden. Die Ritter der Luft und ihre Heldentaten wurden von den Heranwachsenden adaptiert und als nachahmenswerte Vorbilder der eigenen Lebenswelt angepasst. ${ }^{1528}$ Der Opferritus des Helden wurde zu einem Rollenkonzept, dem es nachzueifern galt. ${ }^{1529}$ Das Album UNIFORMEN IM NEUEN DEUTSCHLAND weist explizit auf die Intention des Sammelbandes hin, den Jugendlichen nicht nur die Wehrmacht vorzustellen, sondern auch die Tugenden des deutschen Soldaten wie „Ehre, Opferbereitschaft, Mut, Gehorsam und Kameradschaft“1530 zu vermitteln. Angesichts der militärischen Bedeutung der Luftwaffe war das anvisierte Ziel der NSMachthaber, potentielle Kampfflieger sowie Nachwuchs für die Weiterentwicklung der Luftfahrttechnik zu rekrutieren. Das NS-Regime benutzte die Zigarettenalben ebenso wie andere zeitgenössischen Medien zur emotionalen Mobilmachung und subtilen Nachwuchsakquise.

\footnotetext{
1524 Göring, Hermann (1934): „Der alte Fliegergeist lebt“. Rede zum Abschluß des Deutschlandfluges am 24. Juni 1934. In: Gritzbach (1938): Reden, S. 123 Reunion (1933): Volk von Fliegern, Einleitungstext, Einleitungstext Kapitel: A. Gleit- und Segelflugzeuge, unpag.

1526 Vgl. Stambolis (2016): „Junge Adler“, S. 224

1527 Campbell, Joseph (2007): Die Kraft der Mythen. Düsseldorf: Albatros, S. 24

1528 Vgl. Esposito (2011): Moderne, S. $179 \mathrm{ff}$.

1529 Vgl. Campbell (2007): Kraft, S. 23

1530 Aviatik (1936): Uniformen, Die Pflichten des deutschen Soldaten, S. 2
} 
„Nicht nur ein flüchtiges Sammelspiel sind darum diese Bilder; gewiß, sie sollen Freude bereiten. Aber aus der farbigen Fülle der Uniformen, Waffen, Geräte und Ausrüstungsstücke, die dieses Buch enthält, soll noch mehr erwachen: Vor unseren Augen soll das Gesamtbild unserer neuen Wehrmacht entstehen; und die Kenntnis des äußeren Kleides soll der deutschen Jugend die Augen öffnen auch für den inneren Wert, für Arbeit, Können und Aufgaben unserer Soldaten zu Lande, zur See und in der Luft." ${ }^{\prime 1531}$

„Aber die Berührung mit der Fliegerei fängt bereits sehr viel früher an. Nach einem Erlaß des Reichserziehungsministers beginnt bereits in der Schule die Einführung in das Flugwesen und die praktische Betätigung. Die Kleinsten lernen am Modell das Wesen des Fluges kennen, sie bauen selbst Modelle und machen sich mit allem, was in der Fliegerei wissenswert ist, dadurch spielend vertraut. "1532

"So ist der Segelflug zum Sport der deutschen Jugend geworden und man hat in ihm etwas geleistet, was die Anerkennung der ganzen Welt verdient. - Hoffen wird, daß der Flugsport noch viel mehr das ganze Volk begeistert, um das zu erreichen, für das auch unsere toten Kameraden gekämpft haben: für Ehre, Freiheit und Vaterland!" ${ }^{1533}$

Die Mobilisierung der Jugend für den künftigen Kriegseinsatz war politischer Konsens, denn „,wer die Jugend, auch die Zukunft hat.“1534 In Anbetracht der Relevanz der Opferbereitschaft als Bestandteil der NS-Ideologie hatte die Wiederbelebung und mediale Verbreitung des selbstlosen Heroismus im Kontext des Nationalsozialismus hohen propagandistischen Wert. Die Opfer der Kampfflieger wurden dem Volk als moralische wie nationale Verpflichtung auferlegt, sich gleichfalls selbstlos in den Dienst der Gemeinschaft zu stellen um die Schande von Versailles abzuwaschen. ${ }^{1535}$

\footnotetext{
$1531 \quad$ Ebd., Vorwort, S. 3

1532 Greiling (1936): Wunder des Segelfluges, Kapitel: Wie wird man Flieger?

1533 Reunion (1933): Volk von Fliegern, S.17

1534 Zinnecker, Bruno (1933): „Die Jugendfliegerbewegung“. In: Jünger (Hg.): Luftfahrt, S. 177

1535 Der Opfertod der Soldaten des Weltkrieges stand bereits in der Weimarer Republik im Zentrum des medialen Diskurses der politischen Rechten. Sie waren eine Mahnung an die nachfolgenden Generationen, die Schmach von Versailles zu rächen. Beispielhaft dafür ist das Gedicht „Treudeutsch“ von Hausmann: „[...] Heraus, sofern ist noch unser gedenkt! Die Schmach getilgt! Die Ketten gesprengt! Die Toten fordern ihr Recht. Die alte Treue vom jungen Geschlecht! Zit. nach: Lorenz (2008): Weltgericht! S. 229ff.
} 
In dem Album DeUTSCHER RuHM wird im Kapitel „Deutsche Helden der Luft“ mit dem Gelübde am Grab des Fliegerhelden Oswald Boelcke Opferbereitschaft eingefordert:

„Helden kämpfen nie vergebens!

Kann man ihren Sieg nicht melden,

Bilden sie doch neue Helden

Aus den Opfern ihres Lebens. ${ }^{1536}$

Die Verpflichtung, ein Opfer für die Gemeinschaft zu leisten, wurde den Kindern und Jugendlichen auf vielfältige Weise vermittelt. Die Zigarettenalben greifen das Thema der Opferbereitschaft im Dienst der Gemeinschaft auf. Der Sammelband BildDOKumente unserer Zeit MAPpe 2, Deutsche Jugend - UnSER StOlZ - UnSERE ZuKUNFT zeigt Angehörige der Hitler-Jugend beim Sammeln für das Winterhilfswerk WHW. Der freiwillige Dienst für das WHW war ein beliebtes Motiv, ${ }^{1537}$ das in den zeitgenössischen Medien vielfach bedient wurde, um für den selbstlosen Dienst an der Gemeinschaft zu werben. In dem Kapitel „Jugend sammelt für das Winterhilfswerk" sind neben Erwachsenen auch Gruppen von Jugendlichen abgebildet, die sich in den Dienst des Gemeinwohls stellen und an die Opferbereitschaft der Volksgemeinschaft appellieren (Abb. 21).

„Die Volksgemeinschaft, die Laufe weniger Monate im neuen Reich zu lebensvoller Wirklichkeit geworden war, findet ihren überzeugenden Ausdruck in Opfer- und Tatbereitschaft aller derer, die es als ihre Ehrenpflicht ansehen, der Not der Bedürftigen zu wehren [... “ ${ }^{\prime 1538}$

Mit diesen Sammelalben wurde nicht nur die Bevölkerung zum Spenden animiert, sondern den Kindern wurde das Gefühl vermittelt, einen wichtigen Beitrag für die Volksgemeinschaft zu leisten. Bei den Jugendlichen wurde so bereits früh der Opfergedanke installiert, der alle Lebensbereiche umfasste.

\footnotetext{
1536 Bergmann (1933): Ruhm, Bd.1, Kapitel: Deutsche Helden der Luft, unpag.

1537 Neben den kommerziellen Sammelalben warb das WHW auch mit Bildheften und nutzte damit Sammelleidenschaft der Jugendlichen aus. Vgl. Mielke (1982): Bilderbuch, S. 177 


\subsection{Technikfaszination}

Die starke Fokussierung der Technik in den Zigarettenalben reflektiert die damalige Faszination für technische und wissenschaftliche Themen. Die Sammelwerke korrespondieren aufgrund ihrer großen Anzahl und Auflagenhöhe mit den zeitgenössischen Publikationen. Wissenschaftliche Zeitschriften sowie Technik- und Science-FictionRomane, in denen Ingenieure zu Helden stilisiert wurden, ${ }^{1539}$ erfreuten sich in den 1930er Jahren insbesondere bei Jugendlichen großer Beliebtheit. Die Technik, so konstatiert Gründel, ist der „Abgott der Jugend“, der „gleich nach dem Sport kommt. [...] Diese Jugend verwechselt vielleicht Sinfonie und Simonie, aber bestimmt nicht BMW und DKW.“1540 Das NS-Regime hatte erkannt, dass es mit der Wissensvermittlung auf die Jugend einwirken und sie in einen ideologischen Diskurs involvieren konnte. Da es „[I]in der Erziehung vor allem „um die Vermittlung von Wissen“1541 geht, konnte die Technikfaszination der Jugendlichen dazu genutzt werden, sie über die Wissensvermittlung im Geist des Nationalsozialismus erziehen.

Insbesondere das NSKK und das NSFK nutzten die Begeisterung der Jugend für Technik und Naturwissenschaft. ${ }^{1542}$ Die Jugendlichen konnten bereits in der MotorHJ, deren Ziel es war, Soldaten für den Einsatz im Heer auszubilden, ${ }^{1543}$ eine Fahrausbildung erhalten. Das NSKK sah sich als Avantgarde und verband die technische Ausbildung mit Leibesertüchtigung und politischer Schulung. ${ }^{1544}$ Darüber hinaus erfüllten die Flugsportvereine eine sozialpsychologische Funktion, denn sie

\footnotetext{
1539 Würmann/ Warner (2008): Pausenraum. Bern/ Berlin: Peter Lang, S. 14. Die bekanntesten populärwissenschaftlichen Zeitschriften waren und ,Kosmos' und ,Unsere Welt'. Müller, Dorit (2008): „Populärwissenschaftliche Zeitschriften im 'Dritten Reich'“. In: Ebd., S. 24 und 33

1540 Gründel (1932): Sendung, S. 140

1541 Luhmann, Niklas (1995): Soziologische Aufklärung 6. Der soziologische Mensch. Opladen: Westdeutscher Verlag, S. 218f.

1542 Fack, Dietmar (2004): „Motorschule der Nation und Avantgarde der Volksmotorisierung. Formationserziehung und Formationskultur des Nationalsozialistischen Kraftfahrerkorps". In: Helsper, Werner/ Breyvogel, Wilfried/ Kamp, Martin/ Stelmaszyk, Bernhard (Hg.): Schule und Jugendforschung zum 20. Jahrhundert. Wiesbaden: VS Verl. für Sozialwissenschaften, S. 128

1543 Ebd., S. 189. 1944 wurde die Aktion "Jugend und Technik" ins Leben gerufen. Unter dem Motto „Technik hilft siegen“ sollte die Technikbegeisterung weiter gesteigert werden. Ziel war es, Nachwuchs für den Krieg zu akquirieren. Ebd., S. 173 
versprachen den Jugendlichen in einer aus dem Takt geratenen Welt der Nachkriegszeit mit dem Mangel an Perspektive und Identifikationsmöglichkeit das Gefühl der Gruppenzugehörigkeit sowie die Förderung ihrer Talente. ${ }^{1545}$

Ein weiterer bedeutender Bestandteil der vormilitärischen Erziehung war der Flugzeugmodellbau, der fester Bestandteil des Ausbildungsplans des NSFK war. ${ }^{1546}$ Damit wurde ein Trend aufgegriffen, der sich bereits in den 1920er Jahren etabliert hatte. Die NS-Regierung war sich über die Relevanz des Modellbaus als pädagogisches Instrument der Wehrerziehung bewusst und nutzte das spielerische Moment, ${ }^{1547}$ um den Jugendlichen die Grundlagen aerodynamischer Forschung zu vermitteln. ${ }^{1548}$ Ab 1934 wurde auf Erlass des Reichserziehungsministers Rust der Modellflugzeugbau Bestandteil des Lehrplans. Am Ende des Jahres 1939 wurde der „Flugzeugmodellbauunterricht als Pflichtfach für männliche Schüler in allen 6. und 7. Klassen“1549 eingeführt. Unter dem Motto „Es gilt dem Vaterland, wenn wir zu spielen scheinen“, 1550 wurde der Modellbau „Keimzelle der Flugtechnik“. ${ }^{1551}$

Die Zigarettenalben greifen die Technikbegeisterung der Jugendlichen auf, wenn auch mit unterschiedlicher Motivation. Sammelbände wie DAS DEUTSCHE VOLK MUSS EIN VOLK VON FLIEGERN WERDEN oder WUNDER DES SEGELFLUGES vermitteln anschaulich aerodynamische Grundlagen, Strömungstechnik sowie den Einfluss meteorologischer Faktoren, die beim Segelflug zum Tragen kommen, werben aber gleichzeitig für

1545 Desillusionierung, Hoffnungslosigkeit und der Mangel an Identifikationsmöglichkeit mit den politischen und kulturellen Gegebenheiten in der Weimarer Republik machte die Jugendlichen anfällig für die Flucht in eine uniformierte Ordnungsstruktur. Vgl. Nassen (1987): Jugend, S. 23

1546 Für Schüler ab dem 11. Lebensjahr war der Modellflugbau Teil des schulischen Lehrplans. Vgl. Kehrberg (1942): Fliegerkorps, S. 55

1547 Der pädagogische Wert des Modellflugbaus wurde vom Staat im gesamten Ausbildungsbereich gefördert. Die Luftwaffe konnte so aus dem NSKK und der HJ ihren Nachwuchs rekrutieren. Vgl. Kehrt (2010): Krieger, S. 241f. In der zeitgenössischen Literatur zum Modellbau wird der Flugzeugmodellbau als Vorschule für das Fliegen betrachtet und nicht als reines Freizeitvergnügen. Vgl. Wegner, Hugo (1926): Flugzeugmodellbau. Halle: Selbstverlag Hugo Wagner, S. 25

1548 Vgl. Erfurth (2011): Luftfahrt, S. 22

1549 Zegenhagen (2007): Mädel, S. 156f.

$1550 \quad$ Kehrberg (1942): Fliegerkorps, Bildunterschrift und Fotografie, unpag.

1551 Vgl. Lippisch, Alexander (1933): „Der Modellflugbau“. In: Jünger (Hg.): Luftfahrt, S. 194 
NS-Fliegerorganisationen. Auch andere Alben knüpfen an den staatlichen Lehrauftrag an und werben ostentativ für den Segelflugsport und die Flugsportabteilungen der HJ und des NSFK.

„Nach einem Erlaß des Reichserziehungsministeriums beginnt bereits in der Schule die Einführung in das Flugwesen und die praktische Betätigung. Die Kleinsten lernen am Modell das Wesen des Fluges kennen [...] ${ }^{\prime 1552}$

„Jeder Flieger soll durch die Segelflugschulung gehen. Das Nationalsozialistische Flieger-Korps ist Träger der fliegerischen Ausbildung. Über die Luftsportscharen der HJ und die Fliegerstürme der NSFK steht jeden jungen Deutschen der Weg zur Fliegerei offen. ${ }^{\prime 1553}$

Eine Ausnahme bildet die Firma Garbáty. Sie folgt dem Trend des Modellflugzeugbaus und bietet dem Sammler im zweiten Band DIE EROBERUNG DER LUFT einen kolorierten und detailreicher Bastelbogen des Verkehrsflugzeuges Junkers F 13 an, ${ }^{1554}$ der auf das jugendliche Publikum zugeschnitten ist, verzichtet aber gänzlich auf patriotische Orchestrierung oder auf Werbung für NS-Organisationen (Abb. 22). Die neutrale Haltung korrespondiert mit dem gesamten Inhalt beider Alben, die von Völkerverständigung und dem politischen Tenor der Weimarer Jahre geprägt sind. Die Zigarettenalben reihen sich aber insgesamt in das erzieherisches Gesamtkonzept ein, mit dem das NS-Regime Nachwuchs für das NSKK und NSFK heranziehen wollte. Ferner kann davon ausgegangen werden, dass die Begeisterung für Technik und Naturwissenschaften angefacht werden sollte, um den rückläufigen Studentenzahlen ${ }^{1555}$ an technischen Hochschulen entgegenzuwirken.

\footnotetext{
1552 Greiling (1936): Wunder, Kapitel: Wie wird man Flieger?

1553 Monopol (1937): Deutschland, Kapitel: Segelfliegerei, unpag.

1554 Vgl. Garbáty (1932): Die Eroberung der Luft (Ausland). Bd. 2

1555 Ludwig, Karl-Heinz (2004): „Das Dritte Reich, seine Technik und Ingenieure“. In: Lorenz, Werner/ Meyer, Torsten (Hg.): Technik und Verantwortung im Nationalsozialismus. Münster: Waxmann, S. 27
} 


\subsection{Werbung für Jugendorganisationen}

Ziel des NS-Regimes war die systematische Erfassung der Jugendlichen, um sie im Geist des Nationalsozialismus zu erziehen. Das Erziehungskonzept umfasste neben psychologischer Indoktrination auch die organisatorische Disziplinierung in den parteieigenen Jugendorganisationen wie der Hitlerjugend (HJ) und dem Bund deutscher Mädel (BDM). Aufgrund der Bedeutung dieser Organisationen wurden die Jugendverbände massiv beworben. Da die Zigarettenalben ein von den Jugendlichen favorisiertes Medium waren, wurden auch diese vom NS-Regime als Werbeplattform genutzt, um die Jugend für einen Eintritt zu animieren. Bei ihren Werbemaßnahmen für die Organisationen verstanden es die Propagandastrategen, den Tatendrang und Enthusiasmus der jungen Generation für sich zu nutzen, ${ }^{1556}$ in dem sie insbesondere die $\mathrm{HJ}$ als dynamische Bewegung präsentierte, in der die Jugendlichen gefördert werden.

Die HJ, die in den 1920er Jahren von der SA gegründet wurde, hatte das Erbe der deutschen Jugendbewegungen wie dem Wandervogel und der bündischen Jugend ${ }^{1557}$ der wilhelminischen und Weimarer Zeit übernommen. ${ }^{1558}$ Nach der Machtübernahme wurden die Jugendverbände gleichgeschaltet, womit eine „Monopolisierung und Zentralisierung“1559 einherging, mit dem Ziel, die Jugend ideologisch zu

\footnotetext{
1556 Vgl. Thamer (1986): Verführung, S. 408

1557 Unter der 'Bündischen Jugend' wurden unterschiedliche Jugendbewegungen zusammengefasst, darunter Verbände der Arbeiterbewegung, der Kirchen und Parteien. Vgl. Speitkamp, Winfried (1998): Jugend in der Neuzeit: Deutschland vom 16. bis zum 20. Jahrhundert. Göttingen: V\&R, S. 185. Die Wandervogel-Bewegung war geprägt von einem „neuen Gemeinschaftsbedürfnis und -erlebnis."

Die Bewegung war eine Reaktion auf die Industrialisierung und die verkrusteten gesellschaftlichen Strukturen der wilhelminischen Ära. Schäfers, Bernhard (1998): Soziologie des Jugendalters: Eine Einführung, 6. Aufl. Wiesbaden: VS Verlag für Sozialwissenschaften, S. $53 \mathrm{ff}$.

1558 Nach der Gleichschaltung hatten ab 1937 auch christliche Organisationen keinen Einfluss mehr. Vgl. Thamer (1986): Verführung, S. 404f. Neben den Jugendverbänden wurden mit der Machtübernahme auch die Sportverbände zerschlagen, wobei einige Sportvereine ihre Mitglieder freiwillig überführten. Vgl. Buddrus, Michael (2003): Totale Erziehung für den totalen Krieg Hitlerjugend und nationalsozialistische Jugendpolitik, Teil 1. München: K. G. Saur, S. 229 
indoktrinieren und auf eine militärische Laufbahn vorzubereiten. ${ }^{1560}$ Die unterschiedlichen Gruppierungen hatten ihre Wurzeln in der gleichen Sozialkrise, die die Gesellschaft der Nachkriegszeit erfasst hatte. Viele antibürgerliche Jungendbünde sowie Nationalsozialisten verband der Gedanke der "Zivilisationskritik" und der „verpflichtenden Gemeinschaftsformen.“ Die Bünde blieben jedoch einer elitären bürgerlichen Gedankenwelt verhaftet ${ }^{1561}$ und lehnten die „plebejisch verstandene Massenbewegung der NSDAP“1562 ab. Die HJ partizipierte aber von dem antibürgerlichen Protestgedanken ${ }^{1563}$ und dem starken Identifikationsmoment der Mitglieder, das „zum Selbstbewusstsein und zur Identifikation mit der Organisation beitrug. “1564 Der antibürgerliche Charakter der Jugendbewegungen, der in romantischer Naturverbundenheit, ${ }^{1565}$ Musizieren, Wandern und Zelten seinen Ausdruck fand, wurde von der HJ übernommen. Im Unterschied zur bündischen Jugend wurde der gemeinschaftliche Charakter bei der HJ in eine „Kameradschaft des politischen Soldaten“1566 umgewandelt.

„Die Hitlerjugend bekennt sich deswegen zur Front weil sie sich als Trägerin dieser sozialistischen Tradition empfindet, die das "Wir" der Gemeinschaft höher stellt als das „Ich“ des einzelnen.“1567

Der kleine Hitlerjugendführer ist zugleich politischer und wehrmäßiger Träger seiner Idee, er ist seinen Kameraden der Verkünder der nationalsozialistischen Lehre [...]." ${ }^{\prime 1568}$

\footnotetext{
1560 Vgl. Vondung, Klaus (1971): Magie und Manipulation. Göttingen: V\&R, S. 59

1561 Speitkamp (1998): Jugend, S. 194

1562 Thamer (1986): Verführung, S. 403

1563 Vgl. Ebd., S. 402

1564 Kollmeier, Kathrin (2007): Ordnung und Ausgrenzung: die Disziplinarpolitik der Hitler-Jugend. Göttingen: V\&R, S. 94

1565 Vgl. Schreckenberg, Heinz (2001): Erziehung, Lebenswelt und Kriegseinsatz der deutschen Jugend unter Hitler. Münster: LIT, S. 202. Die Jugendbewegungen standen dem Nationalsozialismus ambivalent gegenüber. Es verband sie aber die Hoffnung auf Veränderung und Erneuerung. „Die Attraktivität der nationalsozialistischen Revolution lag nicht zuletzt in den Versprechungen, mit denen sie eine in Bewegung geratene Gesellschaft und eine nach Dynamik, Bewährung und Identität, nach Veränderung und Aufstieg strebende junge Generation lockte." Thamer (1986): Verführung, S. 400ff.

1566 Ebd., S. 402

1567 Reemtsma (1933): Deutschland, Sonderbeitrag von Reichsjugendführer Baldur von Schirach: Die Hitlerjugend, S. 59

1568 Ebd., S. 62
} 
Um die Eigenständigkeit der nationalsozialistischen Jugendorganisationen hervorzuheben, wurde nach der Machtübernahme die Usurpation der Jugendverbände und ihrer Traditionen bestritten. In dem Band DEUTSCHLAND ERWACHT unterstreicht Baldur von Schirach vehement die Unterschiede zum Wandervogel:

„So steht die Hitlerjugend in ihrer Auflehnung gegen überalterte Formen und gegen die im gestürzten Staate verkörperte falsche Autorität Ähnlichkeit aufweist mit der früheren Wandervogelbewegung, wie sehr sie im Willen zur Natur und im Dienst am Volkstum dieser großen Bewegung von einst vergleichbar ist, so sehr unterscheidet sie sich aber auch darin von ihr, daß die Hitlerjugend in folgerichtiger Durchführung ihrer Idee den Führergedanken, den Gedanken der Autorität nach unten und der Verantwortung nach oben zu einem von ihrer jungen Front untrennbaren Begriff formte, während die Wandervogelbewegung die wunderbaren Anfänge ihres Marsches vergaß und sich und ihre Idee in einer ständig fortschreitenden Demokratisierung variiert und damit sich selbst aufgab. " ${ }^{1569}$

„Mögen geistige Berührungspunkte zwischen der Jugendbewegung von einst und der Hitlerjugendbewegung von heute soviel als möglich vorhanden sein, der wirkliche Vorläufer der Hitlerjugend ist weder der Wandervogel noch irgendein anderer Jugendbund. “1570

Die Herausforderung für die NS-Jugendorganisationen bestand nicht nur darin, die Jugend für die NS-Organisationen zu begeistern, sondern auch, sie den Einflusssphären anderer sozialer Gemeinschaften zu entziehen. Die Verantwortlichen waren sich insbesondere der Gefahr erzieherischer Einflüsse seitens des Elternhauses bewusst. Bei der Akquise für die NS-Organisationen musste die Propaganda daher auch darauf ausgerichtet werden, den Einfluss der Eltern zu unterminieren. In dem Zigarettenalbum BILDDOKUMENTE UNSERER ZEIT aus dem Jahr 1934 richten sich die Bilder, die die spannenden Aktivitäten der HJ zeigen, nicht nur an die Jugendlichen, sondern es ergeht auch ein eindeutiger Appell an die Eltern, ihre Kinder in die Obhut der HJ zu geben. Ihnen wird suggeriert, ihre Kinder andernfalls aus der sozialen Gemeinschaft auszugrenzen. Da eine Mitgliedschaft explizit mit einem Bekenntnis für Hitler

\footnotetext{
1569 Ebd., S. 58

1570 Ebd.
} 
verknüpft wird, wird eine Verweigerung unterschwellig mit einer ablehnenden Haltung gegenüber dem Führer und dem Nationalsozialismus verbunden.

„Und Du, deutscher Junge, deutsches Mädel, die Du noch abseits stehst. Du, deutscher Vater, deutsche Mutter, die Du bisher noch zögertest, Dein Kind zu uns zu geben: Betrachte die Bilder mit besonderer Kritik: unsere Jugend will nichts weiter sein, als Ausdruck des Glaubens an die Zukunft unseres Vaterlandes und ein starkes Bekennen zu seinem Führer Adolf Hitler. [...] Jugend marschiert!

Marschiere mit uns für Deutschlands Zukunft!

Jugend heraus!" ${ }^{\prime 1571}$

Aller Propagandamaßnahmen zum Trotz, die Jugend für einen Beitritt in die NS-Organisationen zu animieren, blieben die Mitgliederzahlen hinter den Erwartungen zurück. Obwohl das NS-Regime die Begeisterung der Jugendlichen für Sport, Motorsport und „Abenteuer- und Lagerfeuerromantik“1572 zu nutzen wusste, waren im Jahr 1935, als die HJ zur „Reichsjugend“1573 erhoben wurde, lediglich 48,3 Prozent der Jugendlichen den Organisationen beigetreten. Auch massive Werbekampagnen konnten den Trend der stark rückläufigen Zahlen an Neuzugängen sowie die hohe Austrittsquote nicht verhindern. Bereits 1934 zählte die HJ 300.000 Austritte und im Jahr 1935 kam es zu einer Stagnation der Mitgliederzahlen. ${ }^{1574}$ Da die NS-Führung und der Reichsjugendführer von Schirach die gesamte Jugend der HJ und dem BDM zuführen wollten, bestand Handlungsbedarf. Die nationalsozialistischen Organisationen nutzen daher verstärkt populäre Medien wie Radio und Presse als Plattform, um die Jugendlichen für die HJ und den BDM zu begeistern. ${ }^{1575}$ Dabei wurden auch die unter Jugendlichen beliebten Zigarettenalben für die facettenreiche Propaganda eingesetzt:

\footnotetext{
1571 Kosmos (1934): Bilddokumente, Mappe 2, unpag.

1572 Speitkamp (1998): Jugend, S. 224

1573 Buddrus (2003): Erziehung, S. 257

1574 Vgl. Ebd., S. 255. Auch die zunehmende Militarisierung machte den Dienst in der HJ unattraktiv und bewog viele zum Austritt. Vgl. Speitkamp (1998): Jugend, S. 226

1575

Vgl. Thamer (1986): Verführung, S. 406
} 
„Jungvolk und Hitler-Jugend! [...]

Seht Euch unsere Bilder an, lacht Euch dann nicht das Herz? Welcher Junge, welches Mädel möchte nicht dabei sein bei unseren Wanderungen, die nicht nur der Gesundheit dienlich, die in höchstem Maße Charakter und Geist schulen wollen! Und Thr Älteren: Seid Thr nicht beinahe neidisch auf uns, wenn Ihr bedenkt, wie Eure Jugend verlief? [...]“1576

Die Zigarettenalben vermitteln den Jugendlichen ein idyllisches Bild von der HJ und präsentieren die zahlreichen Aktivitäten wie Wassersport, Zelten, Bergwandern und Geländespiele. 1577 Die Sammelbände machen sich daher ebenso „[D]die anthropologisch konstanten Bedürfnisse der Jugend, sich vom Elternhaus zu lösen",1578 zunutze wie das Bedürfnis nach Abenteuererlebnissen inmitten Gleichgesinnter (Abb. 23). Exemplarisch für die zielgruppenadäquate Präsentation ist der Sammelband BILDDOKUMENTE UNSERER ZeIT. Die eigentlichen Ambitionen der Freizeitabenteuer, die Jugendlichen militärisch auszubilden, werden unterschwellig zum Ausdruck gebracht. Das Bildmaterial zeigt nicht nur Jugendliche bei sportlichen Betätigungen, die darauf abzielen, sie auf einen Kampf vorzubereiten, ${ }^{1579}$ sondern auch Aktivitäten, mit militärischem Charakter wie Aufmärsche, Appelle und Musikzüge sowie sportlichen Übungen. Der militärische Kontext kommt ferner durch die Zeichnungen der Uniform- und Dienstgradabzeichen der HJ zum Ausdruck. ${ }^{1580}$

Vergleichbare Motive wie Aufmärsche, Zeltlager und sportliche Aktivitäten in freier Natur zeigt das Album Jugend IN FRONT. BILDER AUS DEM LeBEN VON HitLER-JugEND UND -JUNGVOLK. Das kleinformatige Taschenbuch im Leporello-Falz hat aufgrund seines handlichen Formates, das in jede Hosentasche passt und der Bilder, die an Schnappschüsse von einem Ferienspaß erinnern, nahezu den Charakter eines kleinen

\footnotetext{
1576 Kosmos (1934): Bilddokumente, Mappe 2, unpag.

1577 Vgl. Ebd., Bilder auf den Seiten 59 - 98. Bilder des Albums: Lande (1932): Jugend in Front. Bilder aus dem Leben von Hitler-Jugend und - Jungvolk (Taschenbuch). Dresden, ohne Bildnummern, unpag.

1578 Maubach, Franka (2007): „Expansionen weiblicher Hilfe“. In: Steinbacher, Sybille (Hg.): Volksgenossinnen, S. 99

1579 Bei den Aktivitäten der HJ standen sportliche Übungen im Mittelpunkt. Sie waren integraler Bestandteil vormilitärischer Erziehung. Vgl. Buddrus (2003): Erziehung, S. 175 
persönlichen Fotoalbums, ${ }^{1581}$ was die Identifikation der jugendlichen Bildersammler erhöht haben könnte. Der militärisch konnotierte Titel und die Bilder, die nicht nur reine Freizeitaktivitäten zeigen, sondern auch vormilitärisches Training wie „Übung im Drahtverhau“, 1582 zeugen von der Strategie des NS-Regimes, mit dem Reiz des Abenteuers zu locken, aber gleichzeitig „Disziplin und freudige[r] Unterordnung“1583 im Rahmen einer vormilitärischen Ausbildung zu fordern.

Während in den Alben, die bis in die 1930er Jahre publiziert wurden, die Jugend primär mit spannenden Freizeitaktivitäten zum Eintritt in die HJ animiert wurde, weicht ab Ende der 1930er Jahre die subtile Propaganda einem imperativen Tenor. Der Sinn der Gelände- und Sportspiele, der der körperlichen Ertüchtigung im Rahmen einer vormilitärischen Ausbildung diente, wird nicht mehr als Freizeitspaß verschleiert oder in den Rahmen der Volksgesundheit gesetzt. ${ }^{1584}$ In dem Sammelband SYMBOLE Und AbZeICHEN Des DRITTEN ReICHeS, ${ }^{1585}$ eines der wenigen Alben, die im Jahr 1938 erschienen sind, werden die Pflichten der Jugendlichen und die erzieherischen Zielsetzungen kurz und prägnant artikuliert. Neben der nationalsozialistischen Weltanschauung sollen Verhaltensweisen wie Disziplin und Gehorsam antrainiert werden, die beim Militär gefordert werden.

„[...] die HJ. hat seit der Machtübernahme die Aufgabe gestellt erhalten, die gesamte deutsche Jugend in die nationalsozialistische Weltanschauung einzuführen [...] sie körperlich zu ertüchtigen. Die HJ. soll gehorchen lernen und Disziplin üben [...].

Von der Jugend hängt die Zukunft des deutschen Volkes ab. Die gesamte deutsche Jugend muß deshalb auf ihre künftigen Pflichten vorbereitet werden. $[\ldots]^{\mu 1586}$

\footnotetext{
1581 Der Eindruck eines Fotoalbums wird darüber hinaus dadurch verstärkt, dass außer Bildunterschriften kein Begleittext vorhanden ist. Vgl. Lande (1932): Jugend, ohne Bildnummern, unpag.

1582 Ebd.

1583 Reemtsma (1933): Deutschland erwacht, Kapitel: Sonderbeitrag von Reichsjugendführer Baldur von Schirach: Die Hitlerjugend, S. 64

1584 Vgl. Buddrus (2003): Erziehung, S. 255

1585 Standard (1938): Symbole und Abzeichen des Dritten Reiches. Berlin

1586 Ebd. S. 44
} 
Der Sammelband verharrt in diesem imperativen Ton und zitiert Auszüge aus dem 1936 erlassenen ,Gesetz über die Hitlerjugend', das die Jugendlichen an ihre Pflichten erinnert:

$\S 2$. Die gesamte deutsche Jugend ist außer in Elternhaus und Schule in der Hitlerjugend körperlich, geistig und sittlich im Geiste des Nationalsozialismus zum Dienst am Volk und zur Volksgemeinschaft zu erziehen.."1587

Auf der Basis dieser Verordnungen konnten HJ-Mitglieder für den Wehrdienst und andere Verpflichtungen herangezogen werden wie Ernteeinsatz sowie Grenz- und Luftschutz, ${ }^{1588}$ ein Einsatz, der unter anderem vom Reichsluftschutzbund geforderte wurde. ${ }^{1589}$ Da das NS-Regime aufgrund des geplanten Angriffskrieges Soldaten für die Wehrmacht benötigte, war es bereits 1937 zu einer Kooperation zwischen HJ und Wehrmacht gekommen. Damit konnte das Militär auf Rekruten zurückgreifen, die in der HJ auf den Wehrdienst vorbereitet waren. ${ }^{1590}$ Die Zigarettenalben trugen mit der Werbung für die HJ dazu bei, dass die Jugendlichen in den NS-Organisationen nicht nur im Geist des Nationalsozialismus erzogen wurden, sondern auch eine vormilitärische Ausbildung erhielten.

\subsection{Resümee}

Viele Zigarettenalben waren primär auf die Zielgruppe der Jugendlichen zugeschnitten. Die Sammelwerke reihten sich in das gesamte Erziehungskonzept des NSRegimes ein, das das Ziel hatte, soziale Wertmaßstäbe und kulturelle Deutungsmuster in das Bewusstsein der Jugendlichen zu implementieren. Die Zigarettenalben entsprachen mit ihrer Komplementarität von Bild und Text einem modernen Lernkonzept, das auch bei Schulbüchern und Medien der Populärkultur angewandt wurde.

\footnotetext{
1587 Ebd., S. 44. In der Novellierung des Gesetzes vom 1. Dezember 1939 wurde die „Jugenddienstpflicht" erlassen. Jugendliche sollten von ihrem 10. bis 18. Lebensjahr in der HJ Dienst tun. Sie konnten durch Polizeibehörden dazu angehalten werden. Vgl. Buddrus (2003): Erziehung, S. 225

1588 Vgl. Ebd., S. 277

1589 Der Luftschutz dient der Abwehr und Verteidigung. „Unsere Jungen werden und sollen sich nicht begnügen mit Vorbereitungen gegen die Gefahr aus der Luft“. Teetzmann (1934): Schicksalsfrage, S. 245ff.

1590 Vgl. Buddrus (2003): Erziehung, S. 182
} 
Aufgrund der Sammeltätigkeit waren die Zigarettenalben ein pädagogisch wertvolles Instrument der Wissensvermittlung. Durch das Sammeln und Memorieren konnte Wissen in seiner Gesamtheit vermittelt werden und das Zusammenspiel von Bild und Text erleichterte die Wissensaufnahme und das Erinnern der Lerninhalte. Das nationalsozialistische Erziehungs- und Bildungssystem, das vollständig auf die politische Gesinnungsbildung ausgerichtet war, wollte den Jugendlichen Werte wie Opferbereitschaft, Pflichtbewusstsein, Kameradschaft und Gehorsam vermitteln. Das gelang unter anderem mit der Rückbesinnung auf die Kriegshelden des Ersten Weltkrieges, die als heroische Vorbilder installiert wurden. Mit den Heldennarrationen wurde der preußische soldatische Pflichtkanon vermittelt. Dieser Wertekanon wurde als erstrebenswertes Ideal verherrlicht und medial verbreitet. Neben Schulbüchern wurden vor allem Medien der Populärkultur wie die Zigarettenalben benutzt, um diese Werte in das Bewusstsein der Bevölkerung zu implementieren, wobei insbesondere die Jugendlichen Zielgruppe fokussiert wurde.

Da der Weltkrieg und seine Helden sowie die preußischen militärischen Tugenden in der Weimarer Republik nicht nur an Geltung verloren hatten, sondern aus dem kollektiven Bewusstsein der Jugendlichen weitestgehend eliminiert waren, konnte über die Zigarettenalben ein Generationenzusammenhang hergestellt werden. Die Erinnerungskultur wurde insbesondere mit den Fliegern des Ersten Weltkrieges, die in den Zigarettenalben einen großen Stellenwert einnehmen, installiert. Mit den Fliegerassen von einst wurde eine Tradition gestiftet, die von soldatischen Tugenden geprägt war. Die Kriegshelden wurden zu heroischen Vorbildern, denen die Jugendlichen nacheifern sollten. Die Zigarettenalben trugen damit maßgeblich dazu bei, dem Erinnerungsprozess eine neue Dynamik zu verleihen. Die Jugendlichen erhielten damit neue Sinnhorizonte und Identifikationsräume. Die NS-Ideologie konnte über das populäre Massenmedium Zigarettenalbum subtil die Lebenswelt der Jugendlichen infiltrieren und sie für einen künftigen Krieg mobilisieren. 
Um die jugendliche Zielgruppe für sich einzunehmen, nutzte die Propaganda nicht nur die Technikfaszination und die Begeisterung für Abenteuerliteratur, sondern auch anthropologische Bedürfnisse dieser Altersgruppe, wie Loslösung von sozialen Einflussspähren und der Identifikation innerhalb einer Gemeinschaft von Gleichgesinnten. Da die Zigarettenalben ein von der Jugend favorisiertes Massenmedium war, konnten die Propagandastrategen die anvisierte Zielgruppe direkt erreichen. Damit gelang es nicht nur, den Jugendlichen Einstellungen und tragende Werte der NS-Ideologie zu vermitteln, denn durch die Indoktrination konnte die Zielgruppe zu gewünschtem sozialen Handeln motiviert werden. 


\section{Konklusion}

Die Zigarettenalben entwickelten sich in den 1930er Jahren zu einem vitalen Instrument der Wirtschafts- und Gesellschaftskommunikation. Da sowohl die Zigarettenindustrie als auch das NS-Regime manipulativ auf soziale Gruppen einwirken wollten, war es folgerichtig, dass Wirtschaft und Politik das beliebte Massenmedium als Kommunikationsinstrument einsetzten, um von dem propagandistischen Synergieeffekt zu profitieren. In den Zigarettenbildern mit NS-Inhalten manifestiert sich die Assimilation ökonomischer und propagandistischer Interessen, die seit Beginn der Professionalisierung von Werbung und Propaganda eingesetzt hatte. Die NS-Propaganda knüpfte bei der strategischen und operativen Planung an die Forschung der Weimarer Zeit an, die sich mit den sozialpsychologischen Grundlagen der Propaganda, Massenkommunikation und Werbewirkung sowie der Propaganda der Entente während des Ersten Weltkrieges auseinandergesetzt hatte.

Die kommunikationspolitische Allianz zwischen Politik und Wirtschaft beruhte nicht auf gesellschaftspolitischer Konformität, sondern auf einem vielschichtigen, beidseitigen Abhängigkeitsverhältnis. Die Beteiligung der Zigarettenindustrie an der NSPropaganda war bis auf wenige Ausnahmen kein Ausdruck einer politischen Gesinnung, sondern rein monetären Motiven geschuldet oder wie bei Reemtsma auch unternehmenspolitische Strategie. Letztendlich profitierten die Zigarettenfabrikanten wirtschaftlich, denn sie konnten an dem gesellschaftpolitischen Interesse der Bevölkerung in Bezug auf NS-Themen im Rahmen der Sammelwerke partizipieren. Aber auch das NS-Regime profitierte wirtschaftlich. Neben den finanziellen Vorteilteilnahmen und der Multiplikation der NS-Ideologie profitierte das NS-Regime von den Zigarettenbildern auch als psychologisches Instrument der Truppenbetreuung, denn das 
Oberkommando der Wehrmacht erachtete die Zigarettenbilder für die Betreuung der Soldaten als unerlässlich. ${ }^{1591}$

Mit der Nutzung der Zigarettenalben begab sich aber auch das NS-Regime in Abhängigkeit zur Zigarettenindustrie, denn Populärkultur erfordert effektive Produktionsmittel und Distributionskanäle, die die Multiplikation der Medien gewährleisten sowie ambitionierte Unternehmer, die eine Gewinnmaximierung verfolgen. ${ }^{1592}$ Das RMVP musste der Wirtschaft daher einen gewissen Freiraum bei der Themenwahl belassen, damit das Medium insgesamt nicht an Akzeptanz bei der Bevölkerung verlor. Angesichts der Tatsache, dass die so genannte Bekenntnisliteratur bei der Bevölkerung nie auf große Resonanz gestoßen und ab 1934 kaum noch nachgefragt war, bildeten die Zigarettenalben eine der wenigen Plattformen, auf der das NSRegime über soziale Schichten hinweg Bevölkerung erreichen konnte. Die Einflussnahme des NS-Regimes war damit ebenso begrenzt, wie die der Unternehmen, denn beide mussten den sozialpsychologischen Bedürfnissen der Bevölkerung Rechnung tragen. Sowohl Wirtschaft als auch Politik mussten, um Akzeptanz zu finden, die Themen bedienen, die vom Rezipienten nachgefragt wurden.

Die Untersuchungen belegen, dass die Zigarettenalben, die in den 1930er Jahren publiziert wurden, nicht ausschließlich zur Verbreitung nationalsozialistischer Propaganda verwendet wurden, sondern auch von Gemeinschaften genutzt wurden, die ihre spezifischen politischen und ideologischen Interessen vertreten wollten. Neben den Vertretern des sozialistischen Lagers war es die SA, die die Zigarettenalben als Sprachrohr für ihre eigenen Interessen in Anspruch nahm. Bei der Parteiarmee war es insbesondere der sozialistisch geprägte Flügel um Ernst Röhm, der mit den Alben der sympathisierenden Firma Sturm seine Interessen vertrat, die primär darin bestanden, eine Partizipation an der Macht zu legitimieren und einzufordern. Darüber hinaus boten die Zigarettenalben der Parteiarmee die Möglichkeit, die eigene Historie in der

\footnotetext{
$1591 \quad$ Vgl. Lindner (2007): Reemtsmas, S. 236

1592 Maase, Kaspar (2013): „Populärkultur - Unterhaltung - Vergnügung. Zur Systematik des Forschungsfeldes." In: Bareither et al. (2013): Unterhaltung, S. 31
} 
deutschen Geschichte zu verorten und eine Traditionslinie bis zu den Freiheitskriegen zu ziehen. Damit konnte die SA mit den Sturm-Alben sowohl eine faschistische Bewegungskultur etablieren, als auch eine eigene Historie installieren. Die SA und ihre Mitglieder erhielten so einen Identifikationsraum, der ihnen die Möglichkeit bot, sich als selbstbewusste und eigenständige Organisation zu definieren.

Die Lenkungshoheit über die Medien und die nationalen Symbole erlaubte es dem NS-Regime, die kommunikationspolitischen Maßnahmen stringent nach den eigenen politischen Zielen auszurichten. Da die Autonomie des Öffentlichkeitssystems völlig aufgehoben und alle Publikationen der staatlichen Kontrolle unterlagen, mussten auch die Zigarettenfabrikanten die Inhalte der Sammelalben regimekonform ausrichten. Dennoch konnten weder Politik noch Industrie bei der Kommunikationspolitik völlig autark agieren, denn aufgrund der Wechselbeziehung zwischen Kommunikator und Rezipient waren beide Parteien gezwungen, die Bedürfnisse der Bevölkerung und ihre sozialpsychologischen Identifikationsräume zu berücksichtigen. Die Propaganda des Nationalsozialismus war daher, wie in den Kommunikationswissenschaften vielfach dargestellt, kein dispositionales Konzept, bei dem das Individuum einem Reiz-Reaktions-Schema folgt.

Die Berücksichtigung der sozialpsychologischen Bedürfnisse der Rezipienten wurde insbesondere bei der Integrationspropanda verfolgt. Da sich die Demonstrationspropaganda, mit der sich das NS-Regime den Weg zur Macht geebnet hatte, nach 1933 weitestgehend erschöpft hatte und für den Machterhalt inopportun war, musste die Propaganda neu ausgerichtet werden und sich anderer Strategien bedienen. An ihre Stelle trat die Integrationspropaganda, die sich verstärkt der Medien der Populärkultur bediente wie der Zigarettenalben. Nachdem das NS-Regime nach 1933 einen Paradigmenwechsel von der Demonstrations- zur Integrationspropaganda vollzogen hatte, bediente es sich einer Vielzahl an Praktiken und Medien der Populärkultur wie den Zigarettenalben. Aufgrund ihrer Charakteristik war die Populärkultur prädestiniert, um für die Integrationspropaganda eingesetzt zu werden. Während die Popu- 
lärkultur zu Beginn ihrer Entwicklung von reinen Unterhaltungsangeboten geprägt war, die primär im privaten Umfeld konsumiert wurden, wurde sie ab 1920 „eingebettet in eine Vielzahl kultureller, sozial sich mehr und mehr vermischender Praktiken“,1593 die zunehmend von „Ideologisierung“ und „Heroisierung“ geprägt waren. ${ }^{1594}$ Da die Populärkultur auf Unterhaltung ausgerichtet ist, kann sie aber nur dann bestehen, wenn ein gewisser Grad an politischer Freiheit sowie eine Pluralisierung der Angebote vorhanden sind, denn nur die Wahlfreiheit ermöglicht es den Rezipienten, aus dem Angebot die Produkte auszuwählen, die ihren Bedürfnissen entsprechen. ${ }^{1595}$ Propaganda, die sich Medien der Populärkultur zunutze macht, muss unterhalten und Themen bedienen, die von den Konsumenten gewünscht werden. „Populärkultur unterhält, sonst ist sie keine, und die Propaganda mit und in ihr findet da ihre Grenze, wo das Produkt diese Funktion nicht mehr erfüllt $[\ldots]^{\text {“1596 }}$ Die NS-Propagandastrategen konnten daher bei der Wahl der Themen und deren Aufbereitung nicht völlig autark agieren, sondern mussten, ebenso wie die Wirtschaft, Konzessionen an die Bedürfnisse der Bevölkerung machen.

Mit dem Zigarettenalbum konnte das RMVP nicht nur das Bedürfnis der Bevölkerung nach Unterhaltung befriedigen, sondern auch gleichzeitig seine Propagandaabsicht verschleiern. Ein weiterer Vorteil bestand in der kontinuierlichen Schaltung des schichtübergreifenden Marketinginstrumentes. Die NS-Propaganda erhielt damit die erforderliche permanente Präsenz und konnte in breite Segmente der Bevölkerung diffundieren und dazu beitragen, das NS-Regime zu stabilisieren. Da die Zigarettenalben von der Privatwirtschaft erstellt und vertrieben wurden, konnte das NS-Regime nicht nur von dem hohen Propagandawert der Alben profitieren, sondern auch unentgeltlich die Ressourcen der Zigarettenindustrie nutzen. Durch die Inanspruchnahme des Distributionsnetzes des Bilderdienstes belastete die Propaganda in eigener

\footnotetext{
1593 Hügel, Hans-Otto (Hg.) (2003): Handbuch Populäre Kultur: Begriffe, Theorien und Diskussionen. Stuttgart: J. B. Metzler, S. 19

$1594 \quad$ Ebd., S. 18

1595 Maase (2013): „Populärkultur“ - Unterhaltung - Vergnügung. Zur Systematik des Forschungsfeldes." In: Bareither et al. (2013): Unterhaltung, S. 31 
Sache nicht das Budget des Propagandaministerium, denn, wie der Staatswissenschaftler Johann Plenge betonte: „Ausstreuen von Propaganda kostet viel Geld.“1597

Für die Phase der Integrationspropaganda waren Zigarettenalben ein ideales Medium für ein ausgefeiltes Kommunikationsmanagement, denn die relativ schnelle Produktion der Alben erlaubte eine zeitnahe Reaktion auf politische und gesellschaftliche Ereignisse. Der Propagandaerfolg der NS-Alben basierte demnach sowohl auf der Lenkungshoheit der Medien als auch auf dem vielseitigen Angebot und der zeitnahen Berücksichtigung der Publikumswünsche. So konnten längerfristige Propagandastrategien koordiniert und kurzfristig terminierte operative Maßnahmen zeitnah umgesetzt werden. Die thematische Vielfalt ermöglichte eine zielgruppenadäquate Ansprache unterschiedlicher Konsumentengruppen. Da die Zigarettenbilder einem Produkt beigelegt wurden, das von Erwachsenen aller sozialen Milieus konsumiert wurde, die Bilder aber insbesondere von Jugendlichen gesammelt wurden, erreichte das Medium breite Bevölkerungsschichten. So konnten Angehörige unterschiedlicher sozialer Milieus und Generationen vom Kriegsveteranen bis zum Jugendlichen erreicht werden.

Das NS-Regime bediente sich darüber hinaus Methoden und Medien der Wirtschaftswerbung, womit es gezwungen war, sich den Mechanismen der Wirtschaftskommunikation zu unterwerfen. Da sowohl die Bedürfnislage der Rezipienten, die sozialen und politischen Rahmenbedingungen sowie die Zielsetzungen der Werbeund Propagandatreibenden einem Wandel unterworfen sind, müssen die Strategien der Wirtschafts- und Gesellschaftskommunikation immer neu ausgerichtet werden. Andernfalls können die Empfänger nicht erreicht und unterschiedliche soziale Gruppen nicht zu gewünschtem Handeln motiviert werden. Entsprechend war nicht nur die Wirtschaft gezwungen, sich den wandelnden sozialpolitischen Rahmenbedingungen anzupassen, sondern auch das NS-Regime. Die Propaganda musste in den Jahren der Herrschaft immer wieder neu justiert werden. Um den Bedürfnissen der

1597 Plenge, Johann (1922): Deutsche Propaganda. Die Lehre von der Propaganda als praktische Gesellschaftslehre. Bremen: Angelsachsen-Verlag, S. 22 
Bevölkerung gerecht zu werden, knüpfte die Propaganda an Themen an, die von der Bevölkerung präferiert wurden. Populäre Themen und Propaganda konnten so in den Zigarettenalben verbunden und zielgruppenadäquat aufbereitet werden.

Das NS-Regime machte sich die Technikbegeisterung, von der die Majorität der Gesellschaft geprägt war, zunutze und machte sie zum integralen Bestandteil der Propaganda. Die Alben sowie der Zeitraum der Veröffentlichung reflektieren daher nicht nur die Bedürfnislage der Bevölkerung hinsichtlich ihrer sozialpsychologischen Identifikationsräume, sondern auch die Zielsetzungen des NS-Regimes. Es „trafen sich Politik und Propaganda, Populärkultur und Publikumswünsche“. ${ }^{1598}$ Technische Themen waren nicht nur aufgrund ihrer Beliebtheit prädestiniert, um von der NS-Propaganda vereinnahmt zu werden. Technik und Mobilität ermöglichten es dem NS-Regime auch, seine eigene Dynamik und Mobilität zum Ausdruck zu bringen, denn der „Mobilitätsappell“ bestimmte maßgeblich die „Selbstdarstellung und Werbekraft"1599 des NS-Regimes, dessen mediale Außendarstellung insgesamt von Modernität geprägt war. ${ }^{1600}$ Darüber hinaus ermöglichten Technik und Mobilität dem Staat auch eine Omnipräsenz.

Die Faszination für den technischen Fortschritt war ein gesellschaftlicher Trend, der bereits um 1900 eingesetzt hatte und sich in Deutschland zwei Dekaden später insbesondere in den technischen Schlüsselinnovationen des Automobilismus und der Aviatik manifestierte. Die Technik bot mit ihren Facetten einen weiträumigen Hintergrund, vor dem das NS-Regime seine vielfältigen Propagandaziele realisieren konnte. Entsprechend erfährt die Technik in den Zigarettenalben, die nach 1933 publiziert wurden, eine neue Konnotation. Während die Zigarettenalben, die in der Zeit der Weimarer Republik publiziert wurden, von einem internationalen wie völkerverbin-

\footnotetext{
1598 Kessel, Martina (2007): “Gewalt schreiben". In: Hartwig (Hg.): Ordnungen, S. 250

1599 Thamer (1986):Verführung, S. 400

1600 Vgl. Sachse, Rolf (2006): „Zur Kontinuität von Bauhaus und Moderne im NS-Staat". In: Böhnigk, Volker/ Stamp, Joachim (Hg.): Die Moderne im Nationalsozialismus. Bonn: University Press, S. 13. In den Zigarettenalben ist die Agrarromantik eine Marginalie, die sich vereinzelt im Themenspektrum wiederfindet wie in Adel der Arbeit und Deutschland baut auf
} 
denden Gedanken geprägt waren und technische Innovationen in den Kontext von Völkerverständigung und Handelsbeziehungen gesetzt wurden, erfuhren diese Themen in den Zigarettenalben mit der Machtergreifung der Nationalsozialisten eine Neukonnotation.

Dieser Paradigmenwechsel kommt insbesondere in den Aviatik-Alben zum Ausdruck. Die Luftfahrt besaß aufgrund ihrer vielschichtigen Themenbereiche eine starke Kohäsionskraft, mit der viele unterschiedliche Zielgruppen in eine Volks- und Gesinnungsgemeinschaft integriert werden konnten. Mit ihren Helden, Pionierleistungen und flugtechnischen Innovationen konnte sie als Integrationskraft für unterschiedliche Zielgruppen innerhalb der Bevölkerung eingesetzt werden. Die Luftfahrt war darüber hinaus eine Sinnressource für breite Teile der Bevölkerung und letztendlich auch ein vitales Symbol und sichtbarer Ausdruck für die erlösende Zeitenwende. Die Restriktionen und der Kriegsschuldartikel des Versailler Vertrages hatten eine traumatisierte Nation hinterlassen, die nach einer Befreiung vom kollektiven Trauma suchte. Im Kontext des Versailler Vertrages wurde insbesondere die Luftfahrt mit ihren technischen Errungenschaften zum Symbol der Wiederauferstehung und zur Projektionsfläche nationaler Größe und Triumph über die Schmach. In den Zigarettenalben werden die herausragenden technischen Leistungen, die von deutschen Technikern und Ingenieuren erbracht wurden, daher besonders fokussiert. Die Propaganda entsprach damit den kollektiven Bedürfnissen breiter Bevölkerungsschichten, denn mit den technischen Errungenschaften konnte nicht nur Deutschlands Ehre wiederhergestellt, sondern auch das Image als Kulturnation restauriert werden. Darüber hinaus war die Technik metaphysische Kraft und vitaler Impuls zur Restauration des nationalen Selbstbewusstseins. Die breite Rezeption in den Zigarettenalben reflektiert so die propagandistische Relevanz, die das Vertragswerk im Rahmen der Luftfahrt besaß. 
Der Versailler Vertrag wird nicht in allen Zigarettenalben gleichermaßen instrumentalisiert. Während in den Aviatik-Alben mit der Kampfkraft vermeintlicher Aggressoren ein Bedrohungsszenario errichtet wird, um den Aufbau einer Luftwaffe und eines Luftschutzes zu legitimieren, verzichten die Nautik-Alben darauf, die Rezipienten in diesen Diskurs zu involvieren. Die Propaganda verzichtet nicht nur aufgrund mangelnder Meriten und Reputation darauf, die Marine und ihre Helden zu instrumentalisieren, sondern auch aufgrund kriegsstrategischer Planung. ${ }^{1601}$ Während des Zeitraumes der Publikation der Zigarettenalben hatten andere Waffengattungen aufgrund der geplanten Ostexpansion Priorität. Ein Krieg zur See, insbesondere gegen England, stand nicht auf der Agenda. Die Wiederaufrüstung der Marine sollte erst zu einem späteren Zeitpunkt im Geheimen vonstattengehen.

Die inhaltliche Analyse der Zigarettenalben hat gezeigt, dass die thematische Aufbereitung mit den innen- und außenpolitischen Strategien des NS-Regimes korrespondiert. Während pazifistische Signale nach außen gesandt wurden, bediente sich die NS-Propaganda einer Palette an kommunikationspolitischen und sozialpsychologischen Instrumenten, um die kriegsmüde Bevölkerung für einen geplanten Angriffskrieg emotional zu mobilisieren. Gleichzeitig wurde im Hintergrund die geheime Aufrüstung für einen Angriffskrieg vorangetrieben. Die Divergenz zwischen den wahren Ambitionen des NS-Regimes und der Außendarstellung war propagandistisches Kalkül,1602 das auch in den Zigarettenalben verfolgt wurde. Da die Wiederaufrüstung in diesen Jahren im Geheimen vonstattenging, beschränkte sich der Staat darauf, militärische Tugenden zu propagieren. Die geheime Rearmierung konnte so

1601 Neben der geplanten Ostexpansion bestanden auch Differenzen zwischen der Marineleitung und Hitler, so dass bis 1939 kein einheitlicher Kurs für die Aufrüstung der Marine verfolgt wurde. Raeder forderte 1938 den Ausbau der Flotte, darunter Schlachtschiffe und 160 U-Boote., vermochte sich aber noch nicht durchzusetzen und begann mit der Ausarbeitung des Z-Planes. Erst ein Jahr später befahl Hitler den Ausbau der Flotte. Vgl. Rahn (2005): "Strategische Optionen und Erfahrungen der deutschen Marineführung 1914 bis 1944". In: Ders. (Hg.): Marinen, S. 218. Der Z-Plan erwies sich jedoch als kaum realisierbar und scheiterte bereits 1939 an wirtschaftlichen Schwächen wie mangelnder Ressourcen an Rohöl und klaren Zielsetzungen. Vgl. Deist (1979): „Aufrüstung“, S. 465 - 472

1602 Plenge betont bereits, dass Propaganda als "soziale[n] Antriebserteilung“ nicht auf Wahrheiten beruhen muss. Plenge führt hier das Gerücht als Variante, respektive Vorstufe der Propaganda an, das eine große Wirkungsmacht entfalten kann. Plenge (1922): Propaganda, S. 16f. 
erfolgreich vor der Weltöffentlichkeit und vor der deutschen Bevölkerung verschleiert werden. ${ }^{1603}$ Damit konnte auch eine militärische Nachwuchsakquise, mit der bereits vor der Gründung der Wehrmacht begonnen wurde, getarnt werden. ${ }^{1604}$ Die janusköpfige Strategie fand ihren Ausdruck auch in der Einkreisungspropanda, die Deutschland vor der Weltöffentlichkeit und der eigenen Bevölkerung als wehrlose Nation präsentieren sollte. Diese Propaganda, die bis in die Jahre 1935/36 verfolgt wurde, nimmt in den Zigarettenalben einen breiten Raum ein. Die Relevanz dieser Strategie belegt sowohl die Anzahl an Alben, die sich monothematisch mit der Einkreisung Deutschlands beschäftigen, als auch die Fokussierung der Einkreisungspropaganda im gesamten Themenspektrum der Zigarettenalben.

Ab den Jahren 1935/36 erfährt die Propaganda in den Zigarettenalben einen Wandel. Die Einkreisungspropaganda wird durch eine mediale Waffenparade, die von einem aggressiven Tenor begleitet wird, abgelöst. Während weiterhin Friedensbeteuerungen ausgesandt werden, wird Deutschland als Nation präsentiert, die ihre Wehrhoheit zurückerlangt hat und im Angriffsfall bereit ist, Freiheit und Ehre mit Waffengewalt zu verteidigen. Die Propaganda in den Zigarettenalben korrespondiert mit der zeitgenössischen Außendarstellung des NS-Regimes, das sich weiterhin der Friedensrhetorik bediente, aber gleichzeitig auf seine Wehrkraft verwies. Die Wehrmacht wurde der Öffentlichkeit als „Friedensheer“1605 präsentiert, während gleichzeitig auf das militärische Potential verwiesen wurde. Dieser Paradigmenwechsel, bei dem die Einkreisungspropaganda von der „Einschüchterungspropaganda“ abgelöst ${ }^{1606}$ wurde, erfolgte sukzessive und verlief parallel mit Gründung der Wehrmacht im Jahr 1935 und der Einführung der Wehrpflicht im Jahr 1936.

\footnotetext{
1603 Wette (1991): Militarismus, S. 170

1604 Während die Nachwuchswerbung bis zur Einführung der Wehrpflicht noch getarnt von statten ging, wurde ab 1935 offiziell geworben. Insbesondere an höheren Schulen wurden Anwärter für die Offizierslaufbahn akquiriert. Kersting, Franz-Werner (1989): Militär und Jugend im NS-Staat. Rüstungs- und Schulpolitik der Wehrmacht. Wiesbaden: DUV, S. 72 - 93. Die Wehrpflicht war nach den Statuten des Versailler Vertrag abgeschafft worden. Draeger (1933): Vertrag von Versailles, S. 26

1605 Wette (1991): Militarismus, S. 172

1606 Ebd., S. 171
} 
Innen- und außenpolitisch war diese Rhetorik darauf ausgelegt, Rechenschaft für eingeleitete Maßnahmen abzulegen, Friedensabsichten zu unterstreichen oder für eine kalkulierte Diplomatie für „Nichtangriffspakte“ oder „Abrüstungsvorschläge“. ${ }^{1607}$ Im Bereich der Innenpolitik trugen die Zigarettenalben dazu bei, eine Integrationspropaganda zu verbreiten. Diese war erfolgreich, weil sie die Bedürfnisse der Rezipienten berücksichtigen konnte. Solange die Propaganda sich für die Revision des Versailler Vertrages aussprach, hatte sie innerhalb der Bevölkerung eine positive Resonanz. Auch die vom NS-Regime propagierte Friedenspolitik und die Wiederherstellung der Reputation Deutschlands ohne kriegerische Auseinandersetzungen stießen auf ein positives Echo. Die Propaganda verlor erst dann an Akzeptanz, als sie begann, die kriegsmüde Bevölkerung für einen Krieg zu mobilisieren. ${ }^{1608}$ Entsprechend hatte die Kriegspropaganda kaum Resonanz. Der Versuch, mit dem Sammelband RAUBSTAAT ENGLAND ein Feindbild zu installieren, scheiterte letztendlich aber nicht nur aufgrund der vertikalen Ausrichtung der Kriegspropaganda und der kriegsmüden Bevölkerung. Da ein Feindbild nur dann entstehen kann, wenn durch Lernprozesse negative Assoziationen ${ }^{1609}$ installiert werden, war das Zeitfenster zu klein, um die Bevölkerung in einen permanenten Diskurs zu involvieren und neu zu konditionieren.

Das NS-Regime setzte Mythen und ein vielschichtiges Symbolsystem ein, um Einfluss auf die Einstellungen und auf das Verhalten der Bevölkerung zu nehmen. Mythen und Symbole wurden verwendet, um ein Kollektivgefühl ${ }^{1610} \mathrm{zu}$ evozieren und um die Massen für die Ideen und Propagandaziele des NS-Regimes zu emotionalisieren. Dabei wurden der Erste Weltkrieg und seine Helden, die in der Weimarer Zeit weitgehend aus dem Kollektivgedächtnis eliminiert waren, in den Zigarettenalben wiederbelebt und in das kulturelle Gedächtnis implementiert. Die Propaganda knüpfte

\footnotetext{
1607 Vgl. Schmidt (2002): Außenpolitik, S. 53

1608 Vgl. Zimmermann, Clemens (2007): Medien im Nationalsozialismus. Wien/ Köln: Böhlau, S. 21

1609 Vgl. Wendt, Dirk (1989): „Feindbild Seine biologischen und psychologischen Ursachen“. In: Voigt, Rüdiger (Hg.): Politik der Symbole. Symbole der Politik. Opladen: Leske und Budrich, S. 75

1610 Döveling. Katrin (2005): Emotionen - Medien - Gemeinschaft. Eine kommunikationssoziologische Analyse. Wiesbaden: VS Verlag für Sozialwissenschaften. S. 131f.
} 
dabei an das vermeintlich kollektive Erbe der Kriegshelden und ihres Wertekanons an, der nachfolgenden Generationen auferlegt wurde. Es wurde ein Heldenkult installiert, der von Pflicht- und Opferbewusstsein geprägt war, mit dem Ziel, die Bevölkerung für einen Krieg zu konditionieren.

Der Heldenkult wurde über unterschiedliche Kommunikationskanäle massenhaft verbreitet, wie Massenveranstaltungen, Riten sowie Printmedien wie den Zigarettenalben. Kollektive historische Vorstellungen wurden damit auch über die Zigarettenalben nachhaltig geprägt und gesteuert. Die Protagonisten der Mythen wurden durch diese mediale Inszenierungen wiederbelebt und magisch aufgeladen, was ihnen eine starke Suggestivkraft verlieh. Damit wurde eine gedächtnisstiftende Erinnerungskultur für nachfolgende Generationen geschaffen. Mythen wurden zum inhärenten Bestandteil und „narrative Grundlage“1611 der NS-Propaganda. Bei der Installation neuer Mythen und Helden nahmen die Fliegerasse des Ersten Weltkrieges eine exponierte Stellung ein. Da sich der gesellschaftliche Charakter der Erinnerung aufgrund der zeitlichen Distanz gewandelt hatte, ${ }^{1612}$ konnte die Geschichtserinnerung leicht mit national-völkischem Gedankengut unterfüttert werden. Herausgelöst aus dem historischen Kontext erfuhren die Fliegerasse auch in den Zigarettenalben eine mediale Wiederauferstehung und wurden zu mythischen Heldenfiguren stilisiert, die sich für ihre Nation geopfert hatten. Mit der neuen Konnotation wurden sie Teil des deutschen Mythenrepertoires und des kollektiven Erbes. Die Mythen um ihre Protagonisten wurden mittels Variationen modifiziert, so dass historische Ereignisse neu bewertet werden konnten. Geschichte konnte mit Bedeutungen aufgeladen und als Ressource für eine Sinn-Mobilisierung eingesetzt werden. Die Heroen erinnerten damit nicht nur an eine ruhmreiche Vergangenheit, sondern wurden auch zu einem Glaubenselixier, das den Weg in eine verheißungsvolle Zukunft weisen sollte. In der mythischen Geschichtsinterpretation manifestierte sich auch das erlangen, die Demütigung der Nation durch den Versailler Vertrag zu kompensieren und „sinnhafter

\footnotetext{
1611 Münkler (2009): Mythen, S. 15

1612 Vgl. Assmann (2006): Schatten, S. 27
} 
Integration“1613 zuzuführen. Mit den Fliegerhelden konnte der Schicksalsschlag, der auf der Seele der Nation lastete, als Ressource sakraler Sinnstiftung umdefiniert werden. Die Zigarettenalben, die im Kontext des Nationalsozialismus stehen, enthalten textliche und visuelle Codierungen, die ideologisch besetzte Botschaften transferierten und durch permanente Wiederholung den Eindruck einer „Kulturellen Kontinuität“1614 vermittelten. Die symbolisch besetzten Inhalte der Propaganda entfalteten eine gesellschaftliche Relation und erzeugten Bedeutungen im Sinne der NS-Ideologie. Mythen und Symbole wurden damit zu Trägern neuer Scheinwirklichkeiten, die von der Bevölkerung als reale Lebenswelt wahrgenommen und Teil des identifikationsraumes wurden. Die Zigarettenbilder dienten so dazu, Mythen und Symbole als allgemeines Wissen zu installieren und eine kollektive Identität zu etablieren. Die Sammelwerke trugen dazu bei, eine „Kollektividentität“ zu installieren, denn für die „,soziale Gruppenbildung“ ist „die Konstitution von symbolischen Identitätskernen in Form von Wissensbeständen"1615 unabdingbar. Den Nationalsozialisten gelang damit eine eigene historiografische Neukonnotation, mit der Werte einer faschistischen Massengesellschaft vermittelt wurden. Mit den Variationen, die um den Kern der Mythen herausgebildet wurden, konnte das NS-Regime ein kulturelles Gedächtnis installieren, um die politischen und sozialen Strukturen neu zu gestalten. Damit wurden „Versatzstücke religiöser Mythologien“ nicht nur benutzt, um einen Krieg zu rechtfertigen und vorzubereiten, sondern auch, "um totalitäre Machtausübung zu legitimieren“. ${ }^{1616}$ Das NS-Regime konnte damit seine eigene Macht stabilisieren und gleichzeitig eine Sinn-Mobilisierung in Gang setzen, um die eigenen politischen Zielsetzungen zu realisieren. Die Umstrukturierungen im kulturellen Gedächtnis reflektieren die

\footnotetext{
1613 Schirmer (1989): „Deutungsmuster“, S. 37

1614 Scheeske, Andreas: Zeichen einer Bilderkultur als Gedächtnis, in: Sachs-Hombach, Klaus/ Rehkämper, Klaus (Hg.) (1998): Bild - Bildwahrnehmung - Bildverarbeitung, Wiesbaden: DUV, S. 65

1615 Gründer, René (2008): Germanisches (Neu-)Heidentum in Deutschland. Entstehung, Struktur und Symbolsystem eines alternativreligiösen Feldes. Berlin: Logos, S. 28

1616 Voigt, Rüdiger (1989): „Mythen, Rituale und Symbole in der Politik“. In: Ders. (Hg.): Politik der Symbole. Symbole der Politik. Opladen: Leske und Budrich, S. 10
} 
„imaginären Vorstellungsbilder“, 1617 die für diese historische Epoche prägend waren. Die in den Zigarettenalben transportieren Vorstellungen ermöglichen daher auch Einblicke in die zeitgenössischen Lebenswelten und geben Aufschlüsse über die damalige Mentalität. ${ }^{1618}$

Die Zigarettenalben waren thematisch auf die Rezipienten zugeschnitten. Dazu zählten primär Kinder und Jugendliche, denn das Sammeln von Zigarettenbildern war besonders in diesen Altersklassen ein gesellschaftliches Phänomen und eine mit Passion betriebene Freizeitgestaltung, die in fast allen Familien, insbesondere von Rauchern, betrieben wurde. ${ }^{1619}$ Die Propagandastrategen bedienten sich daher Themen, die von den Jugendlichen favorisiert wurden und setzten diese in einen Kontext, der den eigenen propagandistischen Zielvorstellungen entsprach. So konnten beispielsweise über die Aviatik-Alben die Fliegerhelden und der Erste Weltkrieg in das Bewusstsein dieser Generation implementiert werden. Die Zigarettenalben wurden damit Teil des Bildungs- und Erziehungssystem, das der jungen Generation nicht nur das neu konnotierte Weltkriegsgeschehen in Erinnerung rief und damit ein Geschichtsbild im Sinne der NS-Ideologie zeichnete, sondern auch, um ihnen soldatische Werte zu vermitteln. Mit der Fokussierung auf den Ersten Weltkrieg und seine Helden wurde aus dem Konvolut des nationalen Speichergedächtnisses eine Auswahl an Bildern getroffen, die den Rezipienten, respektive der Bevölkerung Identitätsraum und Orientierung boten. ${ }^{1620}$ Damit wuchsen die Jugendlichen in eine mit DefinitionsMacht ausgestattete Gesellschaft" ${ }^{\text {‘1621 }}$ und in dem kulturell und ideologisch geprägten Umfeld der NS-Ideologie auf. Das Interpretationsspektrum der Kinder und

\footnotetext{
1617 Simonis, Annette (2013): "Mythos und fraktale Form, Figurationen der Hadesreise in Moderne und Gegenwart“. In: Krüger/ Stillmark (Hg.): Mythos, S. 158f.

1618 Vgl. Ebd.

1619 Geoffrey (2000): Erzieherische Rolle, S. 242

1620 Assmann, Aleida: „Zur Mediengeschichte des kulturellen Gedächtnisses.“ In: Erll, Astrid/ Nünning, Ansgar (Hg.) (u. Mitarbeit von Birk, Hanne/ Neumann, Birgit/ Schmidt, Patrik) (2004): Medien des kollektiven Gedächtnisses. Konstruktivität - Historizität - Kulturspezifität, Berlin: de Gruyter, S. 54. Als kulturelle Speichergedächtnisse gelten Einrichtungen wie Museen, Bibliotheken oder Universitäten, die auch Wissen speichern, das nicht zum eigenen kulturellen historischen Hintergrund gehört und damit keine identitätsstiftende Funktion im Rahmen der eigenen Kultur und Historie erfüllen. Assmann, A. (2004): Mediengeschichte, S. 52 Renckstorf (1977): Massenkommunikationsforschung, S. 29
} 
Jugendlichen war damit aufgrund ihrer Disposition eingeschränkt, denn sie hatten kaum die Möglichkeit, sich anderweitig über soziale Alternativwelten zu informieren. Neben Schule und den Jugendorganisationen waren alle Medien, darunter auch die Zigarettenalben, darauf ausgerichtet, die junge Generation zu infiltrieren ${ }^{1622}$ und ihr die nationalsozialistischen Ideale und soldatische Tugenden zu vermitteln. Die Propaganda eroberte sukzessive die Lebenswelt der Kinder und Jugendlichen und schränkte ihren Erfahrungshorizont derart ein, dass ein Mangel an „alternativen Handlungskonzepte[n] ${ }^{\prime 1623}$ entstand und die NS-Ideologie als alleiniger Lebensentwurf betrachtet wurde. Aufgrund der Einseitigkeit der Massenkommunikation konnte auch über die Zigarettenalben eine „[M]manipulative Moralisierung“ erfolgen, bei der den Jugendlichen Werte von Pflichtbewusstsein und Opfer implementiert wurden und sie sich in einer „implizit zugemuteten Rolle ${ }^{\text {"1624 }}$ widerfanden, mit der Selbstwert und Identifikation verbunden waren. So konnte in den Zigarettenalben ein Rollenverhalten eingefordert werden, das stark von sozialen Determinanten bestimmt war. Die Art, wie Geschichte in den Zigarettenalben aufbereitet wurde, gibt Auskunft darüber, welche Ereignisse in der Vorstellungswelt in der Weimarer Republik und in der NSZeit dominierten und wie diese im zeitgeschichtlichen Kontext imaginiert wurden. Die Zigarettenalben reflektieren damit den damaligen medialen Diskurs von historischen Ereignissen und ihrer Protagonisten, ihre Diffusion und Konnotation. Auch der Zeitraum der Veröffentlichung gibt einen Einblick in die inhärenten Meinungen und Vorstellungswelten der Gesellschaft, sowie in die Ambitionen der Machthaber. Die Zigarettenalben spiegeln damit soziokulturelle Assoziationen und Imaginationen des kollektiven Bewusstseins der Bevölkerung in der Zeit des Nationalsozialismus wider.

1622 Vgl. Kollmann (2006): Schulbücher, S. 115. Bücher wie „Kampf um Deutschland“ oder "Schriften zur Geschichte der Nationalsozialistischen Bewegung", die an Schulen und in NS-Organisationen Pflichtlektüre waren, transferieren identische Inhalte wie die Alben Kampf um's Dritte Reich, Adolf Hitler oder Deutschland erwacht. Adam (2010): Lesen, S. 121

1623 Renckstorf (1977): Massenkommunikationsforschung, S. 26

1624 Luhmann, Niklas (1979: „Öffentliche Meinung“. In: Langenbucher, Wolfgang R. (Hg.) (1979): Politik und Kommunikation. Über öffentliche Meinungsbildung. München: R. Piper \& Co., S. 35f. 


\section{Abbildungen}
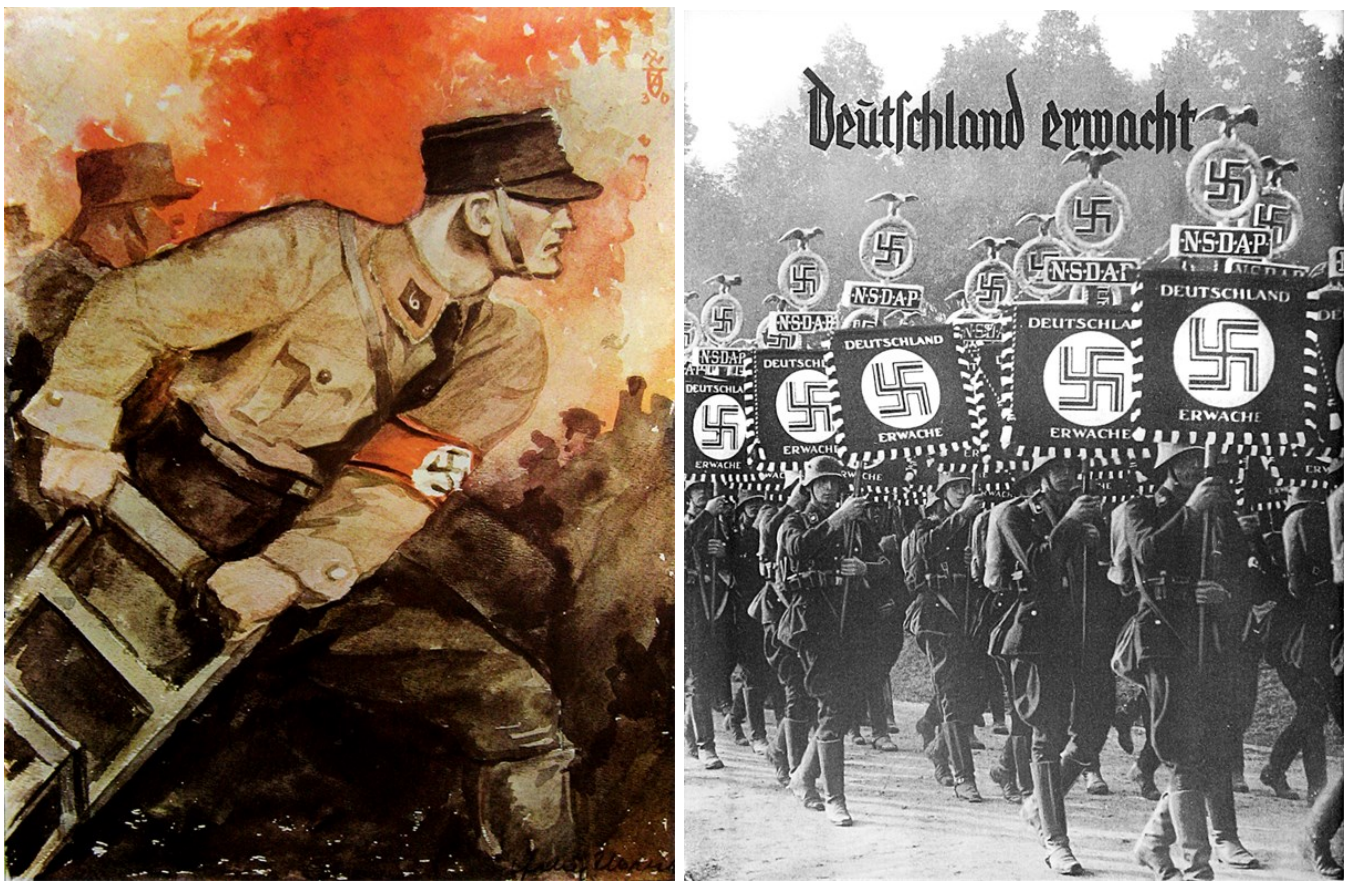

Abbildung 1: Saalschlacht ${ }^{1625}$

Abbildung 2: Titelbild „Deutschland erwacht"1626
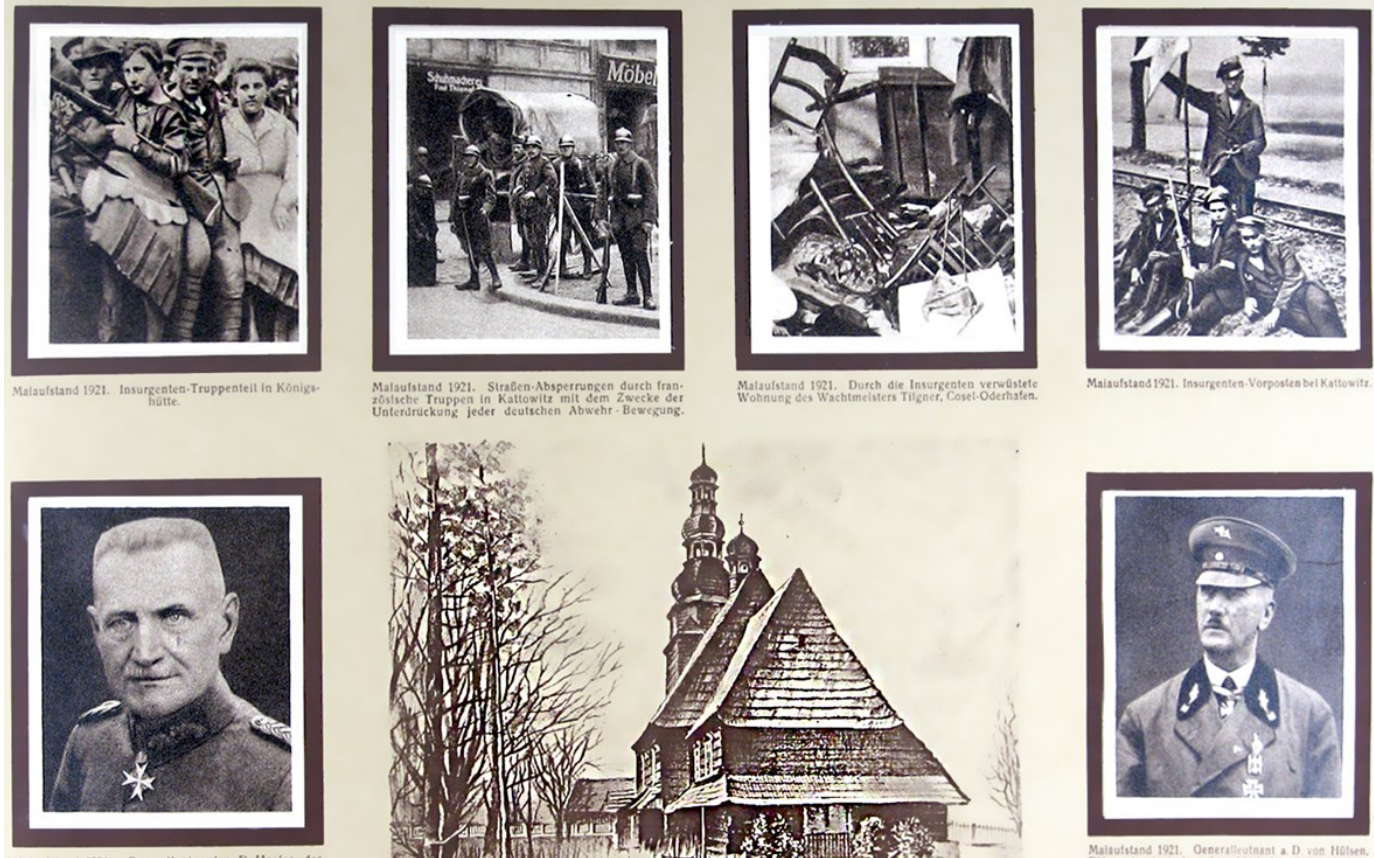

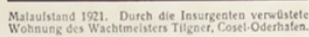
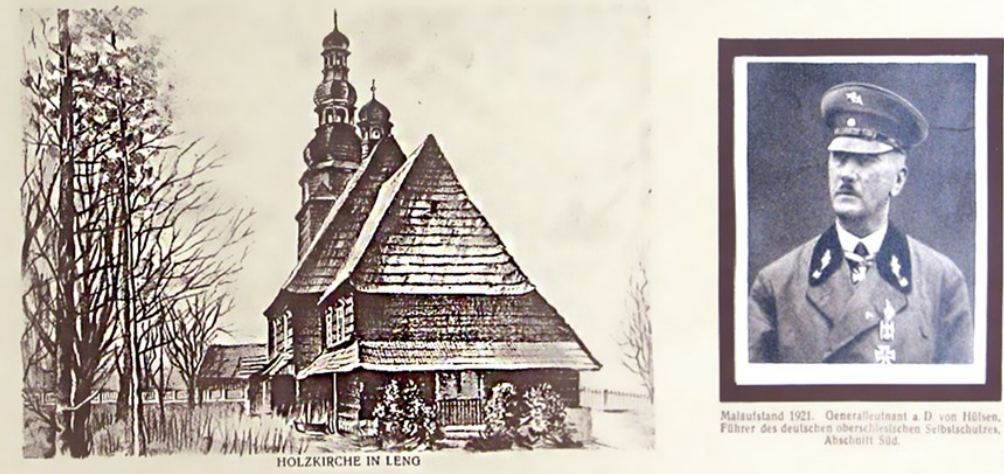

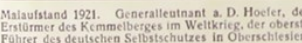

Abbildung 3: Maiaufstand $1921^{1627}$

1625 Bildlegende: „Dem Terror von links kann man nur mit noch schärferem Terror begegnen“. Reemtsma (1933): Deutschland erwacht, ohne Bildnummer

1626 Ebd. 

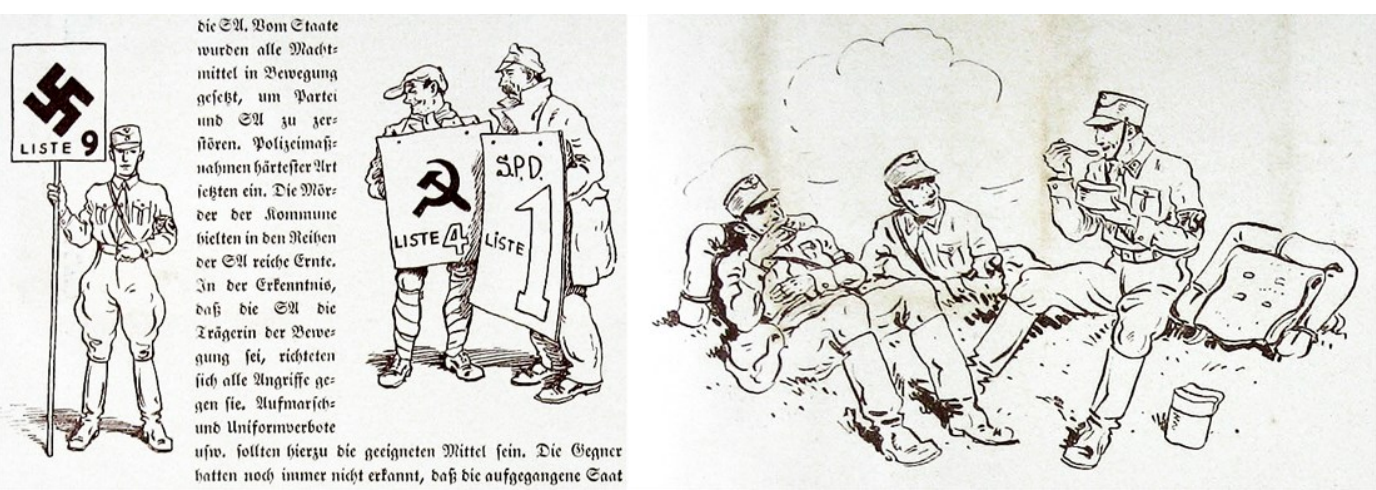

Abbildung 4: Illustrationen im Sturm-Album "SA SS HJ“1628
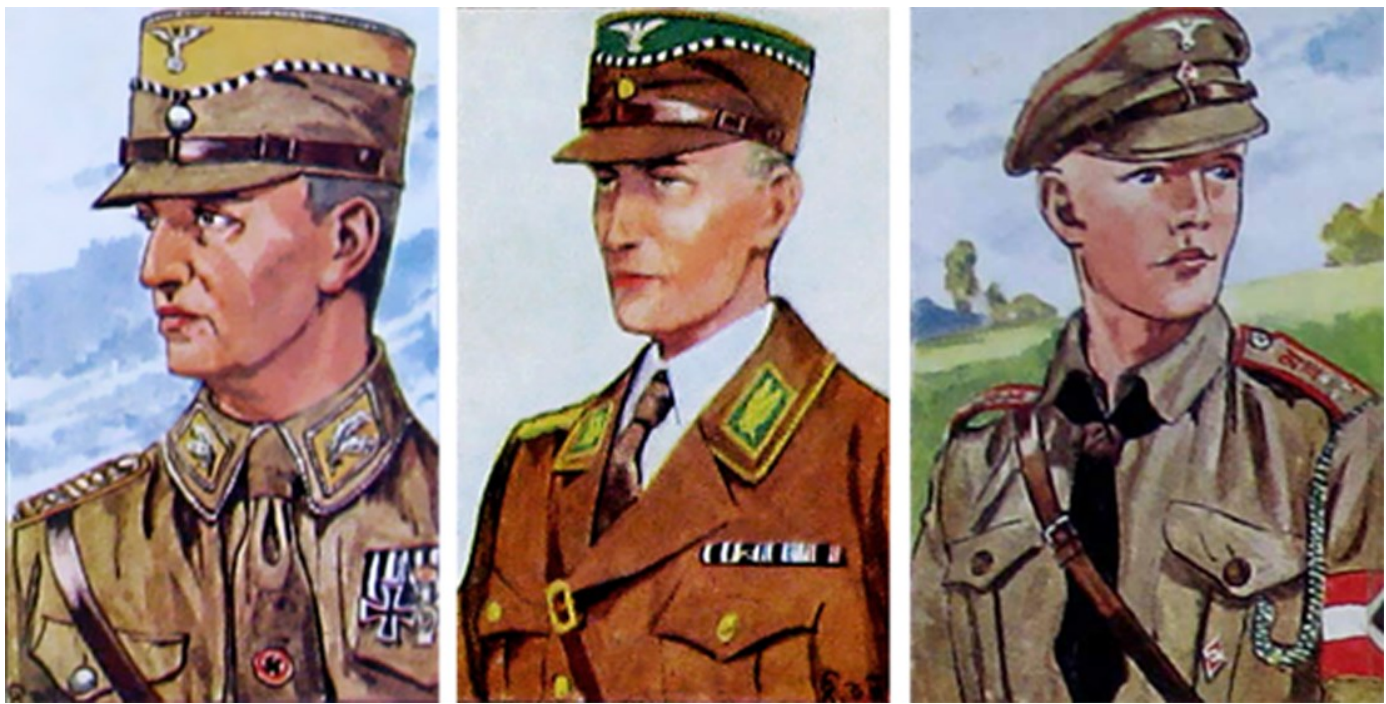

Abbildung 5: Abzeichen der $S A^{1629}$

Bildlegenden von links nach rechts: „Maiaufstand 1921. Insurgenten-Truppenteil in Königshütte“ / "Maiaufstand 1921. Straßenabsperrung durch französische Truppen in Kattowitz mit dem Zwecke der Unterdrückung jeder deutschen Abwehrbewegung“ / "Maiaufstand 1921. Durch die Insurgenten verwüstete Wohnung des Wachtmeisters Tilgner, Cosel-Oderhafen." / „Maiaufstand 1921. Insurgenten-Vorposten bei Kattowitz.“ / „Maiaufstand 1921. Generalleutnant a. D. Hoefer, der Erstürmer des Kemmelberges im Ersten Weltkrieg, der oberste Führer des deutschen Selbstschutzes in Oberschlesien." / Grafik: „Holzkirche in Leng“ / „Maiaufstand 1921. Generalleutnant a. D. von Hülsen, Führer des oberschlesischen Selbstschutzes, Abschnitt Süd.“ Doms (1933): Oberschlesien, ohne Bildnummern, unpag. Illustrationen im Album: Sturm (1933): SA SS HJ, Textseiten 6f.

1629 Bildlegenden: „Oberführer“ / ,Oberführer im Ausgehanzug“ / „Gefolgschaftsführer. Obergebiet 2 (Nord) SA., Gebiet 7 Nordsee Oberbann 1 Weser-Ems, Bann 91 Oldenburg, Unterbann III, Gefolgschaft 2.“ Ebd., Bilder 22, 102, 187 


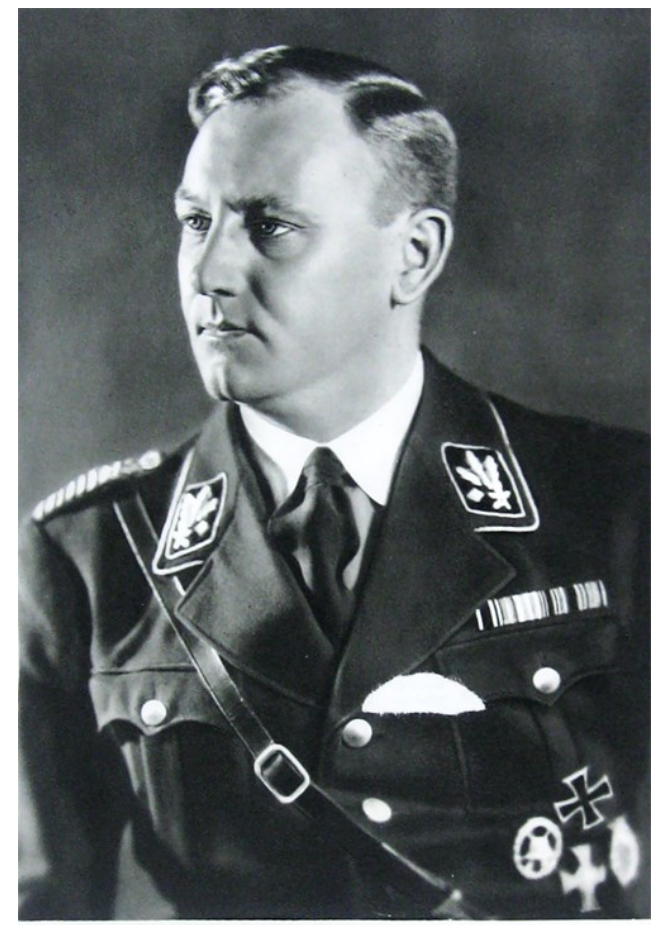

Etabodief $M i o ̈ h m$
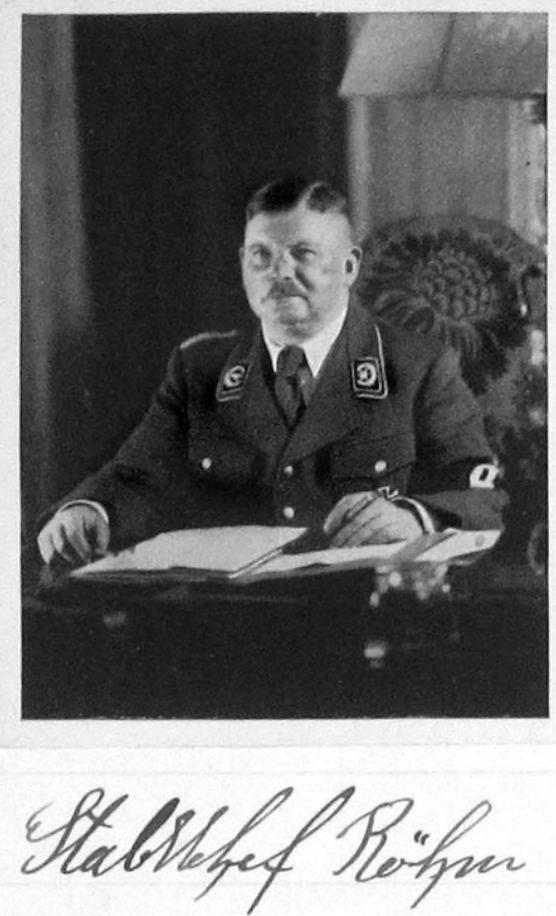

Abbildung 6: Chef des Stabes

Abbildung 7: „Stabschef Ernst Röhm“1630

"Stabschef Röhm"1631

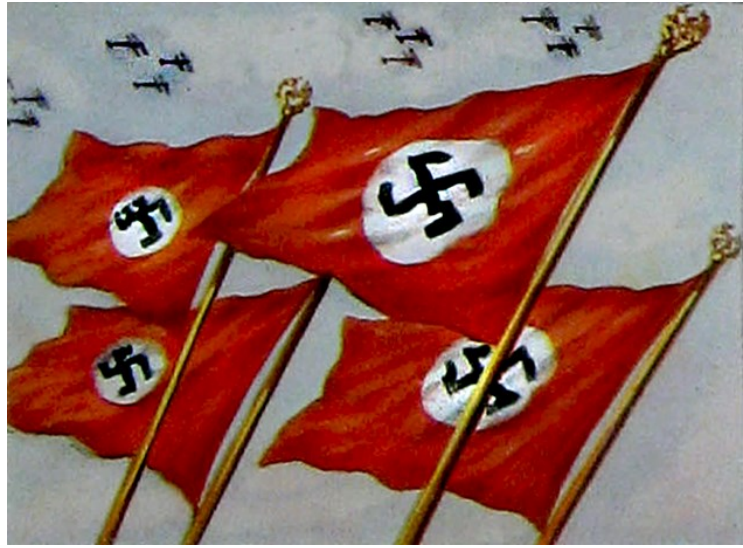

Abbildung 8: "Deutsche Ehr-deutsche deutsche Wehr"1633

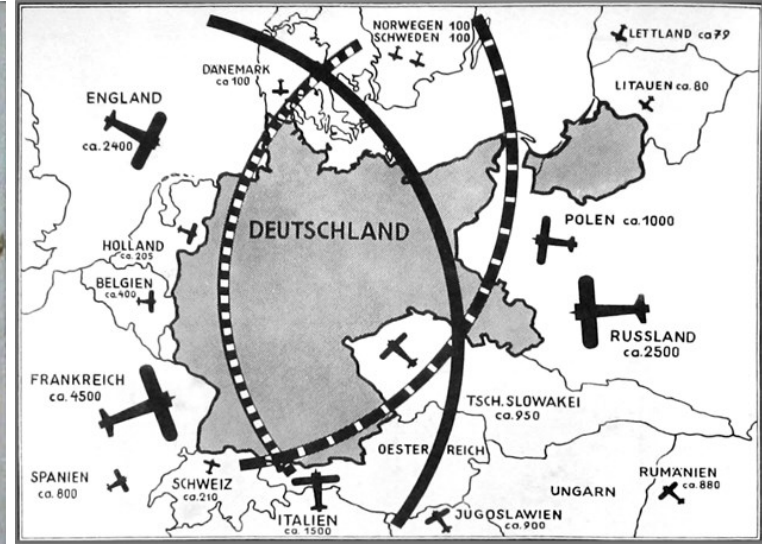

Abbildung 9: Grafik Einkreisungspropaganda ${ }^{1632}$

1630 Zigaretten-Industrie (1934): Der Staat der Arbeit und des Friedens. o.O. Album aus der Sammlung Köberich, Goethe-Universität Frankfurt/M., Historische Fakultät

1631 Reemtsma (1933): Deutschland erwacht (Röhm-Ausgabe), S. 52

1632 Borg (Vereinigte Tabak- und Zigarettenfabriken) (1934): Europa in Waffen

1633 Monopol (1937): Deutschland, Kapitel: Die Wehrmacht, unpag. 


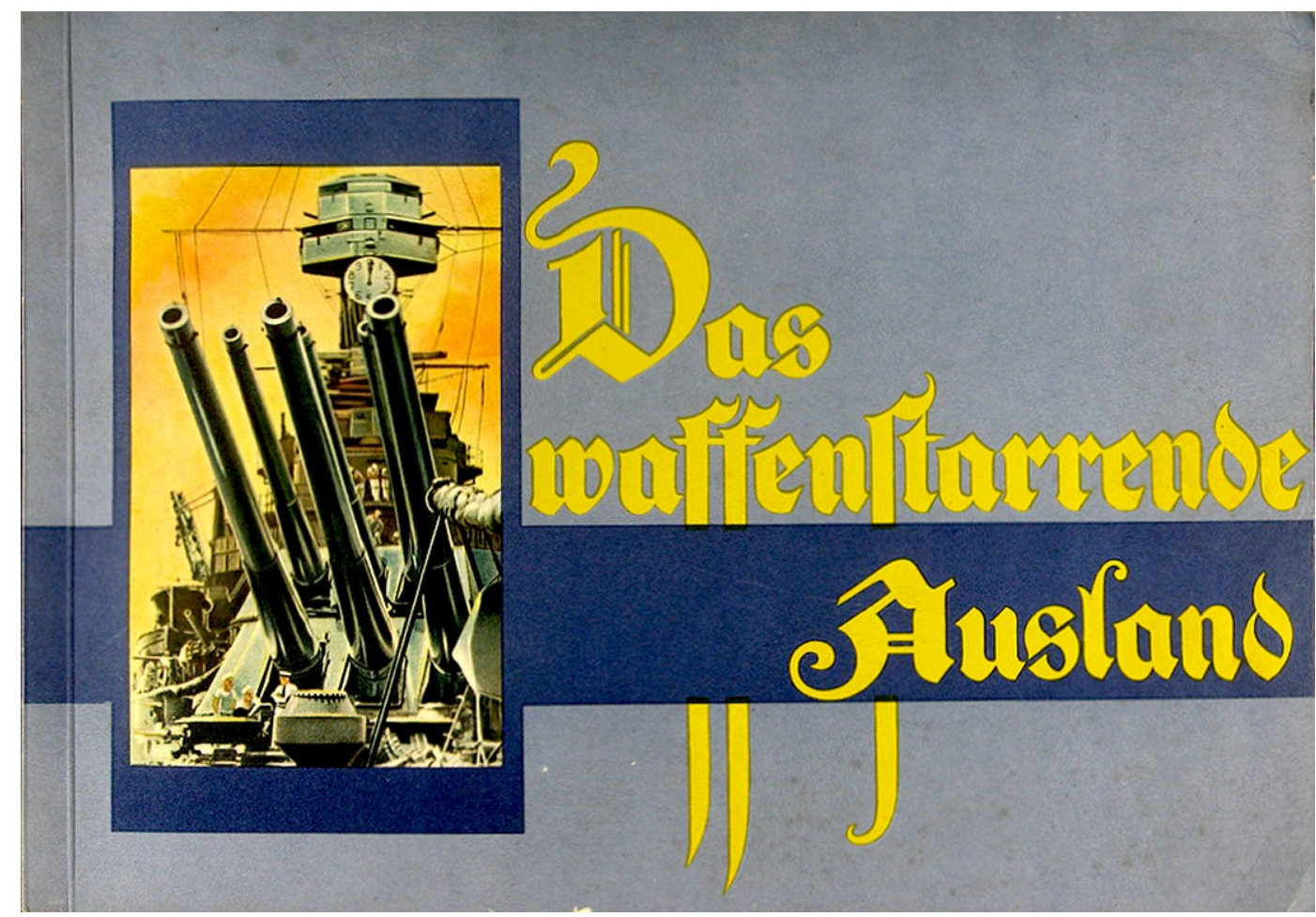

Abbildung 10: Titelbild: "Das Waffenstarrende Ausland“1634
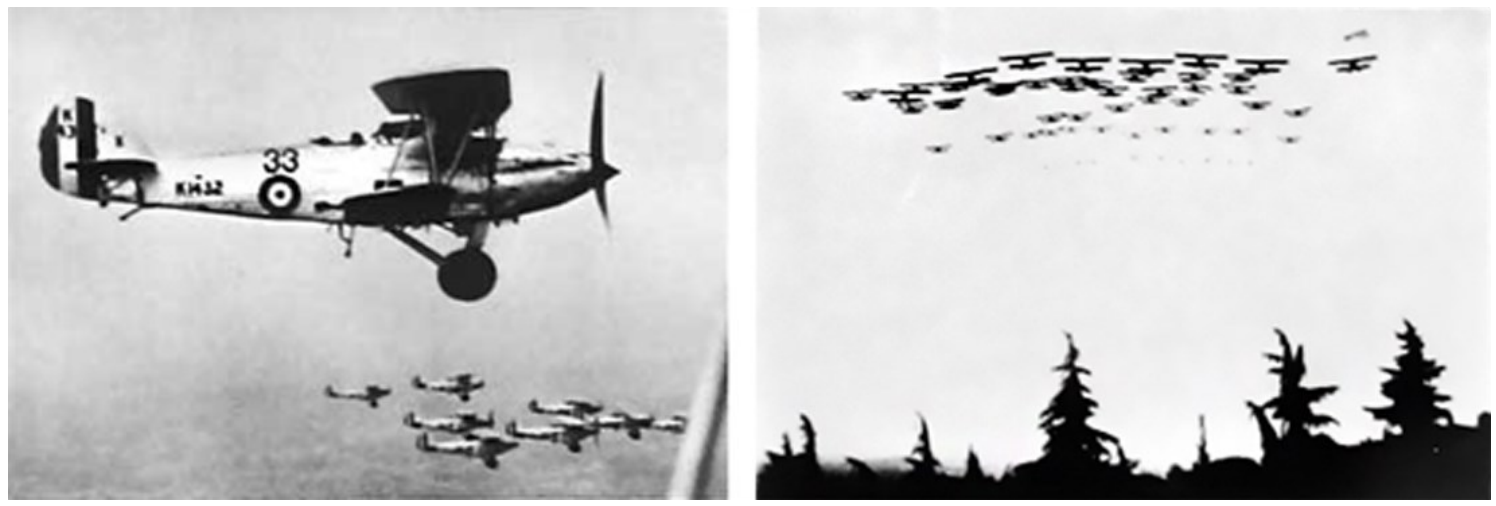

Abbildung 11: Bedrohung aus der Luft ${ }^{1635}$

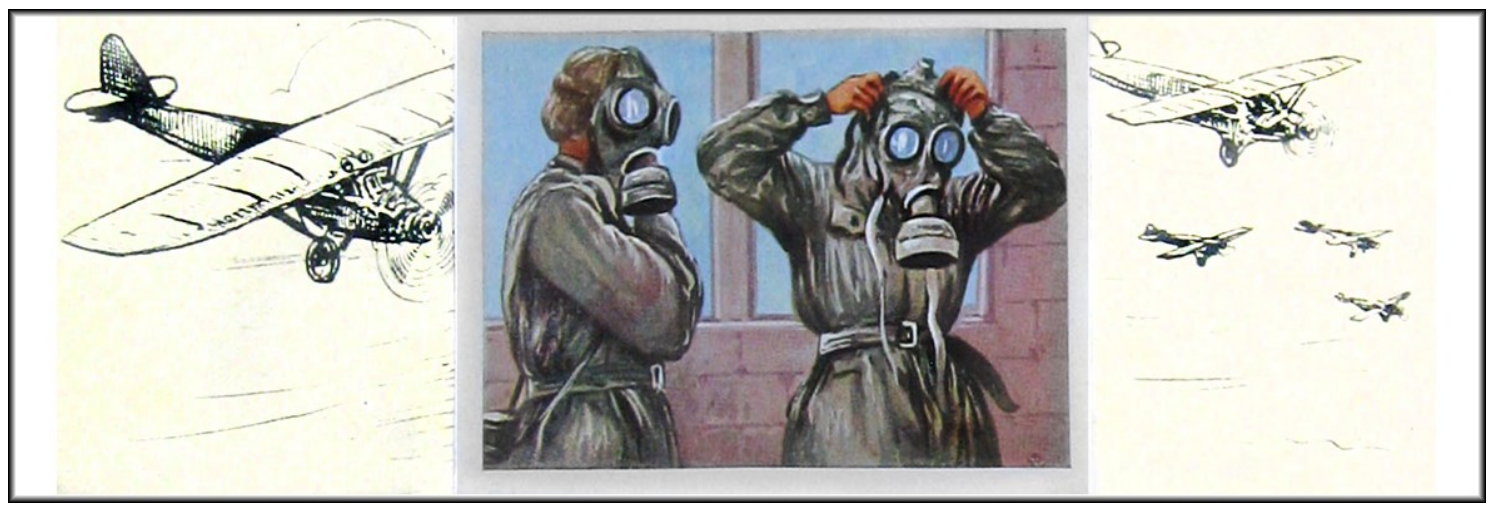

Abbildung 12: Luftschutzübung mit Gasmasken ${ }^{1636}$

1634 Titelbild: Brinkmann (1934): Das Waffenstarrende Ausland.

1635 Orami (1933): Helden der Luft, Bd. 1, Bilder 172 und 173 

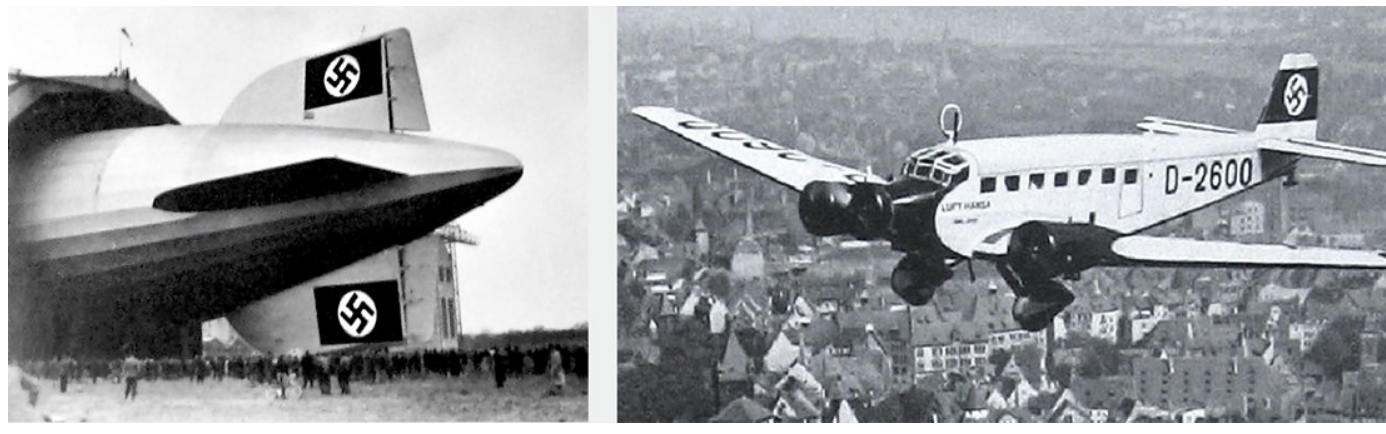

Abbildung 13: Usurpation durch das Hakenkreuz ${ }^{1637}$
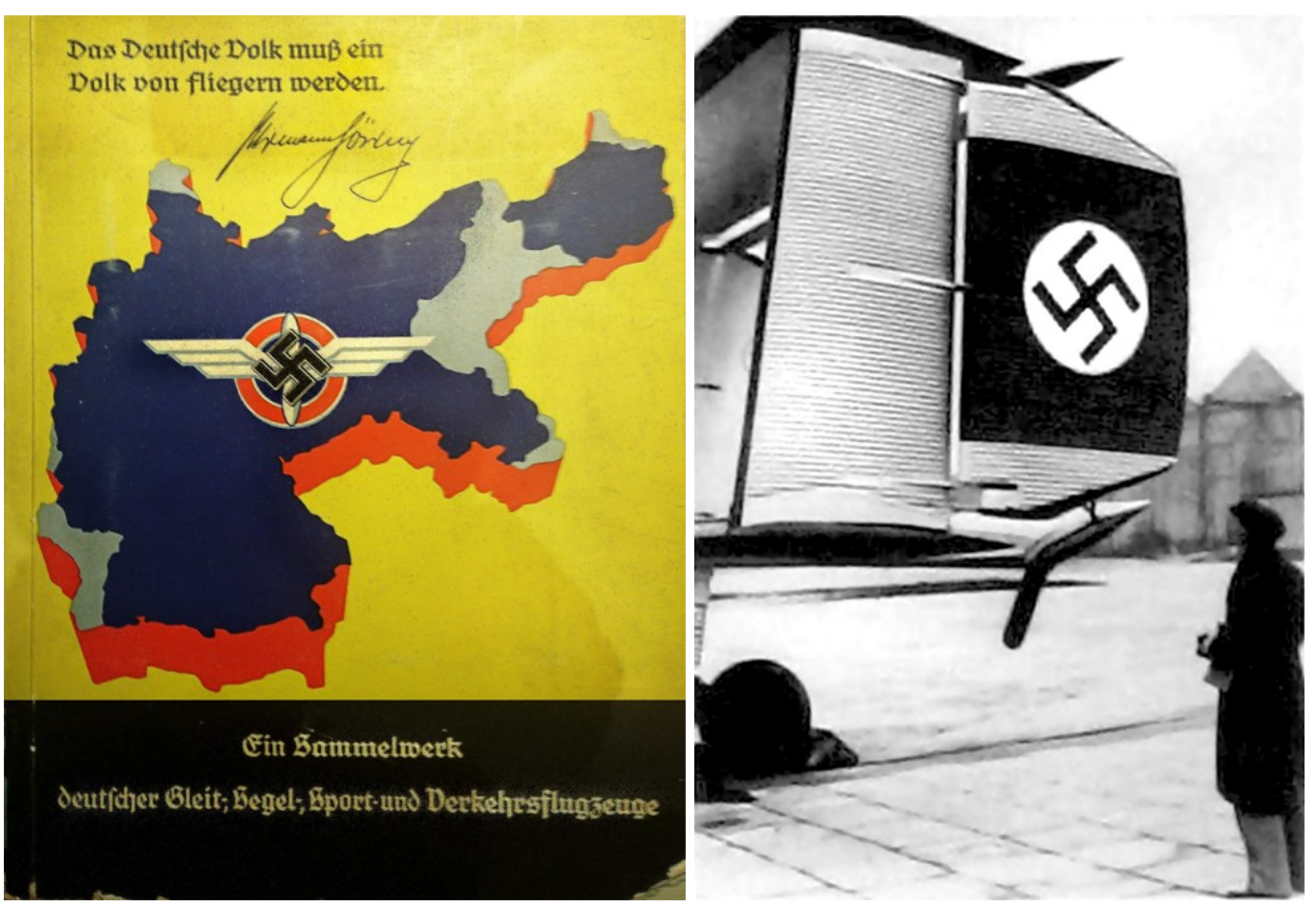

Abbildung 14: Titelbild "Das deutsche Volk Abbildung 15: "In hoc signo vinces!" muß ein Volk von Fliegern werden" 


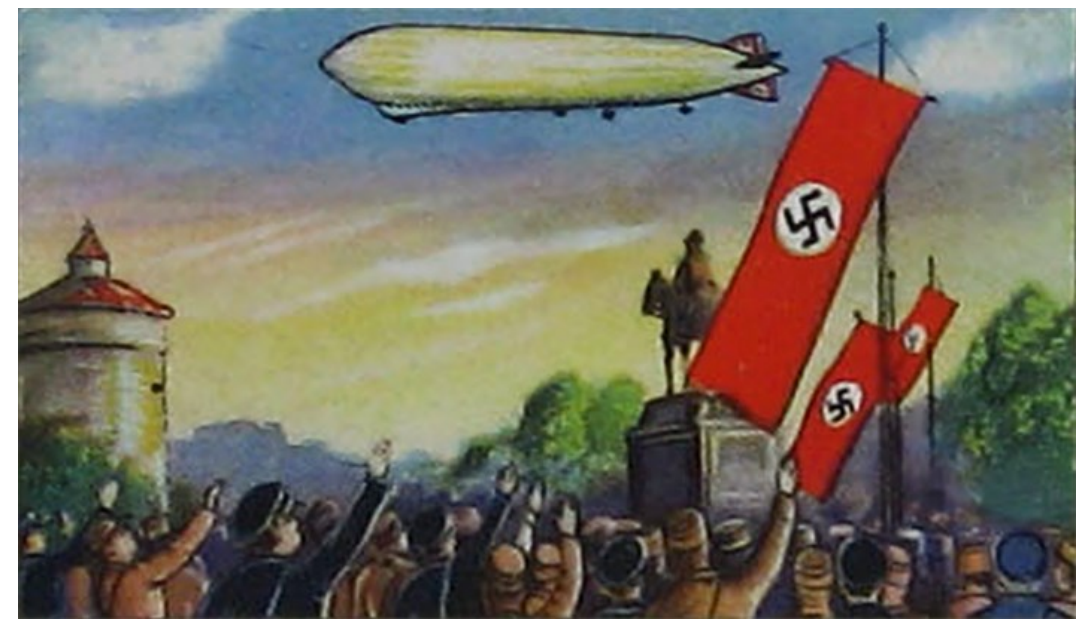

Abbildung 16: Luftschiff „Graf Zeppelin“ über Nürnberg1638
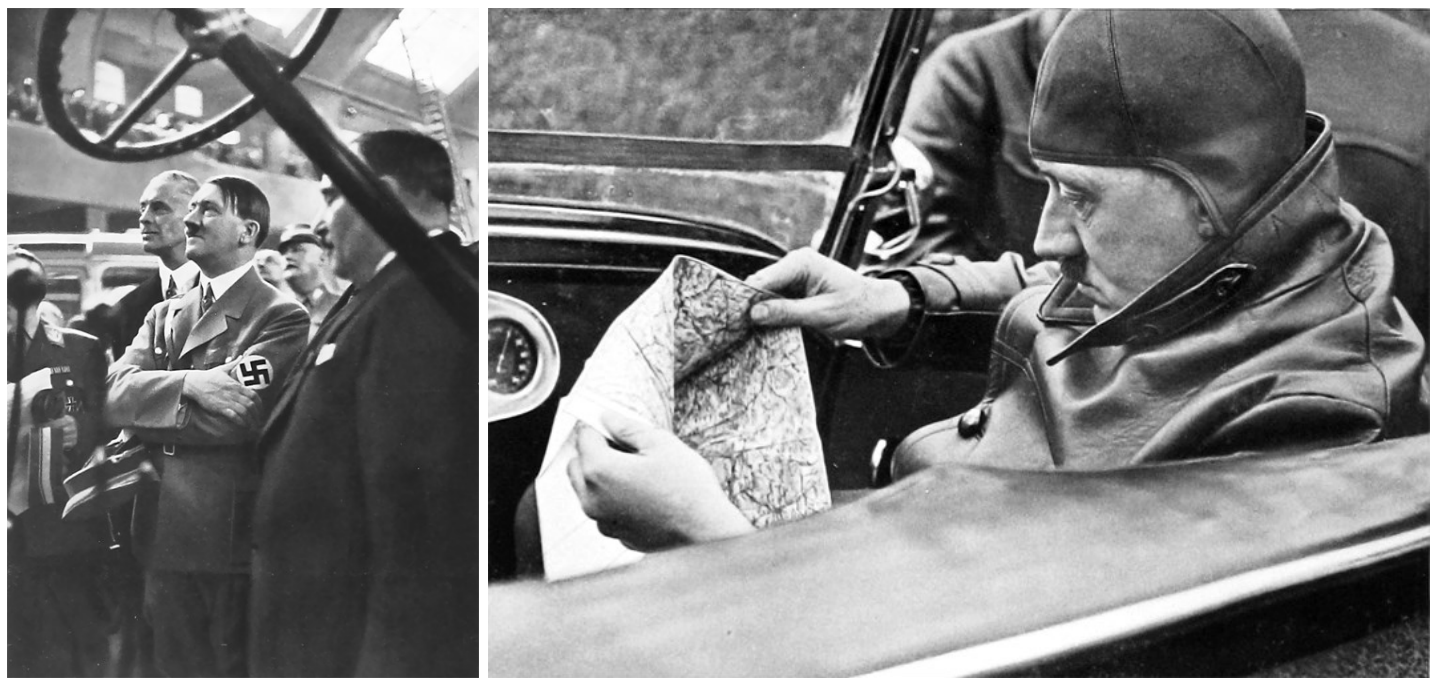

Abbildung 17: Internationale Abbildung 18: "Der Führer legt die Reiseroute fest"1639 Automobilausstellung

in Berlin $1935^{1640}$

1638 Brinkmann (1934): Deutschland hoch in Ehren, S. 66, ohne Bildnummern

1639 Reemtsma (1936): Hitler, S.15, Der Führer auf Reisen, ohne Bildnummern

1640 Ebd., Kapitel: Der Führer und der deutsche Arbeiter, S.62, ohne Bildnummern 


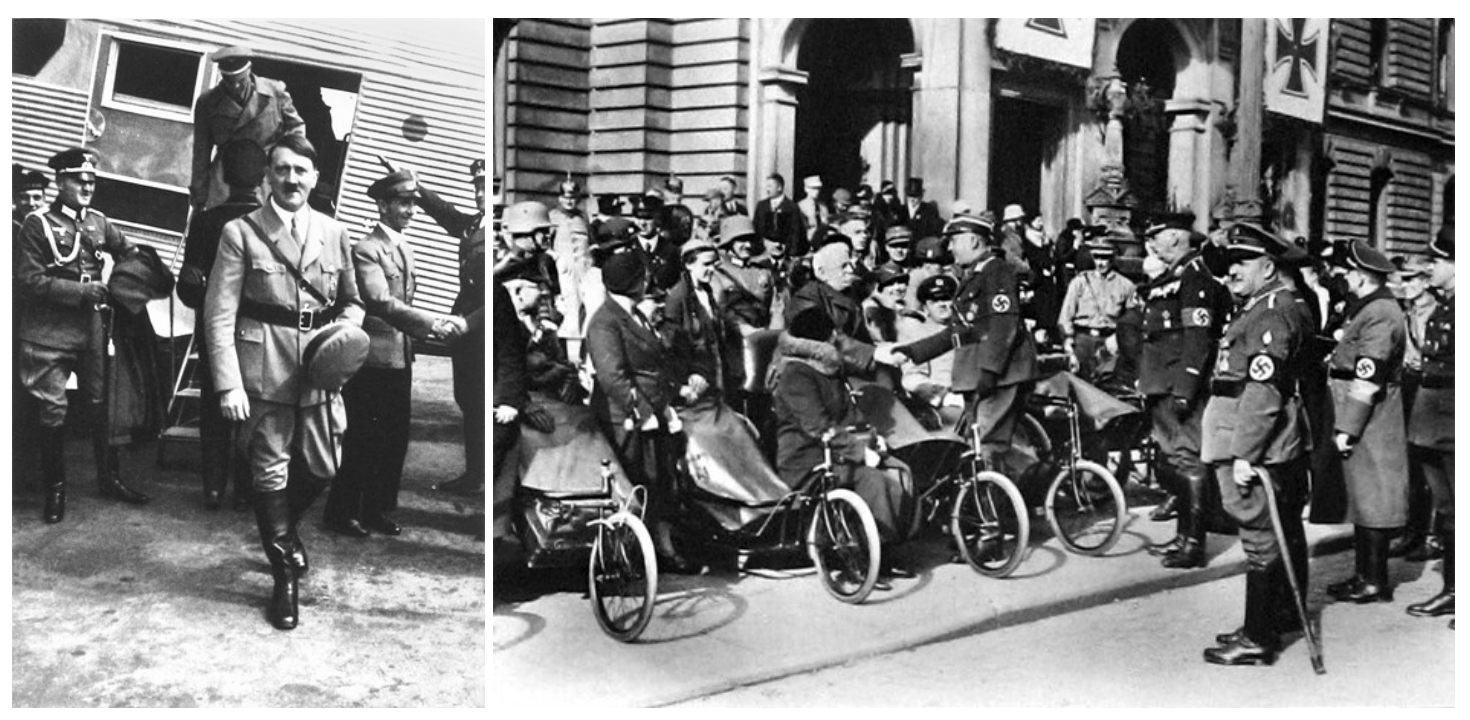

Abbildung 19: „Der Führer fördert Abbildung 20: Schwerkriegsbeschädigte des Ersten durch sein Beispiel die Luftfahrt"1641 Weltkrieges ${ }^{1642}$
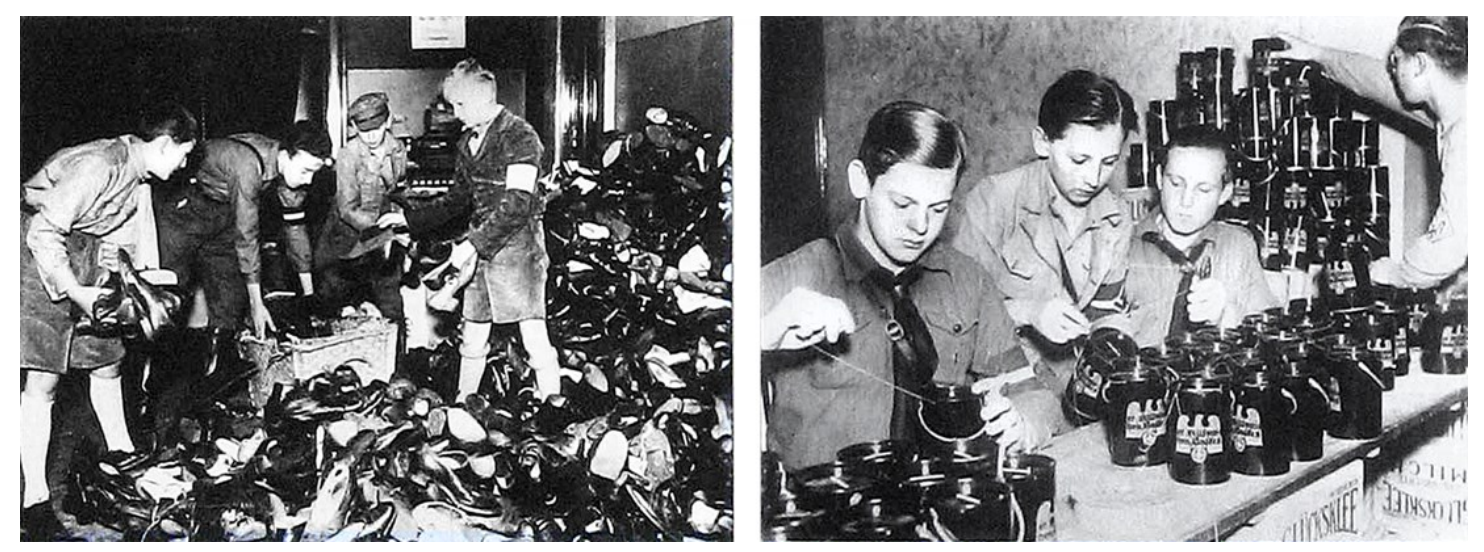

Abbildung 21: Hitler-Jugend bei gemeinnützigen Aufgaben ${ }^{1643}$

1641 Ebd., Kapitel: Der Führer auf Reisen, S. 9, ohne Bildnummern

1642 Kosmos (1934): Bilddokumente, Mappe 2, S. 31

1643 Kosmos (1934): Bilddokumente, Mappe 2, S. 28, ohne Bildnummern 


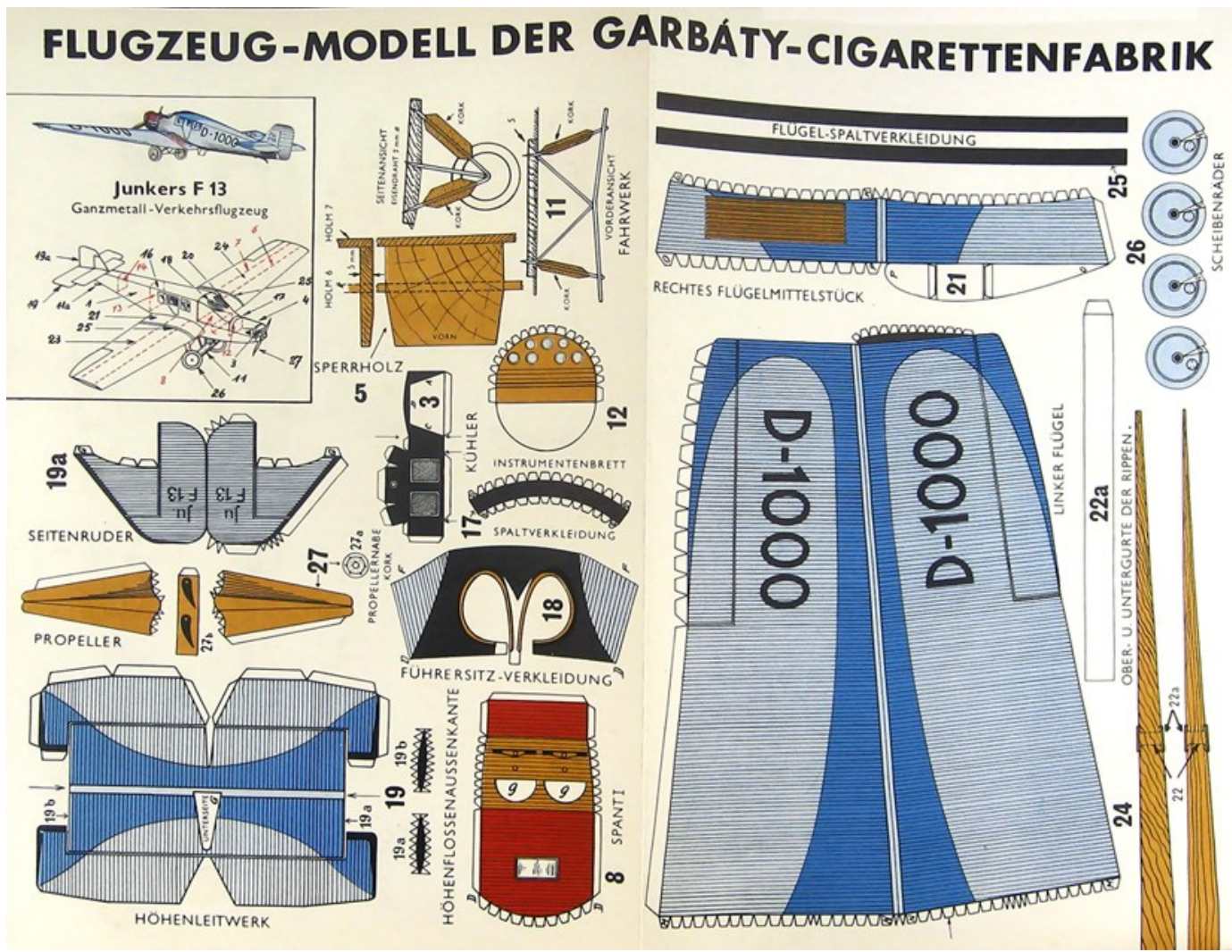

Abbildung 22: Bastelbogen für Junkers F $13^{1644}$
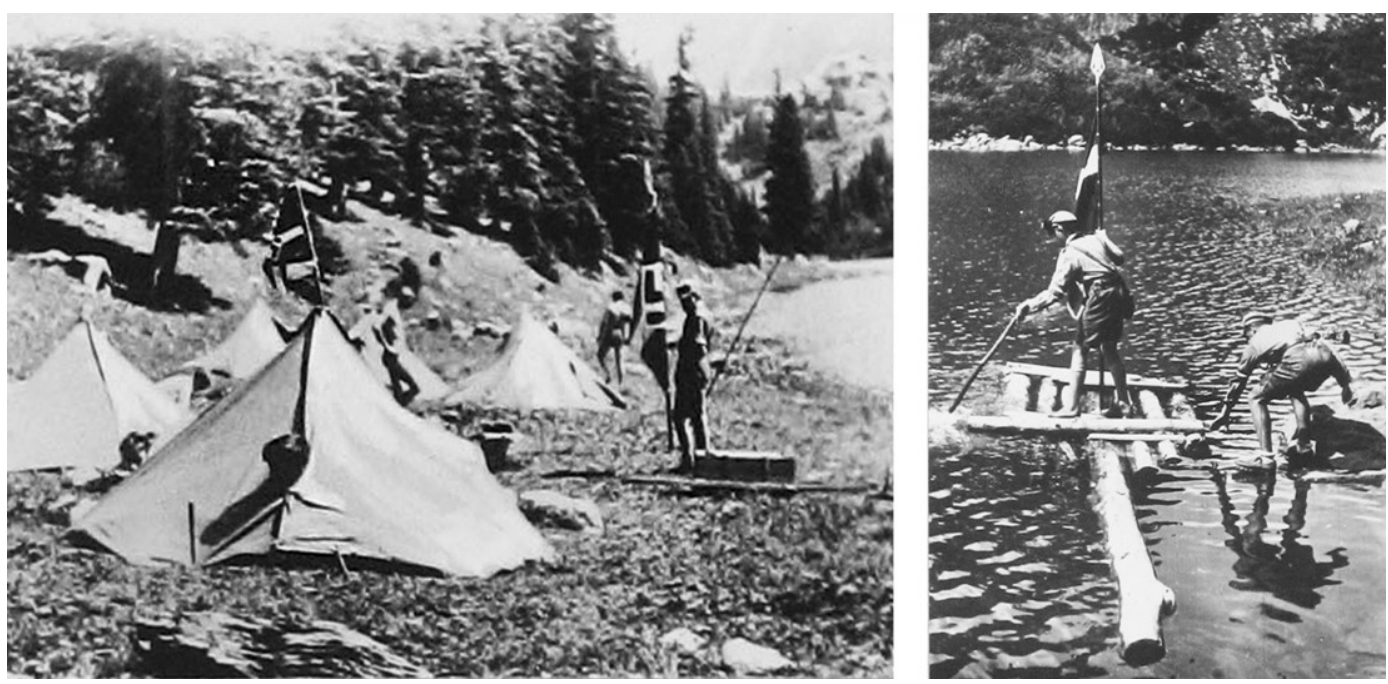

Abbildung 23: Hitler-Jugend im Zeltlager ${ }^{1645}$

1644 Garbáty (1932): Die Eroberung der Luft (Ausland), Bd. 2.

1645 Kosmos (1934): Bilddokumente, Mappe 2, S. 72f., ohne Bildnummern 


\section{Quellenverzeichnis Zigarettenalben}

Abadie (1928): Flaggen und Wappen der Welt 1. Wien

Abdulla (1931): Automobile des bekanntesten Marken des In- und Auslandes, Bd. 1 und 2. Berlin

Abdulla (1932): Im Auto mit Abdulla durch die Welt, Bd. 3. Berlin

Arosa (1933): Ehemalige deutsche Kolonien. Dresden

ASS (1932): Der Weltkrieg 1914-18. München

Aurelia (1933): Deutsche Zunftwappen. Die Adelszeichen deutscher Arbeit und Staat der Arbeit und des Friedens. Dresden

Aurelia (1933): Führer und Volk im dritten Reich. Reichsparteitag Nürnberg. Erster deutscher Erntedanktag und andere wichtige Tage. Dresden

Aurelia (1934): Film und Sport im Buntbild. Dresden

Austria (1934): Taschenbuch der Luftwaffe 1. München (Vorwort von Ing. B. u. H. Von Römer, München)

Austria (1940): Adolf Hitler und sein Weg zu Großdeutschland. Wie die Ostmark ihre Befreiung erlebte. München

Aviatik (1934): Wunder der Technik in Gegenwart und Zukunft. Breslau

Aviatik (1936): Uniformen im neuen Deutschland. Wehrmacht. Breslau

Aviatik (1937): Rekrut Peter Müller. Heiteres und Ernstes aus dem Soldatenleben. (Idee, Dichtung und Entwürfe Franz Barth). Breslau

Bergmann (1933): Deutscher Ruhm, Bd 1. Dresden

Bilderdienst Dresden (Reemtsma, Gemeinschaftsausgabe) (1937): Der Weltkrieg. o.O.

Borg (Vereinigte Tabak- und Zigarettenfabriken) (1934): Europa in Waffen. Ein Dokument in 180 Bildern, welches den Rüstungsstand der europäischen Armeen, Ende des Jr. 1933 zeigt. Offenbach

Bravour (1933): Bravour-Bilder Film und Sport. Berlin

Brinkmann (1932): Lloyd-Flottenbilder. Deutsche Marine. Bremen

Brinkmann (1933): Lloyd-Flottenbilder. Die Welthandelsflotte. Bremen

Brinkmann (1933): Lloyd-Flottenbilder. Reedereiflaggen der Welthandelsflotte. Bremen 
Brinkmann (1934): Deutschland hoch in Ehren. Von Hermann dem Cherusker bis zum "Ja" am 9. Nov. 1933. Bremen

Brinkmann (1934): Wie die anderen gerüstet sind...! Trotz vertraglicher Abrüstungspflicht. Bremen

Brinkmann (Yosma) (1934): Männer im Dritten Reich. Bremen

Brinkmann (YOSMA) G.M.B.H. (1934): Alles für Deutschland - 2000 Jahre deutsche Geschichte und deutsches Heldentum. (Textbearbeitung von M. Gutewort und Oberstleutnant Hänichen). Bremen

Brinkmann G.M.B.H. (1934): Das Waffenstarrende Ausland. (Text und sämtliche Abbildungen von F. Hohm. Verantwortlich für die Herausgabe Oberst a. D. von Struensee). Bremen

Bulgaria (1932): Bulgaria-Sport-Photos. Dresden

Deutsche Front (1933): Die Braune Mappe. Berlin

Deuzig Zigarettenfabrik (1933): Unsere Reichsmarine- und Handelsflotten. Dresden

Dimitriou (1932): Mitglieder des deutschen Reichstages. Hamburg-Altona

Doms (1933): Der Kampf um Oberschlesien. 100 Bilder Deutscher Grenzlandsnot u. deutsche Grenzlandstreue. Ratibor

Doms (1934): Führer der deutschen Wehrmacht im Weltkrieg 1914 - 1918. Ratibor

Eckstein (1932): Wunder aus Technik und Natur. Dresden

Eifro - Eiserne Front (1932): Die Vorkämpfer des Sozialismus. München

Garbáty (1932): Die Eroberung der Luft, Bd. 1. Berlin-Pankow

Garbáty (1932): Die Eroberung der Luft (Ausland), Bd. 2. Berlin-Pankow

Garbáty (1934): Das Auto von heute. Berlin

Greiling (1933): Das Neue Reich. Dresden

Greiling (1933): Zeppelin Weltfahrten I. Buch. Dresden

Greiling (1934): Adel der Arbeit. Bilder aus dem Berufsleben des schaffenden deutschen Volkes. Dresden

Greiling (1934): Männer und Ereignisse unserer Zeit, Bd. 1. Dresden

Greiling (1934): Männer und Ereignisse unserer Zeit, Bd. 2. Dresden 
Greiling (1934): Zeppelin Weltfahrten II. Dresden

Greiling (1936): Wunder des Segelfluges. Dresden

Greiling (1937): LZ 129 Hindenburg. Zeppelin Weltfahrten III. Dresden

Greiling (1938): 13 historische Tage 1937. Reichsparteitag der Arbeit. Staatsbesuch Mussolinis. Dresden

Haus Bergmann (1932): Bergmanns bunte Bücher, Buch 2, 21.-22. Aufl. Dresden

Jasmatzi (1934): Unsere Reichsmarine. Aus dem Leben der Matrosen. Dresden

Josetti (1929): Die Welt in Bildern, Album 4. Berlin (Nach Köberich herausgegeben von der Zigarettenindustrie, beteiligte Firmen: Jasmatzi, Josetti, Salem, Sulima, Waldorf-Astoria)

Kameradschafts-Zigarettenfabrik (1933): Erwachendes Deutschland. Gera

Kameradschafts-Zigarettenfabrik (1935): Die deutsche Wehrmacht. Gera

Kosmos (1933): Bilddokumente unserer Zeit, Bd. 1. Dresden

Kosmos (1933/1934): Film Photos, Serie 1 und 2. Dresden

Kosmos (1934): Bilddokumente unserer Zeit. Mit Sonderabteilung Deutsche Jugend - unser Stolz - unsere Zukunft, Mappe 2. Dresden

Kosmos (1934): Vorwärts durch eigene Kraft! Dresden

Kosmos (1935): Schutz und Wehr für Friede und Ehr. Dresden

Kosmos (1937): Deutsche Männer, Deutsche Taten! Dresden

Kyriazi (1930): Vom Einbaum bis zur Europa. Cairo / Hamburg

Kyriazi (1933): Deutsche Helden. (Bilder bearbeitet und zusammengestellt von der Firma Propaganda-Högner, Dresden. Die historischen, zeitgeschichtlichen Texte schrieb Prof. Dr. R. Rolle). Cairo / Hamburg

Lande (1932): Jugend in Front. Bilder aus dem Leben von Hitler-Jugend und -Jungvolk, (Taschenbuch). Dresden

Lande (1934): Das Deutschtum im Ausland, Bd. 1, Grenzdeutschtum. Dresden

Lande (1934): Das Deutschtum im Ausland, Bd. 2, Europa. Dresden

Lande (1934): Der Rattenfänger von Hameln. Dresden

Monopol (1937): Deutschland baut auf. Dresden 
Muratti (1934): Brennpunkte des deutschen Sports. Zwischen den Olympischen Spielen, Bd. 1. Berlin

Neudeutsche Zigarettenfabrik (1933): Rang- und Gradabzeichen der SA. Dresden

Niki (1933): Deutschlands ehemalige Kolonien. Dresden

Orami (1933): Helden der Luft, Bd. 1. Dresden

Orami (1933): Helden der Luft, Bd. 2. Dresden

Osten (O. J.): Querschnitt vom Aufbau der Sowjet-Union. Dresden

Reemtsma (Cigaretten-Bilderdienst Altona / Bahrenfeld) (1936): Adolf Hitler. Bilder aus dem Leben des Führers. (Auswahl und künstlerische Bearbeitung der Bilder Heinrich Hoffmann, München). Hamburg-Bahrenfeld

Reemtsma (Cigaretten-Bilderdienst Altona/Bahrenfeld) (1932): Moderne Malerei. Vom Impressionismus bis zur Gegenwart. Hamburg-Bahrenfeld

Reemtsma (Cigaretten-Bilderdienst Altona/Bahrenfeld) (1935): Vom Werden deutscher Filmkunst. 1. Teil: Der stumme Film. Hamburg-Bahrenfeld

Reemtsma (Cigaretten-Bilderdienst Altona/Bahrenfeld) (1936): Vom Werden deutscher Filmkunst. 2. Teil: Der Tonfilm. Hamburg-Bahrenfeld

Reemtsma (Cigaretten-Bilderdienst Altona/Bahrenfeld) (1938): Malerei des Renaissance. Hamburg-Bahrenfeld

Reemtsma (Cigaretten-Bilderdienst Altona/Bahrenfeld) (1940): Malerei des Barock. Hamburg Bahrenfeld

Reemtsma (Cigaretten-Bilderdienst Altona/Bahrenfeld) (1941): Raubstaat England. Hamburg Bahrenfeld

Reemtsma (Cigaretten-Bilderdienst Hamburg-Bahrenfeld) (1933): Deutschland erwacht, (Röhmausgabe) Auflage ab 200.000 (Auswahl und künstlerische Durcharbeitun der Lichtbilder Heinrich Hoffmann, München. Texte: Wilfrid Bade und Sonderbeiträge div. Autoren). Hamburg-Bahrenfeld

Reemtsma (Cigaretten-Bilderdienst Hamburg-Bahrenfeld) (1933): Deutschland erwacht. Werden, Kampf und Sieg der NSDAP, Auflage 876 - 975 (Auswahl und künstlerische Durcharbeitung der Lichtbilder Heinrich Hoffmann, München. Texte: Wilfrid Bade und Sonderbeiträge div. Autoren). Hamburg-Bahrenfeld

Reemtsma (Cigaretten-Bilderdienst Hamburg-Bahrenfeld) (1936): Die Olympischen Spiele 1936, Bd. 1. Hamburg-Bahrenfeld 
Reemtsma (Cigaretten-Bilderdienst Hamburg-Bahrenfeld) (1936): Die Olympischen Spiele 1936, Bd. 2. Hamburg-Bahrenfeld

Reemtsma (Cigaretten-Bilderdienst Hamburg-Bahrenfeld) (1939): Aus Wald und Flur 2 - Tiere unserer Heimat. Hamburg-Bahrenfeld

Reunion (1933): Das Deutsche Volk muß ein Volk von Fliegern werden. Ein Sammelwerk deutscher Gleit-, Segel-, Sport- und Verkehrsflugzeuge. Obercunnersdorf

Reunion (1933): Reunion-Weltkriegsbilder 1914-1918. Obercunnersdorf

Reunion (1938) (zuvor publiziert von Mahalesi 1934): Ruhmestaten der deutschen Marine. Obercunnersdorf

Solidarität (1933): Aus der Geschichte der Revolution. Berlin

Solidarität (1933): Köpfe aus der Arbeiterbewegung. Berlin

Standard (1938): Fahnen und Standartenträger des Deutschen Reiches 1871-1918, Buch 1. Berlin

Standard (1938): Symbole und Abzeichen des Dritten Reiches. Berlin

Standarte und Steiger (1933): Unsere Führer. Breslau

Standarte und Steiger (1934): Schlesien im Dritten Reich. Breslau

Standarte und Steiger (1934): Schlesische Heimat, Bd. 1. Breslau

Sturm (1932): Deutsche Uniformen Zeitalter deutscher Freiheitskriege (Texte:

Militärschriftsteller Dr. Martin Lezius. Bilder: Militärmaler Herbert Knötel, Berlin). Dresden

Sturm (1932): Zeitalter Friedrichs d. Großen (Texte: Militärschriftsteller Dr. Martin Lezius. Bilder: Militärmaler Herbert Knötel, Berlin). Dresden

Sturm (1933): Deutsche Uniformen Album: SA SS HJ (Literaturbearbeitung: Oberführer von Calrshausen, Oberste SA-Führung, München. Bilder: Militärmaler Herbert Knötel, Berlin). Dresden

Sturm (1933): Zeitalter der Deutschen Einigung 1864 - 1914, Album III, Bd. 1 (Texte: Militärschriftsteller Dr. Martin Lezius. Bilder: Militärmaler Herbert Knötel, Berlin). Dresden

Sturm (1933): Zeitalter der Deutschen Einigung 1864 - 1914, Album IV, Bd. 2 (Texte: Militärschriftsteller Dr. Martin Lezius. Bilder: Militärmaler Herbert Knötel, Berlin). Dresden 
Sturm (1934): Volk ans Gewehr! Abschluß-Album des Werkes „Deutsche Uniformen“ (Bilder: Militärmaler Herbert Knötel, Berlin). Dresden

Sturm (beteiligt: Aladin) (1934): Flaggensprache der Welt. Dresden

Sturm (beteiligt: Dressler) (1934): Seefahrt tut not! Die Entwicklung deutscher Seeschiffahrt von der Frühzeit bis 1871 (Texte: Militärschriftsteller Dr. Martin Lezius. Bilder: Militärmaler Herbert Knötel, Berlin). Dresden

Sturm (beteiligt: Dressler, Kios) (1934): Hindenburg. Dresden

Verbands-Zigarettenvertrieb (1932): Deutsche Krieger aller Zeiten. Dresden

Verbands-Zigarettenvertrieb (1932): Geeinte Front. Stahlhelm Reichsführertagung Hannover 1933. Dresden

Waldorf-Astoria (1931): Vom Segelwagen zum Achtzylinder. München

Wehrverbands-Zigarettenvertrieb (1934): Geeinte Front, Serie 1. Dresden

Werbegemeinschaft Saarlauterner Zigarettenfabriken (1937): Deutscher Kraftfahrsport, Teil 1, Wagen- und Motorradrennen, o.O.

Zigaretten-Industrie (Gemeinschaftsausgabe, beteiligte Firmen: Alva-Yosma, Bergmann, Bulgaria, Constantin, Eckstein, Garbáty, Greiling, Jasmatzi, Josetti, Kyriazzi, Lande, Salem, Waldorf-Astoria (1936): Deutsche Kolonien, o.O.

Zigaretten-Industrie (Gemeinschaftsausgabe, beteiligte Firmen: Alva-Yosma, Bergmann, Bulgaria, Eckstein, Garbáty, Greiling, Jasmatzi, Josetti, Kyriazzi, Lande, Salem, Waldorf-Astoria, Yenidze) (1936): Die Deutsche Wehrmacht. o.O.

Zigaretten-Industrie (Gemeinschaftsausgabe, beteiligte Firmen: Bulgaria, Constantin, Delta, Jasmatzi, Josetti, Salem) (1934): Kampf um's dritte Reich. Eine historische Bilderfolge (Text von: L. von Schenkendorf, Truppenführer der S, Berlin.. Die Auswahl und künstlerische Durcharbeitung der Lichtbilder Heinrich Hoffmann, München) o.O.

Zigaretten-Industrie (Gemeinschaftsausgabe, beteiligte Firmen: Bulgaria, Constantin, Delta, Jasmatzi, Josetti, Salem) (1934): Der Staat der Arbeit und des Friedens. o.O.

Zimmer (1934): Bildwerk vom deutschen Arbeitsdienst. Dresden 


\section{Literaturverzeichnis}

Adam, Christian (2010): Lesen unter Hitler. Berlin: Galiani

Adjouri, Nicholas (2004): Alles, was Sie über Marken wissen müssen. Wiesbaden: Gabler

Adorno, Theodor W. (1995): Studien zum autoritären Charakter. Frankfurt/M.: Suhrkamp

Alkemeyer, Thomas (1996): Körper, Kult und Politik. Fanktfurt/M./ New York: Campus

Amenda, Lars (2013): "Arbeitsmigration vs. >Volksgemeinschaft $<$ ?“ In: Reeken, Dietmar von/Thießen, Malte (Hg.): >Volksgemeinschaft< als soziale Praxis. Paderborn: Ferdinand Schöningh

Asendorf, Christoph (1997): Super Constellation - Flugzeug und Raumrevolution. Die Wirkung der Luftfahrt auf Kunst und Kultur der Moderne. Wien: Springer

Assmann, Aleida (2006): Der lange Schatten der Vergangenheit. Erinnerungskultur und Geschichtspolitik. München: C.H. Beck

Assmann, Aleida (2004): „Zur Mediengeschichte des kulturellen Gedächtnisses“. In: Erll, Astrid/ Nünning, Ansgar (Hg.): Medien des kollektiven Gedächtnisses. Konstruktivität - Historizität - Kulturspezifität, Berlin: de Gruyter

Assmann, Jan (1992): Das kulturelle Gedächtnis. München: C.H. Beck

Bade, Wilfrid (1938): Das Auto erobert die Welt. Eine Biografie des Kraftwagens. Berlin: Zeitgeschichte-Verlag

Baird, Jay W. (1990): To die for Germany: heroes in the Nazi pantheon. Bloomington: Indiana Univertity Press

Bajohr, Frank (2001): Parvenüs und Profiteure. Frankfurt/M.: S. Fischer

Balister, Thomas (1996): „Die Tatpropaganda der SA. Erfolg und Mythos“. In: Diesener, Gerald/Gries, Rainer (Hg.) (1996): Propaganda in Deutschland - Zur Geschichte der politischen Massenbeeinflussung im 20. Jahrhundert. Darmstadt: Primus

Ballsteadt, Steffen-Peter (2006): „Didaktisches Design für Abbilder“. In: Gorbach, Rudolf Paulus (Hg.): Bilder lesen und erkennen. Ein Symposium der Typographischen Gesellschaft München. München: TGM

Barbian, Jan-Pieter (2015): „Die Arbeits- und Lebensbedingungen der Schriftsteller“. In: Geschichte des deutschen Buchhandels im 19. und 20. Jahrhundert. Drittes Reich, Teil 1. Berlin: de Gruyter

Barbian, Jan-Pieter (2015): „Die organisatorische, personelle und rechtliche Neuordnung des deutschen Buchhandels." In: Geschichte des deutschen Buchhandels im 19. und 20. Jahrhundert. Drittes Reich, Teil 1. Berlin: de Gruyter 
Bareither, Christoph/ Maase, Kaspar/ Bausinger, Hermann (Hg.) (2013): Unterhaltung und Vergnügung. Beiträge der Europäischen Ethnologie zur Populärkulturforschung. Würzburg: Königshausen \& Neumann

Bärsch, Claus-Ekkehard (2002): Die politische Religion des Nationalsozialismus. München: Wilhelm Fink

Bärsch, Claus-Ekkehard (2004): Der junge Goebbels. Erlösung und Vernichtung. München: Wilhelm Fink

Bartetzko, Dieter (1985): Illusion in Stein. Stimmungsarchitektur im deutschen Faschismus. Ihre Vorgeschichte in Theater- und Film-Bauten. Reinbek bei Hamburg: Rowohlt

Bastian, Till (2005): High Tech unterm Hakenkreuz. Leipzig: Militzke

Baudrillard, Jean (2001): Das System der Dinge, 2. Aufl. Frankfurt/M./New York: Campus

Bauer, J. Franz (2004): Das „lange“ 19. Jahrhundert. Stuttgart: Reclam

Bauer, Kurt (2008): Nationalsozialismus. Ursprünge, Anfänge, Aufstieg und Fall. Wien/ Köln: Böhlau

Baumann, Zygmunt (2005): Moderne und Ambivalenz. Hamburg: Hamburger Edition

Bavaj, Riccardo (2003): Die Ambivalenz der Moderne im Nationalsozialismus. München: Oldenbourg

Becker, Sascha (2013): Spiel, Technik und Krieg. Marburg: Tectum

Behrenbeck, Sabine (1996): ,,,Der Führer“. Die Einbindung eines politischen Markenartikels“. In: Diesener, Gerald/Gries, Rainer (Hg.) (1996): Propaganda in Deutschland - Zur Geschichte der politischen Massenbeeinflussung im 20. Jahrhundert. Darmstadt: Primus

Behrenbeck, Sabine (2011): Der Kult um die toten Helden. Nationalsozialistische Mythen, Riten und Symbole. Köln: shVerlag

Behrenbeck, Sabine/ Nützenadel, Alexander (Hg.) (2000): Inszenierungen des Nationalstaates. Politische Feiern in Italien und Deutschland seit 1860/71. Köln: shVerlag

Behringer, Wolfgang/ Constance Ott-Koptschalijski (1991): Der Traum vom Fliegen. Zwischen Mythos und Technik. Frankfurt/M.: S. Fischer

Behrmann, Carolin/ Karsten, Arne/ Zitzlsperger, Philipp (Hg.) (2007): Grab - Kult Memoria: Studien zur gesellschaftlichen Funktion von Erinnerung. Wien/ Köln: Böhlau

Behrmann, Jörn (1986): „Grundlagenforschung im totalitären Staat“. In: Stöhr, Martin (Hg.): Von der Verführbarkeit der Naturwissenschaft. Frankfurt/M.: Haag + Herchen 
Berek, Mathias (2009): Kollektives Gedächtnis und die gesellschaftliche Konstruktion der Wirklichkeit. Wiesbaden: Harrassowitz

Berghoff, Hartmut (2007): „Marketing im 20. Jahrhundert. Absatzinstrument Managementphilosophie - universelle Sozialtechnik“. In: Ders. (Hg.): Marketinggeschichte. Die Genese einer modernen Sozialtechnik. Frankfurt/M./ New York: Campus,

Bergien, Rüdiger (2005): „Flotte und Medien im Kaiserreich“. In: Rahn, Werner (Hg.): Deutsche Marinen im Wandel: Vom Symbol nationaler Einheit zum Instrument nationaler Sicherheit. München: Oldenbourg

Bergmann, Jürgen (1989): „„,Das Land steht rechts!“ Das „agrarische Milieu“.“ In: Lehnert, Detlef/ Megerle, Klaus (Hg.): Politische Identität und nationale Gedenktage. Opladen: Westdeutscher Verlag

Bernays, Edward Miller/ Introduction: Mark Crispin (2005): Propaganda. New York: Ig Publishing Bewley, Charles (1956): Hermann Göring. Göttingen: Göttinger Verlagsanstalt

Bley, Wulf (1934): SA marschiert. Leben und Kampf der brauen Bataillone. Berlin: Verlag Deutsche Kultur-Wacht

Blume, Judith (2019): Wissen und Konsum. Eine Geschichte des Sammelbildalbums 1860-1952. Göttingen: Wallstein Verlag

Bloch, Ernst (1980): Abschied von der Utopie? Vorträge. In: Gekle, Hanna (Hg.): Frankfurt/M.: Suhrkamp

Blumberg, Hans (2006): Arbeit am Mythos. Frankfurt/M.: Suhrkamp

Bogedain, Clemens (2016): Lothar von Arnauld de la Perière. Erfolgreichster U-Bootkommandant der Seekriegsgeschichte - ein vergessener "Kriegsheld“?. Stuttgart: Franz Steiner

Böhringer, Joachim/ Böhler, Peter/ Schlaich, Patrick (2008): Kompendium der Mediengestaltung für Digital- und Printmedien, Bd. 1, 4. Aufl. Berlin/Heidelberg: Springer

Borsó, Vittoria/ Liermann, Christiane/ Merzinger, Patrick (2010): “Transfigurationen des Politischen. Von Propaganda-Studien zu Interaktionsmodellen der Medienkommunikation - eine Einleitung“. In: Dies. (Hg.): Die Macht des Populären. Bielefeld: transcript

Bourdieu, Pierre (1987): Die feinen Unterschiede. Frankfurt/M.: Suhrkamp 
Brandt, Dina (2008): „,, Und die Welt sah, was deutscher Geist“. Der deutsche Zukunftsroman im 'Dritten Reich'.“ In: Würmann, Carsten/Warner, Ansgar (Hg.): Im Pausenraum des 'Dritten Reiches'. Zur Populärkultur im nationalsozialistischen Deutschland. Bern/ Berlin: Peter Lang

Braun, Hans-Joachim (1995): „Britische und deutsche Luftrüstung in der Zwischenkriegszeit". In: Hansen, Ernst Willi/Schreiber, Gerhard/Wegner, Bernd. Militärgeschichtliches Forschungsamt (Hg.): Politischer Wandel, organisierte Gewalt und nationale Sicherheit: Beiträge zur neueren Geschichte Deutschlands und Frankreichs. München: Oldenbourg

Bretz, Hans (1938): Bernd Rosemeyer. Ein Leben für den deutschen Sport. Berlin: Wilhelm Limpert

Brinkhus, Jörn (2007): „Ziviler Luftschutz im „Dritten Reich“. Wandel seiner Spitzenorganisation“. In: Süß, Dietmar (Hg.): Deutschland im Luftkrieg. München: Oldenbourg

Brockhaus Enzyklopäie (2006): Band 22, 21. Aufl. Leipzig/ Mannheim

Brockhaus, Gudrun (1997): Schauder und Idylle. München: Antje Kunstmann

Bruhn, Manfred (2014): Unternehmens- und Marketingkommunikation: Handbuch für ein integriertes Kommunikationsmanagement, 3. Aufl. München: Vahlen

Buddrus, Michael (2003): Totale Erziehung für den totalen Krieg: Hitlerjugend und nationalsozialistische Jugendpolitik, Teil 1. München: K. G. Saur

Budraß, Lutz (1998): Flugzeugindustrie und Luftrüstung in Deutschland 1918 - 1945. Düsseldorf: Droste

Buggeln, Marc/ Wildt, Michael (Hg.) (2014): Arbeit im Nationalsozialismus. München: de Gruyter

Burmann, Christoph/ Halaszovich, Tilo/Hemmann, Frank (2012): Identitätsbasierte Markenführung. Wiesbaden: Gabler

Bussemer, Thymian (2000): Propaganda und Populärkultur. Konstruierte Erlebniswelten im Nationalsozialismus. Wiesbaden: DUV

Bussemer, Thymian (2005): Propaganda - Konzepte und Theorien. Wiesbaden: VS Verlag für Sozialwissenschaften

Büttner, Ursula (2008): Weimar. Die überforderte Republik 1918-1933. Stuttgart: Klett-Cotta

Calvesi, Maurizio (1987): Der Futurismus. Kunst und Leben. Köln: Taschen

Campbell, Joseph (2007): Die Kraft der Mythen. Düsseldorf: Albatros 
Campbell, Joseph (2011): Der Heros in tausend Gestalten. Berlin: Insel

Canetti, Elias (1996): Masse und Macht. Frankfurt/M.: S. Fischer

Cassirer, Ernst (1964): Philosophie der symbolischen Formen, Erster Teil, Die Sprache, 4.Aufl. Darmstadt: Wissenschaftliche Buchgesellschaft

Cassirer, Ernst (2002 ): Vom Mythus des Staates. Hamburg: Meiner

Cassirer, Ernst (2010): Philosophie der symbolischen Formen. Zweiter Teil. Das mythische Denken. Hamburg: Meiner

Cilleßen, Wolfgang (2002): "Altäre für das Vaterland". Der Niederrhein als national-patriotische Denkmallandschaft. Wesel: Selbstverlag des Stadtarchives Wesel

Ciolina, Erhard und Evamaria (1985): Garantiert Aecht. Das Reklame-Sammelbild im Spiegel der Zeit. München: Edition Wissen und Literatur/Flade u. Partner

Ciolina, Erhard und Evamaria (2003): Reklamebilder. München: Weltbild

Ciolina, Evamaria/ Ciolina, Erhard (2007): Das Reklamesammelbild, 2. Aufl. Regenstauf: Battenberg

Clemens-Schierbaum, Ursula (1995): Mittelalterliche Sakralarchitektur in Ideologie und Alltag der Nationalsozialisten. Weimar: VDG

Cordts, Georg (1988): Junge Adler. Vom Luftsport zum Flugdienst 1920 - 1945. München: Bechtle

Cornelißen, Christoph (2001): ,,,Schuld am Weltfrieden“: Politische Kommentare und Deutungsversuche deutscher Historiker zum Versailler Vertrag 1919-1933“. In: Krumeich, Gerd (Hg.) in Zusammenarbeit mit Silke Fehlmann: Versailles 1919 Ziele - Wirkung - Wahrnehmung. Essen: Klartext-Verlag

Dähnhardt, Dirk (1978): Revolution in Kiel. Neumünster: Karl Wachholtz

Day, Uwe (2005): Silberpfeil und Hakenkreuz. Autorennsport im Nationalsozialismus. Berlin: be.bra

Deist, Wilhelm (1976): Flottenpolitik und Flottenpropaganda. Das Nachrichtenbüro des Reichsmarineamtes 1897- 1914. Stuttgart: Deutsche Verlags-Anstalt

Deist, Wilhelm (1979): „Die Aufrüstung der Wehrmacht“. In: Ders./Messerschmidt, Manfred/Volkmann, Hans-Erich/Ders. Ursachen und Voraussetzungen der deutschen Kriegspolitik. Militärgeschichtliches Forschungsamt (Hg.): Das Deutsche Reich und der Zweite Weltkrieg. Bd. 1. München: Deutsche Verlags-Anstalt 
Delbrück, Hans (früher Sachverständige [sic!] für die Schuldfrage bei der Deutschen Friedensdelegation in Versailles) (1921): „Allgemeine Bestimmungen“. In: Lersner, Freiherr von, MdR (Hg.): Versailles! Volkskommentar des Friedensdiktates von Versailles. Berlin: Verlag für Politik und Wirtschaft

Deutscher Marinebund e.V. (Hg.) (2004): Das Marine-Ehrenmal in Laboe "Für die Ewigkeit, zeitlos, klar...". Hamburg: Convent

Deutsches Reich. Kriegspresseamt, Auslandstelle (1918): Die Entwicklung des U-Bootkrieges seit Herbst 1917 im Urteil des Auslandes/Abgeschlossen am 1. Februar 1918. Berlin: Norddt. Buchdr. und Verl.anst

Diehl, Paula (2005): Macht Mythos Utopie. Berlin: Akademie Verlag

Dietzel, Heinrich (2007): Beiträge zur Geschichte des Sozialismus und Kommunismus. Norderstedt: BoD

Doering-Manteuffel, Anselm (Hg.) (2006): Strukturmerkmale der deutschen Geschichte des 20. Jahrhunderts. München: Oldenbourg

Domarus, Max (1965): Hitler. Reden und Proklamationen 1932 - 1945, Bd.1, erster Halbband. München: Süddeutscher Verlag

Domizlaff, Hans (1931): Propaganda-Mittel der Staats-Idee. Altona-Dithmarschen: Selbstverlag

Domizlaff, Hans (2005, Erstausgabe 1939): Die Gewinnung des öffentlichen Vertrauens. Ein Lehrbuch der Markentechnik. Hamburg: Marketing Journal

Dörner, Andreas (1996): Politischer Mythos und symbolische Politik. Der Hermannmythos: zur Entstehung des Nationalbewußtseins der Deutschen. Reinbek bei Hamburg: Rowohlt

Döveling, Katrin (2005): Emotionen - Medien - Gemeinschaft. Eine kommunikationssoziologische Analyse. Wiesbaden: VS Verlag für Sozialwissenschaften

Draeger, Hans (Vorwort) in Verbindung mit dem Arbeitsausschuß Deutscher Verbände herausgegeben für Volk und Jugend (1933): Der Vertrag von Versailles. Die Grundursache der deutschen Not. Berlin: Heinrich Beenken „Der Türmer“

Dreeßen, Carl (2000): Die deutsche Flottenrüstung in der Zeit nach dem Vertrag von Versailles bis zum Beginn des Zweiten Weltkrieges und ihre Darstellung und Behandlung im Nürnberger Prozeß von 1945/46. Diss. Universität Hannover Hamburg: Mittler.

Dülffer, Jost (1973): Weimar, Hitler und die Marine. Düsseldorf: Droste 
Duppler, Jörg (1992): „,Revisionismus oder Weltmachtstreben? Maritimes Denken in der nationalsozialistischen Zeit“. In: Elvert, Jürgen/ Jensen, Jürgen/ Salewski, Michael (Hg.): Kiel, die Deutschen und die See. Stuttgart: Franz Steiner Verlag,

Durkheim, Émile (2007): Die elementaren Formen des religiösen Lebens. Frankfurt/M.: Verlag der Weltreligionen

Eckart, Dietrich (1934): „Sturmlied“. In: Gille, Hans (Hg.): Das Neue Deutschland im Gedicht. Bielefeld/Leipzig: Velhagen \& Klasing

Edelmann, Murray (1990): Politik als Ritual. Die symbolische Funktion staatlicher Institutionen und politischen Handelns. Frankfurt./M.: Campus

Eliade, Mircea (1984): Kosmos und Geschichte. Frankfurt /M.: Insel

Eliade, Mircea (1988): Mythos und Wirklichkeit, Frankfurt am Main: Insel-Verlag

Elvert, Jürgen/ Jensen, Jürgen/ Salewski, Michael (Hg.) (1992): Kiel, die Deutschen und die See. Stuttgart: Franz Steiner

Erfurth, Helmut (2011): Luftfahrt im Dritten Reich. Ziviler Flugverkehr und Luftwaffe 1933-1945. München: GeraMond

Erll, Astrid (2011): Kollektives Gedächtnis und Erinnerungskulturen, 2. Aufl. Stuttgart: J.B. Metzler

Erll, Astrid/ Nünning, Ansgar (Hg.) (2004): Medien des kollektiven Gedächtnisses. Konstruktivität - Historizität - Kulturspezifität. Berlin: de Gruyter

Esch, Franz-Rudolf (2011): Strategie und Technik der Markenführung, 6. Aufl. München: Vahlen

Esposito, Fernando (2011): Mythische Moderne. München: Oldenbourg

Eusebius/ Translation Maier, Paul L. (1999): The Church History. Grand Rapids: Kregel Academic

Evans, Richard J. (2006): Das Dritte Reich, Bd. 2/1. München: Deutsche Verlags-Anstalt

Faulstich, Werner (2004): Medienwandel im Industrie- und Massenzeitalter. Göttingen: $\mathrm{V} \& \mathrm{R}$

Fest, Joachim (2006): Hitler. Eine Biographie, 9. Aufl. Berlin: Ullstein

Foertsch, Hermann (1934): Der deutsche Soldat. Leipzig: Seemann

Förster, Jürgen (2007): Die Wehrmacht Im NS-Staat: Eine Strukturgeschichtliche Analyse, Bd 5. München: Oldenbourg 
Foucault, Michel (2005): Analytik der Macht. Frankfurt/M.: Suhrkamp

Frevert, Ute (1997): „Das Militär als „Schule der Männlichkeiten“. Erwartungen, Angebote, Erfahrungen im 19. Jahrhundert“. In: Frevert, Ute (Hg.): Militär und Gesellschaft im 19. und 20. Jahrhundert. Stuttgart: Klett-Cotta

Frevert, Ute (1997): Militär und Gesellschaft im 19. und 20. Jahrhundert. Stuttgart: Klett-Cotta

Friedländer, Saul (2007): Kitsch und Tod. Der Widerschein des Nazismus, erweiterte Auflage. Frankfurt/M.: S. Fischer

Fritzsche, Peter (2007): „Historical Time and Future Experience”. In. Hartwig, Wolfgang (Hg.): Ordnungen in der Krise. München: Oldenbourg

Fuchs, Max (2011): Die Macht der Symbole: ein Versuch über Kultur, Medien und Subjektivität. München: Herbert Utzter

Fuge, Janina (2009): „Zwischen Kontroverse und Konsens.“ In: Schmid, Harald (Hg.): Geschichtspolitik und kollektives Gedächtnis. Göttingen: V\&R unipress

Fuhrmann, Horst (1992): Pour le Mérite. Über die Sichtbarmachung von Verdiensten. Sigmaringen: Thorbecke

Geoffrey, Giles (2000): „Die erzieherische Rolle von Sammelbildern in politischen Umbruchzeiten“. In: Papenfuß, Dietrich/Schieder, Wolfgang (Hg.) (2000): Deutsche Umbrüche im 20. Jahrhundert. Wien/ Köln: Böhlau

Giedion, Sigfried (1982): Die Herrschaft der Mechanisierung. Frankfurt/M.: Europäische Verlagsgesellschaft

Goebbels, Joseph. In: Heiber, Helmut (Hg.) (1991): Goebbels Reden 1932-1945. Düsseldorf: Gondrom

Goote, Thor (1938): Der Führer der Luftschiffe. Mit einem Geleitwort vom Oberbefehlshaber der Luftwaffe Generalfeldmarschall Hermann Göring. Frankfurt/M: dbg

Grabner-Haider, Anton/ Strasser, Peter (2007): Hitlers mythische Religion. Theologische Denklinien und NS-Ideologie. Wien/Köln: Böhlau

Graeb-Könneker, Sebastian (Hg.) (2001): Literatur im Dritten Reich-Dokumente und Texte. Stuttgart: Reclam

Gries, Rainer/ Schindelbeck, Dirk/ Ilgen, Volker (1995): Ins Gehirn der Masse kriechen. Werbung und Mentalitätsgeschichte. Darmstadt: Wissenschaftliche Buchgesellschaft

Gritzbach, Erich (Hg.) (1938): Hermann Göring. Reden und Aufsätze. München: Franz Eher Nachf. 
Groß, Gerhard P. (2005): „Eine Frage der Ehre? Die Marineführung und der letzte Flottenvorstoß 1918.“ In: Rahn, Werner (Hg.): Deutsche Marinen im Wandel: Vom Symbol nationaler Einheit zum Instrument nationaler Sicherheit. München: Oldenbourg

Großbongardt, Annette/ Klußmann, Uwe/ Pötzl, Norbert F. (Hg.) (2011): „Chronik“. In: Die Deutschen im Osten Europas. München: Deutsche Verlags-Anstalt

Grossweiler, Kurt (2012): Kapital, Reichswehr und NSDAP. Köln: PapyRossa

Gruber, Walter (Hg.) (1935): Volk ans Gewehr. Das Buch vom neuen Deutschland, 3. Aufl. Berlin: Nibelungen

Gründel, E. Günther (1932): Die Sendung der jungen Generation. Versuch einer umfassenden revolutionären Sinndeutung der Krise. München: Beck

Gründel, E. Günther (1934): Jahre der Überwindung. Breslau: Wilhelm Gottl. Korn

Gründer, René (2008): Germanisches (Neu-)Heidentum in Deutschland. Entstehung, Struktur und Symbolsystem eines alternativreligiösen Feldes. Berlin: Logos

Grunert, Frank/ Kimmich, Dorothee (Hg.) (2009): Denken durch die Dinge. Siegried Kracauer im Kontext, München: Wilhelm Fink

Günther, Jutta/ Jajesniak-Quast, Dagmara (Hg.) (2006): Willkommene Investoren oder nationaler Ausverkauf?: Ausländische Direktinvestitionen in Ost-Mitteleuropa im 20. Jahrhundert. Berlin: Berliner Wissenschaftsverlag

Haffner, Sebastian (1987): Von Bismarck zu Hitler. München: Kindler

Hagemann, Karen (1997): „Heldenmütter, Kriegerbräute und Amazonen. Entwürfe „patriotischer" Weiblichkeit zur Zeit der Freiheitskriege“. In: Frevert, Ute (Hg.): Militär und Gesellschaft im 19. und 20. Jahrhundert. Stuttgart: Klett-Cotta

Hansen, Ernst Willi (1978): Reichswehr und Industrie. Rüstungswirtschaftliche Zusammenarbeit und wirtschaftliche Mobilmachungsvorbereitungen 1923 - 1932. Reihe: Wehrwissenschaftliche Forschung. Abteilung Militärgeschichtliche Studien, 24. Boppard am Rhein: Boldt

Härtel, Christian (2004 ): Stromlinien Wilfrid Bade - Eine Karriere im Dritten Reich. Berlin: be.bra

Hattendorf, John B. (2005): „Deutschland und die See: Historische Wurzeln deutscher Seestreitkräfte bis 1815.“ In. Rahn, Werner (Hg.): Deutsche Marinen im Wandel: Vom Symbol nationaler Einheit zum Instrument nationaler Sicherheit. München: Oldenbourg

Hattenhauer, Hans (2006): Deutsche National Symbole, 4. Aufl., München: Olzog 
Haubner, Barbara (2001): „Automobilismus im Kaiserreich. Auftakt zur Massenmotorisierung oder Freizeitvergnügen für Wohlhabende“. In: Boch, Rudolf (Hg.): Geschichte und Zukunft der deutschen Automobilindustrie. Stuttgart: Franz Steiner

Hauff, Wilhelm (2015): „Reiters Morgenlied“. In: Guth, Karl- Maria (Hg): Gedichte. Berlin: Contumax-Hofenberg

Hein, Heidi (2006): „Historische Mythos- und Kultforschung.“ In: Tepe, Peter/ Semlow, Tanja (Hg.): Mythos No. 2. Politische Mythen, Würzburg: Königshausen \& Neumann

Hein-Kircher, Heidi (2011): „Überlegungen zum Verhältnis von Erinnerungsorten und politischen Mythen. Eine Annäherung an zwei Modebegriffe“. In: Tepe, Peter/Semlow, Tanja (Hg.): Mythos No. 3. Mythos in Medien und Politik. Würzburg: Königshausen \& Neumann

Helsper, Werner/ Breyvogel, Wilfried/ Kamp, Martin/Stelmaszyk, Bernhard (Hg.) (2004): Schule und Jugendforschung zum 20. Jahrhundert. Wiesbaden: VS, Verl. für Sozialwissenschaften

Hemmann, Thomas (2011): Die Lüneburger Bilderhandschrift aus den Jahren 1807 - 1808 in der Nachzeichnung von Herbert Knötel. Norderstedt: BoD

Henkel, Jost (1934): Die volkswirtschaftliche Bedeutung der Werbung (einschl. Zugabewesen und politischer Werbung). Düsseldorf: Bagel

Herbst, Ludolf (1982): Der totale Krieg und die Ordnung der Wirtschaft. Die Wirtschaft im Spannungsfeld von Politik, Ideologie und Propaganda 1939-1945. Stuttgart: Deutsche Verlagsanstalt

Herz, Rudolf (1994): Hoffmann \& Hitler. Fotografie als Medium des Führer-Mythos. München: Klinghardt \& Biermann,

Heske, Henning (2015): Und morgen die ganze Welt: Erdkundeunterricht im Nationalsozialismus Norderstedt: BoD

Hesse, Kurt (1922): Der Feldherr Psychologos - Ein Suchen nach dem Führer der deutschen . Berlin: E. S. Mittler

Heusler, Andreas/ Spoerer, Mark/T rischler, Helmuth (Hg.) (2010): Rüstung, Kriegswirtschaft und Zwangsarbeit im "Dritten Reich". München: Oldenbourg

Heyden, Ulrich van der (2001): Rote Adler an Afrikas Küste. Die brandenburgisch-preußische Kolonie Großfriedrichsburg in Westafrika, 2. Aufl. Berlin: Selignow

Hillesheim, Jürgen/ Elisabeth Michael (1993): Lexikon nationalsozialistischer Dichter Biographien. Analysen. Würzburg: Königshausen \& Neumann

Hitler, Adolf (1930): Mein Kampf, 2. Aufl. München: Frz. Eher Nachf. 
Hochstetter, Dorothee (2005): Motorisierung und "Volksgemeinschaft" -

Das Nationalsozialistische Kraftfahrerkorp (NSKK) 1931-1945. München: Oldenbourg

Hoegen, Jesko von (2011): „Der Hindenburg-Mythos. Genese, Inhalte und Funktionen des Personenkults um Paul von Hindernburg. “ In: Tepe, Peter/ Semlow, Tanja (Hg.): Mythos No. 3. Mythos in Medien und Politik. Würzburg: Königshausen und Neumann

Hoffmann, Heinrich (1938): Hitler wie ihn keiner kennt. München: Zeitgeschichte-Verlag

Hoffmann, Heinrich (Hg.) (1937), Geleitwort Dr. Otto Dietrich: Der Parteitag der Arbeit 75 Bilddokumente vom Reichsparteitag zu Nürnberg 1937. Berlin: Zeitgeschichte-Verlag

Hoffmann, Heinrich (Hg.) (1941): Me 109 der siegreiche deutsche Jäger. Entwicklung.Bau. Einsatz. München: Verlag Heinrich Hoffmann (in Zusammenarbeit mit der Messerschmidt A.G.)

Höhler, Sabine (2001): Luftfahrtforschung und Luftfahrtmythos. Frankfurt/M./ New York: Campus

Hoppe, Bert (2007): In Stalins Gefolgschaft. Moskau und die KPD 1928 - 1933. München: Oldenbourg,

Hormann, Jörg-M. (1988): Elite im Dritten Reich. Garbsen: Info-Verlag

Hubatsch, Walther (1975): Kaiserliche Marine. München: Lehmann

Hügel, Hans-Otto (Hg.) (2003): Handbuch Populäre Kultur: Begriffe, Theorien und Diskussionen Stuttgart: J. B. Metzler

Ilgen, Volker/ Schindelbeck, Dirk (2006): Am Anfang war die Litfaßsäule. Illustrierte deutsche Reklamegeschichte. Darmstadt: Primus

llgen, Volker/ Schindelbeck, Dirk (1997): Jagd auf den Sarotti-Mohr. Frankfurt/M.: S. Fischer

Jacobs, Tino (2007): „Zwischen Intuition und Experiment. Hans Domizlaff und der Aufstieg Reemtsmas, 1921 bis 1932“. In: Berghoff, Hartmut (Hg.), Marketinggeschichte. Die Genese einer modernen Sozialtechnik. Frankfurt/M./New York: Campus

Jacobs, Tino (2008): Rauch und Macht. Göttingen: Wallstein

Jamme, Christoph (2013): „Mythos - Kulturphilosophische Zugänge.“ In: Krüger, Brigitte/ Stillmark, Hans-Christian (Hg.): Mythos und Kulturtransfer: Neue Figurationen in Literatur, Kunst und modernen Medien. Bielefeld: transcript

Johannes, Werner (2009): Knight of Germany. Havertown: Casemate

Jünger, Ernst (1922): Der Kampf als inneres Erlebnis. Berlin: E.S. Mittler \& Sohn 
Jünger, Ernst (2014) (Erstausgabe 1932): Der Arbeiter. Stuttgart: Klett-Cotta

Jünger, Ernst (Hg.) (1933): Luftfahrt ist not! Leipzig: Vaterländischer Buchvertrieb Thankmar Rudolph

Junker, Detlef (1999): „Kontinuität" der Ambivalenz. Deutsche Bilder von Amerika, 1933 - 1945.“ In: Wala, Michael (Hg.): Gesellschaft und Diplomatie im transatlantischen Kontext. Stuttgart: Franz Steiner

Jussen, Bernhard (Hg.) (2002): Atlas des historischen Bildwissen. Liebigs Sammelbilder (Vollständige Serien 1 - 1138). Max-Planck-Institut für Geschichte, (DVD)

Jussen, Bernhard (Hg.) (2007): Atlas des historischen Bildwissens 2. Bilder der Jahre 1870-1970, 2. Aufl. Berlin: Directmedia Publ.

Kaiser, Alexandra (2010): Von Helden und Opfern. Frankfurt/M./ New York: Campus

Karlson, Paul (1933): Segler durch Wind und Wolken. Berlin: Ullstein

Karmasin, Helene (2004): Produkte als Botschaften, 3. Aufl. München: Redline

Keegan, John (2004): Der Erste Weltkrieg, 3. Aufl. Reinbek bei Hamburg: Rowohlt

Kehrberg, Arno (1942): Das Nationalsozialistische Fliegerkorps - die Vorschule der deutschen Flieger. Berlin: Anton Schuhmacher

Kehrt, Christian (2010): Moderne Krieger. Paderborn: Ferdinand Schöningh

Kershaw, Ian (1980): Der Hitler-Mythos: Volksmeinung und Propaganda im Dritten Reich. Stuttgart: Deutsche Verlags-Anstalt

Kershaw, Ian (1988): Der NS-Staat. Reinbek bei Hamburg: Rowohlt

Kersting, Franz-Werner (1989): Militär und Jugend im NS-Staat. Rüstungs- und Schulpolitik der Wehrmacht. Wiesbaden: DUV

Kessel, Martina (2007): “Gewalt schreiben". In: Hartwig, Wolfgang (Hg.): Ordnungen in der Krise. München: Oldenbourg

Kiekel, Stefan (2007): Die Reichsmarine zwischen Küstenverteidigung und Weltmachtstreben. Militärgeschichte und Wehrwissenschaften Bd. 9. Bonn: Bernard \& Graefe

Kilian, Jette (2008): „Propaganda für die deutschen Kriegsanleihen im Ersten Weltkrieg.“ In: Wilke, Jürgen (Hg.): Massenmedien und Spendenkampagnen vom 17. Jahrhundert bis in die Gegenwart. Wien/Köln: Böhlau

Kiesel, Helmuth (2007): Ernst Jünger. München: Siedler 
Kieselbach, Ralf J. F. (1982): Stromlinienautos in Deutschland - Aerodynamik im PKW-Bau 1900-1945. Stuttgart: Kohlhammer

Kivelitz, Christoph (1999): Die Propagandaausstellung in europäischen Diktaturen. Konfrontation und Vergleich: Nationalsozialismus in Deutschland, Faschismus in Italien und die UdSSR der Stalinzeit. Bochum: Winkler

Klein, Fritz (2001): „Versailles und die Linke“. In: Krumeich, Gerd (Hg.) in Zusammenarbeit mit Silke Fehlmann. Versailles 1919 - Ziele - Wirkung - Wahrnehmung. Essen: Klartext

Kleinheins, Peter (1994): LZ 120 „Bodensee“ und LZ 121 „Nordstern" - Luftschiffe im Schatten des Versailler Vertrages. Friedrichshafen: Zeppelin-Museum

Kleinschmidt, Christian (2008): Konsumgesellschaft. Göttingen: V\&R

Klemperer, Victor (1996): Ich will Zeugnis ablegen bis zum letzten. Tagebücher 1933 -1941. Nowojski, Walter unter Mitarbeit von Klemperer, Hadwig, 8. Aufl. (1996) Berlin: Aufbau-Verlag

Klemperer,Victor (2007): LTI Notizbuch eines Philologen, 22. Aufl. Stuttgart: Reclam

Kliem, Konstantin (2007): Sport in der Zeit des Nationalsozialismus. Saarbrücken: VDM Verlag

Knäusel, Hans G. (2002): Zeppelin, 2. Aufl. Oberhaching: Aviatik

Knäusel, Hans G. (2003): Mythos Zeppelin. Oberhaching: Aviatik

Knieper, Thomas/ Müller, Marion G. (Hg.) (2001): Kommunikation visuell. Das Bild als Forschungsgegenstand-Grundlagen und Perspektiven. Köln: Herbert von Halem

Köberich, Hartmut (2003): Köberich's Reklame- und Sammelbilder. Katalog zur Bewertung der Sammelalben aus der Zeit von 1872 - 1945, 4. Aufl. Rabenau: Lumdatal

Koch, Christian (2013): Das Deutsche Propaganda Atelier und die NS-Feindpropaganda im Zweiten Weltkrieg. Norderstedt: BoD

Koch, Hannsjoachim W. (2002): Der deutsche Bürgerkrieg - Die Geschichte der deutschen und österreichischen Freikorps 1918-1923. Dresden: Edition Antaios

Koch, Jörg (2013): Von Helden und Opfern. Darmstadt: Wissenschaftliche Buchgesellschaft

Köller, Wilhelm (2004): Perspektivität und Sprache Zur Struktur von Objektivierungsformen in Bildern, im Denken und in der Sprache. Berlin: de Gruyter

Kollmann, Michaela (2006): Schulbücher im Nationsalsozialismus. Saarbrücken: VDM 
Kollmeier, Kathrin (2007): Ordnung und Ausgrenzung: die Disziplinarpolitik der Hitler-Jugend. Göttingen: V\&R

König, Wolfgang (2004): Volkswagen, Volksempfänger, Volksgemeinschaft. $>$ Volksprodukte< im Dritten Reich. Vom Scheitern einer nationalsozialistischen Konsumgesellschaft. Paderborn: Ferdinand Schöningh

Koop, Volker (2016): Alfred Rosenberg: Der Wegbereiter des Holocaust. Eine Biographie. Wien/Köln: Böhlau

Korzetz, Ingo (2009): Die Freikorps in der Weimarer Republik: Freiheitskämpfer oder Landsknechthaufen? Marburg: Tectum

Kotler, Philip/ Armstrong, Gary/ Saunders, John/Veronica Wong (2003): Grundlagen des Marketing, 3. Aufl. München: Pearson Studium

Kracauer, Siegfried (1984): Von Caligari zu Hitler. Frankfurt/M: Suhrkamp

Kroll, Frank-Lothar (1998): Utopie als Ideologie. Paderborn: Ferdinand Schöningh

Krüger, Brigitte/ Stillmark, Hans-Christian (Hg.) (2013): Mythos und Kulturtransfer: Neue Figurationen in Literatur, Kunst und modernen Medien. Bielefeld: transcript

Kube, Alfred (1987): Pour le Mérite und Hakenkreuz - Hermann Göring im Dritten Reich, 2. Aufl., München: Oldenbourg

Kuehnemund, Richard (1946): Psychologisch-Historischer Hintergrund im deutschen Sendungsbewusstsein. Monatshefte, Vol. 38, No. 8. Madison: University of Wisconsin Press

Kühberger, Christoph (2006): „Emotionaler Rausch: Zu den Mechanismen der Gefühlsmobilisierung auf faschistischen und nationalsozialistischen Festen“. In: Klimó, von/ Malte, Rolf (Hg.): Rausch und Diktatur. Inszenierung, Mobilisierung und Kontrolle in totalitären Systemen. Frankfurt/M./ New York: Campus

Kuhn, Ekkehard (2016): Flucht Vertreibung Integration: Über das Schicksal der Deutschen nach dem Zweiten Weltkrieg. Norderstedt: BoD

Kühner, Angela (2008): Trauma und kollektives Gedächtnis. Gießen: Psychosozial-Verlag

Kunze, Thomas/ Stommer, Rainer (1982): „Geschichte der Reichsautobahn“. In: Stommer, Rainer (Hg.): Reichsautobahn: Pyramiden des Dritten Reichs: Analysen zur Ästhetik eines unbewältigten Mythos. Marburg: Jonas

Le Bon, Gustave (1982): Psychologie der Massen. Stuttgart: Kröner

Leeb, Rudolf (1992): Konstantin und Christus. Berlin: de Gruyter 
Lemke, Bernd (2005): Luftschutz in Großbritannien und Deutschland 1923 bis 1939. Zivile Kriegsvorbereitungen als Ausdruck der staats- und gesellschaftspolitischen Grundlagen von Demokratie und Diktatur. Militärgeschichtliches Forschungsamt (Hg.). München: Oldenbourg

Lersner, Freiherr von, MdR (1921): „Deutschlands Grenzen“. In: Ders. (Hg.) Versailles! Volkskommentar des Friedensdiktates von Versailles. Berlin: Verlag für Politik und Wirtschaft

Lersner, Freiherr von, MdR (1921): „Strafbestimmungen“. In: Ders. (Hg.) Versailles! Volkskommentar des Friedensdiktates von Versailles. Berlin: Verlag für Politik und Wirtschaft

Lewalter, Doris (1997): Lernen mit Bildern und Animationen. Studie zum Einfluß von Lernermerkmalen auf die Effektivität von Illustrationen, Münster: Waxmann

Lindenberg, Christoph (1985): Die Technik des Bösen Zur Vorgeschichte und Geschichte des Nationalsozialismus, 3. Aufl. Stuttgart: Verlag Freies Geistesleben

Lindner, Erik (2007): „Garbáty. Eine Zigarettenfabrik in Pankow“. In: Biggeleben, Christof/ Schreiber, Beate/Steiner, Kilian J.L. (Hg.): Arisierung in Berlin. Berlin: Metropol

Lindner, Erik (2007): Die Reemtsmas. Hamburg: Hoffmann und Campe

Lippisch, Alexander (1933): „Der Modellflugbau“. In: Jünger (Hg.): Luftfahrt ist not! Leipzig: Vaterländischer Buchvertrieb Thankmar Rudolph

Lochner, R. K. (1982): Die Kaperfahrten des Kleinen Kreuzers Emden. München: Heyne Verlag

Loiperdinger, Martin (1987): Rituale der Mobilmachung. Opladen: Leske und Budrich

Longerich, Peter (1999): Die braunen Bataillone. Augsburg: Bechtermünz

Lorenz, Detlef (2000): Reklamekunst um 1900. Berlin: Reimer

Lorenz, Thomas (2008): „Die Weltgeschichte ist das Weltgericht!“ Der Versailler Vertrag in Diskurs und Zeitgeist der Weimarer Republik. Frankfurt: Campus

Lorenzen, Till (2010): Unternehmerische Handlungsspielräume der Bayerischen Motoren Werke im Flugzeugmotorenbau 1933-1940. In: Heusler, Andreas/ Spoerer, Mark/ Trischler, Helmuth (Hg.): Rüstung, Kriegswirtschaft und Zwangsarbeit im "Dritten Reich". München: Oldenbourg

Lörke, Tim (2010): Die Verteidigung der Kultur: Mythos und Musik als Medien der Gegenmoderne. Würzburg: Königshausen \& Neumann

Ludendorff, Erich (1919): Meine Kriegserinnerungen. Berlin: E. S. Mittler 
Ludwig, Karl-Heinz (2004): „Das Dritte Reich, seine Technik und Ingenieure“. In: Lorenz, Werner/ Meyer, Torsten (Hg.): Technik und Verantwortung im Nationalsozialismus. Münster: Waxmann

Luhmann, Niklas (1979): „Öffentliche Meinung“. In: Langenbucher, Wolfgang R. (Hg.): Politik und Kommunikation. Über öffentliche Meinungsbildung. München: R. Piper \& Co.

Luhmann, Niklas (1995): Soziologische Aufklärung 6. Der soziologische Mensch. Opladen: Westdeutscher Verlag Bajohr

Maase, Kaspar (1997): Grenzenloses Vergnügen: der Aufstieg der Massenkultur 1850 - 1970. Frankfurt/M.: S. Fischer

Maase, Kaspar (2013): „Populärkultur - Unterhaltung - Vergnügung. Zur Systematik des Forschungsfeldes. In: Bareither, Christoph/ Maase, Kaspar/ Bausinger, Hermann (Hg.): Unterhaltung und Vergnügung. Beiträge der Europäischen Ethnologie zur Populärkulturforschung. Würzburg: Königshausen \& Neumann

Macek, Bernhard A. (2012): Kaiser Karl I.: der letzte Kaiser Österreichs. Erfurt: Sutton

Mackensen, Rainer/ Reulecke, Jürgen/ Ehmer, Josef (Hg.) (2009): Ursprünge, Arten und Folgen des Konstrukts "Bevölkerung" vor, im und nach dem Dritten Reich. Wiesbaden: VS Verlag für Sozialwissenschaften

Magnus, Gilbert (2011): „Die populäre Literatur als Textsorte? Eine Begriffsbestimmung.“ In: Agard, Olivier/ Helmreich, Christian/ Vinckel-Roisin, Hélène (Hg.): Das Populäre. Untersuchungen zu Interaktionen und Differenzierungsstrategien in Literatur, Kultur und Sprache. Göttingen: V \& R

Maier, Helmut (Hg.) (2002): Einleitung in: Rüstungsforschung im Nationalsozialismus: Organisation, Mobilisierung und Entgrenzung der Technikwissenschaften. Göttingen: Wallstein

Markovi' c, Predrac J. 2006): „Vom sozialistischen Realismus bis zum sozialistischen Ästhetizismus: Die merkwürdige Entwicklung der ästhetischen Ideologie der jugoslawischen Kommunisten“. In: Richter, Angela/ Beyer, Barbara (Hg.): Geschichte (ge-)brauchen. Literatur und Geschichtskultur im Staatssozialismus: Jugoslawien und Bulgarien. Berlin: Frank \& Timme

Marohn, Norbert (2011): Röhm. Ein deutsches Leben. Leipzig: Lychatz

Marszolek, Inge (2014): „Vom Proletarier zum „Soldaten der Arbeit“. In: Buggeln/ Wildt, Michael (Hg): Arbeit im Nationalsozialismus. München: de Gruyter 
Medebach, Friedrich (1941): Das Kampfplakat. Aufgabe, Wesen und Gesetzmäßigkeit des Plakats, nachgewiesen an den Plakaten der Kampfjahre von 1918 bis 1933. Zeitung und Zeit. Schriftenreihe des Instituts für Zeitungswissenschaft an der Universität Berlin. Reihe A, Band 19. Frankfurt/M.: Moritz Diesterweg

Meffert, Heribert/ Burmann, Christoph/Koers, Martin (Hg.) (2002): Markenmanagement: Grundfragen der identitätsorientierten Markenführung. Wiesbaden: Gabler

Meighörner, Wolfgang (2003): Pioniere des industriellen Designs am Bodensee. Friedrichshafen: Robert Gessler

Meißner, Jörg/ Deutsches Historisches Museum. (Hg.) (2004): Strategien der Werbekunst 1850-1933. Bönen: DruckVerlag Kettler

Melville, Gert (Hg.) (2001): Institutionalität und Symbolisierung. Wien/ Köln: Böhlau

Merkel, Kerstin/ Dittrich, Constance (Hg.) (2011): Spiel mit dem Reich Nationalsozialistische Ideologie in Spielzeug und Kinderbüchern. Wiesbaden: Harrassowitz

Merki, Christoph Maria (1998): Die nationalsozialistische Tabakpolitik - Vierteljahreshefte für Zeitgeschichte, Jahrgang 46, Heft 1. München: Oldenbourg

Messerschmidt, Manfred (1979): „Außenpolitik und Kriegsvorbereitung“. In: Deist, Wilhelm/ Messerschmidt, Manfred/ Ders./ Wette, Wolfram. Ursachen und Voraussetzungen der deutschen Kriegspolitik. Militärgeschichtliches Forschungsamt (Hg.): Das Deutsche Reich und der Zweite Weltkrieg. Bd. 1. München: Deutsche Verlags-Anstalt

Metz, H. Karls (1998): „Solidarität und Geschichte“. In: Bayertz, Kurt (Hg.): Solidarität Begriff und Problem. Frankfurt/M.: Suhrkamp

Metzsch, Horst von (1935): Schlummernde Wehrkräfte. Neue soldatische Blickfelder. Oldenburg/ Berlin: Gerhard Stalling

Meyer, Guschti (2013): Sprache der Bilder, 2. Aufl. Leipzig: Seemann/ Henschel

Michalczyk, Andrzej (2010): Heimat, Kirche und Nation. deutsche und polnische Nationalisierungsprozesse im geteilten Oberschlesien (1922 - 1939). Wien/ Köln: Böhlau

Mielke, Heinz-Peter (1982): Vom Bilderbuch des kleinen Mannes. Köln: Rheinland

Moeller, Felix (1994): „Blitzkrieg und die nationalsozialistische Filmpropaganda. Aus den Tagebuchaufzeichnungen von Joseph Goebbels 1939 bis 1941“. In: Daniel, Ute/ Siemann, Wolfram (Hg.): Propaganda. Meinungskampf, Verführung und politische Sinnstiftung 1789-1989. Frankfurt/M.: Fischer 
Mommsen, Hans (1997): „Militär und zivile Militarisierung in Deutschland 1914 bis 1938.“ In: Frevert, Ute (Hg.): Militär und Gesellschaft im 19. und 20. Jahrhundert. Stuttgart: Klett-Cotta

Mommsen, Wolfgang J. (2004): Der Erste Weltkrieg - Anfang vom Ende des bürgerlichen Zeitalters. Frankfurt/M.: Fischer

Mosse, Georg L. (1976): Die Nationalisierung der Massen. Berlin: Ullstein

Mosse, George L. (1991): Die völkische Revolution. Über die geistigen Wurzeln des Nationalsozialismus. Frankfurt/M.: Anton Hain

Mosse, George L. (1993): Gefallen für das Vaterland. Nationales Heldentum und namenloses Sterben. Stuttgart: Klett-Cotta

Mosse, George L. (1997): Das Bild des Mannes. Zur Konstruktion der modernen Männlichkeit. Frankfurt/M.: Büchergilde Gutenberg

Mücke, Hellmuth von (1915): Emden. Berlin: Scherl

Mühl-Benninghaus, Wolfgang (2004): „Das Bild der Technik in den audiovisuellen Medien“. In: Pichol, Karl/ Weber, Wolfhard/ Bluma, Lars (Hg.): Technikvermittlung und Technikpopularisierung. Historische und didaktische Perspektiven. New York/ Berlin: Waymann

Müllenbach, Herbert (1941): Eroberung der Luft - „Vom "fliegenden Menschen“ zum "Großen Dessauer", 4. Aufl. München: Frz. Eher Nachf.

Müller, Dorit (2008): „Populärwissenschaftliche Zeitschriften im 'Dritten Reich'“. In: Würmann, Carsten/ Warner, Ansgar (Hg.): Im Pausenraum des 'Dritten Reiches'. Zur Populärkultur im nationalsozialistischen Deutschland. Bern/Berlin: Peter Lang

Mumford, Lewis (1984): Mythos der Maschine. Kultur, Technik und Macht. Frankfurt/M.: S. Fischer

Münkler, Herfried (2009): Die Deutschen und ihre Mythen, 2. Aufl. Berlin: Rowohlt

Nassen, Ulrich (1987): Jugend, Buch und Konjunktur 1933-1945. München: Wilhelm Fink

Nationalsozialistischer Deutscher Marine-Bund (Hg.) (1936): Das deutsche Marine-Ehrenmal. Berlin: Marine-Verlag Heinrich Beenken

Nieke, Erdmute (2007): Religiöse Bilderbogen aus Neuruppin: Eine Untersuchung zur Frömmigkeit im 19. Jahrhundert. Bern/Berlin: Peter Lang

Niethammer, Ortrun/ Preusser, Heinz-Peter/ Rétif, Francoise (Hg.) (2007): Mythen der sexuellen Differenz. Übersetzungen - Überschreibungen - Übermalungen. Heidelberg: Universitätsverlag Winter 
Nolte, Maik (2005): „....mit Anstand zu sterben verstehen.“ Flottenrüstung zwischen Tirpitzscher Tradition, strategischer Notwendigkeit und ideologischem Kalkül 1933 - 1943. Lübeck/ Hamburg; Der Andere Verlag

Nolzen, Armin (1986): „Der Durchbruch der NSDAP zur Massenbewegung seit 1929.“ In: Thamer (Hg.): Verführung und Gewalt: Deutschland 1933-1945.München: Siedler

Nolzen, Armin (2013): „Nationalsozialismus und >Volksgemeinschaft $<$ Plädoyer für eine operative Semantik“. In: Reeken, Dietmar von/Thießen, Malte (Hg.): >Volksgemeinschaft< als soziale Praxis. Paderborn: Ferdinand Schöningh

Nonn, Christoph (2007): Das 19. und 20. Jahrhundert. Orientierung Geschichte, 2. Aufl. Paderborn: Ferdinand Schöningh

Nöth, Winfried (2000): Handbuch der Semiotik, 2. Aufl. Stuttgart: J.B. Metzler

Ortemeyer, Benjamin (2010): Mythos und Pathos statt Logos und Heros, 2. Aufl. Weinheim: Beltz

O'Shaughnessy, Nicholas J. (2004): Politics and Propaganda: Weapons of Mass Seduction. Manchester: Manchester University Press

Ottmer, Hans-Martin (1991): „Skandinavien in der deutschen marinestrategischen Planung“. In: Bohn, Robert/ Elvert, Jürgen/Rebas, Hain/ Salewski, Michael (Hg.): Neutralität und totale Aggression. Nordeuropa und die Großmächte im Zweiten Weltkrieg. Stuttgart: Franz Steiner

Ottomeyer, Hans/ Atzbach, Rainer/ Lüken, Sven (Hg.) (2010): Mythos Burg. Eine Ausstellung des Germanischen Nationalmuseums Nürnberg. Dresden: Sandsteinverlag

Pandel, Hans-Jürgen (2010): Historisches Erzählen. Schwalbach/Ts.: Wochenschau Verlag

Paul, Gerhard (1989): „Die Nationalsozialisten.“ In: Lehnert, Detlef/ Megerle, Klaus (Hg.): Politische Identität und nationale Gedenktage. Opladen: Westdeutscher Verlag

Paul, Gerhard (1990): Aufstand der Bilder. Die NS-Propaganda vor 1933. Bonn: J.H.W. Dietz Nachf.

Pepels, Werner (2004): Marketing: Lehr- und Handbuch, 4.Aufl. München: Oldenbourg

Petermann, Sandra (2007): Rituale machen Räume. Bielefeld: transcript

Peukert, Detlev J. K. (1987): Die Weimarer Republik. Krisenjahre der klassischen Moderne. Frankfurt/M.: Suhrkamp

Pieper, Dietmar (2011): „Die Waisen von Versailles“. In: Großbongardt, Annette/ Klußmann, Uwe/ Pötzl, Norbert F. (Hg.): Die Deutschen im Osten Europas. München: Deutsche Verlags-Anstalt 
Pieske, Christa/ Museum für Deutsche Volkskunde Berlin (1983): Das ABC des Luxuspapiers. Herstellung, Verarbeitung und Gebrauch 1860 bis 1930. Katalog Ausstellung des Museums für Deutsche Volkskunde Berlin Staatliche Museen Preußischer Kulturbesitz. Berlin: Dietrich Reimer

Plenge, Johann (1922): Deutsche Propaganda. Die Lehre von der Propaganda als praktische Gesellschaftslehre. Bremen: Angelsachsen-Verlag

Popp, Valerie (2008): „Aber hier war alles anders...”. Würzburg: Königshausen \& Neumann

Prinz, Michael/ Zitelmann, Rainer (1994) (Hg.): Nationalsozialismus und Modernisierung, 2. Aufl. Darmstadt: Wissenschaftliche Buchgesellschaft

Ptak, Ralf (2004): Vom Ordoliberalismus zur Sozialen Marktwirtschaft. Stationen des Neoliberalismus in Deutschland. Wiesbaden: Springer

Rahn, Werner (Hg.) (2005): Deutsche Marinen im Wandel: Vom Symbol nationaler Einheit zum Instrument nationaler Sicherheit. München: Oldenbourg

Rahner, Stefan (Hg.) (2010): Werbewelten made in Hamburg. 100 Jahre Reemtsma. Hamburg: Junius

Ranke-Graves, Robert von (1960): Griechische Mythologie. Quellen und Deutung, Bd. 1. Hamburg: Rowohlt

Recker, Marie-Luise (2010): Die Außenpolitik des Dritten Reiches, 2. Aufl. München: de Gruyter

Redlich, Fritz (1935): Reklame - Begriff - Geschichte - Theorie. Stuttgart: Ferdinand Enke

Reeken, Dietmar von/ Thießen, Malte (Hg.) (2013): >Volksgemeinschaft< als soziale Praxis. Paderborn: Ferdinand Schöningh

Reemtsma (o. J.): 100 Jahre deutsche Industriegeschichte 1910 - 2010: o.O.: epub, Helios Media, Firmenpublikation

Regenthal, Gerhard (2003): Ganzheitliche Corporate Identity. Form, Verhalten und Kommunikation erfolgreich gestalten. Wiesbaden: Gabler

Reichardt, Sven (2007): „Totalitäre Gewaltpolitik?“ In: Hartwig, Wolfgang (Hg.): Ordnungen in der Krise. München: Oldenbourg

Reichhardt, Sven (2009): Faschistische Kampfbünde. Gewalt und Gemeinschaft im italienischen Squadrismus und in der deutschen SA, 2. Aufl. Wien/ Köln: Böhlau

Reichel, Peter (2006): Der schöne Schein des Dritten Reiches. Hamburg: Ellert \& Richter Zeitgeschichte 
Reichel, Peter (2012): Glanz und Elend deutscher Selbstdarstellung. Nationalsymbole in Reich und Republik. Göttingen: Wallstein

Reinhardt, Dirk (1993): Von der Reklame zum Marketing. Berlin: Akademie Verlag

Reinicke, Helmut (1998): Deutschland hebt ab. Köln: PapyRossa

Renckstorf, Karsten (1977): Neue Perspektiven in der Massenkommunikationsforschung. Berlin: Volker Spiess

Reuß, Eberhard (2006): Hitlers Rennschlachten. Berlin: Aufbau Verlag

Riedel, Peter (1984): Vom Hangwind zur Thermik. Erlebte Rhöngeschichte 1927-1932. Stuttgart: Motorbuch Verlag

Ritli, Martin (Wissenschaftlicher Mitarbeiter und Regisseur der UFA-Kulturabteilung) (1938): Flieger Funker Kanoniere. Berlin: Schützen Verlag

Ritter, Karl Bernhard (1922): „Religiöse Grundeinstellung der Jugend“. In: Moeller, van den Bruck/ Gleichen-Russwurm, Heinrich von/ Boehm, Max Hildebert (Hg.): Die Neue Front. Berlin: Verlag Gebrüder Pätel

Ritter, Wolfgang (1970): Die bessere Idee. Pfullingen: Neske

Röhm, Ernst (1930): Die Geschichte eines Hochverräters, 2. Aufl., München: Frz. Eher Nachf.

Ronge, Tobias (2010): Das Bild des Herrschers in Malerei und Grafik des Nationalsozialismus. Eine Untersuchung zur Ikonografie von Führer- und Funktionärsbildern im Dritten Reich. Berlin: LIT

Rösch, Mathias (2002): Die Münchner NSDAP 1925 - 1933. Eine Untersuchung zur inneren Struktur der NSDAP in der Weimarer Republik. München: Oldenbourg

Rose, Arnold M. (1967): „Systematische Zusammenfassung der Theorie der symbolischen Interaktion“. In: Hartmann, Heinz (Hg.): Moderne amerikanische Soziologie. Stuttgart: Ferdinand Enke

Rosemeyer-Beinhorn, Elly (1938): Mein Mann, der Rennfahrer. Der Lebensweg Bernd Rosemeyers. Berlin: Deutscher Verlag

Rosenberg, Alfred (1930): Der Mythus des 20. Jahrhunderts. Eine Wertung der seelisch-geistigen Gestaltenkämpfe unserer Zeit, Aufl. 936-965 1942. München: Hoheneichen

Rübner, Hartmut (2005): Konzentration und Krise der deutschen Schiffahrt, Bd. 1. Bremen: H.M. Hauschild

Rücker, Matthias (2000): Wirtschaftswerbung unter dem Nationalsozialismus. Frankfurt/M.: Peter Lang 
Runk, Claudia (2006): Grundkurs Typografie und Layout. Bonn: Gilieo Design

Sachse, Rolf (2006): „Zur Kontinuität von Bauhaus und Moderne im NS-Staat". In: Böhnigk, Volker/ Stamp, Joachim (Hg.): Die Moderne im Nationalsozialismus. Bonn: Univertity Press

Sachs-Hombach, Klaus/ Rehkämper, Klaus (Hg.) (1998): Bild - Bildwahrnehmung Bildverarbeitung. Wiesbaden: DUV

Salewski, Michael (1998): In: Elvert, Jürgen/ Lippert, Stefan (Hg.): Die Deutschen und die See: Studien zur deutschen Marinegeschichte des 19. und 20. Jahrhunderts, Band 1, Stuttgart: Franz Steiner

Schäfers, Bernhard (1996): Soziologie und Gesellschaftsentwicklung: Aufsätze 1966-1996. Wiesbaden: Springer

Schäfers, Bernhard (1998): Soziologie des Jugendalters: Eine Einführung, 6. Aufl. Wiesbaden: VS Verlag für Sozialwissenschaften

Scharnberg, Harriet (2014): „Arbeit und Gemeinschaft. Darstellungen „deutscher" und „jüdischer" Arbeit in der NS-Bildpropaganda“. In: Buggeln, Marc/ Wildt, Michael (2014): Arbeit im Nationalsozialismus. München: de Gruyter

Scherner, Jonas (2008): Die Logik der Industriepolitik im Dritten Reich. Stuttgart: Franz Steiner

Schilling, René (2002): „Kriegshelden“ Deutungsmuster heroischer Männlichkeit in Deutschland 1813-1945. Paderborn: Ferdinand Schöningh

Schilling, René (2006): „Reichswehr, Wehrmacht und nationale republikanische Rechte“. In: Epkenhans, Michael/Militärgeschichtliches Forschungsamt Potsdam (Hg.):

Die Suche nach Orientierung in deutschen Streitkräften 1871 bis 1990. Norderstedt: BoD

Schirmer, Dietmar (1989): „Politisch-kulturelle Deutungsmuster: Vorstellungen von der Welt der Politik in der Weimarer Republik." In: Lehnert/ Megerle (Hg.): Identität Schivelbusch, Wolfgang (2001): Die Kultur der Niederlage. Berlin: Rowohlt

Schmidt, Rainer F. (2002): Die Außenpolitik des Dritten Reiches 1933 - 1939. Stuttgart: Klett-Cotta,

Schmitz, Hermann (2013): Die mittelalterliche Malerei in Soest: Zur Geschichte des Naturgefühls in der deutschen Kunst. Staufen: Omena

Schmitz-Berning, Cornelia (2007): Vokabular des Nationalsozialismus. München/ Berlin: de Gruyter

Schmokel, Wolfe W. (1967): Der Traum vom Reich. Gütersloh: Sigbert Mohn 
Schnatz, Jörg (2013): Söhne von Kriegen und Bürgerkriegen". Generationalität und Kollektivgedächtnis im Werk Ernst Jüngers 1920-1965. Würzburg: Ergon

Schneider, Wolf (2014): Der Soldat - ein Nachruf. Reinbek bei Hamburg: Rowohlt

Scholtz, Harald (2009): Erziehung und Unterricht unterm Hakenkreuz. Göttingen: V \& R

Schreckenberg, Heinz (2001): Erziehung, Lebenswelt und Kriegseinsatz der deutschen Jugend unter Hitler. Münster: LIT

Schreckenberg, Heinz (2003): Ideologie und Alltag im Dritten Reich. Frankfurt/M.: Peter Lang

Schug, Alexander (2007): „Hitler als Designobjekt und Marke. Die Rezeption des Werbegedankens durch die NSDAP bis 1933/34“. In: Berghoff, Hartmut (Hg.): Marketinggeschichte. Die Genese einer modernen Sozialtechnik. Frankfurt/ M./ New York: Campus

Schüler, Andreas (1990): Erfindergeist und Technikkritik. Stuttgart: Franz Steiner

Schultz, Maria (2012): „Erinnern und Erzählen für ein Massenpublikum“. In: Carl, Horst/ Planert, Ute (Hg.): Militärische Erinnerungskulturen vom 14. bis zum 19. Jahrhundert: Träger - Medien - Deutungskonkurrenzen. Göttingen: V\&R unipress

Schultze-Pflaelzer, Gerhard (1923): Propaganda, Agitation, Reklame. Eine Theorie des gesamten Werbewesens. Berlin: Georg Stilke

Schultze-Pflaelzer, Gerhard (1938): Die Luftschmiede von Dessau. Berlin: Theodor Weicher Verlag

Schultze-Pflaelzer, Gerhard (o. J., um 1934): Deutsche Geschichte 1918-1933. Vom Zweiten zum Dritten Reich. Berlin: Otto Stollberg

Schulz, Maria (2012): „,Für Gott, König und Vaterland. Erinnern und Erzählen für ein Massenpublikum“. In: Carl, Horst/ Planert, Ute (Hg.): Militärische Erinnerungskulturen vom 14. bis zum 19. Jahrhundert: Träger-Medien - Deutungskonkurrenzen. Göttingen: V\&R unipress

Schulz, Petra Maria (2004): Ästhetisierung von Gewalt in der Weimarer Republik. Münster: Westfälisches Dampfboot

Schulze, Hagen (1969): Freikorps und Republik 1918 - 1920. Boppard am Rhein: Harald Boldt

Schumann, Renata (2012): Hedwig von Schlesien - eine Frau für Europa. Görlitz: Bergstadtverlag

Schütz, Erhard/ Gruber, Eckhard (1996): Mythos Reichsautobahn. Berlin: Ch. Links 
Schwarzwäller, Wulf C. (1998): Hitlers Geld. Wien: Ueberreuter

Schweer, Henning (2010): Popularisierung und Zirkulation von Wissen, Wissenschaft und Technik in visuellen Massenmedien. Eine grundlegende historische Studie am Beispiel der Sammelbilder der Liebig Company und der Stollwerck AG. Dissertationsschrift, Universität Hamburg

Schwerber, Peter (1930): Nationalsozialismus und Technik. Geistigkeit der nationalsozialistischen Bewegung. Nationalsozialistische Bibliothek/ Heft 21. München: Frz. Eher Nachf.

Seebohn, Joachim (2001): Gabler Kompakt-Lexikon Werbepraxis, 2. Aufl. Wiesbaden: Gabler

Sennebogen, Waltraud (2004): „Von jüdischer Werbung zu deutscher Werbung. Sprachregelung in der nationalsozialistischen Wirtschaftswerbung." In: Greule, Albrecht/ Dies. (Hg.): Tarnung - Leistung - Werbung. Untersuchungen zur Sprache im Nationalsozialismus. Frankfurt/M.: Peter Lang

Sennebogen, Waltraud (2008): Zwischen Kommerz und Ideologie. München: Martin Meidenbauer

Shannon, Kasia (2006): „Etatismus und Wirtschaftsnationalismus in Ost-Oberschlesien“. In: Günther, Jutta/ Jajesniak-Quast, Dagmara (Hg.): Willkommene Investoren oder nationalerAusverkauf?: Ausländische Direktinvestitionen in Ost-Mitteleuropa im 20. Jahrhundert. Berlin: Berliner Wissenschaftsverlag

Showell, Jack Mallmann (2008): Die Geschichte der deutschen U-Boot-Waffe seit 1906. Stuttgart: Motorbuch

Simmel, Georg (1989): Über sociale Differenzierung - Aufsätze 1887-1890. Die Probleme der Geschichtsphilosophie. Frankfurt/M.: Suhrkamp

Simmel, Georg (2008): Individualismus der modernen Zeit. Frankfurt/M.: Suhrkamp

Simonis, Annette (2013): „Mythos und fraktale Form, Figurationen der Hadesreise in Moderne und Gegenwart“. In: Krüger, Brigitte/Stillmark, Hans-Christian (Hg.): Mythos und Kultur- transfer: Neue Figurationen in Literatur, Kunst und modernen Medien. Bielefeld: transcript

Soeffner, Hans-Georg (2010): Symbolische Formung. Weilerswist-Metternich: Verlbrück

Sommer, Manfred (1999): Sammeln - Ein philosophischer Versuch. Frankfurt/M.: Suhrlamp

Sontag, Susan (2003): Im Zeichen des Saturn, 3. Aufl. Frankfurt/M.: S. Fischer

Speitkamp, Winfried (1998): Jugend in der Neuzeit: Deutschland vom 16. bis zum 20. Jahrhundert. Göttingen: V\&R

Speitkamp, Winfried (2010): Die Ohrfeige, Duell und Ehrenmord. Stuttgart: Reclam 
Sprenger, Matthias (2007): Landsknechte auf dem Weg ins Dritte Reich. Zu Genese und Wandel des Freikorpsmythos. Paderborn: Ferdinand Schöningh

Stahl, Friedrich (1927/ Neuaufl. 1986): Der Versailler Vertrag vom 28. Juni 1919 als ein Instrument der Ausbeutung, Erniedrigung und Schikanierung Deutschlands. Bremen: Faksimile- Verlag

Stambolis, Barbara (2016): „Der Film „Junge Adler" (1944) in Generationellen Kontexten“. In: Dies./ Köster, Markus (Hg.): Jugend im Fokus von Film und Fotografie. München: V\&R unipress

Stammen, Theo/ Weber, Wolfgang E. J. (Hg.) (2004): Wissenssicherung, Wissensordnung und Verarbeitung. Das europäische Modell der Enzyklopädien. Berlin: Akademie Verlag

Stark, G. (1930): Moderne politische Propaganda. 1. Heft der Schriftenreihe der Reichspropaganda-Abteilung. Dr. Goebbels (Hg.). München: Verlag Frz. Eher Nachf.

Steinbacher, Sybille (Hg.) (2007): Volksgenossinnen: Frauen in der NS-Volksgemeinschaft. Göttingen: Wallstein

Stern-Rubarth, Edgar (1921): Die Propaganda als politisches Instrument. Berlin: Trowitzsch \& Sohn

Stöber, Gunda (1998): Pressepolitik und Notwendigkeit Zum Verhältnis von Staat und Öffentlichkeit im Wilhelminischen Deutschland 1890-1914. Stuttgart: Franz Steiner

Stöber, Rudolf (1998): Die erfolgverführte Nation: Deutschlands öffentliche Stimmungen 1866 bis 1945. Stuttgart: Franz Steiner

Stoffels, Michaela (2011): Kriegerdenkmale als Kulturobjekte. Wien/ Köln: Böhlau

Stommer, Rainer (Hg.) (1982): Reichsautobahn: Pyramiden des Dritten Reichs: Analysen zur Ästhetik eines unbewältigten Mythos. Marburg: Jonas

Strobel, Matthias/ Dippel, Andrea (2011): Die Kunst des Sammelns. Phänomene des Ordnens, Archivierens und Präsentierens. Nürnberg: Verlag für moderne Kunst

Stuck, Hans (1967): Tagebuch eines Rennfahrers. München: Moderne Verlags-GmbH

Subrt, Jirí/ Pfeiferová, Stepánka: „Kollektives Gedächtnis und historisches Bewusstsein“ (2013): In: Lehmann, René/ Öchsner, Florian/ Sebald, Gerd (Hg.): Formen und Funktionen sozialen Erinnerns. Wiesbaden: Springer VS

Süß, Dietmar (Hg.) (2007): Deutschland im Luftkrieg. München: Oldenbourg

Swett, Pamela E./ Wiesen, S. Jonathan/ Zatlin, Jonathan R. (Hg.) (2007): Seeling Modernity. Advertising in Twenteeth-Century Gemany. Durham/London: Duke University Press 
Sywottek, Jutta (1976): Mobilmachung für den totalen Krieg. Opladen: Westdeutscher Verlag

Szczepaniak, Monika (2011): Militärische Männlichkeiten in Deutschland und Österreich im Umfeld des Großen Krieges. Würzburg: Königshausen \& Neumann

Tauchner, Paul (2004): „Politik und Industrie: Zigarettenmarken im historischen Rückblick.“ In: Meißner, Jörg/Deutsches Historisches Museum (Hg.): Strategien der Werbekunst 1850-1933. Bönen: DruckVerlag Kettler,

Tavernaro, Thomas (2004): Der Verlag Hitlers und der NSDAP - Die Franz Eher Nachfolger $\mathrm{GmbH}$. Wien: Praesens

Teetzmann, Otto (Hg.) (1934): Die deutsche Schicksalsfrage. Mit einem Geleitwort von Reichsminister der Luftfahrt und preußischen Ministerpräsidenten Hermann Göring. Berlin: Schönfeld's Verlagsbuchhandlung,

Tepe, Peter (2013): „Terminologische Sensibilisierung im Umgang mit dem Mythos.“ In: Krüger, Brigitte/Stillmark, Hans-Christian (Hg.): Mythos und Kulturtransfer: Neue Figurationen in Literatur, Kunst und modernen Medien. Bielefeld: transcript

Tepe, Peter/ Semlow, Tanja (Hg.) (2006): Mythos No. 2. Politische Mythen. Würzburg: Königshausen \& Neumann

Teuteberg, Hans Jürgen (Hg.) (2004): Die Revolution am Esstisch. Stuttgart: Franz Steiner

Thamer, Hans-Ulrich (1986): Verführung und Gewalt. Deutschland 1933 - 1945. Berlin: Siedler

Thimme, Annelise (1969): Flucht in den Mythos. Die Deutschnationale Volkspartei und die Niederlage von 1918. Göttingen: V\&R

Thoms, Robert/ Poschanke, Stefan (2001): Handbuch zur Geschichte der deutschen Freikorps. Bad Soden-Salmünster: MTM Verlag

Tietz, Jürgen (1997): „Das ostpreußische Tannenberg-Nationaldenkmal“. In: Institut Norddeutsches Kulturwerk (Hg.): Das Denkmal im nördlichen Ostmitteleuropa im 20. Jahrhundert. Politischer Kontext und nationale Funktion. Lüneburg: Verlag Norddeutsches Kulturwerk

Torp, Claudius (2011): Konsum und Politik in der Weimarer Republik. Göttingen: V\&R

Treusch von Buttlar Brandenfels, Horst Frhr., Kapitänleutnant (1931): Zeppeline gegen England, 2. Aufl. Zürich/ Leipzig: Amalthea

Tümmler, Holger (2010): SA - SS - NSKK im "Führerstaat". Uniformen und Abzeichen. Wolfenbüttel: Melchior

Udet, Ernst, (1935): Mein Fliegerleben. Berlin: Ullstein 
Ullmann, Hans-Peter (1995): Das Deutsche Kaiserreich 1871-1918. Frankfurt/M.: Suhrkamp

Voigt H., Johannes (1986): „Die TH Stuttgart während der Zeit des Nationalsozialismus“. In: Stöhr, Martin (Hg.): Von der Verführbarkeit der Naturwissenschaft. Frankfurt/M.: Haag + Herchen

Voigt, Rüdiger (1989): „Mythen, Rituale und Symbole in der Politik“. In: Ders. (Hg.): Politik der Symbole. Symbole der Politik. Opladen: Leske und Budrich

Volkmann, Hans-Erich (1979): „Die NS-Wirtschaft in Vorbereitung des Krieges.“ In: Deist, Wilhelm/ Messerschmidt, Manfred/ Ders./Wette, Wolfram. Ursachen und Voraussetzungen der deutschen Kriegspolitik. Militärgeschichtliches Forschungsamt (Hg.): Das Deutsche Reich und der Zweite Weltkrieg. Bd. 1. München: Deutsche Verlags-Anstalt

Volkmann, Hans-Erich (1979): „Die NS-Wirtschaft in Vorbereitung des Krieges.“ In: Deist, Wilhelm/ Messerschmidt, Manfred/ Volkmann, Hans-Erich/ Wette, Wolfram (Hg.): Ursachen und Voraussetzungen der deutschen Kriegspolitik. München: Deutsche Verlags-Anstalt

Vondung, Klaus (1971): Magie und Manipulation. Göttingen: V\&R

Vondung, Klaus (1988): Die Apokalypse in Deutschland. München: DTV

Vondung, Klaus (2013): Deutsche Wege zur Erlösung - Formen des religiösen Nationalsozialismus. München: Wilhelm Fink

Walsdorf, Hanna (2010): Bewegte Propaganda. Politische Instrumentalisierung von Volkstanz in den deutschen Diktaturen. Würzburg: Königshausen \& Neumann

Wasem, Erich (1987): Das Serienbild. Medium der Werbung und Alltagskultur. Dortmund: Harenberg

Wedekind, Michael (2005): Ethnisch-soziale Neuordnungskonzepte im besetzten Europa (1939-1945) Forschungsperspektiven von Fallstudien zum Alpen-Adria-Raum. In: Mackensen, Rainer/ Reulecke, Jürgen (Hg.) Das Konstrukt "Bevolkerung" vor, im und nach dem „Dritten Reich". Wiesbaden: VS Verlag für Sozialwissenschaften

Wedemeyer-Kolbe, Bernd (2004): Der neue Mensch. Würzburg: Königshausen \& Neumann

Wegner, Bernd (2008): Hitlers politische Soldaten: Die Waffen-SS 1933-1945, 5. Aufl., Paderborn: Ferdinand Schöningh

Wegner, Hugo (1926): Flugzeugmodellbau. Halle: Selbstverlag Hugo Wegner

Weinrich, Harald (1971): „Mythologie der Ehre“. In: Fuhrmann, Manfred (Hg.): Terror und Spiel. Probleme der Mythenrezeption. München: Wilhelm Fink 
Weiss, Hilde/ Reinprecht, Christoph (1998): Demokratischer Patriotismus oder ethnischer Nationalismus in Ost-Mitteleuropa? Wien/ Köln: Böhlau

Weißmann, Karlsheinz (1991): Schwarze Fahnen, Runenzeichen - Die Entwicklung der politischen Symbolik der deutschen Rechten zwischen 1890 und 1945. Düsseldorf: Droste

Welch, David (2001): Propaganda and the German Cinema, 1933-1945. Oxford: Oxford University Press

Wende, Peter (2006): „Modell und Menetekel. Jacob Venedeys 'England'.“ In: Hein, Dieter/ Schulz, Klaus/ Hildebrand, Andreas (Hg.): Historie und Leben: Der Historiker als Wissenschaftler und Zeitgenosse. München: Oldenbourg

Wendt, Dirk (1989): „Feindbild Seine biologischen und psychologischen Ursachen. In: Voigt, Rüdiger (Hg.): Politik der Symbole. Symbole der Politik. Opladen: Leske und Budrich

Wenzel, Richard (1930): Richthofen - Flieger. Dem Gedächtnis des großen Fliegers und seines heldenhaften Geschwaders. Karlsruhe: Badische Zeitung

Westphal, Uwe (1989): Werbung im Dritten Reich. Berlin: Transit

Wette, Wolfgang (2008): Militarismus in Deutschland. Geschichte einer kriegerischen Kultur. Darmstadt: Primus

Wette, Wolfram (1979): „Ideologien, Propaganda und Innenpolitik als Voraussetzungen der Kriegspolitik des Dritten Reiches.“ In: Deist, Wilhelm/ Messerschmidt, Manfred/ Volkmann, Hans-Erich/ Ders. (Hg.): Ursachen und Voraussetzungen der deutschen Kriegspolitik. Militärgeschichtliches Forschungsamt (Hg): Das Deutsche Reich und der Zweite Weltkrieg. Bd. 1. München: Deutsche Verlags-Anstalt

Wette, Wolfram (1991): Militarismus und Pazifismus. Auseinandersetzung mit den deutschen Kriegen. Bremen: Donat

Weyers, Dorle/ Christoph Köck; Landschaftsverband Westfalen-Lippe, Westfalisches Freilichtmuseum Detmold (Hg.) (1992): Die Eroberung der Welt. Sammelbilder vermitteln Zeitbilder. Bielefeld: Print und Kommunikation

White, Jerry (2015): Zeppelin Nights. London in the First World War. London: Vintage Books

Wilcke, Gudrun (2005): Die Kinder- und Jugendliteratur des Nationalsozialismus als Instrument ideologischer Beeinflussung, Frankfurt/M.: Peter Lang

Wilke, Jürgen (Hg.) (2008): Massenmedien und Spendenkampagnen vom 17. Jahrhundert bis in die Gegenwart. Wien/ Köln: Böhlau 
Winckler, Lutz (1985 ): Studie zur gesellschaftlichen Funktion faschistischer Sprache, 4 . Aufl. Frankfurt/M.: Suhrkamp

Winkelmann, Rita (2013): Was bedeuten Farben in den Bildern? Einführung in die Farbanalytische Ikonographie. Nordhausen: Traugott Bautz

Wippermann, Wolfgang (1981): Der deutsche Drang nach Osten. Ideologie u. Wirklichkeit eines politischen Schlagwortes. Darmstadt: Wissenschaftliche Buchgesellschaft

Wippler, Hugo (1936): Die volkserzieherische Bedeutung des deutschen Bilderbuches. Schulungsvortrag der Reichswaltung des NSLB. Erarbeitet im Auftrag und in Gemeinschaft mit der Jugendschriftenabteilung der Reichsverwaltung des NSLB. Leipzig: o.V

Wirsching, Andreas (2006): „Politische Generationen, Konsumgesellschaft, Sozialpolitik. Zur Erfahrung von Demokratie und Diktatur in der Zwischenkriegszeit und Nachkriegszeit“. In: Doering-Manteuffel, Anselm (Hg.): Strukturmerkmale der deutschen Geschichte des 20.Jahrhunderts. München: Oldenbourg,

Wirths, Werner (1922): „Das Erlebnis des Krieges“. In: Moeller, van den Bruck/GleichenRusswurm, Heinrich von/Boehm, Max Hildebert (Hg.): Die Neue Front. Berlin: Verlag Gebrüder Pätel

Wittek, Thomas (2005): Auf ewig Feind?: Das Deutschlandbild in den britischen Massenmedien nach dem Ersten Weltkrieg. München: Oldenbourg

Wodianka , Stephanie (2009): Zwischen Mythos und Geschichte : Ästhetik, Medialität und Kulturspezifik der Mittelalterkonjunktur. München: de Gruyter

Wolfgramm/ Kreisgruppe Breslau des Nationalsozialistischen Lehrerbundes (Hg.)

(1933): Schriften zu Deutschlands Erneuerung, Nr. 3, 5. Aufl. Breslau: Verlag Heinrich Handel

Wolnik, Gordon (2004): Mittelalter und NS-Propaganda: Mittelalterbilder in den Print-, Ton- und Bildmedien des Dritten Reiches. Münster: LIT

Wolz, Nicolas (2013): "Und wir verrosten im Hafen“. Deutschland, Großbritannien und der Krieg zur See 1914-1918. München: DTV

Woschech, Anke (2012): „Technikfunktionen im frühen deutschen Tonfilm“. In: Fraunholz, Uwe/ Woschech, Anke (Hg.): Technology Fiction. Technische Visionen und Utopien in der Hochmoderne. Bielefeld: transcript

Wulf, Christoph/ Zirfas, Jörg (Hg.) (2004): Die Kultur des Rituals. Paderborn: Wilhelm Fink

Würmann, Carsten/ Warner, Ansgar (Hg.) (2008): Im Pausenraum des 'Dritten Reiches'. Zur Populärkultur im nationalsozialistischen Deutschland. Bern/ Berlin: Peter Lang 
Wüst, Wolfgang (2004): „Die 'Gelehrten Sachen' in den aufgeklärten Intelligenzblättern. Regionale Alternative oder Rezeption der 'großen' Enzyklopädie?“ In: Stammen, Theo/ Weber, Wolfgang E. J. (Hg.): Wissenssicherung, Wissensordnung und Verarbeitung. Das europäische Modell der Enzyklopädien. Berlin: Akademie Verlag

Zachmann, Karin (2004): Mobilisierung der Frauen: Technik, Geschlecht und Kalter Krieg in der DDR. Fankfurt/M./ New York: Campus

Zegenhagen, Evelyn (2007): "Schneidige deutsche Mädel": Fliegerinnen zwischen 1918 und 1945. Göttingen: Wallstein

Zeichmann, Vera (2010): Werbemittel Sammelbild. Zigarettenbilderalben im Dienst der NS-Propaganda. Diplomarbeit Universität Wien

Zeller, Joachim (2008): Bilderschule der Herrenmenschen. Koloniale Reklamesammelbilder. Berlin: Ch. Links

Zenone, Daniela (2002): Das Automobil im italienischen Futurismus und Faschismus: seine ästhetische und politische Bedeutung/[WZB, Wissenschaftszentrum Berlin für Sozialforschung, Forschungsschwerpunkt Technik, Arbeit, Umwelt]. Berlin: WZB, Forschungsschwerpunkt Technik, Arbeit, Umwelt. Online http://docplayer.org/25133565-Working-paper-das-automobil-im-italienischenfuturismus-und-faschismus-seine-aesthetische-und-politische-bedeutung.html Zuletzt abgerufen am: 20.12.2019

Zeppelin, Ferdinand Graf (1908): Die Eroberung der Luft. Ein Vortrag gehalten im Saale der Sing-Akademie zu Berlin am 25. Februar 1908. Stuttgart: Deutsche Verlags-Anstalt

Zimmermann, Clemens (2007): Medien im Nationalsozialismus. Wien/ Köln: Böhlau

Zinnecker, Bruno (1933): „Die Jugendfliegerbewegung“. In: Jünger (Hg.): Luftfahrt ist not! Leipzig: Vaterländischer Buchvertrieb Thankmar Rudolph

\section{Archive und Zeitungen}

Bayerische Staatsbibliothek, Münchner Digitalisierungszentrum

Bundesarchiv

Deutsches Historisches Museum

Hamburger Institut für Sozialforschung

Sächsisches Staatsarchiv

Völkischer Beobachter, 46. Jahrgang, 60. Ausgabe, Norddeutsche Ausgabe A, Erstes Beiblatt, Mittwoch, 1. März, 1933 


\section{Eidesstattliche Erklärung}

Ich versichere an Eides statt durch meine eigene Unterschrift, dass ich die vorstehende Arbeit selbständig und ohne fremde Hilfe angefertigt und alle Stellen, die wörtlich oder annähernd wörtlich aus Veröffentlichungen genommen sind, als solche kenntlich gemacht habe. Die Versicherung bezieht sich auch auf in der Arbeit gelieferte Zeichnungen, Skizzen, bildliche Darstellungen und dergleichen.

Datum:

Unterschrift: 